


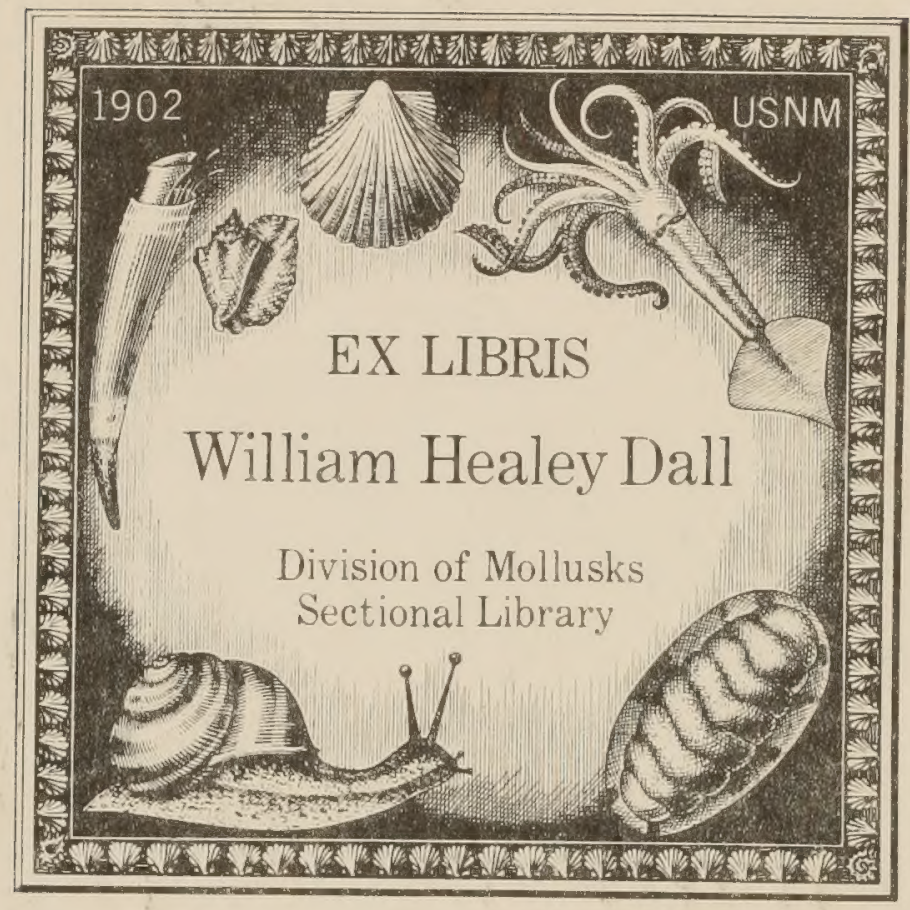


Division of Mollest Sectional tibronty 


Oartiod

Filo $256 a$

With the Author's Compliments

On Bergh's Malacologische Untersuchungen

BY

R. WINCKWORTH

Reprinted from the Proceedisgs of the Matacorogroal Socmery or Losdow, Volume 27, part 1, 21 May 1946. 



\section{ON BERGH'S MALACOLOGISCHE UNTERSGCHUNGEN}

\section{By R. WINCKWORTH \\ (Read 12 April 1946) \\ SEMPER's REISEN}

Dr. R. Bergh (1821-1909), whose full name was Ludvig Sophus Rudolph Bergh, published a large part of his work on nudibranchs and other mollusca in Semper's Reisen. This work is by no means confined to the material collected by Semper in the Philippines, but includes a survey of all available material and literature of most groups of nudibranchs, the pleurobranchs and Lamellariidae (Marseniaden) of the world, and various other groups.

The volumes of Reisen im Archipel der Plilippinen von Dr. C. Semper all bear the subheading 'Zweiter Theil. Wissenschaftliche Resultate' No 'Erster Theil' was ever published; Semper's account of his travels in the Philippines (1858-1865) was not completed, but in part published in four papers in Z. wiss. Zool. ${ }^{1}$ Owing to the misplaced ingenuity of Bergh and his publisher the work is subdivided in a manner which leads to much confusion in citation: for example the title pages of the part dealing with Bulla, etc., bear the references ${ }^{2}$ Theil 2, Band 7, Abtheilung 4, Abschnitt 3, Jieferung 1; Abtheilung 4 is also referred to as Theil 5 and Lieferung 1 as Heft 5 .

Altogether eight subdivisional names are nsed:

Theil 2 (portion) of the whole work, unnecessary, since the first portion was not published ;

Band 2,7,9 (volume) ${ }^{3}$ of the whole work as published ;

Band 1, 2, 3 (subrolumc) of Bergh's work in rolume?

Theil 1-6 (division) of Bergh's work in the three volumes 2, 7 and 9;

Abtheilung (section); Heft (part); Abschnitt (subsection); Lieferung (number).

The following table gives the subdivisions of Bergh's work.

Bavn 2.

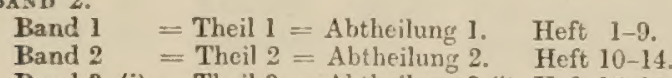

Band 3 (i) $=$ Theil $3=$ Abtheilung 3 (i). Heft 15-18.

Band 3 (ii) $=$ Theil $4=$ Abtheilung 3 (ii). Suppl. Heft. 1-4

The supplement of four parts is separately paged from the preceding 18 parts.

Hefte $1-14$ are also referred to as Lieferungen $1-14$ in an advertisement, issued by Kreidel's Verlag.

Band 7.

Theil $5=$ Abtheilung 4. Abschnitt 1. Lieferung 1-3 = Heft 1-3.

" $\quad$ " $\quad$ Abschnitt 2. Lieferung 1 $1=$ Heft 4.

" $\quad$ Abschnitt 4. Lieferung $1=$ Heft 7.

BAND 9.

Theil 6 ( = Band 6, in Band 7, p. 371-379). Lieferung 1-3= Heft 1-3.

1 For an obituary, portrait and bibliography of Semper, see A. Schulerg, 1895, Arb. Zool. Zoot: Inst. Würzburg, 10, part 2.

3 For convenience I abbreviate Siebenter Band, ete. to Band 7 , etc.

3 Other volumes deal with other groups, e.g. Band 1, Holothurians, Band 3, Land Mollusca, Band 4, Sipunculids, etc. 

A proper and sufficient referenco therefore should give the volutie $(2,7$ or 9$)$ and page, adding Suppl.after 2 in the case of Theil. 1. Thus :

$$
\begin{aligned}
& \text { Bergh, R. 197.1. Semper's Reisen, 2, 309-314. } \\
& \text { Bergh, R. 1S50. Semper's Reisen, 2 Suppl. } 21 . \\
& \text { Bergh, H. 1905. Semper's Reisen, 9, } 69 .
\end{aligned}
$$

If further detail is required the number of the Heft may be adder betreen rolume and page: Rergh, R. 1876. Malac. Unt. Semper's Reisen, 2, Heft 10, 413.

The dates of publication, as far as I have traced them, are given below. Up to 1878, the dates are those given by Bergh in part 14, page xlii; the dates for the first three parts of volume 7 are given on page 158 of that volume; the other dates are dates of receipt at the British MIuseum (Natural History).

\begin{tabular}{|c|c|c|c|c|c|}
\hline 20 Feb. & 1870 & 1 & $1-30$ & $1-8$ & Flabellina. \\
\hline 10 July & 1871 & 2 & $49-118$ & $9-16$ & Phyllobranchus. Cyerce. \\
\hline 8 Nay & 1872 & 3 & $137-176$ & $17-20$ & Stiliger. Plakobranchus. \\
\hline 15 Dec. & 1872 & 4 & $177-203 \cdot$ & $21-24$ & Elysiadac. \\
\hline 25 Oct. & 1873 & 5 & $205-246$ & $25-31$ & Lima pontia. Phylliroe. Acura. \\
\hline 10 June & 1874 & 6 & $247-285$ & $32-35$ & Pleurophyllidia \\
\hline 21 Sep. & 1874 & 7 & $287-314$ & $36-39$ & Bornella. Hero. \\
\hline $10 \mathrm{Mar}$. & 1875 & 8 & $315-313$ & $40-45$ & Scyllaca. \\
\hline $30 \mathrm{Sep}$. & 1875 & 9 & $345-376$ & $46-48$ & Tethys. Melibe. \\
\hline 4 May & 1876 & 10 & $377-427$ & $49-53$ & Phyllidia... Kentrodoris. \\
\hline 28 Apr. & 1877 & 11 & $429-491$ & $51-57$ & Chromadoris. \\
\hline 15 Dec. & 1877 & 12 & $495-516$ & $58-61$ & Platydoris \\
\hline 8 July & 1878 & 13 & $51^{\prime} 7-601$ & $62-65$ & Hexabranchus... Fracessa. \\
\hline 23 Dec. & 1878 & 14 & $\left\{\begin{array}{l}603-610 \\
i-1 i\end{array}\right.$ & $66-68$ & $\begin{array}{l}\text { Lamellidoris.... Asteronotus. } \\
\text { Ucbersicht, Register, u.s.w. }\end{array}$ \\
\hline 3 Dec. & 1884 & 15 & $617-751$ & $69-76$ & Chromodoris... Marionia. \\
\hline $2 \mathrm{~A}$ & 1888 & $16, \mathrm{i}$ & $755-814$ & $77-81$ & $\mathrm{Nu}$ \\
\hline 27 Nar. & 1889 & $16, \mathrm{ii}$ & $815-872$ & $82-84$ & Nud. Mauritius. \\
\hline & 1890 & 17 & $873-991$ & 8589 & Nud. Sunda-Mecres, u.s.w. \\
\hline 22 & 1892 & 18 & $995-1168$ & - & System, Register. \\
\hline
\end{tabular}

Semper's Reisen, volune ?-Nalacologische Untersuchungen

date part pages plates contents

Supplement to volume 2

$\begin{array}{lccccc} & 1880 & 1 & 1-78 & \text { A-F } & \text { Nachträge. } \\ 19 \text { May } & 1881 & 2 & 79-128 & \text { G-L } & \text { Nachtrïgc. } \\ \text { 26 July } & 1887 & 131-225 & \text { MI-R } & \text { Marseniaden. } \\ \text { 26 } & 227-289 & \text { S-Z, E Marseniaden. }\end{array}$

Semper's Reisen, volume 7-Malacologische Untersuchungen

* Mar. 18971 1-51 1- 4 Pleurobranchaea.

* Dec. $1897 \quad 2$ 53-115 5-8 Oscaniopsis... Oscaniella.

* Nov. 1898 3. 117-158 9-12 Pleurobranchus.

27 Mar. 1900 4 159-20S 13-16 Haminaca... Plakobranchus.

29 Jall. $1901 \quad 5 \quad 209-256 \quad 17-20$ Bullacer.

15 Oct. 19016 257-312 21-24 Bullacea.

7 Oct. 19027 313-382 25-29 Acteon... Oscaniella.

* Received at the British Siuseum, 6 A pril 1897, 15 February 1898 and 22 Norcmber 1898. 

Semper's Reisen, volume 9-NIalacologische Untersuchungen
2 Feb. 1901
$1-55$
1-4. Nudihranchien.
7 Mar. $1905257-115$
5- 8 Berthella... Chelyonotus.

18 July 1908

$119-178$

9-12 Voluta... Uebersicht.

This Uebersicht on pages 165-178 contains a useful bibliograplyy of Tergh's work on mollusca, listing the species described. By a curious error, no doubt duo to a shunto of tho pages of tho maruscript, more than two-thirds of the spiccics treated of in the Siboga Exmedition report of 1905 , which should follow on naco 178 are actually printed on pago 169 (beginning with Cyerce clegans, line 13 from bottom) and page 170 , and the papers of 1906 and 1907 on pago 171 were no doubt intended to end tho list. One paper, his last, is to be addod to make the list complete: Appondix, in Schepman, 1908, Prosobranchia, Siboga Exp. 49 (i), 90-107.

\section{Journal des Museum Godeffroy}

Bergh's 'Neue Nacktschnecken der Südsec, Malacologische Untersuchungen' consists of a series of four papers published in the Journal des Muscum Godeffroy. The chicf ingenuity here is three sets of pagination, of the volume, of the part and of the offprint. It may also be noted that the Hefte (parts) of the volumes are not all consecutive.

Band 1: Hefte 1, 2, 4. Band 3: Hefto 6, 8, 10. Barid 5: Hefto 12, 14 . Band 2: Hefte 3, 5, 7, 9, Band 4: Hefte 11, 13, 15.

Bergh's Neue Nacktschnecken occurs with the following pagination.

I 1873 Band 1, 137-168. Heit 2, 65-96: Scparate, 1-32. Pl. 9-12.

II 1874 Band 3, 91-116. Heft 6, 91-110. Separate, 1-26. Pl. 1-1.

III 1875 Band 3, 185-232. Heft 8,53-100. Separate, 1-48. Pl. 7-11.

IV 1879 Band 5, 1-50.* Heft 14, 1-50. Separate, 1-50. Pl. 1-5.

- Tho paging should bo 179-2:8, but this does not occur. Bergh quotes this as 1878 but tho titto page is datod 1879. 




\title{
REISEN
}

IMI

\section{ARCHIPEL DER PHILIPPINEN}

\section{C. SEMPER}

PROFESSOR DER ZOOLOGIE UND VEIRGLICHENDEN ANATOME IN WÜRZBURG.

\author{
ZWEITER THEIL. \\ WISSENSCIIAFTLICIIE RESULTATE. \\ ZNEITER BAND. \\ SUPPLEMENTE
}

MALACOLOGISCHE UNTERSUCHUNGEN

VON

D? RUD. BERGH.

NUDIBRANCHIEN.

NACHTRÄGE UND ERGÄNZUNGEN.

DIE MARSENIADEN.

\section{WIESBADEN.}

C. W. KREIDEL'S VERLAG. 


\title{
N U I) I B R A N C H I E N.
}

\author{
MALACOLOGISCHE UNTERSUCHUNGEN
}

\section{$D^{R}$ RUD. BERGH.}

sititisOnitio

APR 271989

NACHTRÄGE UND ERG ÄNZUNGEN.

\section{WIESBADEN.}

C. W. KREIDEL'S VERLAG.

$$
1880-1881 \text {. }
$$






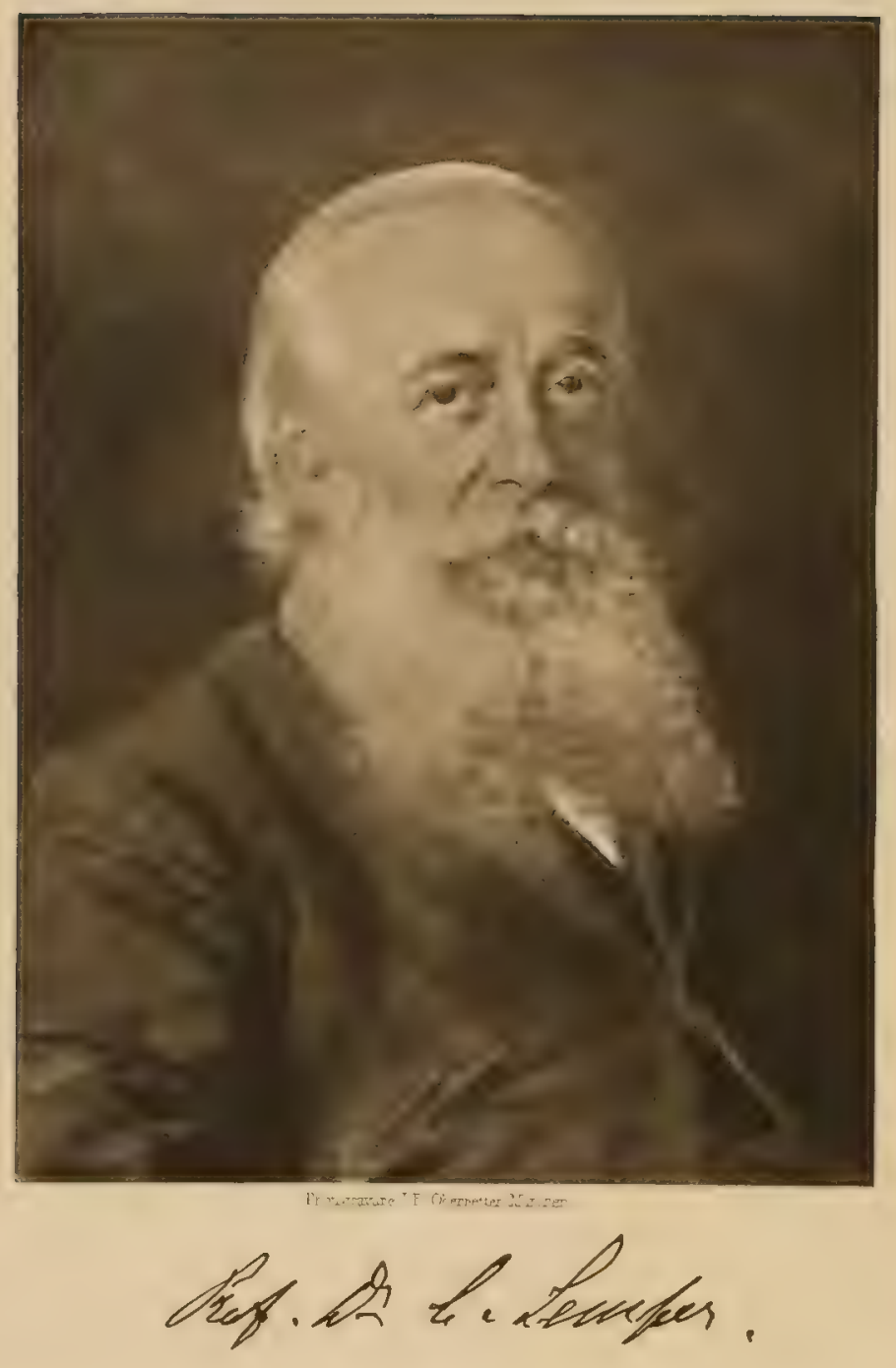




\section{CARL SEMPER *}

YON

DR AUGUST SCHUBERG. 

Carl Gottfried Semper wurde am 6. Juli 1832 zil Altona als Sohn des Fabrikanten Johany Carl Semper geboren. Sein Vater, der hochbetagt starb, war ein Bruder des berihmten genialen Architekten und Aesthetikers GotTrRied SEMPEr.

Seine Jugend verbrachte SEMPER in seiner Vaterstadt, wo er das Gymnasium bis Sekunda besuchte, um dann 1848 in die von der schlestrig-holstein'schen "provisorischen Regierung ${ }^{\star}$ gegründete Seekadettenschule in Kiel einzutreten. Da die Ungunst der Verhältnisse indessen für diese Schule wenig verlockende Aussichten bot, verliess er sie -bald wieder und trat als Freiwilliger bei der Artillerie ein. Als solcher machte er den kurzen Feldzug gegen die Dänen mit, in welehem er die Feuertaufe erhielt. Nach Beendigung des Feldzuges, der bekauntlich Schleswig-Holstein vollständig unter dänische Herrschaft brachte, versuchte er in die junge preussische Marine einzutreten, was ihm indessen abgeschlagen wurde. Da ihm somit die seemännische Karriere verschlossen war, blieb nichts anderes uibrig, als einen andern Beruf zu ergreifen. Er wählte, wohl unter dem Einflusse des väterlichen Rathes, das Studium der technischen Wissenschaften und studirte zu diesem Zwecke während der Jahre 1851-1854 auf der polytechnischen Schule zu Hannover. Indessen vermochte der Beruf des Technikers Senrper's Interesse nicht dauernd zu fesseln; die Lust zu wandern, der Drang in die weite Welt, der ihn zum Seemannsberuf gezogen hatte, lebte von neuem auf und war es wohl in erster Linie, was ihn zum Studium der Naturwissenschaften aufmunterte. Denn noch in späteren Jahren hat er es für eine der schönsten Seiten der Naturwissenschaft gehalten, dass sie, wie er meinte, darauf dränge, dass der einzelne Forseher sich hinausbegebe, um die Natur auch in andern Verhältnissen, als nur in den heimischen, kennen zu lernen. Damit war schon eines der Gebiete vorgezeichnet, auf denen SEMPER seine herrorragendsten Erfoige erzielen sollte.

Das Studium auf der Universität Würzburg (1854-1856), wo er vor allem unter den $A$ ugen von Költiker, Leydig und Gegenbaur seine erste wissenschaftliche Anleitung erhielt, führte ihn freilich vorerst in andere Gebiete. Vergleichende Morphologie und Histologie, in die er hier hauptsächlich eingeführt wurde, beschättigten ihn zunïchst, und die vielversprechenden Förderungen, welche diese Wissenschaften gerade zu jener Zeit auf der Würzburger Hochsehule durch die genannten Lehrer SExren's erfuhren, lassen es begreiflich erscheinen, dass er auch für diese Zweige der Zoologie Interesse gerwann: 
ein Interesse, das nicht vorubergehend war, sondern sich als ein neues Element der früheren und in erster Linie antreibenden Neigung anf die Daucr beigesellte. Und auch auf diesen Gebiete, dem der morphologischen Forschung, sollte denn später SExPER nicht mindere Verdienste erringen, als er sich solehe als naturwissenschaftlicher Forschungsreisender errungen hat.

Nach Absolvirung seiner Studien in Wuirzburg verbrachte SEMPER den Herbst 1856 in T'riest. Am 20. Dezember des gleichen Jahres wurde er auf Grund seiner bereits frihler eingereichten Dissertation an der Universität Wüzburg zum Doctor philosophiae promovirt. Scine Dissertation: "Beitraige zur Anatomie und Physiologie der Pulmonaten", welche unter Leitung seines Lehrers KöLLHER entstanden war, zeigt ebenso, wie die Thesen, welehe bei der Promotion vertheidigt wurden, und einige weitere kleinere Arbeiten aus jener Zeit, dass sich SEMPER damals besonders mit morphologischen und vor allem mit vergleichend histologischen Fragen beschäftigte.

Im Jahre 1857 setzte SExper theils in Würzburg, theils an der Kieler Hochschule seine Studien fort, um sodann im November desselben Jahres eine grössere Rundreise durch Deutschland, Frankreich, Spanien und die Niederlande anzutreten, von der er erst Anfang Juni 1858 nach Altona zurickkehrte.

Zweck dieser Reise war - nach seinen eigenen Worten - : theils Studien in Museen und Bibliotheken zu treiben, theils auch Gefährten zu suchen, die bereit vären, sich mit ihm zu einer grösseren naturwissenschaftlichen Reise zu verbinden". Demn jetzt sollte endlich — dank dem verstiundnisvollen Eingehen eines liberalen Vaters auf die Pläne eines selbstständig denkenden Sohnes - dessen heissester und lange im Herzen getragener Wunseh in Erfülung gehen: er sollte die Natur der Tropen aus eigener Anschaumg kennen lemen, die verschwenderische Fülle von Formen, die gar viele und merkwiirdige Forschungsergebnisse erwarten liess, zum Gegenstande eigener eingehender Studien machen diurfen. Als Ziel der Reise wurde - auf den Rath eines viiterlichen Freundes - die Inselgruppe der Philippinen bestimmt, und, da es nicht gelungen war, Genossen zu finden, so entschloss sich Senper, die Reise allein zu unternehmen.

Es war wohl nicht nur die Erwartung, besonderen Gewinn hicraus fiur seine wissenschaftlichen Absichten zu erzielen, sondern vielleicht auch noch etwas die alte Freude am Seemannsberufe, die SEMrer veranlasste, die Reise nach den Philippinen auf cinem Segelschiffe zurückzulegen. Am 20. Juni 1858 verliess er Hamburg auf dem Kauffahrteifahrer "Conradine Lackmann", um nach einer zum Theil sehr stiirmischen Leise um das Kiap der guten Hoffnung und nach kurzem Aufenthalte in Singapore und in China, im Dezember 1858 in Manila einzutreffen. Die Ausbeute wälhrend der Seereise war allerdings eine sehr greringe; mit um so grösserer Freude ging daher SExren bei seiner Ankunft in Manila an die Arbeit.

Das erste halbe Jahr etwa benutzte er vor allem dazu, um sich über Land und Leute zu orientiren und um der Landessprache Herr zu werden; seine zoologischen 
Exkursionen bewegten sich daher zunächst nur in der näheren Umgebung von Manila. Erst im August 1859 wurde die erste grössere Reise - nach dem Suiden der Philippinen - in Angriff genommen. Während eines siebenmonatlichen Aufenthaltes in der Umgebung ron Zamboanga und auf Basilan beschäftigte er sich, neben seinen zoologischen und anderen naturwissenschaftlichen Studien, auch mit der anthropologischen und ethnographischen Erforschung der dort wohnenden muhamedanischen Malayen. Im März 1860 nach Manila zurückgekehrt, begann er bereits im April des gleichen Jahres eine zweite grössere Reise, die ihn nach dem Nordosten der Insel Luzon führte; hier hatte er neben vielfachen zoologischen Studien Gelegenheit, die heidnischen Malayenstiamme kennen zu lernen und ebenfalls in anthropologischer und ethographischer Hinsicht neue und schätzbare Erfahrungen zu sammeln. Eine heftige Erkrankung an Wechselfieber und Ungunst der Jahreszeit zwangen zu einer vorzeitigen Beendigung dieser Reise. Auch eine zweite, im April 1861 nach dem Norden von Luzon angetretene Reise musste in Folge heftiger Erkrankung - an Dysenterie - im November unterbrochen werden. In Manila, wohin Semper zuriuckkehrte, fand er eine liebevolle Pflegerin in seiner Braut, Anna Heruann aus Hamburg, die er in Manila kennen gelernt und mit der er sich dort verlobt hatte.

Der Rath des behandelnden Arztes, zur völligen Wiederherstellung der höchst angegriffenen Gesundheit eine Seereise zu unternehmen, sollte SEMrER zur Erfüllung eines schon länger gehegten Wunsches bringen, dessen Befriedigung allerdings — wie sich nachher ergab - mancherlei und schwere Gefahren in sich barg, andererseits aber auch werthvolle wissenschaftliche Früchte zeitigte.

Ein Kapitän Woodn, der, auf der westlichsten Gruppe der Karolinen, den 'PalauInseln, Trepanghandel trieb, war im Begriffe, mit seinem Schiffe zu einem auf 4-5 Monate berechneten Aufenthalte dorthin auszulaufen. Mit Freuden ergriff SEMPER die dadurch gebotene Gelegenheit, die Koralleninseln des Stillen Oceans aus eigener Anschauung kennen zu lernen und schloss sich; begleitet von einem Diener und einem jungen Mestizen, einem angehenden Maler, dieser Expedition an.

Aber schon bald nachdem der kleine Schoner - am 31. Dezember 1861 — den Hafen von Manila verlassen hatte, begannen die ersten Gefahren, welche diese Reise zu einer der mühseligsten von SEMPER's Tropenfahrten machen sollten. Denn schon in den ersten Tagen wurde das alte Fahrzeug so leck, dass melhrmals und an verschiedenen Inseln angelaufen werden musste, um dasselbe nur auf das Nothdürftigste seetiichtig zu erhalten. Als das Schiff aber gar bei der Reise auf dem freien Ocean mit starken Meeresströmungen und immer heftiger wüthenden Stürmen zu kämpfen hatte und mehr und mehr Wasser aufnahm, da war die angestrengteste Thätigkeit aller Insassen, selbst des Kapitäns und der Passagiere nothwendig, um das Schlimmste zu vermeiden.

Am 22. März endlich kam die suidlichste Insel der Palau-Gruppe in Sicht und am 25. Mirz erfolgte die Landung im Hafen des Dorfes Aibukit auf der Insel Babelthaub. 
Die erste Zeit benützte SEMPER zur Aufklärung gewisser kriegerischer Vorgänge, welche sich kurze Zeit vorher auf der Insel abgespielt hatten, und ihren Ursprung dem Tionkurrenzneide eines englischen Haindlers verdankten. Da die Reparatur des Schiffes, mit dem er wieder zurickfahren wollte, roraussichtlich eine Dauer von mindestens 3-4 Monaten in Anspruch nehmen musste, so baute er sich mit Hilfe der Eingeborenen in der Nähe des Meeres ein seinen Zwecken entsprechendes Haus. Mit grosser Gewandtheit verstand er es auch hier, wie bereits früher hei seinen Reisen auf den Philippinen, mit den Eingeborenen, die mit Europäern nur sehr wenig in Berührung gekommen waren, bald in ein freundschaftliches Verhältniss zu kommen, jedoch so, dass sie ihn doch immer als eimen besonders Hochgestellten achteten. Bald galt er den Eingeborenen als einer ihrer Vornehmen, als ein "Rupack" und die Freundschaft des "Era T'abatteldil", des Herrn von "l'abatteldil" - so hiess der Platz, wo sein Haus stand - war von ihneu gesucht und hochgeschiitzt. Diese Stellung, die er unter den Eingeborenen einnahm, war nicht nur für seine zoologischen, sondern vor allem auch für seine anthropologischen und ethnologischen Studien von grösster Bedeutung. Mehrere, zum Theil recht beschwerliche und gefahrvolle Exkursionen zur Erforschung der Korallenriffe, sowie die Erkundung der Sitten, Gebråuche, Sagen, Religions- und Sprachverhältnisse etc. wurden nur hierdurch ermöglicht.

Allerdings sollten die reichen wissenschaftlichen Ergebnisse - ganz abgesehen von den Gefahren, welche vielfach der Moment mit sich brachte - nicht ohne schwere Erfahrungen geborgen werden. Denn nachdem SEMPER bereits mehr als das Doppelte der ursprünglich geplanten Zeit auf den Inseln zugebracht hatte, konnte die Abreise noch immer nicht in's Werk gesetzt werden, da es seinem Kapitän noch nicht gelungen war, das alte baufällige Schiff wieder sectüchtig zu machen. Eine andere Gelegenheit zur Heimfahrt aber war - für SEurER wenigstens - nicht vorhanden; und ebensowenig konnte er Nachrichten uiber seine Lage nach Manila gelangen lassen.

Als endlich, nach langem Harren, die Arbeiten am Schiffe ein gliickliches Ende zu erreichen schienen, da nahm SEMrer von seinen „wilden“ Freunden, die iln schon zu den Thren zu zïhlen begonnen hatten und nur sehr ungern scheiden sahen, Abschied, um noch die südlich von seinem Wohnort gelegene Insel Peleliu zu besuchen, von wo ihn sein Kapitän nach zwei Wochen abholen sollte. Aber nun begann erst recht eine schwere Zeit; denn aus den zwei Wochen wurden zwei Monate und an einer Riickkehr nach seinem früheren Wohnort wurde er durch die Eingeborenen gehindert. Als das sehnsuichtigst erwartete Schiff endlich - am 26. Januar 1862 - ankam, da hatte SEMPER bereits angefangen, an dem Nothwendigsten, an Kleidung, Schuhen u. s. w. Noth zu leiden. Ein 'Trost sollte es wenigstens für ihn sein, dass auch diese schlimme Zeit an interessanten wissenschaftlichen, insbesondere ethnologischen Ergebnissen reich war.

Nach seiner Rückkehr nach Manila — von wo man gerade bei seiner Ankunft ein Schiff auslaufen lassen wollte, um ihn zu suchen — feierte er seine Vermählung. Bald 
darauf begab er sich, zusammen mit seiner Gemahlin, nach der nördlich von Mindanao gelegenen Insel Bohol, von wo aus er noch im gleichen Jalre kïrzere Expeditionen nach den anliegenden Inseln Cebú, Leyte und Mindanao unternahm. Mit reicher zoologischer Ausbeute kehrte er dann wieder nach Manila zurick.

Eine von Mai bis Dezember 1864 dauernde Reise nach dem Osten und in's Innere von Mindanao bildete den Abschluss seiner grösseren 'T'ouren auf den Philippinen, die er im Mai 1865 von Manila aus verliess. Nachdem er auf der Heimreise noch Hongkong; Saigon, Ceylon und Aegypten kurz berihurt hatte, traf er im Juli 1865 in seiner Heimat Altona ein.

Nun galt es fïr ihn nicht nur, die reichhaltige Ausbeute seiner Reise zu bearbeiten, sondern auch in der Heimat eine Lebensstellung zu erringen.

Am 11. November 1865 richtete Sexper ein Gesuch an die Philosophische Fakultait der Universität Würzburg behufs Zulassung als Privatdozent für Zoologie. Die Zulassung erfolgte ohne eine besonders zu diesem Zwecke abgefasste IIabilitationssehrift, auf Grund seiner bis dahin veröffentlichten Schriften, und insbesondere auf Grund der im Jahre 1862 von der Utrechter Gesellschaft fiir Kunst und Wissenschaft mit dem ersten Preise gekrönten Arbeit: "Entwickelungsgeschichte der Ampullaria polita, nebst Mittheilungen iber die Entwickelungsgeschichte einiger anderer Gastropoden aus den 'Iropen". Bei der am 24. Februar 1866 stattfindenden Vertheidigung der aufgestellten 'Thesen opponirten dio Professoren Leiblein, Kölliker und SAndberger; das Thema der Probevorlesung lautete: "Eine kurze Schilderung der Typen der thierischen Organisation im Allgemeinen". - Im Sommersemester 1866 zeigte SEMPER seine erste Vorlesung „über Zoologie und vergleichende Anatomie" an; im Wintersemester $1866 / 67$ las er über ${ }_{\text {}} \mathrm{Pa}$ rasiten".

Schon nach kurzer Zeit, am 24. Februar 1869, wurde er zum ausserordentlichen Professor mit einem Jahresgehalt von 800 Gulden ernannt; bald darauf, am 6. März, wurde ihm die Vertretung des erkrankten Professors Leiblein iibertragen; und als dieser gestorben war, erhielt er am 13. August des gleichen Jahres seine Ernennung zum ordentlichen Professor und Direktor des Zoologischen Kabinets, unter Erhöhung seines Gehaltes auf 1200 Gulden.

Eine im Jahre 1870 erfolgte Berufung nach Göttingen lelınte SEuPER ab; in Anerkennung dessen erhielt er, ausser einer Gehaltserhöhung, als weiteres Nominalfach das der ,vergleichenden Anatomio übertragen, sowie dio Zusicherung, „dass zu einer Reorganisation des Zoologischen Kabinets geschritten und diese in 5-6 Jahren durchgeführt werden solle".

SEmper's Vorgänger, J. Letblern, war in seiner wissenschaftlichen Richtung durchaus ein Systematiker der vor-darwinischen Schule. Seine Hauptthätigkeit bestand in der Vergrösserung, Ordnung und Aufstellung des von seinem Amtsvorgänger, dem P. BonavitA BLANK, gegründeten Zoologischen Kabinets, dem er anscheinend eine grosse Sorgfalt an- 
gedeihen liess, freilich in einer Weise, die mehr auf das Aeussere, als auf den wirklich wissenschaftlichen Werth der Samnilung Nachdruck legte. Zu wissenschaftlichen Forschungen wurde diese Sammlung auch von LEIBLEIN selbst kaum benutzt; sie bestand aus z. T'h. schr schlecht prïparirten Bälgen, aus Insekten, Conchylien und sehr wenigen und nicht sehr werthvollen Spirituspriiparaten. Wirbellose Thiere - mit Ausnahme der genannten Formen - waren fast ebensowenig vorhanden, wie anatomische Priparate und Skelette. Die vergleichend anatomische Richtung der Zoologie war eben noch gar nicht zur Geltung gekommen und irgend welche praktische Unterweisung von Schiilern auf diesen Gebieten war daher vollständig ausgesehlossen gewesen, wie es denn zu jener Zeit noch gar wenige "zoologische Institute" im heutigen Sinue gegeben hat.

Aus dieser Sachlage ergab sich für SEMPER, der natiurlich die moderne vergleichendmorphologische Richtung der Zoologie nicht nur als Forscher, sondern auch als Lehrer vertreten wollte, die Nothwendigkeit, für einen praktischen Unterricht iberhaupt erst den nöthigen Raum zu schaffen, was ihm durch Umstellung der Sammlungen, die sich im alten Universitätsgebäude betanden, auch gelang. Es gelang ihm ferner, einige Mittel für seine Zwecke verfügbar zu bekommen und so nothdürftig die ersten Anfänge zu einem "Zoologischen Institut" anzubahnen. Die Anlage einer vergleichend-anatomischen und Skelett-Sammlung wurde gleichzeitig in Angriff genommen. Dabei muss betont werden, dass er vielfach eigene Opfer nicht scheute, um seinem Zweeke näher zu kommen. Die Umänderung, die SExPER dadureh in der Lehrthätigkeit des Fachzoologen herbeifiihrte, wurde am 9. Dezember 1871 durch Beschluss des akademischen Senates insofern anerkannt, als das ehemalige "Zoologische Kabinet" zu einem "Zoologisch-zootomischen Institut" erweitert wurde.

Bald begamn sich eine Anzahl von Schülern um Sexper zu schaaren, die ihm ihre Unterweisung in der Zoologie und die Anleitung zu eigener Forschungsarbeit verdankten. Manche werthvolle Arbeit entstand unter seinen Augen und auf seine Anregung, zum Theil auch direkt im Anschlusse an seine eigenen Forsehungen, die er mit ungewöhnlichem Eifer und grossem Fleisse, neben seiner Thätigkeit als akademischer Lehrer, fortsetzte. Freilich fuhlte er sich in beider Hinsicht, als Forscher sowobl wie als Lehrer, durch die ungenügenden Mittel und Räumlichkeiten seines Institutes eingeengt. Insbesondere war die Betreibung experimentell biologischer Studien fast völlig ausgeschlossen, was er um so schmerzlicher empfand, als er gerade diesen wenig gehegten Zweig der Zoologie, der vor Allem von den Fachzoologen fast ganz vernachlïssigt wurde, energischer in Angriff zu nehmen gedachte. Ein in einem Kellerraume nothdürftig eingerichtetes Aquarium ermöglichte zwar, einige Arbeiten in dieser Richtung auszuführen, erwies sich indessen doch als zu ungenügend und ermuthigte deshalb wenig zu weiteren Forschungen auf dem schwierigen Gebicte.

Insbesondere aus diesem Grunde, aber auch wegen des sonst höchst mangelhaften Zustandes der Institutsräumlichkeiten, war SEMPER mit grossem Eifer bestrebt, den Neu- 
bau eines eigenen zoologischen Institutes zu erlangen, was allerdings grosse Schwierigkeiten darbot. Denn obwohl die Universitait bereits im Jahre 1875 einen von der Stadtgemeinde Würzburg erworbenen Bauplatz für die Errichtung eines zoologischen Institutes bestimmt hatte, konnte der Bau noch lange nicht in Angriff genommen werden, da es nicht gelang, die Bewilligung der nöthigen Mittel zu erhalten. Fiir den rasch vorwärtsstrebenden und energischen Geist SEMPER's war diese lange Verzögerung eine hüchst schwere Probe, zumal er sich in seiner Lehr- und Forschungsthätigkeit beengt fühlte.

Mehrmals wurde SExper's 'Thätigkeit an der Würzburger Hochschule unterbrochen: zuerst im Jahre 1870. Die nationale Begeisterung, die ihn früher in die Reihen der Kämpfer gegen den Unterdrücker seiner engeren Heimat geführt hatte, liess ihn auch jetzt nicht zu Hause ruhen; mehrmals unternahm er die Leitung von Transporten von Lebensmitteln und Verbandzeug aut den Kriegsschauplatz, wobei seine charaktervolle Energie zu voller Entfaltung kam. Seine Thäigkeit wurde durch Verleihung der Kriegsdenkmünze füj 1870/71 anerkannt.

Für seine wissenschaftliche l'hätigkeit bedeutungsvoll war sein Aufenthalt auf Helgoland in den Jahren 1873 und 1874, sowie auf den Balearen, wo er im Jahre 1876 in Gemeinschaft einiger Schüler mehrere Monate zubrachte. Der Aufenthalt in Helgoland ist durch die grundlegenden Untersuchungen über die Exkretionsorgane der Haie von grösster Wichtigkeit geworden.

Im Jahre 1877 war es ihm vergönnt, auch einen Theil der "Neuen Welt" aus eigener Anschauung kennen zu lernen. Es war die ehrenvolle Aufforderung an ihn ergangen, in den Monaten Oktober bis Dezember dieses Jahres im Lowell-Institute zu Boston einen Cyklus von 12 Vorträgen zu halten, und er benützte diese Gelegenheit zu einer Reise bis nach dem Westen von Nord-Amerika. Aus diesen Vorträgen ging eines seiner bedeutendsten Werke, "die natürlichen Existenzbedingungen der Thiere" hervor.

Die Hauptanziehung als akademischer Lehrer übte SEMPER wohl am Ende der 70 er und $\Lambda$ nfang bis Mitte der 80er Jahre aus.

Das Jahr 1887 sollte leider eine traurige Wendung in sein Leben bringen. Ein Schlaganfall, der den rüstigen Mann in die äusserste Lebensgefalır brachte, lähmte für die Zukunft den einst so hochstrebenden und mit seltener Energie begabten Geist. Zwar schien sich Anfangs SEMPER's Gesundheitszustand in iuberraschend guter Weise wieder herzustellen, aber langsam und allmählich machte sich doch das Weiterschreiten des Krankheitsprozesses, der zu seinem Tode führen sollte, deutlicher bemerklich. Schonung liess sich freilich SEMPER nicht angedeihen, so wenig er es früher jemals gethan, und wohl sicher zu seinem Schaden.

Aber eine Freude, die ihn noch über mancherlei andere trübe Erfahrungen seiner letzten Lebensjahre hinwegsetzte, sollte ihm doch noch beschieden sein.

Als endlich im Jahre 1887 der bayerische Landtag eine ansehnliche Summe zum Neubau eines zoologischen Instituts bewilligt hatte, da war es ihm wenigstens noch ver- 
XIV

gönnt, diesen in seinem Sinne auszuführen und ihn nicht nux am 2. November 1889 dem Gebrauche zu ibergeben, sondern auch sich seiner Schöpfung noch einige Zeit zu erfreuen. Allerdings nalum seine Gesundheit bald darauf in dem Maasse ab, dass er nicht mebr im Stande war, selbst diejenigen Forschungen zu unternehmen, für welche er die Einrichtungen des neuen. Instituts angelegt hatte, und dass er sogar zu Ende des Jahres 1892 um Dispensirung von seiner Thätigkeit als akademischer Lehrer nachsuchen musste. Die Ernennung des gegenwärtigen Leiters des zoologischen Instituts, am Beginne des Sommersemesters 1593 enthob ihn seiner Verpflichtungen; doch sollte ihm nur eine kurze Zeit des Ruhestandes vergönnt sein. Denn schon am 29. Mai 1893 brachte ihm - nach einem letzten halben Jahre voll niederdrückendster Sorgen und voll schweren körperlichen Leidens - ein sanfter Tod die von ilhm selbst ersehnte Erlösung. -

Die litterarische 'Thätigkeit SEMPER's in einer kurzen Schilderung zusammen zu fassen, wie es hier versucht werden soll, ist mit nicht geringen Schwierigkeiten verbunden.

SEmper war, obwohl auch er sich natürlich mit einigen Gebieten besonders eingehend befasste und sie, wenigstens zeitweise, bevorzugte, vor allem frei von der Art. nSpecialismus", wie sie leider mitunter gefunden wird und wie sie - allerdings mit grossem Unrecht - ofter der gesammten Naturwissenschaft zum Vorwurf gemacht wird. Es giebt wohl wenige Forscher, welche sich in solcher Weise mit. den verschiedensten Gruppen des Thierreiches durch eigene Forschungen vertraut gemacht hätten, wie dies SEmper gethan hat. Und in ebenso ausgedehnter Weise beschäftigte er sich mit den verschiedenartigsten Zweigen der Zoologie: Anatomie, Histologie, Embryologie, Physiologie und allgemeine Biologie, Systematik und geographische Verbreitung - auf allen diesen verschiedenartigen Disciplinen hat er sich durch eigene Untersuchungen hervorgethan, sodass man wohl sagen kann, dass es wenige Gebiete der Zoologie giebt, die ur nicht betreten häitte.

Dazu kommt dann noch ferner, dass er auch mit anthropologischen und ethnographischen Studien sich abgab und auch hier litterarisch thätig war.

Es ist ja nun freilich nicht zu leugnen, dass diese seltene Vielseitigkeit durch das lange 'T'ropenleben SEMreR's in hohem Maasse begünstigt wurde. Denn wenn man, wie er, in der Lage ist, durch einen Zeitraum von $7^{1}, 2$ Jahren die an den mannigfaltigsten und interessantesten Thierformen überreiche Natur der Tropen, unbekümmert um aussere Umstände und ohne irgend welche Verpflichtungen, zu studirens dann sind dies Verhältnisse, wie sie wohl nur wenigen Zoologen in gleichem Maasse günstig gewesen sein dürften. Aber trotzdem muss anerkannt werden, dass er diese Zeit des gliicklichsten und unabhängigsten Forschens auf den Philippinen in einer Weise ausgenutzt hat, die nicht nur für seine ausserordentliche Energie, sondern auch für ein von 
vornherein vielseitiges und gleichmässiges Interesse für alle Zweige der Zoologie Zeugniss ablegt. Und dass er dieses besessen hat, zeigt eben ferner auch seine spätere Thätigkeit, wo er sich wiederholt auf neue, von ihm früher noch nicht betretene Gebiete begab.

Den Ausgangspunkt für SEMPER's zoologische Studien bildeten vergleichend-morphologische und histologische Untersuchungen, wie sie der von seinen Würzburger Lehrern vertretenen Richtung entsprachen. Seine ersten Arbeiten vor der Philippinenreise (1-7) ${ }^{1}$ ) - vor allem auch seine Dissertation (1) — sowie die ersten Untersuchungen auf den Philippinen, die er zuerst in einigen "Reiseberichten" $(8,9,14,15)$ bekannt gab, bewegen sich in dieser Richtung.

Die Forschungen, die er auf den Philippinen anstellte, erstreckten sich auf äusserst zahlreiche und verschiedenartige Thiergruppen und gaben zu mehreren wichtigen Entdeckungen Anlass $(12,13,16-19,21-23,35,37,67-69,71)$. Von besonderem Interesse sind die Mittheilungen über die Entstehung der Korallenriffe (22, 24), uber Trochosphaera (35) und über den Generationswechsel bei Steinkorallen (37).

Dass er bei dem sich darbietenden übergrossen Reichthum an Formen, nicht widerstehen konnte, auch die spezielle Morphologie und Systematik einzelner T'hiergruppen zum Gegenstande eigener Forschungen zu machen, kann nicht Wunder nehmen, und die Bearbeitungen seiner Reiseausbeute an Holothurien und Landmollusken zeigen, dass er dies mit Geschick und Erfolg gethan hat. Die in seinem grossen Reisewerke veröffentlichten Monographien iiber diese Formen $(17,31)$ werden noch für lange von grundlegender Bedeutung bleiben.

Auch die Beschäftigung mit thiergeographischen Fragen, die sich in mehreren späteren Werken $(76,84)$ kundgiebt, dürfte wohl hauptsächlich durch die Philippinenreisen veranlasst worden sein. Vor allem aber gilt dies wohl hinsichtlich seines Interesses für allgemeine biologische Fragen, zu denen ihn sicherlich die Beobachtungen in den Tropen besonders angeregt haben - in gleicher Weise, wie dies bekanntlich bei DARWIN und WALLACE der Fall gewesen ist.

An dem Ausbau der von diesen beiden grossen britischen Naturforschern begründeten Descendenzlehre hat SEMPER lebhaften Antheil genommen und zwar nicht nur in der Weise, dass er in einzelnen Schriften selbst einige Fragen der Lösung näher zu führen suchte $(77,78)$, sondern ferner auch durch objektive Kritik, indem er einige auf dem neubefruchteten Gebiete allzu ůppig wuchernde Schösslinge auf das richtige Maass zurechtzuschneiden versuchte $(39,40,43,45,61-63)$.

Vor allem waren es zwei Werke, durch welche SEMPEr die durch den Darwinismus angeregten Fragen förderte.

Das eine davon - richtiger gesagt, die eine Reilhe von zusammengehörigen Abhandlungen $(48-51,53,55,56,59,60,64,66,70,74,75)$ — suchte die Descendenzlehre

1) Die Zahlen beziehen sich auf die Nummern des Verzeichnisses von SuærPER's Sehriften; vergl. pag. XIX, XX, XXI. 


\section{XVI}

insofern zu festigen, als der Versuch gemacht wurde, eine grosse Ǩluft auszufüllen, deren Ueberbrickung fïr die Begründung der Descendenzlehre nothwendig erschien.

Eine wichtige Entdeckung, die SEAPER fast gleichzeitig mit dem englischen Embryologen BALFOUR machte, war die Beobachtung, dass bei Haifischen und zwar nicht nur bei Embryonen, sondern auch bei ausgewachsenen Thieren, Segmentaltriehter vorkommen. Diese Thatsache schien SEMren eine grosse Uebereinstimmung im Bau des Urogenitalsystems der Wirbelthiere mit dem der Anneliden darzuthun, und er glaubte nun die Brủcke gefunden zu haben, die von dem Typus der Wirbelthiere zu den Wirbellosen zu schlagen sci. Er verhehlte sich freilich von Anfang an keineswegs die Schwierigkeiten, die sich seiner Theorie der Abstammung der Wirbelthiere von gegliederten Würmern eutgegenstellten; aber überzengt von der Richtigkeit seiner Anschauung suchte er dieselbe nach jeder Richtung zu festigen. So entsprang, im konsequenten Ausbau der auf die erstgefundene Beobachtung gegründeten Theorie, eine Reihe von Untersuchungen, in welchen er die Uebereinstimmung im Bau der Wirbelthiere und Gliederwürmer auch noch für andere Organsysteme als den Urogenitalapparat nachzuweisen suchte, und in welchen er einige höchst wichtige Probleme der thierischen Morphologie, vor allem das der Segmentirung, der Knospung und Strobilation etc., sowoll durch eigene Beobachtungen, wie durch eingehende logische Zergliederung wesentlich förderte.

Es ist SEmper nicht gelungen, mit seiner Anschauung von der Abstammung der Wirbelthiere zu allgemeiner Anerkennung durchzudringen; er hat indessen durch die in seinen diesbeziuglichen Werken niedergelegten Beobachtungen und Betrachtungen nicht nur für die berïhrten speziellen Gebiete, sondern auch für die allgemeinen Fragen einen ausserordentlich anregenden Einfluss auf die weitere Entwickelung der berührten Probleme ausgeübt. Von den hierher gehörigen speziellen Untersuchungen sind in erster Linie diejenigen ủber die Urogenitalorgane der Haie und die über die Knospungsvorgänge bei Wiirmern von bleibendem Werthe. -

Das zweite Werk, durch das SEMPER die durch DARWIN neu angeregten Probleme der Zoologie förderte, ist sein Buch über "Die natürlichen Existenzbedingungen der Thiere (84), das, wie früher erwähnt, aus den im Jahre 1877 in Amerika gehaltenen Vorträgen hervorgegangen ist.

Der Grundgedanke, von dem er in diesem. Werke ausgeht, ist der, dass man endlich einmal anfangen muisse, der DARwin'schen Lehre dadurch eine weitere, festere Grundlage zu verleihen, dass man das Wesen der Begriffe mit denen sie operire, auf experimentellem Wege näher zu begründen versuche. Als Ausgangspunkt hierfür erschien ihm die Variabilität der Organismen am geeignetsten zu sein, da man hier am eliesten hoffen könne, durch exakt angestellte Untersuchungen die Einwirkung bestimmter Ursachen festzustellen. Um diese Aufgabe vorzubereiten, sei in erster Linie eine Sammlung und Sichtung des vorhandenen Materials nothwendig. Diese giebt er denn auch, indem er den Einfluss der verschiedenen äusseren Bedingungen auf die lebenden Organismen ermittelt. 
Indessen ist das ausserordentlich anregend geschriebene Buch durchaus keine Compilation. Denn abgesehen davon, dass der Gegenstand vielfach durch neue Ideen durchdrungen und gefördert wird, ist eine sehr grosse Menge von eigenen biologischen Beobachtungen, die grösstentheils auf seine Reiseerfahrungen zurickzufuihren sind, darin enthalten. Besonders bemerkenswerth ist im Speziellen die Darstellung seiner schon früher an anderer Stelle begrïndeten Theorie über den Bau und die Entstehung der Korallenriffe, die zum grrossen Theil eine mühsam erworbene Frucht seines Aufenthaltes auf den Palau-Inseln darstellt. -

Ausser den in Vorstehendem besprochenen, grösstentheils grundlegenden Schriften hat Sexper die Zoologie noch um eine ganze Reihe kleinerer Arbeiten bereichert, die meistens mehr in's Einzelne gehende Probleme berühren und deren genauere Schilderung hier wohl iubergangen werden kann; das Angeführte diirfte wohl auch geniigen, um den Charakter SEMPER's als zoologischer Sehriftsteller in grossen Zügen anzudeuten.

Einen Theil seiner eigenen Arbeiten hat er zusammen mit Arbeiten seiner Schüler in den "Arbeiten aus dem zoologisch-zootomischen Institut zu Wuirzburg" zusammen herausgegeben. Die Zahl von 10 Bänden, die erreicht worden ist, zeigt wohl deutlich, dass SeMPER in reichem Maasse zu eigenem Forschen anzuregen vermochte. -

Aber auch noch auf anderem Gebiete ist SEMPER litterarisch thätig gewesen. Seine Reisen auf den Philippinen führten ihn sehr oft in Gegenden, die vorher nur sehr wenig von Europäern betreten worden waren und deren anthropologische und ethnographische Kenntniss noch mehr oder weniger in den Anfängen lag. So war es denn nur natürlich, dass er auch diese Dinge mit zum Gegenstande seiner Forschung machte, und in der 'That dankt man ihm auch in genannter Hinsicht manche werthvolle Aufklärung. Wenn man von einigen einzelnen Aufsätzen $(10,11)$ absieht, sind es insbesondere zwei Schriften, die werthvolle Zeugnisse für diese Seite seiner wissenschaftlichen Thåtigkeit abgeben: Die erste derselben "Die Philippinen und ihre Bervohner" (24) beschäftigt sich besonders mit den geographischen und ethnologischen Verhältnissen der Inselgruppe, die zweite, „Die Palau-Inseln im Stillen Dcean" giebt eine höchst werthvolle abgerundete Darstellung der gesammtten, höchst interessanten. ethnologischen und geographischen Verhältnisse der PalauInseln, die um so werthvoller ist, als vorher fast gar nichts über dieselben bekannt gewesen war.

Das Interesse SEMPER's für ethnographische und anthropologische Forschung, wie die Anerkennung, die er als Forscher auch auf diesen Gebieten gefunden hat, wird auch dadurch bekundet, dass er vom Jahre 1869 an unter die Zahl der Herausgeber des von ECKer und Lindenschmid begründeten "Archiv's für Anthropologie" eintrat.

Subjektiv und unmittelbar lohnender als litterarische Produktion ist vielleicht noch die akademische Lehrthätigkeit, wenigstens dann, wenn talentvolle Schüler dem Lehrer eine Gewähr dafür bieten, dass das, was er gewollt, auch uber die Dauer seines eigenen Lebens hinaus in gleicher Weise weiter gehegt und gepflegt werden wird. Auch in dieser 
Hinsicht durfte SEMPER in späteren Jahren auf eine gesegnete und ruhmreiche Thäigkeit zuruickblicken.

SEMrer hat es verstanden, eine selten stattliche Zahl dankbarel Schüler an sich zu ketten. Vor allem war es die Art und Weise, wie er dem Schuiler gegenübertrat, die diesen anzichen musste. Auch in dem juingeren noch Belehrung suchenden Fachgenossen achtete er schon den selbstständig denkenden Collegen; collegial und freundschaftich war demgemäss der Verkehr, den er mit seineu Schillern pflegte und der sich durchaus nicht nur auf die Stunden des offiziellen Lehrens und Lernens beschrainkte. Die Sehiiler des Würzburger Institutes bildeten zu der Zeit, da SEMPER auf der Höhe seiner Lehrthätigkeit stand, eine Familie, deren Haupt er bildete. Dabei verstand er es aber in mustergiiltiger Weise, nicht nur den individuellen 'Ziigen des Einzelnen gerecht zu werden, sondern, was beinahe woch wichtiger war, jeden Einzelnen zur Ausbildung seiner eigenen Individualität, d. h. zur Selbstständigkeit anzuregen. SExrer hat dadurch, obwohl er viele Schüler hatte, in eigentlichen Sinne des Wortes keine Schule gebildet. Denn das njurare in verba magistri" war bei ihm nicht Grundsatz, und er war sich selbst zu sehr seiner eigenen Selbstståndigkeit bewusst, als dass er diese an anderen geringer geschiitzt hiitte, als an sich selbst. -

Die Errfolge SEMren's als Lehrer hängen - wie das ja ganz natïrlich ist - auf's Engste mit der Eigenartigkeit seines persönlichen Charakters zusammen.

Als Grundzüge seines Charakters aber muss man in erster Linie das Bedürfniss nach Selbststäudigkeit und das Vertrauen auf die eigene Krraft bezeichnen; sie befähigten ihn dazu, seine Tropenreisen, welehe nicht gewöhnliche zoologische Sammelexkursionen, sondern zum 'Theil recht schwierige und geführliche Forschungsreisen gewesen sind, auszufulhren, sie charakterisiren seine 'Thätigkeit als wissenschaftlicher Schriftsteller, sie befühigten ihn schliesslich nicht zum Geringsten zu dem hervorragenden Einfluss, den er als Lehrer ausgeübt hat. Deun dem Lernenden gegenüber, der den Werth des Lehrers mehr nur dem Gefühl nach und vor allem in subjektiver Weise empfindet, ist der persönliche Eindruck von nicht geringerer Wichtigkeit, als die rein objektive wissenschaftliche Bedeutung. Beides vereinigte sich bei SEMPER in harmonischer Weise. Man empfand, wenn man ihm gegenubertrat, unmittelbar, dass man es mit einem hervorragenden und selbstständig denkenden Manne zu thun hatte. In gleicher Gestalt wird er aber nicht nur im Herzen seiner dankbaren Schüler, sondern auch in der Geschichte der Wissenschaft lebendig bleiben.

Das diesem Lebensabriss beigegebene Porträt SEnI'ER's wurde nach einem in seinen letzten Lebensjahren von Fräulein MARIA LÜBBES ausgeführten Oelgemälde, mit freundlicher Genehmigung der Künstlerin, durch J. B. OBERnetTer in München in Heliogravüre hergestellt. 


\section{Terzeichniss von Semper's Schriften.}

1. Beiträge zur Anatomie und Physiologie der Pulmonaten (Dissertat.). In: Zeitschr. f. wiss. Zool. VIII. 1856.

2. Ueber die Bildung der Flügel, Schuppen und Haare bei den Lepidopteren. Ibid. VIII. 19506.

3. Zur Anatomie und Entwickelungsgeschichte der Gattung Mysostoma. Ibid. IX. 1857.

4. Lettre sur le Cyphonautes compressus. In: Bull. Acad. Brux. 2 Sér. T. III. 1857.

5. Zum feineren Bau der Molluskenzunge. In: Zeitschr. f. wiss. Zool. IX. 1858.

6. Ueber die Entwickelung der Eucharis multicornis. Ibid. IX. 1858.

7. Zoologische Notiz (Ueber die Polypen der Cephea tuberculata). In: Arch. f. Naturgesch. 24. Jahrg. 1858.

8. Reiseberichte I. In: Zeitschr. f. wiss. Zool. X. 1859.

9. Reiseberichte II. Ibid. XI. 1860.

10. Reise durch die nordöstlichen Provinzen der Insel Luzon. In: Zeitschr. f. allgem. Erdkunde N. F. Band X. 1861 .

11. Reise durch die nördlichen Provinzen der Insel Luzon. In: Zeitschr, fo allgem. Erdkunde N. F. Band XIII. 1862.

12. Entwickelungsgeschichte der Ampullaria polita Deshayes nebst Mittheilungen über die Entwickelungsgeschichte einiger anderer Gastropoden aus den Tropen. In: Natuurkund. Verlandel. Utrechtsch Genontsch. van Kunsten en Wetensch. Utrecht 1862.

13. Einige Worte über Euplectella aspergillum Owen und seine Bewohner. In: Archiv f. Naturgeschichte Jahrg. 33. 1867.

14. Reiseberichte III. In: Zeitschr. f. wiss. Zool. XIII. 1863.

15. Reiseberichte IV. Ibid. XIV. 1864.

16. Ueber einige tropische Larvenformen. Ibid. XVII. 1867.

17. Holothurien. (Reisen im Archipel der Philippinen: II. Theil; Wissenschaftliche Resultate, I. Band.) Leipzig 1868.

18. Some remarkes on the New Genus Macrobrachium of Mr. Spence Bate. In: Proceed. Zool. Soc. London 1868 .

19. Ophiocrinus, eine neue Comatuliden-Gattung. In: Arch. f. Naturgesch. 34. Jahrg. Band I. 1868.

20. Holothurien aus Ost-Afrika (von der Decken's Reisen in Ost-Afrika. Band III. 1. Abth. 1869).

21. Ueber neue Kieselschwämme von den Philippinen. In: Verhandl. der Phys. Med. Ges. Würzburg. N. F. Band I. 1869. Würzburg.

22. Ueber Entstehung der Korallenriffe. Ibid.

23. Ueber die Gattung Rhopalodina. Ibid.

24. Die Philippinen und ihre Bewohner. Würzburg 1869.

25. Eine neue Testacellidengattung in Australien. In: Zeitschr. f. wiss. Zool. Band XIX. 1869. (Auch in: Nachrichtsbl. d. deutsch. Malak. Ges. 1. Jahrg. 1869.)

26. Zur Kenntniss von Gibbulina. In: Nachrichtsb1. d. deutsch. Malak. Ges. 1. Jahrg. 1869. 


\section{IX}

27. Zur Anatomie der Glandina algira Brug. In: Nachrichtsbl. d. deutsch. Malak. Ges, 1. Jahrg. 1869.

23. Nochmals Rhytida inaequalis. In: Nachrichtsb1. d. deutsch. Malak. Ges. I. Jahrg. 1869.

2!) Hoffentlich zum letzten Mal Rluytida inaequalis. In: Nachrichtsbl, d. deutsch. Malak. Ges. 2. Jahrg. 1870.

(i). Rhytida Strangei eine Testacellide. In: Nachrichtsbl. d. deutsch. Nalak. Ges. 2. Jahrg. 1870.

:31. Landmollusken. (Reisen im Archipel der Philippinen; II. Theil; wissenschaftliche Resultate. III. Band.) Wiesbaden 1870 - 93 .

:2. Die Kiefer von Philonycus carolinensis Bosc. und australis Bergh. In: Nachrichtsbl. d. deutsch. Malak. Ges. 3. Jahrg. 1871.

:::. Australische Testacelliden. In: Nachrichtsbl. d. deutsch. Malak. Ges. 3. Jahrg. 1871.

:I. Ueber Stoliczka's Untersuchungen indischer Landschnecken. In: Malakozool. Blätter 19. Band. 1872.

ii. Zoologische Aphorismen. In: Zeitschr. f. wiss. Zool. XXI1. 1872

: ii. Ueber das Wathsthum von Lymmaeus stagnalis. Vorläufige Mittheilung. In: VerhandI. d. Phys. Med. Ges. WVürzburg.. N. F. 3. Band. 1872.

:37. Ueber Generationswechsel bei Steinkorallen und über das M. Edward'sche Wachsthumsgesetz der Polypen. In: Zeitschr. f. wiss. Kool. XXII. 1872.

:i५. Die Palau-Inseln im Stillen Ocean. Leipzig 1873.

:99. Kurze naturwissenschaftliche Bemerkungen zu Herrn Huber's Kritik von Straus' neuestem Buche. In: Beil. z. Allg. 'Ztg. vom 16. Jan. 1873.

40. Fin letztes Wort. Ibid. 5. Febr. 1873.

41. Das zoologisch-zootomische Institut ler Universität Würzburg. In: Arbeiten a. d. zool.-zoot. Institut Würzburg. I. 1874.

42. Ueber Pycnogoniden wnd ihre in Hydroïden schmarotzenden Larvenformen. Ibid. I. 1874.

43. Kritische Günge. I. Morphologische und physiologische Untersuchungsmethoden. Ibid. I. 1874.

14. Ueber die Wachsthumsbedingungen des Lymnaers stagnalis. Ibid. I. 1874.

45. Kritische Gänge. II. Zoologie und vergleichende Anatomie. - III. Die Keimblättertheorie und die. Genealogie der 'I'hiere. Ibid. I. 1874.

46. Kurze anatomische Bemerkungen über Comatula. Ibid. I. 1874.

47. Ueber die Entstehung der geschichteten Cellulose-Ejpidermis der Ascidien. Ibid. II. 1874.

14. Ueber die Stammverwandtschaft der Wirbelthiere und Anneliden. In: Centralbl. f. med. Wissensch. 1874. No. 35.

4!. Segmentalorgane bei ausgewachseuen Haien. Ibid. 1874. No. 52.

:1). Das Urogenitalsystem der höheren Wirbelthiere, erklärt durch das der Plagiostomen. Ibid. 1874. No. 59/60.

¿1. Die Stammverwandtschaft der Wirbelthiere und Wirbellosen. In: Arbeiten a. d. zool.-zoot. Institut Würzburg. II. 1874 .

5).-. Bemerkungen über den Apparat zum Halten von niederen Seethieren. In: Zool. Gart. Band XV. 1874.

;:i. Kurze Bemerkungen über die Entstehungsweise der Mïller'schen und Wolf'schen Günge. In: Centralbl. f. d. med. Wissensch. 1875. No. 29.

j4. Ueber die Goette'sche Discontinuitätslehre des organischen Lebens. In: Arb. a. d. zool.-zoot. Institut Wüıburg. II. 1875.

‥ Bildung und Wachsthum der Keimdrüsen bei den Plagiostomen. In: Centralbl. f. d. med. Wissensch. 1875.

56. Ueber das Urogenitalsystem der Plagiostomen und seine Bedeutung für das der übrigen Wirbelthiere. Ibid. II. 1875. (Erschien anch zusammen mit No.51 in separater Ausgabe unter dem Titel: Die Verwandtschaftsbeziehungen der gegliederten Thiere; Würzburg 1875).

万i. Lettre à M. H. de Lacaze-Duthiers. In: Arch. de zool, exp. et gén. IV. 1875.

$\therefore$. On the Embryogeny of the Rhizozephala. In: Aun. Mag. Nat. Hist. 4. Ser. Vol. 15. 1875.

.)!. Die Identität im Typus der Gliederwürmer und Wirbelthiere. Vorläufige Mittheilung. In: Verhandl. d. Würzb. Phys. Med. Ges. N. F. IX. 1876. 
60. Die Verwandtschaftsheziehungen der gegliederten Thiere. III. Strobilation und Segmentation. In: Arb. a. d. zool.-zoot. Inst. Würzburg. III. 1876.

(i1. Der Haeckelismus in der Zoologie. Hamburg 1876.

(i.2. Die Grenzen und die Deduktion in der Zoologie. In: "Das Ausland". 1876.

6:3. Offener Brief an Herrn Professor Haeckel in Jena. Hamburg 1877.

15t. Ueber die morphologische Identität des Nervensystems und den allgemeinen Bautypus bei Wirbelthieren und Wirbellosen. In: Verh. d. Phys. Med. Ges. N. F. Band X. Würzburg, 1877.

(i5. Einige Bemerkungen über die Nephropneusten von Jhering. In: Arbeiten a. d. zool,-zoot. Institut Würzburg. III. 1877.

16i. Bciträge zur Biologie der Oligochaeten. In: Arbeiten a. d. zool.-zoot. Institut Würzburg. IV. 1877.

6i. Ueber die Entwickelung der Rückenangen von Onchidium. In: Verh. d. Pbys. Med. Ges. Würzburg. N. F. XII. Band 1878. Sitz.-Ber. f. 1876-77.

68. Ueber Schneckenaugen vom Wirbelthiertypus, nebst Bemerkungen über einige andere histologische Eigenthümlickeiten verschiedener Cephalophoren. In: Arch. f. mikrosk. Anat. 1877.

6!). Ueber Sehorgane rom Typus der Wirbelthieraugen auf dem Rücken von Schnecken. (Ergänzungsheft z. 1II. Band der Reisen im Archipel der Philippinen. Wiesbaden 1877.)

71. Sind die Segmentalorgane der Anneliden homolog mit denen der Wirbelthiere? In: Morpholog. Jahrb. Band IV. 1878.

71. Ueber die Lunge von Birgus latro. In: Zeitschr. f. wiss. Zool. XXX. 1878.

T2. Ueber eine Mcthode, Axolotl-Eier jederzeit zu erzeugen. In: Zool. Anz. Band I. 1878.

73. Die systematische Stellumg von Pfeifferia. In: Nachrichtsbl. d. deutsch. Malak. Ges. X. Jahrg. 1878.

7t. Zur Wahrung meines prinzipiellen Standpunkts. Erwiderung auf Herrn Prof. Fürbringer's Artikel "Ueber die Homologie etc." In: Morphol. Jahrb. Band V. 1879.

75. Herr Prof. Fürbringer als Philosoph. In: Arbeiten a. d. zool.-zoot. Institut Würzburg. V. 1879.

iti. Ueber die Aufgaben der modernen Thiergeographie. In: Samml. gemeinv. wiss. Vorträge. (Virchow). H. 322. 1879.

77. Ueber die Abstammung der Organismen. In: Monatsbl, d. wiss. Clubs in Wien. Jahrg. I. 1879.

78. Ueber die Anwendbarkeit der monophyletischen und polyphyletischen Abstammungs-Hypothese. In: Vierteljabrsschrift f. wiss. Philos. IV. 1880.

79. Einige Bemerkungen über den Kalksack des Samenleiters der Zonitiden. In: Nachrichtsbl. d. deutsch. Malak. Ges. 1880.

80. Anatomische Beschreibung von Caracollus marginella. Ibid. 1880.

81. Anatomische Beschreibung von Helicophanta magnifica Fér. Ibid. 1880.

8.2. Ueber eine chamnisfarbene Spielart der Hausmaus. In: Zoolog. Garten. 1880.

\&:; Mein Amselprozess, die Amsel-Fanatiker und der Vogelschutz. Würzburg 1880.

84. Die natürlichen Existenzbedingungen der Thiere. 2 Theile. Leipzig 1880. (Auch in engl. Uebersetzung. London 1880.) (Internat. wissensch. Bibl. Band XXXIX.)

85. Neue Methode anatomische Präparate herzustellen. In: Verhandl. d. Phys. Med. Ges. Würaburg. N. F. Bd. XV. (1881).

86. Bemerkungen zu Herrn Dr. Riehm's Notiz: „Eine neue Methode der Trockenpräparation“. In: Zool. Anz. Band V. 1882.

87. Zoologie und Anatomie. Eine Erwiderung auf Herrn von Köl]iker's Rede: „Die Aufgaben der anatomischen Institute". In: Arbeiten a. d. zool.-zoot. Institut Würzburg. VII. 1884.

S8. Ueber Brock's Ansichten über Entwickelung des Mollusken-Genitalsystems. Ibid. VIII. 1887.

\&:!. Beobachtungen ans den Aquarien des neuen zoologischen Instituts. Ibid. X. 1891.

911. Ueber die Niere der Pulmonaten. Aus dem Nachlasse von Dr. C. Semper herausgegeben und ergänzt von Dr. H. Simroth. Wiesbaden 1894. 



\section{Ordo ASCOGLOSSA.}

\section{Familie 1. ELYSIADAE.}

Vergl. Heft IV. 1S72. p. 175-203.

Gen. Elysia, (Risso) autt.

Vergl. 1. c. p. $176-190$.

El. viridis, (MTG.).

Elysia viridis. Verdis, Catal. 1846. p. 19. 'Tav. II. Fig. 1.

- R. BERGH, malacolog. Unters. Heft IV. 1872. p. 178-185.

G. O. SARS, Bidr. til Kundsk. on Norges arlst. Fauna. I. Moll. reg. arct. Norv. 1878, p. 322. Tab. XVI. Fig. 14abc].

Aus der zoologischen Station von Trieste erhielt ich durch Dr. GliafrFe in den ersten Wochen von März 1880 sechs lebende Individuen dieser Art, die während der 5 tägigen Reise sich im selbigen Mecreswasser lebend und munter erhalten hatten, und sich lebend, wie ron GrAY ${ }^{1}$ ) und Meyer und Mö̈IUS ${ }^{2}$ ) näher geschildert, verhielten. Doch muss noch, bemerkt werden, dass diese Thiere so zu sagen nur am und mit dem vorderen Fussstiicke kriechen und den Körper dann nachziehen. Die an den Seiten der Pokale abgesetzten schnurförmigen fast farblosen Laiche bildeten jeder einen grossen Bogen; dessen Chorde eine Liinge ron etra $15 \mathrm{~mm}$ bei einer Breite des Laiches von etwa $1,5 \mathrm{~mm}$ hatte. ${ }^{3}$ ) In einem ganz geschlossenen Pokale von einem Gelalt von etwa anderthalb Liter Wasser habe ich die Thiere (unter stetiger Abnahme an Grösse) volle $2 \frac{1}{2}$ Monate lebend crlialten.

Die grössten dieser Individuen erreichten eine $\mathrm{L}$ ïnge bis $4 \mathrm{Cm}$. bei einer Breite bis $4 \mathrm{~mm}$; die Breite jedes Fliigels bis $6 \mathrm{~mm}$, die Rhinophorien bis $3 \mathrm{~mm}$ hoch, die Breite der Fusssolle bis $3,5 \mathrm{~mm}$. - Die Farbe der oberen Seite war grüinlichbraunschwarz oder dunkel grünbraungran; die Rhinophorien längs der Ränder der Spitzc

1) Grar, note on the habits of Aplysiopterus viridis. Anz. mngz. n. h. 3 S. IV. 1859. p. 239.

2) Merer und Mübrus, Fauna der Kieler Bucht. I. 1865. p. 10.

3) Vergl. Verant, l. c. p. 19.

Semper, Philippinen. II, II (Bergh, Ergänzungsheft I.). 
weiss oder weisslich, von eben derselben Farbe war auch eine langgestreckte Gegend um die schwarzen Augen, welche sich weiter gegen den Grund der Rhinophorien fortsetzte; die Seitentheile und das Hinterende des Pericardiallö̈ckers weisslich, so auch die Gegend der Analpapille und ein Streifen vou derselben bis an die Querfurche des Fusses hinab; der Rand der Fliigel hier und da weiss. An der Aussenseite der Fluigel nur ganz schwache Spuren ron weissen Punkten; die Innenseite derselben heller als die Aussenseite, die Rïckenschnitre und ihre Aeste sehr deutlich, grauweisslich. Der Vorderrand des Kopfes schwar\%, die Mindgegend weisslich. Der Vorderrand des Fusses und fast seine ganze Mittellinie weisslich, sonst ist die Fusssohle graulich mit durchschimmernden dichtstehenden, verzweigten, kleinen griinlichen Figuren. - Etwa am Anfange des zweiten Drittels der Fusslinge oder mehr vorne schimmerte ein weisser oder weissgelber ovaler Körper (die Schleimdrise) hindurch.

Von dem vordersten Theile der Seitenränder des Pericardialhöckers gingen bei zwei Individuen 2-3 kleinere Schnüre aus, vou der Mitte des Seitenrandes eine stärkere; die zwei langen Rïckenschnïre verhielten sich hier wie gewöhnlich.

Zwei Individuen wurden genauer (anatomisch) untersucht.

Das Centralnervensystem wurde an zwei Individuen untersucht. Die zwei grüsstẹ der 7 Ganglien, die cerebralen, in der Mittellinie oben zusammenstossend, gegen unten durch eine kurze deutliche Commissur mit den pedalen und gegen hinten (und oben) durch eine :ihnliche mit den visceralen verbunden. Die pedalen Ganglien cin wenig kleiner als die cerebralen, unten durch eine ziemlich schmale (vom Genitalganglion bedeckte) Commissur verbunden, deren Breite kaum die Hälite des Querdurchmessers der Ganglien betrug; von jedem Ganglion gingen drei starke Nerven aus, die zwei vorderen, die Nn. epipodiales, fuir die Epipodien (Rückenflügel), der lhintere, N. pediacus, fuir den Fuss selbst. Die visceralen Ganglien an den Uebergangsstellen zwischen den cercbralen und pedalen Ganglien ruhend, durch eine ziemlich kurze deutliche Commissur mit dem Gehirnknoten verbunden, an den Fussknoten fest (und wahrscheinlich) durch eine kurze Conmissur geheftet; gegen hinten auch durch eine kurze Commissur mit dem umparen Genitalganglion verbunden. Das linke Ganglion war kleiner als das rechte, und die Nervenzellen desselben grösser. Jedes Ganglion gab dem Rücken einen langen starken N. pallialis. Das mit den beiden Visceralganglien in Verbindung stehende genitale Ganglion, das nur einen an der visceralen Commissur stirker entwickelten Nervenknoten darstellt, etwas groösser als die Visceralgauglien, fast so gross wie die pedalen; aus demselben entspringen zwei starke Nerven, von denen der eine der $N$. genitalis ist, welcher an die vordere Genitalmasse geht und sich in mehrere Aeste theilt, von denen der N. penis in das Begattungsorgan hineintritt und sich mit seinen Aesten weit hinein verfolgen liisst; der andere Nerv geht vielleicht an die Niere. ${ }^{\text {) }}$

1) Vergl. II. v. Juening, vergl. Anat. d. Nervensyst. u. Phylogenie der MIollusken. 1S77. p. 200. 
Die kalkweissen Drüsenmassen des Vorderendes des Schlundkopfes wie gewöhnlich. Der Selilundk op etwa $1,25 \mathrm{~mm}$ lang. In der oberen Zahnplattenreihe der Zunge (an beiden Individuen) 9 entwickelte und eine unentwickelte Zahmplatte, in der unteren 12-14 Zahmplatten und in dem kleinen Raspelsacke etwa 20. Die Zahnplatien ganz wie früher von mir (1. c. p. 181) beschrieben. - Der Magen und die Leberginge wie frither angegeben.

Die Samenblase kugelrund, ron etwa 0,S mm Durchmesser. Die Ampulle des Samenganges am oder im Grunde des Penis wic geroühnlich. Der Penis stark, kegelförmig, ein wenig gebogen, 1,6-2 mm lang; am Grunde etwas schwarz pigmentirt; eine starke Art. penis trat am Grunde des Organs in dasselbe und konnte eine Strecke weit verfolgt werden.

GraffFe sah die Thiere in Triest schon im Jamuar laichen und hier in Kopenhagen setzten sie im Mairz den Laich an den Wiinden des Glases ab. Der Laich bildet nach GrafFFe ein abgeflachtes bandfürmiges, in eine einfache kurze flache Spirale gerolltes Band; GraEFFE sah "dasselbe Thier mehrere solche Laichschnire ablegen". ${ }^{1}$ )

El. viridis (MTG.), var. lactea.

? El. timida, Rrsso. Hist. nat. - de l'Eur. mér. IV. 1826. 1. 45.")

Hab. M. mediterr. (Adriat.).

Von diesem wunderschönen Thiere erhielt ich im October 1579 aus der zoologischen Station von Trieste durch Dr. GraffFe, in Sccwasser lebend und munter, cin Individuum. - Die Liinge des Thieres betrug bis $11 \mathrm{~mm}$ bei einer Breite bis 2 und einer Höhe bis 2,5 mm; die Länge der Rhinophorien war fast 3, dic des Schwanzes etwa $1 \mathrm{~mm}$; die Breite des Fusses beiläufig. $1 \mathrm{~mm}$. Der Kiopf und besonders die Stirn ron schöner milchweisser Farbe; an den Lippen schimmerten grine, feine, gegen die Mund¿ffumug gerichtete Streifchen hindureh; am Kopfe ïberall sparsam zerstrente, stark rothe, runde Fleckehen von einem Diam. bis etwa $0,3 \mathrm{~mm}$. Die Rhinophorien auch milchweiss an der Hinterseite und an den Rïndern, mit einzelnen zerstreuten, den oben erwïhnten :ihnlichen rothen Fleckchen; die Innenseite der Organe im unteren Drittel dagegen griin, und dieses Grime auch unten an der Aussenseite durchschimmernd; dieselbe Farbe setzte sich noch weiter iber die Seitentheile des IIalses fort. Hinter dem Grunde des

1) Trinchese hat (Rendic. delle sessioni dell'accad. - di Bologna. 1S79. p. 12S) neulich einige kurze Notizen über die Eifurchung der Elysia viridis geliefert.

2) Auch Verasy (Catal. des moll. - des envir. de Nice. Jouru. de conchyl. IV. 1S53. p. 391) scheint die El. timida mit der typischen Art zu identificiren.

Der von Risso früher (sur quelques gastér. nouv. Nudibr. et Tectibr, observées dans la mer de Nice. Journ. de phys. LXXXVII. 1S1S. p. 375) beschricbene Notarchus timidus, den er da mit seiner El. timid̉a identificirt, wird wahrscheinlich eine Aplysiade sein.

Einige von Broxs (Ergebn. meiner naturh.-öconom. Reisen I. 1826. p. 1\$1) nachgelassene Notizen flössen keiu grosses Vertrauen in die Wissenschaftlichkeit ron Risso eill. 
Hinterrandes der Rhinophorien die schwarzen Augenflecken. Die durchschimmernde grine Farbe des Halses setzt sich gegen oben hinter dem (wie der Kopf) weissen und mit den oben erwähnten :ihnlichen rothen Fleckchen versehenen Pericardialhöcker in die griine Farbe des Riickens fort, wiihrend sie gegen hinten sich in ein durchschimmerndes dunkel grasgriines Band verlïngert, das sich oberhalb des Fussrandes bis an das Ende der Fussflügel hinzieht. Die Fussfligel sind an der Aussenseite auch schön milchweiss, mit ziemlich zahlreich zerstreuten, den oben erwähnten ganz ähnlichen karminrothen Fleckchen, unter denen hinten und unten sich cinzelne rothgelbe und schwarzgrine eingemischt finden; der Rand der Flügel dagegen ganz ohne Fleckchen; die Inmenseite der Fussflügel so wie der eigentliche Rücken lebhaft grasgrün, mit einem medianen helleren Streifen. Der l'uss weiss, der Mitte entlang und zwar besonders in dem vorderen Stuicke, mit einem durchschimmernden breiten grünen Bande; der Schwanz milchweiss.

Die Formverhailtnisse des Thieres waren ganz wie gewöhnlich, nur die Rhinophorien ungevöhnlich gross.

Das Thier hatte nach 12 tïgiger Gefangenschaft an Grösse abgenommen, sonst war es sehr munter.

Das in schwachem Alcohol getödtete Thier fand sich, in Alcohol bewalırt, auf $5 \mathrm{~mm}$ zusammengezogen. Die Farbe war (nach 10 Monaten) ganz weiss, aber die grösseren rothgranen Punkte noch iiberall unter der Loupe sichtbar. Die grossen Rhinophorien und die liiickenschniure wie gewölnnlich.

Das Centralnervensystem wie in der typischen Form; das linke viscerale Ganglion auch kleiner als das rechte. - Die Augen verhillnissmäissig gross, von kurzer [Biruform, mit dem, wie gewölnnlich, nicht kurzen N. opticus als Stiel; der liingste Durchmesser etwa $0,16 \mathrm{~mm}$ betragend. Die Ohrblasen ganz kurzstielig, kugelrund, von ctwa $0,03 \mathrm{~mm}$ Diam.; der Otolith stark lichtbrechend, gelblich, kugelrund, von beiläufig 0,013 mm Durchmesser, ron strahligem Bruche.

Dic Drisenmassen an Vurderende des Schlundkopfes wie gewöhnlich. Der Schlundkopf ziemlich kurz, von gewönlicher Form. In der oberen Zahnplattenreihe 3 entwickelte und eine unentwickelte Platte, in der unteren 7, und in dem Raspelsacke wurden I8 gezihlhlt, von denen die kleinsten $0,08 \mathrm{~mm}$ massen. Die Zahnplatten waren sehr schwach gelblich, etwas mehr gestreckt als gewöhnlich, und die Zähnelung bei starker Vergrüsserung (800 mal) eben nur sichtbar; die Li̊nge der Zahnplatte der Zungenspitze belief sich auf 0,123 , und die der hintersten der Raspelscheide war beiläufig $0,13 \mathrm{~mm}$.

Der I'enis ron gewöhnlicher Form; der Samenleiter konnte durch seine ganze Liinge bis an die Spitze verfolgt werden.

Ubgleich in den Verhiiltnissen der Zahmplatten ron der typisehen etwas abweichend, wird diese Form sich doch wohl nux als eine Varietiit des in Farbentracht so sehr variablen El, viridis heransstellen. 


\section{Familie 2. PLAKOBRANCHIDAE.}

Vergl. Heft III. 1S72. p. $145-174$.

Gell. Plakobranchus, van Hass.

Vergl. 1. c. p. $146-174$.

Diese vor einigen Jahrzehuten (1824) von VAN HASSELT aufgestellte Gattung war vollständig unbekannt und unverstanden geblieben, bis sie vor einigen Jahren (1872) in diesem Worke einer monographisirenden Durchmusterung unterzogen wurde. Es wurde hier eine anatomische Untersuchung von 6 verschiedenen meistens nenen Arten ${ }^{1}$ ) geliefert. Die Kenntniss der Gruppe wird unteustehend noch mit der Untersuchung einer vou PEASE in seiner Zeit (1871) aufgestellten Art bereichert.

\section{Pl. variegatus, PEase.}

Placobranchus variegatus, P. Americ. Journ. of conchology. VI, 4. 1871. p. 303. pl. 21. Fig. 2 a b.

Plakobr. variegatus, P. BGir., 1. c. 1872 . 1\% $166^{\circ}$.

Color in universum brumescente griscus; plicae dorsales virides; pagina externa alarum pediaearum ocellis albidis ochracee pupillatis sicut anuulis et punctis nigris numerosis ornata: podarium ocellis minus numerosis, nigro pupillatis.

Dentes lingrales et hamus penis fere ut in Pl. ocellato.

H a b. Oc. pacific. (ins. Huaheine).

Taf. D. Fig. 30-33.

Von dieser, von PEASE (1871) beschriẻbenen und sonst bisher unbekannt gebliebenen Form hat Hr. Garrert in 1875 dem MIuseum Godefrizor ein in Alcohol gut berahrtes Individum geschickt, das er wieder bei der Insel Huaheine gefischt hatte.

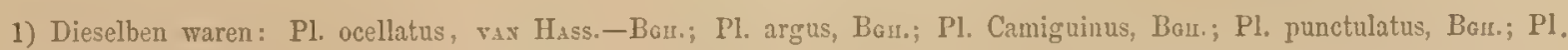
laetus, Bgrs.; Pl. priapinus, Barr. 
Pease zufolge erreichen die lebenden Thiere cine Länge von 21/2". Die Farbe soll durchgehend bräinlich-grau sein, heller an, der Unterseite; die Rückenfalten schön grin; der Kopf, der Pericardialhöeker und die Aussenseite der Fussflügel mit kleinen Augenflecken dicht bedeckt, ron denen die meisten eine gelbe oder ockergelbe Pupille und weisse Iris zeigen, unter denselben kommen zerstreute schwarze Punkte und Ringe vor; die Augenflecken des Körperrandes sollen besonders schönfarbig sein; an der Unterscite des Körpers (dem Fusse) sollen die Augenflecken sparsamer sein und schwarz pupillirt.

Die Linge des in Alcohol bewahrten Individuums betrug 13,5 bei einer Breite (vorne) bis 7 und einer Höhe bis $3,5 \mathrm{~mm}$; die Dieke an der Nitte des Kürpers (hintex dem Pericardialhöcker) etwa $2,5 \mathrm{~mm}$. - Die Farbe war am Pericardialhöcker und am Riicken (mit der oberen Seite der Fussflugel) hell (gelblich) weiss, am Kopfe mehr gelblich und noch mehr an Kö̈rper, heller an der Unterseite. An dem Kópfo vorne Andentungen ron kleinsten hellen Augenflecken, hinter denselben und wie in 2 undeutlieh geschiedenen Querreihen gestellte ziemlich grosse ockergelb pupillirte Augenflecken mit schwarzer Iris, unter denselben gemischt einzelne runde schwarze Flecken; hinter denselben und bis an den Periendialhöcker, vorne wie in $3-4$ undeutlich geschiedenen Reihen geordnet, otwas kleinere, auch ockergelb pupillirte, meistens mit braungelber Iris versehene Augenflecken, die oft noch einen weissliehen Hof zeigten. An der Aussenseite der Fussflïgel eine Menge ron kleinen goldgelben, meistens weisslich eingefassten Punkten (Augenfleckchen), unter denselben auch solche mit braunlicher oder schwairzlicher Iris. Am Körperrande eine meistens einfache, mitunter auch doppelte oder dreifache Reihe von ziemlich grossen Augenflecken, den oben erwähnten am Stirnrande ähnlich, aber noch grösser. Jer Vorderrand des Fusses schwarz. Die Fusssohle mit zerstreuten kleineren und grösseren, tiefsehwarzen, meistens wie yon einem hellen Hof ungebenen, rundlichen Flecken, die doch nicht die Grösse der grossen Randflecken erreichten. Das Körperende fast violetgrau.

Die Form die grewöhnliche. Der Pericardialhöcker wenig hervortretend, breitherzförmig. Die Falten des Ruickens ziemlich sehmal, an der Mitte der Körperlïnge etwa 30 betragend; der Rand der Fussfliigel mit der gewöhnlichen Randfurche. Die Anal- und Genitalöfthung an den gewöhnlichen Stellen. Die Länge des vorderen Fussetiiekes 2 mm oder etwa $1 / \%$ der ganzen Fusslïinge betragend.

Das Centralnervensystem wie bei anderen Formen ${ }^{1}$ ); das Gangl. genitale ron der Grösse der Fussknoten, das rechte viscerale Ganglion griosser als das linke.

Die A ugen mit pechschwarzem Pigmente. Die Ohrblasen von etwa $0,08 \mathrm{~mm}$ Diam., mit stark lichtbrechendem gelblichem Otolithe von fast $0,012 \mathrm{~mm}$ Diam. (Fig. $30 \mathrm{c}$ ).

Das Vorderende des Selilundkopfes ron den gewöhnlichen 4 grosen weisslichen Driisemmassen bedeckt. Die Länge desselben etwa $1,25 \mathrm{~mm}$. betragend; die Querreifen

1) Vergl. 1. c. Taf. XVII. Fig. S. 
wie gewöhnlich, in Anzahl etwa 12-13; der kropfartige Ansatz wie gewöhnlich. Die Zahl der oberen Zahnplatten betrug.10 (9 entwickelte und eine unentwickelte); die der unteren war 9, wozu noch die (wenigstens etwa 90) des grossen runden Raspelsackes kamen. Die Platten hell horngelb, von gewöhnlichen (Fig. 31) Formverhältnissen; die Zahl der Zähnchen meistens 17-18 und am Grunde des Hakens noch dazu Andeutungen ron 2-3 kleineren. Die Liinge der Platte der Zungenspitze (Fig. 31 a) 0,14, die der jüngsten etwa $0,147 \mathrm{~mm}$ betragend.

Die Speiseröhre wie gewöhmlich, ebenso der Magen, der fast kugelfürmig; von kaum 0,6 mm. Durehmesser war.

Die Genital-Follikel wie gerwöhnlich. Die Schleimdriise etwa 3 mm lang; die zwei kugelfürmigen Samenblasen wie gewöhnlich. Der Penis etwa $2 \mathrm{~mm}$ lang; der Haken des Penis ziemlich stark gekriimmt (Fig. 32), hinter der Spitze ron 0,037 mm Diam., mit Oeffnung an der Spitze, aber die Unterseite des Inakens noch stachelförmig hervortretend (Fig. 33).

Diese Art stimmt in der Form der Zahmplatten, sowie des PenisStachels so ziemlich mit dem Pl. ocellatus, wie derselbe von mir beschrieben ist (vgl. 1. c. p. 147-151. Taf. XIX. Fig 1-13), und vielleicht wird sie sich nur als cine Varietät desselben bei späterer Untersuchung zeigen. Die Farbenverhältnisse, besonders die der Fusssohle und des Kürperendes scheinen doch aber nicht recht übereinzustimmen, wesshalb ich das Thier wenigstens vorläufig als besondere Art habe stehen lassen. 


\section{Ordo POROSTOMATA.}

Vergl. Heft X. 1876. Umschlagblatt.

R. Bergir, Die Doriopsen des atlantischen Meeres. Jahrb. der deutsch. malakozool. Ges. VI. 1879. p. 42.

\section{Familie 1. PHYLLIDIADAE.}

Gen. Phyllidia, (Cuv.) BGr.

Vergl. Heft X. 1876. p. 379 .

Ph. varicosa, Luck. var.

Vergl. Heft X. 1876. pag. $350-351$.

Von dieser schönen Varietät hat Dr. STUDer am 2. Mai 1875 während der Expedition der Gazelle aus einer Tiefe von etwa 50 Faden im Dampierre-Archipel (in der Nähe der Nord-Westkiiste von Australien) ein einziges Individum aufgefischt, das ich im Berliner Museum (Juli 1876) vorfand.

Das Individuum war von mittlerer Grösse, etwa 4,5 Cm. lang und im Leben, Studer zufolge, kaum vicl grösser. Das Thier gab, nach dem Zeugnisse Studers's, keinen Geruch von sich. Der colorirten Skizze und den mir freundlich geliehenen Notizen Studer's zufolge zeigte das lebende 'Thier an der Ruickenseite ein continuirliches medianes blauschwarzes Band und lïngs des Randes jederseits ein breiteres von ähnlicher Farbe, zwischen jenem und diesen ein hellblanes Band; die Riickenknoten so wie der Mantelrand hochgelb. Die Tentakel und die Fusssohle hellblau; die Unterseite des Mantels blanschwarz, der Rand hochgelb. - Das in Alkohol bewahrte Individumm unterschied sich kaum von anderen Individuen der Ph. varicosa. Anatomische Untersuchung wurde nicht gestattet. 


\section{Familie 2. DORIOPSIDAE.}

VergI. Heft X. 1S76. p. 3St-3S7.

Gen. Doriopsis, Pease.

Vergl. 1. c. p. 385 .

Später habe ich in XIV. Hefte des Journ. des Ilus. Godefrioy (1879. p. 22) die fruher gegebene Uebersichtsliste ron Doriopsen noch erweitert und in meinen "Doriopsen des atlantischen Meeres" (Jahrb. d. deutschen malakozoolog. Ges. VI. 1879. 1).42-64) noch eine neue Art (I) atropos aus dem Ix́üstengebiete vou Brasilien) zugefiigt. Die Ciruppe sollte somit etwa 49 (angegebene) Arten umfassen. Hierzu kommen noch einzelne rou Abrahan (Proc. zool. soc. 1877, II) in nenerer Zeit angegebene, mehr oder weniger zweifelhafte Formen, ${ }^{1}$ ) welche, zum 'Theil selbst der Herkunft nach unbekannt, den Umständen nach besser ganz unerwähnt geblieben wiren, wie ich sie im Brit. Museum auch unbericksichtigt liess.

50. Dor. australiensis, ABr. l. c. p. 263. pl. XXX. Fig. 25, 26.

Oc. pacif. (New South Wales).

51. - obscura, Ais. 1. c. p. 263. pl. XXX. Fig. 29, 30.

IIab.?

52. - fumea, Aвr. 1. c. p. 264. pl. XXX. Fig. 31, 32.

Hab.?

53. - foedata, ABr. 1. c. p. 264. pl. XXLX. Fig. 22.

Hab.?

54. - inornata, Aвr. 1. c. p. 265. pl. XXX. Fig. 33-35.

M. mediterr. ${ }^{2}$ )

55. - subpellucida, ABR. I. c. p. 265. pl. XXX. Fig. 36.

I. antillense (St. Vincent).

56. - mammosa, ABr. 1. c. p. 266. pl. XXIX. Fig. 20, 21.

Hab.? (Oc. antarct.?)

1) Eine von Aвraнıм (Proc. 2001. soc. 1S77. II. p. 259. pl. XXIX. Fig. 27, 2S) angegebene „Doris Wellingtonensis" (aus der Umgegend ron New-Zealand) scheint auch eine Doriopse und zwar die Doriopsis lacera (C'vr.) zu sein.

2) Diese Art ist woll nur eine der vielen Varietäten der Doriopsis limbata (Crv.).

Semper, Plilippinen. II, Ir (Bergh, Erginzungsheft I). 
57. Dor. variata, ABR. 1. c. p. 267. pl. XXIX. Fig. 23, 24.

II. chinense (Ningpo).

58. - parra, ABR. 1. c. p. 267. pl. XXX. Fig. 27, 28.

Hab.?

1. D. debilis (PEASE).

- Doris debilis, PeAse. Americ. Journ. of conchol. VII. 1872, 1. (1871) p. 11. pl. 5. Fị. ?.

Doriopsis debilis, (Pease) BaH. Journ. d. Mus. Godeffroy. Heft VIII. 1875. p. 86.

Color fundamentalis e brunneo rubescens vel olivaceus vel niger, supra albide maculatus et punctatus; margo pallialis caerulescens; rhinophoria lamellis brunneis, apice albido; branchia olivacea.

H a b. Oc. pacific. (ins. Huaheine).

Taf. D. Fig. 27-29.

Diese ron PEAse gefundene Form - die wahrscheinlich der D. nigra (StIMPson; IIANCOCK $)^{1}$ ) sehr nahe steht - scheint PEAse zufolge in der Farbenzeichnung auch sehr variabel. Derselbe fand das Thier an Algen, in ziemlich geschützter Lage und erwähnt die Iebhaften Bewegungen desselben.

Hr. GAIRET' hat in 1875 als gleichfalls bei der Insel Huaheine gesammelt dem Mus. Goddefroy das unten untersuchte Individuum der ${ }_{n}$ Doris debilis, PEAse ${ }^{*}$ geschickt.

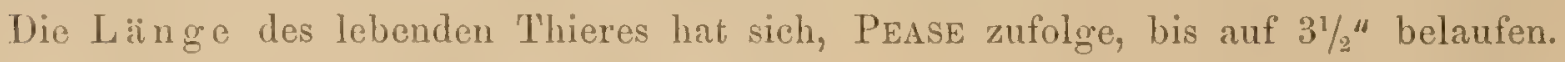
Die Liinge des in Alcohol bewahrten Individuums betrug etwa $12 \mathrm{~mm}$ bei einer Höhe bis 5 und einer Breite bis $7 \mathrm{~mm}$, die Breite des Nantelgebrämes belief sich bis auf 2; die Breite der Fusssohle war 4; die Höhe der Rhinophorien 1,5, die der Kieme 2 mm. - Die I a r be war oben durehgehend schwarz mit olivengrünem Schimmer und uiberall mit einer Unzahl von weissen Punkten und Pinktehen bedeckt; die Seiten grau; die obere Seite des Fusses schwiirzlich, ebenso mit grünlichem Schimmer, die untere etwas heller; die Rhinophorien von der Riickenfarbe, mit weissrandigen Lamellen und gelblicher Spitze; die Krieme von der dunklen Rỉickenfarbe.

Die von PEASE angegebene grössere-Schmalheit des Vorderkörpers fand sich am untersuchten Individum nicht vor. Die Mundöffnung wie gewöhnlich; kaum irgend eine Spur von Tentakeln; die Rhinophorien mit etwa 16 Blättern. Der R iicken ganz glatt; das Mantelgebrime ganz dium, wellenförmig herauf- und herabgeschlagen. Die Kieme sehr weit nach hinten stehend, PEASE zufolge wihrend des Lebens sehr gross; wie auch

1) Alder and HAxc., notice of a coll. of nudibr. moll. made in India. Trans. zool. soc. V, 3. 1564. p. 128-129. 
Ton PEASE angegeben, aus quadripinnaten Federn gebildet, die hinterste jeder Seite am Grunde wie aus 2-3 kleineren zusammengesetzt. Die Analpapille abgeplattet, rundlich. Die Seiten nicht niedrig; die gelbliche Genitalöfnung wie gerwöhnlich. Der Fuss bei dem lebenden Thiere, PEASE zufolge, das Mantelgebräme hinten nur unbedcutend iiberragend; das Vorderende ziemlich breit, mit der gewöhnlichen Randfurche.

Die Eingeweide nicht hindurchschimmernd. - Das Peritonaeum war farblos.

Das Centralnervensystem wie gewöhnlich. Die A ugen mit schwarzem Pigmente, gelblicher Linse; die Ohrblasen kleiner als die vorigen, mit etwa 150_200 Otokonien gewöhnlicher Art. Die Blätter der Rhinophorien nicht dün, ohne Spikeln. In der Ha ut zerstreute ganz kurze Spikeln.

Die (zurüickgezogene) Mundröhre etwa 1,5 mm lang, aussen und innen schwarz; ron dem gelblichen, nur am Grunde grauen, kurz-kegelförmigem Schlundkegel ausgefuillt, der von gewöhnlichem Baue war. - Die querovale, ziemlich lappige, gelblichweisse Mund $\mathrm{d}$ ỉs e von 2,5 mm gxösstem Diam.; der Ausführungsgang wie grewöhnlich.

Der Schlundkopf etwa $4 \mathrm{~mm}$ lang, in der vorderen Hälfte etwas enger. Die Speiseröhre etwa $6 \mathrm{~mm}$. lang, in der vorderen Hälfte wenig weiter als der Schlundkopf, in der letzten mit unregelmäissigen Einschnürungen; dic bindegervebige Hülle derselben etwas schwärzlich pigmentirt. Die Cardia- (Speichel-) driisen wie gewöhnlich. Der Darm wie gewöhnlich. Die Leber etwa $8,5 \mathrm{~mm}$ lang, graugelblich; das Hinterende gerundet, aber mit der gewöhnlichen tiefen, medianen Kluft; das Vorderende halsartig hervortretend; ihre Wände (Fig. 27) sehr dün. - Die Nierenspritze und die weite Urinkammer wie gewöhnlich.

Die vordere Genitalmasse etwa $2,5 \mathrm{~mm}$ lang. Die Ampulle kurz. Der Samenleiter aus den gewöhnlichen zwei Abtheilungen bestehend. Die Lünge des stacheligen Endes (Fig. 28) des Penis gegen 0,3 mm betragend; die Hühe der sehr sehwach gelblichen, wenig gekrummten Haken nur bis $0,008 \mathrm{~mm}$ steigend. Die Spermatotheke kugelförmig, von etwa $1 \mathrm{~mm}$ Diam.; die Spermatocyste etwas lainglicher, nur ron der lialben ränge. Am Uebergange des grossen Samenblasenganges in die Vagina fand sich eine gestreckt-stundenglasförmige, chitinisirte Auskleidung (Fig. 29), aihnlich der bei D. tristis nachgewiesenen. ${ }^{1}$ ) Die Drüse am Schleimdrüsengange klcin.

2. D. grisea, $\mathrm{B}_{\mathrm{GH}}$. n. sp.

Color fundamentalis cinereus, supra maculis parvis brunnescentibus; rhinophoria olivacea, branchia albescens.

$\mathrm{Hab}$. Oc. pacific. (ins. Huaheine).

Taf. A. Fig. 3-6.

Herr GanReTt, der in 1875 von dieser Art ein einziges Individuum , unter einem

1) Vergl. R. Bergu, neue Nacktschnecken d. Südsee, III. Journ. des MIus. Goderfrox. Heft VIlI. 1S75. p. 93. Taf. XI. Fig. 5. 
Corallen-Blocke am "iusseren Riffe" von Huaheine gefunden hat, bemerkt ausdrücklich, dass dasselbe von allen den ron PEASE beschriebenen Thieren specifisch verschieden sei. - Das im Mus. Godkfrey niedergelegte 'Thier wurde exviscerirt.

Friechend hat, Garretr zufolge, das Thier cine Liinge von $42 \mathrm{~mm}$. Die Farbe war nach ihm wihlend des Lebens aschgrau (-ashy-gray") mit kleinen braumen Fleckchen; die Rhinophorien nlivenfarbig (.,light olive"), die Kieme fast farblos („colourless6). - Das in Alcolıol bewahrte Individuum hatte cine Länge von etwa $18 \mathrm{~mm}$ bei einer Tühe bis 10 und einer Breite bis $12 \mathrm{~mm}$; die Breite des Fusses bis 10 , die Höhe der Rhinophorien 2,3, die der (zurickgezogenen) Kieme 3, und die Breite des Mantelgebrimes bis $4 \mathrm{~mm}$ betragend. Die Farbe durchgehends weisslich, am diunen Mantelgebrime etwas, mehr gelblich; am Kiieken iiberall eine Menge von braungrauen Punkten und darunter sparsam zerstrente grössere unregelmässige Fleckchen ähnlicher Farbe; am Vorderende des Mantelgebrämes waren die I'unkte besonders stark; die Rhinophorien hellgelblich, ebenso die Kieme, beide mit einzelnen bräunlichen Fleckehen.

Die Form des lebenden 'I'hieres scheint ziemlich gestreckt, das Mantelgebräme bei dem lebenden wie bei dem todten Thiere schr stark wellenförmig hinauf- und hinabgeschlagen. Der Ii icken glatt, erst unter einer starken Loupe traten ganz kleine, wenig erhabene Papillen hervor. $\left.{ }^{1}\right)$ Die Mundöftinung und die 'Tentakel wie gewöhnlich. Die Kenle der Rhinophorien mit etwa 30 breiten Blittern. Jie querovale Kiemenoffunug ron einem Durchmesser von fast $2 \mathrm{~mm}$; die (zuriickgezogene) Kieme aus 6 unglcichgrossen tripinnatifiden Federn gebildet. $\left.{ }^{2}\right)$ Die Analpapille kurz-conisch, etwa $1,5 \mathrm{~mm}$ hoch, mit einigen starken Längsfalten der Imnenseite. Die Seiten des Körpers niedrig. Der Fuss rorne wie hinten gerundet.

Dic Eingeveide nirgends hindurchschimmernd.

Das Centralnervensystem nicht breit; die cerebralen Knoten kleiner als die visceralen, mit denen die pedalen in Grösse fast iibereinstimmten. Die (proximalen) Iilechknoten zwiebelfürmig; die buccalen Ganglien wie grewöhnlich, nur das linke etwas grrösser als das rechte.

Die A ugen kurzstielig, mit pechschwarzem Pigmente und gelber Linse. Die Ohrblasen hinter der cerebro-visceralen Furche liegend, kleiner als die Angen, von Otokonien gewöhnlieher Art stratzend. Die Blätter der Rhinophorien olne erhärtete Zellen. Solche kamen auch nur sehr sparsam in der IIa ut vor; im Mantelgebräme dagregen grosse gelbe Dritisen, hier und da selbst in Menge.

Die ganz zuriekgezogene weisse, langgestreckte M undröhre von etwa $3,5 \mathrm{~mm}$ länge; hinten in derselben das etwa 1,3 mm lange, gestreckt-kegelförmige, herein-

1) Auch Garnetr bemerkt, dass das in Ganzen sehr weiche („very soft ${ }^{\star}$ ) Thier an der Rüclienseite fein granulirt („,minutely granulated") sei.

2) Garrett gielut deren nur 5 an. 
gestulpte Vorderende des weisslichen Schlundkopfes; lings des letzteren konnte das Ende des Munddruisenganges verfolgt werden. - Die Munddruse (wie der Schlundkopf und die Speiseröhre) weisslich, abgeplattet, herzfürmig, von etwa $3 \mathrm{~mm}$ grösstem Diam.; an der Unterseite eine Vertiefung, aus der der Gang mit den zwei Wurzeln hervortrat.

Der Schlundkopf ausgestreckt etwa 12,5 mm lang, in etwas mehr als der vorderen Hiilfte diinn, in der ubrigen dicker (bis cinem Diam. von etwa $1 \mathrm{~mm}$ ). Am himteren Ende jederseits die gewöhnliche Drïse, die weiss war und im Vorderende halsartig verschmälert. Die Speiseróh re ansgestreckt etwa 18 mm lang; im Canzen etwa ein halbes Mal so dick wie der Schlundkopf, in der rorderen Strecke (etwa Hälfte) mehr cylindrisch und ein wenig enger als in der hinteren, die mehrere Einschnirungen zeigte und durch einen ziemlich langen Hals mit der Leber verbunden war. Der Darm wie gewöhnlich. Die Verdanungshöhlo leer. - Die Leber zeigte im gerundeten Hinterende die gewöhnliche tiefe mediane Kluft; am Vorderende war sie wegen der vorderen Cienitalmasse ziemlich tief ausgehöhlt.

Die Blätter der Pericardial-Kieme weniger als gewöhnlich entwickelt. Die weisse Blutdriise etwa von der Grösse der Munddriise, melır abgeplattet. - Die N'ierenspritze ron beiläutig $1,5 \mathrm{~mm}$ Länge.

Die vordere Genitalmasse ron etwa $5,5 \mathrm{~mm}$ Lünge bei einer Höhe von 4 und einer Dicke von 3,5 mm, Die Ampulle des weisslichen Zwitterdriisenganges von etwa 3 mmi Länge, kurz-wurstförmig, braungrau. Der Samenleiter, wie gewöhnlich, sehr lang, aus den zwei gewöhnlichen Abtheilungen bestehend, in seiner äussersten Strecke kaum erweitert. Der mit Stacheln besetzte Penis-'Theil (zum grössten 'Theile ausgerissen?) kurz, mit etwa 15 Reihen von Haken, welche eine Hühe bis otwa $0,02 \mathrm{~mm}$ erreichten. Die Spermatotheke birnförmig, 2,5 mm lang; die Spermatocyste in Länge kaum $1 / 6$ ron jener und im Volumen noch vicl weniger betragend, kurz-birnförmig. Die Drise am weisslichen Sehleimdrisengange fast $1,5 \mathrm{~mm}$ lang, stark, graubraun. Die Schleimdrise zeigte an der Ininterseite einen Theil der gelblichen Masse (Eiweissdriise), die den Kern derselben bildete. 


\section{Ordo DORIDIDAE.}

Vergl, Heft X. 1S76. p. 3ss.

\section{Familie. DORID. CRYPTOBRANCHIATAE.}

Gen. Chromodoris, Ald. et Hanc.

Vergl. R. Bergir, Neue Nacktschn. d. Südsee. III. Journ. d. Mus. Goderrrox, Heft VIII. 1S75. p. 72-S2.

R. Bergh, Unters. d. Chromod. elegans u. villafranca. Malakozool. Bl. XXV. 1878. p. 1-36.

R. Beror, Neve Chromodoriden. Malakozool. Bl. N. F. I. 1879. p. $87-116$.

\section{Chr. villafranca (Risso).}

Chromodoris villafranca (Risso). R. BErgh, Unters. d. Chromod. elegans u. villafranca. Malakozool. Bl. XXV. 1878. p. 22-33. 'Taf. IV. Fig. 5-12.

H. v. JHerisa, Beitr. zur Kenntn. der Nudibranchien des Mittelmeeres. Malakozool. B1. N. F. II. 1880. p. 19-21.

Ha b. M. mediterr.

Von der Art habe ich wieder 11 Individuen zur Untersuchung gehabt, mir durch Dr. Graeffe aus der Zoologischen Station von Trieste geschickt, jn deren Nihe sie sich ,nicht selten finden soll, besonders an Steinen, die mit Bryozoen, Polypen oder Ascidien iiberzogen sind."

Die der Adria gehörende Varietait dieser Art weicht nicht wenig von der bei Neapel vorkommenden und daselbst von mir untersuchten ab. GraEFFE hat dem Leben nach zwei farbige Abbildungen jener geliefert; die Grundfarbe ist, diesen und den beifolgenden Notizen nach, himmelblan, meistens kommen am Ritcken ein medianer Doppelstreif und jederseits zwei einfache laterale von gelber Farbe vor; mehrere hellblaue Flecken, die ausserhalb der lateralen Riuckenstreifen von GraffFe erwähnt werden, reprïisentiren wohl die ron mir beschriebenen hellblauen Querbiinder des Riickens, dagegen sind die von mir erwïhnten ähnlichen hellblanen senkrechten Bänder der Seiten des Körpers in der Abbildung GraEFFE's sehr deutlich, sowie die sehrägen hellblauen Strichelchen derselben; , die Rhinophorien sowie die Kieme sind hellblau mit weissen Kanten an den Blättern jener, sowie die Hauptrippe der Kiemenblätter auch weiss"; während 
jene Ränder und diese Rippen bei den ron mir friher untersuchten Individuen gooldgelb waren.

Die 11 in Alcohol oder in GOADBY's Flüssigkeit bewahrten, von mir untersuchten Individuen, deren Länge zwischen 8 - $18 \mathrm{~mm}$ schwankte, stimmten im Ganzen mit einander sehr überein. Die (friiher hellblauen) Querbänder des Riickens und der Körperseiten (welehe als specifisches Merkmal doch vielleicht zu verwerthen sind) waren nie sichtbar. An der meistens zicmlich lebhaften und tiefen graublauen Grundfarbe traten die (friiher gelben) Linien weiss herwor. Nur bei einem Individuum fand sich eine fast so starke Anastomosirung der $R$ iickenbänder, wie von mir beschrieben. Das mediane Rückenband war bei einem Individuum stark und einfach durch seinen ganzen Verlauf; bei einem anderen auch fast ganz so, doch mit zwei Inselbildungen; bei allen den anderen bestand es aus zwei schmäleren, dicht nebeneinander verlaufenden, und mehr oder weniger häufig anastomosirenden Linien. Ausserhalb des medianen fanden sich die lateralen Bänder und dicht am Riickenrande ein fast ebenso starkes; zwischen diesen an zwei Individuen noch eine feinere Linie; zwischen den Längslinien kamen bei einzelnen Individuen noch schräge Strichelchen vor. Der Rïckenrand durch eine ziemlich starke Doppellinie geziert. Die Seiten des Körpers zeigten dicht am Rüickenrande ein feineres Band, auf etwa der Mitte der Höhe fand sich ein stïrkeres und dicht am Fussrande ein wieder etwas schwächeres, das mitunter doppelt war. Die zwischen den Bändern meistens vorkommenden Strichelchen gewöhnlich schräge (von oben nach vorne oder nach hinten) oder auch horizontal gehend.

Drei Individuen wurden geöffnet, und die Mundtheile derselben untersucht. - Der Schlundkopf von zwei untersuchten Individuen von grïlichgrauer Farbe, besonders an der Unterseite; 2,5 bis $4 \mathrm{~mm}$ lang, und die Raspelscheide noch 0,75 $\mathrm{mm}$ hervortretend. Die Lippenplatten unten von einander ganz geschieden, bis etwa $1,1 \mathrm{~mm}$ breit, hell schmutziggelb; die Elemente derselben an der Spitze mitunter gabelig. Die Zunge mit schöner griiner, schillernder Raspel, in weleher 25-26 Zahmplattenreihen, von denen die 2-3 ersten etwas incomplet; weiter gegen hinten 21-27-28 entwickelte und 6 nicht ganz entwickelte Reihen; die Gesammtzahl somit 52-58-60 betragend. In den hintersten Reihen der Zunge fanden sich bis 53-56-61 Platten vor. Die Platten hellgelblich mit schwachem grünlichem Schimmer, sonst wie fruher beschrieben. An der Rhachis (mitunter) schmale, abgeplattete unaichte Platten.

\section{Chr. gracilis (RArP).}

Doris gracilis, RAPP. Ueb. das Molluskengeschlecht Doris. Nov. Act. A. L. C. Nat. Curios. XIII, 2. 1827. p. 52. Tab. XXVII. Fig. 10. DElle Chiaje. Descriz. e notomia degli an. invertebr. della Sic. citer. ed. II. 1841. p. 20. 
Chromod. gracilis (RApP). BGH., 1. c. Journ. d. Mus. Godefrroy, Heft VIII. 1875. p. 74 .

- - delle Chimje. H. v. Jiering, l. c. p. 11-15. Taf. I. Fig. 3, Taf. II. Figg. 1-3.

Hab. M. mediterr. (Napoli, Trieste).

Diese seit langer Zeit (1827) dureh RAPp bekannte Form, mit der wahrscheinlich die ron DELlE ChIAJE erwihnte identisch sein wird, wurde erst ganz neulich, durch Jhering, genaucr bekannt. Die Art ist, Jiering zufolge, die „im Golfe von Neapel gemeinste Chromodoride", bei 'Trieste scheint sie dagegen viel seltener.

Die von Jinkring und von mir untersuchten Individuen stimmen in der Farbentracht mit einander sehr überein. JuEring hat eine Untersuchung des Schlundkopfes (der Lippenplatte und der Raspel) geliefert.

Ein Individuum dieser Art, das mir durch Dr. Graeffe im März 1880 lebend aus der Station ron Triest geschickt wurde, hatte eine Länge von 12 bei einer Breite bis $3 \mathrm{~mm}$. - Die Grund farbe des Riickens und der Körperseiten war dunkel schwarzblau. Am Riicken ein medianer gelber Streifen sich von der Gegend vor den Rhinophorien bis an das Kiemenloch erstreckend, den Rand desselben einfassend und sich durch das Schwanzsegel median fast bis an den Rand fortsetzend; der Strich theilweise in 2, mit einander anastomosirende aufgelöst. An jeder Seite des medianen Streifens ein schmälerer gelber, welcher vorne den Rand der Rhinophorhöhle einfasst, hier aber mehr weisslich ist; hinten setzt sich diese gelbe Linie bis an die Gegend der Kieme fort. Längs des Mantelrandes und in der Nähe desselben verliuft dann eine schmale himmelblaue schimmernde Linie, welche sich in der Gegend der Kieme und der Rhinophorien verliert. Der Mantelrand selbst ist endlich ron einer stärkeren doppelten, (ungleich) schmalen gelben Linie eingefasst, welche in eine breitere Linie verschmolzen das Schwanzsegel und das Stimsegel einfasst, an dem letzteren ist sie von mehr weisslicher Farbe. Unterhalb dieser Mantelrandlinie oder also an dem obersten Theile der Seite des Körper's wieder eine schmale himmelblane schimmerude Linie, welche sich etwa so weit wie die des Riickens erstreckt; längs der Mitte der Körperseite, vorne bis an die Tentakel und hinten bis an die Schwanzwurzel sich erstreckend, eine gelbe Linie; ganz unten, lïngs des Fusses endlieh eine starke (in 2-3 Stucke getheilte) weissliche Linie, hinten sich an den Seitentheilen des Schwanzrickens fortsetzend. Die Rhinophorien schwarblau; der Hinterrand der Kenle azurblau schimmerud, und diese Farbung unten in eine weissliche Einfassung des Grundes der Kieule ibergehend. Die Kiemenblätter blaugrau mit starker weisser Rhachis der Aussenseite. Der Kopf mit den Tentakeln blau, die Unterseite des Stirn- und Schwanzsegels graublau. Am Schwanzricken ein starkes medianes weissliches Band und an jeder Seite desselben, wie oben erwihnt, ein schmäleres. 
Das lebhafte 'Thier erhielt sich in dem ziemlich grossen Glase, worin es aus 'l'rieste ankam, volle 3 Wochen lebend und munter. Während des strengen Winters stand der Behälter dicht am Fenster, wo die Temperatur des Wassers bis - $2,5^{\circ}$ C. sank; das Thier. wurde dann mehrmals auf dem Rücken am Boden des Glases wie todt liegend gefunden; wenn der Behälter dann in eine erwärmte Stube gesetzt wurde, belebte es sich wieder und wurde wie friher munter. Kíriechend trug es die etwas gebogenen Rhino- phorien fast senkrecht an dem Kopfe. An der Wassersfliche kroch es sehr viel herum, und wurde oft 2-3 Cm. unter derselben an einem ganz diinnen Schleimfaden senkrecht hängend gesehen. Während einer kurzen Abwesenheit rou meiner Heimath starb das Thier, und konnte nicht aufgefunden werden.

\section{Chr. Inte0-rosea (RAPP).}

D. luteo-rosea, Rarp. Ueb. das Molluskengeschl. Doris. Nov. Act. Ac. L. C. Nat.

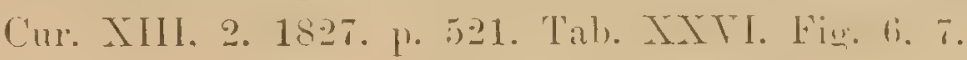

- Rapr. Philipir, enumer, moll. I. 1836. p. 105, II. 1844. p. 80.

Chromod. luteo-rosea (RAPP). R. BerGH, neue Nacktschnecken der Suidsee, III. Journ. d. Mus. Godeffroy, Heft VIII. 1875. p. 77.

- - Rapp. H. v. Jherivg, l. c. 1880. p. 27-30. Taf. 1. Fig. 5, T'af. II. Fig. 7, 8.

Color roseus, supra maculis rotundatis citrinis vel fulvis interclum albo marginatis; margo dorsalis citrinus vel fulvus; rhinophoria violacea vel purpurea, branchia violacea (vel purpurea); cauda supra linea mediana longitudinali fulva.

Ha b. M. mediterr. (Napoli, 'Tergeste).

Von dieser ausgeprägten Art, welche schon RapI', Schultz und Philippi bei Napoli fanden, und welche seitdem bis ganz neulich auf JuErivg doch fast ungekannt geblieben ist, hat mir Dr. GraEfFe in 1878 aus der Station von Trieste nebst colorirter Zeichnung und Notizen 2 in Alcohol und in GoADnY's Lösung conservirte Individuen geschickt. GraEFFE zufolge kommt das Thier ,ziemlich selten an Steinen, die von 1-2 Faden Tiefe heraufgezogen werden, in der Bucht vou Muggia bei Trieste und zwar zu jeder Jahreszeit vor". Auch bei Napoli scheint die Form (JuEnrNG) nicht hiufing gesehen zu werden.

Das Thier, welches von GraEfre als eine der schönsten Doriden des Golfes von Triest bezeichnet wird. misst im ausgestreckten lebenden Zustande $15 \mathrm{~mm}$ bei einer Breite bis $5 \mathrm{~mm}$. Die Grund $\mathrm{farbe}$ ist ein ,prichtiges feines Rosenroth, der Rücken ron einem goldgelben Saume eingefasst und an demselben noch eine Anzahl von unregelSempor, Philippinen. II, II. (Bergh, Ergänzungsheft I). 
mässig vertheilten runden Flecken; Ihlinophorien und Kieme violet-roth; Fuss rosenroth, die Riickenfirste des Schwanzes gelbgestreift".

Die conservirten Thiere hatien eine Länge bis 11 bei einer Höhe bis 4 und eine Breite bis $5,5 \mathrm{~mm}$. An der weisslichen Grund farbe traten am Riicken die (garnicht das Nivean der Hant iiberragenden) runden oder ovalen Flecken noch etwas gelblich, weissgerandet, von einem Durehmesser bis 2 mu hervor; in einzelnen der grössten Flecken kamen wicder central oder excentrisch ganz :ihnliche Fleckchen vor. Die Flecken waren, obgleich im Ganzen sehr variabel in Vertheilung, doch kaum ganz ohne Ordnung gestellt; vor jedem Rhinophor stand ein kleiner Fleck und zwischen denselben ein ähnlicher; an dem iibrigen liiicken dan jederseits eine Reihe von 5-6 Flecken und mehr an der Mitte in 2 Reihen vertheilt $4-6$ sehr grosse Flecken; hinter der Kieme ein grösserer Fleck. der die 2 lateralen Fleckenreihen des Rückens zu verbinden schien und hinter jenem woch einige (2-3) kleinere Flecken. Der noch sehr stark hochgelbe, bis $0,75 \mathrm{~mm}$ breite Ruickenrand innen und aussen ron einer feinen weissen Linie cingefasst. Der Fussriicken mit einem grösseren medianen Flecken und hinten mit Andeutung einer medianen weissen Läingslinie. Die Rhinophorien und die Krienenblätter röthlich. ${ }^{1}$ ) (Die RhinophorLöcher, das Kiemenloch und der Fuss ohne weisse Rand-Einfassung). -- An den Seiten schinmerte die hintere Eingeweidemasse graulich hindurch.

Fiir die Form-Verhailtnisse des Thieres muss auf die friher von mir gelieferte Beschreibung einer Varietät dieser Art (Chr. Jheringi, BGH.) hingewiesen werden. Der Schwanz bei dem lebenden, kriechenden 'Thiere den Riucken nux wenig iiberragend. Die Kieme aus \& Kiemenbliattern bestehend ${ }^{2}$ ); die 2 vordersten viel grösser als die anderen, welche an Grösse gegen hinten abnahmen; die hintersten kaum grösser als die conische Amalpapille. Dic Keule des Khinophors mit etwa 20 Blättern.

Die friher gelieferte anatomische Untersuchung (der Varietit) dieser Art wird hier durch eine Durchmusterung eines typischen Individuums supplirt.

Das distale Gangl. olfactorium viel kleiner als das proximale, ron rundlichem Umrisse. Es fand sich ein kleines Gangl. opticum mit kurzem N. opticus. In der Linse des $A$ uges ein grosser graulicher Kern mit Kernkürperehen. - Die Lippenplatte des Schlundkopfes (jederseits) bis $0,8 \mathrm{~mm}$ breit, hell schmutzig bräunlichgrau; die zwei Hälften oben von einander gesehieden, unten durch ein starkes, breites Zwischenstiick rerbunden. An der Zunge kamen 23, weiter gegen hinten 2.1 entwickelte und 6 nicht vollstïndig entwickelte Reihen vor; die Gesammtzahl derselben somit 53. In den Reihen fanden sich hinten an der Zunge (jederscits) 36 Platten; dieselben waren wie friher beschrieben; an der Rhachis die gewöhnlichen, vielleicht bei den Chronodoriden inmer vorkommenden, Verdickungen.

Die Speicheldrüsen und die Gallenblase ganz wie früher von mir beschrieben. 


\section{Chr. Inteo-rosea, var. Jheringi.}

Chr. Jheringi, BGI. Malakozool. Bl. N. F. I. 1879. p. 89. Taf. IV. Fig. 1-11.

Diese ron mir, ehe ich Gelegenheit gehabt hatte dic typische Form zu untersuchen, mit der Art ron RAPP schon fraglich identificirte l'orm ist sicherlich nur eine blaue Tarietiit der typischen Art. Fü die nähere Kenntniss muss auf die angefuhrte Stelle hingewiesen werden. Auch JHerixg sieht dieselbe nur als eine Spielform der Chr. Iuteo-rosea an.

\section{t. Chr. Rudolphi, Barr. n. sp̣.}

Color fundamentalis aurantiacus. Dorsum supra maculis lacteis; margo dorsalis quasi serta lactea punctis violaceis majoribus ornata instructus. Rhinophoria aurantiaca, apicibus violaceis. Branchia foliolis pallidis, apice violaceis. Latera trunci sicut paçina superior podarii maculis lacteis, margo podarii punctis majoribus violaceis ornata.

Ha b. Oc. pacific. (Tahiti).

Taf. A. Fig. 11-14; Taf. C. Fig. 1-2; Taf. D. Fig. 1-7.

Von dieser schönen Art hat Herr GARnETT in 1875 ein einziges Individuum „an dem iusseren Riffe von Tahiti an der unteren Seite eines Corallenstiickes angeheftet" gefunden und im Mus. Godefreror deponirt. ${ }^{1}$ )

Die Linge des lebenden und kriechenden Thieres ist, Garretr zufolge. $3 \mathrm{Cm}$. - Die Grundfarbe war, den den Museum Goderfror geschickten Notizen G.ıRRETT's zufolge, orangegrelb. ${ }^{2}$ ) Der Rücken mit grösseren, meistens ovalen, milehweissen Iilecken. Der Riickenrand mit einem milchweissen Feston geziert, der noch mit grösseren violetfarbigen Punkten geschmiickt war. Die Seiten des Körpers und die obere Seite des Fusses mit ähnlichen nilchweissen Flecken wie der Ricken geziert, und am Fussrande noch eine Reihe ron den oben erwihnten :ihnlichen violeten P'unkten. Die Rhinoplorien orangegelb, mit violeter Spitze. Die Kienenblïtter bleich mit violeter Spitze.

Die Liinge des einzigen, in Aleohol ganz gut bewahten, nur etwas zusammengezogenen Individu us betrug $2 \pm$ bei ciner Höhe des Kïrpers bis 7 und

1) Dicse sowie die meisten in diesem Hefte fulgenden Untersuchungen waren ursprünglich für das Journal des Mruseum Gonfrrror bestimmt, das Jeider wohl für immer eingegangen ist. Ich habe Erlaubniss erhalten, über die fertig liegenden Untersuchungeu frei zu disponiren.

2) "Colour orange-yellow with remote irregular small creamy white spots along the dorsal region. The margin of the mantle is festoned with creamy-white, in which is a row of violet dots. Dorsal tentacles with orange laminne, tips violet. Gills pale with violet tips. The top of the fuot and sides of the body are ornamentel with spots similar to them on the back and the former with a marginal row ol violet dots". Garretr. 
einer Breite bis $8,5 \mathrm{~mm}$; die Breite der Fusssohle bis 5,5; die Höhe der Rhinophorien bis fast 2, die der Kieme $2 \mathrm{~mm}$ betragend. - Von den früheren Farben war fast Nichts iibrig; die Grundfarbe milchweiss, mit ziemlich zahlreichen, kalkweissen 'Tüpfeln an dem Riicken, an dem Fussrïken, an den Seiten und besonders an dem Fussrande; der Riickenrand weisslich; die Rhinophorien braunlichgrau, ebenso die Krieme.

Die Formverhälnisse etwa wie gewöhnlich, ,etwas zusammengedruckt, etwas lederartig; der Riicken wenig ausgehöhlt"; das Mantelgebräme (bei dem in Alcohol bewahrten Individuum) bis $3,5 \mathrm{~mm}$ breit, bei dem lebenden wie bei dem todten 'Thiere ctwas emporgeschlagen. Die Tentakel klein („kegelfürmig“b); die Rhinophorien mit etwa 40-50 Bliittern. Die Kieme aus 6 Federn gebildet, ${ }^{1}$ ) von denen die beiden vorderen cinen Seitenast trugen, wiłhrend die hintere jeder Seite grösser, wie rom Grunde ab etwas eingerollt und aus drei Federchen zusammengesetzt war; der Bau der gewöhnliche. Die Analpapille bis einen vollen Millimeter hoch, abgestutzt; die Nierenpore sehr deutlich. Der Fuss vorne gerundet; der Schwanz ziemlich lang, hinter dem Mantelgebräme stark hervortretend.

Die Lingeweide schimmerten nirgends hindureh.

Das Centralnervensystem wie gewöhnlich ('Taf. C. Fig. 1); die cerebro-visccoralen Ganglien (Fig. 1 a a) nierenförmig; die pedalen (Fig. $1 \mathrm{c}$ ) von rundlichem Umrisse, grösser als die visceralen. Die (proximalen) Riechknoten abgeplattet zwiebelförmig (Fig. $1 \mathrm{bb}$ ), wenigg grösser als die ziemlich abgeplatteten, dureh eine ziemlich lange Commissur rerbundenen bucealen (Fig. 1f); die gastro-oesophagalen $1 / 6-1 / 8$ der Grösse der letzteren betragend, kurzstielig (Fig. $1 \mathrm{gg}$ ).

Die A ugen (Fig. 1) wie gewöhnlich, mit schwarzem Pigmente und grosser, gelblicher Linse. Die Olnblasen (Fig. 1) an der Unterseite der Gehirnknoten dicht vor der cerebro-visceralen Furche und etwas gegen aussen liegend, kurzstielig, von gुewöhnlichen Otokonien strotzend. Die Blätter der Rhinophorien dunn, vollstindig ohne crhärtete Zellen. - Die Haut ganz olne Spikeln. In der interstitiellen Binde$\therefore$ ubtanz lier und da Spikeln von einer Läinge von $0,04-0,06 \mathrm{~mm}$.

Die (zurickgezogene) M undröhre etwa $2 \mathrm{~mm}$ lang, mit den-gewöhnlichen Falten der Innenseite. - Der Schlundkopf etwa $2,5 \mathrm{~mm}$ lang bei einer Höhe bis beiläufig 2 und einer Breite bis fast $2 \mathrm{~mm}$; die Raspelscheide hinten an der Unterseite etwas herrortretend. Die Lippenplatte hell horngelb (Fig. 2), aus gewöhnlichen hakenfürmigen (bei einer Vergr. ron 750 mal kaum deutlich gestreiften), bis etwa $0,04 \mathrm{~mm}$ langen Elementen (l'af. D. Fig. 1) gebildet. Die Z ung e wie gewöhnlich; in der Raspel 30 Zahmplattenreihen, weiter gegen hinten kamen noch 15 .entwickelte und:3 mentwickelte Reihen vor, die Gesammtzahl derselben betrug somit 48. In den Reihen hinten an der Zunge fanden sich bis 75 Platten Die innerste Zahn platte (Taf. D. Fig. 2 a a, 3 a b) zeigte 
jederseits zwei Dentikel neben der Spitze; an den folgenden (Fig. 3c, 4) kamen meistens 3-5 an dem Aussenrande vor; die zwei oder drei iussersten (Fig. 6, 7) waren von gewöhnlicher gedrängter und abweichender Form; die Höhe der äussersten (Fig. 6a, 7) betrug meistens etwa $0,048 \mathrm{~mm}$.

Die Śpeicheldrïsen wie gewöhnlich, bandfürmig, weiss, die Speiseröhre bis an das Vorderende der hinteren Eingeweidemasse begleitend.

Die Speiseröhre ziemlich weit, mit starken Liingsfalten, etwa an der Mitte des Vorderendes der hinteren Eingeweidemasse in dieselbe hineintretend. Der Darm links vor der Mitte der Eingeweidemasse aus einer tiefen Kkluft herrortretend. - Die Leber vorne gerundet, das Vorderende gegen hinten und unten wie etwas schräge geschnitten und vertieft, das Hinterende gerundet; die Farbe der Leber graubraun, ausgenommen am Vorderende war dieselbe aber iberall von der des gelbweissen, dicken ZwitterdriisenLagers überzogen.

Die grauweisse Blutdriise unregelmässig drcieckig, von etwa 1,5 mm Länge.

Die vordere Genitalmasse etwa 4 mm lang bei einer Höhe und Dicke bis $3 \mathrm{~mm}$. An der Mitte der Hinterseite der sonst kalkweissen und gelblichweissen Schleimdrise eime olivenbraune, feinknotige Parthie (Eiweissdrüse). An dem oben aus dem Zwitterdrüsenlager hervorgehenden $Z$ witterdrüsengang fand sich die Ampulle als eine kurze ( $1 \mathrm{~mm}$ lange), einfache, gelbweisse Erweiterung. Der Samenleiter in einer kurzen Strecke etwa an seiner Mitte erweitert und der eingeschlossene Samengang hier eine Masse von kurzen Windungen bildend. Die Spermatocyste nur wenig kleiner als die etra $1 \mathrm{~mm}$ lange Spermatotheke.

\section{Chr. inoruata, Pease.}

Chrom. inornata, P. Americ. Joum. of conchol. VII, 1. 1871. p. 18. pl. 8. Fig. 3.

Color fundamentalis lacteus, margine palliali aurantiacus, supra punctis purpurcis ormatus; rhinophoria aurantiaea.

Hab. Oc. pacific. (ins. Huaheine),

Taf. D. Fig. 16-21.

Diese Form wird von PEASE als bei der Insel Huaheine gefischt angegeben. GARRETT hat als dieser Art gehörend in 1875 von derselben Localität dem Museum GodefFroy zwei Individuen gesehickt, ron denen das eine exviscerirt wurde.

Die Länge des lebenden "Thieres hat, Pedse zufolge, $1 \frac{1}{2}$ " betragen. Die Grundfarbe ist mileluweiss (, creamy white ${ }^{6}$ ), der Rücken mit oraugenfarbigem Rande und purpurfarbigen Fleckchen ( $\mathrm{d}$ dotted with purple ${ }^{61}$ ), die auch an dem Fussricken vor-

1) Die Beschreibung PEASE'S stimmt mit der von ihm gelieferten Abbildung nicht ganz überein. 
zukommen scheinen; die Rhinophorien orangenfarbig, die Kieme, farblos." Das Thier wird als so durehseheinend angegeben, dass die Rückenfleckchen an der. Unterseite durchschimmern sollen (was iibrigens gar nicht für eine besondere Durchsichtigkeit zeugt).

Die Länge der in Alcohol bewahrten, fast gleich grossen Individuen betrug etwa $10 \mathrm{~mm}$ bei einer Breite bis 5 und einer Höhe bis $3,5 \mathrm{~mm}$; die Breite des Fusses bis $2 \mathrm{~mm}$ betragend; die Höhe der Rhinophorien fast $2 \mathrm{~mm}$, von denen die IIälfte auf die Keule kam; die Höhe der Kieme volle 1,5 mm. - Die Farbe war durehgehends gelblich; am Rücken eine Menge von röthlichgrauen, nicht ganz kleinen (etwa vom Umfange der Rhinophorien), rundlichen Fleckehen; die Keule der Rhinophorien röthlichgelb, die Kieme obenso röthlichgelb.

Das Thier ron ziemlich gestreckter Form; der Ruicken glatt; die Keule der Rhinophorien mit etwa 20 Blïttern, die Kieme aus 9 einfachen Federn ${ }^{1}$ ) gebildet, die Analpapille nicht hoch; bei dem einen Individuum war (Fig. 21) der Penis etwa 0,5 mm hervorgestiilpt; der Fuss wie gewöhnlich.

Das Peritonaeum farblos. Die Eingeweide rothgelb.

Das Centralnervensystem anch röthlichgelb; die cerebro-visceralen Ganglien gestreckt-nierenförmig mit tiefer Einkorbung; die kurz-birnförmigen Fussknoten etwas grösser als die visceralen; die Ricchknoten abgeplattet zwiebelförmig. Die buccalen Ganglien birnförmig, fast unmittelbar mit einander verbunden; die gastro-oesophagalen kurzstielig, ron etwa $1 / 8$ der Grösse der vorigen, mit einer grossen und melıreren kleinen Zellen (Fig. 16).

Die Augen ziemlich gross, mit schwarzem Pigmente. Die Ohrblasen etwas kleiner, von Otokonien strotzend. Die Blätter der Rhinopluorien nicht diunn; in der Axe dieser letzteren grosse, stark erhärtete Spikel. Die II a u t mit zerstreuten, stark erhärteten, kurz-stabförmigen Spikeln von meistens $0,025-0,035$, seltener bis fast $0,08 \mathrm{~mm}$ Länge; im Mantelgebräme eine Masse ron grossen, wasserhellen, balgfürmigen Driisen. - In der interstitiellen Bindesubstanz hier und da Spikeln, meistens grösser als die der Haut.

Die II undröhre gross, etwa $2 \mathrm{~mm}$ lang. - Der Schlundkopf etwa 1,5 mn lang bei einer Breite bis 1,5 und einer Höhe bis $1,4 \mathrm{~mm}$; die Raspelscheide hinten an der Unterseite etwas hervortretend. Die Lippenplatte hell horngelb, gross, aus dieht gedringten, bis etwa $0,035 \mathrm{~mm}$ hohen, am Ende gegabelten Haken gebildet (1Yig. 17). Die Zunge mit 25 Reihen von Zahnplatten, weiter gegen hinten fanden sich noeh 25 entwickelte und 4 nicht vollstindig entwickelte Reihen; die Gesammtzahl derselben betrug somit 5t. In den Reilıen kamen hinten an der Zunge bis 31 Zahnplatten vor, und die Anzahl stieg weiter gegen hinten bis $34-35$. Die innerste Platte an beiden Seiten 
des Hakens gezähnelt (Fig. 18 aa, 19), die zwei äussersten (Fig. 20) ron gewöhnlicher irregulärer Form. Die Verhältnisse der Zahnplatten (Fig. 18) sonst wie gewöhnlich; die Höhe der iussersten (Fig. $20 \mathrm{a} a$ ) meistens etwa $0,045-0,05 \mathrm{~mm}$ betragend. An der Rhachis leichte Verdickungen (Fig. 18).

Die Speicheldriisen (Fig. 16 b) wie gewöhnlich; in der vorderen etwas kiirzeren Strecke dicker und gelblich; in der iibrigen diinmer und weisslich. Jer Ausfuilurungsgang (Fig. 16 a) nicht ganz kurz.

Der Magen, der Darm und die Leber wie gewöhnlich.

Die vordere Genitalmasse $3 \mathrm{~mm}$ lang und ebenso hoch bei einer Dicke ron $2 \mathrm{~mm}$. An der linken Seite der grossen Schleimdrise war die centrale Parthie (Eiweissdriise) rostroth. I)ie Spermatotheke kugelförmig; die S permatocys te birnförmig, länger als die vorige und ihr Gang volle zwei Mal so lang wie die Cyste.

6. Chr. cardimalis, Barr. n. sp.

Ha b. Oc. pacific. (ins. Huahcine).

Taf. C. Fig. 3-4; Taf. D. Fig. $8-15$.

Von dieser im Leben gewiss sehr prachtvollen Art hat Herr GARREIT in 1875 cin einziges Individuum bei der Insel Huaheine gefunden und dem Mus. Gonefrror geschickt; Notizen zu demselben fehlen.

J)as in Alcohol gut conservirte Individuum hatte eine L iange von 13,5 bei einer Breite bis 6 und einer Höhe bis $3,5 \mathrm{~mm}$; die Breite des Mantelgebrämes betruy bis 2 , die der Fusssohle bis $2 \mathrm{~mm}$; die Höhe der Rhinophorien war etwa 1,5, die der Kieme $2 \mathrm{~mm}$. - Die F arbe durehgehends rothriolet, am Stirksten an den Seiten; der eigentliche Riicken vom Mantelgebrïme ringsum durch ein schmales röthlichweisses Band abgegrenzt, mit welchem ein weniger starkes medianes rorne in Verbindung stind, das sich gegen die Kiemengegend hin verlängerte; an der oberen Seite des Mantelgebrämes eine Menge ron ganz kleinen weissen Augenflecken; die Rhinophorien und die Kieme von der sonstigen tiefrothvioleten Farbe.

Die Form war ziemlich gestreckt, etwas niedergedrickt. Die T'entakel klein. Jie Rhinophor-Höhlen bei zurückgezogenen Rhinophorien etwas kuppelartig hervortretend; die Keule mit etwa 20 Blättern. Der R iicken glatt, flach, etwa so breit wie das Mantelgebräme jeder Seite; die Kiemenöffnung her"uförmig; die Kieme aus 6 ungleichgrossen Federn, jederseits 3, gebildet; der Analtubus niedrig; das Mantelgebritme breit, etwas wellenförmig hinauf- und hinabgeschlagen. Die Seiten ziemlich hoch, stark einwärts schriigend; die Genitalöffnung wie gewöhnlich. Der F us langgestreckt, ziemlich 
schmal; das Vorderende gerundet, mit tiefer Randfurche; der Śchwanz nicht kurz, das Nantelgebrime hinten iiberragend.

Das Peritona eum hell violet gefärbt. Die Eingeweide und besonders die hintere Eingeweidemasse mehr oder weniger violetfarbig.

Das Centralnervensystem (Taf. C. Fig. 3) von rothgrauer Farbe; die cerebrovisceralen Ganglien von Nierenform (Fig. $3 \mathrm{a}$ a), die pedalen (Fig. 3cc) kaum grösser als die visceralen; die Riechknoten abgeplattet zwiebelförmig (Fig. $3 \mathrm{bb}$ ). Die buccalen Ganglien (Fig. 3 f) grösser als die Riechknoten, fast unmittelbar mit einander verbunden; die gastro-oesophagalen kaum (Fig. $3 g g$ ) $1 / 6$ der vorigen betragend, nicht ganz kurzstielig, an der einen Seite des Ganglions entwickelt, mit einer grossen und mehreren kleinen T/sellen.

Die A ugen gross (Fig. 3), mit schwarzem Pigmente, gelber Linse. Die Ohrblasen an gewöhnlicher (Fig. 3) Stelle der Unterseite des Gehirnknotens liegend, kleiner als die Augen, ron Otokonien gewöhnlicher Art strotzend. Die weisse Axenparthie der Rhinophorien mit zerstrenten, denen der Haut ähnlichen Spikeln; einzelne derselben ragten in die Blaitter etwas hinein. In der $\mathrm{Haut}$ kamen ziemlich reichlich zerstreute, meistens stark crhärtete, gerade oder gebogene, bis $0,06 \mathrm{~mm}$ lange Spikeln vor (Taf. D. Fig. 15).

Die Mundröhre etwa 1,5 mm lang, sehr kräftig, aussen röthlichgrau wegen der durchschimmeruden stark dunkelgrauvioletten Falten der Innenseite. - Der Schlundkopf etwa 1,5 mm lang bei einer Höhe bis 1,4 und einer Breite bis etwa $1,6 \mathrm{~mm}$; die Farbe ziemlich dunkel violet, besonders stark an der Lippenscheibe und an der stark hervortretenden Raspelscheide. Die grosse und starke Lippenplatte braunlichroth, mit violetem Schimmer, aus dicht gedrïingten Stäbchen gebildet, die eine Liinge bis 0,1 mm erreichten, und in der Spitze mehr oder weniger gekrummt (Taf. D. Fig. 8, 9) waren. Die Zunge wie gewöhnlich; in der Raspel 24 Zahnplattenreihen, weiter gegen hinten noch 16 entwickelte und 4 mehr oder weniger unvollständig entwickelte Reihen, die Gesamntzahl derselben betrug somit 44. In den Reihen kamen hinten an der Zunge bis 33 Platten ror, und die Auzahl stieg weiter gegen linten bis 37. Die Platten von hell horngelber Farbe, eine Höhe bis $0,07 \mathrm{~mm}$ erreichend, die Höhe der äussersten betrug meistens etwa $0,06 \mathrm{~mm}$. Die (Fig. $10 \mathrm{bb}, 11$ ) innerste Platte mit $1-2$ stärkeren Dentikeln an der Inmenseite und mehreren feineren an dem Aussenrande; die folgenden Zahuplatten sich in gewöhnlicher Weise (Fig. 10, 12) entwickelnd, die Zahl ihrer Dentikel bis 10-11 steigend; die äussersten zwei (Tiig. 13, 1t) von gewöhnlicher abweichender Form, einzehe unregelmässig, dentikellos. An der lhachis kamen (Fig. 10a) ziemlich krïftige Verdickungen vor.

Die Speicheldriisen etwa doppelt so lang wie der Schlundkopf, sich an die Unterseite der vorderen Genitalmasse erstreckend; violetfarbig, besonders in der lïngeren hinteren Strecke, in der sie wie um einander geschlungen waren. 
Der Magen, der Darm und die sehr dunkelviolete, fast purpurfarbige Leber wie gewöhnlich.

Die vordere Genitalmasse etwa $3 \mathrm{~mm}$ lang bei einer Höhe bis 2,3 und einer Breite bis $2 \mathrm{~mm}$; die iussere (rechte) Seite violet und gelblich; die imnere (linke) violet, die grosse centrale Parthie (Eiweissdriise) schwarz-purpurfarbig. Die an der inneren Seite der Schleimdrise ruhenden ('Taf. C. Fig. 4e) Windungen des Samenleiters schwarz purpurfarbig. Die Spermatotheke (Taf. C. Fig. 4a) kugelförmig, von etwa $0,4 \mathrm{~mm}$ Diam.; die Spermatocyste (Yig. 4 b) wurstförmig, eingerollt, ziemlich lang; beide gelblich, mit violetem Schinmer, an der äusseren Seite der Schleimdriise ruhend.

\section{Chr. imperialis (PEASE).}

Doris prismatica, var. imperialis, PEAse. Proc. zool. soc. XXVIII. 1860. p. 32. Doriprismatica imperialis, PEASE. Proc. zool. soc. 1863. p. 510.

Color lacteus, margine palliali purpureus; supra et lateribus maculis numcrosis luteis, lateribus et dorso podarii ocellis luteis; rhinophoria aterrima, albide marginata et albide punctata; folia branchialia purpuree marginata.

Hab. Oc. pacific. (ins. Sandwich).

Taf. B. Fig. 1-4.

Die Art ist nur durch die Beschreibung ${ }^{1}$ ) PEase's bekannt. Garretr hat in 1874 dem Museum Godefrror eine Reihe der originalen Zeichnungen Pease's zu mehreren der von dem letzteren veröffentlichten Beschreibungen neuer Nudibranchien geschickt. Nach jenen sind die hier gelieferten Figuren copirt.

\section{Clir. decora (Peasej).}

Doris decora, PEASE. 1. c. p. 29.

Color stramineus, margine palliali albidus purpurce punctatus; linea intramarginalis duplex rosea et lutea (ultima purpuree punctata), nothaeum linea mediana albida purpuree punctata; rhinophoria et branchia albescentia.

1) $n$ - Smooth and convex above. - Branchial plumes ten in number, the six anterior ones simple, the succeeding tro trifurcate, and the posterior pair quadrifurcate; they all decrease in height posteriorly. - Colour pale cream white and spotted above and on the sides with rich yellow; the spots are small, irregular and very slightly raised. The mantle is margined with purple and there are a few broken rings of the same colour on the sides and upper posterior end of the foot, each ring having a yeliow centre. The branchiae are pale and edged with purple. The dorsal tentacles are deep black, minutely speckled with white and marked with two longitudinal white lines, one behind and the other in front. Length 2 inches. ${ }^{*}$ Pense (Grax). Semper, Philippinen. II, II (Bergh, Erginzungsheft I). 
II a b. Oc. pacificum (ins. Sandwich).

Taf. B. Fig. 5-S.

Die Art ist bisher nur durch die Beschreibung PEASE's ${ }^{1}$ ) bekannt. Die hier gelieferten Figuren sind wie die obigen und die nächstfolgenden Copien nach den Originalzeichnungen PEAsE's.

\section{Chr. Peasei, B $\mathrm{GH}$.}

Doris prismatica, var. lineata, PEASE. 1. c. p. 32.

Doriprismatica lincata, PEAsE. Proc. zool. soc. 1863. p. 510.

Color e purpureo clare griseus, margine palliali et podarii violaceus; nothaeum et latera lineis reticulatim connexis albidis; rhinophoria albida, apice et basi clavi aurantiaca; branchia albida, aurantiace marginata.

Ha b. Oc. pacific. (ins. Sandwich).

Taf. B. Fig. 10-13.

Die Art, deren urspringlichen Namen PEASE später änderte, $\left.{ }^{2}\right)$ ist bisher nur durch die Beschreibung dieses Terfassers ${ }^{3}$ ) bekannt. Die gelieferten Figuren nach den Originalzeichnungen copirt.

\section{Chr, vibrata (PEASE).}

Doris vibrata, PEASE. l. c. 1860. p. 28.

Color supra luteus albo maculatus, versus marginem pallialem purpureum purpuree maculatus. Clavus rhinophoriorum violaceus; folia branchialia violacce marginata; podarium albidum.

1) „Oblong, smooth, soft and convexly rounded above. - Branchial plumes small, - , seren in number, decreasing in beight pnsteriorly. - Colour: Dorsal region pale straw-colour, with a medial whitish longitudinal stripe, which is bifurcated posteriorly and dotted with purple. The margin of the mantle is bordered with white and dotted with purple; an intramarginal light red band contiguous to which is a yellow one, which is dotted with purple. Branchiae and tentacles pale. Beneath the mantle is coloured as above, but much paler. Length 1 inch 2 lines." YE.ase.

2) Der Name muss wegen der Doris (Chromodoris) lineata von Sodieret (Voy. de la Bonite. Zool. II. 1852. p. 453. pl. 25. Fig. 5-9) geändert werden.

3) "Elongate, solt, smooth. - Branchiae suall, ten in number. - Colour light greyish purple, along the back and the remainder of the body white, irregular, longitudinal, opaque fine white lines on the dorsal region, some of which are confluent. Margins of foot and boly benutifully edged with violet. Brauchiae whitish and longitudinally striped with orange. Tentacles white, with an orange zonc near the tips and a second near their base. Length 1 inch." PEase. 
Ha b. Oc. pacific. (ins. Sandwich).

Taf. B. Fig. 18-21.

Auch diese Art war bisher nur durch die Beschreibung PEAsE's') bekannt. Die hier gegebenen Figuren auch nach den Zeichnumgen PEASE's.

\section{Chr. marginata (PEASE).}

Doris marginata, PEASE. 1. c. 1860. p. 30.

Color albidus, margine palliali clare ruber; linea intramarginalis lutea.

Hab. Oc. pacific. (ins. Sandwich).

Taf. B. Fig. 22-23.

Auch diese Art war bisher nur durch die Beschreibung PEAsE's ${ }^{2}$ ) bekannt. Die hier gegebenen Figuren sind auch Copien der Originalzeichnungen PEAsE's.

1) "- Mantie smooth, convexely rounded above. - Branchial plumes - seven. - Colour above yellow, irregularly spotted with white, pale towards the margins; which are dotted and edged with purple. Branchial plumes edged with violet. Dorsal tentacles violet, with uncoloured peduncles. Foot white "PE.tsE.

2) „Elongate, sinooth and convexely rounded above. - Branchial plumes seven. - Colour white, mantle edged with light red and an intramarginal tinge of yellow." PEASE. 


\section{CERATOSOIMA, Adams et ReEve.}

Ceratosoma, A. AdAuss. Voy. of the Samarang. Moll. 1848. p. 67.

Bergri, malacol. Unters. (SEMper, Philippinen. II, II) X Heft. 1876. p. $391-410$.

Die Ceratosomen waren bis auf meine vor wenigen Jahren gelieferte Untersuchung fast unbekamt greblieben; dieselbe behandelte eingehend drei Arten, von denen die eine nen. Spiiter sind dureh Frscher und ABrAmalr mehrere neue Arten" zugekommen, in gewöhnlichem unbranchbarem Stile skizzirt.

Die Gruppe, die bisher nur aus warmen Meeresgegenden bekannt ist, umfasst also augenblicklich die folgenden aufgestellten Arten:

1. Cer. cornigerum, AD., Bgrt.

I. indicum, philippin.

$\therefore$ Cer.gracillimu m, SEMPER, BGir.

II. philippin.

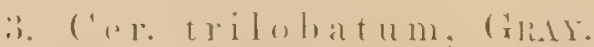

il. rubr.

4. Cer. caledonicum, Fiscrier. Journal de conchyl. 3 S. XVI. 1876. 1. 92. $\left.{ }^{1}\right)$

Oc. pacific. (Nov. Caled.)

$\therefore$ Cer. tenue, Abrainay. Notes on some Genera of nudibr. Moll. Ann. mgz. 11. h. 4 S. XVIII. 1876. p. 141. pl. VII. Fin.

$$
\text { i, 5ab. }
$$

Hab?

(i. Cer. brevicandatum, ABR. 1. c. p. 142. pl. VII. Fig. 6.

II. pacific. ("dustralia").

7. Cer. oblongum, ABr. l. c. p. 143. pl. VII. Fig. 7, 7 a b.

II. pacific. („West-Australia").

1) In den Ietzteren Jahren haben die Herren $C_{\text {ROSSE }}$ und Fischer sich mit Nudibranchien beschältigt, selbstfolglich in gewöhnlicher, wissenschaftlich-unbrauchbarer Dilettantenmanier. Auch die Gattung Ceratosoma ist mit dem neuen Cerat. caledonicum, l. belästigt worden. Die Herren, die noch nicht Goniodoriden von Chromodoriden oder Doriden von Doriopsen zu unterscheiden vermögen, sehen die Ceratosomen als den Thecaceren, Polyceren, Aegiren etc. „sehr nahestehend (très-voisins)“ an. Das Ceratos. caledonicum ist wahrscheinlich aur eine Spielart des Cer. gracillimum. 


\section{Cer. polyomma, Barr. no sp.}

Color fundamentalis brumescens, maculis ocelliformibus coccincis albo-pupillatis et halone albo cinctis ornatus; margo dorsalis et podarii violaceus.

Ha b. Oc. pacific. (ins. Palau).

Taf. B. Fig. 9; Taf. D. Fig. 23-26.

Es muss vorläufig wohl sehr fraglich bleiben, ob diese Form wirklich eine nene Art repriseutirt oder nur eine Varietiat von einer der schon bekannten darstellt. Von dem Cerat. gracillimum wird sie absolut verschieden scin. Möglicherweise stellt sie nur eine Varietät des übrigens ziemlich verschieden gefärbten Cerat. cornigerum dar. Die Farbenverhälnisse des Cerat. trilobatum des rothen Ueeres sind bisher nicht bekannt, und eher könnte vielleicht diese Form sich als mit jener identisch zeigen. Bis zu näherer Auskunft ist die Form hier als neue $A$ rt hingestellt.

Kubany hat im Frühjahre 1875 ein Individuum dieser Form in der Armit-Passage bei Babelthaob an den Palau-Inseln "treibend" gefunden; sonstige Notizen fehlen. Kubary hat aber dem lebenden T'hiere nach (in etwas verkleinerten Maasstabe) zwei Zeichnungen geliefert sowie das Individuum selbst im Nuseum GodefrnoY deponirt, von wolser es mir zur Untersuchung geliefert wurde.

Die Grundfarbe des lebenden Thieres ist, der Zeichnung von Kúvary zufolge, bräunlich; an dem Rücken sowie an den Seiten kamen iiberall grosse carminrothe, ringförmige, weiss pupillirte Flecken mit weissem Hof vor; der Rand des Rückens und des Fusses violet; die Kieme (röthlich-) grau, die Analpapille violet, die (ausgestiilpte) Mundröhre weiss, violet punktirt; die Rhinophorien weisslich mit violetem Vorderrande. Die Länge des in Alcohol bewahrten Individum s betrug $7 \mathrm{Cm}$. bei ciner Höhe bis an die Spitze des Rückenfortsatzes ron $3 \mathrm{Cm}$. und bei einer Breite zwischen den Spitzen der Seitenlappen des Riickens ron 2,5 Cm.; die Breite des Kopfsegels war 1,5 Cm., die der Unterseite des Kopfes $11 \mathrm{~mm}$; die Länge des Schwanzes betrug $3 \mathrm{Cm}$., seine Höhe rorne $11 \mathrm{~mm}$; die Breite der Fusssohle vorne und an der Mitte ihrer Länge 9, dicht vor dem Hinterende $4 \mathrm{~mm}$; die Höhe dex Rhinophorien betrug $6,5 \mathrm{~mm}$, von denen die $2 / 3$ auf die Keule kamen; die der T'entakel 1,5 mm; die Höhe (Länge) der Kiemenblätter stieg bis 11, die der Analpapille war $3 \mathrm{~mm}$. - Die Farbe war am Riicken sowie an dem oberen Theile der Sciten und an dem Schwanze noch sehr schön und stark gelbroth; an diesen Stellen fanden sieh zerstrente kalkweisse Ringe, meistens von einem Durelım. von 1,5-3 mm, mit kalkweissen grossen I'upillen und hellerem Hof; der Rand des Riickens (theilweise auch des Fusses) weiss; der Stiel der Rhinophorien weisslich, die Keule mit kalkweissem Vorder-und Hinterrande; die Kieme rostroth mit 
kalkweissen Fnötchen und Fleckchen innen an den Rhachis-Parthien und an ihrem Mesenteriolum; die Analpapille weisslich, mit kalkweissem Rande und an ihrem Grunde hinten jederseits ein weisser Augenfleck; der iibrige Körper röthlich-weisslich; die Fusssolle gelblichweiss.

Die Formverhältnisse (Fig. 9, 23) waren ganz wie bei anderen Arten, besonders wie bei dem Cer. trilobatum (vergl. 1. c. p. 406). Die Kenle der Rhinophorien mit etwa 40 Blättern. Die Tentakel wie gewöhnlich ganz kurz. Die Kiemen-Oeftnung queroval herzförmig, ron fast $6 \mathrm{~mm}$ grösstem Diam., mit dem rorderen Theile des Randes hervorstehend; die Kieme hat 11 Blätter, ein vorderes und fünf scitliche, das hinterste Paar der letzten ist mehrfach getheilt, während die anderen einfach tripinnat sind. Die Analpapille vorwärts gekrimmt, mit runden und spitzen Zacken des Raudes. Die Nierenpore wie gewöhnlich. Der Rükenfortsatz von dem hinteren Rande der Kiemenuffnumg etwa $10 \mathrm{~mm}$ schraige hinaufragend (Fig. 23); die Seitenränder desselben an dem lebenden (vergl. Fig. 9, 23) sowie an dem todten Thiere zurückgeschlagen, wie es bei dem Cerat. gracillimum (vergl. 1. c. Taf. XXV. Fig. 8) auch der Fall zu sein scheint.

Die Eingeweide schimmerten nirgends hindurch.

Das Centralnervensystem fist ganz wie bei dem Cer. cornigerum (vergl. 1. c. p. 395), dureh seine Capsel gelblich durchschimmernd. Die zwei von dem Scheitel des Ganglion gastro-oesophagale entspringenden Nerven schlängelten sich längs der Speiseröhre hinauf. - Der Nervus opticus nicht pigmentirt.

Der (ganz hervorgestiilpte) Schlundkopf etwa $12 \mathrm{~mm}$ lang bei einer Höhe bis 8 und einer Breite bis $7 \mathrm{~mm}$; die Raspelscheide ragte $2,5 \mathrm{~mm}$ frei von der Unterseite hinab. Die Lippenplatte ziemlich stark, horngelb, oben schmiler und diinner, sonst meistens etwa 2,3 mm breit, ibrigens ganz wie beim Cer. comigerum (vergl. l. c. p. 397), und ebenso ihre Elemente. - Die Zunge wie gewöhnlich gross; in der Raspel 56 Zahnplattenreihen, unter dem Raspeldache und in der Scheide noch 30 entwickelte und 6 nicht ganz entwickelte Reihen, die Gesammtzahl derselben somit 92 betragend. In den Reihen kamen in der Mitte der Raspelseheide 190 Zahmplatten vor. Diese (Fig. 24) waren fast ganz wie bei den anderen Arten (vergl. l. c. p. 397, 404, 407); nur an den äussersten (meistens 8-10) fehlten gewöhnlich die sonst (Fig. 25 a a, 26) rorkommenden feinen 1)entikel.

Die Speicheldrüsen von der gewöhnlichen (vergl. l. c. p. 399) bedentenden Längo.

Die Speiseröhre und ler Mag en wie bei den anderen Arten (vergl. l. c. p. 400 ), in dem vorderen linken Theil des letzteren mehrere starke Falten; die Gallenöftnungen weit, besonders die des hinteren weiten Gallenganges. Der Darm wie bei der typischen Art. - Der Inhalt der Verdaungshöhle unbestimmbare thierische Masse.

Die Leber ron etwa $16 \mathrm{~mm}$ Liinge bei einer Breite vorne von 10 und einer Höhe daselbst von $9,5 \mathrm{~mm}$; die Form wie bei der typischen Art, an jeder Scite zwei 
sehr tiefe; fast senkrechte Furchen; die Farbe hell griinlichgrau, gegen die gelblichweisse Zwitterdruise stark abstechend, welche die Leber mit Ausnahme ihres Vorderendes und oben in der Gegend des Pylorus iiberall iiberzog. Keine Gallenblase.

Das Herz wie gewöhnlich. Die Blutdrisen (röthlich-) gelblich; die rordere irregulär subquadratisch, von etwa $5 \mathrm{~mm}$ Diam.; die hintere gestreckt-dreieckig, von etwa 4 mm Länge. - Die Nierenspritze von (röthlich-) gelblicher Farbe, kurz-binförmig, von etwa 1,75 mm Länge; der Nierenspritzengang sehr kurz.

Die Zwitterdrise wie oben; in den Liappchen grosse oogene Zellen. - Die vordere Genitalmasse etra $11 \mathrm{~mm}$ lang bei einer Höhe ron 12 und einer Dicke von $7 \mathrm{~mm}$, linsenförmig, mit etwas breiterem Oberrande. Die $\perp \mathrm{mpulle}$ des Zwitterdruisenganges schmutziggelblich, bis $14 \mathrm{~mm}$ lang bei einem Durchm. bis $1,5 \mathrm{~mm}$, ein paar Ḱnickungen machend, von den hellgelblichen Windungen des Samenleiters fast ganz bedeckt. Die Länge des Samenleiters in Allem etwa $21 \mathrm{Cm}$. Die Spermatotheke kugelförmig, ron etwa $3,5 \mathrm{~mm}$ Diam., dunkelgrau; in derselben pigmentirte und verfettete Zellen so wie Znospermien. Unten ging diese Samenblase fast in die laugestreckt wurstförmige, spiralig gedrelte Spermatocyste über, die eine Länge ron 9 bei einem Durchmesser von $0,75 \mathrm{~mm}$ hatte und mit Zoospermien erfuillt war. Die gelbliche zungenförmige Druise hatte eine Länge von 7 bei einer Breite bis 2,5 und ciner Dicke bis $2 \mathrm{~mm}$; durch die Achse der Drüse erstreckte sich eine Höhle. - Die Lagerungsverhältnisse der Organe an der vorderen Genitalmasse waren etwa wie bei der typischen Art (vergl. 1. c. p. 402).

Es muss als zweifehthaft hingestellt werden, ob eine Form, die ich im Berliner Museum (Juli 1876), mit einem dem obenstehenden ihnlichen Individuum vertreten, vorfand, hierhin grehört. Dasselbe war von Dr. Studer in Meermaid-Street (an der Nordwestkiiste von Australien) wihlhend der Expedition der Gazelle in einer 'liefe von etwa 2\% Faden an Sandgrund gefischt. Den mir freundlich zur Einsicht gegebenen Notizen STUDER's zufolge zeigt das lebende Thier den Saum des Riickens und der Fortsïtze des vorderen Randes des Fusses violet, von derselben Farbe ist die Kieme; sonst ist die Farbe hellgelblich, braungefleckt." 


\section{HEXABRANCHUS, EHRENBERG.}

Henprici et Emenberg, Symb. phys. Anim. evert. Ser. I. 1831. Dec. tab. I. Moll. 'Tab. I. Fig. 1 A, C.

R. Bergir, malakol. Unters. Heft XIII. 1878. p. 547-566.

Auch diese längst aufgestellte Gattung war bis vor wenigen Jahren unbekannt geblieben, dann wurde eine Uebersicht von 18 (19) Arten geliefert und vier derselben durchgehend untersucht. Untenstehend folgen Abbildungen einer dieser Arten. ${ }^{1}$ ) In letzterer Zeit hat ABRAHAM noch (1. c. 1877, II. p. 259-262) mehrere neue Arten aufgestellt, die wahrscheinlich mit schon beschriebenen identisch sein werden.

18. Hex. orbicularis, ABr. 1. c. p. 260. pl. XXX. Fig. 23, 24.

Oc. africano-ind. (Mauritius).

19. - Mauritiensis, ABR. 1. c. p. 261.

Oc. africano-indic. (Mauritius, Rodriguez).

\section{Hexabr. pulchellus, PEASE.}

Hexabr. pulchellus, Pease. Proc. zool. soc. XVIII. 1860. p. 33.

Color pallidus, medio dorso lutescens, margine palliali albus; medio dorso et versus marginem pallialem carminee punctatus. Rhinophoria pallida apice carmineo. Folia branchialia pallida, carminee marginata.

II a b. Oc. pacific. (ins. Sandwich).

Taf. B. Fig. $14-17$.

Die Figuren sind Copien nach Originalfiguren PEASE's. ${ }^{2}$ )

1) Der zugleich mit dem Hex. pulchellus von PEase"publicirte Hex. nebulosus ist eine Doriopse. Vergl. Journ. d. Mus. Goderrroy, Heft VIII. 1875. p. 95. Taf. VII. Fig. 5, Taf. XI. Fig. 24; Heft XIV. 1878. p. 23-24.

2) n- smooth, and subpellucid - Branchial plumes seven. Colour pale with a light yellow tinge along the dorsal region, where there are also numerous carmine dots; similar coloured dots around the margin of the mantle, which is edged with white. Branchiae pale and edged with carmine. Tentacles pale and tipped with carmine." PE.ase. 


\section{ARCHIDORIS, Brir.}

Archidoris, B. Malncolog. Unters. (SEMPER, Philipp. II, II) Heft XIV. 1878. p. 616. On the nudibranch. gaster. moll. of the north pacific oc. I. 187!. p. 106 (162) (scientific res. of the explor: of Alastia. 1. art. V).

Corpus non durum, subdepressum; dorso granuloso vel tuberculoso. Tentacula brevia, crassa, sulco marginali exteruo. Branchią (retractilis) e foliis tri- rel quadripinnatis sat paucis formata. Podarium sat latum, margine anteriore superficialiter sulcatum.

Armatura labialis mulla. Radula rhachide nuda, pleuris multidentatis; dentes hamati. - Penis inermis; vagina inermis.

Die Arehidoriden sind ron nicht harter, eher weicher Consistenz und von nicht sehr niedergedriekter kriftiger Körperform; der R ii ken ist mehroder weniger k̈̈rnign und knotig. Die 'Tentakel knrz, diek, wie höekerartige Vorspringe an den Seiten des kleinen Kopfes bildend. Die (zurückziehbare) Kieme aus einer geringen Anzahl von tri-oder quadripinnaten Federn gebildet. Der Fuss ziemlich breit, mit einfacher Furche des Vorderrandes. - Die Lippenseheibe nur mit einer dieken Cuticula bekleidet. Dic Raspel mit schmaler uackter Rhachis und zahlreichen Zahnplatten an den Pleurac; die Zahnplatten von der gewöhnlichen gefligelten Hakenform. - Der Penis so wie die Vagina unbervaffuet.

In den äusseren Formverhaitnissen, noch mehr aber im inneren Baue stehen die Arehidoriden den Staurodoriden nale, wehche sich aber von ihmen durch die zahlreichen und einfach gefiederten Kiemenblïtter sowie ferner durch die Entwieklung von Schutz-T'uberkeln am Rande der Rhinophorhöhlen und der Kiemenöftuung unterscheiden. Noch n äher stehen die Archidoriden aber im Aeusseren den ron mir neulich $\left.{ }^{1}\right)$ aufgestellten Homoiodoriden, welche sich hauptsächlich durch eine eigenthimliche Bewaffinung der Vagina unterseheiden.

Von der Gattung sind bisher nux dio untenstehenden Arten bekannt:

1. A. tubereulata (Cur.).

II. atlant.. mediterr.

1) R. Beran, Beitr, zur Kenntn, der japanischen Nudibranchion, II. Verh. d. k. k. zool. bot. Ges. in Wien. XXXI. 1 Ss1.

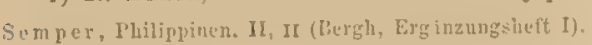


2. A. flammea (A. et $H_{\text {.) }}$.

II. atlant.

3. A. Montereyensis, (Cooper) BGH. ${ }^{1}$ )

M. pacific.

\section{A. tuberculata (Cur.).}

Von der im Mittelmeere vorkommenden Form dieser Art ${ }^{2}$ ) habe ich wieder ein Individum untersucht, ${ }^{3}$ ) von A. VAYssik̀ne und zwar aus dem Golfe von Marseille herstammend.

Das in Alcohol bewahrte Individuum lhatte eine Länge von vollen $3,5 \mathrm{Cm}$. bei einer Breite bis 2,5 und einer Höhe bis 1,6 Cm.; dio Breite des Mantelgebrïmes betrug bis 7, die des Fusses bis $18 \mathrm{~mm}$; die Höhe der Rhinophorien war 5, die der Kieme $6 \mathrm{~mm}$; die der Analpapille beiläufig 2,3 mm; der Diam. der grössten Riuickenwarzen bis 1,25 mm. Die Farbenverhỉltnisse wie sonst. - Die Formverhäiltnisse wie gewöhnlich; die Zahl der Kiemenblätter 7, die Kiemenkrause am Grunde derselben sehr ausgeprägt.

Das Centralnervensystem wie gewöhnlich; die Ganglien an der Unterseite desselben deutlicher geschieden. Die im Ganzen duinne gemeinschaftliche Commissur an beiden Enden breiter und ihre Zusammensetzung aus den drei Commissuren daselbst deutlich. Der aus dem rechten visceralen Ganglion entspringende N. genitalis zeigte etwa am Uebergange zwischen dem ersten und zweiten Drittel seiner Länge eine ganglionäre Anschwellung. Der N. vagus wie gewöhnlich. Die buccalen Ganglien kurz oval, durch cine ganz kurze Commissur verbunden; die gastro-oesophagalen Ganglien beiläufig 1/5 der Grösse der vorigen betragend, ganz kurzstielig, mit einer grossen, 3-4 kleineren und mchreren ganz kleinen Zellen. - Die Augen und die Ohrblasen wie gewöhnlich.

Die Mundröhre etwa 5,5 mm lang. - Der Schlundkopf beiläufig $10 \mathrm{~mm}$ lang bei einer Breite bis 8,5 und einer Höhe bis $10 \mathrm{~mm}$; die starke Raspelscheide hinten noch fast $4,5 \mathrm{~mm}$ hervortretend; die Lippenseheibe wie gewöhnlich. Die Zunge mit 23 Zahmplattonreihen; weiter gegen hinten fanden sich noch 35 entwickelte und 6 nicht oder nicht vollständig entwickelte licihen vor; die Gesammtzahl derselben somit 6t. In den Plattenreihen kamen hinten an der Zunge 79 Platten vor, und die Anzahl der Platten stieg kaum erheblich gegen hinten. Die Platten wie gewöhnlich. - Die SpeichelAr ii s en bandförmig, gelblichreiss, sich längs der Hinter- und der Unterseite des Schlundkopfes erstreckend; ausgestreckt etwa 2,5 Cm. lang bei einer Breite bis $1,5-2,5 \mathrm{~mm}$.

Die Speiseröhre und der Magen wie friber erwilhnt. Der letztere wie gewöhn-

1) Vergl. 1. c. (Alaskia) 1879, p. 107 (163). PI. XVI. Fig. 6, 7.

2) Vergl. 1. c. Heft XIV. 157S. p. 622--624.

3) Als ich in der Homoiodoris (japonica, BGн.) eine Bewaffinung der Vagina vorfand, untersuchte ich in dieser Beziehung wieler die nächststehenden Gattungen Archidoris und Staurodoris; denselben felnlt aber eine solche Bewaffnung. 
lich, etwa $12 \mathrm{~mm}$ lang bei einer Breite bis 9 und einer Höhe bis $7 \mathrm{~mm}$; ron Speisebrei prall gefüllt, der aus rundlichen Ballen von Schwammmasse (mit ihren Spikeln) von einem Diam. von 1-2 $\mathrm{mm}$ fast ausschliesslich bestand. Der Darm in Allem fast $4 \mathrm{Cm}$. lang bei einem Durchmesser von 2,5 (vorne) bis $1,5 \mathrm{~mm}$, lecr. - Die hell ockergelbe hintere Eingeweidemasse (Leber) etwa $22 \mathrm{~mm} \mathrm{lang} \mathrm{bei} \mathrm{einer} \mathrm{Breite} \mathrm{(vorne)} \mathrm{bis} 16$ und einer Höhe bis $12 \mathrm{~mm}$. Die unterhalb der Cardia durch éine senkrechto Grube der Leber hinabsteigende Gallenblase etwa $9 \mathrm{~mm}$ lang bei einem Durchmesser bis $3,5 \mathrm{~mm}$, unten iiber den Rand der Leber hervortretend; mit demselben Speisebrei wie oben gefuillt.

Die (wie der ganze Schlundkopf mit seinen Nebenorganen und den umliegenden Organen) röthlichgelblichen, abgeplatteten Blutdrisen von ziemlich ibereinstimmender Grösse; die vordere an dem vorderen Theile des Schlundkopfes ruhend, herzförmig, etwa $7 \mathrm{~mm}$ lang; die hintere unregelmaissig-dreieckig, den Basalrand gegen hinten kehrend, etwa $7,5 \mathrm{~mm}$ lang bei einer Breite bis $9,5 \mathrm{~mm}$. - Die etwa $3 \mathrm{~mm}$ lange, kurz birnfürmige Nierenspritze sich mit ihrem starken Gange durch die volle $\% / 3$ der Länge der unteren Wand der bis $5,5 \mathrm{~mm}$ weiten Urinkammer fortsetzend.

Die Z witterdrüse mehr rothgelb, sonst wie gewöhnlich. - Die vordere Genitalmasse von zusammengedrickter Pyramiden-Form, etwa $9 \mathrm{~mm}$ lang bei einer Höhe bis 7 und einer Breite eben auch bis $7 \mathrm{~mm}$. Der weissliche Zwitterdriisengang in seiner freien Strecke etwa $12 \mathrm{~mm}$ lang, diinn; die gelbliche Ampulle viel lïnger, aber nicht viel dicker. Der Samenleiter vie gervöhnlich. Der (eingestiilpte) Penis etwa $17 \mathrm{~mm}$ lang bei einer fast durchgehenden Breite von $4 \mathrm{~mm}$; nur der unterste Theil des Organs ist hohl (Praeputium), eine kaum $3 \mathrm{~mm}$ lange, gebogene, kegelförmige Glans enthaltend; der sich durch die ganze Läinge des Penis hinabschlängelnde Samengang konnte bis an die Oeffnung an der Spitze der Glans verfolgt werden. Die Spermatotheke kugelförmig, von etwa $3 \mathrm{~mm}$ Diam.; der vaginale Gang ausgestreckt etwa $16 \mathrm{~mm}$ lang, oben diuner, unten (Vagina) allmählig zu einem Diam. von etwa $2 \mathrm{~mm}$ sehwellend; in dieser letzteren Strecke mehrere (etwa 10) starke Längsfalten, unter denen 1-2 stïrkere. Die Spermatocyste kurz-birnförmig, von etwa $1,75 \mathrm{~mm}$ lïngstem Durchmesser. Die Schleimdruse gelblichweiss, die Eiweissdrise röthlich dottergelb. Im Vestibulum starke Läingstalten. 


\section{STAURODORIS, BGH.}

Staurodoris, BGIr. Malacolog. Unters. Heft XIV. 1878. p. 578.

Corpus non durum, subdepressum, dorso tuberculato. Foveae rhinophoriorum sicut fovea branchialis tubereulis marginalibus elevatis valviformibus defensae. Tentacula brevia, crassa, sulco marginali externo. Branchia e foliis sat numerosis simpliciter pinnatis formata.

Armatura labialis nulla. Lingra rhachide angusta nuda, pleuris multidentatis; dentes hamati. - Penis et ragina inermes.

Die etwas abgeplatteten Staurodoriden sind eher von weicher als von harter Consistenz; der Riicken ist grob tuberculirt; am Rande der Rhinophor-und ler Kicmentröhle sind die Tuberkelklappenatigentwickelt. Die Tentakel wie in den Archidoriden; dic Kiemenblatter dagegen zahlreicher und nur einfach geficdert. - Eine Bewafinung der Lippenseheibe fehlt. Die sehmale Rhachis der Zunge nackt; an den Pleurac dagegen zahleiche hakenförmige Zahnplatten. Der Penis sowie die Vagina unbewaffnet.

Die Staurodoriden unterscheiden sieh von den Ilomoiodoriden und den Arehidoriden leicht durch die einfach geficderten Kiemenblätter', ferner durch die klappenartige Entwicklung der 'Tuberkel am liande der Rhinophor-Oeftinungen und der Kiemenhöhle.

Von der Gattung sind bisher nur die (4) friiher von mir (l. c. p. 579) erwiihnten Arten bekannt. Der Zufall veranlasste mich (s. unten) zu einer, untenstehenden WiederUntersuchung einer frither ron mir beschriebenen Art von der Küiste ron Brasilien (Rio Janeiro). In der letzten Zeit ist vielleicht dureh AnRAIAu eine neue Art zugekommen:

5. St.? pustulata (ABi.).

D. pustulata, ABr. Proc. zool. soc. 1877, H. p. 256. pl. XXIX. Fig. $18,19$.

Oc. pacific. 


\section{St. Januarii, B $\mathrm{B}$.}

Staurodoris Januarii, Bgir. I. c. 1878. p. 583-585. 'Taf. Lxill. Fig. 24; Taf. LXIT. Fin. $8-1:$

Taf. C. Fig. 13-23; Taf. D. Fig. 29.

Während seines Aufenthaltes in Brasilien während des Winters 1877 hat Professor SelexkA einige Nudibranchien in der Nihe von Rio Janeiro gesammelt und mir zu näherer Untersuchung freundlich iiberlassen. Darunter fanden sich 11 Individuen der von mir vor Kurzem (1878) eben aus ganz derselben Localitïit beschriebenen St. Januarii.

SElenka zufolge sollen die lebenden Thiere von fast ganz derselben Farbe wie die in Alcohol bewahrten scin. Diese letzteren sind schmutzig hellgelblich oder (3 Individuen) röthlichgrau (-gelblich) oder (1 Indiv.) graulichweiss mit den Eingerveiden an der Riickenseite schiefergraulich durehsehimmernd. - Die Liinge der Individuen variirte zwischen $S$ und $30 \mathrm{~mm}$. - Zwwei fast ganz gleichgrosse Individuen wurden genauer untersucht. Die Lïnge derselben betrug fast $3 \mathrm{Cm}$. bei einer Breite bis 17 und einer Jü̈he bis etwa $11 \mathrm{~mm}$; die IFöhe der Rhinophorklappen etwa 2,5, die der Rhinophorien selbst bis $4 \mathrm{~mm}$; die Höhe der Kiemenklappen bis 3, 5 , der Kiemenblätter bis $6 \mathrm{~mm}$, die Breite der offenen Kiemenspalte bis $7 \mathrm{~mm}$; die Breite des Mantelgebrimes bis 5,5 , des Fusses bis $13,5 \mathrm{~mm}$; die Höhe und der Durehmesser der Riicken-I'uberkel bis $2,25 \mathrm{~mm}$ betragend.

Die Formverhailnisse wie gewöhnlich. Die (Fig. 13 aa) 'Tentakel nur kurze Lappen an den Seiten des ziemlich (Fig. 13) engen Aussenmundes bildend; mit ganz oberflachlicher Liingsfurehe des Vorderrandes. Die ziemlich engen Rlinopluor-Oefinungen am wenig rorspringenden Rande (Fig. 1f) jederseits nit einer grüsseren Kilappe, welche an der Aussenseite gewölbt, an der Innenseite abgeplattet war"; zwischen den Klappen crhob sieh der liand noch in 1-2 kleinere und meistens ganz kieine klappenartige 'Tuberkel. Durch die Klappen konnte die enge Rhinophoröfluung fast ganz verschlossen werden, so dass dieselbe kaum mehr zu schen war. Das rollstiindigst zuriickziehbare Rhinophor trat (Fig. 14a) gegen hinten gerichtet zwischen (und hinter) den grossen Klappen hervor. Der Stiel derselben war kurz; die Keule sehwach, etwas zusammengedriekt, mit etwa (15-) 20 dünnen Blättern. Die zahlreichen grossen knopfartigen T'uberkel des R iickens (Fig. 14, 18) wie gowöhnlich, zwischen denselben kleinere und kleinste, mehr sessile. An der Aussenseite des nur (Fig. 16) wenig rortretenden Randes des querovalen oder mehr (Fig. 15) rundlichen K i emenloches erhob sich eine etwas variable Anzahl ron (meistens 8-10) grösseren Schutzklappen, die mehr oder weniger zungenfömig, mitunter auch schwach gestielt waren, denen der lihinophor-Oefhumgen etwas ïhnlich, aber schlanker; zwischen den meisten derselben kamen (Fig. 16) etwas kleinere ror, und zwischen diesen und den vorigen noch je 1-2 ganz kleine. Diese Schutzklappen konnten das Kiemenloch, wenn die Kieme ganz zuriickgezogen war, fast rollständig 
decken (vergl. Fig. 15). Die Kieme aus 15 bis 20 fast gleichgrossen, einfachen, ziemlich schwachen Federn (Fig. 17 a) gebildet. Fast central im Kiemenkreise, nahezu in der Mitte einer runden Einsenkung (Fig. 17), deren Rand eine Andeutung der gewöhnlichen KiemenKrause bildete, fand sich die zackig abgestutzte kegelförmige Analpapille; an ihrem Grunde vorne und rechts die ziemlich weite Nierenpore (Fig. 17). An der glatten Unterseite des Nantelgebrämes schimmerte das Netzwerk der Spikelhaufen sehr deutlich hindurch, von stärkeren auf den Rand senkrecht stehenden Balken häufig durchzogen; zwischen den Tuberkeln des Ruickens kam ein :ihnliches, aber schwächeres Netzwerk vor, mit Ausläufern, die in jene hinaufstiegen. Die Genitalpapille mit zwei spaltenförmigen Oeffnungen, die eine ausserhalb der anderen.

Das Centralnervensystem wie gewöhnlich; die subcerebrale und viscerale Commissur dicht an einander liegend (Fig. 20a), die pedale mehr oder weniger von den zwei anderen gelöst (Fig.20e). Der, wie gewöhnlich, längs der rechten Seite des Darmes verlaufende $N$. vagus auch diesen kreuzend und bis an die Nierenspritze zu verfolgen. Die proximalen Riechlinoten zwiebelförmig, fast sessil; die distalen länglich. Die buccalen Ganglien kurz-oval, fast rundlich, durch eine ganz kurze Commissur verbunden. Die gastro-oesophagalen Ganglien rundlich, etwa 1/5 der Grösse der vorigen betragend, kurzstielig; mit einer grossen, 4 kleineren und mehreren ganz kleinen Zellen. Die sympathische Nerven-Verbreitung an dem Magen ungewöhnlich ausgepräigt; an seiner Unterseite ror der Cardia ein grösseres, mehrere Nerven abgebendes Gangl. gastrieum, und sonst mehrere kleinere Nervenknoten ringsum zerstreut.

Die A ugen mit kohlschwarzem Pigment; fast sessil. Die Ohrblasen als kalkweisse Punkte unter der Loupe sichtbar; ron Otokonien strotzęnd, deren Anzahl etwa 3-400 betrug, die selıwach gelblich, meistens oval und von einem grössten Durchmesser bis $0,025 \mathrm{~mm}$ waren. Iic Keule der Rhinophorien fast bis an die Spitze des Endzapfens mit Spikeln iusserst reichlich ausgesteuert, und die diunen Blaitter derselben stark durch solche abgesteift (Fig. 19); im Stiele kommen die Spikeln etwas sparsamer vor. Die Spikeln sehr schwach gelblich, meistens stark erhärtet, gestreckt-spindelförmig, meistens lang, die Liunge bis etwa $0,35 \mathrm{~mm}$ betragend bei einem Durchmesser bis $0,03 \mathrm{~mm}$. Unregelmiissige Haufen von ähnlichen Spikeln bildeten das Netzwerk an der Unterseite des Mantelgebrämes, wo sie aber mitunter bis gegen die doppelte Länge ermeichten bei einer nicht viel bedeutenderen Dicke. In der Rücken-II aut, sowie in den Tuberkeln von jener waren die Spikel kleiner, kamen aber massenweise vor. In der interstitiellen Bindesubstanz kamen sparsam zerstreute grosse Spikel auch vor; in der Ifülle des Centralnervensystems einzelne (Fig. 22) von einer Lïnge bis 0,5 bei cinem Durchmesser bis $0,05 \mathrm{~mm}$, ganz erhïrtet und fast farblos.

Der Schlundkopf $4 \mathrm{~mm}$. lang bei einer Breite bis 3,5 und einer Höhe bis $3,5 \mathrm{~mm}$; die etwas gegen obeu gebogene Raspelscheide noch $2 \mathrm{~mm}$ hervortretend. Die 
Cuticula der ovalen Lippenscheibe weisslich oder sehe hell gelblichweisslich, unten bei dem einen Individuum (wegen des vortretenden Cylinderepithels) unregelmissige Reihen von feinsten Höckerchen bildend. Die Zunge bei dem einen Individuum 27, bei dem anderen 23 Zahnplattenreihen enthaltend; unter dem Raspeldache und in der Raspelscheide kamen noch 17-20 entwickelte und 4 mehr oder weniger unvollständig entwickelte Reihen ror; die Gesammtzahl derselben somit 48-47. An der Zungenspitze fanden sich noch Spuren ron 3-4 ganz ausgefallenen Reihen. Die ersten 2-3 Reihen sehr incomplet, und so auch die nächstfolgenden; in der ersten ganz completen, der 11-10ten der Zunge, bei dem einen 63, bei dem anderen 55 Platten; die Anzahl dann gegen linten bis 66 und 61 steigend. Die Zahnplatten (Fig. 21) wie friher von mir beschrieben. Kurzhakige (Fig. 21 a) und Doppelzahmplatten (Fig. 22) fehiten nicht.

Die Speicheldrüs cn weisslich, bandförmig, etwa noch ein halbes Mal so lang wie der Schlundkopf.

Die Speiseröhre etwa $7 \mathrm{~mm}$ lang bei einem Durchmesser bis $1 \mathrm{~mm}$. Der mit seiner vorderen Hälfte aus der Leberkluft hervorragende Magen etwa $10 \mathrm{~mm}$ lang bei einem Durchmesser bis $5 \mathrm{~mm}$. Der Darm unbedeutend geschlingelt bis an die Analpapille verlautend, etwa $2,1 \mathrm{Cm}$. lang bei einem Durchmesser bis 1,2 mm. - Der Inhalt der Verdauungshöhle (des Magens) fast ausschliesslich Schwammmasse mit Masson von nadelförmigen Spikeln.

Die gelbliche hintere Eingerveidemasse (Leber) etwa $16 \mathrm{~mm}$ lang bei einer Breite bis 11,5 und einer Töhe bis fast $9 \mathrm{~mm}$; das Vorderende abgestutat, mit einer tiefen Kluft in der linken (oberen) Hailfte für den Magen, an der rechten (unteren) eine Abplattung fiir die vordere. Genitalmasse; das Hinterende gerundet; an den Seiten tiefe Furchen für die Gefïse; die Höhle wie geroöhnlich. Die Gallenblase in einer von der Gegend der Cardia gegen den unteren Rand des Vorderendes der Leber fast senkrecht hinuntersteigenden oberfächlichen Furche gelagert, gestreckt-schlauchförmig, etwa $5 \mathrm{~mm}$ lang.

Das Herz und die Nierenspritze wie gewöhnlich; der Gang der letzteren sich an das Vorderende der Leber erstreckend; der Urinleiter weiter als der Nierenspritzengang. - Die Blutdrüsen weisslich, abgeplattet; die vordere von ovaler Form, etwa 4,5 mm lang; die hintere von ähnlicher Grösse, mehx dreieckig.

Die Zwitterdriise durch ihre gelbliche oder weissliche Farbe gegen die hell gelbgraue oder braungraue Lebersubstanz contrastirend, welche, mit Ausnahme der Tiefe der Kluft am Vorderende, fast iiberall mit einem diimnen Lager von jener iberzogen war. Der Zwitterdrisengang rechts fast am oberen Rande des Hinterendes der Leberkluft mit zwei Aesten, einem aus jeder Seite, entspringend, an der Hinterseite der vorderen Genitalmasse die gelblichweisse Ampulle bildend, welche mehrere Biegungen machte und ausgestreckt etwa $12 \mathrm{~mm}$ bei cinem Durchmesser bis $1,2 \mathrm{~mm}$ maass. Dic vordere 
Genitalmasse etwas zusammengedruckt, etwa $10 \mathrm{~mm}$ lang bei einer Höhe bis 7 und ciner Breite bis $4,5 \mathrm{~mm}$; der Hinteruand schärfer; die Schleimdrüse gelblichweiss, die Eiweissdrise gelblich. Der aus der Ampulle des Zwitterdrisenganges entspringende männliche Zweig gleich in die ziemlich lange, schmutzig braunlichgelbe oder gelbliche, mehrere Knnickungen bildende Prostata ibergehend, welche der bei der Staurod. verrucosa (1. c. p. 583) nachgewiesenen fast iihnlich, nur etwas kürzer war; die Prostata ging in len kürzeren, weisslichen, viel duinneren Samenleiter iiber; an der Uebergangsstelle heftete sich der starke M. retractor; der Samenleiter ohne Grenze in den kurzen Penis ubergehend. Die Spermatotheke (Fig. 23a) kugelförmig oder mehr gestreckt, von etwa $4 \mathrm{~mm}$ Diam.; der vaginale Gang (Fig. 23d) etwas geschlingelt, stark; der uterine (Fig. 23e) kiurzer, viel diinner, an seiner Wurzel die schlauchfürmige (Fig. 23b) Spermatocyste durch einen kurzen Gang angeheftet tragend, der grösste Durchmesser dieser Samenblase etwa 2,5 mm betragend. 
PELTODORIS, BGII. N. gen.

Corpus subdepressum, circumferentia ovali, subrigidum, supra minutissime grannlatum. Tentacula digitiformia. Apertura branchialis rotundata; branchia pancifoliata, foliis tripinnatis.

Armatura labialis nulla. - I ingra pleuris multidentatis, dentibus hamatis.

Prostata magna; penis. (et vagina) inermes.

Die Peltodoriden sind ziemlich niedergedrickt, von ovaler. Form, etwas steif oder lederartig und am Riicken ganz fein granulirt; die Tentakel sind fingerfürmig; die Kiemenöflnung rundlich, und die (zurickzichbare) Kieme ans wenigen. (6) tripinnaten Blittern gebildet. - Die Lippenseheibe ist nur von einerkriftigen Cuticula iiberzogen (ohme besondere Bewaffnumg.) Die Zunge mit schmaler nackter Rhachis; an den I'leurae ziemlich zalhlreiche (Seiten-) Zahnplatten von der bei den mehr typischen Doriden häufigst vorkommenden Hakenform. Es kommt cine grosse Prostata vor; der Penis (so wie die Vagina) ist un bewaffuet.

In den allgemeinen Form- und :iusseren Verhïlnissen stimmen die Peltodoriden auffallend mit den Discodoriden, sind aber von härterer. Consistenz: sio haben die Tentakel und die Kieme der Discodoriden, mit welehen sie ferner in der Beschaffenheit der Raspel sowie in dem Dasein einer grossen I'rostata und eines unbewaftneten Penis ïbercinstimmen. Von den I)iscodoriden unterseheiden sich die Peltodoriden abel am Schiirfsten durch die unbewaffnete, glatte Lipluenscheibe.

Das bei den harten Platydoriden sowie bei einzelnen Discodoriden bcobachtete') Abstossen ron Stieken des Mantelrandes ist auch bei den bisher bekannten Peltodoriden gesehen.

Von der Gattung sind bisher nur die zwei untenstelıenden Arten bekannt:

1. P. atromaculata, BGII. m. sp.")

II. mediterr.

2. - crucis (Oersted).

M. antillense.

1) Vergl. Heft XII. 1577. p. 496, $51 \mathrm{~S}$.

2) Wird in den "Mittheilungen aus der zool. Station in Neapel" (II. 18s0) veröflentlicht. Semper, l'hilippinen. II, II (Lirgh, Ergàzungsheft I). 


\section{P. crucis (Oersted).}

Doris (Dendrodoris) crucis, OErsт. in schedulis. Mörch, Journ. de conchyl. $3 \mathrm{~S}$. III. 1863. p. 32 .

Discodoris crucis, (Oensted) BGH. Vergl. Ueft XII. 1877. p. 519.

Color dorsi prasinus maculis majoribus nigrescentibus; rhinophoria nigrescentia, branchia flavescens; pagina inferior limbi dorsalis albescens, maculis majoribus minoribusque griseis; podarium infra brunnescens maculis magis saturatis.

Ha b. M. antillense (St. Thomas, St. Croix).

Taf. A. Fig. 1-2.

Dieso Art ist von Professor Oensted (1860) in der. Nachbarschaft von St. Croix und ron Herru Apotheker Rrise bei St. 'Thomas an Corallen in einer 'Tiefe von 3' Wasser (am 23. Juni 1858) gefiseht. Wen Mittheilungen Oersten's (an Mörcu) zufolge stossen die Thiere ihr Mantelgebrime sehr leicht ab; bei einem der von mir untersuchten Individuen fehlte dasselbe an den Seiten fast so vollständig, als ob es mit einer Scheere weggenommen wïre; bei den ankleren dagegen fand sich dasselbe etwas vollstindiger bewahrt.

Von der Art haben mir in Allem drei, für genauere Untersuchung zwei grössere Individuen vorgelegen, beide aus dem Neere um St. Thomas herstammend; diese zwei sind dieselben, welehe Dr. O. Mörci zur Untersuchung gehabt hat. Die Individuen waren ziemlich contrahirt und erhïrtet, sonst ganz gut conservirt; beide wurden der anatomischen Untersuchung geopfert.

Den, den lebenden Thieren nach von OErsted gemachten (später vom Maler Truornay ausgefuhrten) Skizzen zufolge (Fig. 1, 2) hat das Thier eine Länge von etwa 8 bei einer Breite von beiliufig $4 \mathrm{Cm}$. gehabt. Die Farbe der Riickenseite ist denselben gemaiss (ziemlich dunkel) grasgruin mit ziemlich zahlreichen, grösseren, runden, schwirzliehen Flecken; die Keule der Rhinophorien schwarz, die Kieme gelblich; die Unterseite des Mantelgebräimes weisslich, mit einer Unzahl von kleinsten und kleinen granen Tüpfelehen; die Unterseite der Fusssollle hell (röthlich-) braun mit dunkleren rundlichen Flecken. - Die zwei grösseren in Alcohol bewahrten Individuen hatten eine Lüinge ron $7-6$ und eine Breite von 4,3 Cm.; die Höhe betrug 15-18 mm; die Breite des Mantelgebrimes war 10-18, die der Fusssohle 17-19, die Inohe der Rhinophorien 4, die Lïnge der 'lentakel 4,25 und die Höhe der Kieme 8 mm. Die Grundfarbe war weisslich oder gelblich, an der Riickenseite mitunter mit einem griinlichen Anfluge; an dieser Seite traten die grossen, verschwommenen granen und schwïrzlichen Flecken herror; und nn der Unterseite des weisslichen Mantelgebrämes sowie an den anch weisslichen Seiten und an der weissliehen Oberseite des Fusses die Kleineren, zalıI- 
reichen und mehr graulichen 'liipfelchen (die bei dem einen Individum ganz fehlten): der Aussenmund sowie die Unterseite der oberen Lippe des Vorderrandes des Fusses ockergelb; die Fusssohle gelb oder gelblich, auch mit zerstreuten kleinen graulichen Fleckehen. Die Rhinophorien sowie die Tentakel weisshich; die Stielparthien der Kieme weisslich, die Blätter graulich oder braungrau; die Analpapille mitunter gelblich.

Die Form des Thieres liinglich oval, der Riicken ziemlich gewölbt, das Mantelgebrime breit. - Der Aussenmund rund, zusammengezogen; ausserhalb desselben jederseits der fingerförmige zugespitzte Tentakel (Fig. 2). Die Rhinophoröffunngen nur wenig hervortretend, der Rand fein rundzackig; die Kenle der Rhinophorien stark gegen hinten gebogen, jederseits mit etwa 40 steifen, doch diunen und breiten Blïttern. - Die ganze obere Seite des Körpers sehr fein chagrinirt, mit dem nackten Auge sichtbaren, feinsten Körnchen dicht bedeckt. Das Mantelgebrime ziemlich breit, ringsum fast dieselbe Breite bewahrend, ziemlich dick, gegen den Rand hin verdünnt, an der unteren Seite glatt. Die Kiemenöfinung fast rund, ron bis etwa $9 \mathrm{~mm}$ Diam., mit glattem, mitunter etwas umgeschlagenem Rande. Die Kieme aus 6 tripinnaten Blättern gebildet; hinten in dem Ausschnitte die abgestutzte, in dem Rande fein crenclirte Analpapille; rechts ror derselben die feine runde Nierenpore. Die Seiten niedrig; die Genitalpapille an gewöhnlicher Stelle, bei dem einen Individuum ragte das ausgestülpte Vestibulum aus derselben fast $3 \mathrm{~mm}$ hervor. Der F'us durch acine ganze Liinge fast von derselben Breite, hinten gerundet, vorne ebenso. Der Vorderrand in zwei Lippen gespalten; die obere Lippe die untere überragend, dureh einen medianen Einsehnitt getheilt; die untere mit ciner Querfurche.

Die Eingerveide schimmerten nirgends hindurch. Das Peritonaeum farblos.

Das Centralnervensystem wie bei verwandten Formen. Die pedalen Ganglien ron rundlichem Umrisse, ebenso die visceralen Knoten, die etwa von derselben Grösse waren. Die buccalen Kinoten etwa ron der Grösse der Gl. olfactoria, ziemlich abgeplattet, von rundlichem Umrisse, fast unmittelbar mit cinander verbunden. Die gastrooesophagalen Knoten mehr als 1/3 der Grösse der vorigen betragend, kurzstielig oder fast sessil, rundlich.

Das A uge von etwa $0,25 \mathrm{~mm}$ grösstem Diam., mit schwarzem Pigmente, grelber Linse. Die Ohrblase von beiläufig 0,13 mm Diam., von Otokonien gewöhnlicher Art strotzend. Die Blätter der Kécule der Rhinophorien durch starke, parallellaufende, langgestreckte Spikel schr stark abgesteift. ${ }^{1}$ ) Die 'lentakel bis an ihre Spitze im höchsten Grade mit hauptsiichlich langen und im Ganzen grossen Spikehn versehen. Die Ha ut des Rückens und die feinen Hauthöekerchen ganz in der Art der Kentrodoriden mit Spikeln ausgestenert, welche in etwa ehenso grosser Menge auch in der Unterseite 
des Mantels sowie fast iiberall in der Maut, auch in der Iisssohle vorkamen. - In der interstitiellen Bindesubstanz kamen auch Spikel vor, besonders massenweise um die Ausführungsgünge des Genitalapparats. - Die Spikel waren hauptsiichlich langgestrecktspindelfömig, eine Linge bis wenigstens etwa 0,5 bei einer Breite bis beilïufig $0,026 \mathrm{~mm}$ erreichend, farblos, meistens mit glatter Oberfliche, und stark erhiairtet.

Die If undröhre stark, $7-8 \mathrm{~mm}$ lang bei ciner nur wenig geringeren Höhe und Breite, an der Innenseite mit starken ockergelben Längsfalten. - Der Schlundkop f́ S mm lang bei einer Breite von 7 und einer Höhe von 6-6,25 mm. Die Bekleidung der MIundöffnung weiss, aus ciner dicken, starken, glatten Cuticula gebildet; die Retractoren wie gewöhnlich. Die Zunge stark, breit; die Raspel die Wainde der tiefen Irluft bekleidend. In der Raspel kamen 11-13 Reihen von Zahnplatten vor, unter dem Raspeldache und in der Seheide funden sich noch S-9 entwickelte und 3 unentwickelte Tieihen, die Gesammtzahl derselben betrug somit 29-25; vor der Raspel fanden sich aber noch Spuren von 2-3 granz ausgefallenen Reihen. In den Reihen kamen von der 9-10ten ab 49--50 Zahnplatten vor. Die Zahnplatten waren von sehr hellgelber Farbe, im Ganzen gross und stark, von derselben Grundform wic bei den Kientrodoriden; dic Höhe des IIakens stieg dureh die erste Hiilfte der licilı allmählig, etwa in dem iussersten Sechstel mahm sie wieder ab; an ler Nitte und hinten an der Zunge betrug die Höhe (ron der BasalHii bis an die IIakenspitze) der äussersten Zahnplatte etwa (0,1-) 0,18 mm; die der folgenden 0,25, und die Höhe stieg dann bis 0,32 und $0,46 \mathrm{~mm}$. Die Form der '/ahnplatten war :ihnlich wie bei den Kentrodoriden, der Körper an den meisten langgestreckt, an der Aussenseite mit einem schmalen Flịgel versehen; der Haken unter einem ziemlich offenen Winkel emporsteigend, stark, am Ende ziemlieh stumpf. Die inuersten Zahnplatten zeighten den Kürper kïrzer, den Haken mehr gekrimmt; an den iibrigen Zahnplatten war der Taken mehr alhuihlig gebogen, nur an den iussersten melir gerade emporsteigend. $\left.{ }^{2}\right)$

J)ie Speichcldrisen waren langrgestreckt, etwa 2,5 Cm. lang, mündeten wic in den rordersten Theil der Speiseröhre ein; das vorderste etwa $1 / 5$ war fast wurstfümigy, grelblich, ron etwa $1,5 \mathrm{~mm}$ Diam., kniegebeugt, nahe seiner Mitte vorwairts grebogen; die ibrige lange Strceke war abgeplattet, weisslich, etwa $1 / 3-1 / 5$ des Diam. der vorigen betragend, sich gegen hinten und unten an der unteren Seite der vorderen Genitalmasse erstreckend.

Die Speiseröhre ziemlich weit, etwa $2 \mathrm{Cm}$. lang, an der Innenscite mit starken

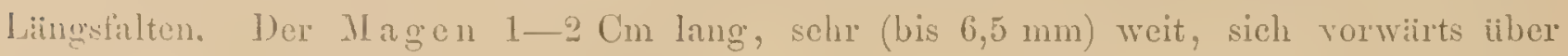
die vordere Genitalmasse erstreckend. Der (3,5-5 mm lange) D arm wieder enger, hampts:ichlich in einer Furehe dex rechten Seite der Leber ruhend; die Innenseite zeigte in der ersten Strecke an der einen Seite starke, in der ganzen iibrigen Strecke sehwache 
Läingsfalten. - An dem einen Individum war die grösste Linge des Magens und des Darmes wegen des Inhaltes röthlich. Derselbe bestand aus unbestimmbarer thieriseher Masse mit einer Unzahl von feinen, bis 0,16 , selten bis $0,2 \mathrm{~mm}$ langen Nadeln vermischt, und mit cinzelnen Spikeln von Schwämmen und mit Nessel-Elementen vermischt.

Die Leber von etwa 22-25 $\mathrm{mm}$ Liinge bei einer Höhe von $10-11$ und ciner Breite ron 11-13 mm; an der Oberfliche wegen der Z/witterdriise hell gelblich-weiss, an Durelıchnitten gelblich; das Vorderende mit einer tiefen fast medianen Kluft, das Hinterende abgestutzt-gerundet. Die Iöhle der Leber, wie gewöhnlich, mit grossen Vertiefungen.

Das. P'ericar di um wie gewöhnlich. Die If erzkammer gross (bis $4,5 \mathrm{~mm}$ lang), die Vorkammer grüsser (bis etwa $6 \mathrm{~mm}$ lang). Die Hauptarterien wie gewöhnlich. - Die Blutdrisen wie gewöhnlich, weisslich, die hintere noch dazu (sovie die BindesubstanzCapsel des Centralnerrensystems) schwiirzlich pigmentirt; die vordere $5-7 \mathrm{~mm}$ lang, oval-ciförmig oder zungenförmig, mehr als die hintere abgeplattet, die nur eine Lainge von $3-4 \mathrm{~mm}$ hatte und ron drei- oder viereckiger Form war.

Das Nierengewebe wie gewöhnlich. Die Nierenspritze melonenfürmig, von ctwa $2 \mathrm{~mm}$ Diamo, mit starken Falten.

Die Läppehen der weissliehen Zwitterdrü zeigten grosse oogene Zellen. Die vordere Genitalmasse gross, $11 \mathrm{~mm}$ lang bei einer Breite ron $6,5-7,5$ und einer Höhe von $7 \mathrm{~mm}$; die obere Seite derselben allmählig gerv̈̈lbt, die untere abgeplattet; die linke Seite gewölbt, die rechte applanirt; das Hinterende allnählig schrïgent, das Vorderende fast senkrecht abfallend. Der grösste 'Theil der Masse war von der Schleimdriise selbst gebildet, ron der die Ausfihrungsgïnge noeh $3 \mathrm{~mm}$ hervorragten; die Drise selbst weisslich, die an der linken Seite hervortretende Eiweissdrüso gelblich. Die Ampulle des Zwitterdrisenganges gestreckt oder gebogen, weisslich, 6-S mm lang. Der Erhärtungszustand der Masse erlaubte keine genauere Untersuchung: an ihrem Vorderende fand sich eil ovaler oder eifürmigner, höckerigger, etwa 3 mm langer, gelblicher, mit Zoospermen gefuilter Sack (Samenblase?). Der Penis etwa 2 mm lang; an dem Organe ganz bestimmt keine Bewaffuung. Die Oefhumgen im Vestibulum schwiirzlich pigmentirt.

\section{P. atromaculata, BGI. n. sp.}

Color fundamentalis lacteus, dorso et pagina superiore porlarii maculis atris majoribus minoribusve; rhinophoria albida; folia branchialia albida, 'rhachidibus internis nigris.

Ha b. M. mediterr. (Napoli).

Diese grosse und schöne Art, welehe ich in diesem Friihjalıre (1880) in der zoolo- 
gischen Station ron Napoli vorfand, wird in den Mittheilungen aus der zoologischen Station in Neapel nächstens mehr eingehend beschrieben und abgebildet werden.

Das lebende Thier hatte eine L ïng e von 4,6 Cm. bei einer Breite bis 2,5 und einer Höhe bis $1,5 \mathrm{Cm}$. Die Grundfarbe des Rückens war fast milchweiss, von den schwarzen Flecken fast verdrängt; diese letzteren waren schwarz mit bräunlichem Schimmer, eckig-rundlich oder quer-oval, von etwas wechselnder Grösse, theilweise sehr gross, und die grösseren, wie es schien, einigermassen regelmässig vertheilt. Die Rhinophorien mit weisslichem Stiele und (schwach gelblich-) weisser Kenle. Die Kiemenblätter weiss, nur die Taupt-Rhachides und die Neben-Rhachides erster Ordnung an der Innenseite sclıwarz. Der Rand der Genitalöfinung schwarz. An der oberen Seite des Fussgebrämes und am Schwanze eine Reihe von grösseren und kleineren schwarzen Flecken.

In der Keule der Rhinophorien (jederseits) etwa 22 Blätter. Die Anzahl der tripinnaten Kiemenblaitter war sechs.

Die Lippenscheibe von einer weisslichen Cuticula überzogen. An der Zunge 7 Zahmplattenreilien; die Gesammtzahl derselben nur 20. Die Anzahl der Zahmplatten in den Reihen bis 55-56 steigend. Die Zahmplatten von gewöhnlicher Form. - Die Prostata stark; der Penis und die Vagina unbervaftnet. 


\section{DISCODORIS, BGIF.}

Vgl. Heft XII. 1877. p. 518, 568.

Die ron mir (1877) aufgestellten Discodoriden zcichnen sich aus durch ihre abgeplattete Form von ovalem oder rundichem Umrisse und von meistens weicher Consistenz. Die Riickenseite ist fein granulirt. Die Kiemenüffnung ist leicht rundgezackt oder zweilappig. Die Tentakel fingerförmig. Die Lippenplatten aus dicht gedrängten Stïbchen gebildet. Die Raspel mit nackter Rhachis, an den Pleurae mit zahlreichen hakenförmigen Zahnplatten. Die Prostata gross, der Penis unbew a f f n e t.

An oben angefuhrter Stelle lıabe ich eine Liste von 10(11) Arten, die mit grösserer oder geringerer Sicherheit dieser, besonders in den wiirmeren Mecresgegenden vertretenen, Gattung zugezählt werden können, geliefert. Die untenstehende Form war daselbst nur genannt, nicht beschrieben. Die übrigen untenstehenden, später beschriebenen ${ }^{1}$ ) Formen werden vielleicht auch hierher gerechnet werden müssen.

11. Discod.? restita (ABR.).

Doris vestita, ABr. l. c. p. 252. pl. XXVIII. Fig. 5, 6. Oc. Pacific. (Fret. Magellan.)

12. - ? raripilosa (ABR.).

D. raripilosa, ABR. 1. c. p. 257. pl. XXIX. Fig. 29, 30. Halo.?

13. - ? stragulata (ABR.).

D. stragulata, ABR. 1. c. p. 251. pl. XXYVIII. Fig. 7, 8. Hab.?

Dise. Schmeltziana, (Garro) Ban.

Discod. Schmeltziana, (GARr.) BGII. 1. c. p. 519.

Color dorsi griseus, aurantiacus et e rubro brumeus; rhinophoria et branchia purpurascente brumea; pagina inferior limbi pallialis albida brunuee punctata, in pallio

1) Agramas, revision of the Anthobranch. Nudibranch. BIoll. Proc. 20ol. soc. 1S77, 1I. p. 196-269. pl. XXVII-XXX. 
ut in pagina superiore podarii simul maculae aurantiacae, pagina inferior podarii caerulescens.

Ha b. Oc. pacif. (ins. soc.)

Taf. A. Fig. 15-19.

Diese Art, die ron Herrn GarretT dem unermidlichen und immer dienstfertigen Custos des Mus. Godefrror, dem Herm G. D. Schieltz, gewidmet ist, ist "unter Steinen an den Riffen der Gesellschafts-Inseln" gefunden, und scheint sehr selten zu sein. Es lag im Muscum ausser den dem Leben nach ausgeführten Zeichnungen GArretr's cin gut erhaltenes Individum ror. - Das lebende 'Thier hatte, Garnetr zufolge, cine L i $\mathrm{inge}$ bis $75 \mathrm{~mm}$ bei einer Breite von $35 \mathrm{~mm}$. Die F arbe ist am Rüicken "grau-, hell orange- und rothbraun-scheckig" gewesen; die Kieme war purpurbran sowie auch die Rhinophorien, welche nur noch eine weisse Spitze zeigten. Die Unterseite des Mantelgebrämes ist wachsweiss mit zalilreich zerstreuten chocoladebraunen Punkten. Die Fusssohle ist an ihrer Nitte noch dazu hell blïnlich (pale watery blue), so wie der innere Theil der Unterscite des Mantelgebrimes und die obere Seite des Fusses mit unregelmïssigen, hell orangefarbigen Fleckehen versehen.

Die Laingedes in Alcohol bewahrten Individums betrug 22 bei einer Breite bis 15 und einer Hühe bis $9 \mathrm{~mm}$; die Breite des Mantelgebrämes belief sich bis auf 8 , die der Fusssohle auf $6,5 \mathrm{~mm}$; die Länge der Tentakel war etwa $2 \mathrm{~mm}$; dic Hühe der Keule der Rhinophorien war 2,3, die der Analpapille 1, der Kieme 4 mm. Die Grundfarbe war weisslich; am Rücken zeigten sich viele grosse (ron cinem Diam. bis $4,5 \mathrm{~mm}$ ), runde und unregelmïssige, graue, unter der Loupe fein dunkler punctirte Flecken; an der oberen Seite des Mantelgebräms fand sich eine grosse Menge ron kleineren ahnlichen Jilecken, welche auch massenweise an der oberen Seite des Fusses und an der Fussolile so wie viel sparsamer an der. Unterseite des Mantelgebräimes rorkommen; der I'uss war ibrigens von mehr gelblicher Farbe, die Kieme fast ebenso, und die Ihhinophorien auch schmutzig gelb, wie jene mit zahlreichen feinen violettschwarzen Punkten.

Die Körperform ist, den Notizen Ganietre's zufolge, linglich oval, mit fast parallelen Sciten :indern, stark niedergedriekt (strongly depressed), der liiicken doch etwas convex. Der lïicken zeigt sich sehr rauh und fein granulirt; das Riiickengebräme ziemlich diinn und mitunter wie unregelmaissig zerrissen (lacerated), die Unterseite desselben viel weniger rauh als die obere. Die Keule der Rlinophorien ziemlich kurz und kräiftig, mit etwa 30 Bliittern; der Rand der Rhinophorhühlen rundgezackt (Fig. 18). Die 'Tentakel cylindrisch oder fingerförmig, am Ende grexundet. Die Kieme ziemlich klein, ron 6 tripinnaten Federu gebildet; der Rand der Kienenhöhle mit sechs kleinen Vorsprïngen; die Analpapille fast cylindrisch, mit rundgezacktem Rande. Der Fuss gerundet an beiden Enden, kïrzer als der Rücken, und von demselben hinten sebr wenig gelöst. 
Die Eingeweide schimmerten nirgends hindurch. Das Peritonaeum farblos. ${ }^{1}$ )

Das Centralnervensystem (vgl. 1. c. Fig. 9) sehr abgeplattet; die einzelnen Ganglien sonst wie gewöhnlich; die buccalen Knoten von rundlichem Umrisse, fast unmittelbar zusammenstossend; die gastro-oesophagalen etwa $1 / 6$ der vorigen betragend, mit einer sehr grossen Zelle.

Die Augen (vgl. l. c. Fig. 9) von gewöhnlicher Grösse, mit schwarzem Pigmente, hellgelblicher Linse. Die O hrblasen nur wenig kleiner als die Augen, von einer grossen Menge von Otokonien gewöhnlicher Art erfüllt. Die sehr breiten Blätter der Rhinophorien ganz ausserordentlich stark mit sehr erhärteten, langen, kräftigen, an dem Rande der Blätter meist senkrecht stehenden Stïbchen abgesteift. Die Tentakel in der Oberfläche wie in der Tiefe im höchsten Grale mit ähnlichen, in den verschiedensten Richtungen liegenden Stäbchen ausgesteucrt, welche fast nur die Spitze freiliessen. . Die Haut des Rückens in sehr hohem Grade. mit Spikeln versehen, welche zum grössten Theile in kleinen Gruppen gelagert waren, zwischen welchen aber iberall auch grössere einzelne Spikel vorkamen; die Höckerchen waren (vergl. 1. c. Fig. 10) sehr stark abgesteift. Die Spikel waren stark erhärteten Röhren ähnlich, spindelförmig oder cylindrisch, in der Oberfläche öftestens wie erodirt oder sehr fein punktirt (vergl. 1. c. Fig. 10), von der verschiedensten Lïnge, bis etwa $0,035 \mathrm{~mm}$ breit. Die Haut der Sciten verhielt sich wie die des Ritckens. Die Analpapille selbst olne Spikel, am Grunde derselben aber eine Menge; die Rhachis-Parthieen der Kieme mit Spikeln wohl ausgestenert, die Verzweigung von jenen mit ihren Blättern ohne solche. - Die interstitielle Bindesubstanz sowie das Peritonaeum oft nur mit sparsamen und kleineren, meistens länglichen Spikeln ausgestattet; sehr reichlich und von bedeutenderer Grösse kommen dagegen solche um die Hauptausführungsgånge des Genitalapparates vor (vergl. l. c. Fig. 11).

Dic Mundröhre stark, etwa 2,5 mm lang, mit starken Lingsfalten ausgesteuert. - Der Schlundkopf $3,3 \mathrm{~mm}$ lang, bei einer Breite bis 2,8 und einer Höhe bis $2,25 \mathrm{~mm}$; die Raspelscheide ziemlich wenig hervorspringend. Die beiden Hiilften der bis $0,6 \mathrm{~mm}$ breiten, gelblichen, ziemlich starken Lippenplatte unten vereinigt, oben durch eine Furche geschieden; dieselbe war aus dicht gedrängten, gelblichen, an der Spitze ein wenig abgeplatteten, fein streifigen, bis etwa $0,09 \mathrm{~mm}$ hohen fast geraden Stäbchen gebildet. ${ }^{2}$ )

Die Zunge wie gewöhnlich; in der hellgelblich schillernden Raspel kamen 15, weiter gegen hinten noch 9 entwickelte und 2 unentwickelte Reihen ron Zahnplatten vor; die Gesammtzahl derselben betrug somit 26. In den Reihen der Zunge kamen in der fünften Reihe 34, hinten an derselben bis 35 Zalınplatten vor, und die Zahl stieg. (in der hintersten entwickelten Reihe) nur bis 37. Die Zahnplatten waren von sehr

1) Eine kleine Reihe von Figuren, die die Untersuchung dieses Thieres erläutern, ist (ohne Text) im Journ. d. Mus. Goderrroz (Heft XIV. 1878. Taf. V. Fig. 9-15) geliefert.

2) Journ. des Mus. Godefrroy, Heft VIII. 1875. Taf. VIII. Fig. 31-37.

Semper, Philippinen. II, II (Eergh, Ergānzungsheft I). 
hellgelblicher Farbe; die Hohe der iusscrsten betrug (in der erwähnten fuinften Reihe) 0,11 , die der folgenden $0,12-0,13-0,14$ bis $0,18 \mathrm{~mm}$, die innersten nahmen wieder in Grösse etwas ab. Der Haken der Platten war immer ohne Spur von Zähnchen. Der Haken der innersten Platte war niedrig (rgl. 1. c. Fig. $12 \mathrm{bb}$ ), an den folgenden (4-5) wuchs die Höhe schnell und erhielt sich dureh alle die iubrigen (vgl. l. e. Fig. 13), wihlurend die Grösso des Kiörpers an den drei äussersten (vgl. l. c. Fig. 14) und zwar besonders an der (rgl. I. c. Fig. 14aa) äiussersten sehr·bedeutend abnahm.

Die Speicheldruisen (rgl. l. c. Fig. 15) langgestreckt; in der vorderen Strecke dick, gelb; in der iibrigen bandförmig, weisslich; die Ausführungsgäinge kurz (vgl. l. c. Fig. 15a).

Die Speiseröhre etwa $6 \mathrm{~mm}$ lang, weit; in der ersten Strecke sehr starke Längsfalten; der hinterste Theil etwas erweitert. Der Magen wie getwöhnlich. Der Darm etwa $18 \mathrm{~mm}$ lang; an seinem Anfange etwas erweitert. - Die Verdauungshöhle leer.

Die Leber etwa 12,5 mm lang bei einer Breite bis 8 und einer Höhe bis $6 \mathrm{~mm}$; das Vorderende in der oberen Hälfte einen tiefen breiten Einschnitt (für die Speiseröhre und den Magen) darbietend, in der unteren schief gegen binten (wegen der vorderen Genitalmasse) wie abgeschnitten; das Hinterende gerundet. Die Gallenblase wie gewöhnlich, nur ziemlich diinnwandig.

Das Herz wie gewöhnlich. Die vordere Abtheilung der B lutdrüs e etwa $2,5 \mathrm{~mm}$ lang, kurz zungenförmig, convex-coneav (vgl. l. c. Fig. 9 a); die hintere kaum $2 \mathrm{~mm}$ lang, subquadratisch, querliegend (vgl. 1. c. Fig. 9 b); beide grau, fein schwarz punktirt. - Die Nierenspritze etwa $1 \mathrm{~mm}$ lang, von gewöhnlichem Bane.

Die vordere Genitalmasse (in situ) etwa $4 \mathrm{~mm}$ lang bei einer Breite bis 6 und einer IIöhe bis $6,5 \mathrm{~mm}$; plan-convex. Die A mpulle des $Z$ witterdrisenganges gelblichweiss; in der ersten Strecke gerade, nachher etwas gewunden verlaufend, (ausgestreckt) etwa $8 \mathrm{~mm}$ lang bei einer Dicke (Diam.) bis $1 \mathrm{~mm}$. Die erste (etwa $4 \mathrm{~mm}$ lange) Strecke des Samenleiters (bei dem untersuchten Individuum) stark erweitert (von einem Diam. von etwa $2 \mathrm{~mm}$ ); die übrige im Ganzen nicht sehr lang, viel düner. Am Boden des stark zurickgezogenen und eingestiilpten Penis (Praeputium) eine gerundete Papille (Glans). Die kugelförmige Samenblase von etra $3,5 \mathrm{~mm}$ Diam., die andere birnförmige von beiläufig 2,5 mm Länge; der vaginale Ausführungsgang ziemlich lang, dünn. Die Eiweissdrüs gross, dunkelgelb; die Schleimdrüse milchweisslich. 
HOPLODORIS, BGI. Nov.G.

Corpus fere ut in Discodoridibus, sicut margo anterior podarii et tentacula.

Armatura labialis e baculis minutissimis formata. - Armatura lingralis fere ut in Discodoridibuis.

Ventriculus liber. - Prostata magna. Penis fere ut in Platydoridibus armatus. Glandula hastatoria et hasta cornuformis.

Dic Hoplodoriden stimmen im Aeusseren im Ganzen ziemlich mit den Discodoriden, seheinen doch etwas weniger abgeplattet und weniger weich, aber am Rücken auch granulirt oder eher selbst wie etwas villös, in viel geringerem Grade aber als die Thordisen. Die Kiemenöffunng erimert an die der Platydoriden. Die Tentakel fingerförmig. Der vordere Fussrand zweilippig, die obere Lippe gekluftet. — Die Lippenplatte schmal, aus dümen Stäbchen gebildet. Die Raspel fast wie bei den Discodoriden, olne mediane Zahnplatten; die Seitenplatten zahlreich, hakenförmig. Der. Magen gross, frei. Die Prostata gross; der Penis mit Reihon von Kegeln, einigermaassen wie bei den Platydoriden. Eine Stacheldrüse sowie ein starker (hornförmiger) kalkartiger Stachel.

Die Hoplodoriden werden im Aeusseren wohl schwer von den Discodoriden zu unterscheiden sein, von denen sie sich dureh den bewaffneten Penis und durch die Stacheldruse und den Stachel so wesentlich unterscheiden. In mehreren Beziehungen bilden sie ein Zwischenglied zwischen den Platydoriden und den Asteronoten.

Von der Gattung ist bisher nur die untenstehende neue Art aus der Siidsee bekannt.

\section{H. desmoparyphi, Ban。 n. sp.}

Hab. Oc. pacif. (Ins. Palau).

Taf. C. Fig. 5-9; Taf. F. Fig. 1-18.

Von der Art lagen zwei Individuen vor, von Herm Kubary an den Palau-Inseln in Gemeinschaft mit Astex. bertrina gefischt und dem Museum Godifrror geschickt. Sonstige Notizen fehlten. - Beide Individuen wurden exviscerirt. 
Die in Alcohol ganz gut bewahrten Individuen waren einander in Grösse sowie sonst im Aeusseren sehr ähnlich. Die Länge betrug etwa $6,5-6,8 \mathrm{Cm}$. bei ciner Breite bis 5 und einer Höhe bis 2,5 Cm.; die Breite des Mantelgebrämes etwa $2 \mathrm{Cm}$. betragend; die Lainge des Fusses fast 4,5 Cm. bei einer Breite bis $11 \mathrm{~mm}$; die Weite der Kiemenöffnung (bei hervorgestreckter Kieme) etwa $18 \mathrm{~mm}$, die Höhe der Kieme beiläufig 6-8 mm; die Länge der T'entakel etwa 5,5; die Höhe der Rhinophorien fast 8, von denen etwa $2 / 3$ auf die Keule kamen. - Die Grundfarbe schmutzig gelblichweiss; am Rücken braungrau scheckig. Etwa an der Mitte der Unterseite des Mantelgebrämes ein ganz hell-rothbrames, hier und da in kleinere Fleckchen aufgelöstes, breites Band, und zerstreute Fleckehen :ihnlicher Farbe kamen noch zwischen diesem und dẹm folgenden peripodialen Bande vor. Dieses letzte ist noch breiter als das vorige, von dunkler (schwirzlicher) Chocoladenfarbe; bei dem einen Individuum ringsum zusammenhängend, kurze breite Zacken auswärts schickend; bei dem anderen in mehrere Stücke aufgelöst. Die Kर́ieme griunlichgelblich; der Stiel der Rhinophorien rothbraun punktirt. Die obere Seite des Fusses rothbraun wie das (iussere) Band des Mantelgebrämes.

Die Eingeweide schimmerten nirgends hindurch.

Die Kürperform kräftig. Der Riicken ziemlich stark gewölbt; mit breitem dickem, rom eigentlichen Riicken scharf abgesetztem Gebräme; die obere Seite iuberall mit feinsten Nöppehen bedeckt. Die Rhinophor-Scheiden fast $2 \mathrm{~mm}$ hervortretend, etwas zusammengedrủckt; die Oeffnungen länglich, mit zackigem Rande; der Stiel stark, in der Kieule etwa 50 Bliitter. Die Tentakel (Fig. 17) stark abgeplattet, am Grunde versehmälert, am Aussenrande kaum eine Andeutung einer Furche. Der Rand der weiten Kiemen-Oeffnung nur wenig (bis $3,5 \mathrm{~mm}$ ) hervortretend, rundzackig, der mediane vordere und hintere Lappen stärker. Die Kieme ${ }^{1}$ ) aus 6 grösseren Bäumchen und einem kleineren vorderen medianen bestehend. Hinten an dem von denselben umschriebenem Raume, vor dem Zwischenraume zwischen den beiden hinteren Kiemenbäumchen die etwa 2,5 mm hervorstehende, abgestutzte und in 5 Zapfen endigende Analpapille; vor derselben und rechts die Nierenpore. Die Unterscite des Mantelgebrämes glatt. Der F'uss fast gleichbreit, vorne nur wenig schmäler, hinten etwas zugespitzt; der Vorderrand zweilippig; die obere Lippe die untere iberragend und in der Mittellinie gespalten.

Das Centralnervensystem wie bei verwandten Formen, oder die Ganglien noch weniger geschieden; die Oberflache iberall fein lnotig. Die Comntissur jederseits ihre Zusammensetzung aus drei sehr deutlich zeigend. - Die bucealen Ganglien (Fig. 5aa) fast unmittelbar mit cinander verbunden; die gastro-oesophagalen Ganglien nicht ganz limzstielig, etwa 1/3 der. Grösse der vorigen betragend, mit einer grossen und mehreren kileinen Zellen (Taf. C. Fig. 5 b).

1) Bei dem cinen Indiridum lildete die hervorgestrechte Kieme eine ganz ähnliche Figur wie ron Covar bei der "D. lacera" (I. c. pl..1. Fig. 1) abgebildet. 
Die $\Lambda$ ugen von etwa $0,16 \mathrm{~mm}$ Diam., mit kohlschwarzem Pigmente und sehr hellgelblicher Linse. Die $\mathrm{O}$ h $\mathrm{rb}$ la s en von etwa derselben Grösse, von Otokonien strotzend, die einen Diam. bis etwa $0,016 \mathrm{~mm}$ erreichten. Die Blätter der Rhinophorien durch lange, schräge und senkrecht an dem Rande stehende, sehr dicht liegende Spikel sehr stark abgesteift; dieselben waren stark erhärtet, die meisten durch krümlige Masse, sehr viele auch mehr oder weniger compact.verkalkt. Die Tentakel im höchsten Grade mit stark erhärteten, meistens compacten, ohne Ordnung gelagerten Spikeln ausgesteuert. - Die Haut des Rückens fast iberall mit farblosen, dichtstehenden; ganz weichen, bis $2 \mathrm{~mm}$ hohen Spitzen (Fig. 16) bedeckt, die hauptsächlich aus Gallertgewebe gebildet waren. In der Rückenhaut sehr reichliches, schwarzbraunes, Massen von Sternen bildendes Pigment, aber fast gar. keine Spikel, welche dagegen von gewöhnlicher Länge und stark erhärtet in den Rändern der Kiemen- und der Rhinophor-Oeffnungen und noch stïrker in der Unterseite des Mantelgebrämes vorkamen.

Die Mundröhre wie gewöhnlich; 5-6 mm lang; an der Imnenseite, und zwar besonders hinten, schwärzlich-chocoladenfarbig. - Der Schlundkopf ron etwa 6,5 bis $7 \mathrm{~mm}$ Länge bei einer Höhe bis 7 und einer Breite bis $6 \mathrm{~mm}$; die Raspelscheide hinten an der Unterseite wenig $(2-2,5 \mathrm{~mm})$ hervortretend. Die Lippenplatte ${ }^{1}$ ) von brïunlichgelblicher Farbe, aus (bis etwa $0,2 \mathrm{~mm}$ ) langen, diinnen Stiubchen (Taf. C. Fig. 6) in gewöhnlicher Art zusammengesetzt. Die Zunge wie gewöhnlich breit; in der horngelben Raspel 25-28 Reihen von Zahnplatten, weiter gegen hinten kamen noch 17-18 ganz entwickelte und 6 nicht vollstiindig entwickelte Reihen vor, dic Zahl derselben betrug in Allem 48-52. In den Reihen kamen hinten an dem Zungenrícken (bei den zwei Individuen) 91-95 Zahnplatten vor, und die Zahl schien weiter gegen hinten nicht bedeutend grösser (bis 100-103) zu sein. Die Zahnplatten waren von hell horngelber Farbe; die Höhe der äussersten (Fig. 4 aa) betrug meistens etwa $0,08 \mathrm{~mm}$, ausserhalb derselben kam aber sehr oft noch eine kleinere und mehr irreguläre Platte vor, die kaum die Hälfte oder ein Drittel dieser Höhe hatte. Die Formverhältnisse der Platten waren die (Fig. 1-4) gewöhnlichen, die äusserste (oder die zwei äussersten) viel kleiner, aufrechtstehend (Fig. 4aa).

Die Speicheldris en sehr langgestreckt, bis etwa $3-3,5 \mathrm{Cm}$. lang, sich zwischen dem Magen und der vorderen Genitalmasse und sich weiter gegen hinten zwisehen dieser und dem Vorderende der hinteren Eingeweidemasse und selbst noch etwas weiter gegen hinten an der Unterseite derselben erstreckend; in der vorderen Strecke (etwa Drittel) bis ctwa 1,5-2 $\mathrm{mm}$ breit, gelblich, in ihrer ubrigen Längo allmählig viel diinner, weisslich. An beiden untersuchten Individuen war die linke Drise stärker und länger; bei dem einen waren die Driisen in der vorderen Strecke um cinander geschlungen.

Die Speiseröhre etwa 17 -22 mm lang bei einem Durchmesser bis 2 mm; mit ziemlich starken Längsfalten. Der Magen etwas abgeplattet, etwa $1 \mathrm{Cm}$. lang bei ciner

1) Die Lippenplatte scheint einen ziemlich schmalen Gürtel zu bilden, existirte aber an den zwei untersuchten Indiriduen nur stellenweise, war an den meisten Stellen abgefallen odcr ausgerissen. 
Breite bis $7 \mathrm{~mm}$. Der von dem Vorderende rechts mit einer Einschnürung abgehende Darm ausgestreckt volle $5 \mathrm{Cm}$. lang bei einem Durchmesser bis $2,5 \mathrm{~mm}$. Die Innenseite des Magens zeigte starke Längsfalten, die des Darmes ebenso. - Der Inhalt der Verdauungshöhle war sparsame, unbestimmbare thierische Masse.

Die Leber etwa 3,8-4 Cm. lang, bei einer Breite bis 18-21 und einer Höhe bis $15-17 \mathrm{~mm}$; das Hinterende stark gerundet; das Vorderende ausgerandet, und die Ausrandung sich in eine tiefe Spalte fortsetzend; (fast) die vordere Hälfte der Unterseite ist durch Druck der vorderen Genitalmasse stark applanirt. Die Farbe (an Schnittflichen) graugrün. Die Gallenblase weisslich, etwa $5,5 \mathrm{~mm} l a n g$, bei einem Durchmesser oben von $1,5 \mathrm{~mm}$.

Die Vorkammer etwa so lang wie die (beiläufig $7-8 \mathrm{~mm}$ lange) gelbliche II erzkammer. Die Arterienverzweigung ungemein deutlich. Die Aorta theilte sich fast an ihrem Grunde in einen gegen vorne gehenden Stamm, und zwei gegen hinten gehende. Jede Aorta posterior giebt an ihrem Grunde eine querlaufende Art, hepatica ant. ab und schickt withrend ihres Verlaufes an der Oberfläche der Leber ferner noch $4(-5)$ :ihnliche Artt. hepaticae aus, welche oben in den Furchen der Leber eingelagert sind und zahlreiche Seitcuaste abgeben. Die Aorta ant. giebt erst eine Art. ventriculi post. längs des hinteren Randes des Magens ab, dann eine Art. ventriculi ant. liings des vorderen Randes; beide verzweigen sich an den Flïchen des Magens. Der Stamm geht damn unterhalb des Darmbogens an der oberen Seite der Speiseröhre, giebt links eine starke Art. gl. sangvineae ab, die sich als Art. cerebr. fortsetzt, folgt der Speiseröhre an dem hinteren oberen 'Theile der vorderen Genitalmasse, giebt die Art. genitalis ab und setzt sich als die $\Lambda$. bulbi phar. fort, welche die Art. lingvalis abgiebt und weiter vorwiirts die Art. circul. tubi oralis bildet. Die Art. genitalis schien sich wie bei anderen untersuchten Formen zu verhalten.

Die Blutdriisen braungrau, sehr abgeplattet, somit ziemlich dün, langgestreckt; die vordere unregelmässig viereckig, $7-8 \mathrm{~mm}$ lang; die hintere 5,5-9 $\mathrm{mm}$ in Lïnge messend, unregehniissig dreicekig, wie gewöhnlieh bis an den Darmbogen reichend.

Die Nierenspritze beiläufig $4,5 \mathrm{~mm}$ lang, gelblich.

Die Zwitterdrü ỉ iberzog die Leber iiberall mit Ausnahme in der Tiefe der vorderen Spalte als ein oben fast durchgehends $3-3,5 \mathrm{~mm}$ dickes gelbliches Lager, welches an der Unterseite der Leber kium die Hälfte dieser Dieke hatte. In den grossen peripherischen Liippehen der Zwitterdrüe grosse oogene Zellen, in den Centralparthien entwickelte Koospermien.

Die rordere Genitalmasse etwa 2-2,5 Cm. lang bei einer Breite bis 17-19 und einer Itöhe bis $14-17 \mathrm{~mm}$. Der dunne weissliche Z witterdrisengang fast plützlich in die $A m p u l l e$ iibergehend, die von weissgelber Farbe und mit neben einander liegenden Biegungen ein abgeplattetes (18 mm langes, 9 breites und $3,5 \mathrm{~mm}$ dickes) Knimel links und vorne an der oberen Seite der GenitaImasse bildet; ausgestreckt 
hatte diese an der Spermatotheke ruhende Ampulle eine Länge von 7-9 Cm.; der Durchmesser der Ampulle betrug bis 2,5 mm und dieselbe zeigte durch ihren ganzen Verlauf noch wie eine Menge ron durchscheinenden feinsten Windungen, die abor nur aus Ziigen ron Zoosperm-Massen gebildet waren. Die das Vorderende der Genitalmasse bildende Prostata eine gelbliche, unregelmässig-herzförmige Masse (Taf. F. Fig. 7 a) von etwa $12-13 \mathrm{~mm}$ gröstem Diam. bei einer Dicke bis $8 \mathrm{~mm}$ darstellend; mit fast ebener, nur wie fein granulirter, von zahlreichen, rerzweigten, seichten Furchen durchzogener Oberfläche; cine eigentliche Höhle kommt im Innern der Druise nicht vor; aus der Tiefe des starken Hilus der äusseren Seite (Fig. 7) trat der kurze (mit dem Penis zusammen im Ganzen nur 17-18 mm in Lünge messende) dicke Samenleiter (Fig. $7 \mathrm{~b}$ ) hervor, durch dessen Axe sich der eigentliche Samengang himab schlängelte, Der Penis etwa $1 / 2$ der Liinge des Samenleiters betragend, wenigstens doppelt (unten bis fast 3,5-4 mm) so dick wie dieser letzte (Fig. $7 \mathrm{c}$ ). Die Wände desselben sind sehr dick; die Innenseite desselben mit mehreren, oben etwa 8 , unten beiliufig 12-15 nicht immer scharf geschiedenen Längsfalten, die immer cine Anzahl ron fest anhäingenden (meistens je 12_-15) kalkweissen Höckerchen trugen, welche sich als ähnliche Bricken, wie sie in den Platydoriden nachgewiesen sind, erzeigten. Dieselben liessen sich mit sammt der Cuticula der Innenseite leicht ablösen und bildeten einfache mit Siiuren fast gar nicht brausende Verdickungen (Taf. C. Fig. 7) derselben. Sie waren scheibenförmig (Taf. F. Fig. 8, 9), an der Mitte sich in einen senkrecht stehenden oder etrias gekrimmten Kegel erhebend, der eine Höhe bis 0,28-0,80 mm erreichte. Die hinter der Prostata liegende Spermatotheke ron etwa 13-15 mm grösstem Diam., fast kugelförmig (Taf. H. Fig. óa), mit Detritus und rerfetteter Zellenmasse gefuillt. Dic Spermatocyste (Fig. כ̌) der des Aster. bertrana etwas ähnlich, gelblichweiss, ausgestreckt etwa 7-12 $\mathrm{mm}$ messend, mit Samen gefüllt; die Cyste jenseits der Mitte des Ganges befestigt (Fig. 5). Der vaginale Gang der Spermatotheke (Fig. 5 b) stark, länger als die Samenblase, unten etwas erweitert die etwa 3,5-6 mm lange Vagina (F'ig. 5 c) bildend, die an der Innenseite Längsfalten und einen Ueberzug ron einer starken, fast farblosen, einfachen Cuticula (von einer Dicke von etwa $0,04 t \mathrm{~mm}$ ) zeigte. An der Aussenseite des (vaginalen) Samenblasenganges, oberhalb der Vagina fand sich eine abgeplattet-kugelförmige oder mehr herzförmige, gelblichweisse (Fig. 5 f) Stacheldriise (Gl. hastatoria) ron etra $5 \mathrm{~mm}$ grösstem Diam.; der aus dem Hilus unten hervortretende Driisengang (Fig. $5 \mathrm{~g}$, 6a) im Innern der Druise erweitert, stark verästelt (Fig. 6). Der Gang dünn, etwas liinger als die Driise, am Seheitel einer kleinen, rundlichen Seitentasche (von etwa 2-3 mm Diam.) an der Seite der Vagina (Fig. $5 \mathrm{~h}$ ) eintretend, die fast genau einen Stachel (Hasta) umschliesst, der mit seiner Spitze immer durch die runde Oeffnung in die Vagina lineinragte (Fig. 11c). Der Stachel umkleidet eine Papille, die sich fast bis an die Spitze desselben hinauf erstreckt und von einer Fortsetzung des Ganges durchbohrt ist (I'af. C. Fig. 8b); der Stachel ist iiber dieser Papille genau abgeformt. Dersclbe (Fig. 12-1t) ist sehr kräftig, kalkartig-gelb- 
weiss ausschend, wenig biegsam; die Oberflache glatt, aber wie streifig und reticulirt aussehend; die Ilöhe (in gerader Linie) etwa 3-3,5 mm messend; die Form wie hornartig, gegen die Spitze cin Bisehen zusammengedrickt, ein wenig seitwïrts gedreht. Der Grundtheil des Stachels ist sattelartig, quer zusammengebogen (Fig. 12), die Breite (Fig. 13, 14) hicr etwa $2,5 \mathrm{~mm}$ betragend; der Rand umgeschlagen, bis fast (Fig. 12) $1 \mathrm{~mm}$ dick (wihrend die Dicke der Wand des Stachels sonst meistens etwa $0,33 \mathrm{~mm}$ betrug). Dieser Kragen ist noch von einem. feinzelligen, dicken, unerhäirteten Epithele ubberzogen, wåhrend der Stachel iibrigens von solchem ('Taf. C. Fig. 9) in melur erhairtetem Zustande gebildet ist; mit Siiuren brauste die Substanz nur sehr wenig. An der convexen Seite des Stachelendes fand sich die Oeffnung als ein lïnglicher Schlitz (T'af. F. Fig. 15a). - Der allergrösste, der ganze obere Theil der grossen Schleimdruso von gelbweisser Farbe, aus zahlreichen feinen Gyri gebildet; der untere kleinere T'heil von mehr grauer, ganz unten wieder von mehr gelblicher Farbe. Das Vestibulum genitale mit Flecken von graulicher Chocoladenfarbe; das Ende der Falte des Schleimdriisenganges von :ihnlicher Farbe. 


\section{PLATYDORIS, BGII.}

Vgl. Heft XII. 1S77. 1). 1950517.

Die ror einigen Jahren aufgestellte Gattung I'latydoris zeigt rienlich ausgepraigte Charactere. Die fast immer grossen Thiere sind. von stark abgeplatteter, runder oder ovaler Form; hart, lederartig; der Riicken ist platt, f'cin chagrinirt oder fein granulirt; die Kiemenöfnung mehrlappig, fast sternförmig; die 'Tentakel tingerförmig; der vordere l'ussrand zweilippig, dio obcre Lippe gespalten. Lippenplatten fehlen. ${ }^{3}$ Die Raspel mit schmaler nackter Rhachis; an den Pleurae zahlreiche hakenförmige Seitenzahmplatten. Der. I'enis (Praputium) mit lieihen von haten Scheiben besetzt; die Vagina mit ciner dieken cinfachen Cuticula oder mit :ihnlichen Scheiben. Es findet sich eine grosse Prostata.

Im Habitus stehen die Platydoriden den $\Lambda$ steronoten nahe, welche sich aber durch die vollstindig glatte und weniger harte Natur der Bedcekungen unterscheiden, wihrend sie im inneren Bane besonders dureh das Unbewaffnetsein des Penis und der Vagina so wie durch das Dascin einer Stacheldrise und da\%u geloürenden Stachels differiren. Auch mit den II oplodoriden zeigen die l'latydoriden Verwandtsehaft; jene sind aber weicher, tragen eine ljowaffnumg der lippenscheibe und sind anch mit einer Stacheldriise und mit Stachel versehen.

Von dieser Gattung, die den wiirmeren und tropisehen Mecresgegenden anzugehüren scheint, habe ich friiher (1. c. p. 496) eine licilie von 15(16) Arten zusammengestelit. Zu diesen werden sich wahrscheinlich jetzt die nachstehonden neuen und auch die untenstehenden, spaiter ${ }^{2}$ ) beschriebenen Formen gesellen, insofern dieselben nicht mit schon vorliegenden Arten congruiren.

17. Pl. vicina, BGII. 11. sp.

Oc. pacif. (ins. 'I'onga).

1) Vergl. doch unten die I'l, variegata.

2) Asranas, revision of the snthobranch. Nudibr. Moll. Proc. zool. soc. 1577, II. p. 196-269. pl. XXVII-XXX.

Der Verfasser scheint ohne Vorkenntuisse zu seinen "Studien" über Nullbranchien gegangen zu sein. Lis wundert daher nicht besonders in der D. infranaevata clieses Verfassers (1. c. p. 218. pl. XXVII. Kig. S) und wallrseheinlich auch in seiner D. sulstumida (1. c. p. 250. pl. XXVII. Fig. 10, 11) wahrscheinlich nur die Lisxísche D. argo wiederzufinden.

Es ist überhant cin Anachronismus ohne anatomische Untersuchung "Arten" zu besclireiben, welehe, wie dieses bei den sogenannten Nudibranchien so oft der Fall ist, olne solche nicht generisch verwerthbar sind.

Semper, Philippinen. II, II (Berghı, Lirginzungsheft I). 
1S. - coriacea (ABRAHAM).

D. coriacea, ABR. 1. c. p. 247. pl. XXVII. Fig. 1-4.

Oc. africano-indic. (Seychellen).

19. - inframaculata (ABR.).

D. inframaculata, ABR. 1. c. p. 248. pl. XXVII. Fig. 5-7.

Oc. indic. (Amboina).

20. - tabulata (AзR.).

D. tabulata, ABr. 1. c. p. 249. pl. XXVII. Fig. 9.

Hab?

21. - hepatica (Aвr.).

D. hepatica, ABr. 1. c. p. 249. pl. XXVII. Fig. 9.

Oc. pacific. (Riciniola).

22. - speciosa $(A B R$.$) .$

D. speciosa, AвR. I. c. p. 250. pl. XXVII. Fig. 10, 11.

Oc. indic. (Amboina).

23. - murrea (ABR.).

D. murrea, ABr. 1. c. p. 252. pl. XXVIII. Fig. 12-14.

Oc. africano-ind. (Mauritius).

\section{Pl. arrogans, $B \in G$, rar.?}

Pl. arrogans, BGrr. Malacol. Unters. 1. c. p. 512-517. Taf. XLI. Fig. 2; Taf. LIX. Fig. 19-25; t. LX. Fig. 3-9.

Ha b. Oc. pacific. (ins. 'Tonga).

Taf. E. Fig. 3-9.

Von dieser Art lag nur ein einziges Individuum, olnne beifolgende Notizen, vor, von Herrn Dr. Graeffe in 1870 bei der Insel Tonga gefischt.

Das Thier hat eine Länge von fast $8 \mathrm{Cm}$. bei einer Breite gegen $6 \mathrm{Cm}$. und einer Höhe bis fast $14 \mathrm{~mm}$; die Breite des Mantelgebrämes betrug bis gegen 2,5 Cm.; die Länge des Fusses gegen $5 \mathrm{Cm}$. bei einer Breite bis gegen $12 \mathrm{~mm}$; die Höhe der Rhinophorien 5,5 mm, von denen mehr als die Hälfte auf die Keule kam, die Höhe der Kieme fast $8 \mathrm{~mm}$. - Die Farbe durehgehends schmutzig braungrau; an der Rückenseite dunkler braungrau marmorirt und uberall mit einer Masse ron kurzen schwarzbraunen Strichen, die viel gröber als bei der typischen Pl. arrogans waren, am Mantelgebrïme meistens eradiirend, sonst in allen möglichen Richtungen verliefen; :̈hnliche, aber längere und gröbere Striche kamen auch an der Unterseite des Nantelgebrämes vor, meistens strahlig, nur innen mit dem Fusse parallel verlaufend; an der oberen Seite des Fusses fanden sie sich sehr reichlich ror, meistens, besonders in der Nihe des freien Randes, in die Quere 
gehend. Die Rhinophorien grau. Die Rhachis-Parthien der Kiemenfeder schwärzlich; die Analpapille der Höhe nach schwärzlich gestreift.

Die Formverhältnisse des ganz lederartigen Thieres ganz wie gewöhnlich. Die Tentakel kurz fingerförmig. Die Keule der $\mathrm{R} h \mathrm{in}$ ophorien mit etwa 40 breiten Blättern. Die (6) Klappen der Kiemenhöhle etwa 3,5 mm hervortretend, die vordere und hintere grösser als die lateralen. Die Kieme aus 3 Paaren von Federn gebildet, die von vorne gegen hinten an Höhe wuchsen. Die Analpapille etwa 2,5 mm hoch, oben abgestutzt. Der Rüken durch feinste Nöppchen chagrinirt. Der Fuss wie gewöhnlich.

Das Peritonaeum farblos, fast ganz olne Spikel.

Das Centralnervensystem zeigte die Ganglien von einander wenig gesehieden. Die grosse Commissur jederseits am Grunde aus 3 Straingen zusammengesetzt. Die buccalen Ganglien rundlich, durch eine kurze Commissur verbunden. Die gastro-oesophagalen kurzstielig, kaum 1/4 der Grösse der bucealen betragend, mit einer sehr grossen, einer grossen und mehreren kleineren Zellen; von dem einen Granglion gingen gegen oben drei Nerven aus, an dem andern waren diese drei in einen vereinigt.

Die A ugen mit schwarzem Pigmente, gelblicher Linse. Die Ohrblasen etras kleiner als die Augen, von Otokonien gewöhnlicher Art strotzend. Die Blätter der Rhinophorien durch sehr dichtliegende, lange, stark crhärtete Spikel abgesteift. Die Ha ut sowie die Nöppchen des Rückens mit sehr stark erhärteten, einfachen Spikeln im höclisten Grade ausgesteuert.

Die Mundröhre etwa $7 \mathrm{~mm}$ lang, an der Innenseite, besonders an ihren starken Falten, feine schwärzliche Längsstriche. - Der Schlundkopf etwa 7,5 mm lang bei einer Höhe bis 5 und einer Breite bis $5,25 \mathrm{~mm}$; die grosse Raspelscheide hinten an der Unterseite stark hervortretend. Die Lippenscheibe mit einem schmutzig-braungelben Ueberzuge, hauptsiachlich von der starken Cuticula gebildet. ${ }^{1}$ ) Die Zunge zeigte in der braungelben Raspel etwa 25 Zahnplattenreihen, weiter gegen hinten noch 21 entwickelte und 4 nicht vollständig entwickelte Reihen; die Gesammtzahl derselben betrug somit 50 . In den Reihen kamen hinten an dem Zungenricken bis $112 \mathrm{Zahnplatten} \mathrm{vor,} \mathrm{und} \mathrm{die}$ Zahl stieg kaum bedeutend weiter gegen hinten., Die Höhe der äussersten Platte (Fig. 5) betrug meistens etwa $0,08 \mathrm{~mm}$. Die Platten waren (Fig. 3-5) von gewöhnlichen Formverhältnissen; die äussersten $3-4$ von der (üblichen) abweichenden Form und zwar besonders die äusserste (Fig. 5 aa).

Die Speicheldrüsen sehr langgestreckt; in dem vorderen Drittel gelblich, bis etwa $2 \mathrm{~mm}$ breit; in der übrigen Strecke weisslich, viel dünner, mit dem hinteren Theile an der Unterseite der hinteren Genitalmasse etwas ausgebreitet; die rechte Drise sich weiter gegen hinten als die linke erstreckend.

1) Es fand sich ganz bestimmt keine Spur einer Lippenplatte. 
Die Speiseröhre weit, etwa $10 \mathrm{~mm}$ lang. Der Magen 10,5 mm lang bei einer Breite bis 5 und einer Höho bis $4 \mathrm{~mm}$. Der Darm etwa $3,5 \mathrm{Cm}$. lang, bei einem fast durehgehenden Diam. rou 2,5 mm. - In der Verdauungshöhle zerbröckelte Spongienmasse mit ihren Spikeln, Stiicken von Hydromedusen und Diatomeen; losgerissene unbeschädigte Zahmplatten und Stiicken von solchen fehlten nicht.

Die Leber etwa $24 \mathrm{~mm}$ lang bei einer Breite (vorne) bis 14 und einer Höhe bis $11 \mathrm{~mm}$; das Hinterende gerundet; das Vorderende gerundet, mit einer tiefen, fast dureh das vordere Drittel der oberen Seite reichenden Kluft; die Leber war von braunlichgraner Farbe. Die Gallenblase wie gewöhnlich, etwa $3,5 \mathrm{~mm}$ hoch.

Die Blutdriisen röthlichgrau, jede etwa $3 \mathrm{~mm}$ lang, die vordere von rundlichdreieckigem Umrisse, dicker; die hintere, auf dem Centralnervensystem ruliende, herzförmig, mehr abgeplattet, planeonvex. - Die Nierenspritze etwa $1,5 \mathrm{~mm}$ lang, sich in den dickeren Gang ummittelbar fortsetzend, der, an der Innenseite mit selir starken Vegetationen besetzt, bis an die Leberkluft verfolgt werden komnte, längs des rechten Randes kurze starke Zweige ausschickend.

In den Lippehen der Zwitterdrïse keine entwickelten Geschlechtsproducte. Die vordere Genitalmasse etwa $8 \mathrm{~mm}$ lang bei einer Breite bis 6,5 und einer Höhe bis $7 \mathrm{~mm}$; die Hauptausfïhrungsgäinge dazu noch $2 \mathrm{~mm}$ hervortretend. Die Ampulle des Zwitterdrisenganges schmutziggelblich, mehrere Zilizakwindungen bildend, die ausgestreckt im Ganzen 1,5 Cm. bei einem Durchmesser von 1,2 mm maassen; mit einem kurzen Halse in die schmutziggelbliche, kurz-sackförmige, etwa $4 \mathrm{~mm}$ lange Prostata iibergehend. Der aus dem unteren Pole derselben hervortretende Samengang in der ersten Strecke (ron etwa $3 \mathrm{~mm}$ ) diinn, aufgerollt; dann dicker (bis zu einem Diam. von $1 \mathrm{~mm}$ reichend) und ohne äusserlich deutliche Grenze in den Penis ïbergehend, mit diesem letzteren zusammen ausggestreckt etra $1,5 \mathrm{Cm}$. messend. Die hohle Strecke des Pen is (Pracputium) etwa $5 \mathrm{~mm}$ lang; an der Imnenseite die gewöhnliche Cuticula-Bekleidung mit ihren einigermanssen in 4 Lüngsreihen geordneten Bricken (Scheiben), die ungewöhnlich (bis etwa 0,68 mm) liinglich waren (Fig. 8), in jeder Reihe kamen kaum mehr als 10 Bricken vor. Die liugelfömige Spermatotheke ( $F i g .6$ a) ron etwa 2,5 mm I)iam; der uterine Gang lang, sehr gewunden (Fig. 6 b c), an derselben hing an einem langen Halse (Fig. $6 \mathrm{~d}$ ) die kleinere, birnförmige Spermatocyste; der vaginale Gang (Fig. $6 \mathrm{f}$ ) kurz, in die Vagina übergehend. Diese letztere (Fig. $6 \mathrm{~g}$ ) selur stark, etwa $7 \mathrm{~mm}$ lang, etwas abgeplattet, mit blaugrauen durchschimmernden Streifen; die feste, dicke Wand zeigte die Innenseite mit starken (etwa 10) Längsfalten ausgesteuert, die wieder durch starke Querfurehen (Fig. 7) getheilt waren; die iiberziehende gelbliche Cuticula etwa $0,08-0,1 \mathrm{~mm}$ dick. Die Schleimdriise gelblich und gelblichweiss. Die Drise an der Oeffnung des Peuis weiss, an der Oberfläche feinknotig, etwa $3 \mathrm{~mm}$ laug, abgeplattet-birnförmig. Das Vestibulum genitale mit schwirzlichen Längstrichelchen. 
2. PI. einrychlamys, B

Platyd. eurychlanys, Bar. Malacolog. Unters. (Semper, Philipp. II, II) Heft XIT. 1877. p. 510-513. Taf. LIX. Fig. 11-18; 'Taf. LX. Fig. 1-2.

II a b. Oc. pacific. (ins. Tonga).

Taf. E. Fig. $10-11$.

Dieser Art gehörte vielleicht oder wahrscheinlich ein ziemlich grosses abgeriehenes Individum einer Platydoris, von Dr. Grawere als bei der Insel Tonga gefischt dem Mus. Goderfror geschickt.

Die Länge des in Alcohol bewalırten Individumms betrug etwa $9 \mathrm{Cm}$. bei ciner Breite bis 6,5 Cm. und einer Höhe bis $13 \mathrm{~mm}$; die Breite des Mantelgebrims war $3 \mathrm{Cm}$., die des Fusses $14 \mathrm{~mm}$ bei einer Liinge vou 5,5 Cm.; die Linge der Tentakel fast $5 \mathrm{~mm}$, die Höhe der Rhinophorien $6 \mathrm{~mm}$; die Weite der Kiemenöftnung $11 \mathrm{~mm}$, die IIöhe der Kieme $9 \mathrm{~mm}$.

Die Formterhältnisse, die Rhinophorien und die Kieme wie bei der Plat. eurychlamys.

Das CentraInervensystem wie gewöhnlich; ebenso die Augen und die Ohrblasen, so wic dic Spikel (Fig. 10).

Die II undröhre etwa $10 \mathrm{~mm}$ lang, an den Falten der Innenseite dunklo Längsstriche. - Der Schlundkopf etwa $9 \mathrm{~mm}$ lang bei einer Breite von 6 und einer Hühe von $5 \mathrm{~mm}$; die Raspelscheide stark hervortretend. In der Raspel 21 Zahnplattenreihen; weiter gegen hinten kamen noch $2 t$ entwickelte und 4 nicht vollständig entwickelte Reihen vor; die Gesammtzahl derselben war somit 49. In der 18 ten Reihe der Zunge fanden sich 114 Platten, und die Anzahl stieg weiter gegen hinten bis 116. Die Zahnplatten waren im Ganzen denen der Pl. argo ähnlich, am meisten die äusseren ( 1 ig. 11 aa).

Die Speicheldriisen im Ganzon etra 4,5 Cm. lang; die vordere etwa $13 \mathrm{~mm}$ lange Strecke graubräunlich, bis 1,5 mm breit; die ïbrige weisslich, im Minterende abgeplattet und etwas verbreitet.

Die Speiseröhre, der Magen, der Darm, die Leber und die Gallenblase wie gewöhnlich.

Die vordere Blutdrüs e von dreieckiger Form, von etwa $3 \mathrm{~mm}$ Länge; die hintere von viereckiger Form und ron 4,5 mm liingstem Durclmesser; beide graugelblich.

Die vordere Genitalmasse etwa $17 \mathrm{~mm}$ lang bei einer Hühe von 13 und einer Dicke von $8 \mathrm{~mm}$; die Ausfilırungsgäinge noch $5 \mathrm{~mm}$ hervortretend. Die Ampulle des Zwitterdriisenganges gelblichgrau, ausgestreckt etwa $15 \mathrm{~mm}$ lang. Dio Prostata von ovalem Unrisse, von etwa $5 \mathrm{~mm}$ Lïnge, gelblichgrau. Der Penis ctwa $16 \mathrm{~mm}$ lang bei cinem Durchmesser bis 1,2 mm; die ovalen Bricken denen der Pl. eurychlamys sehr ähnlich, in zwei Reilien gestellt, in jeder etwa 14; die 2-3 ganz oben kaum halb so 
gross als die iibrigen. Die Penis-Drüse unten am Vestibulum von etwa 3 mm Länge, fast kugelrund, gelblichgrau. Die kugelförmige Spermatotheke von etwa $6,5 \mathrm{~mm}$ Diam., die birnförmige Spermatocyste etwa $3 \mathrm{~mm}$ lang. Die Vagina etwa $8 \mathrm{~mm}$ lang bei einer Breite bis 2,5 mm, die (7) starken Längsfalten der Innenseite an der Aussenseite durchschimmernd. Die grosse Schleimdrüsen-Masse an der linken Seite (Eiweissdriise) bräunlich, sonst weiss oder gelblichweiss.

3. Pl. vicima, $\mathrm{B}_{\mathrm{aH}}$. n. sp.

Ha b. Oc. pacific. (ins. Tonga).

Taf. E. Fig. 16-21.

Diese Form scheint im Aeusseren der Pl. eurychlamys nahe verwandt, und ron derselben sich vielleicht hauptsächlich nur durch andere Form der Bricken (Scheiben) des Penis (Praeputium) unterscheidend.

Nur ein einziges, von Herrn Dr. GraefFe in 1870 in der Nachbarschaft von der Insel Tonga gefundenes Individuum fand sich im Mus. Godeffroy vor.

In Aeussern, in Form- wie in Farben-Verhältnissen, stimmte das Thier ziemlich mit der Pl. eurychlamys. Der Farbenanflug war nur im Ganzen etwas bräunlich; die Rhachis-Parthien der Veråstelung der Kiemenfeder schwärzlich, ebenso die Analpapille. Die Länge betrug gegen 5, bei einer Breite von vollen $3 \mathrm{Cm}$., die Höhe etwa $1 \mathrm{Cm}$. ; die Breite des Mantelgebräms belief sich bis auf $13 \mathrm{~mm}$; die Länge des Fusses war fast $3 \mathrm{Cm}$. bei einer Breite bis $11 \mathrm{~mm}$; die Höhe der Rhinophorien war 3,5 mm, von denen die volle Hälfte auf die Keule kam; die Höhe der Kieme etwa 4,5 mm. - Die Rhinophorien mit etwa 40 Blättern. Die Ki e m enöffnung wie gewőhnlich 6 lappig, der hintere Lappen grösser als der vordere. Die Kieme aus 6 tripinnaten Federn gebildet; die Analpapille etwa $1,6 \mathrm{~mm}$. hoch; die Nierenpore wie gervöhnlich.

Das Centraluervensystem mit sammt den Riechknoten und der grossen Commissur wie bei der Pl. eurychlamys. Die buccalen Ganglien eiförmig, fast unmittelbar mit einander verbunden; die gastro-oesophagalen birnförmig, etwa 1/8 der Grösse der vorigen betragend, kurzstielig, mit einer sehr grossen Zelle.

Die Augen, die Ohrblasen, die Rhinophorien und die Haut wie bei der erwähnten Art. In der interstitiellen Bindesubstanz um die Ausfiuhrungsgänge des Genitalapparats, besonders um die Vagina, sehr reichliche lange Spikel.

Die Mundröhre etwa $4 \mathrm{~mm}$ lang bei einer Breite hinten von $2,3 \mathrm{~mm}$; die Retractoren stark; die Innenseite mit einigen starken Längsfalten. - Der Schlundkopf etwa $4,5 \mathrm{~mm}$. lang bei einer Höhe von 3,5 und einer Breite von $4 \mathrm{~mm}$. Keine Spur von Lippenplatte; die Mundöftnung mit Umgegend nur von einer einfachen Cuticula iiberzogen. Die Zunge mit etwa 19 Reihen von Zahnplatten, weiter gegen hinten kamen 
noch 18 entwickelte und 4 nicht vollständig entwickelte Reihen vor; die Gesammtzahl derselben betrug somit 41. In den Reihen kamen hinten am Zungenricken bis 85 Zahnplatten vor, und die Anzahl schien weiter gegen hinten bis 95 zu wachsen. Die Zahnplatten denen der erwähnten Art ähnlich, eine Höhe bis etwa 0,25 mm erreichend (Fig. 16); die 2-3 äussersten (Fig. 18a) aufrechtstehend, die åusserste mitunter auch von abenteuerlicher Form, die naichsti̊usserste mitunter serrulirt (Fig. 18).

Die Speicheldrüsen bandförmig; im vorderen Drittel gelblich, bis $1 \mathrm{~mm}$ breit; sonst diunner, weisslich; beide waren in der vorderen Strecke gegen oben und vorne uber den Schlundkopf hin geschlagen, dann gegen hinten.

Speiseröhre, Magen und Darm wie sonst; ebenso die Leber und die Gallenblase.

Die Blutdriisen gelblichweiss, abgeplattet; die vor dem Centralnervensysteme liegende von rundlichem Umrisse bei einem Durchmesser von $2 \mathrm{~mm}$; die hinter jenem herzförmig, von $3,5 \mathrm{~mm}$ grösstem Diam.

In den Läppehen der Zwitterdrüse keine entwickelten Geschlechtselemente. - Die vordere Genitalmasse verkümmert, $4 \mathrm{~mm}$ lang bei einer Höhe von 3 und einer Dicke ron nur 1,5 mm. Die Ampulle des Zwitterdrüsenganges schmutziggelblich; die Prostata grösser als die Spermatotheke. Der Penis (Präputium) mit 4 Reihen von Bricken, in jeder Reihe kaum mehr als 10-12; diese (Fig. 20, 21) waren ungewöhnlich kurz und gedrungen, eine Höhe bis $0,4 \mathrm{~mm}$ erreichend. Die Spermatotheke kugelförmig; die Spermatocyste viel kleiner, birnförmig. Die Vagina so dick wie der Penis, mit starker Cuticula.

\section{PI.? variegata, $B_{G H}$ n. sp.}

Color fundamentalis lacteus, dorso ubique nubeculis et striolis purpureo-brumnescentibus sicut maculis majoribus aurantiacis; podarium supra et infra striolis purpureobrunnescentibus; rlinophoria e purpureo-brunnescentia; branchia cinerascens, rhachidibus purpureis.

Hab. Oc. pacific. (ins. 'Tahiti).

Taf. A. Fig. 7-10; Taf. E. Fig. 12-15, 22, 23; Taf. F. Fig. 16-21.

Von dieser Art hat Herr Garnett in 1875 dem Mus. Godefrror ein Individuum sowie eine Zeichnung und derselben gehörende Noten geschickt. Das Thier wurde von mir exviscerirt.

Diesen Noten zufolge hat GARRETT nur dieses einzige Individuum an äusseren Riffe von Tahiti unter einem Corallensticke gefunden; das Thier scheint ihm ${ }_{n}$ der D. cruenta von Quoy und Gamarid nahe zu stehen."

Kriechend hatte das Thier eine Länge von 3". Die Grundfarbe ist milchweiss („creamy-white") mit Schattirungen von hell Purpurbraun, mit dunkler braunen Strichen 
und mit mehreren grossen versehwimmenden orangegelben Flecken. Die Rhinophorien purpurbram mit weissrandigen Lamellen. Die Kiemenblitter hellgraufarbig ( of ashywhite huc" $)$, von purpurbramen Rhachides durehzogen. Der Fuss oben wie unten mit zahlreichen purpurbraunen Strichen.

Die Liinge des in Aleohol bew a hrten lederartigen Individuums betrug 6,5 bei ciner Breite bis $3,5 \mathrm{Cm}$. und einer Möhe bis $7 \mathrm{~mm}$; die Breite der Fusssohle bis 8, die des Mantelgebrimmes bis etwa $15 \mathrm{~mm}$ betragend; die Liinge des Fusses $42 \mathrm{~mm}$; die Ir̈̈he der Rhinophorien $3,5 \mathrm{~mm}$, ron denen die $\% / 3$ auf die Keule kamen; die Breite der Kiemenspalte bis 6, die Töhe der Kieme etwa $5 \mathrm{~mm}$. - Die Grundfarbe war schmutzig-weisslich; die Riickenseite mit branngranen Schattirungen und mit einer Masse von :ihnlich gefairbten der Liinge nach und schräge gehenden Strichen; diese letzteren kamen auch an den Körperseiten sowie an der oberen und unteren Seite des Fusses vor, der Körperseite nïichst und an der Fussohle der Lïnge nach, gegen den Fussrand hin in die Qucre laufend; an der Unterseite des linken Mantelgebrämes vorne ein grosser, an den Rändern versehwimmender rostgelber Fleck; die Keule der Rhinophorien graubraun mit weisser Spitze, der Stiel mit :ihnlichen Querbändern; die Theilungen der Kiemenfeder mit braungranen Rhachis-Parthien; die Analpapille mit braungrauen Lïngsstrichen.

Das sehr abgeplattete, lederartige 'I'hier war von länglich-ovaler I'orm mit fast parallelen Seitenrindern. Die Ruickenseite äusserst fein chagrinirt, wie auch von GARRET (doch wohl ctwas iblicrtrieben) angegeben ("slightly asperous"); der Rand des Mantelgebrämes diim, (x.Arinewl zufolge etwas zackig (, minutely laccrated"), an dem in Alcohol bewahrter Individum nur mit sehr seichten wellenförmigen Biegungen und ganz einzelnen tieferen Einschnitten. Die Rlıinophor-Ḧ̈hlen bis 2,5 mm kuppelartig hervortretend mit rundzackiger Oeffumg; die Kíeule der Rhinophorien ziemlich diek, mit etwa 30-40 ziemlich steifen Bläterm. Die I'entakel klein (boi dem lebenden 'Thiere fingerfümig). Die Kiemengegend bis $3 \mathrm{~mm}$ hervortretend; der Rand mit sechs tiefen Einschnitten, die vordere und hintere Klappe bedentend grösser als die zwei lateralen jederscits. Die (tief zuriickgezogene) Kieme aus 6 tripimnatifiden Federn gebildet, drei zu jeder Seite, die ron vorne bis hinten in Grösse zunahmen. Die Analpapille 1,5 mm hoch, conisch; die Nierenpore rechts, ein wenig vorwirts. Der Fus rorne und hinten gerundet, der Vorderrand wie gewöhnlich.

Das Peritonaeum farblos, fast vollstindig ohne Spikel.

Das Centralnervensystem zeigte die Ganglien ziemlich dick, die risceralen grösser als die cerebralen und auch ein wenig grösser als die pedalen. Die grosse Commissur erwies sich an ilnen Urspringen deutlich aus zweien zusammengesetzt, von denen die vordere (obere) wieder aus zweien gebildet schien. Die bucealen Ganglien (Taf. L. Fig. 12 a) fast herzoörmig, fast ohne Commissur mit cinander verbunden; die gastro-oesophagalen kurzstielig; ron gerundet-dreieckigem Umrisse, mit zwei grossen Zellen (Fig. 12 bb). 
Die Augen mit pechschwarzem Pigmente, gelblicher Linse. Dic Ohrb Iasen etwas kleiner als die Augen, ron Otokonien gewöhmlicher Art strotzend. Die Blätter der Rhinophorien in gewöhnlicher Weise mit langen, cinfachen, stark erhärteten Spikeln gesteift. Die Haut mit einer ausserordentlichen Menge von liingeren und kiirzeren, stark erhärteten, geraden oder ein wenig gebogenen, cinfachen Spikeln ausgestattet; dic Nöppchen der Rückenhaut durch senkrechte Spikel in gewöhnlicher Weise rerstiirkt. In der interstitiellen Bindesubstanz der Organe kamen grüssere Spikel sonst fast gar nicht ror.

Die Mundröhre etwa 5 mm lang bei cinem Durchmesser hinten bis $2,5 \mathrm{nmm}$ : ihre Retractoren sehr stark; an der Innenseite einige wenige starke Längsfalten, dic mit ähnlichen Lïngsstrichchchen wie die der Haut geziert waren. - Der Schlundkopf etwa $4,5 \mathrm{~mm}$ lang bei einer Höhe bis 2,75 und einer Breite bis $3 \mathrm{~mm}$; die Raspelscheide hinten an der Unterseite stark lervortretend; die Retractoren sehr stark. Die Lippenscheibe mit einer einfachen, nicht dicken, fast farblosen Cuticula iiberzogen; tief in der Mundspalte eine kleine, gelbliche, wie es schien, ringförmige Lippenplatte, aus fein quer und schräge gestreiften, blassgelben Stäbehen gebildet, deren Hühe kaum $0,06 \mathrm{~mm}$ ïberstieg (Taf. F. Fig. 19). Die Zun ge mit 21 Zahuplattenreihen; weiter gegen hinten kamen noch 18 entwickelte und 4 nicht rollstindig entwickelte Reihen ror; die Gesammtzahl der Reihen betrug somit 43. In den Reihen kamen linten an der Zunge bis 87 Zahnplatten vor, und die Anzahl selien gegen hinten kaum bedeutend zu wachsen. Die Zahnplatten von gewöhnlichen Formverhältnissen, die imersten (Fïg. 13) wie die äusseren (Fig. 14, 20); nur die zwei äussersten zeigten meistens (Fig. 20 aa) cine feine unregelmässige Serrulirung; die Höhe der äussersten Platte betrug meistens etwa $0,08 \mathrm{~mm}$.

Die Speicheldriisen langgestreckt, bandförmig, erst nach rome geschlagen, sich dann gegen hinten bis über die vordere Hälfte der Unterseite der hinteren Eingeweidemasse erstreckend; fast in ihrer vorderen Hilfte gelbweiss, bis 1,2 mm breit; in der ibrigen Strecke weisslich, viel dimner, hinten wieder etwas verbreitert (Fig. 15).

Die Speiseröhre etwa $6 \mathrm{~mm}$ lang, weit. Der Magon etwa $6 \mathrm{~mm}$ lang bei einer Breite bis 3,5 und einer Dicke bis $3,25 \mathrm{~mm}$; bei dem untersuchten Individuum war. die obere Seite mitsamt dem Pylorus in die Magenlöhle eingesunken (vergl. Taf. C. Fig. 10). Der Darm volle 2 Cm. lang bei cinem Durchmesser (rorue) bis $1,5 \mathrm{~mm}$. Die Verdaungshöhle fast leer, nur im Magen eine geringe Menge unbestimmbarer thierischer Masse.

Die Leber etwa $21 \mathrm{~mm}$ lang, bei einer Breite vorne bis 8 und einer Hölıe bis $6 \mathrm{~mm}$; die untere Seite sowic die obere wenig gewölbt; das Hinterende gerundet; das Vorderende mit tiefer breiter Kluft, die rechte Hälfte desselben weiter gegen vorne als die linke reichend; die Farbe braungelb, ron der helleren, weisslichen Zwitterdrüse überall, ausgenommen in der Tiefe der Kiluft, bedeckt. Die Gallenblase ron mehr weisslicher Farbe, birnförmig, etwa 2,5 mm hoch. 
Das II re von dunkel selmutziggelber Farbe. Die ror dem Centralnervensystem liegende BIutdrise linglich oval, etwa $4 \mathrm{~mm}$ lang, weniger abgeplatiet, aber mehr lappig als die länglich-herzfürmige, auch fast $4 \mathrm{~mm}$ lange, hinter jener liegende; beide gelblichweiss. - Die Nierenspritze etwa $1 \mathrm{~mm}$ lang, sich in den dicken Gang fortsetzend, der eine lange Strecke nach vorne verfolgt werden kounte.

In den Läppchen der Z witterdrüse keine entwickelten Geschlechts-Elemente. Die vordere Genitalmasse wenig entwickelt, etwa $4,5 \mathrm{~mm}$ lang bei einer Breite bis 2,5 und einer Itöhe bis 3,5 mm. Die Ampulle des Zwitterdrüsenganges lang, schmutziggelb. Die Spermatotheke blasenförmig, ron etwa $2 \mathrm{~mm}$ Diam., leer; die Spermatocyste birnfömig, etwa $1 \mathrm{~mm}$ lang, auch leer; beide weisslich. Die Prostata etra $3 \mathrm{~mm}$ lang. Der l'en is etwa $10 \mathrm{~mm}$ lang, oben compact mit dem geschlängelten Samenleiter (Taf. F. Fig. 21 a), unten Lohl; an der Imnenseite mit zwei (?) Reihen von den gewöhnlichen Bricken (Taf. E. Fig. 22), deren ITaken aber in dem einen Rande ungewöhnlich gerade verliefen (Fig. 23); in jeder Reihe etwa 8-10 Bricken (Scheiben), die oben kleiner waren (Fig. 22), sonst eine Hühe ron etwa $0,36-0,38 \mathrm{~mm}$ erreichten, von denen mehr als die Hiilfte auf den Haken kam; am oberen Ende des Penis (Präputiums) eine Papille mit der Mündung des Samenleiters, rings um dieselbe ein Kranz von Höckerchen, von denen einige kleine Bricken trugen (l'af. F. Fig. 21). Die Vagina etwa $6 \mathrm{~mm}$ lang, etwa so weit wie der Penis; an der Innenseite melirere starke Laingsfalten, welche sich hier und da höckerartig erhoben, und von einer Menge von feineren Querfalten gekreuzt wurden; die Höhle von einer starken farblosen Cuticula ausgekleidet. 


\section{ASTERONOTUS, EIIRENBRrg.}

Vergl. Heft XIV. 1879, p. 626-615.

Die in den gröberen Ziigen seit langer Zeit (1831) bekamnten Asteronoten sind grosse, abgeplattete, mitunter am Rüeken mit medianem Kamme und mit Knoten versehene, wie lederartige Thiere, die cine sternfürmige Kiemenüfnung zeigen; der vordere Fussrand ist zweilippig, die obere Lippe in der Mittellinie gekluftet. Die Lippenscheibe ist ohne Bewaffnung. Die Rhachis der Raspel schmal, nackt; an den Pleurae viele hakenförmige Zahnplatten. Das Genitalsystem zeigt eine grosse Prostata, einen Stachel mitstarker. Stacheldrise, aber den Penis (und die Vagina) unbewaffuet.

Die Asteronoten stehen in Habitus den Platydoriden ziemlich nahe, sind aber weniger lart und zerbrechlich als diese letztern. Eine Lippenplatte fehlt den Asteronoten wie den Platydoriden. Während die Asteronoten keine Bewaftnung des Penis (oder der Vagina) besitzen, haben sie dagiegen (einigermaassen wie die Hoplodoriden) eine starke Stacheldriise mit Stachel.

Die Gruppe gehört den tropischen und subtropisehen Meeresgegenden. An angefïhrter Stelle sind als zu derselben gehörend 6 Formen hingestellt, wozu später keine neuen hinzugekommen sind.

\section{A. bertrana, Bar.}

Asteronotus bertrana, BGir. l. c. p. 629-644. Taf. LXVII. Fig. 10-22; Taf. LXVIII. Fig. 6-14, vergl. Note 1 p. 629.

Ha b. Oc. pacif. (Ins. Palaos).

Von dieser colossalen, im philippinischen Mecre, wie es scheint, ziemlieh läufig rorkommenden Art fand sich im Mus. GodefFroy nur cin einziges Indvidum ror, ron Herm Kubair an den Palau-Inseln 1873 gefiselit. Dasselbe war ganz gut conservirt; nur etwas erhärtet. 
Die L ing ge des in Aleohol bewahrten Individuums betrug fast $11 \mathrm{Cm}$. bei einer Breite bis 8,5 und einer ITöhe bis volle $2 \mathrm{Cm}$; die Breite des Mantelgebrämes belief sich bis zu 3,5, die des Fusses bis zu 2 Cm.; die Höhe der Rhinophorscheiden war 5,5, die der Lappen der Ǩiemenhöhle $10 \mathrm{~mm}$; die Länge der-Tentakel war 5,25; die Höhe der Rhinophorien 6, von denen etwa die Hälfte auf die Keule kam; die Höhe der Kieme $13 \mathrm{~m}$. - Die Farbe der oberen Seite schiefergrau, an den Rhinophorscheiden und auf der Mitte des Riiickens hier und da mehr gelblichweiss. Die Fusssohle schmutzig gelblich, die obere Seite des Fusses schmutzig violetgrau. Die niedrigen Seiten griinlichgelblichweiss; nächst an denselben stösst, ganz innen an der Unterseite des breiten Nantelgebrimes, ein bis $8 \mathrm{~mm}$ breites, in den Rändern etwas verschwommenes, violetgraues Band, das gegen aussen von einem breiteren gelblichweissen gefolgt wird, das durch Ausliufer unterbrochen ist, welche sich vom rorigen an den breiten, violetgrauen Rand der Unterseite des Mantelgebrämes erstrecken. Die Rhinophorien so wie die Tentakel gelblichwciss, die Kicme braungrau.

Die Form niedergedriickt, mit sehr breitem, den Fuss ringsum weit iberragendem Mantelgebrime. - Der A ussenmund eine senkrechte Spalte mit gelblicher Bekleidung bildend. Die T'entakel kurz fingerförmig, etwas abgeplattet, mit ziemlich scharfem Aussen-, dickerem Innenrande; an der Wurzel etwas eingeschnirt. Der Rand der Rhinophor-Scheiden fast durch seine ganze Höhe in zwei seitliche, etwas schräge gegen einander gestellte, gerundet oder mehr spitz zulaufende Zipfel getheilt; der Stiel der Rhinophorien wenigstens so hoch wie die Keule, welche jederseits etwa 40 Bliitter zeigte. - Der grössere Nitteltheil des Rüekens mit Andentung eines medianen Liingskammes und zu jeder Seite desselben mit grossen, im Durchmesser bis $18 \mathrm{~mm}$ haltenden, glatten, unregelmäissigen Kinoten bedeckt, während an dem Gebräme dicke, mit dem Rande parallel-laufende Falten durch lïngere Strecken hinter- und nebeneinander verliefen. Die querovale oben etwa $2 \mathrm{Cm}$. im Diam. haltende Kiemenöffnung durch ihre dicken zusammengeklappten Lappen fast ganz verschlossen. ${ }^{1}$ ) Diese waren sehr liriftig, stark hervortretend, (bis $7 \mathrm{~mm}$ ) dick, in Anzahl 6, von denen der (mediane) vordere und hintere (der grösste) fast viereckig, die lateralen dreieckig. Die Kieme zu jeder Seite aus 3 (im Ganzen also aus 6) kriftigen tri- und quadripinnaten ${ }^{2}$ ) Blättern bestehend. Die Analpapille abgestutzt-conisch, etwa $5 \mathrm{~mm}$ hoch, vor und zwischen dem hintersten Kiemenblatî-Paare stehend; am Ende eines kurzen Auslïufers vom Grunde derselben rechts die runde Nierenpore. - Die Seiten sehr niedrig; die Genitalpapille abgeplattet, ron etwa $5 \mathrm{~mm}$ Diam., mit sternförmiger Oeffnung. Der Fuss kräftig, bis etwa $7 \mathrm{~mm}$ ïber die Seiten hervortretend, fast gleichbrcit; das wenig verschmälerte, hinten gerundete, frei hervortretende Hinterende etwa $9 \mathrm{~mm}$ lang; die obere Lippe des Vorderendes $6 \mathrm{~mm}$ lang, mit tiefer, enger, medianer Spalte.

1) Vergl. R. Bran, über das Geschlecht Asteronotus, E. Jahrb. d. D. malakozool. Ges. IV. 1577. Taf. II. Fig. 4. 2) Solches lässt sich freilich nur bei der mikroskopischen Untersuchung bestimmen. 
Die Eingeweide schimmerten nirgends durch die doch weich anzufihlende lederartige Hautbedeckung. Das Peritonacum farblos.

Das Centralnerrensystem wie gewöhnlich; die Oberfläche der Ganglien iiberall knotig. Die buccalen Ganglien durch eine Commissur verbunden, welche etwa so lang wie die kuxz-eifürmigen Ḱnoten selbst war; die gastro-ocsophagalen unilateral entwickelt, kurzsticlig, wenigstens $1 / 4$ der Grösse der vorigen betragend, mit einer sehr grossen und einer grossen Zelle; an dem stärkeren der zivei von den gastro-oesophagalen Ganglion entspringenden Nerven eine laterale Ganglion-Entricklung und in den Zweigen desselben eingesprengte Nervenzellen.

Die A ugen von etwa $0,28 \mathrm{~mm}$ Diam., mit schwarzem Pigmente, grosser gelber Linse. Die Ohrblasen etwas kleiner als die Augen, ron Otokonien gewöhnlicher Art strotzend. Die Blätter der Keule der Rhinophorien in gewöhnlicher Art abgesteift, die Spikel derselben wie bei der rorigen Art. Die 'Tentakel wie bei der vorigen Art. Die Ha ut des Rüickens ron sehr zäher Natur, im Ganzen nur sparsam und fast nur mit kleineren Spikeln ausgesteuert. Das schwarze Pigment sehr schöne Netze und Sterne bildend.

Die (zurïckgezogene) M undröhre etwa $11 \mathrm{~mm}$ lang bei einer Breite bis $9 \mathrm{~mm}$; die starken Falten der Innenseite vorne gelbgrau. - Der Schlundkopf beiliufig. $14 \mathrm{~mm}$ lang bei einer Höhe bis 9,5 und einer Breite bis $11 \mathrm{~mm}$; die Raspelscheide hinten an der Unterseite stark hervortretend (hier $7 \mathrm{~mm}$ lang). Die Bekleidung der MIundspalte dick, mit Querfalten, kalkweiss, aus ciner dicken cinfachen Cuticula gebildet. Die Zunge wie gewöhnlich; die Cuticula-Bekleidung ausserhalb der Raspel auch fast kalkweiss. In der horngelben Raspel kamen 23, weiter gegen hinten noch 19 entwickelte und 4 noch nicht vollständig entwickelte Reihen vor; die Gesammtzahl derselben betrug somit 46. In der 18 ten Reihe der Zunge fanden sich 62 Zalınplatten, und die Anzahl stieg weiter gegen hinten nur mit 2-3. Die $\mathrm{Zahnplatten} \mathrm{horngelb,} \mathrm{die}$ äusserste meistens etwa $0,068-0,075 \mathrm{~mm}$ hoch, die nächste 0,12 , die folgende etwa $0,22 \mathrm{~mm}$ messend. Sie waren in Form- und Grössen-Verhältnissen kaum deutlich von denen der folgenden Art verschieden; nur die äusserste schien in Form etwas abzuweichen, mit kürzerem Körper ausgestattet. ${ }^{1}$ )

Die Speicheldrïson etwa 2,5 Cm. lang, bandförmig, gelblich, in mehr als der rorderen Hiilfte $2-2,5 \mathrm{~mm}$ breit.

Die Speiseröhre $15 \mathrm{~mm}$ lang, in dem vorderen Theile mit starken Laingsfalten. Der $1 \mathrm{ag}$ gen gross, $22 \mathrm{~mm}$ lang bei einer Breite bis $12 \mathrm{~mm}$, mit Speisebrei gefuillt. Der Darm ausgestreckt etwa 7,5 Cm messend; seine Höhle leer. Die Grallenblase grau, 4,5 mm lang bei einem Durchmesser bis $3 \mathrm{~mm}$, mit schönen Falten der Innenseite.

1) Vergl. R. Bragu, über das Geschlecht Asteronotus. 1. c. Taf. Il. Fig. 5. 
Die Leber vorne breit, gegen hinten zugespitzt; $32 \mathrm{~mm}$ lang bei einer Breite bis 25 und einer Höhe bis $17 \mathrm{~mm}$; das Vorderende mit einer breiten Kluft, die sich an der Riuckenscite durch mehr als das vordere Drittel der Leber erstreckte; das Hinterende gerundet; die Farbe (wegen der iberziehenden Zwitterdrüse) gelbgrau, nur vorne und an den Durehschnitten griingrau.

Das Pericardium gross, etwa $17 \mathrm{~mm}$ lang. bei einer Breite bis $22 \mathrm{~mm}$. Dic gelbliche (zusammengezogene) Herzkammer etwa $10 \mathrm{~mm}$ lang bei einer Breite bis $8 \mathrm{~mm}$.

Die Blutdrusen von brïunlich lelımgraner Farbe, an den Flächen und an den Rïndern oberfikichlich gelappt, ziemlich abgeplattet, meistens von einer Dicke von 2,5-3,5 mm; die vordere heraförmig, die Spitze nach hinten kehrend, etwa $12 \mathrm{~mm}$ lang bei einer Breite von $10 \mathrm{~mm}$; die hintere gerundet dreicekig, gegen vorne spitz, $9 \mathrm{~mm}$ lang bei ciner Breite ron 8 .

Die Urinkammer wie bei der vorigen Art. Die Nierenspritze kurz-feigenförmig, an der Aussenseite wie cannelirt, etwa $6 \mathrm{~mm}$ lang bei einem Durchmesser bis $4,5 \mathrm{~mm}$; die Falten der Innenseite stark und hoch.

Die Zwitterdrüse gelblichweiss, die Leber, ausgenommen in der Tiefe ihrer (vorderen) Kluft, iiberziehend; in den Läppchen derselben grosse oogene Zellen und Zoospermien. Der Zwitterdrỉsengang mit mehrexen kurzen Aesten in der Tiefe der Leberkluft entspringend, sich längs der rechten Wand derselben vorwärts erstreckend, nur wenig an Dicke zunehmend, an die obere Seite der vorderen Genitalmasse hinubertretend, plötzlich zu der dreifachen Dicke (bis zu einem Diam. Fon etwa 1,2 mm) anschwellend und die fast kalkweisse $\Lambda \mathrm{mpulle}$ bildend, welehe sich in dichten kurzen Windungen, die ausgerollt eine Lïnge von fast $2 \mathrm{Cm}$ hatten, zwischen der Prostata und der Spermatotheke und Schleimdrise hinzog. Die vordere Genitalmasse etwa $15 \mathrm{~mm}$ lang bei einer Höhe von 16 und einer Dicke bis $7,5 \mathrm{~mm}$; die Ausfuhrungsgäinge noch dazu fast $11 \mathrm{~mm}$ frei hervortretend. Die Ampulle fast unmittelbar in die umregelmässig birnförmige, etwa $13 \mathrm{~mm}$ lange, bis $5 \mathrm{~mm}$ im Durchmesser haltende Prostata iibergehend, ans deren oberem Ende der Samenlejter hervortrat, sich längs der Seite von jener hinunter erstreckte, dünner wurde, ein kleines abgeplattetes Kinäuel bildete und sich dann, wieder ein wenig erweitert, in den Grund des Penis fortsetzte. Dieser letztere war kurz und dick und hatte nur eine Liinge von etwa $1,75 \mathrm{~mm}$; in der sehr dicken Wand viele kleine Spikel; der obere Theil solide, von den Korkzieher-Windungen des Samenganges durchbohrt; der untere Theil (Praeputium) hohl, mit starken Lingsfalten und im Ganzen mit einer starken horngelben Cuticula ausgekleidet, aber absolut ohne Haken. Die Spermatotheke gelblichweiss, kugelförmig, von $7 \mathrm{~mm}$ Diam., mit Samen und verfetteter' 'Lellenmasse gefullt. Der uterine Ausführungsgang derselben lang', mehrere Windungen bildend und in die Einsenkung am Grunde des Schleimdrüsenganges zwischen den Höckern der Schleimdrüse eintretend, indem er unmittelbar vorher die cigenthümliche Spermatocyste aufnimmt. Der vaginale Austührungsgang etwas länger 
als die grosse Samenblase, fast gerade verlaufend, weiter unten an der Hinterscite eincr ovalen grösseren Drise (Stacheldriise) hinabsteigend, das untere Ende derselben durchbohrend und sich als Vagina in das Vestibulum offnend. Dic Spermatocyste langgestreckt, in gerader Linie etwa $10 \mathrm{~mm}$ bei einer Breite bis $t \mathrm{~mm}$ messend, gelblichweiss, wurstförmig mit vielen seitlichen Loculamenten, von Samen strotzend, dessen Elemente einen rundlichen Kopf von etwa $0,0025 \mathrm{~mm}$ zeigten; unten hing die Samenblase durch eine Einschnirung an dem Ductus uterinus der Spermatotheke. Die Stacheldriise (Gl. hastatoria) ${ }^{1}$ ) etwa $12 \mathrm{~mm}$ lang bei cinem Durchmesser bis $5 \mathrm{~mm}$, ciförmig, graugelblich, mit körniger Oberflïche; oberhalb der Mitte der Aussenseite trat der (im Inneren der Drise von 3-4 Aesten gebildete) Ausfiilntungsgang ${ }^{2}$ ) hervor, welcher ctwas geschlängelt; in Allem etrva $1 / 2$ Mal so lang als die Drise, hinuntersteigt und in den viel dickeren, etwa $1,8 \mathrm{~mm}$ langen $\mathrm{Stachelsack}$ (Saccus hastatorius) ${ }^{3}$ ) hiníbergeht, der sich neben dem Penis öffnet. Von dem Boden des Sackes erhebt sich der Stachel (Hasta), der cine Länge von etwa $1,5 \mathrm{~mm}$ hatte bei einer Breite unten von etwa 0,45 und an der Spitze von $0,01 \mathrm{~mm}$; derselbe ${ }^{ \pm}$war horngelb, etwas abgeplattet (nur halbwegs vorgestreckt). - Die Schleimdrise kalkweiss und gelblich; die Eiweissdrïse grau; die Falte des Schleimdriisenganges sehr stark, graugelb. Das Vestibulum genitale schwärzlich pigmentirt.

2. A. mabilla, Barr. n. sp.

Doris mabilla, Bgir. Abraifani, 1. c. p. 249. pl. XXVIII. Fig. 1-4.

Asteronotus mabilla, BGI. 1. c. Heft XIV. 1879. p. 644.

Ha b. Oc. indico-afr. (Seychellen, Samoa).

Taf. C. Fig. 10.

Von dieser schönen Art habe ich im Brit. Museum (1873) drei Individuen gesehen, die als von den Seychellen und von Dr. E. P. Wrigrit („69.6.12. 11.“) herrihrend bezeichnet waren. Eines der grösseren Individuen (8 Cm. lang) wurde mir zur genaneren Untersuchung von Dr. GraY mit grosser Freigebigkeit iuberlassen. Später hat Herr Abrahai von denselben Exemplaren eine Art Beschreibung geliefert.

Die in Alkohol bewahrten Individuen hatlen eine Liinge von $7-10 \mathrm{Cm}$. bei einer Breite von 4,5-6 und einer Höho ron 1-2,5 Cm.; die Breite des Mantelgebrämes war 18-32 mm; die Höhe der Rhinophorscheiden 2,5-3, die der Rhinophorien etwa 7-10 mm, von denen die Hiilfte auf die Keule kam; die Lïnge der Tentakel 4-6 mın

1) Vergl. 1. c. Taf. II. Fig. 6 a.

2) Vergl. 1. c. Taf. II. Fig. 6b.
3) Vergl. l. c. Taf. II. Fig. $6 \mathrm{c}$.

4) Vergl. I. c. Taf. II. Fig. 7, S. 
betragend; die Lïnge des Fusses 5-7 Cm. bei einer Breite von 12-24 mm. - Die Grund farbe schmutzig-weisslich. Auf der Ruickenseite war sie blaugrau scheckig in der Art, dass die weisslichen Parthien als rundliche, ovale und unregelmiissige, mitunter erhabene, an der Mitte oft wieder blaugraue Inseln bervortraten; durch die ganze Liingo des eigentlichen Ritickens zog sich ein ungleich breites, medianes, weissliches Band; an dem Mantelgebräime waren die Inseln oval und länglicher. An der Unterseite des ziemlich dicken Mantelgebrämes schimmerte das Blaugraue der Rủekenseite schwach hindurch. An der Uebergangsstelle des Mantelgebrämes in die Seite des Körpers fand sich ein ringsherum laufendes, etwas ungleich $(4-10 \mathrm{~mm})$ breites Band ron heller Chocolade- oder chocoladegrauer Farbe; dasselbe war meistens ganz continuirlich, nur hinten eine kleine Unterbrechung darbictend, seltener perlenkranzartig oder an mehreren Stellen stärker unterbrochen; immerhalb des Bandes fanden sich mitunter einzelne längliche, ähnlich gefärbte Flecken. Die Fusssohle hell chocoladenbraun oder mehr schwärzlich, an dem Rande (in ciner Breite von etwa 2-3,5 $\mathrm{mm}$ ) gelblich oder grünlichgelb; die obere Seite des Fusses und mitunter die angrenzende Strecke der Seite hell chocoladetarbig oder grau. Die Tentakel und die Rhinophorien gelblichweiss, die Kieme braunlichgelb.

Die Form oval. Die obere Seite mit, wie es schien, unregelmässig stchenden, gerundeten, glatten, grossen, nur an der Mitte mehr hervortretenden Höckern. Die Ränder der Rhinophor-Höhlen 2-3 mm hervorstehend, die Oeffnung derselben eine Längsspalte; an der Keule jederseits etwa 40-45 Blitter. Die Tentakel zusammengedruckt, etwas sichelfömig gebogen, gleichbreit, am Ende gerundet. Die Ki e m en öfnung 6 lappig; die Lappen ungleich gross, öfter in Grösse alternirend oder'eine vordere und hintere grössere und zwei seitliche, $3-9 \mathrm{~mm}$ in die Oeffnung hereintretend. Die Kieme aus 6 tripinnaten Buischen gebildet, die eine Höhe von $8-13 \mathrm{~mm}$ erreichten. Die Analpapille hinten im Ausschnitte des Kiemenkreises, 3-5,5 mm hoch, cylindrisch, am Ende etwas ausgebreitet und 5-6lappig; die kleine Nierenpore rechts. Der Fuss 4-5 mm ron den Seiten hervortretend; die Oberlippe des Vorderrandes gekluftet.

Das Peritonaeum war fast farblos.

Das Centralnervensystem wie bei verwandten Formen. - Die A ugen von etiva 0,2 mm grösstem Diam., mit schwarzem Pigmente, gelber Linse. Die O hr b las en nur wenig kleiner als die Augen, mit Otokonien gewöhnlieher Art prall gefüllt. Die Blätter der Rhinophorien in gewöhnlicher Art mit langen, ziemlich dünnen, stark erhärteten Spikeln abgesteift. Die 'T'entakel in ausserordentlichem Grade mit Spikeln ausgestattet. Die sehr zithe Haut von Bïndeln von meistens gegliedert-verkalkten, sehr (wenigstens bis $1 \mathrm{~mm}$ ) langen Spikeln in den verschiedensten Richtungen durchzogen. Die Spikel in dem Rande der Rhinophorhöhlen stark entwickelt. In der interstitiellen Bindesubstanz hier und da, besonders um die Ausführungsgïinge des ganzen Genitalapparats, eine Menge von kleineren und grösseren Spikeln. 
Die (zurückgezogene) M undröh $\left.\mathrm{re}^{1}\right) 7 \mathrm{~mm}$ lang bei einer Breite hinten von $6 \mathrm{~mm}$, mit starken Längsfalten der vorne und unten etwas graufarbigen Innenseite. - Der Schlundkopf etwa $11 \mathrm{~mm}$ lang bei einer Höhe bis 8 und einer Breite auch bis $8 \mathrm{~mm}$ : die Raspelscheide hinten an der Unterseite etwas hervortretend. Die Mundöffnung mit einer dicken, weissen, unberwaffneten Cuticula überzogen. Die Zung g gross, breit. In der bräunlich-horngelben, schillemden Raspel 19 Zahnplattenreihen; weiter gegen hinten kamen noch 9 entwickelte und 4 nicht vollständig entwickelte Reihen vor; die Gesammtzahl derselben war somit 32. In den hintersten Reihen der Zunge fanden sich bis 54 Zahnplatten vor, und die Anzalıl schien nicht viel höher zu steigen. Die Farbe der Platten war horngelb. Die äusserste sehr klcine Platte hatte meistens nur eine Höhe von etwa 0,016-0,02 mm; die Höhe der Platten stieg (hinten in der Scheide) bis beiläufing $0,4 \mathrm{~mm}$. Die zwei innersten Zahnplatten hatten eine ungewöhnlich quere Schrägstellung; der Haken der innersten war ziemlich kurz. Die Form der Zahnplatten die sonst allgernein rorkommende. Die äusserste oder die zwei äussersten von ganz ungewöhnlich geringer Grösse. $\left.{ }^{2}\right)$

Die Speicheldriisen langgestreckt, etwa 16-18 $\mathrm{mm}$ lang, in der rorderen gelblichen Strecke bis $2 \mathrm{~mm}$ breit, in der etwas längeren hinteren dünner, gelblichweiss.

Die Speiseröhre (Fig. 10 a) etwa 14 mm lang. Das Vorderende des Magens (Fig. 10 b) aus der Leher hervorragend; die Magenhöhle mit sehr grossen Gallenöffnungen, leer (wie die ibrige Verdauungshöhle). Aus dem Vorderende des Magens entsprang mit einer (etwa $8 \mathrm{~mm}$ langen) an der oberen Seite selır dickwandigen und daselbst stark eingedrückten Erweiterung der D a rm (Fig. 10 c), dessen weiter vorwärts steigende Strecke eine Länge von etwa $7 \mathrm{~mm}$ hatte, wihrend die Länge der gegen hinten in mehreren Krümmungen verlaufenden Strecke etra $4 \mathrm{Cm}$. bei einer Breite bis $1,5 \mathrm{~mm}$ betrug.

Die Leber (Fig. 10 de) etwa 3,5 Cm. lang bei einer Breite bis 19 und einer Höhe bis $12 \mathrm{~mm}$. Die Farbe schmutziggrau, mit schwach grünlichem Anfluge, an Durehsehnitten der Leber noch grünlicher. Das Vorderende (Fig. 10) von oben gegen unten und vorwärts ausgelıöhlt, das hintere Viertel plötzlich verschmälert, am Ende gerundet. Die Gallenblase (Fig. 10) etwa 4,5 mm lang, bei einem Durchmesser bis $1,5 \mathrm{~mm}$, bräunlich.

Das Herz wie gewöhnlich, die Kammer etwa $5,5 \mathrm{~mm}$ lang. - Die Blutdrisen graulichgelb; die vordere oval, $6 \mathrm{~mm}$ lang bei einer Breite von 4,5 und einer Dicke von $1 \mathrm{~mm}$; die hintere $6 \mathrm{~mm}$ breit bei einer Länge von 3,5 und einer Dicke wieder von $1 \mathrm{~mm}$; beide in der Oberfläche lappig, besonders stark die hintere.

Die Ni erenspritze abgeplattet-melonenförmig, von $4 \mathrm{~mm}$ grösstem Diam. - Die Urinkammer eng.

1) Bei hervorgestrecktem Mnndrohre fand sich bei dem einen Individuum jederseits ein gelbbrauner Fleck; ist dieser die von Abranam (1. c. p. 250) erwähnte "small chitinous plate"?

2) Vergl. die im XIV. Hefte des Journ. des Mus. Goderkroy (1579. Taf. V. Fig. 19-23) gegebene Abbildungen. Semper, Philippinen. II, Ir (Bergh, Ergänzungsheft I). 
Die schmutziggelbliche $\mathrm{Zwitterdrüse,} \mathrm{welche} \mathrm{die} \mathrm{Leber} \mathrm{fast} \mathrm{vollständig} \mathrm{mit}$ Ausnahme eines Theils des Vorderendes iiberzog, zeigte in den Ovarial-Follikeln ziemlich grosse oogene Zellen, in den Testicular-Partien entwickelte Zoospermien. - Die vordere Genitalmasse von etwa $13 \mathrm{~mm}$ Länge bei einer Breite bis 7 und einer Höhe bis fast $9 \mathrm{~mm}$; die Ausfuhrungsgänge ragten noch dazu in einer Länge von etwa $5,5 \mathrm{~mm}$ hervor. Die schmutzig-graugelbe Ampulle des Zwitterdrüsenganges erstreckte sich in Pfropfzieherähnlichen Windungen (ausgestreckt in einer Länge von etwa 3,5 Cm.) längs der Unterseite der Masse. Der Anfang des Samenganges setzt sich gleich in die birnförmige, etwa $1 \mathrm{Cm}$. lange, grülichgraue Prostata fort, deren dickeres Ende das Hinterende dieser granzen Genitalmasse bildete. Der Samengang setzte sich dann als ein dünner Strang in vielen, ein grosses Knäuel bildenden Windungen bis an den Penis fort, der eine Länge von $3 \mathrm{~mm}$ bei einem Durchmesser von etwa 1,5 $\mathrm{mm}$ hatte; aus dem Ende desselben ragte noch die unbewaffnete Glans penis $1,5 \mathrm{~mm}$ hervor. Die grosse, gelbliche, kugelförmige Samenblase von etrva $6,5 \mathrm{~mm}$ Diam.; die andere mehr gräulich und fast wurstförmig, fast von einer Länge von 1 . Cm., sehr weit von der vorigen, nahe an der Einmuindungsstelle des uterinen Ganges stehend; der vaginale Gang der Spermatotheke kiirzer, mehr geschlängelt, am Ende (Vagina) wenig erweitert, aber mit stärkeren Falten. Neben der Vagina muindete in das Vestibulum ein sehr dickwandiger Gang (Stacheldrüsengang), der aus dem Nabel einer abgeplatteten, gelbgraulichen, in Diam. etwa $4 \mathrm{~mm}$ haltenden Druise (die im Inneren eine Zusammensetzung aus rundlichen Lappen zeigte) entsprang und etwa doppelt so lang als der grösste Diam. dieser (Stachel-) Druise war; das Ende des Ganges (der Stachelsack?) zeigte starke Falten und war mit einer dickeren Cuticula ausgekleidet; cin Stachel fehlte. Die Schleimdriise hatte eine Länge von 8 bei einer Höhe von 6 und einer Dicke von $4,5 \mathrm{~mm}$; sie war gelblich-kalkweiss; die Eiweissdrüse grau; die Innenseite des Ausführungsganges schmutzig-blaugrau. Von dieser Farbe war auch das mit starken Längsfalten versehene Vestibulum. 
DICTYODORIS, BGir. N. gen.

Corpus depressum, consistentia coriacen; nothaeum laeve; apertura branchialis rotundata; branchia paucifoliata, foliolis compositis; tentacula digitiformia; podarium antice vix bilabiatum.

Armatura labialis nulla. Lingva rhachide nuda, pleuris multidentatis, dentibus hamatis, externis apice pectinatis. - Penis inermis.

Die Dictyodoriden sind wie die vorhergehenden Gruppen stark abgeplattet, von etwas lederartiger Consistenz; der Rücken glatt (in der bisher bekannten Art mit eigenthümlichen durch Spikel-Züge gebildeten Figuren); die Kiemenöffinung rundlich, mit wenig vorspringendem Rande; die Kieme aus wenigen (4), zusammengesetzten Blättern gebildet; die Tentakel fingerförmig; der Vorderrand des Fusses nicht (oder kaum) zweilippig. - Die Lippenscheibe unbewaffnet. Die Raspel mit nackter, enger Rhachis; an den Pleurae zahlreiche hakenförmige Seitenzahnplatten, von denen die äussersten kammförmig. Der Penis ist unbewaffnet.

Diese Gruppe unterscheidet sich schon im Aeusseren, durch die runde Kiemenöffnung, sowie durch andere Beschaffenheit der Kieme, der Tentakel und des vorderen Fussrandes, von den vorherstehenden Gattungen, hauptsächlich aber durch das Fehlen von Bewaffnung an den Ausführungsgängen des Genitalapparats. Die Lippenscheibe ist unbewaffnet wie bei den Asteronoten; die Bervaffnung der Zunge wie bei den vorherstehenden Gattungen, die äussersten Platten sind aber bei der einzigen bisher bekannten Art kammförmig gezähnelt.

Die Gruppe gehört den subtropischen Meeresgegenden an. Bisher ist mit Sicherheit nur eine Art bekannt.

1. Dictyod. tessellata, BGr. n. sp.

Oc. pacif. (ins. Palau).

2. - ? Incii (ALDER).

D. Incii, Alder. Gray, figures. III. 1850. Tab. 226. Fig. $1^{1}$ ). Oc. pacif. ('Torres-Straits).

1) Vielleicht liesse sich die Figur auch als eine Sphaerodoris deuten. Vergl. Heft XIII. 1S78. p. 587. 
Dictyod. tessellata, $B$ ar. n. sp.

H a b. Oc. pacific. (Palau-ins.).

Taf. C. Fig. 11-12; Taf. F. Fig. 22-23.

Von der Art hat Hr. Kubary bei den Palau-Inseln 1873 ein einziges Individuum gefunden und dem Museum Gonefrroy in Alcohol bewahrt geschickt.

Das untersuchte Individuum hatte eine Länge von 15 bei einer Breite bis 8 und ciner Ilühe bis fast $3 \mathrm{~mm}$; die Länge der Tentakel fast $1 \mathrm{~mm}$; die Höhe der Rhinophorien betrug 2, die der Kieme etwa 1,5 mm; die Breite des Fusses war beilåufig 2,25 mm, die der Unterseite des Mantelgebrämes (vom Fusse ab) bis etwa 3,75 mm. - Die Grundfarbe des Rüickens war ziemlich hell rothgelb, war aber zum grossen Theile von länglichen, eckigen, schwarzen, fein gelb punktirten Fleckchen verdrängt. Die Unterseite des Mantelgebrämes weisslich, ringsum mit zerstreuten, doch meistens in einer Linie neben dem Rande angebrachten rundlichen und längliehen, sehwarzen oder sehwärzlichen Fleckchen. Aehnliche, aber zum grossen Theile zusammenschmelzende Fleckchen fassten den Grund des Fusses ein, der Schwanzricken tief schwarz; neben dem Fussrande oben hier und da zerstreute schwarze Fleckchen. Das Vorderende des Kopfes mit zerstreuten schwarzen Punkten; die Tentakel gelblich; die Keule der Rhinophorien schwarz, der Stiel gelblich. Die Blätter der. Kieme gelblich, an den Spitzen schwårzlich; die Unterseite des Fusses gelblich.

Die Form des Thieres lïnglich-oval, niedergedríckt. Das Vorderende des Kopfes abgeplattet, mit scnlirechter Mundspalte; die T'entakel kegelförmig, nicht abgeplattet; die Kieule der Rhinophorien nur wenig höher als der Stiel, ziemlich breit, die Zahl der Blätter etwa 30 betragend. Der Rücken fast eben, gegen den Rand hin etwas schrägend (und verdunut). An der Mittelpartie schimmerten vor den Rhinophorien eine, zwischen diesen und der Krieme 3 (Fig. 23), und hinter derselben (Fig. 22) zwei communicirende sternförmige (röthliche) Figuren mit meistens etwas hervorstehender Mittelpartie hindurch; die krïftigen Radien derselben waren oft wieder gegabelt, und diese Zweige anastomosirten meistens wieder und schienen wieder anastomosirende Zweigen gegen den Rand hinauszuschicken ${ }^{1}$ ) in den in dieser Weise umschriebenen Räumen kamen die erwähnten schwarzen, gelbpunktirten (Fig. 22) Inseln vor. An der Unterseite des Mantelgebrämes zeigten sich mehr oder weniger deutlich und auf dem Rande senkrecht stehend, düne, am Ende oft gegabelte (weissliche) Spikelhaufen. Die rundlich-herzförmige Kiemenüffnung (Fig. 22) mit niedrigem, umgeschlagenen Rande; die Krieme (Fig. 22) jederseits aus zwei

1) Das ganze Terhältniss erinnert einigermaassan an die Figur von Doris Incii, Arder (Grar, Figures. III.. 1S50. Tab. 226. Fig. 1; $1 \mathrm{a}, 1 \mathrm{~b}$ ) ron Torres-Straits, von der übrigens gar. Nichts bekannt ist. 
starken Blättern bestehend, die unten einfach geblikttert, oben ein paar Mal getheilt waren, die kurzen Zweige einfach geblättert. Die Analröhre (Fig. 22) cylindrisch, meistens die Hïlfte der Höhe der Kieme betragend, zwischen deu zwei hintersten Blättern stehend; die Nierenpore rechts an ihrem Grunde. - Die Genita I̋ffn ung an gewöhnlicher Stelle. - Der Fuss ziemlich schmal, vorne gerundet und mit Randfurche, fast gleichbreit, nur ganz hinten ein wenig zugespitzt.

Die Eingerveide schimmerten nirgends hindurch. - Das Peritonaeum farblos, nur an der Mittellinie hier und da brïunlich.

Das Centralnervensystem zeigte die cerebro-visceralen Ganglien fast nierenförmig; die cerebralen grösser (und zwar besonders breiter) als die visceralen; die pedalen von ovalem Umrisse, grösser als die visceralen. Die Riechknoten sehr kurzstielig, zwiebelförmig. Die buccalen Ganglien etwa doppelt so gross wie die vorigen, fast unmittelbar mit einander verbunden, von kurz-ovalem Umrisse.

Die A ugen sehr kurzstielig, kugelig, von etwa 0,12 mm Diam.g mit hellgelber Linse, schwarzem Pigmente. Die Ohrblasen an der Auskerbung der cerebro-visceralen Ganglienmasse liegend, von ovalem Umrisse und etwa 0,08 mm Diam., mit Otokonien gew ihnlicher Art prall erfuillt. Die Blätter der Rhinophorien in gewöhnlicher Art mit starken Spikeln abgesteift. Die Tentakel mit meistens quer und schrigge liegenden Spikeln im höchsten Grade ausgestattet. Die zähe Haut des Riuckens zeigte starke Spikel, theils sehr grosse (den erwähnten sternförmigen Bildungen folgend), theils kleinere; das dunkel rothbraune Pigment theils punktförmig, theils sehr schön sternförmig vertheilt.

Die Mundröhre etwa 1,5 mm lang, an der Imnenseite mit starken Längsfalten, welche schwarze Flecken trugen, denen ähnlich, die am Aussenmunde vorkamen. - Der Schlundkopf etwa $2 \mathrm{~mm}$ lang, fast ebenso hoch, aber etwas schmäler; die Raspelscheide hinten an der Unterscite stark hervortretend, aufwärts geschlagen. Die Mundspalte von einer ziemlich starken, einfachen Cuticula iiberzogen. Die Zunge kurz und breit, mit etwa 14 Zahnplattenreihen; weiter gegen hinten fanden sich noch 32 entwickelte und 4 nicht vollstindig entwickelte Reihen vor; die Gesammtzahl der Reihen betrug somit 50. In den Reihen kamen hinten an der Zunge (jederseits) 48-52 Zahnplatten vor. Die Zahnplatten von hell olivengelber Farbe; die Höhe derselben betrug bis $0,16 \mathrm{~mm}$, die der äussersten war meistens etwa 0,035 , die der folgenden $0,05-0,06 \mathrm{~mm}$. Die meisten Zahnplatten waren von gewöhnlicher Hakenform mit dem gewöhnlichen Flïgel des Kürpers; die innersten mit sehr kurzem Haken ${ }^{1}$ ). Die äussersten 5-6 aufrechtstehend, ron anderer Form (Taf. C. Fig, 11), an der Spitze sehr fein kammförmig getheilt (Taf. C. Fig. 12). Die Speiseröhre und der Magen wie gewöhnlich; die Gallenblase auch wie sonst, ebenso der Darm. In der Verdauungshöhle unbestimmbare thierische Masse, mit von der Zunge abgerissenen Zähnen vermischt.

1) Vergl. die früher im XIV. Hefte des Journ. des MIus. Godefrrox (1S79. Taf. V. Fig. 16-19) gegebenen Darstellungen. 
Das Herz wie gewöhnlich. Die Blutdrüisen gelbroth, die vordere grösser. Die Nierenspritze birnförmig.

In den Läppchen der, über die Leber ausgebreiteten, $Z_{w}$ itterdr üs e entwickelte Zoospermien. - Die vordere Genitalmasse breit, gelblichweiss, zu stark erhärtet um eine genügende Untersuchung zu gestatten. Die Ampulle des Zwitterdrüsenganges langgestreckt, wurstförmig, eine einfache Schlinge bildend. Die eine Samenblase gross, kugelförmig; die andere kleiner, wurstförmig, zusammengebogen, von Samen strotzend. Der Penis (Praeputium) dunkel-rothbraun pigmentirt, keine Spur von Bewaffnung am Grunde desselben. 


\section{Familie ELYSIADAE.}

Gen. Elysia, (Risso) autt.

Elysia, (Rrsso) autt. R. Bergir, malacolog. Unters. (Semper, Philipp. II, II) Ileft IV. 1872. p. 175-203.

Pterogasteron, Pease. Descr. of new species of Moll. from the Sandwich isl. Proe. zool. soc. XXVII. 1860. p. 35.

In seiner Zeit hat (vergl. l. c. p. 191) Mörncr mich eine Zeichnung sehen lassen, die von PEASE herstammend eine seiner Pterogasteren darstellen sollte, und ich meinte dieselbe auf eine Tridachia deuten zu müssen. Später habe ich im Museum Godrfrror: die originellen Zeichnungen PEAsE's zu seinen beiden Pterogasteren vorgefunden, unl dieselben stellen sicherlich nur Elysien vor. Wahrscheinlich wird sich also auch einc Tridachia im stillen Meere vorkommend zeigen. Diese beiden Arten (welche ich also [1. c. p. 191] früher als Tridachien aufgeführt habe) werden jetzt der von mir (l. c. 1). 178) gelieferten Liste von Elysien hinzuzufiigen sein. Die Zeichumgen PEAsE's, die zur' Publication in dem leider nicht mehr erscheinenden Journale des Museum Godefrior bestimmt waren, werden hier, um die spätere Verifieation dieser Arten zu ermöglichen, veröffentlicht.

\section{El. bella (PEase).}

Pterogasteron bellum, PEASE. 1. c. p. 36.

"- Colour brownish-red, and closely spotted with small, irregular, greyish-white spots. Eyes with white areolae.

Length 1 inch.

II a b. Oc. pacif. (ins. Sandwich)

Taf. G. Fig. 19.

\section{El, ormata (PELSE).}

Pterogasteron ornatum, PEASE. 1. c. p. 36.

"- Colour olive green, paler along the foot, spotted with faded yellow, and S emper, Philippinen. II, I. (Bergh, Ergānzongsheft II). 
dotted with black. Body margined with bright orange-red and edged with black, in which are a few white dots. Upper surface of the body paler than below, punctured with black and light red, and margined the same as beneath."

Hab. Oc. pacif. (ins. Sandwich) on the rocky coast, among sea-weed.

Taf. G. Fig. 18 .

3. El: sp.

Diese Form ist von PEASE abgebildet, sonst ist uiber dieselbe Nichts bekannt.

Hab. Oc. pacificum.

Taf. G. Fig. 20.

Familie AEOLIDIADAE.

Gen. Coryphella, Gray.

Vergl. I. Berar, Beitr. zur Tenntn. d. Aeolidiaden. III. Verh. d. k. k. zool bot. Ges. in Wien. XXV. 1S75. p. 633-640. VI. 1. c. XXVIII. 1878. p. 563-565.

Cor. parvula (PEASE).

Aeolis parvula, P'EASE. 1. c. 1860. p. 35.

Coryphella parvula (PEASE). R. Bergh, l. c. III. p. 635.

„Body smooth, subpellucid, tapering to a point posteriorly. Six pair of branchial tufts arranged longitudinally, the last on the posterior point of the body. Foot furnished anteriorly with lateral auricular appendages. 'Tentacles elongate-oval. Labial appendages elongato-subulate. Head and body subpellucid, uncoloured, freckled with vermilion. Branchial tufts olive, freckled with dusky.

Length 5 lines."

II a b. Oc. pacific. (ins. Sandwich)

Taf. G. Hig. 17. 


\section{Familie DORIDIDAE.}

\section{Chromodoris, Alder et Hanccer.}

Vergl. R. Bergir, Neue Nacktschnecken d. Südsee. III. Journ. d. Mus. Goderfroy, Heft VIII. 1S75. p. 72-S2. - IV. Heft XIV. 1578. p. $1-21$.

R. Beran, Unters. d. Chromod. elegans u. villafranca. MIalakozool. Bl. XXV. 1S7S. p. 1-36.

R. Beron, Neue Chromodoriden. MFalakozool. BI. N. F. I. 1879. p. 87-116.

R. Bergir, Malakologische Untersuch. (Sesper, Philipp. II, x). Ifeft XI. 1877. p. 461-491; Supplementheft I. 1S80 p. $14-27$.

In der von mir (1. c. III. 1875) gelieferten Liste der Chromodoriden finden sich die untenstehenden Arten erwähnt, die bisher nur durch die kargen Beschreibungen PEAse's bekannt sind. Im Museum GodefFroy fanden sich die zu denselben gehörenden originalen Handzcichnungen, die fiir ein fünftes Heft meiner .Nenen Nacktschnecken der Südsee" im "Journale des Muscum Godefrroy" bestimmt waren; dasselbe wird, wie bekannt, leider nicht fortgesetzt werden können, und diese Zeichnungen erseheinen somit hier als die wahrscheinlich einzigen zuverlissigeren Documente für spätere Verification dieser Arten.

\section{Chr. propiuquata (Pease).}

Doris propinquata, P. Descr. of new sp. of Moll. from the Sandwich islands. Proc, zool. soc. XXVIJI. 1860. p. 28.

Ha b. Oc. pacific. (Ins. Sandw.)

Taf. G. Fig. 1. 2.

,Form, when at rest, oblong, substance very soft. Mantle convex above and covered with rather distant, depressed, irregular-sized, white papillac, which do not extend to the margins. Extremities rounded, rather wider posteriorly, not concealing the foot behind; margins thin, and much undulated. Branchial plumes large, suberect, 12 in number, linear, nearly quadrangular in their transverse section, ciliated, decreasing in height posteriorly, surrounding the vent and retractile into a common simple cavity. Anal tube erect and very prominent. Dorsal tentacles rather large, nearly erect, elongately ovate, obliquely finely lamellate and retractile into simple cavities. Head prominent and furnished with elongate, cylindrically tapering tentacular appendages. Foot 
elongate, tapering postcriorly to a point far behind the mantle. Colour above bright rellow, becoming white at the margins; which are bordered irregularly with purple; four oblong dots of the same colour in front of the dorsal tentacles. Dorsal tentacles purple.on the outer portion. Branchial plumes edged with the same colour. ${ }^{1}$ )

Length 1 inch 3 lines.

This Doris possesses the same labit of vibrating its branchial plumes as the Doris vibrata."

\section{Chr. picta (Pease). $\left.{ }^{2}\right)$}

Doris picta, P'EASE. l. c. 1) 29.

II a b. Oc. pacif. (Ins. Sandwich)

Taf. G. Fig. $3-5$.

"Form; when at rest, oval; soft, similarly rounded at both extremities, and convexely rounded above. Nantle not concealing the foot, rather widest in the middle, and the margins thin and very slightly undulated. Branchiae small, suberect, curving centrally, 10 in number, decreasing in size posteriorly, encircling the vent. - Dorsal tentacles rather small, ovate, with short peduncles. - Colour white, with small irregular white spots. Obsolete yellow spots along the margin, which, as well as the foot, is bordered with orange. The angular edges of the branchiae edged with carmine. 'T'entacles tipped with orange.

Leugth 1 inch 6 lines."

3. Chr. albopustulosa (Pease).

Doris albopustulosa, P. l. c. 1) 30.

II a b. Oc. pacific. (Ins. Sandwich)

Taf. G. Fig. 6, 7 .

"When at rest, of an oblongo-ovate form,-soft. Mantle rounded at both extremities, edges thin and mululated and concealing the foot; the upper surface is covered with white depressed, irregular-shaped and unequal-sized pustules, which do not quite reach the margins. Branchial plumes 6, rather small, erect, incurved, pinnate, surrounding the rent - Iorsal teutacles somewliat large, oblong-ovate, coarsely and obliquely lamellated -. Head is prominent. - Colour above lemon-yellow, pustules white, and the margins of the mantle edged with purple. Dorsal tentacles reddish-brown, with white lamellac. Branchiae white. Foot and beneath the mantle white.

Length 1 inch."

1) Die Farbenangaben des Textes stimmen nicht ganz mit denen der Figuren.

2) Die Chromod. picta (Suncutz) ist mit der Chr. elegans (Cintr.) synonym. Vergl. 1. c. XXV. 1S7S. p. 6. 


\section{Chr. villafrauca (Risso).}

Chromodoris villafranca (R.). BGH., I. c. XXV. 1878, p. 22-33, Taf. IV. Fig. $5-12$.

Ha b. M. mediter.

Taf. K. Fig. 9, 10.

Die an oben angefihrter Stelle gegebenen Darstellungen des Mundapparats dieser Art werden hier dureh Abbildungen der Rhachisparthic (Fig. 9) der Raspel und der äussersten Zahmplatten (Fig. 10) verrollstïndigt.

\section{Chr. coerulea (Risso).}

Doris cocrulea, Risso. Journ. de plyys. T. LXXXVII. 1818. p. 370. - Hist. nat. IV. 1826. p. 32.

Chromodoris coerulea (Risso). R. Bergi, nene Nacktschnecken der Suidsce, III. Journ. d. Mus. Godefrroy, ILeft VIIT. 1875. p. 74.

Doris tricolor, Cantr. Malacol. méditerr. 1840. p. 57. pl. 3. Fị. 5.

Chromodoris tricolor, C. H. T. Jierrng, Beitr. zur Kenntn. der Nudibranchien des Mittelmeeres. Malakozool. Bl. N. F. IJ. 18s0, p. 9-1i. 'Taf. I. Fig. 2.

Goniodoris vivida, Forbis. Rep. on the Moll. and Radiata of the Aegean Sea. liep, of the br. ass. for adv. of se. for $18+3$. p. 186. ${ }^{1}$ )

Color coeruleus margine dorsali albo (rel luteo) et linea dorsali mediana longitudinali alba, lateribus linea longitudinali alba.

Dentes (laterales) non multi, margine laevigato.

Hab. M. mediterr.

Taf. K. Fig. 1-S.

Diese crst von Rrsso (1S18) in der Niihe von Villafranca gefischte Form und aufgestellte Art, mit welcher von Pmilipr und Grube, aber kaum mit Recht (vgl. Jinering, 1. c. p. 11), die D. gracilis von RAlP identificirt wird, ist späiter vou GrubE (Ein Ausflug nach Triest und dem Quarnero. 1861. p. 121; Die Insel Lussin. 1864. p. 45) im adriatischen Busen wiedergefunden. An etwa derselben Localitait, unter Algen des Leuchíthurmdammes von 'T'riest, fand Dr. GraEfFe neulich dieselbe wieder', zwischen den an den Algen vorkommenden Hydroidpolypen langsam umherkriechend. Von den 4 mir geschickten Individuen wurden 2 anatomisch untersueht.

1) „G. corpore subquadrato coeruleo, dorso fascia centrali alba, albo marginato; branchiis 7 , coeruleis. Long. 3/10 Unc." 
Es kann kaum bezweifelt werden, dass die Doris tricolor von CANTRAINE (1840) nur eine gelbgerandete Varietät der Form von RIsso (1818) ist, wie sie auch ron Jirerivg aufgefasst wird, dessen Abbildung eben auch diese Varietät darstellt. Der Name von Risso muss dann aber auch wieder in seine Rechte eintreten.

Das lebende T'hier hatte, Graffee zufolge, eine Liinge bis etwa $15 \mathrm{~mm}$. Die Grundfarbe war "schimmernd himmelblau"; der farbigen Skizze GrAEFFE's zufolge war der Ritcken von einem schmalen blanen Rande und innerhalb desselben von einem etwas breiteren weisslichen Bande ringsum cingefasst; ein medianes weisses Band zog sich von der Gegend zwischen den Rhinophorien bis an die Kieme; die Rhinophorien und die Kiemè dunkler blau; der Schwanz oben mit einem medianen weissen Längsbande. ${ }^{1}$ )

Die eingesandten in $\Lambda$ leohol bewahrten Individuen hatten eine Länge von 5 bei einer Breite bis 2 und einer Höhe bis $1,75 \mathrm{~mm}$; die Breite der Fusssohle bis 1,1, die Höhe der Rhinophorien und der Kieme bis $0,75 \mathrm{~mm}$. Die Farbe durchgehends schmutzig grimblau, dunkler am Riicken; an dem letzteren eine schmale, abstechend weisse mediane Liingslinie, sich von der Gegend hinter oder zwischen den Rhinophorien bis an das Kiemenloch erstreckend; eine (mehr) blauliche ähnliche Linie fassto dicht am Riickenrande den Riicken ringsum ein; an der Nitte der Seiten des Körpers eine mehr oder weniger unterbrochene weisse Längslinie, welche sich an den Schwanzriicken mitunter mit der (stark bläulich schillernden) medianen, weissen Längslinie desselben velbindet; der Fussrand heller, mehr grau. - Die Form die gewöhnliche, Stirn- und Schwanzgebräime wie gewöhnlich, ohne Knoten; der Mantelrand an den Sciten wenig vorspringend; die Rhinophorien wie gewöhnlich, dic Kenle mit, wie es sehien, etwa 15-20 Blättern; $\left.{ }^{2}\right)$ die Kricme weit nach hinten stehend; aus, wie es schien, 5-6 Blättern ${ }^{3}$ ) gebildet; die 'T'entakel fast wie eingestuilpt; der vordere Fussrand mit tiefer Randfurche; der Schwanz nicht lang.

Das Peritonaeum war griulich, besonders am Riicken.

Das Centralnervensystem zeigt die unregelmässig-cifürmigen cerebro-visceralen Ganglion dicker im vorderen Ende; die cerebralen grösser als die visceralen, und diese etwa so gross wie die pedalen; die grossen Commissuren nicht deutlich von einander geschieden; die proximalen Ganglia olfactoria fast sessil, fast doppelt so gross wie dic kugelfürmigen distalen. Die buccalen Ganglien ein wenig grösser als die grossen Riechknoten, durch eine kurze Commissur mit einander verbunden; die gastro-oesophagalen Ganglien kurzstielig, rundlich, etwa $1 / 10$ der Grösse der vorigen betragend.

Die A ugen nicht ganz kurzstielig, mit schwarzem Pigment, gelber Linse. Die Ohrblasen an gewöhnlicher Stelle, mit etwa 25 Otokonien, die rundlich oder lïnglichoval waren und cine Liinge bis etwa $0,016 \mathrm{~mm}$ erreichten. Die Bliitter der Rhino-

1) Für die Varietäten dieser Art muss auf Jierno (1, c.) hingewiesen werden.

2) Jueara giebt (1. c. p. 11) deren nur 9 an.

3) lirsso giebt die Anzahl der Kiemenblätter zu 5 an, Jurang zu 7-9. 
phorien dünn, ohne Spikeln; dagegen kamen solche im Stiele derselben und in der Axe der Kieule vor. Im Stiele und in der Rhachis der Kiemenblitter kamen ähnliche grössere Spikeln reichlichst vor. In der $\mathrm{H}$ a ut des Rückens ziemlich zahlreiche, meistens grosse, bis etwa $0,3 \mathrm{~mm}$ lange (bei cinem Durchmesser bis fast $0,02 \mathrm{~mm}$ ), mitunter schwach griinlich schillernde, stark erhärtete, spindelfürmige Spikeln.

Die Mundröhre grösser als der Schlundkopf, grïnlichblau. Der Schlundkopf 0,6-0,75 mm lang; die Raspelscheide gegen unten hinab ziemlich stark vorspringend. Die Lippenplatte gelblich, ringförmig, bis etwa $0,45 \mathrm{~mm}$ breit, aus wenigstens 55 Reihen von Häkchen gebildet (Fig. 1), die von der gevöhnlichen Grundform waren (Fig. 1-4), eine Länge bis $0,02 \mathrm{~mm}$ erreichend, mit cinfachem, doppeltem oder dreifachem Haken. Die Zunge breit; dic Raspel schwach blaulichgrau, in derselben 22-25 Zahnplattenreihen, von denen die 2-4 vordersten sehr incomplet; weiter gegen hinten noch 17-16 entwickelte und etwa 4 unentwickelte Reihen; die Gesammtzahl derselben somit 43-45. In den Reihen kamen hinten an der Zunge (jederseits) 23-24 Zahnplatten vor; dieselben waren sehr schwach gelblich, erreichten eine Höhe bis etwa $0,03 \mathrm{~mm}$. An der Rhachis (Fig. 5a) schwache, vorne etwas stärkere Verdickungen. Die innersten Zahnplatten (Fig. $5 \mathrm{bb}, 6$ ) mit einem inneren Dentikel, sonst wie die ubrigen nur mit Doppelhaken (Fig. 7); die iusseren niedriger als die anderen, sonst von derselben Form (Fig. 8) und glattrandig.

Die Speicheldruisen sehr langgestreckt, wenigstens $2 \frac{1}{2}$ Mal so lang wie der Schlundkopf, weisslich. - Der Darm grünlich; mit starken Längsfalten. Die Leber oben grïlich, sonst und in der Substanz gelblichweiss; die Gallenblase läinglich, weisslich. - Das Herz, die grünlichgrauen Blutdrüsen und die Nierenspritze wie gewöhnlich. - Die Zwitterdrüse wenig entwickelt, ebenso die graulichweisse vordere Genitalmasse; die Samenblasen, der Samenleiter und der Penis wie gewöhnlich.

Die Art zeichnet sich von den anderen streifigen Arten des Mittelmeeres (Chr. gracilis, messinensis, Krohnii, elegans, villafranca) ausser durch ganz andere Firbung, durch eine viel geringere Anzahl von (glattrandigen) Zahmplatten in den Reihen aus. 


\section{ARCHIDORIS, BGH.}

Vergl. Heft XIV. 187S. p. 616. - Supplementheft I. 1SS0. p. 33.

Die an angeführter Stelle gegebene Liste der bisher gekannten Archidoriden wird jetzt mit den untenstehenden neuen Arten bereichert.

4. A. marmorata, BGH. n. sp.

M. meditcrr.

5. A. Kerguelensis, BGH. n. sp. ${ }^{1}$ )

M. indic. austr.

6. A. australis, BGII. n. sp.

M. indic. anstrale.

A. marmorata, BGIr. n. sp.

D. tuberculata, Cuv. Philipri, en. moll. Sic. II. 1844. p. 79. Taa. XIX. Fig. 11.

Color corporis e rubro brunnens, infra clarior; supra (dorso) brunnescente-nigro marmoratus granulis ubique sparsis majoribus minoribusve albidis ornatus; clavus rhinophoriorum nigro-riolaceus, branchia cinerascente albida.

Ha b. M. mediterr. (ad 'Tergestem; Panormum, Neapolim [PurLippi]).

Taf. H. Fig. 1-10.

Die hier vorliegende 'T'bierform ist dẹn Farbenverhältnissen nach ganz deutlich die von Pummpr (l. e.) dargestellte Art. welche aber von ihm mit der von Cuvrer erwähnten D. tubereulata unrichtig identificirt wird, so wie mit der von RAPP (Nov. Act. A. L. C. Nat. Cur. XIII, 2. 1527. p. 521. 'T'ab. XXVII. Fig. 4, 5) abgebildeten, ebenso benannten Form. Das 'Thier musste deshalb umgetauft werden.

Von dieser Art bekam ich 1879 aus der zoologischen Station von 'Trieste durch die Giite des Inspectors Dr. Graeffe 4 durch Chromsäure getödtete und in Alcohol bewahrte. Individuen nebst zwei Zeichnungen und einigen Notizen. Die Form soll nicht häufig in der Nähe von Trieste gefischt werden, und ist an Steinen des tieferen Wassers getroffen worden. - Seitdem habe ich sechs andere Individuen, in Alcohol getödtet und

1) Diese so wie die folgende Art werden in dem Report of Scientific Results of the Challenger-expedition, für welchen ich die Nudibranchien zu bearbeiten habe, verüffentlicht werden. 
bewahrt, von Dr. GraEfFE auch aus der Nähe von T'riest herstammend bekommen, dic in Grössen- und Formverhältnissen mit den anderen ganz iibereinstimmten und nur etwas dunkler gefärbt waren. - Vier Individuen wurden fur die anatomische Untersuchumg verwendet.

Die L ïnge ${ }^{1}$ ) des lebenden Thieres betright, Graeffe zufolge, bis volle 5,5 Cm. bei einer Breite bis 3,3 Cm. Die F arbe ist durchgehends "rothbraun ", an der" Unterseite des Mantelgebrimes und an der Fusssohle heller; der Rücken mit dunklerem Rothbraun marmorirt und iiberall mit grösseren und kleineren, weisslichen Knötehen bedeckt. Der Stiel der Rhinophorien "braunroth; die Kenle schwarzviolet mit weisser Spitze. Die Kieme griäuliclıweiss. "

Die Länge der (4) in Aleohol bewalnten Individuen variirte zwischen 3,5-4,2 Cm. bei einer Breite bis 2,2 und ciner Höhe bis 1,3-1,5 Cm.; die Linge des Fusses war 3-3,2 Cm. bei emer Breite von 10-14 mm; die Liinge des Schwanzes bis $5 \mathrm{~mm}$. Die Breite des Mantelgebrimes 5,5-7 mm, die Länge der 'Tentakel 2,5-3, die Höhe der Rhinophorien 3,5-4,5 und die der Kieme 5-5,5 mm; die Knötehen des Riiekèns erreichten einen Durchmesser bis $1 \mathrm{~mm}$; an einem dieser Individuen war der Penis $2 \mathrm{~mm}$ hervorgestreckt. - Die F a r be war (dureh die Einwirkung der Chromsäure) durchgehends in ein (grïinliches) Braungrau geändert, mitunter waren die Fusssohle und die Umgegend der Genitalpapille und des Mundes doch schmutziggelblich; die Rhinophorien dunkler, die Kieme heller als der iibrige Kürper.

Die Form des weichen Körpers länglich-oval, etwas niedergedrickt. Der ziemlich gewölbte $R$ ücken überall und bis an den Rand mit Knötchen ganz dicht bedeckt, die sessil und glatt waren; die viel geringere Menge derselben war ron einer (Fig. 1) gewissen Grösse (bis zu $1 \mathrm{~mm}$ Diam.), die ibrige Masse war von ganz geringer oder (wieder in untergeordneter Menge vorkommend) von mittlerer Grüsse. Das Mantelgebräme ringsum ziemlich breit, gegen den Rand verdinnt; die Unterseite ganz glatt. Die Umgegend des nur wenig vortretenden, rundzackigen Randes der ziemlich weiten $\mathrm{lh}$ in op horhöhlen anch bis an den Rand mit kleinsten Knötchen bedeckt. Der starke Stiel der Rhinophorien etwas küirzer als die Keule, die (jederseits) etwa 25 Blätter zeigte (die zum allergrössten Theile in der Mittellinie vorne und hinten in einander ibergehen) und cine kräftige, an der Spitze nitunter etwas eingesenkte Endpapille. Die Umgegend des gegen aussen (bei hervorgestreckter Kieme) etwas umgescblagenen Randes der (bis $10 \mathrm{~mm}$ ) weiten, schwach rundzackigen Kiemenöffnung auch bis an den Rand mit feinsten Knötchen bedeckt. Die Kieme aus 8 nicht grossen, tripinnaten Blättern gebildet, von denen die zwei hintersten (seltener an der einen Seite die drei) jeder Seite am Grunde genauer vereinigt waren oder ein tief zerklïftetes Kiemenblatt simulirten, dessen hinterer Theil fast immer kleiner war; am Grunde, dicht an der Analpapille waren sie durch die gewöhnliche 
(perianale) Kiemenkrause vereinigt. Die Analpapille dicht an dem hinteren Ausschnitte des Kiemenkreises stehend, nicht niedrig (bis etwa $1,5 \mathrm{~mm}$ hoch); oben abgestutzt, mitunter nach hinten abfallend, mit rundzackiger Oeffnung. Dicht vor der Analpapille, ein wenig rechts die spaltenartige Nierenpore. Der Kopf ziemlich klein, mit sternartigem oder senkrechtem Aussenmunde (in einem Falle war der Schlundkopf zum grössten Theile aus demselben hervorgestreckt); am Grunde desselben die nicht kleinen, kegelförmigen Tentakel, die durch eine Falte mit dem Fussrande verbunden sind. Die

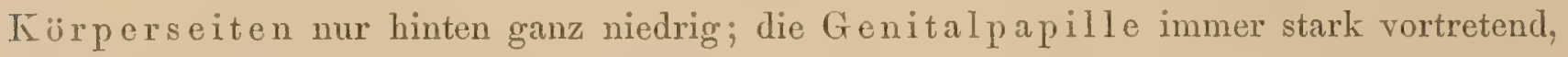
mit zwei kleineren vorderen spaltförmigen und einer hinteren weiteren Oeffnung; mitunter war der kegelförmige, am Grunde viel dickere Penis aus der vordersten 4-5 mm hervorgestreckt. Der Fuss stark, an den Seiten nicht stark (bis fast 2,5 mm) vortretend; der etwas zugespitzte Schwanz ahgeplattet; der Vorderrand gerundet, mit Randfurche, welche sich eine Strecke nach hinten fortsetzt, die obere Lippe in der Mittellinie gespalten.

Die Eingeweide schimmerten nirgends hindurch. - Das Peritonaeum farblos.

Das Centralnervensystem aus sciner losen Capsel nicht leicht auszulösen, ziemlich stark abgeplattet. Die cerebro-visceralen Ganglien mehr oder weniger länglichnierenförmig, mit deutlicher Grenze zwischen den zwei Abtheilungen, hinten kaum dicker; die pedalen Ganglien von rundlichem Umrisse, etwas grösser als die visceralen Ganglien. Die gemeinschaftliche Commissur ziemlich kurz, etwa noch ein halbes Mal so lang wie der Querdurchmesser des Centralnervensystems, bandförmig-breit; die viscerale Portion an zwei Individuen rechts an ihrer Wurzel von den anderen eine kurze oder ganz kurze Strecke gelöst; der von dieser Strecke in diesen Fällen entspringende N. genitalis an seiner Wurzel bei dem einen Individuum mit einem und bei den anderen noch weiter hinab mit einem zweiten Ganglion versehen. Das erste dieser Ganglien von ovaler Form, von etwa 0,4 mm. Länge, kleinzellig. Der N. genitalis konnte mit Sicherheit in die Tiefe zwischen den Windungen des Samenleiters verfolgt werden und schien mit einem rundlich-dreieckigen Ganglion von etwa 0,4 mm Diam. in Verbindung zu stehen, das zwischen Penis und Vagina lag, beiden, wie es schien, Nerven spendend. Die proximalen liechknoten nicht gross, zwiebelförmig, fast sessil; die distalen eine längliche, oben dickere (wie gewőhnlich ganz kleinzellige) Anschwellung am Nerven bildend, aus dem nach oben mehrere Nerven ausgehen. Die buccalen Ganglien fast doppelt so gross wie die unteren Riechknoten, von ovaler Form, fast unmittelbar mit cinander verbunden. Die gastro-oesophagalen Ganglien ziemlich kurzstielig, an der einen Seite des Nerven entwickelt, von ovaler Form, kaum 1/6 der Grösse der vorigen betragend, mit zwei grossen und mehreren kleinen Nervenzellen; zwei Nerven abgebend.

Die A ugen ziemlich gross, von etwa $0,4 \mathrm{~mm}$ läıgstem Durchmesser, von ovaler Form, mit grosser (Diam. 0,18 mm) brïunlich-horngelber glänzender Linse und sehwarzen l'igmente. Der N. opticus etwas länger als das Auge, bei einen Individuum in der iusseren Iälfte zchwarz pigmentirt. Die Ohrblasen etwas kleiner als die Augen, als 
etwas abgeplattete Säckchen vor dem cerebro-pedalen Connective deutlich vortretend, ron (etwa 200) Otokonien ge̊wöhnlicher Art ganz erfuillt, welche von gelblicher Farbe waren, cinen Durehmesser bis $0,02 \mathrm{~mm}$ erreichend. Die Blätter der Keule der Rhinophorien breit, diinn und, wie schon unter der Loupe sichtbar, in gewöhnlicher Weise durch lange, cylindrische, glatte, gegen die Enden zugespitzte Spikeln steif gemacht, die nux wenig erhärtet waren, einen Durclimesser bis etwa $0,025 \mathrm{~mm}$ erreichend; im Stiele der Rhinophorien waren die Spikeln stärker und stärker (krümmelig) erhärtet. In den Tentakeln kamen ihnliche oder noch stärkere Spikeln ziemlich reichlich vor, so auch in der Haut-des Riickens und in deren Tuberkeln, von denen besonders die kleineren mit aufrechtstehenden Spikeln und kleinen Bündeln von Spikeln ausgesteuert waren, welche aber meistens sich wenig erhärtet zeigten. - In der interstitiellen Bindesubstanz kamen grössere Spikeln gar nicht, und erhärtete Zellen überhaupt nur sehr sparsam vor.

Die I undröhre etwa so lang wie der Schlundkopf, mit den gewöhnlichen, starken 3 Paaren von sehr langen Retractoren; die Innenseite mit den gewöhnlichen Längsfalten und der hinteren circuliren. - Der Schlundkopf gross und kräftig; die :iussere Form sowie die starken und langen Retractoren wie gewöhnlich; die Länge desselben bei den grossen Individuen $8 \mathrm{~mm}$ bei einer Breite bis 6 und einer Höhe bis $6 \mathrm{~mm}$ betragend, die kräftige Raspelscheide noch fast $2 \mathrm{~mm}$ nach hinten und unten vortretend; an zwei kleinen Individuen betrugen dieselben Maasse etwa $6-4,75-3,3$ und kaum $1 \mathrm{~mm}$. Die Lippenscheibe oval mit senkrecht $\mathbb{1}$-förmiger Oeffnung; nur von einer ziemlich starken weisslichen Cuticula iiberzogen. Die Zunge breit, mit tiefer Furche; an der Spitze Spuren von 2-3 ausgefallenen Zahnplattenreihen; die Raspel nicht breit, fast farblos oder schwach gelblich, an den grossen Individuen mit 14-15, an den kleinen mit 12-13 Zahuplattenreihen; weiter nach hinten kamen bei jenen 13 entwickelte, 2 halb entwickelte und 2 gar nicht entwickelte Reihen vor, bei diesen 12, 12, 2 und 2; die Gesammtzahl der Reihen somit 31-32 und 28-29. In den Zahnplattenreihen kamen linten an der Zunge an dem grossen Individuum (jederseits) 46 und 52, an dem kleinen 44 und 55 Zahnplatten vor; weiter nach hinten wuchs die Anzahl derselben, wie es schien, nur noch mit 2-3. Die Zahnplatten sehr schwach gelblich, die Linge der innersten (Fig. 2 aa) betrug bis $0,28 \mathrm{~mm}$; die Höhe der Platten bis fast (Fig. 3) 0,4 mm steigend; die Höhe der drei äussersten meistens $0,16-0,25-0,28 \mathrm{~mm}$ betragend. Die Formverhåltnisse der Platten die ganz gewöhnlichen. Die åusserste Platte (Fig. 4a, 6) mit küirzerem Körper.

Die Speicheldriisen mit ihren Gängen sehr lang, die linke etwas lïnger als die rechte, bis $3,5 \mathrm{Cm}$. lang. Die Giinge sehr lang und duinn (Fig. 7), etwa $2 / 3$ der ganzen Länge betragend. Die weisslichen Drisen mit ihren Verästelungen iber die vordere Hälfte der Unterseite der hinteren Eingeweidemasse verbreitet, abgeplattet, nur 0,3-0,6 mm breit (Fig. 8,8); die Drisenmasse noch eine kurze Strecke nach vorne den Speicheldruisengang als ein diinnes Lager bekleidend. 
Dic Speiseröhre etwa 2,2 Cm. lang bei einem Durchmesser bis 2,5 mm; die Innenseite mit den gewöhnlichen feinen Lïngsfalten. Die Cardia-Oeffnung von einem rorspringenden scharfen Rande begrenzt. Der Magen sich in einer Länge von etwa 1t-15, bei einer Breite ron 4-4,5 mm nach rorne erstreckend; dann in den Darm ibergehend, der nach hinten in einer Länge von $26-28 \mathrm{~mm}$ verlüuft; der Durehmesser in der crsten Strecke des Darmes 3-3,5, in der letzteren 2-2,5 $\mathrm{mm}$; an der Innenseite feine Längsfalten. - In der Verdauungshöhle unbestimmbare thicrische Masse.

Die hintere Eingeweidemasse (Leber) bis 2,2--2,4 Cm. lang bei ciner Breite bis 1,1-1,5 und einer Höhe von $8 \mathrm{~mm}$ bis $1 \mathrm{Cm}$; das Hinterende gerundet; das Vorderende gerade oder schief (nach rechts) abgestutzt, nach unten und hinten schräge abfallend, facettirt, mit einer medianen Kluf́t, die immer bis an die Cardia hineindringt; die obere Seite abgeplattet, mit flacher breiter Furche für den Darm, am letzten. Drittel eine tiefe mediane Einscnkung (für die Urinkammer), welehe doch nicht bis an das Hinterende reicht; an den Seiten 2-3 tiefe Qucrfurchen (besonders eine vor der Nierenspritze), die iiber die convexe Unterseite hinabsteigen. Die Lebersubstanz schmutzig gelblichweiss, an den in Alcohol getödteten Individuen rostroth. Die Leberhöhle etwa $8 \mathrm{~mm}$ lang bei einer Höhe bis $3,5 \mathrm{~mm}$; die (4-5) Gallenhöhlungen weit. - Die Gallenblase senkrecht längs der rechten Seite des Cardia-Theils des Magens hinabsteigend, etwa $4-5,25 \mathrm{~mm}$ hoch bei einem Durchmesser bis $1,5 \mathrm{~mm}$, gelblichweiss, nicht sehr dickwandig; die Innenseite mit feinen Liingsfalten, besonders unten.

Das Pericardium, das Herz und die Arterienverzweigung fast wie gewöhnlich. Dic rordere Blutdris e von eiformigem Umrisse mit der Spitze nach vorne; etwa 6,5 mm lang, binten in der Mitte bis $2 \mathrm{~mm}$ dick, gegen die Seitenränder und nach vorne diuner; an der oberen Seite mehr eben. Die hintere Blutdrise theilweise das Centralnervensystem deckend, ron dreieckigem Umrisse, die Spitze nach hinten kelnend, ron etwa $5 \mathrm{~mm}$ Länge; die Dicke und Dickenverhailtnisse wie in der vorderen. Die beiden Drüsen schmưzig röthlichgrau oder hellbraun, mit etwas lappigen Rändern, sowie die Unterseite von ähnlicher Beschafienheit.

Die Nierenspritze weissgelblich, stark, $3-4 \mathrm{~mm}$ lang bei einem Durchmesser bis 2-2,6 mm. Die Niere mit iluen Kolben wie gewöhnlich; die Urinkammer ziemlich dickwandig, liurz; der Urinleiter von der Gegend der Eimmindung der Nierenspritze sich an die Nierenpore erstreckend, ziemlich diumwandig. - Die kurzen starken lateralen Retractoren der Kieme wie gewöhnlich.

Die Z Zitterdrise die Leber am Vorderende, an der oberen Fläche und an den Seiten netzartig iberziehend, durch stärkere gelblichweisse Farbe gegen die aussen mehr grauliche Leber contrastirend. In den Läppehen der Drüse grosse oogene Zellen

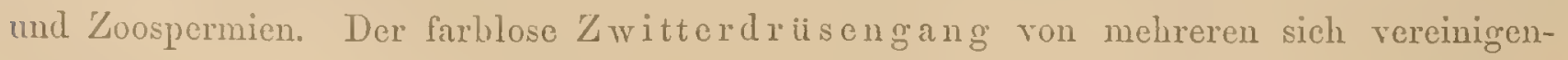


den Zweigen im vorderen Theile der Leberkluft oberhalb des Cardia-Theils der Speiseröhre, unterhalb des Jarm-Knies gebildet, rechts (in einer Lïnge von 6-7 mm) sich längs der Vorderseite der Leber erstreckend und in die Ampulle ansehrellend. Diese (Fig. $9 \mathrm{~h}, 10 \mathrm{a}$ ) letztere ist von gewöhnlicher opak-weisslicher Farbe, ziemlich duinn (nur ron cinem Diam. bis $1-1,5 \mathrm{~mm}$ ), und nicht kurz (bis $1,5-2,5-3,5 \mathrm{Cm}$. lang), laings der Hinterseite der vorderen Genitalmasse in einem Bogen hinabsteigend und am unteren Rande sowie an der vorderen Seite ein kleines Kiniuel oder eine Reihe ron kurzen Biegungen bildend, oder ganz an der unteren und vorderen Seite liegend.

Die vordere Genitalmasse querliegend; bei den kleineren Individuen 13-14 mm breit bei einer Höhe bis $8-12$ und einer Längre (von vorne nach hinten) von $9,5-11 \mathrm{~mm}$; bei einem grossen Individuum betrugen dieselben Maasse 17, 13 und 9,5 mm; die Ausfuhrungsgiinge noch $3-3,5 \mathrm{~mm}$ hervoriretend. Die Nasse von ganz unregelmaissiger Form, von. vorne uach hinten ciwas zusammengedriickt; die vordere Seite etwas gervölbt; die hintere etwas ausgehöhlt; an der vorderen Seite links die Prostata, dann ein Theil der Ampulle des Zwitterdriisenganges, und rechts die Schleimdrise mit oben an derselben ruhendem Samenleiter und Penis; an der hinteren Seite links wieder die grosse Prostata, dann in der vertieften Mitto die weissliche Spermatotheke, dann rechts die Schleimdriisc und an der oberen Seite derselben ruhend die Tagina, unterhalb derselben noch ihre Drise und meistens die Spermatocyste, und ganz oben ein Theil des Penis und ein grosser Theil des Samenleiters. - Das Ende der Ampulle des Zwitterdriisenganges stark rerschmälert; der männliche (Fig. 9i, 10b) Zweig gleich in die grosse Prostata iibergehend. Diese (Fig. 10 c) ist ein grosser, schlauchförmiger, etwas abgeplatteter, weisslichgelber, an der Oberfläche meistens wie äusserst fein granulirter Körper, der nach oben zusammengebogen ist, der linke Theil etwas lïnger wie der rechte und besonders dicker; die Länge von jeder Hälfte bis etwa 10-11 mm betragend, die Breite der linken Hälfte bis $4,5-6,5$ bei einer Dicke bis $3-4,5 \mathrm{~mm}$; durch fast die ganze Länge des Organs erstreckt sich nicht gauz central eine nicht ganz enge Höhle ron ovalem Durchmesser. I)er Bau ist der bei diesem Organe gewöhuliche. Aus dem oberen Ende der Prostata entspringt der eine Anzall von Kinickungen bildende, graubraune prostatische Theil (Fig. $10 \mathrm{~d}$ ) des Samenleiters, welcher ausgestreckt eine Läuge von beiliiufig 1,2 -1,8 Cm. bei einem Durchmesser vou meistens $0,75 \mathrm{~mm}$ hatte. Dieser Theil geht allmählig in den weisslichen muskulöseu Theil iiber, weleher ein sehr grosses Kínäuel ron Windungen bildet, welche entwirrt im Ganzen etwa 10,5-11,5 Cm. bei einem Durchmesser von meistens $0,5 \mathrm{~mm}$ maassen. Der Samenleiter wird schliesslich allmählig dicker und setzt sich ohne Grenze in den Penis fort, weleher sehr stark ind (eingestiilpt) mehr oder weniger gebogen oder etwas eingerollt war und cine Länge ron 18 -20 mm bei einem Durchmesser oben von 0,5-2,5, unten von $1-3 \mathrm{~mm}$ hatte. Der Penis ist sehr muskulös; wenn zuríckgezogen, zeigt er sich nur in dem untersten $1 / 1-1 / 6$ (Pracputium) hohl, und die IIöhle ron der kegelförmigen Glans fast ausgefitllt, welche an der 
Spitze eine feine Oeffnung hat. Die Spermatotheke (Fig. 9 a) kugelförmig, weisslich, die Kluft zwischen den zwei Beinen der Prostata ausfuillend, von einem Durehmesser ron 4,5-6,5 mm; mit verfetteten Zellen und Detritus erfuillt. Der uterine Gang (Fig. $9 \mathrm{f}$ ) stark geschlängelt; dicht vor seinem Ende durch einen kurzen Stiel befestigt die Spermatocyste tragend ( Fig. $9 \mathrm{~g}$ ), welche von mehr oder weniger gestreckter Eiform war, gelblich, von etwa $3-3,5 \mathrm{~mm}$ Länge, von Samen strotzend. Der vaginale Gang (Fig. $9 \mathrm{~b}$ ) von seinem Ursprunge ab sehr stark, gegen unten in einem stärkeren oder schwächeren Bogen hinabsteigend und allmählig dicker auch allmaihlig unten die Vagina (Fig. 9c) bildend; die Liinge desselben etwa $10-12,5 \mathrm{~mm}$ betragend bei einem Durchmesser oben von 1,5-2, unten von 3-4 $\mathrm{mm}$; die nicht so sehr dicke Wand innen starke Längsfalten zeigend, die besonders oben anastomosirten. In den untersten Theil der Vagina mündet eine gelbliche, etwas abgeplattete, ovale (Fig.9d) vestibulo-vaginale Druse durch einen Gang (Fig. 9e), der kaum halb so lang oder etwa so lang wie die Drüse war, ein; die Driise hat eine Läinge von beiläufig $3,5-4,5 \mathrm{~mm}$, durch ihre Axe rieht sich eine enge Höhle. Der Ausfiihrungsgang ziemlich diinnwandig, innen fast ohne Falten. - Die Schleimdrüse den kleineren Theil der ganzen vorderen Genitalmasse bildend, rundlich, von vorne nach hinten nur ein wenig abgeplattet; die Breite und Höhe etwa 5-10 $\mathrm{mm}$ bei einer Dicke (von vorne nach hinten) von 4-6 $\mathrm{mm}$ betragend, weisslich; die verhiiltnissmiissig grosse eigelbe, oder bei den in Alcohol getödteten Individuen russrothe Eiweissdrüse den unteren Rand und den grösseren unteren Theil der Hinterseite einnehmend. Das Vestibulum genitale mit Läingsfalten, unten bråunlich pigmentirt.

Ich habe friher (Heft XIV. 1878. p. 624, Note) darauf aufmerksam gemacht, dass ALdER und Hancock eine anatomische Untersuchung einer "Doris tuberculata, VeranY" geliefert haben, welche offenbar von der D. tuberculata, Cuv. verschieden sein muss. Jene Form ist aller Wahrscheinlichkeit nach die hier von mir untersuchte; die vestibulovaginale Driise (I. c. pl. XV. Fig. $4 \mathrm{k}$ ) ist sehr deutlich dargestellt, der Penis aber viel zu kurz und zu schwach.

Ob diese Art nun wirklich der Gattung Archidoris gehört, muss vorläufig dahingestellt bleiben. Sie weicht in der Form der Tentukel und, was den inneren Bau betrifft, besonders in dem Dasein einer mächtigen Prostata ab.

Arch. marmorata, Bar. var.

Color dorsi sordide rubidus, medio albide varius; rhinoploria fusca apice albo; branchia rhachidibus rubescente-griseis fronde clare brunnescente-grisea albide varia; caput et pagina inferior limbi pallialis e rubro flavescentia clare-brunneo varia; pagina inferior podarii e flavo ruber.

Hab. M, adriaticum (ad Tergestem). 
Unter lebonden Nudibranchien, welche mir durch Dr. GraEFfe Mitte Mhirz 1880 aus der Station von 'I'riest geschickt wurden, fanden sich zwei sterbend ${ }^{1}$ ) hier (in Kopenhagen) anlangende, in Farbe etwas abweichende Individuen dieser Art, die deshalb genauer untersucht wurden.

Das grösste der (bei der Ankunft lebend ummittelbar untersuchten) ganz weich anzufühlenden Individuen hatte ein $\mathrm{L}$ ån ge von $4,7 \mathrm{Cm}$. bei einer Körperbreite bis 3,4 und einer Höhe bis $1,8 \mathrm{Cm}$; die Höhe der (halb zurickgezogenen) Rhinophorien schien etwa $6 \mathrm{~mm}$ zu betragen, die Länge der frei hervorragenden Tentakel $6 \mathrm{~mm}$, die Höhe der (halb ausgestreckten) KKieme $7 \mathrm{~mm}$; die Breite des Mantelgebråmes (vorne) bis $12 \mathrm{~mm}$; die Breite des Fusses (vorne) bis $2 \mathrm{Cm}$. - Die F a rbe der oberen Seite (nicht dunkel) schmutzigrothbraun, an der Mitte etwas dunkler und auch weisslich-scheckig, die Granulationen meistens dunkler, so auch die Umgebung der (bis $2,5 \mathrm{~mm}$ tveiten) Rhinophoröffnungen; die Rhinophorien dunkel (schmutzig) schwarzbraun mit weisser Endpapille; die Rhachis-Parthien der Kieme röthlichgrau, das Laub hell bräunlichgrau und weissscheckig, von dieser letzteren Färbung war auch die Analpapille. Der Kopf hellroth, die 'Tentakel ctwa wie die Unterseite des Mantelgebrämes, aber heller gefürbt. Diese letztere Unterseite sowie die Körperseiten ziemlich hell (etwas schmutzig) gelbroth, etwas hell bräunlich scheckig; der Rand der Genitalöffnung schwärzlich, die Penisöffnuang röthlich. Der Fuss an der oberen Seite bräunlich, dunkler gegen den freien Rand; die Unterseite schön gelbroth.

Die Länge der grössten der in Alcohol bewahrten Individuen betrug fast $4 \mathrm{Cm}$. bei einer Breite bis 2,8 und einer Höhe bis 1,3 Cm.; die Länge der Fusssohle cin wenig mehr als 3 bei einer Breite von $2 \mathrm{Cm}$; die Breite des Mantelgebrämes bis $11 \mathrm{~mm}$, die Länge des Schwanzes $5 \mathrm{~mm}$, die der Tentakel $3,5 \mathrm{~mm}$; die Höhe der (zuriickgezogenen) Rhinophorien etwa 5,5, die der (zuriickgezogenen) Kieme fast $12 \mathrm{~mm}$. - Die F arbe des Riickens gelbgraulich, am Mantelgebräme heller und mehr gelblich; die ganze Unterseite gelblich; die Rhinophorien gelblich, die Kieme gelblichweiss.

Die Form verhïltnisse die gewöhnlichen. Die Knötchen des Rückens im Ganzen etwas kleiner, und die Anzahl der grösseren geringer. Der Rand der Rhinophorhöhlen etwas stärker zackig; die Rhinophorien wie gewöhnlich, auch mit etwa 25 Blättern. Die Kieme aus 8 Blättern gebildet; die Analpapille $2 \mathrm{~mm}$ hoch. Der Kopf mit den 'Tentakeln, sowie der Fuss mit dem Schwanze wie oben.

Das Centralnervensystem ganz wie oben; auch hier fund sich die viscerale Commissur in ihrem rechten Viertel von der sonst gemeinschaftlichen gelöst. Die buccalen Ganglien mehr rundlich-dreieckig, planconvex; die gastro-oesophagalen etwa $1 / 5$ der Grösse der vorigen betragend. - Die Augen wie oben. Die Ohrblasen als kalkweisse Punkto unter der Lupe sichtbar, uibrigens wie oben.

1) Die Uebersendung erfordert 5 Tage. 
Der Schlundkopf $7 \mathrm{~mm}$ lang bei einer Höhe bis 6 und einer Breite bis $5,5 \mathrm{~mm}$; die Raspelscheide weniger vortretend; die Lippenscheibe wie oben. In der Raspel der Zu n ge 14 Zahuplattenreihen und an der Zungenspitze noch Eindriicke von 3 ausgefallenen Reihen; weiter nach hinten 16 Reihen, von denen 4 noch nicht vollständig entwickelt; die Gesammtzalıl der Reihen somit 30. In den Reihen kommen hinten an der Zunge 43 Platten vor, und die Anzahl schien weiter nach hinten nur mit 2-3 zu wachsen.

Die Speicheldrüson wie oben. Die Speiseröhre etwa $2 \mathrm{Cm}$. lang bei einem Durchmesser bis $4 \mathrm{~mm}$. Der Magen $11 \mathrm{~mm}$ lang bei einem Durchmesser von 4. Die erste, nach rorne gehende Strecke des Darmes ganz kurz; die nach hinten gehende 2,3 Cm. lang bei einem Durchmesser von 4-2,5 mm. In der Mundröhre fand sich eine $5 \mathrm{~mm}$ lange Rissoa (?), und die Verdauungshöhle war ibrigens mit nicht näher bestimmbarer thierischer Masse erfiillt. - Die hintere Eingeweidemasse (L e b e r) 2,2 Cm. lang bei einer Breite (vorne) bis 1,5 und einer Höhe bis $1 \mathrm{Cm}$., sonst wie gewöhnlich, so auch die Gallenblase.

Die Blutdrisen gelblich; die vordere seitwïrts weit hinabreichend, daher etwa $12 \mathrm{~mm}$ breit bei einer Liinge von 2,5 mm; die hintere $6 \mathrm{~mm}$ lang bei einer Breite von 4.

Die vordere Genitalmasse etwa $12 \mathrm{~mm}$ breit bei einer Höhe ron $1 \mathrm{l}$ und ciner Dicke (von rorn nach hinten) ron $7,5 \mathrm{~mm}$. Die Ampulle des Zwitterdriisenganges wie oben, etwa $2,5 \mathrm{Cm}$. lang bei einem Diam. von $1 \mathrm{~mm}$. Die Lageverhältnisse der Organe wie oben. Jede Hälfte der Prostata etwa $11 \mathrm{~mm}$ lang, die linke viel dicker (von etwa $5 \mathrm{~mm}$ Diam.). Der prostatische, rothbraune Theil des Samenleiters etwa $3 \mathrm{Cm}$. lang bei einem Durchmesser ron $0,75 \mathrm{~mm}$; der muskulüse 'Theil etwa $9 \mathrm{Cm}$. lang bei einem Durchmesser ron etwa $0,5 \mathrm{~mm}$. Der Pen is wie oben, etwa $2 \mathrm{Cm}$. lang bei einem Durchmesser oben ron $1 \mathrm{~mm}$, unten ron fast $6 \mathrm{~mm}$; die Spitze der $6 \mathrm{~mm}$ langen Glans aus dem Praeputium hervorragend (an derselben eine dreieckige Oeffnung). Die Spermatotheke kugelförmig, von 5,5 mm Durchmesser; die Spermatocyste auch (etwas abgeplattet-) kugelförmig, von $3,5 \mathrm{~mm}$ grösstem Diam.; der vaginale Gang mit der Vagina beiläufig $1 \mathrm{Cm}$. lang bei einem Durclimesser oben von 1,5 , unten von etwa $4,5 \mathrm{~mm}$. Die vestibulo-vaginale Drüse von etwa $2,5 \mathrm{~mm}$ Länge. Die Schleim- und Eiweissdruise wie oben. 


\section{STAURODORIS, BGH.}

Vgl. Heft XIV. 1SiS. p. 57S; Supplementheft I. 1550. p. 36.

Der an oben angefuhrten Stellen gegebenen Liste von 4 (5?) Arten wird jetzt die untenstehende neue Form aus dem Mittelmeere hinzuzufiigen sein.

\section{Staurod, ocelligera, B(ir. n. sp.}

Color supra variabilis, lutescens vel e coerulco clare nigrescens vel niger, tuberculorum apice ocellis obscurioribus; rhinophoriis albescens, branchia coerulescens.

Hab. M. mediterr. (ad Tergestem).

$$
\text { Taf. H. Fig. 11-21. }
$$

Von dieser schönen Form erhiclt ich von Dr. (indFFFe im Frühjahr 1879 drei Individuen (in Alcohol betvahrt), die im April d. J. anf Algen an der Hafenmaner von Triest gesammelt waren, nebst einer colorirten Zeichnung des lebenden Thieres und einigen Notizen.

Die Länge des lebenden Thieres war, Gramere zufolge, fast 0,5 Cm. Die Farbe scheint "ziemlich variabel, oben hell bläulich-schwarz, am Riickengebräme heller (wie in der Zeichnung von GraEFfE) oder fast ganz schwarz oder melr gelblich, die Rückenwärzchen an der Spitze mit einem dunklen Augenflecke; die Kénle der Rhinophorien weisslich; die Kieme bläulich. Der ganze Körper des Thieres ist etwas durchscheinend ". Die Form lïnglich-oval, der Mantel den F'uss ringsum stark iiberragend: die Kieme 5 blätterig.

Die Lïnge der in Alcohol bewahren Indiriduen betrug 7- $8 \mathrm{~mm}$ bei einer Breite bis 3,5-3,75 und einer Hühe bis 2-2,5 mm; die Breite des Fusses rorne 2-2,5 mm; die Höhe der Rhinophorklappen $0,75 \mathrm{~mm}$, die der Ritckempapillen bis etwa die Hälfte betragend; die Weite der Kiemenüftnung bis etra 0,S; die Hölıe der Ihhinophorien sowie der Kieme kaum 0,8 mm. Die Farbe durchgehends gelblich, an der Spitze von meistens jedem Rücken-Tuberkel ein dunkler P'unkt; oder die Farbe war bleigrau mit gelblichem Kípfe, Tentakeln und Fusse. Die Consistenz ist zienilich hart. 
Der R ücken iberall mit zahlreichen ziemlich starken, niedrigen, eylindrischen, oben abgeplatteten oder convexen (Fig. 11) Tuberkeln bedeckt, zwischen denen kleinere, doch nicht in sehr grosser Menge; die grösseren nehmen an Nenge auf dem Rückengebrime ab. Die kleinen runden Rhinophor-Oeffnungen mit zwei grossen, aufrecht stehenden lateralen Klappen (Fig. 12), deren Aussenseite convex und ziemlich glatt, deren Innenseite glatt war, und die aneinander gelegt ein schr grosses T'uberkel simulirten. Die Thinophorien selbst kurzstielig, kräftig; in der Keule etwa 20 breite Blätter. Der wenig rorspringende Rand des querovalen, nicht weiten Kiemenloches immer mit 6 vorspringenden 'Tubcrkeln, die denen der Rhinophor-Oeffnungen ähnlich, aber nicht grösser wie die grösseren des Rüickens oder kaum so gross waren. Die Kieme aus 7-8 sehönen pinnaten Blättern gebildet; die ziemlich hohe Analpapille fast central im Kiemenkreise, neben derselben vorne und rechts die runde Nierenpore. Die Unterseite des Mantelgebrämes glatt, mit durchschimmernden weisslichen eradiirenden Spikelziigen. Die Körperseiten verschwunden; die Genitalöffnung eine dreieckige Spalte. Der Ko pf klein, mit senkrechter Mundspalte; zu jeder Seite derselben der gerundet-dreieckige, ziemlich dicke Tentakel, mit tiefer Furche der Unterseite. Der Fuss stark und breit; der Vorderrand gerundet-abgestutzt, mit tiefer Furche, die obere Lippe derselben in der Mittellinie zerkliiftet; von den Kürperseiten ziemlich vortretend, das Hinterende gerundet.

Zwvei Indiyiduen, ein gelbliches und ein graues, wurden anatomisch untersucht; sie stimmten in den wesentlichen Verhältnissen iiberein. - Das Peritonaeum farblos.

Das Centralnervensystem (Fig. 14) ziemlich abgeplattet. Die cerebro-visceralen Ganglien ziemlich kurz (Fig. 14a), nierenförmig; die cerebrale Abtheilung etwas breiter (vorne) und ein wenig grösser wie die viscerale; die pedalen Ganglien (Fig. 14bb) ron rundlichem Umrisse, wenigstens so gross wie die cerebralen. Die drei Commissuren (Fig. 14c) zu einer gemeinschaftlichen, nicht weiten vereinigt. Die (Fig. 14) proximalen Riechknoten fast sessil, abgeplattet-zwiebelförmig; die distalen viel kleiner, nur eine rundliche Anschwellung am Nerren bildend. Die buccalen Ganglien (Fig. 14d) grösser als die unteren Riechknoten, von ovalem Umrisse; die gastro-oesophagalen (Fig. 14 ce) kurzstielig; etwa 1/10 der Grösse der vorigen betragend, mit einer sehr grossen und mekrereu kleinen Zellen.

Die A ugen (Fig. 14) ganz kurzstielig, ziemlich gross, mit schwarzem Pigmente, gelber Linse. Jie Ohrblasen (Fig. 15) etwas kleiner als die Augen, an der Unterseite (Fig. 14) der Gehirnknoten fast sessil, mit etwa 80 sehwach gelblichen Otokonien gewöhnlicher Art gefillt. Die dünen Bläter der Rlinophorien mit nur wenigen, aber starken, theilweise nur krümelig crhärteten Spikeln; im Stiele und in der Scheide kamen solche dagegen reichlicher, mitunter massenweise vor, meistens kürzer und dicker, auch theilweise nur kximelig erhärtet, zum grossen Theile querliegend. Die T'entakel waren in ähnlicher Weise wie die Riicken-I'uberkel, aber weniger reichlich mit Spikeln ausgesteucrt. Die Haut ïberall und in reichlichster Weise mit Spikeln versehen, 
die meistens sehr (Fig. 13) stark waren, lang, meistens spindelförmig, meistens selır stark erhärtet, fast glasklar. Die Klappen der Rhinophorien verhielten sich (Fig. 12) wie die Tuberkel des Riickens (Fig. 11). Diese letzteren, besonders die grossen, zcigten einen centralen Kern von mehr untereinander geworfenen Spikeln und von demselben gegen die Peripherie eradiirende isolirte Spikel, welche aber fast nie uber die Oberflïche hervorragten. - In der interstitiellen Bindesubstanz kamen dio Spikel fast überall reichlich vor. Durch die Rhachis der Kiemenblitter zogen sich, besonders unten, Buindel von langen Spikeln, von denen Ausläufer hier und da selbst in die Kiemenblaitter hineinragten. In der Umgegend der Hauptausführungsgänge des Genitalapparats fanden sich Spikel in ganz vorziiglicher Menge und von ganz bedeutender Grösse (cine Länge bis wenigstens 0,55 bei einem Durchmesser bis $0,025 \mathrm{~mm}$ erreichend).

Die (zuruickgezogene) MIndräre etwa 1,5 mm lang; die Retractoren und die Innenseite wie gevöhnlich. - Der Schlundkopf etwa von derselben Länge wie die Mundröhre, die Höhe ein wenig geringer, und die Breite wieder ein wenig kleiner; die Raspelscheide hinten und unten etwas vortretend; die Retractoren wie gewöhnlich; die Lippenscheibe von einfacher Cuticula überzogen. In der Raspel der breiten Zung o kamen bei den zwei Individuen 11-17 Zahnplattenreilien vor; weiter nach hinten fanden sich noch 13-15 entrickelte und 4 noch nicht vollständig entwickelte lieihen; die Gesammtzahl derselben somit 28-36. In der 11. und 15. Reihe der Zunge fanden sich bei den respectiven Individuen 24 und 39 Platten, und die Anzahl derselben stieg weiter nach hinten kaum iber 30 und 49. $\left.{ }^{1}\right)$ Die Zahnplatten von sehr schwach schmutzig-gelblicher Farbe; die Töhe der imnersten Platten etwa $0,015 \mathrm{~mm}$ betragrend, die Höhe der Platten sich allmählig bis zu $0,06 \mathrm{~mm}$ erhebend, um an den äussersten wieder bis etwa 0,035 abzunchmen. Die Form der Platten (Fig. 19) die gevöhnliche; die innerste mit ganz nicdrigem Haken (Fig. 16 aa, 17 aa, 18); die 3-4 äussersten ganz schlank, aufrecht (Fig. 20).

Die Speicheldriison (wenigstens $3 \mathrm{~mm}$ ) lang, bandförmig, im vorderen Viertel dicker, kalkweiss, entweder beide oder nur die linke unter der Schleimdriise iiber den vorderen 'Theil der Leber hin sich erstreckend; im letzteren Falle zog sich die rechte mit der Speiseröhre bis an die Cardia. Die Ausfuihrungsgiange kurz.

Die Speiseröhre (Fig. 21 a) lang, ziemlich weit, mit den gewöhnlichen Längsfalton der Innenseite. Der grosse, freie $M$ agen (Figg. $21 \mathrm{~b}$ ) etwa $2 \mathrm{~mm}$ lang bei ciner Breite bis etwa $1,5 \mathrm{~mm}$. Die Liinge des (Fig. $21 \mathrm{~d}$ ) Darmes etwa 4 mm betragend. Die Verdauungshöhle leer. - Die hintere Eingeweidemasse (L e b e r) vorne schräig abgestutzt; nach hinten ein wenig schmäler, am Hinterende gerundet; die Liinge etwa $3 \mathrm{~mm}$ bei einer' Höhe und Breite von 1,8 mm; die Farbe gelblichweiss. Die Gallenblase (Fig. 21e) nach unten schrïig fast bis an den Unterrand der Leber hinabsteigend, etwa $0,75 \mathrm{~mm}$ lang.

1) Die geringere Anzahl ron Zahnplattenreihen und von Platten in den Reihen kam bei dem blei-graufarbigen Indivilumm vor. 
Das Herz wie gewöhnlich. Die Blutdrüsen weisslich oder graulich; die vordere queroval, ron etwa $0,75 \mathrm{~mm}$ kurzestem Diam.; die hintere ein wenig kiirzer und breiter. - Die Nicre wie gewöhnlich, so auch die Nierenspritze.

Die Zwitterdrüse wenig entwickelt; in ihren Läppehen keine entwickelten Geschlechtsclemente. - Die vordere Genitalmasse deshalb auch nicht gross, von etwa $1,25 \mathrm{~mm}$ Breite bei einer Höhe und Länge (von vorne nach hinten) von $1 \mathrm{~mm}$. Die Ampulle des Zwitterdrüsenganges wie bei der typisehen Art. Die Prostata und der Samerleiter wie bei der letzteren Art, ebenso der an der Uebergangsstelle befestigte starke Muskel; ebenso ferner der Penis. Die kuģelförmige Spermatotheke und die kleine birnförmige Spermatocyste wie gewöhnlich, die letztere von Samen strotzend; so auch die Vagina. Die Eiweissdrüise gelblich, die Schleimdrüse weisslich.

Diese Form wird sich kaum als eine jugendliche der typischen St. verrucosa erweisen. Schon in der Farbenzeichnung etwas von derselben abweichend, differirt sie in der Beschaffenheit des Ǩiemenapparats ziemlich bedeutend. 


\section{ROSTANGA, BGI.}

Rostanga, Bergir. Gatt. nörd. Doriden. Arch. f. Naturgesch. 45, 1. 1879. p. 353.

Corpus sat depressum. Nothaeum papillis minutis hispidis obtectum. Tentacula (depresso-) digitiformia. Rhinophoria retractilia, clavo perfoliato. Branchia retractilis, foliis non paucis $(9-10)$ simpliciter pinnatis formata.

Armatura labialis fortis e baculis minutis dense confertis formata. Tialula rhachide nuda; - pleuris multidentatis; dentibus internis solidioribus, corpore magno, hamo parvo; reliquis minus validis, corpore minore, hamo elongato, tenuiori, apice quasi bifido. Penis inermis.

Diese Gruppe wurde von mir (1879) ohne Untersuchung der typischen Form, allein nach den von ALDER und HANCOCK ${ }^{1}$ ) gegebenen anatomischen Daten aufgestellt. Die später von mir angestellte Untersuchung hat die Angaben der englisehen Verfasser bekräftigt und erweitert und die Berechtigung der aufgestellten nenen Gruppe behauptet.

Die Körperform der Rostangen ist ziemlich niedergedriickt. Der Riicken ist mit kleinen eigenthümlichen, spitzentragenden Papillen dicht besetzt. Die Tentakel etwas niedergedrickt, fingerförmig. Dic Rhinophorien retractil, mit durchblïtterter Keule. Die zurükziehbare Kieme aus mehreren (9-10) einfach-gefiederten Bläitern. zusammengesetzt. - Die Mundöffnung mit einer aus kleinen Stibchen gebildeten starken Einfassung. Die Rhachis der Zunge nackt; an den Pleurae viele Zalınplatten, von denen die imneren kräftiger und niedrig sind, mit starkem Körper und Kleinem IIaken; aus dieser Form entwickelt sich dann allmählig dic der meisten Zahnplatten, welche einen kleinen (fligelartigen) Körper und einen langen, aufrechten, etwas gebogenen, dümen, (wegen eines langen Dentikels) an der Spitze tief gespaltenen Haken zeigen. - 1)er Penis ist unberraffinet.

Die Rostangen sind bisher nur durch zwei Arten aus dem atlantischen und dem Mittelmeere bekannt, ron denen die eine (untenstehende) neu.

1) Alner and Harcock, Jionogr. part 1V. 191S. fam. 1. pl. 7; part VII. 1855. pl. 46 supplem. Fig. 6. Haxcocr and Easietox, on the anatomy of Doris. Philos. Trans. 1552. p. 212, 215, 220, 222, 233. pl. IV, Fig. 3. 
1. R. co c cinea (Folbes).

I. atlant., mediterr.

2. - perspicillata, BGH. n. sp.

II. mediterr.

\section{IR. coccinea (Forbes).}

D. coccinea, Fonses. Rep. Brit. ass. for 1843. p. 133.

F. Alder and HANC., Monogr. part IV. 1848. fam. 1. pl. 7 ; part VIT. 1855. p. 2, pl. 46 suppl. Fig. 6.

- F. Hancocr and Enbleton, on the anatomy of Doris. Philos. Trans. 1852. p. 212, 215, 220. pl. XV. Fig. 3.

Doris rubra, D'Orb. Mém. sur - Nudibr. Magaz. de Zool. 1837. p. 2. pl. 102. ${ }^{1}$ ) liostanga coccinea, BGII. l. c. p 353.

Corpus supra coccineum nigro maculatum; rhinophoria lutescentia, brunnco maculata, circumferentia proxima flarescens; branchia rosacea; solea podarii rubescente-carnea.

II a b. M. atlant., mediterr.

Taf. H. Fig. 22-32; Taf. J. Fig. 16.

Diese Form wurde vor vielen Jahren von Forbes im aegaeischen Meere (Syra, Naxia) gefischt, und einige Jahre nachher von ALDER und HANCock die Identitit dieser Form mit der an den englischen Küsten vorkommenden constatirt. Die englischen Verfasser haben die Zungenbewaffnung dieser Form dargestellt, sonst seheint iiber dieselbe Niehts bekannt geworden. Die Art scheint auch an der Kiiste von Norwegen ${ }^{2}$ ) rorgefunden zu sein.

Von der Art habe ich ein Individum zur Untersuchung gehabt, welches Dr. v. MARExzelder in 1875 bei Zante gefischt und nach der Abbildung von Alder und IIAXCock als die Art von ForBes bestimmt hatte. Notizen lagen nicht vor; die anatomische Untersuchung wurde mir aber von MArExzeLLer freundlichst gestattet und sehien in der That die Identitit des Thieres mit der von den englisehen Verfassern beschriebenen Form zu bestitigen. Später habe ich an einem von Dr. Graefre in der Niahe von Triest gefangenen, in Alkohol bewahrten fast ebenso grossen Individum eine NachUntersuchung machen können.

1) Die von LEacr (Moll. Brit. synopsis. 1S52. p. 21) erwühnte D. coccinea, MIT. („MISS.“) mit ilhem "tuberculirten Rïcken" kann aber nicht hierhin gehören.

2) Vergl. G. O. S.irs, Mloll. xeg. aret. Norv. 1S7S. p. 364. 
Das erste in Alcohol ziemlich stark erhärtete Individuum hatte eine $L \ddot{i n g} \mathrm{~g}^{1}$ ) von 8,5 bei einer Breite bis 5,2 und einer Höhe bis $2 \mathrm{~mm}$; die Breite des Mantelgebrämes war 2, die des Fusses $2 \mathrm{~mm}$; die Höhe der Rhinophorien ctwa 1,3, die der Kieme etwa 1,2 mm. - Die Farbe des Riuckens (wegen der Höckerchen) weisslich mit schwach röthlichgelblichem Schimmer an der Mitte; überall an dem Riicken, besonders in der Kiemengegend und am Mantelgebrime unregelmaissig zerstrente kleinste schwarze Punktchen, welche hauptsächlich dem Boden zwisehen den Nöppchen gehörten; die Keule der Rhinophorien hell gelblich; die Innenseite der Kriemenblätter hell grinlichgrau; die Unterseite des Thieres weisslich, der Fussrand hinten gelblichweiss.

Die Form etwas niedergedriickt, länglich-oval, mit fast parallelen Seiten; das Fussende kaum das Mantelgebrime ïberragend. Der Rucken mit eigenthümlichen feinsten Nöppchen bedeckt, welche eine Höhe bis etwa $0,25 \mathrm{~mm}$ erreichten und schon bei einer stïkeren Loupe ihre eingesenkte Mitte von Spitzen umstellt (Fig. 24) deutlich zeigten. Das mittelmässig breite Mantelgebräme an der Unterseite glatt. Die Rhinophor-Oeffuungen sternförmig, die Nöppchen fehlten auch nicht an dem kaum rortretenden Rande; die Organe mit kurzem starkem Stiele und kurzer starker Keule mit etwa 12 nicht breiten, starken Blittern. ${ }^{2}$ ) Die weit nach hinten liegende, bis zu $0,6 \mathrm{~mm}$ zusammengezogene Kiemen-Oeffnumg sternfürmig oder queroval; der Rand kaum vorstehend, auch mit Nöppchen bedeckt. Die ziemlich kleine Kieme ${ }^{3}$ ) aus 9 fast gleichgrossen, einfach gefiederten Bliittern gebildet (von denen das eine an der Spitze zerklüftet); etwa in der Mitte des Kriemenkreises die niedrige An I papille. Der Kopf klein mit zusammengezogenem Aussenmund; an jeder Seite von diesem der fingerfürmige, etwas abgeplattete, schwach zugespitzte Tentakel. Dio Seiten des Körpers ganz niedrig; die zusammengezogene Genitalpapille an gewöhnlicher Stelle. Der Fuss vorne gerundet, mit tiefer Randfurche, und die obere Lippe des Vorderrandes in der Mitte getheilt; der Schwanz kurz.

Die Eingeweide an der Mitte des Riickens schwach hellgelblich durchschimmernd. - Das Peritonaeum farblos.

Das Centralnerrensystem abgeplattet (Taf. J. Fig. 16); die cerebro-risceralen Ganglien nierenfürmig (Fig. 16 ab), ihre zwei Abtheilungen fast von gleicher Grösse; die pedalen Ganglien rundlich (Fig. $16 \mathrm{cc}$ ), kaum grösser als die visceralen; die drei Commissuren vereinigt (Fig. 16d). Die proximalen Riechlnnoten fast sessil, zwiebelförmig (Fig. 16); die distalen viel kleiner, von ovalem Umrisse. Die buccalen Ganglien (Fig. 16 e) mehr als doppelt so gross wie die grossen Riechknoten, von ovalem Umrisse, durch ganz kurze Commissur mit einander verbunden; dic gastro-oesophagalen (Fig. 16 c) kurz-

1) Arder und Hixcock geben die Länge zu $1 / 2$ " an.

2) Arder und Haxcock geben nur 10 Blätter an.

3) Arder und Hascacis geben deren 10 an. 
stielig, oval, etwa $1 / 4-1 / 6$ der Grösse der vorigen betragend. Mit dem rechten visceralen Ganglion scheint ein kleines fast sessiles Gangl. genitale in Verbindung zu stehen. Vor der Cardia an der Speiseröhre ein ovales Ganglion von $0,05 \mathrm{~mm}$ grösstem Diam.

Die kurzsticligen $\Lambda$ ugen (Fig. 16) ziemlich gross, von etwa 0,14 mm Diam., mit schwarzem Pigmente, gelber Linse. Die rundlichen Otocysten (Fig. 16) von etwa 0,08 mm Diam., von Otokonien strotzend, welche in Form (rund, oval) und Grösse (Diam. bis $0,013 \mathrm{~mm}$ ) bedeutend variirten, und in Anzahl wenigstens etwa 200 betrugen. Die Bliatter der Rhinophorien mit sparsamen, schräge oder senkrecht gegen den Rand stehenden Spikeln; in der Axe und besonders in dem Stiele grössere knoten- und kugelförmige erhärtete Körper und Haufen von solchen, mit einzelnen kiirzeren Spikeln wie die der Haut. Die Haut, besonders die des Ruickens, mit Spikeln reichlichst ausgesteuert, welche meistens stark erhärtet, lang, stabfürmig, von einem Durchmesser bis etwa $0,02 \mathrm{~mm}$, gerade oder etwas gebogen, gegen die Enden meistens zugespitzt waren. Die eigrenthümlich eleganten Nöppchen des Rückens ${ }^{1}$ ) eine Höhe bis etwa 0,3 mm erreichend, unten etwas schmäler, kurz umgekehrt-kegelförmig, oben in mehrere (meistens 3-7) spitze Arme mehr oder weniger verbreitert, welche an illrem Grunde zwischen sich eine kleine Vertiefung fassen, von deren Mitte ein gelblicher Körper gewölbt hervorsteht (Fig. 22-24); dieser Körper, weleher auch dureh die Seiten der Nöppchen oben hindurchschimmert, schien aus kleinen zellenähnlichen Elementen gebildet (Fig. 22, 23). Die Nöppehen, mit Ausnahme eines 'T'heils der kleineren, durch senkrecht stehende und besonders in die Arme stark austretende Spikeln ${ }^{2}$ ) stark abgesteift (Fig. 22). In der interstitiellen Bindesubstanz kamen rerkalkte Zellen uberhaupt an den meisten Stellen selten und grössere fast gar nicht vor.

Die Mundröhre etwa so lang wie der Schlundkopf; um den Aussenmund Massen von Spikeln und ein Drüsenlager. - Der Schlundkopf von gewöhnlicher Form, etwa 1,5 mm lang bei einer ähnlichen Höhe und einer Breite bis $1,7 \mathrm{~mm}$; die ziemlich dicke Raspelschcide unten an der Hinterseite stark hervortretend. Die Lippenscheibe rund, mit $\perp$-Oeffinung; diese letztere von einem gelben, starken, in der Mittellinie oben und unten, wie es schien, unterbrochenen, kaum unten breiteren Ring (von ciner Breite bis $0,18 \mathrm{~mm}$ ) eingefasst, welcher aus etwa 12-15 Reihen von dicht zusammengedrängten, starken, bis etwa $0,05 \mathrm{~mm}$ hohen Stäbchen (Fig. 25) zusammengesetzt war, von denen die vordersten (Fig. 26) vorne etwas kopfartig angesehwollen waren. Die Zunge breit, mit tiefer Furclie, welche bis iber die oberen Ränder von der farblosen oder wenigstens nur sehr schwach gelblichen Raspel bekleidet war. In der Raspel lamen etwa 25-30 Zahnplattenreihen vor; weiter gegen hinten unter dem kurzen Raspeldache und in der Raspelscheide fanden sich noch 20-30 entwickelte und, wio es

1) Die eigenthümliche Form derselben ist nicht von ArDer und Haxcock (rergl. 1. c. pl. 7. Fig. 7) aufgefasst worden. $\Rightarrow$ Etrra so sind die Spikeln auch von Arder und Haxcock (1. c. pl. 7. Fig. S) gezeichnet. 
schien, 6 jüngere Reihen vor; die Gesammtzabl derselben somit etwa 51-66. ${ }^{1}$ ) Die Rhachis nicht schmal, eben, unbewaffnet. In den Reilien der Pleurae 60-65 Zahnplatten. ${ }^{2}$ ) Die (etwa S) innersten derselben (Fig. 27-29) mehr niedrig, der breite Körper oben in eine Spitze vortretend, der Haken klein; an den folgenden Platten (Fig. 29) entwickelt sich der Haken mehr, wïhrend der Körper im Verhïlniss zu der wachsenden Höhe der Platten kaum an Grösse zunimmt; durch eine Reihe von im Ganzen etwa 19-20 Platten (Fig. 30) entwickelt sich dann die dureh den Rest der Reihen bleibende Form der Platten. Diese zeigen unten den kleinen fast flügelförmigen Körper (Fig. 30), welcher oben in den schön gebogenen, gegen oben schmächtigeren Haken übergeht, der am Anfange scines letzten Drittels an ziusseren Rande einen langen, diunnen, mit dem Haken selbst parallelen, aber nicht gas an seine Spitze reichenden Dentikel träigt (Fig. 29-32); an den crsten Dentikel-tragenden Platten (Fig. 29 b) ist der Dentikel kiirzer, bewahrt aber an den iibrigen seine Grösse. Die inneren Zahmplatten sind am Körper horngelb, die ibrigen sehr schwach gelblich. Die Höhe der innersten betrug bis $0,04 \mathrm{~mm}$ und stieg dann allmählig bis etwa 0,3 (in gerader Linie vom Fusse der Platten bis an die Spitzo gemessen), um rom :iusseren etwa $1 / 4$ der Reihen ab wieder allmihlig (unter fortdauerndem Schwåchtigerwerden der Haken) bis etwa $0,08 \mathrm{~mm}$ zu sinken (Fig. 32). Die juingeren Zahuplatten waren sehr biegsam.

Die Speicheldrisen waren langgestreckt, etwa so lang wie der Schlundkopf, weisslich.

Die Speiseröhre etwa $1,5 \mathrm{~mm}$ lang, dinn, median oben an dem Vorderende der Leber dicht unter dem Darme eintretend. Die zienlich geriumige Höhle der Leber scheint als Magen zu fungiren; sie zeigt die gewöhnlichen weiten Gallenöffnungen. Der Darm dicht vor der Mitte der Länge der Leber fast median hervortretend, sein Knie unmittelbar vor dem Leberrande bildend, und längs des rechten Randes der Leber seiner ganzen Liinge nach verlaufend, dam zu der Analpapille limaufsteigend. Die Leber $3,8 \mathrm{~mm}$ lang; hinten gerundet; das Vorderende schräg gegen unten und hinten abgestutzt; von graubrauner Farbe, an Schnitten mit röthlich-gelbem Anfluge. Eine Gallenblase konnte nicht nachgerviesen werden.

Das Herz wie gewöhnlich. Die gewöhnliche kleine vordere und hintere weissliche, ovale BI utdrü se sehr stark abgeplattet. - Das Nierenlager mit sehr schönen Federn die obere Seite der Leber bedeckend; die Urinkammer ziemlich weit.

Die Zwitterdris e mit enem dicken weisslichen Lager die Leber nit Ausnahme des Vorderendes ganz einhuillend; in den Liippehen derselben Zoospermien und grosse oogene Zellen. - Die vordere Genitalmasse ziemlich gross, mehr als 1/3 der Grösse der hintersten Eingeweidemasse betragend, das ganze Vorderende der Leber bedeckend.

1) Arder und Haxcock geben eine ähnliche Anzahl von Peihen (65) an.

2) Alder und Harcock sahen 60 Platten in den Reihen. Ihre Abbildung (1. c. pl. 46 supplera. Fig. 6 ) ist zu schematisch. Semper, Philippinen. II. II. (Bergh, Ergänzuagsheft II). 
7) ie Ampulle des $Z$ witterdrisenganges stark, gelblich weiss, fast $1 \frac{1}{2}$. Spiralwindungen machend, ausgestreckt etwa $3 \mathrm{~mm}$ lang; an ihrem Vorderende schnirt sich die Ampulle fast plötzlich zusammen, und der hier entspringende mänuliche Zweig selivillt fast gleich in ein gestreckt-sclilauchförmiges, an der Aussenseite plattes, etwas gebogenes Organ (Prostata), welches innerhalb seiner Wand dichte schraubenartige Windungen (des Samenleiters) zeigt; die Luinge des Organs betrug etwa 2,5 bei cinem Durchmesser bis beiliufig $0,6 \mathrm{~mm}$. Das Organ, in dessen unterem Theile der prostatische Theil des Samenleiters mehr gestreckt verlief, setzt sich damn in den dïnneren, mehr festwandigen muskulïsen Samenleiter fort und dieser wieder in einen etwa ebenso langen dickeren und gregen unten allmïhlig dicker werdenden Theil (Penis), dessen Innenwand melarere starke Liingsalten und cinen zienlich dicken, gelblichen Cuticula-Ueberzug zeigte. Der Samenleiter und der Penis zusammen etwa so lang wie das obenerwåhnte Organ (Prostata); an dem untersuchten Individum keine Spur von einer Berraftnung des Penis. Die Spermatocyste weisslich, birnförmig, ron etwa $0,6 \mathrm{~mm}$ Länge; ihr Gang nur wenig linger als das Organ selbst. Die Spermatotheke war bedeutend grösser, kugelförmig. Dic Scluleimdrise weiss, die Eiweissdrü use dottergelb. ${ }^{1}$ )

\section{R. perspicillata, Bar. n. sp.}

Corpus supra ut infra e brunneo rubrum, podarium attamen interdun clarius, fere scarlatinum; dorsum ubique punctis et annulis nigrescentibus minutis obsitum, ante perspicillo interrlinophoriali albo ornatum; limbus dorsalis ut plurimum obseurior, interdum niger, semper minute albide punctatus; rhinophoria (flarescente-) albida, branchia e brunneo nigra vel e rubro brunnea.

Hab. M. mediterr. (ad 'Tergestem).

Taf. J. Fig. 1-15.

Von dieser durch ihre weisse Brille Ieicht erkennbaren Art erhielt ich durch die Giite des Directors Prof. Claus und des Inspectors Dr. GraefFe im Oct. 1879 und spaiter im Niirz 1880 unter anderen lebenden Nudibranchien je ein Individuum aus der zoologischen Station ron 'l'riest. Die Thiere, die in ihren Bewegungen sehr trigge waren, nahmen wïhend der 12-14 'Tage, die sie in der Gefangenschaft lebten, in gewöhnlicher Weise an Grösse allmählig ab, starben dann. Später habe ich (im Mai 1880) in der Station von Triest noch cin etwas grösseres Individuum lebend untersucht.

Ganz ausgestreckt $\mathrm{m}$ assen die zwei ersten untersuchten Indiriduen etwa $10 \mathrm{~mm}$ bei einer Breite bis 4,5 und einer Höhe bis fast $1,75 \mathrm{~mm}$, die Höhe der Rhinophorien ständig correct.

1) Die ron Haxcock und Exbletos (1. c. pl. XV. Fig. 3) gegebene Darstellung des Generationssystems ist also voll- 
und der Kieme kaum $1 \mathrm{~mm}$; wenn kricchend, uberragt der Schwanz des Thieres den Tücken um einen vollen mm. Die Länge des grössten Individuums betrug 13 bei einer Breite bis $6 \mathrm{~mm}$. - Die Farbe des (lebenden) Thieres lebhaft braunroth oder mehr ziegelroth: die Unterseite des Körpers, besonders die Fusssohle meistens etwas heller, mitunter scharlachroth. Der Rücken überall mit ziemlich zahlreichen zerstreuten scliwarzen und schwarzgrauen Pünktchen und Ringelchen; dic Randparthie des Rückens meistens dunkler, mitunter fast schwärzlich, mit weissen Pünktehen mehr (besonders hinten) oder weniger dicht bedeckt; an einem Individuum fanden sich ähnliche Punkte über den ganzen Rücken sparsam zerstreut. Die Umgegend der Rhinophor-Oeffinungen (punktirt) weiss, und die weissen Flecken durch ein (nach vorne) gebogenes oder winkeliges Band ahnlicher Art verbunden, wodurch das Aussehen einer abstechend-weissen Brille hervorgebracht wird. Die Rhinophorien (schwach gelblich-) weiss. Die Kieme rothbraun; wenn zurüickgezogen, fast schwarzbraun.

Am Ruicken schimmerten die Eingeweide vor der Kieme als eine dunklere Gegend lindurch.

Die Form etwas niedergedriekt, vorne ein wenig breiter als hinten; das Mantelgebräme nicht schmal. Die Consistenz des Thieres nicht weich. Wenn kriechend, trug das Thier die kurzstieligen, kurzen, eylindrischen, oben abgestutzten und mit einer ron der oberen Fläche emporragenden kleinen Spitze versehenen Rhinophorien aufrecht; die Zahl der Blätter der Keule, wie es schien, etwa 20. Die Kiemenöffnung klein, rund oder kurz queroval; die Kieme, wenn ausgestreckt, ein wenig niedriger als die Ihinophorien, aus, wie es schien, 12 einfach-gefiederten Blättern gebildet; die Analpapille niedrig; abgestutzt-kegelförmig. Die Körperseiten ganz niedrig; die Genitalöfnnung stark zusammengezogen. Der Aussenmund eine senkrechte Spalte; die Tentakel kurz-fingerförmig, etrvas abgeplattet. Der Fuss vorne abgestutzt-gerundet, mit Randfurche; an den Kö̈persciten etwas rortretend; das Hinterende (Schwanz) etwas zugespitzt, auch bei dem kriechenden 'Ihicre kaum den Riucken iiberragend.

Die Länge der in Alcohol bewahrten Individuen etwa $6,5-7 \mathrm{~mm}$ bei einer Breite bis 3,5-4 und einer Hühe bis $2-2,25 \mathrm{~mm}$, die Breite des Fusses bis 1,8-2 $\mathrm{mm}$, die Weite der Rhinophorhöhlen 0,5, die der Kiemenöftnung $0,6 \mathrm{~mm}$, die Ilöhe der (zuriekgezogenen) Rhinophorien etwa 0,8-1, die der Kieme etwa 0,6 mm. - Die F a r be dieser Individuen am Rücken hell graulich mit schwarzen Bodenflecken und Punkten, iiberall mit helleren Nöppehen dicht bedeckt; zwischen den Lhinophorien noch Andeutung eines hellen Querbandes; die glatte Unterseite des Nantelgebrimes ganz hell graulich; dic Rhinophorien gelblich, mit rotbbraunen Punkten an den oberen Theile zerstreut; die Kieme schwärzlich; der Fuss weissgelblich.

Bei einem so sparsamen Materiale von noch dazu einem so kleinen. Thiere liess sich eine durchgehende anatomische Untersuchung nicht liefern. - Das Peritonaeum punktirt schwärzlich grau, besonders aber das Pericardium. 
Das Centralnervensystem (Fig. 1) abgeplattet; die (Fig. 1 a b) cerebro-visceralen Ganglien fast nierenförmig, die Grenze zwischen den zwei fast gleich grossen Abtheilungen deutlich zeigend; die rundlichen Pedal-Ganglien (Fig. 1 cc) ein wenig grösser als die visceralen. Die gemeinschaftliche Commissur (Fig. 1 b) ziemlich eng. Die zwiebelförmigen proximalen Riechknoten (Fig. 1) ziemlich gross, die distalen viel kleiner, rundlich. Die buecalen Ganglien (Fig. 1 d) rundlich, durch eine ganz kurze Commissur verbunden; die gastro-oesophagalen kurzsticlig, riel kleiner als die vorigen ( $\mathrm{Fig}$. 1d).

Die A ugen (Fig. 1) nur ganz kurzstielig, gross, nicht viel kleiner als die nebenstehenden Riechknoten, mit grosser gelblicher Linse, schwarzem Pigmente. Die (Fig. 1) Ohrblasen nicht halb so gross wie die Augen, von (60-100) rundlichen und ovalen Otokonien gewöhnlicher Art (und ron einer Länge bis etwa $0,013 \mathrm{~mm}$ ) strotzend. Die Blätter der Rhinophorien mit (wenigstens bis $0,25 \mathrm{~mm}$ ) langen, duinnen (von einem Durchmesser bis etwa $0,007 \mathrm{~mm}$ ), stark erhärteten, spindelförmigen Spikeln sehr stark ausgestenert; in der Axe und bis in die Endpapille der Rhinophorien noch viel reichlichere Spikel, meistens quer und schräg gelagert. Die 'Tentakel mit ähnlichen Spikeln versehen. Die II a ut iberall, auch an den Körperseiten wie am Fusse, mit Massen von Spikeln versehen, den oben crwälnten ganz ihnlich, kaum viel linger oder dicker. Die niedrige Scheide der Rhinophorien sowie die Randparthie der Kiemenöffnung unten mit . in die Quere gehenden Spikelziigen, oben mit gegen den Rand senkrecht aufsteigenden Spikeln und Spikelhaufen. Die dichtstehenden Nüppehen des Rüickens (Fig. 2) von einer Höhe bis etwa 0,2 (selten 0,25$) \mathrm{mm}$; meistens fast bechérförmig mit mehr oder weniger gespreiztem Oberende; durch Spikel gewöhnlicher Art, besonders in der Peripherie, stark ausgesteuert, welche oben mehr oder weniger stark hervortraten. - In der interstitiellen Bindesubstanz hier und da zerstrente Spikel, in der die Hauptausführungsgänge des Genitalapparats einhiillenden aber Massen von solchen stark erhärteten und grossen (von einer Linge bis etwa $0,45 \mathrm{~mm}$ ).

Die zuriekgezogene Mundröhxe ron etrva $1 \mathrm{~mm}$ Länge; die Retractoren wie gewöhnlich, so auch die Innenseite; in der Wand eine Menge von grossen, in der verschiedensten Weise gelagerten Spikeln. - Der Schlundkopf ein wenig kiurzer als die Mundröhre, höher als lang, die Retractoren wie gewöhnlich; die Raspelseheide hinten und unten ziemlich stark vorspringend. Die runde Lippenseheibe, die sonst von einer einfachen Cuticula iberzogen ist, zeigt am Eingange in die Mundspalte einen bis etwa 0,12 $\mathrm{mm}$ breiten, hell graugelblichen Gürtel als einen oben und unten schmäleren, aber, wie es schien, continuirlichen Greifring, aus cinander (Fig. 3) dachziegelartig deckenden, nach vorne allmählig grösseren Stäbchen gebildet, welche an der breitesten Stelle in Anzahl etwa 20 von innen nach aussen betrugen; die vordersten erreichten eine Länge bis etwa $0,05 \mathrm{~mm}$ und waren am Ende ein wenig kopfartig angesehwollen (1 ig. 4). - Die 'Zunge von gewöhnlicher Form, mit tiefer İluft des Rückens; in der fast farblosen Raspel, wie es schien, 30-34 Zahnplattenreihen, weiter nach hinten kamen deren noch etwa 
21-23 vor, von denen die 3-4 hintersten noch nicht ganz entwickelt; die Gesammtzahl somit etwa 51-57. Die (Fig. 11 a) Rhachis nicht ganz schmal, nackt. Die Zahnplatten fast farblos; die innerste eine Höhe bis etwa $0,016 \mathrm{~mm}$ erreichend, die Höhe der. Platten bis etwa $0,08 \mathrm{~mm}$ steigend, um nach aussen wieder und bis zu etwa $0,04 \mathrm{~mm}$ abzunehmen. In den Reihen schienen bis etwa 50-70 Platten vorzukommen. Die (Fig. 6-8) innersten 15-20 von den ibrigen in Form abweichend, breit, wesentlich von derselben Grundform wie in der vorigen Art, der Körper oben in eine kurze Spitze rortretend, der Haken gebogen; die innerste Platte noch am Haken mit 4-6 feinen und spitzen Dentikeln versehen (Fig. 5, 11). Durch jene, besonders aber an den folgenden Platten entrickelt sich allmählig der Haken stärker, während der Zahn des Körpers allmählig verkiimmert (Fig. 7). Die grüsste Anzahl der Platten dam fast ganz von derselben Form wie in der vorigen Art, mit kleinem flïgelförmigem Körper und langem spitzem, etwa in iussersten Drittel grekliftetem Haken (Fig. 9,13). Die ïussersten Platten, wio erwähnt, niedriger und schlanker als die anderen (Fig. 10, 14).

Die Speicheldrisen langgestreckt, dün, weiss.

Die Speiseröhre ziemlich lang und weit, mit den gewöhnlichen Liingsfalten. Dor Magen und der Darm ganz wie in der vorigen Art. In der Verdaunngshöhle pflanzliche Masse. Die Leber auch ganz wie in der typischen Form, nur an der OberHäiche (wegen der Zwitterdrüse) weisslich, an Schnitten gelblich.

Das Herz wie gewöhlich. Das Nierenlager wie in der vorigen Art, die Urinkammer ziemlich weit, die Nierenspritze wie gewöhnlich.

Die Zwitterdrüse weisslich, den grössten 'Theil der Leber überziehend; in den Läppchen derselben grosse oogene Zellen sowie Zoospermien. - Die vordere Genitalmasse gross, von Form wie in der vorigen Art. Die Ampulle des Zwitterdrisenganges graulich, sonst wie oben. Auch die Prostata schien sich wie in der R. coccinea zu verhalten; der prostatische Theil (Fig. 15a) des (im Ganzen nicht langen) Samen leiters kiirzer als der muskulöse, welcher (Fig. 15 b) allmählig in den etwas dickeren, stark muskulösen (Fig. 15c) Pen is iiberging, am Boden der kurzen Höhle desselben die wenig vortretende, abgestutzte, unberaffnete Glans. Die Spermatotheke (Hig. 15d) gross, kugelförmig; der vaginale Gang nicht (Fig. 15e) viel länger als der uterine (Fig. 15h), der untreit ron seinem Ursprunge die kleine, schlauchförmige kurzstielige Spermatocyste (Fig. 15i) trug; die Vagina (Fig. 15f) kräftig, von einer starken gelblichen Cuticula ausgefütert. Die Schleimdrïse weisslich, die Eiweissdrüse dottergelb; im Vestibulum genitale (Fig. $15 \mathrm{~g}$ ) starke Lïngsfalten.

Diese neue Form unterscheidet sich hauptsächlich in der Farbenzeichnung, durch die Brille, von der typischen Art, scheint aber auch in mehreren Punkten des inneren Baues zu differiren. 
DISCODORIS, BGH.

Vgl. Heft XII. 1877. p. 518, 568. - Supplementheft 1. 1SS0. p. 47.

Die an den angegebenen Stellen gelieferte Liste von 12 (13) Arten wird hier um eine neue Form aus dem Mittelmeere vermehrt.

\section{Disc. indecora, $B_{G H}$. $n$. sp.}

Corpus supra oleaginee brunneum prominentiis minutis albidis ubique sparsis; margo pallialis albescens, punctis oleaginee brunneis; caput et podarium flavescentia, punctis oleaginee brunneis.

Hab. M. Adriaticum (ad Tergestem).

Taf. J. Fig. 26-33; Taf. K. Fig. 11-19.

Unter lebenden Nudibranchien, welche ich Mitte März 1880 durch Dr. Graeffe aus der Station von Triest bekam, fand sich ein sterbend hier (in Kopenhagen) anlangendes Individuum dieser Art.

Das (bei der Ankunft unmittelbar untersuchte) weich anzufühlende, aber doch in der Beschaffenheit etwas steife Individuum hatte eine $L$ äng e ron 21 bei einer Körperbreite bis 11 und einer Höhe bis $6 \mathrm{~mm}$; die Höhe der (vorgestreckten) Rhinophorien betrug 2,3, die der 'Tentakel etwa 1, die der (ausgestreckten) Kricme fast $3 \mathrm{~mm}$; die Breite des Mantelgebrämes bis $3,3 \mathrm{~mm}$; die Länge des Fusses $16 \mathrm{~mm}$ bei einer Breite (etwa an der Mitte) bis $5,5 \mathrm{~mm}$. - Die Farbe der oberen Seite ziemlich hell punktirt-olivengriubraun mit sehr zahlreich zerstreuten kleinen und grösseren (Diam. bis fast $1 \mathrm{~mm}$ ), weisslichen, nur wenig erhabenen, rundlichen Fleckchen; der Stiel der Rhinophorien weisslich, die Rỉnder der Blätter aber von der gewöhnlichen Rückenfarbe; die Kieme mit weisslichen Rhachis-Parthien, das Laub wie die Grundfarbe des Riickens aber dunkler, mit weissen Blätterspitzen. Die Unterseite des Mantelgebrämes mit sammt dem flachen Rande desselben weisslich mit unregelmässig zerstreuten rundlichen oder ovalen, grünbraunen, feinsten Fleckchen. Jer Kopf mit den 'Tentakeln, die obere und besonders die Unterseite des Fusses gelblich mit zahlreichen, den letzt erwähnten ähnlichen Pünltchen 
und Fleckchen. An der hinteren Hälfte der Fusssohle schimmerte die hintere Eingeweidemasse graulich hindurch.

Das in Alcohol getödtete und bewahrte Individuum zeigte (13 Monate später) die Farbenverhältnisse wenig geändert, nur blässer. Die Länge betrug volle $18 \mathrm{~mm}$ bei einer Breite bis 10 und einer Höhe bis $7 \mathrm{~mm}$; die Breite des Mantelgebrämes bis 3,25; die Länge des Fusses 15 bei einer Breite bis fast $6 \mathrm{~mm}$; die Höhe der Rhinophorien 2,5, die Lïnge der 'Tentakel 1,25 und die Höhe der Kieme $4 \mathrm{~mm}$.

Die Kürperform lïnglich-oval, nicht sehr niedergedrückt. Der Rücken an seiner schmäleren Mittelparthie fast ganz glatt; an den Seitenparthien mit weisslichen, harten kleinen knötchenartigen Erhabenheiten (von einem Durchmesser bis etwa 0,6 mm) ziemlich reichlich bedeckt, zwischen diesen kamen noch kleinere und kleinste vor; der Riuckenrand nicht scharf, wie abgestutzt; die Unterseite des nicht schmalen Mantelgebrimes glatt. Der Rand der runden $R$ hinophor-Oeffnungen wenig vortretend, ganz fein rundzackig. Die Rhinophorien ziemlich schlank; der (auch fein farbig punlitirte) Sticl fast so hoch wie die Keule, die etwa 15 (-20). Blätter und eine starke Endpapille zeigte. Der Rand der quer-ovalen, bei vorgestreckter Kieme fast $2,5 \mathrm{~mm}$ breiten Kiemenöffnung wenig vortretend, glatt. Die Kieme aus 6 hohen, schlanken, fast gleichgrossen tripimnaten Blättern gebildet, von denen die zwei lateralen noch einen starken hinteren Ast zeigten. Vor und zwischen den hinteren Kiemenblättern die kaum $1 \mathrm{~mm}$ hohe cylindrische, abgestutzte, am Rande fein rundzackige Analpapille; dicht vor derselben und rechts die feine Nierenpore. Die Körperseiten ganz niedrig. Die Genitalpapille stark zusammengezogen. Dor Kopf klein mit senkrechtem Mundschlitze; zu jeder Seite desselben der kegelförmige, längs der Unterseite mit einer submedianen Furche (Fig. 26) versehene 'Tentakel. Der Fuss kriftig; der Vorderrand an den Ecken gerundet, mit starker Randfurche; die breitere Oberlippe in der Mitte geklüftet; die Ründer an den Körperseiten ziemlich stark vortretend; der Schwanz (fast $2 \mathrm{~mm}$ lang) gerundet-zugespitzt.

Das Peritonacum zeigte sich fast farblos.

Das Centralnervensystem (Fig. 11) sehr stark abgeplattet. Die cerebrovisceralen Ganglien (Fig. $11 \mathrm{a}$ ) nierenförmig, die cerebrale Abtheilung kaum kleiner als die viscerale; die rundlichen Fussknoten (Fig. $11 \mathrm{bb}$ ) kaum grösser als die visceralen Ganglien. Die gemeinschaftliche Commissur (Fig. 11 c) sehr kurz, selır eng die Speiseröhre und die Speicheldrüisen(-Güinge) umfassend. Die proximalen Ganglia olfactoria (Fig. 11 d) ganz kurzstielig, zwiebelförmig; die distalen eine längliche Anschwellung am Grunde der Keule der Rhinophorien. Die buccalen Ganglien (Fig. 11 e e) mehr als doppelt so gross wie die grossen Riechknoten, rundlich-dreieckig, fast unmittelbar mit einander verbunden; die gastro-oesophagalen (Fig. $11 \mathrm{ff}$ ) ganz kurzstielig, etwa 1/5 der Grösse der vorigen betragend.

Die A u gen (Fig. 11) ganz kurzstielig; mit schwarzem Pigmente, gelber Linse. Die Ohrblasen (Fig. 11) etwas kleiner, mit einer grossen Anzahl (wenigstens 200) von 
Otokonien gowöhnlicher Art prall gefüllt. Die diinnen Blïtter (Fig. 27) der Keule der Rhinophorien durch sehr stark erhärtete, lange, spindelförmige Spikel in gewöhnlicher Weise steif gemacht; die Spikel hatten aber hier so wie im Ganzen durch die Rhinophorien die Weichtheile fast verdriingt. Die Spikel erreichten hier eine Länge von wenigstens 0,3 bei einem Durchmesser bis wenigstens $0,026 \mathrm{~mm}$; im Stiele waren sie meistens in die Quere und im Kreise gelagert. Auch die Tentakel waren im höchsten Grade und fast bis kurz vor der Spitze mit, wie es schien, ganz unregelmässig liegenden, ähnlichen Spikeln versehen. ${ }^{1}$ ) Die Haut und besonders die des Rückens auch mit den obigen ähnlichen Spikeln reichlichst versehen, welche aber zum Theile etwas duimner und (Fig. 28) im Ganzen auch etwas kleiner waren; die knotenartigen harten Erhabenheiten des Riickens mit Spikeln überfüllt. - In der interstitiellen Bindesubstanz kamen Spikeln nur sehr sparsam vor; nur um die Ausfuihrungsgänge des Genitalapparats fanden sich deren viele und ziemlich grosse.

Dic II undröhre birnförmig, etwa $4 \mathrm{~mm}$ lang, bei einem Durehmesser von $3,5 \mathrm{~mm}$; die starken Retractoren wie gewöhnlich; die Innenseite ganz wie gewöhnlich. - Der (mit der Lippenscheibe tief in die Mundröhre eingetretene) Schlundkopf etwa $5 \mathrm{~mm}$ lang bei einer IHöhe bis 4 und einer Breite auch bis $4 \mathrm{~mm}$; die Raspelscheide (hinten noch etwas schräg gegeu oben gekrimmt) fast $3 \mathrm{~mm}$ vortretend. Die abgestutztkegelförmige Lippenscheibe $2 \mathrm{~mm}$ hervortretend, mit dreicekiger Mundspalte (nit der Spitze nach oben), deren Ränder (mit Ausnahme in der Mittellinie unten) hart und schwärzlich waren; die starken Retractoren wie gewöhnlich. Die Lippenscheibe von einer ziemlich starken gelblichen Cuticula überzogen, die an und in der Mundöffinung (Fig. 29) ron cinem härteren, schmutzig dunkelgelben Ueberzuge rertreten ist, das an der oberen Seite sich weiter nach hinten erstreckt und in der Mittellinie längs der oberen Seite der Lippenscheibe dunkel hindurchschimmert; das Vorderende dieser Lippen-Bewaff$\mathrm{n} u n \mathrm{~g}$ (Fig. 12) ist in einer Breite von etwa $0,2-0,8 \mathrm{~mm}$ härter, dicker und schwarzbraun; dasselbe ist mit den langen oberen Riindern dieser Bewaffnung der Fall. In der Mittellinie erreicht die Bewaflumng der einen Seite nicht die der anderen, sondern beide sind durch einen ganz schmalen Zwischenraum geschieden; noch dazu ist die Bewaffnung jeder Seite durch 1-2 schmale Furchen, die mit dunkelgelber Cuticula bekleidet sind, in 2-3 Stiicke zerfallen. Die Bervaffnung ist aus dichtstehenden Stïbehen zusammengesetzt, die an den Seiten wenigstens 50-60 unregelmässige Reihen bildend, sich von einer ganz winzigen Grösse ab nach vorne allmählig. (Fig. 14, 15) zu einer Höhe von beilïufig $0,13 \mathrm{~mm}$ erheben. Die Stäbehen von schmutzig gelblicher Farbe, ziemlieh schlank, mit einer kleinen, spitz zulaufenden kopfartigen Anschwellung oben (Fig. 15). - Die Zunge von gewöhnlicher breiter Form; an ihrer Spitze Spuren von zwei ausgefallenen Zahmplattenreihen. Die Raspel ziemlich schmal, gelblich, am Rande schwärz-

1) Ein starker N. tentacularis konnte durch den Fühler hinaus verfolgt werden. 
lich braun, mit 15 Zahnplattenreihen; weiter nach hinten fanden sich noch 29 entwickelte und wenigstens 4 noch nicht ganz entwickelte Reihen; die Gesammtzahl derselben betrug somit 48. In der funfzehnten Reihe der Zunge 19 Zahnplatten, die Anzahl weiter nach hinten kaum mit melı als 1 steigend. Die (Fig. 30a) Rhachis schmal, vorne an der Raspel mit Querfurchen. Die Zahnplatten sehn schwach gelblich; die Höhe der innersten etwa $0,105 \mathrm{~mm}$, sich durch die Zahnplattenreiho bis zu beiliufig $0,25 \mathrm{~mm}$ crhebend, um nach aussen allmilhlig und durch die drei änssersten wieder bis zu 0,08 -0,06-0,04 mm zu sinken. Die Zahmplatten vou der gewöhulichen Form, aber plump (Fig. 31, 16, 17); der Fliigel (Fig. 30) wie gewöhnlich, die Unterseite des Körpers etwas ausgehöhlt, das Hinterende desselben gekliiftet (Fig. 17). Die iusserste Platte (Fig. 32 a) kürzer.

Die Speicheldriis en langesestreckt, wenigstens 1,5 Cm. lang; woiss, duinn; etwa im vorderen Sechstel ihrer Lünge fast doppelt so dick (von etwa $0,5 \mathrm{~mm}$ Dicke) wie in der íbrigen Strecke; die Ausführungsgininge ganz kurz.

Die Speiseröhro (Fig. 19 a) etwa $4 \mathrm{~mm}$ lang, ziemlich eng, sich in einen umregelmaissig-querovalen, in Breite etwa $3 \mathrm{~mm}$ messenden, in der Leberkluft liegenden (Fig, 19 b) Magen öfhend, weleher hinten durch eine runde Oeffumg (Fig. 19f) in die Leberliöhle, links in den Darm übergeht; die Imnenseite des Magens mit starken querlaufenden Filtehen. Der $\mathrm{D} a \mathrm{r}^{\circ} \mathrm{m}$ ist in seiner ersten vorwärtsgehenden (etwa $4 \mathrm{~mm}$ langen und bis 2,5 mm weiten) Strecke vicl weiter (Fig. 19c), in der ubrigen (etwa $14 \mathrm{~mm}$ langen) viel enger; die Innenseite mit zahlreichen Lïngsfittehen. - Der Inhalt der Verdaumgshöhle ganz unbestimmbare thicrische Masse.

Die lintere Eingeweidemasse (Leber) kegelfürmig, etwa $9 \mathrm{~mm}$ lang bei einer Breite vorne ron 5,5 und einer. Höhe bis $5 \mathrm{~mm}$; das Vorderende abgestutzt, wegen des Magens und des I'ylorus-Theils des Darmes ausgehöhlit, unten durch die rordere Genitalmasse facettirt; die Farbe der Lebermasse braungrau; die Höhle weit, mit weiten Oeffinungen. Die Gallenblase etwa $3 \mathrm{~mm}$ hoch, gestreckt birnfömig, gelblich; längs der Wurzel des Darmes bis an die Oberfliche der Leber fast senkrecht emporsteigend; sich ganz vome in dic Leborhöhle, neben dem Gallengange iffinend (Fig. 19*).

Das Pericardium selnr gross, mit zerstrenten feinen ovalen Oeffinungen durch die Wand (welche keine Spikeln zeigt). Das Herz gross, die Kammer etwa 2,5 mm lang. Die Blutdriisen stark abgeplattet, weisslich; die vordere abgestutzt-ciförmig, vome breiter, etwa 2,5 mm lang; die hintere etwa von derselben Linge, aber bis volle $6 \mathrm{~mm}$ breit. - Dic Niere sehr stark, den grössten Theil der hinteren Eingerveidemasse ïberziehend, von starken (bis etwa $0,5 \mathrm{~mm}$ in Diam. Laltenden) weisslichen, meistens querlaufenden, oft Feder- oder Netzbildenden Rülıren durchzogen; die Urinkammer sehr krifftig, etwa $0,6 \mathrm{~mm}$ in Durchmesser haltend, von der Nicrenspritze $11 u$ bis an die Mitte der Leberlänge reichend. Die Nicrenspritzo birnfömig, etwa 2 mm lang; ihr Hals kurz, mit den gewöhnlichen Vegretationen der Innenseite. Der Urinleiter kurz. Semper, Philippinen. II, II (Bergh, Ergänzangsheft' II). 
In den rundlichen Läppchen der $\mathrm{Zwitterdrüse} \mathrm{kaum} \mathrm{reife} \mathrm{Geschlechts-}$ elemente. - Die vordere Genitalmasse von gestreckt-eiförmigem Umrisse, querliegend, concav-convex, von vorne nach hinten ziemlich zusammengedrickt; etwa $5 \mathrm{~mm}$ brest bei einer Höhe von etwa $2,3 \mathrm{~mm}$ und einer Dicke (von vorne nach hinten) von beiliufig $1,5 \mathrm{~mm}$. Der diunne, weisse, oberhalb des Magens etwas rechts ans der Zwitterdrise hervortretende $\mathrm{Z}$ witterdrusengang plötzlich in die schlanke, wurstförmige, S-förmig gebogene, opak graugelbe $\mathrm{m}$ p ulle anschwellend, dic sich an der Hinterseite der vorderen Genitalmasse dem unteren Rande nahe schlïngelte. Der aus jener vortretende kurze männliche $\Lambda$ st in eine Prostata schwellend, die in der ersten gestreckten Strecke weisslich und diuner war, dam mehr gelblich und dicker wurde, knieförmig unbog, sich noch cine lsurze Strecke fortsetzte und in den Samenleiter iiberging; dic erste Strecke der Prostata etwa $4 \mathrm{~mm}$ lang bei einem Durchmesser bis $1 \mathrm{~mm}$, dic folgende beilaiufig 2,5 mm lang. Die erste prostatische Strecke des Samenleiters gelblich, etwa $1 \mathrm{~mm}$ lang; die folgende beiläufig $3 \mathrm{~mm}$ lang, weisslich und düuner. Der Penis kurz, unbervafuet. Die Spermatotheke weisslich, kugelförmig, von etwa $1 \mathrm{~mm}$ Durehmesser; der raginale Gang etwa $2 \mathrm{~mm}$ lang, diinn, dio Vagina kurz; der uterine Gang etwas kiijzer als der raginale; die Spermatoeyste birnförnig; ron etwa - $0,5 \mathrm{~mm}$ Läinge, ilır Gang fast halb so lang wie jene. Die Samenblasen olne entrvickclten Samen. Die Schleimdriise weisslich, die Eiweissdruise mehr gelblich. Neben dem Penis schien sich eine hübsche, etwas lappige Drüse in das Vestibulum zu öffnen. ${ }^{1}$ )

Ob diese Form nun wirklich den Discodoriden gehört, muss vorläufig dahingestellt bleiben. Die wenig weiche Beschaffenheit des Körpers, der Granulationszustand des Rückens, die Beschaffenheit der 'I'entakel u. M. könnten wohl in dieser Beziehung Zweifel entstehen lassen.

1) Das ungenügende Material erlaubte keine genauere Bestimmung der Verhältnisse der Ausführungsgänge der rorderen Genitalmasse. 


\section{JORUNNA，BGII.}

Vergl. R. BErgir, malacolog. Unters. Heft X. 1876. p. 414, Note.

R. Bergi, Gatt. nörd. Doriden. Arch. f. Naturg. XXXV, 1. 1S79. p. 346.

R. Berarr, on the nudibr. gasteropod Moll. of the North pacific ocean. II. 1SS0. (Dari, scientific res. of the explorat. of Alaska. I. art. VI) p. 195-201.

Corpus molle, subdepressum; dorsum minutissime granulatum, subasperum; branchia e foliis tripinnatis formata; tentacula digitiformia; podarium sat latum, margine anteriore sulcatum, labio superiore latiore et medio fisso.

Armatura labialis nulla. Radula rhachide nuda, pleuris multidentatis, dentibus hamatis. - Penis inermis; glandula et hasta amatoria.

Urspriinglich wurde diese Gattung ${ }^{1}$ ) ron mir (1876) für die Doris Jolnstoni nur nach den ron HANCock und EMBLETOx gegebenen anatomischen Characteren aufgestellt. Die vom Verfasser spiiter (1880) unternommene Untersuchung der typischen Form zeigte die nahe Verwandtschaft derselben mit den friiher (1876) von mir aufgestellten Kentrodoriden. ${ }^{2}$ ) Diese letzteren werden doch, wenigstens bis auf emenerte Untersuchung, nufrecht zu halten scin; sie sind ron etwas anderem Ilabitus, sehr weich, die obere Lippe des Vorderrandes des Fusses in eigenthiimlicher WVeise entwickelt, und die innerste Platte der Zungenbewaffinung ron den anderen Platten in eigenthimlicher Art verschieden; ein Liebessporn ist bei ihnen nicht nachgewiesen worden, wohl aber cine mit ciner besonderen Drise in Verbindung stehende Papille.

Die Jor'unnen sind zienlich niedergedrickt; der Riicken durch gleichgrosse feinste Papillen ganz fein granulirt; dié Tentakel sind fingerförmig; die (zurickziehbare) Kieme aus tripinnaten Blikttern gebildet; der Vorderrand des breiten Fusses ist tief gefurcht, die breite Oberlippe in der Mittellinie gekliffet. - Die Lippenseheibe ist ron einer einfachen Cuticula iiberzogen. Die Rhachis der Zungenberaffnung nackt, die Pleurne mit zahlreichen hakenfürmigen Zahnplatten. Im Vestibulum genitale finden sich vier Oeffnungen, eine für den nicht bervaffneten Penis, eine andere für den mit einer besonderen

1) Jorunna, Björnis filia. Laxtäla Saga. Hafuiae. 1S26. p. 21.

2) Vergl. Heft X. 1S76. p. 413-427. Taf. XLIX-LI. 
Drise in Verbindung stehenden Liebessporn, ${ }^{1}$ ) eine dritte für die Vagina und eine vierte für den Schleimdriisengang.

Der Laich der typischen Art ist duxch Alder und Hancock bekannt, über die biologischen Verhältnisse dieser 'Thiere sonst Nichts.

Die Gruppe umfasst bisher nur die

1. Jor. Johnstoni (ALD. et HANC.).

M. atlant., M. mediterr.

Var. Jor. alba, BGII.

M. mediterr.

2. Jor. atypha, BGI. n. sp.

II. mediterr.

1. J. Jolunstoui (Alder et $\mathrm{H}_{\Delta x c}$ ).

Doris Johnstoni, Alden and Hanc. Monogr. part I. 1845. fam. 1. pl. 5; part V. 1851. fam. 1. pl. 2. Fig. 8-11.

HAnc. and Embleton. Anatomy of Doris. Philos. Tr. 1852, II.

p. 212, 215, 216, 220, 233; pl. XII. Fig. 2, 10; pl.

XIV. Fig. 9, 10; pl. XV. Fig. 1, 2; pl. XVII. Fig. 2, 3. Fonb. and HANley. Hist. of br. Moll. III. 1853. p. 564.

Jorunna Johnstoni (A. et H.). R. Bergi, 1. c. II. 1850. p. 196-201; pl. VIII.

Fig. 19; pl. IX. Fig. 1-11.

Corpus cinerascente-albidum rel flavescens, dorso interdum maculis fuscis seriatis ornatum; branchia albescens, rhinophoria albescentia interdum fusco maculata.

Ha b. M. atlant., mediterr.

Taf. K. Fig. 20-2S.

$\mathrm{Ob}$ die unten untersuchte Form nun wirklich die Doris Johnstoni des atlantischen Meeres ist, muss bei der ungenïgenden Kenntniss der letzteren, besonders der anatomischen Verhältnisse derselben, vorliufig dahingestellt bleiben. Die Angaben von ALder und HANCOCK in Beziehung auf die Rhinophorien und die Kieme könnten wohl eine Verschiedenlıeit angeben; ebenso eine Angabe von Hancock und Enbleton (1. c. p. 220) in Beziehung auf den Liebesstachel.

Die Doris tomentosa von Cuvier ist jetzt eine apocryphe Art, die von Fischer ${ }^{2}$ )

1) Eine ähnliche Bildung findet sich bei üen Asteronoten. Vergl. Supplementheft I. 1S50. p. 67.

2) Fischer, note sur quelques espèces du genre Doris décrites par Curier. Journ. de conchyliol. 3 S. X. 1S70. p. 292; XV. 1875. p. 211, Note. 
fraglich mit der Doris coccinea von Fonises und der Doris rubra von D'OrBIGNy identificirt wird. Die Doris tomentosa von PHILIPp I ${ }^{1}$ ) ist von jener wahrseheinlich ganz rerschieden, sowie auch von der Joris tomentosa von VErANY ${ }^{2}$ ), die wahrscheinlich auch nicht mit der unten beschriebenen Form zusammenfällt.

Von dieser Form habe ich cin cinziges Individuum, von Dr. E. Graffere in 1879 in der Nihe von 'Triest gefischt, untersuchen können; dasselbe war von einer colorirten Zeichumng (olune Notizen) begleitet.

Die Linge des lebenden Thieres hat, der Zeichumg GratrFe's zufolge, etwa $8,5 \mathrm{Cm}$. bei einer Breite bis $4,7 \mathrm{Cm}$. betragen; die Höhe der Rhinophorien wenigstens $6 \mathrm{~mm}$, die der Kiemenblätter wenigstens $1 \mathrm{Cm}$. Die F a r b e ist graulich-oder gelblichgrau-weiss gewesen. Die Frorm niedergedrückt, lïnglich-oval, hinten breiter als vorne; das Mantelgebräme breit, unregelmiissig buelıtig und selbst wie etwas zerrissen aussehend; die Kieme, der Zeichnung GrafFre's nach, aus 12 Blaittern gebildet; das zugespitzte Fussende hinten das Mantelgebräme ein wenig iberragend.

Das in Alcohol bewahrté, stark zusammengezogene und zusammengebogene Indiriduum hatte cine Länge von 3,5 bei einer Breite bis 2,7 und einer Höhe bis 1,1 Cm.; die Breite des Mantelgebrämes bis $10 \mathrm{~mm}$; die Lïnge des Fusses 2 Cm. bei einer Breite bis $9 \mathrm{~mm}$; die Länge der 'T'entakel 2, die Hühe der (zuríckgezogenen) Rhinophorien $3,5 \mathrm{~mm}$, die Weite der zusammengezogenen Kiemenöffnung kaum $1 \mathrm{~mm}$, die Höhe der Kiemenblaitter bis $6 \mathrm{~mm}$. - Dic Farbe war durchgehends schnutzig hell gelblich, die Rhinophorien und die Kiemenblïtter kaum dunkler.

Die Form stark niedergedrickt, oval. Der weiche Kiörper zeigte den Riicken durch feinste, dichtstehende Zöttehen sammtartig. Die, wenn zusammengezogen, fast dreieckigen und glattrandigen Rhinophor-Oefinumgen ohne vortretende Ränder; die Rhinophorien kurzstielig, ihre Kienle mit etwa 40 breiten Blättern. Die Kiemenöftnung, wenn zusammengezogen, fast rundlich, olne vortretende Rïnder, dic Zöttchen des Ruickens sich bis an den liand (wie bis an den Rand der Rhinophoröffnungen) erstreckend. Die Kieme aus 10 tripinnaten Blïttem gebildet, von denen die medianen vorderen die grössten, die vier hinteren die kleinsten. Die Analpapille etwa 2 mm hoch, abgestutztkegelförmig, mit rundzackiger Oeffunng; an ihrem Grunde vorne und rechts die spaltartige kleine Nierenpore. Die Unterscite des breiten, unregelmässig gebogenen, mitunter wie im Rande zackigen Mantelgebrämes ganz eben. Die Körperseiten ganz niedrig, die Genitaloffunng stark zusammengezogen. Der A ussenmund eine Längs-

1) Prillippi, en. moll. Sic. I. 1S36. p. 104; II. 1S44. p. 79, tab. XIX. Fig. 9.

2) Verayt, catalogo. 1S46. p. 21.

Hancock and Embleton, 1. c. 1S52. p. 219, 220. 
spalte; die Tentakel in ihrer grössten Liinge angeheftet, mit Längsfurche der Unterseite. Der Fuss sehr kräftig, an den Körperseiten stark vorspringend; das Vorderende gerundet, mit tiefer Randfurche, die obere Lippe gespalten; der Schwanz ziemlich kurz.

Die Eingeweide schimmerten nirgends hindurch. - Das Peritonaeum farblos.

Das Centralnervensystem abgeplattet, in der Hülle ganz fein bräunlich punktirt. Die cerebro-visceralen Ganglien nierenförmig, die viscerale Abtheilung etwas grösser als die cerebrale; die pedalen Ganglien von rundlichem Umrisse, in Grösse zwischen den beiden vorigen stehend. Die gemeinschaftliche (aus den gewöhnlichen 3 zusammengesetzte) Commissur stark, nur etwa doppelt so lang wie die cerebro-viscerale Ganglienmasse. Die proximalen Riechknoten zwiebelförmig, die viel kleineren distalen eine ovale Anschwellung an dem Nerven bildend. Die buccalen Ganglien von ovaler Form, durch eine ganz kurze Commissur verbunden, fast doppelt so gross wie die proximalen Riechknoten; aus jedem Ganglion gelıt gegen hinten cin bald gegabelter Nerv (N. raginae radulae) ab. Die gastro-ocsophagalen Ganglien ziemlich kurzstielig, an der inneren Seite des Nerven entwickelt, von rundlichem Umrisse, etwa $1 \%$ der Grösse der buccalen betragend; mit zwei grossen und mehreren kleineren Nervenzellen; gegen oben zwei Nervi oesophagales abgebend.

Die A ugen ziemlich kurzstielig, von gewöhnlicher Grösse, "mit schwarzem Pigmente, horugelber Linse. Die Ohrblasen als etwas abgeplattete Saickcheri vor dem cerebro-pedalen Connective liegend, mit gelblichen Otokonien gewöhnlicher Art strotzend gefüllt. Die Keule der Rhinophorien mit ziemlich breiten und diunen Blïttern, die durch lange, meistens cylindrische und spindelfürmige, wenig erhärtete Spikeln in gewöhnlicher Weise steif gemacht sind. Die schlanken aufrechten Züttchen der Ha ut, die derselben das sammtartige Aussehen verlcihen, von einer Itühe bis fast $0,5 \mathrm{~mm}$, oben mitunter ein wenig linopfartig angeschwollen (Fig. 20); sie waren durch Spikeln, die denen der Rhinophor-Blätter ganz ähnlich, eben so wenig erhärtet und (Fig. 21) aufrecht waren, steif. In der subpapillairen Haut des Riickens sparsamere und kïrzere Spikeln, theils und meistens diinn und wenig erhärtet, theils dick und seln erhiirtet (Fig. 22). In der übrigen Hant kamen Spikeln im Ganzen etwas sparsamer vor. - In der interstitiellen Bindesubstanz fehlten grössere Spikeln fast ganz, mit Ausnahme in der Umgegend der Hauptausfithrungsgäinge des Genitalapparats.

Dic Mundræ̈lıre stark, etwa 2,5 mm lang; die drei Paar Retractoren sehr stark, ziemlich lang; die Innenseite mit den gewöhnlichen Längsfalten und der hinteren circulären. - Der Schlundkopf ziemlich gedrungen, etwa $5 \mathrm{~mm}$ lang bei einer Breite bis 3 und einer Höhe bis $3,5 \mathrm{~mm}$; dic Retractoren sehr stark und lang; ihr (3-4 liöpfiger) Ursprung dicht vor der Mitte der Länge der Körperseiten; die grosse Raspelscheide (mit bräunlich durchschimmernden Zahnplattenreihen) stark (etwa $2 \mathrm{~mm}$ ) nach hinten und unten vortretend. Die rundliche Lippenscheibe mit $\perp$-Mundöffnung; selbst unter einer 
sehr starken Loupe dem Anscheine nach nur von einer (gelblich-) weissen Cuticula überzogen, und so auch bei genauerer Untersuchung; nur zeigte sich am untersten Theile cine braunlichgraue Strecke, aus dicht gedrängten Längsfïltchen (Fig. 23) von ciner Breitc bis etwa $0,0055 \mathrm{~mm}$ gebildet ${ }^{1}$ ). Die Zunge ist gross und breit, mit tiefer Ruickenfurche; in der horngelben schilleruden Raspel 16 Zahmplattenreihen und an der Spitze noch Spuren von zwei ausgefallenen; weiter nach hinten fanden sich noch 11 entwickelte und 3 nicht vollstiindig entwickelte Reihen, die Gesammtzahl derselben somit 30. In der hintersten Reihe der Zunge 28 Zahnplatten, und die Anzahl schien weiter nach hinten nur mit 1-2 zu steigen. Die Rhachis nicht ganz schmal; rorne (Fig. 24a) mit gebogenen (nach vorne convexen), den Zahnplattenreihen entsprechenden Furchen; hinten glatt. Die Zahnplatten von hell gelllicher Farbe; die Ilühe der drei aiussersten Zahnplatten (hinten an der Zunge) betrug etwa 0,038-0,1-0,12 nm, die der vierten schon $0,15 \mathrm{~mm}$; die Höhe sich dam bis etwa $0,25 \mathrm{~mm}$ erhebend, dann nach imnen abnehmend, die Höhe der imnersten etwa 0,1S mm. Die Zahmplatten von den ganz typischen (Fig. 25) Formverhäilnissen; der (zahnlose) Haken und die fliigelfürmige Entwicklung des Kïrpers ganz wie gewöhnlich. Dic innersten (Fig. 27) Zahnplatten mit kürzerem Ǩ̈̈rper; dic drei äussersten (Fig. 26a, 28 a) ganz schlank und schmächtig.

Die Spcicheldriisen stark abgeplattet, langgestreckt, mit etwas lappigen Rändern, weisslich: die Speicheldriisengänge (etwa $5,5 \mathrm{~mm}$ ) lang und diinn.

Dic Speiserühre ziemlich (etwa $12 \mathrm{~mm}$ ) lang, ziemlich weit, nur in der hintersten Strecke etwas verschmailert; die Liingsfalten sich bis an die Cardia fortsetzend. Der Magen klein. Der I) arm zur linken Seite der Mittellinie vor der Mitte der oberen Seite der hinteren Eingeweidemasse hervortretend, sich in einer Länge von etwa 8 mm nach vorne erstreckend, sein Knie bildend und in einer Länge ron beiläufig $17 \mathrm{~mm}$ nach hinten verlaufend; die Breite in der ersten Strecke durehgehends etwa $2,75 \mathrm{~mm}$, in der iibrigen beiläufig die Hiilfte betragend; an der Innenseite feine Liingsfalten. - Die Verdaumgshöhle mit nicht nüher bestimmbarer thierischer Masse gefüllt.

Die hintere Eingewcidemasse (Leber) etwa $16 \mathrm{~mm}$ lang bei einer Breite bis $\mathrm{S}$ und einer Höhe bis $7.5 \mathrm{~mm}$; das Vorderende selır stark schief nach hinten und unten abgeplattet und facettirt (wegen der vorderen Genitalmasse), das Hinterende wie abgestutzt; die Oberfäche glatt, an der oberen Seite eine ziemlich starke Furche für die erste und eine zweite für die iibrige Strecke des Darmes, zur linken Seite der letzteren eine tiefere für die Urinkammer, an der Unterseite am Anfange des letzten Drittels der Leber eine sehr tiefe Querfurche; die Farbe der Leber, wie an Durchschnitten deutlich, gelblichweiss. Die Leberhöhle mit mehreren (besonders 3) grossen Crypten. Die Gallenblase weisslich,

1) Dieselben simulirten Stäbchen. Eine genauere Bestimmung des Verbreitungsbezirkes dieser Fältchen war an dem einen Individuum nicht möglich. 
etwa $3,5 \mathrm{~mm}$ hoch, mit einer kleiner Facette von etwa 1,3 $\mathrm{mm}$ Diam. neben dem Pylorustheile des Darmes an die Oberflïche der hinteren Eingeweidemasse tretend.

Das Pericardium und das Herz wie gewöhnlich. Die vordere Blutdruise zwischen den Retractoren der Mundröhre sich über dieselbe nach vorne hinschiebend, stark abgeplattet, gestreckt eiförmig mit abgestutztem Vorderrande; das Hinterende ein wenig ausgezogen, vom Vorderende des Centralnervensystems gedeckt, die Räinder ein wenig lappig; etwa 3,5 $\mathrm{mm}$ lang bei einer Breite bis 1,6 mm. Die hintere Blutdrüse queroval, in den Ecken ausgezogen, etwa $7 \mathrm{~mm}$ breit bei einer Länge von $3 \mathrm{~mm}$, auch stark abgeplattet, mit sehr lappigen Riindern. Die Farbe der Blutdrüsen gelblichweiss; die sonst farblose Hülle feim brïunlich punktirt. Die Fortsetzung der Art. gl. sangvineae an die vordere Blutdruise liings der Unterseite des Commiss. interevebralis selur deutlich. Die Urinkammer weit, sich bis an das Vorderende der Eingerveidemasse erstreckend; die schöne baumartige Veristelung der Nierengïnge sehr stark, das Nicrengewebe wie gewöhnlich. Die Nierenspritze wie gewöhnlich.

Die Zwitterdrise ein an den Rïndern zackiges Lager an der oberen Seite und am Vorderende der Leber bildend, durch melır gelbliche Farbe gemen die gelblichweisse Leber abstechend. Der Zwitterdrusengang an der rechten Seite des Cardia'Theils der Speiseröhre frei hervortretend, schriig an die vordere Genitalmasse hiniibergehend. Die vordere Genitalmasse etwa $6,5 \mathrm{~mm}$ lang bei einer Breite bis 3,3 und einer Höhe bis $5,5 \mathrm{~mm}$; die Hauptansfiihungsgänge noch etwa $2 \mathrm{~mm}$ herrortretend. Der Zwitterdriisengang plötzlich in die nicht (erst bis $0,75 \mathrm{~mm}$, dann bis $1,5 \mathrm{~mm}$ ) dickê, opak-weissliche Ampulle schwellend, welche sehräg über die Hinterscite der Genitalmasse linaufstieg, und damn wieder hinabbog; ansgestreckt maass dieselbe etwa $7 \mathrm{~mm}$. Der ganze kurze männliehe Zweig der Ampulle in eine, einen grossen Kíreis beschreibende, ausfgestreckt etwa $15 \mathrm{~mm}$ messende (bei cinem Durchmesser bis etwa $1 \mathrm{~mm}$ ), gelblichwcisse, an Durchschnitten rundliche, mehrfach etwas unregelmässig hier und da eingeschinirte Prostata iibergehend. Der Penis unbewaffnet. Die gelbliche, kugelförmige Spermatotheke von $1,75 \mathrm{~mm}$ Diam., mit Detritus hauptsäichlich gefullt; der uterine Ausfiihrungsgang stark geschliingelt, etwas limger als der vacrinale; dicht vor scinem Ende die wenigstens doppelt so grosse, 'blasenförmige, weiäsliche, mit Samen gefüllte Spermatocyste an eincm ganz kurzen Stiele tragend; der vaginale Ausfiihrungsgang der Spermatotheke kriffiger als der uterine, liings der Spermatocyste hinabsteigend, plötzlich in die starke, etwa $2,3 \mathrm{~mm}$ lange $\mathrm{Vag}$ ina ibergehend, die an der Innenseite mit starken Lüngsfalten versehen war. Die Schleimdrüse weisslich; die Eiweissdritse an beiden Seiten hervortretend, braungelblich; die Falte des Ausfiihrungsganges der Schleimdrise stark. Der stark erhärtete Conservationszustand der Genitalmasse gestattete keine Bestimmung der Verhïltnisse des Liebessporn-Apparats. 
Jor. Johnstoni (A. et $\left.H_{.}\right)$, rar. alba, $B_{G H}$.

Color animalis omnino albus.

Hab. M. adriatic. (ad Tergestem).

Taf. J. Fig. 17-21; Taf. K. Fig. 29-36.

Unter lebenden Thieren, die mir durch Dr. GRAEFFE Mitte Mairz 1880 aus der Station von Triest freundlichst geschickt wurden, fand sich ein Individuum, das wahrscheinlich eine Varietät dieser Art repräsentirt. Von derselben habe ich ferner noch zwei, mir aus derselben Localität geschickte, in Alcohol bewahrte Individuen untersuchen können, welche einer Notiz von GraEfFE zufolge lebend auch "ganz weiss" gewesen waren.

Das lebende Thier war weich anzufühlen (etwas schlaff), von einer Länge von $3,3 \mathrm{Cm}$. bei einer Körperbreite bis 2,3 und einer Höhe bis 1,2 Cm.; die Höho der (halb zurïkgezogenen) Rhinophorien schien $4 \mathrm{~mm}$ zu betragen, die der Tentakel 2,5, die der (ausgestreckten) KKieme fast $6 \mathrm{~mm}$; die Breite des Nantelgebrỉmes 8, die des Fusses (vorne) bis $11 \mathrm{~mm}$; die Genitalpapille bis $2,5 \mathrm{~mm}$ hervortretend. - Die Farbe der oberen wie der unteren Seite des Thieres weiss, am reinsten war dieselbe am Kopfe mit den 'lentakeln, an der Genitalpapille, an den Rhinophorien, sowie an der Kieme; am (eigentlichen) Riicken schimmerten die Eingeweide sehr undeutlich gelblich hindurch. Das träge 'T'hier wurde gleich in Alcohol getödtet.

Das grösste der in Aleohol bewahrten Individuen hatte eine Lärge von $5 \mathrm{Cm}$. bei einer Breite von 3 und einer Höhe von $1,8 \mathrm{Cm}$; die Linge des Fusses betrug $4 \mathrm{Cm}$. bei einer Breite bis 1,8 Cm., die Breite der oberen Lippe des Fussrandes $2,25 \mathrm{~mm}$, die Länge des Schwanzes $7 \mathrm{~mm}$; die Föhe der Rhinophorien 6, die Lüinge der T'entakel $2 \mathrm{~mm}$; der grösste Durchmesser des Kiemenloches $7 \mathrm{~mm}$, die Höhe der Kiemenblätter $1 \mathrm{Cm}$; die Breite des Mantelgebrämes bis $7 \mathrm{~mm}$. - Das zweite der zuletzt erwähnten Individuen war nur unbedeutend grösser als das oben erwähnte ron mir in Alcohol getödtete, und die Maassverhältnisse desselben stimmten fast ganz mit denen des letzteren überein. Bei diesem betrug die Liinge des Körpers 3,2 bei einer Breite bis 2 und einer Höhe bis 1,2 Cm.; die Länge der Tentakel 2,2, die Höhe der Rhinophorien 3,5 mm.; der Diam. des Kiemenloches etwa 5,5 und die Höhe der Kieme $7 \mathrm{~mm}$; die Breite des Mantelgebräimes bis 6, die des Fusses (vorne) $11 \mathrm{~mm}$, die Liange des (das Mantelgebrïme hinten kaum überragenden) Schwanzes $6 \mathrm{~mm}^{2}$ ) - Die Farbe dieser Individuen duxchgehends ganz weiss oder graulichweiss; die Eingeweide schimmerten nirgends hindurch.

1) Auf dieses Individuum beziehen sich meistens und hauptsächlich die unten gegebenen Maasse. Semper, Philippinen. II, II (Bergh, Ergänzungsheft II). 
Die Consistenz der Bedeckungen des Iebenden wie der in Alcohol bewahrten Thiere weich. Die Form schien weniger niedergedrickt als in der Arch. tuberculata, sonst der dieses 'Thieres ziemlich ihnlich. Der Riicken dem unbewaffneten Auge etwas sammetartig, unter der Loupe mit ïusserst feinen Züttehen ganz dicht bedeckt. Der Rand der Rhinophor-Oeffnungen nur sehr wenig vortretend, mit ganz ähnliehen, kaum grösseren Zöttchen bedeckt. Die Rhinophorien stark; der Stiel fast so hoch wie die Kéeule, die (wenigstens) etwa 25 breite Blitter zeigt, die Endpapille stark. Der Rand des Ki emenloches (das rundlich, doch vorne mehr geradelaufend war) ganz wie der der Rhinophoröftnungen. Die Kieme immer aus 10 sehönen und fast gleichgrossen tripimnaten Blittern bestehend, von denen die zwei hintersten an der einen oder an beiden Seiten genauer verbunden waren. Fast im Centrum der Kiemenkrause die niedrige (1,8-2 $\mathrm{mm}$ holıe), vorne ein wenig höhere, also schräge abgestutzte Analpapille, vorne und linten in der Mittellinie mit der Kiemenkrause verbunden; vorne und rechts, dicht an der Analpapille die runde Nierenpore. Das Nantelgebrime kriftig, ziemlich breit; die Unterseite desselben ganz glatt. Der Kopf klein, mit senkrechter (ganz enger oder doch oben erweiterter) Nundspalte; neben ihrem Grunde jederseits der krïftige, kegelfürmige, doch etwas abgeplattete 'Ientakel. Die Körperseiten niedrig; die Genitalpapille etwas vortretend, mit einer vorderen runden Oeffnung (mit 2 Löchern am Boden) und einer hinteren Spalte (in den Schleimdrisengang). Der F us kriftig; der Vorderrand mit tiefer Randfurche, die viel breitere obere Lippe in der Mittellinic gespalten; der Schwanz etwas zugespitzt.

Das Peritonaeum farblos, der Mittellinie nach, und zwar besonders das Pericardium, äusserst fein braungraulich punktirt.

Das Centralnervensystem aus seiner losen, auch fein braungrau punktirten Capsel schwer auszupripariren. Die cerebro-visceralen Ganglien kurz-nierenförmig, mit starker Auskerbung des äusseren Randes (mitunter auch bei stärkerer Zusammenziehung mehr rundlich); die cerebrale Abtheilung kleiner als die viscerale; die pedalen Ganglien ron rundlichem Umrisse, so gross wie die visceralen oder selbst grösser. Die drei Commissuren etwas mehr als doppelt so lang wie der Längsdurchmesser der cerebro-visceralen Gauglien; an den zwei Individuen ganz, an dem dritten nicht vollständig verschmolzen. Die proximalen Riechknoten fast sessil, zwiebelförmig; die distalen viel kleiner, rundlich, nach oben 2 Nerven abgebend. Mit der Unterseite des rechten visceralen Ganglions stánd durch einen nicht ganz kurzen Stiel ein Ganglion genitale in Verbindung"), das wahrscheinlich noch mit einem rundlichen Ganglion von etwa $0,3 \mathrm{~mm}$ Diam. zwischen Vagina und Stachelsack communicirte. Die buecalen Ganglien wenigstens doppelt so gross wie die grossen Riechknoten, von rundlichem oder ovalem Umrisse, planconvex, dureh eine

1) In den dem Genitalapparat gehöreuden Ganglien kommen im Ganzen bei „Nudibranchien" reihegeordnete Zellen ungemein häufig ror. 
ziemlich oder ganz kurze Commissur verbunden; die viel kleineren gastro-oesophagalen Ganglien nicht ganz kurzstielig, an der einen Seite des Nerven entwickelt, mit einer sehr grossen und mehreren kleinen Zellen.

Die A ugen kurzstielig, mit schwarzem Pigmente und stark horngelber Linse; der N. opticus etwas länger als der Längsdurchmesser des Auges, von einer besonderen Zellengruppe entspringend. Die Ohrblasen an gewöhnlicher Stelle der Unterseite der Gehirnknoten sessil, von (beiläufig 150) gelblichen Otokonien gewöhnlicher Art strotzend. Die diunnen Blätter der Kieule der Rhinophorien durch dicht an einander liegende, stark und meistens ganz erhärtete, lange, spindelförmige Spikeln steif gemacht; durch die Axe und "durch den Stiel der Organe auch :ihuliche Spikeh in reichlicher Menge, zum grössten 'Theile in die Quere gelagert. Die 'T'entakel mit ähnlichen Spikeln reichlichst versehen, die meistens in dic Quere und sehraige gelagert waren. Die Haut mit den obigen meist ihhnlichen Spikeln (von einer Länge bis wenigstens 0,5 und einem Durchmesser bis $0,02 \mathrm{~mm}$ ) reichlichst versehen. Die Spikel der eylindrischen, oben gerundeten, meistens etwa $0,18-0,2 \mathrm{~mm}$ hohen Züttchen des Rückens im Ganzen weniger erhäirtet, nur ausnahmsweise an der Oberfläche von jenen hervortretend; die Spitze des Stromas der weichen Zöttchen (innerhalb der dieselben einfassenden, aufrechten, pallisadenartigen Spikeln) scheint verlängert oder eingezogen werden zu können. In der Haut der Körperseiten so wie des Fusses kamen Spikeln auch sehr reichlich vor. - In der interstitiellen Bindesubstanz hier und da, besonders aber um die Ausfuhrungsgänge der vorderen Genitalmasse, zahlreiche, theilweise sehr grosse und stark erhärtete Spikeln. In den Axenparthien der Kiemenblätter grosse und meistens stark erhärtete Spikeln, die aber fast nie in die Blätterchen hinausragten. - Es fanden sich zwei stärkere Retractores branchiae laterales und zwei schwächere Retr. br. mediani.

Die halb ausgestiilpte Mundröhre bei dem grossen Individuum 5,5, bei den kleineren etwa 3,5 mm lang; ihre typischen 3 Paar Retractoren schr (bis 15 und $11 \mathrm{~mm}$ ) lang und stark; die Innenseite des Rohres wie gewöhnlich. - Der Schlundliopf ron gewöhnlicher Form; bei dem grossen Individum 6,5, bei den kleineren etra $4 \mathrm{~mm}$ lang bei ciner respectiven Höhe von 4 und etwa 5 und einer Breite von respective 5 und $4 \mathrm{~mm}$; die Raspelscheide noch 2,25-1,8 $\mathrm{mm}$ nach hinten und unten hervorragend; die starken (bei dem grossen Individuum bis $18 \mathrm{~mm}$ langen) Retractoren wie gewöhnlich. Die rundliche Lippens cheibe mit I- oder $\perp$-förmiger Mundspalte; von einer star̦ken, fast farblosen, einfachen Cuticula überzogen. Die Zunge von gewöhnlicher Form; an der Zungenspitze Eindriicke von 2 ganz ausgefallenen Zahnplattenreihen; in der Raspel an dem grossen Individuum 15, an den beiden kleineren 13 Reihen (von denen die 3-5 vorderen nach aussen mehr oder weniger incomplet); weiter nach hinten bei jenem 17, bei diesen respective 11-16 entwickelte und 3 nicht ganz entwickelte Reihen; die Gesammtzahl derselben war somit 35 und 27-32. In den Reihen kamen hinten an der Zunge bei dem grossen Individuum bis 32, bei den kleineren bis 29 und 31 Platten vor, 
und die Anzahl schien weiter nach hinten kaum zu wachsen. Die nackte Rhachis (an der Zunge) nicht ganz schmal und den Zahnreihen (Fig. 29 a) nach durch gebogene Querfurchen getheilt. Die Zahnplatten von schwach-gelblicher Farbe; die Höhe der innersten (Fig. $29 \mathrm{~b}, 30$ ) an den kleineren Individuen fast $0,25 \mathrm{~mm}$ betragend, sich allmählig bis zu etwa 0,3 erhebend, um an den 3 (Fig. 19, 20) äussersten wieder bis etwa 0,13-0,10—0,07 mm zu sinken. Die Form der Platten die gewöhnlichste (Fig. 18); die drei äussersten, besonders die iiusserste (Fig. 19 a, 20 a) viel kleiner, aufrecht.

Die Speicheldruisen eigenthümỉch fadenförmig (fast gerade laufend); bei dem grossen Individuum etwa 15 , bei den kleinen beiläufig $10 \mathrm{~mm}$ lang; weisslich; hinten an der vorderen Genitalmasse etwas verbreitert; die Ausführungsgänge ganz kuřz, in der Schlundwand liegend.

Die Speiseröhre (Fig. 31 a) an dem grossen Individuum etwa 19, an den kleinen etwa 12-13 mm lang, (bis $5 \mathrm{~mm}$ ) weit, mit ziemlich starken Längrsfalten der Innenseite; in der hinteren Strecke erst etwas enger, dann eine kleine magenartige Erweiterung bildend (Fig. $31 \mathrm{~b}$ ), aus dem der Darm (Fig. 31 c) (bei dem grossen Individuum durch eine Höhe von $9 \mathrm{~mm}$ ) an die Oberfläche der Leber emporsteigt und dann nach vorne biegt und eine kurze Strecke vor der Leber verläuft, dann sein Knie bildet und nach hinten umbiegend bis an die Analpapille verläuft. Bei dem grossen Individuum hatte die nach vorne gehende Strecke eine Länge von etwa 1,6, die nach hinten gehende von fast $3,8 \mathrm{Cm}$. bei einem fast durehgehenden Durchmesser von $5-6 \mathrm{~mm}$; bei den kleineren Individuen betrugen dieselben Maasse $1-1,2 \mathrm{Cm}$., sowie 2,3-2,5 Cm. bei einem Diam. in der ersten Strecke von etwa 3, in der letzteren von 1,5-2 $\mathrm{mm}$. Die Innenseite des Darmes mit feinen Längfailtchen, die sich bis an den Analrand fortsetzten. - Der Inhalt der Verdaungshöhle unbestimmbare thierische Masse.

Die hintere Eingeweidemasse ( $\mathrm{L}$ e b e r) bei dem grossen Individuum etwa $3 \mathrm{Cm}$. lang bei einer Höhe bis 1,8 und einer Breite bis $1,6 \mathrm{Cm}$; bei den kleineren Individuen betrugen dieselben Maasse 1,7-2,1:0,9-0,8 und 1-1,2 Cm.; das ein wenig zugespitzte Hinterende gerundet; das Vorderende abgestutzt, mit einer (etwas rechts liegenden) schrïg nach hinten und unten gehenden Facette (für die vordere Genitalmasse), und mit tiefer, medianer, bis iiber den Magen eindringender, enger Spalte; an den Seiten (besonders der hinteren Hälfte) der Masse 2-3 senkrechte, ziemlich tiefe Furehen; die Farbe der Substanz gelblichgrau oder mehr gelblich; die Höhle (bei dem grossen Individuum bis $7 \mathrm{~mm}$ weit) mit weiten Oeffnungen. Die Gallenblase an der linken Seite des PylorusTheils des Darmes, meistens fast bis an die Leberoberfliche aufsteigend (bei dem grossen Individum stark zusammengezogen, nur $3 \mathrm{~mm}$ hoch; bei den kleinen $4 \mathrm{~mm}$ in Höhe messend), linglich, dunikler gelblich oder heller als die Lebersubstanz.

Das Herz wie gewölınlich; die (schlaffe) Kammer an dem grossen Individuum $4 \mathrm{~mm}$ Iang. - Dio Blutdri îsen stark abgeplattet, weisslich, in ihrer Hülle auch ganz fein braungelblich punktirt. Die vordere unregelmässig-dreieckig, mehr oder weniger 
breit, in den Rändern stark lappig; die obere Fläche ziemlich eben, aber in Läppchen getheilt; die untere weniger eben. Die Länge derselben betrug bei dem grossen Individuum etwa 4,5 bei einer Breite bis 9 und einer Dicke bis $0,75 \mathrm{~mm}$; bei den kleinen Individuen beliefen dieselben Maasse sich etwa zu 2,5:5 und 0,4 mm. Die hintere Blutdriise viel breiter, an den Rändern sowie auch an den Flächen melır lappig; die Breite derselben betrug bei dem grossen Individuum etwa $13,5 \mathrm{~mm}$ bei einer Lainge bis 4 und einer Dicke bis volle $2 \mathrm{~mm}$; bei den kleineren betrugen dieselben Maasse etwa $8: 2$ und $1,5 \mathrm{~mm}$.

Die Nierenspritze birnförmig oder mehr cylindrisch; an dem grossen Individuum war die Länge derselben etwa 4, bei den kleineren 2-2,3 $\mathrm{mm}$; die Imnenseite derselben oben mit starken Längsfalten, die sich nach unten in die gewöhnlichen Vegetationen auflösten. Das Organ dureh einen ganz kurzen dicken Stiel mit der Urinkammer verbunden; an der Innenseite des Stieles wieder dieselben Vegetationen, welehe auch an der Wand der Urinkammer vorkamen, die ziemlich kurz (an dem grossen Individuum etwa $6 \mathrm{~mm}$ lang) und (bis 2,5 mm) weit, sowie ziemlich dinnwandig war. Die Niere mit ihren Blindröhren wie gewöhnlich.

Die Zwitterdriise den grössten Theil der Leber mit einem fast continuirlichen (an dem grossen Individuum bis etwa 1,2 $\mathrm{mm}$ dieken) gelblichweissen Lager überziehend, welches durch feine und feinste Furchen in Inseln und Inselchen getheilt war, die aus kleinen, dicht gedrängten, gerundeten Läppehen wieder gebildet waren; in denselben in gerrölmlicher Weise grosse oogene Zellen und Zoospermien. - Die vordere Genitalmasse etwas zusammengedrickt, also biconvex, das breite Ende rechts kehrend; ihre Breite an dem grossen Individuum 15 bei einer Höhe von 11 und einer Dicke (von vorne nach hinten) vou $8,5 \mathrm{~mm}$; bei den kleinen Individuen betrugen dieselben Maasse $9: 6,5$ und $5,5 \mathrm{~mm}$; die Hauptausführungsgänge noch respective 4 und $2 \mathrm{~mm}$ hervortretend. Dio Hinterseite der Masse (Fig. 32) zeigte immer rechts und unten eine feingyrate Parthie von heller Chocoladenfarbe (Fig. 32d); oberhalb derselben war dio grosse Mittelparthie fast ganz glatt, dunkler oder heller olivenfarbig, mehr oder weniger von weisslichen Adern an der Oberfläche (Fig. 32) wie übersponnen; die Fortsetzung dieser Fläche links und nach oben ist von der Ampulle, den Samenblasen und der weisslichen Prostata gedeckt; zwischen der chocoladefarbigen Parthie und der olivenfarbigen etwa an der Mitte bei den zwei Individuen eine feingewundene, weissliche, gestrecktdreieckige Parthie (Fig. 32). Unterhalb der olivenfarbigen Parthie, am Unterrande der Genitalmasse wieder ein weisslicher Theil. An der Vorderseite dieser Genitalmasse zeigt sich an entsprechender Stelle auch die chocoladenfarbige Masse; übrigens wird die gervundene weisse Schleimdriise zum grössten Theile von der Prostata und den Hauptausfiilurungsgängen des Genitalapparats bedeckt. An dem oberen Rande der Sehleimdriise und ausserhalb derselben (reehts) die starken gelblichen Windungen eines (Fig. 32 e) drüsenartigen Organs. Die Ampulle des Zwittexdriisonganges schmutziggraulichweiss, eine 
grosse Schlinge (Fig. 32 a) bildend, die erst lïngs des rechten Randes der Prostata (an der Hinterseite der Genitalmasse) hinabsteigt, derselben ferner um den unteren Rand der Genitalmasse und weiter an der Vorderseite hinauf nach rechts folgt, dann sich in ihre zwei Aeste theilt; die Länge der (ausgestreckten) Ampulle betrug bei dem grossen Individuum $2 \mathrm{Cm}$. bei einem Durchmesser bis $1,5 \mathrm{~mm}$, bei den kleinen $1-1,5 \mathrm{Cm}$. bei einem Diam. bis $0,75-1 \mathrm{~mm}$. Der stielartige ganz kurze mannliehe $\mathrm{Zweig}$ geht in die grosse, nach ihren Enden hin allmählig zugespitzte Prostata (Fig. 32) gleich iiber. Diese letztere ist (schwach-gelblich-) weiss und bildet eine grosse Schlinge, deren zwei Hïlften etwas zusammengedriickt, an cinander gedrickt und lose angeheftet sind; bei dem grossen Individuum betrug die Liinge der ersten Strecke etwa 12, der letzteren (aufsteigenden) beiläufig $15 \mathrm{~mm}$ bei einer Breite bis 2,5 und einer Dicke bis $1,75 \mathrm{~mm}$; bei den kleineren Individuen beliefen die entsprechenden Maasse sich zu etwa 0,8 und $1 \mathrm{Cm}$. bei einem Durchmesser bis zu $1,5 \mathrm{~mm}$; die Wand des Organs ziemlich dün, und die Höhle somit weit. Der obere Theil (Fig. 32 b) der Prostata setzt sich ohne Grenze, nur ziemlich stark verschmälert in den gelblichweissen, mehrere kurze Biegungen machenden (ausgestreckt bei dem grossen Individuum etrva 2 Cm. messenden) prosta tischen Theil (Fig. 35a) des Samenleiters fort, welcher fernerhin stark verschmälert in (Fig. 35b) den diinnen, muskulösen, einige Biegungen machenden, ausgestreckt etwa $8-6 \mathrm{~mm}$ messenden muskulösen Samenleiter übergeht, der sich in den Scheitel des Penis (Fig. 35e) öffnet. Dieser Penis ist sackförmig, an dem grossen Individum fast $2,5 \mathrm{~mm}$. lang bei einem Durchmesser bis $1,5 \mathrm{~mm}$; die Wand stark, muskulös; die Innenseite mit ziemlich starken Liingsfalten; oben am Scheitel die einfache (dreieckige) Oeffuung des Samenleiters mit vortretendem Rande. Neben der Oeffnung fiir den Penis findet sich die (Fig. $33 \mathrm{f}$ ) des mehr diinnwandigen, mehr oder weniger gestreckten oder verschiedenartig gebogenen, langgestreckten (Fig. 33e) Stachelsackes; derselbe hatte bei dem grossen Individuum (ausgestreckt) eine Länge von etwa 11 bei einem Durchmesser von etwa $1,2 \mathrm{~mm}$; an den kleineren Individuen betrugen dieselben Maasse etwa 7,5 und $1,5 \mathrm{~mm}$; die Innenseite des Sackes mit ganz feinen Längsfältchen. Das obere Ende des Stachelsackes war compact, an demselben hefteten sich (Fig. 33 dd) flache Muskelbänder (Retractoren) und ein (Fig. 33a) drüsenartiges langgestrecktes Organ; seitlich an demselben ragte ferner (Fig. 33c) ein solider länglicher Körper etwa 0,6 -1 mm hervor. Dieser letztere, der Stachelbeutel, ist mit etwa seiner unteren Hälfte in den soliden Scheitel des Stachelsackes eingeschlossen (Fig. 21, 34); die ziemlich dicke muskulöse Wand ist von einer fast farblosen Cuticula überzogen, die sich oben bis an eine kleine (Fig. 34b) Papille am Scheitel des Beutels fortsetzt; die Höhle des Beutels ist oben weit, in dem unteren. Drittel ganz eng. Von jener Papille erhebt sich der Stachel (Fig. 21, 34), welcher sich (zurïckgezogen) mehr gerade oder unregelmässig gebogen durch die grösste Länge des Beutels erstreckt. Derselbe erreichte bei dem grossen Individuum eine Länge von $1,7 \mathrm{~mm}$ bei einem Durchmesser am Grunde 
von 0,06 , dicht hinter der Spitze von etwa $0,007 \mathrm{~mm}$; bei den Kleineren Individuen betrugen die entsprechenden Maasse etwa 1,2-0,05 und 0,006 mm. Der Stachel war farblos, wie von faserigem Baue im Inneren. Neben dem Grunde des Stachels üffnete sich in die Höhle des Stachelbeutels ein diimner, muskulöser, etwas greschlïingelter Ausführungsgang. (Fig. 21 a, 34a) einer kleinen Stacheldriise, deren Verhäilnisse nicht genauer bestimmt werden konnten. In die Höhle des Stachelsackes, unterhalb des soliden Theils, (Fig. 34d) scheint sich endlich ein unregelmässig geschlïingeltes (Fig. 32 e), weisslichgelbes Organ (Nebenstaclieldrise?) zu öfnen, das ausgestreckt an dem grossen Individuum eine Liinge ron etwa 2,3 Cm. bei einem Durelnmesser bis 1,3 mm hatte; die Wand desselben nicht dick. ${ }^{1}$ ) - Der dinne, weissliche, weibliche Ast der Ampulle des 'Lwitterdrisenganges nicht lang, unweit von dem uterinen Gange der Spermatotheke an der Eiweissdrïse einmindend. Dieser uterine Gang (Fig. 36 d) vor der Hitte sciner Länge die Spermatocyste fast sessil tragend (Fig. 36e); diese letztere meistens kugelrund, weisslich oder seltener grüinlichweisslich; bei dem grossen Individuum ron einem Durchmesser von etwa 4, bei den kleinen von 2,5-3 mm; vou Samen strotzend. Die Spermatotheke kugelrund oder etwas mehr lïnglich (Fig. 36 a), von einem Durchmesser bei dem grossen Individuum von 3,5, bei den kleinen von 3-3,5 mm; weisslich, mit verfetteter Zellenmasse und Detritus erfullt. Der vaginale Gang (Fig. 36 b) viel dicker als der uterine, etwa $1 \frac{1}{2}-2$ mal so lang wie die Samenblase, allmïhlig in die V agina (Fig. 36 c) ibergehend. Diese letztere 4--6 mm lang bei einem Durchmesser von $1,5-1 \mathrm{~mm}$; an der Innenseite starke Längsfalten, die sich weiter hinauf durch den vaginalen Gang fortsetzen. Die Schleimdruse (Fig. 32) weisslich, oben und rechts mit der erwähnten grossen chocoladefarbigen Parthie; die Eiweissdrüse gross, wie erwiihnt, olivenfarbig; der hinten und unten liegende Schleimdrüsengang mit der gewöhnlichen starken F'alte.

\section{Jor. ! atypha, Bin. n. sp.}

Color corporis e griseo albidus, branchia similis coloris; rhinophoria albida, apice lamellis brunnescentibus.

Ha b. M. adriatic. (ad Tergestem).

Taf. J. Fig. 2:-25.

Im October 1879 erhielt ich aus der Station von Triest durch D1. GracfFe, in

1) Das sparsame Material, noch dazu mit wenig gutem Conservationszustande der rorderen Genitalmasse gestattete leider keine ganz sichere Bestimmung der Verhältnisse des Samenleiters und des Penis, besonders aber keine der oben erwähnten Gland. hastatoria succenturialis. Auch bei meiner früheren Untersuchung der Jorunnna Johnstoni (1. c.) labe ich wegen Mangel an Material diese Verbältnisse ganz unsicher und unklar lassen müssen. Mangel hinlänglichen Materials ist mir überhaupt bei diesen so oft an und für sich schwierigen Untersuchungen von oft verwickelten anatonischen Verhältnissen leider allzu häufig ein unüberwindlicher Stein des Anstosses getresen. 
Seewasser lebend und wohl bewahrt, ein Individuum dieser ${ }^{1}$ ) Art. - Das von Consistenz ziemlich weiche Thier war ganz ausgestreckt von einer Länge von $17 \mathrm{~mm}$ bei einer Breite bis 9,5 und einer Höhe bis $4 \mathrm{~mm}$; die Länge des Fusses 14 bei einer Breite bis $5 \mathrm{~mm}$; die Höhe der Rhinophorien und der Kieme etwa 1,5, der Tentakel bis $1 \mathrm{~mm}$. Die F a rbe durchgehends graulich milchfarbig; die Rhinophorien mehr weisslich, nur die oberen Blätter etwas bräunlich; die Kieme weisslich. An der Mitte der Fusssohle schimmerte ein grosser länglicher braungrauer Fleck hindurch, welcher auch an der oberen Seite, aber viel schwaicher, sichtbar war.

Während des Kriechens des trägen Thieres überragt der Schwanz mit kaum $1 \mathrm{~mm}$ den Körper; die Rhinophorien wurden aufrecht oder etwas nach hinten gerichtet getragen; die Kieme bildete einen aufrecht stehenden grossen Bogen, dessen Enden sich einander stark nïherten.

Das Thier starb nach 10 tägiger Gefangenschaft, während es an Grösse etwas abgenommen hatte.

Das in Alcohol bewahrte vicl später genauer untersuchte Thier war von ziemlich weicher Consistenz, etwas abgeplattet, von gestreckt-ovaler Form, vorne ein wenig breiter. Die Länge 10,5 mm betragend bei einer Breite bis 5 und einer Höhe bis $4 \mathrm{~mm}$; die Länge des Fusses 8 bei einer Breite bis 2,5 mm; die Breite des Mantelgebrämes $1,4 \mathrm{~mm}$, die Höhe der (halb zuriickgezogenen) Rhinophorien 1,2, die der Kieme $1,5 \mathrm{~mm}$. Die Farbe durchgehends hellgelblichweiss; die Fusssohle ein wenig mehr gelblich.

Der Rücken mit feinsten Nöppchen dicht bedeckt; das Mantelgebräme ziemlich breit, nicht diinn, die Unterseite desselben eben. Der Rand der runden RhinophorOeftnungen kaum vortretend; die Rhinophorien ziemlich gross, der Stiel etwa halb so hoch wie die Keule, die (an dem untersuchten Individum) oben abgestutzt und etwas niedergedrückt war, die Einsenkung sich in eine Furche oben an dem Vorderrande fortsetzend; die Zahl der breiten Blätter schien kaum $20 \mathrm{zu}$ betragen. Der Rand der kurzquerovalen Kiemenöffnung wenig vortretend; die Kieme aus 11 bi- und tripinnaten Blättern gebildet, von denen die vordersten und die hintersten ein wenig kleiner. Dicht vor dem Zwischenraum zwischen den zwei hintersten Blättern die niedrige, abgestutzte Analpapille, rechts vor derselben die Nierenpore. Die Seiten ganz niedrig; die Genitalpapille wenig vortretend. Der Kopf (Fig. 22) klein, mit querem Aussenmunde; zu jeder Seite desselben ein kurzer, abgeplatteter, breiter Tentakel. Der Fuss kräftig, der Vorderrand mit Randfurche, das Hinterende etwas zugespitzt.

Das Peritonaeum war fast farblos.

Das Centralnervensystem nicht abgeplattet, hinten nicht wenig dicker als vorne; die cerebro-visceralen Ganglien nierenförmig, die vordere Abtheilung etwas kleiner

1) àr ripo气, bescheiden. 
als die hintere; die rundlichen pedalen Ganglien kaum grösser als die visceralen. Die gemeinschaftliche Commissur ziemlich eng, aber kraiftig; an beiden Enden dicker, aus den drei Commissuren deutlich zusammengesetzt. Die ganz kurzsieligen proximalen Ganglia olfactoria ziemlich gross, zwiebelförmig; die distalen etwas kleiner, fast kugelrund. Die buccalen Ganglien kaum kleiner als die grossen Riechknoten, von rundlichem Umrisse, durch eine kurze Commissur verbunden.

Die A ugen ganz kurzstielig und, wie es schien, mit einem kleinen Gangl. opticum verbunden; das Pigment schwarz, die grosse Linse liorngelb. Die Ohrblasen an gewöhnlicher Stelle als kalkweisse Punkte schon unter der Loupe sichtbar, mit (etwa 100) Otokonien gewöhnlicher Art gefullt. Die Rhinophorien durch ihre Axe mit langen, stark erhärteten, spindelförmigen Spikeln überfuillt, die anch in den Blättern der Keule in Menge vorkamen und die Weichtheile fast verdringt hatten; der Querdurchmesser der Spikeln bis etwa $0,02 \mathrm{~mm}$ steigend. Auch in dem Gewebe der Tentakel kamen Spikeln reichlich vor. Die $\mathrm{Haut}$ im höchsten Grade mit den oben erwähnten ganz ähnlichen Spikeln ausgesteuert; dic Nöppehen des liiickens meistens $0,3-0,5 \mathrm{~mm}$ hoch, von ganz ähnlichem Baue wie in den Rostangen (K. perspicillata). - Die Axe der Kiemenblätter bis kurz vor ihrer Spitze mit (bis $0,5 \mathrm{~mm}$ ) laugen Spikeln gervöhnlicher Art sehr stark ausgestattet, in den Seiteniisten kamen solche dagegen fast gar nicht vor. In der interstitiellen Bindesubstanz kamen übrigens im Ganzen nicht viele Spikeln vor, mit Ausnahme in der Umgebung der Hauptausfuhrungsgainge des Genitalapparats.

Die (zuriickgezogene) Mundröhre etwa $1,3 \mathrm{~mm}$ lang, von gewöhnlicher Art; ebenso ihre Retractoren. Der Schlundkopf von derselben Länge wie die Mundröhre, die Höhe und die Breite ein wenig grösser als die Länge; die starke Raspelscheide nach hinten noch $0,5 \mathrm{~mm}$ gerade hervorstehend; die Retractoren wie gewölnnlich. Die Lippenscheibe rundlich mit dreieckiger Mundöffnung; von einer einfachen, fast farblosen Cuticula iiberzogen ${ }^{1}$ ). Die breite starke Zunge mit 10 Zahnplatteureihen in der sehr hellgelblichen Raspel, weiter nach hinten kamen deren noch 9 entwickelte und 3 noch nicht ganz entwickelte Reihen vor, die Gesammtzahl derselben somit 22. Die Rhachis schmal. In der hintersten Reihe der Zunge fanden sich (jederseits) 22 Zahnplatten vor, und die Anzahl schien weiter nach hinten nicht weiter zu wachsen. Die Zahnplatten von sehr hellgelblicher Farbe; die Hühe der innersten Platte etwa $0,11 \mathrm{~mm}$ betragend, allmählig bis $0,14 \mathrm{~mm}$ steigend, um durch die drei äussersten zu etwa $0,1-0,08-0,07$ wieder zu sinken. Die Form der Zahmplatten (Fig. 24) die allergewöhnlichste; die innersten etwas niedriger (Fig. 23a); die äussersten 4 schlanker (Fig. 25), besonders die zwei äussersten, und diese letzteren gezähnelt; die iusserste mit 3-1 nicht ganz kurzen spitzen Dentikeln und die nächstäusserste mit 1-3 ähnlichen Dentikeln (Fig. 25 ar).

1) $\mathrm{Ob}$ sich doch nicht oben in einer kurzen Strecke eine Bewaffnung von dünnen Stäbchen rorfindet, liess sich bei dem so beschränkten Materiale nicht mit Sicherheit bestimmen. semper, Philippizen. II, II (Eergh, Ergånzungsheft II). 
Die Speicheldrüsen langgestreckt, dünn, weiss.

Die Speiseröhre ziemlich weit, mit den gewöhnlichen Längsfältchen der Innenseite. Eine magenartige Erweiterung am hinteren Ende der Speiseröhre kam kaum vor. Der Darm in seiner ersten Strecke stark erweitert; die ïbrige, nach hinten gehende viel dünner. Die Leber keģelförmig, vorne schräg abgestutzt, hell gelblich; die Gallenblase konnte nicht nachgewiesen werden.

Die Zwitterdrise zeigte keine entwickelten Geschlechtselemente. Die vordere Genitalmasse sehr wenig entrickelt, nur von einer Breite von kaum $2 \mathrm{~mm}$ bei einer Höhe bis kaum 1 und einer Dicke von etwa $0,5 \mathrm{~mm}$. Die Ampulle des Zwitterdrísenganges etwas geschlängelt; die Spermatotheke kugelförmig. Es kommt eine starke Stacheldruise mit geschlängeltem Ausfïhrungsgange vor, der seitlich am Grunde des Stachelsackes eintritt, in dem letzteren ein Stachel, dem der Jorunna alba fast ganz ihnlich, und innerhalb der ïusseren Scheide etwa $0,56 \mathrm{~mm}$ bei einem Durchmesser am Grunde von etwa 0,03 $\mathrm{mm}$ messend. ${ }^{1}$ )

Ob diese Form nun wirklich der Gattung Jorunna gehört, muss vorläufig dahingestellt bleiben; die Form der Tentakel ist in dieser Beziehung sehr verdächtig. Die Form der äusseren Zahuplatten würde jedenfalls dicselbe als cine neue Art bezeichnen.

1) Eine genauere Untersuchung der Genitalorgane war dem Conservationszustande nach nicht möglich. 
I.

\section{HISTORISCHE EINLEITUNG.}



Unter einer Gruppe von Schalthieren, die sich durch eine kleine Spira, eine grosse letzte Windung und eine sehr weite Oeffnung characterisiren, und die friiher meistens Seeohren (a ures marina e) benannt wurden, figuriren einige, die sich durch Fehlen von Löchern auf der letzten weiten Windung besonders auszeichnen, und mit denen uns schon gegen Ende des 17 ten Jahrhunderts BuONANNr ${ }^{1}$ ) und LISTER ${ }^{2}$ ), ferner Rumpi $^{3}$ ), T'ournefort ${ }^{4}$ ), Pexiver ${ }^{5}$ ), Gualtieri ${ }^{6}$ ), D'Argenville ${ }^{7}$ ) und melirere Verfasser Anfangs des 18 ten Jahrhunderts bekannt gemacht hatten. Als ein eigenes Genus (Stomatia) wurden dieselben dann vom damals verrufenen Engländer JoHN HiLL ${ }^{8}$ ) gesondert; die von ihm gegebene Benennung wurde besonderer Umstïnde wegen aber nicht in die kurz nachher erschienene Arbeit KLEIN's ${ }^{9}$ ) aufgenommen. Der von KLELN gegen die von Tounnefor'T und Linné für die generische Nomenclatur gegebenen Regeln gebildete Gattungsname (Catinus lactis) konnte auch eben deshalb nicht adoptirt werden, wäh-

1) Fintpri Boonaner, observ. circa viventia, quae in rebus non viventibus reperiuntur; cum microgr. curiosa; his accesserunt aliquot anim. testaceorum icones non antea in lucem ed. 1691. pag. 219. f. 14.

Eine hiexhin gehörende Form findet sich dagegen nicht in desselben Verfassers: Ricreazione dell' occhio e delle mente nell' osserv. delle chiocciole, 1681 (oder in der zweiten lateinischen Ausgabe desselben Werkes, Roma, 1684). Mus. Kircherianum (1709), in dem die beiden Arbeiten vereinigt sind, hat die ältere Figur (Taf. XLVIII. Fig. 404. [pag. 11S]); Linné citirt dieselbe zu seiner Helix haliotoidea, während Cuvier (Mém. p. 4) sich dieselbe als die Helix neritoidea, L. darstellend zu betrachten erlaubt. Die Figur von Boonans stellt übrigens den Sigaretus cymba, MIEnke (I830) dar (= Sig. Grayi, Drsu. = Sig. maximus, Pн. = Sig. concavus, Sow. [nec Lsr. cfr. Gray, Spicil. zool. pag. 4]).

2) Mart. Lister, hist. conchyl. 1688. Lib. IV. Tab. 570. Fig. 21.

Die Form wird von Lrswé (S. N. ed. XII) zu H. haliotoidea citirt, bei GMrin fehlt das Citat. Sie scheint mit der von Buoxaxar wenigstens verwandt.

3) Rompr, d'Amboynsche Rariteitkammer. 1705. Taf. 40. Fig. R. Pag. 123 (II Book) VIII. Ist diese Form die Cryptostoma javanica in Griffith, animal kingdom. Tab. 41. Fig. 1.?

4) CF. Gealtierr, index testarum. 1742. praef. p. XVII. nintroductio ad hist. testac. a cel. P. Tournefortio in codice ms. relicta" (p. XVIII. Auris marina).

5) Petrer, gazophylac. nat. et artis. dec. X. 1702-1711. pag. 3. Tab. XII. Fig. 4.

- aquatil. anim. Amboinae. 1713. pag. 4. Tab. 16. Fig. 29 (Copie nach Roupr, wie auch erwähnt).

6) Gualtieri, ind. test. - conchyl. 1742. Tab. 69. Fig. F.

7) Desaluer d'Argervile, hist. nat. éclaircie dans une de ses parties principales, la Conchyliologie. Nouv. édit. 1757. pag. 195.

La conchyliolog:e ou hist. nat. des eoq. par Des. D'Argexvirle. 3ème éd. par Favanse de Monteervelie, père et fils. I. (1780) pag. 590. pl. V. Fig. C. - Der Beschreibung nach eine collective Art, die auch als von Niger, Ostindien, Isle de France, St. Domingo, Martinique und dem Mittelmeere stammend angegeben wird.

8) J. HiLl, a general natural history. III (1752). pag. 119.

Von den 3 Arten, die er beschreibt, wird die zweite (pl. 7) abgebildet ( ${ }_{n}$ Stomatius sp. $2^{4}$ ).

9) Krein, tentamen methodi ostracologici. 1753. pag. 19. Tab. VII. Fiig. 114.

KLErN hat für die von ihm erwänte Form keine Localitätsangabe. 
rend PAtrick Browne') dagegen ein Paar Jahr spaiter die von HiLL gegebene Benennung aufnahm, so wie er die Gruppe schärfer begrenzte.

Der von ADANSON") fast gleichzeitig gegründete "Sigaret" war nach einer Conchylie von der Mündung des Nigers aufgestellt, die den von den früheren Verfassern erwihnten nicht unähnlich war, und die er selbst mit diesen identificirte. Ohne das Thier der Conchylio zu kennen stellte ADANSON, "le Sigaret" nur als eine Art des "l'Ormier" hin, indem er doch nebenbei die zwischen den beiden Arten dieser Gattung bestehenden grossen Unterschiede hervorhebt.

LinnE ${ }^{3}$ ) hatte schon 1735 die Gattung Haliotis aufgestellt, durch „disco longitudinaliter poris pertuso" characterisirt; dieselbe ging ohne wesentliche Aenderungen durch die folgenden Ausgaben des Systems, und erst in der zehnten ist die Zahl der Arten der Gattung bedeutend vergrössert, während die Gattungscharactere noch unverändert stehen blieben. Die Gattung konnte somit nicht die nicht durchbohrten Seeohren der verschiedenen Verfasser aufnehmen; diese nahm Linsé in seine umfassende Gattung Helix auf, imnerhalb deren weiten Characteren sie gut hineinpassten. Sie sind hier unter einer Species, Helix haliotoidea (621), vereinigt, von den anderen Helicen durch die napertura ovali dilatata usque in apicem" (diagn.), und durch die , testa in apicem usque perspicua, ut Haliotis, sed tragus non pertusus" (descr.) unterscheidbar. Neben derselben stehen zwei andere, auch ganz neue Arten, H. perspicua (620), „labro nullo", und H. neritoidea (619), ,rima umbilicali“. Ohne wesentliche Aenderungen gingen diese Arten, die auch in das Mus. Lud. Ulr. aufgenommen und weiter beschrieben gewesen waren, in die XII. Ausgabe des Syst. nat. iber; die Charactere der H. haliotoidea sind

1) PAtrsce Browse, civil and natural history of Jamaica. 1756. pag. 398.

2) Anarsor, hist. nat. du Senegal. 1757. - Gen. VI. l’Ormier. 2. le Sigaret. pag. 21. Tab. 2.

Die genaue Bestimmung der Art, die Adaxsos vorgelegen hat, ist kaum möglich. Verschiedene Verfasser sind der Meinung gewesen, dass Adaxsos zwei Arten ror sich gehabt hat. Dies ist ja möglich; er bildet aber nur eine ab, und für die Bestimmung kann nur auf diese Figur Rücksicht genommen werden, nicht auf die Angaben des T'extes, die von zu grosser Latitude sind. Auch G. B. Sowerny (Number XIX of the gen. of recent and fossil shells) nimmt zwei Arten in jene einbegriffen an, das Cryptostoma Leachii und breviculum ron Brarvrere (während Sowv, also Cr. breviculum mit Anarson's Sigaret p. p, identificirt, erklärt er denselben für das Weibchen des Sigaretus, Cer.!). Die Heimath der von BLanvule angegebenen Arten war ihm unbekannt, und die Schalenform selbst scheint eine Identification mit dem Sigaret ron Adansox zu rerbieten (ron $\mathrm{Cr}$. breviculum fehlte die Schale. Cfr. Dict. sc. nat. XII; Sow. 1. c.). Puidrppr dagegen (Abbild. I. pag. 143. Taf. I. Fig. 5) macht aus dem Sigaret ron Anassox (und Martrsi) seinen Sig. Martinianus; durch die Sculptur scheint derselbe aber verschieden; Ivcalitätsangabe fehlt; der Figur und der Beschreibung nach würde der Sig. Martinianus, P\&. eher einer der westindischen Arten ähnlich scheinen.

An der Küste ron Guinea und Senegal kommen mehrere Arten dieser Gattung ror; eine, dem Sigar. cymba, Mrв. :ilnnlich, aber mit dickerer Schale, mit weniger gewölbtem letztem Anfractus und mit dem vorletzten stärker in die Mündung eintretend, ist wahrscheinlich die Form ron Abussos (Sig. Adansonii, BEck); eine andere riel kleinere, viel mehr niedergedrückte, weissliche mit bräunlicher Spir und oft mit Fleckenreihen an der letzten Windung ist der Sig. apicalis, Beck. Vergl. meine: Bidrag til en Monographi af Marseniaderne. Danske Vidensk. Selsk. Skr. 5 R. Naturvidensk. og mathem. Afdel. 3 B. 1853. pag. 245 Anm.

3) Lusxé, syst. nat. Lugd. Batav. 1735. Cl. IV.

Noch in der VI. Ausgabe (Holmiae. 1745, pag. 74) findet sich nur eine Art.

Ed. X. T. I. 1758. pag. 775. No. 619-621.

Ed. AII. T. I, pars 2. 1767. pag. 1250. No. 711-713.

Mus. Lud. U1r. 176t. pag. 673. - Das MLuseum mit den Originalstücken ist schon in der 10. Ausgabe des Systems citirt. 
hier mit ${ }_{n}$ striis undatis" erweitert, sowie ihro geographische Verbreiung mit "Mare asiat. " erweitert, während Mus. Lud. Ulr., Lister, Buonasni, KLenN und Aldasson den ailteren, schon in der $X$. Ausgabe aufgenommenen, Synonymen zugefügt werden; dagegen werden weder J. HiLL ${ }^{1}$ ) noch P. Browne unter denselben genannt. Auf die H. perspicua ist die kurze Beschreibung von $\mathrm{H}$. Laliotoidea (in der $\mathrm{X}$. Ausgabe) iibertragen; die H. neritoidea steht ganz ungeändert.

Diese drei erwähnten Formen bieten in der Schale eine habituelle Aehnlichkeit dar, die dem scharfen und geibten Auge Livxé's nicht entgehen konnte. Diese Zusammenstellung, die zu seiner Zeit fast berechtigt genannt werden musste, wenn auch durch einen einzelnen Character höchst ungleiche Formen zusammenknüpfend, hat sich, wie die folgende historische Darstellung zeigen wird, noch bis in neuere Zeit bewalurt.

Wenn die Gattung Stomatia von Hill und Browxe jetzt für diese imperforirten Conchylienformen bewahrt worden wäre, würde viele spätere Verwirrung entgangen sein. Nachdem Linvé sich aber dagegen oder wenigstens nicht dafür erklärt hatte, wair Solches nicht zu erwarten. Doch schloss sich. MARTINI ${ }^{2}$ ) nicht vollständig der systematischen Anordnung bei LiNxé an, und sonderte schon 1769 generisch die von Lisisé unter II. haliotoidea vereinigten Formen, für die er aber die Benennung von KLern, Catinus (lactis), adoptirte.

Trotz aller Versuche von HrL, Browne, Ḱlein und Malitixi, diesen Thierformen einen besonderen generischen Platz zu behaupten, wollte Solches den Conchyliologen doch immer nicht gefallen. Sie fuhren noch lange fort, theils dieselben, wie in den früheren Tagen der Conchyliologie, unter den Aures marinae zu bewahren |wie in der

1) Joнs Hru war in verschiedener Weise, darunter auch durch eine verbesserte Anwendung des damals nur wenig benutzten und geachteten Mikroskops, sowie durch scharfe Aeusserungen und noch schärfere Kritiken in Opposition zu den hervorragenden Persönlichkeiten der einflussreichen Royal society gekommen. Seine Bestrebungen, durch populaire Darstellungen, der Naturgeschichte beim grösseren Publicum Eingang $2 u$ verschaffen, werden wohl auch dazu beigetragen haben ihn in den Augen der naturgeschichtlichen Aristokratie seiner Zeit herabzusetzen. Die Form seiner Arbeiten wurde lächerlich gemacht, und man versuchte in jeglicher Weise die Zuverlässigkeit derselben zu verdächtigen. J. HuL rächte sich in eclatanter satirischer Weise, indem er durch sein Review of the works of the Royal society (London, 1751) vor dem grossen Publicum die vielen und groben, fast unglaublichen Sünden gegen die Wissenschaft aufdeckte, deren sich so viele der Mitglieder der Gesellschaft schuldig gemacht hatten. Der Bruch zwischen Hru und der königlichen Gesellschaft, „the great champion of errors" (1. c. pag. 107), war jetzt unheilbar; und an dem ron da ab fortgesetzten Kampfe des Einzelnen nit den Vielen und dea besser Gestellten, mit der mächtigen Gesellschaft musste Hru selbstfolglich zu Grunde gehen. Lrxsé, mit mehreren der Angegriffenen persönlich befreundet, hat in seiner eigenthümlichen Weise gegen ihn Partei genommen; er ignorirte ihn vollständigst und überall; - während J. C. FABricres (Entom. syst. I. [179:] pag. X) scharf das VerdammungsUrtheil der Dazeit mit seinem unbarmherzigen Anathema namnandae vero memoriae JoHs Hul et Lotrs Rersard, qui animalia ficta proposuere" ausspricht. Corier hat schon lange (Hist. nat. des poissons. 1. 1828. pag. 8i-85) Loris lierksad ron freiwilligem Betruge freigesprochen, und Jons HicL hat auch alle berechtigte Forderungen auf solches Freisprechen. Er ist wie jener betrogen worden und hat in gutem Glauben unmögliche Thiere abgebildet; in den allermeisten seiner gewiss oft unglucklichen und ungenauen Figuren erkennt man doch jetzt allgemein bekannte exotische 'Thierformen; ein Theil der Conchylien ist der Zeit und den Umständen nach gar nicht schlecht abgebildet. Die Bestrebungen HiL's waren gewiss redlich, seine Kenntnisse und seine naturgeschichtliche Bildung im Ganzen mehr umfassend als die der meisten seiner Gegner. Joнx HrL war nicht das erste und ward nicht das letzte Opfer wissenschaftlichen Cliquenwesens und akademischer Pänke.

2) Martis, Verzeichn, einer auserlesenen Sammlung von Naturalien. 1767.

Vergl. ferner: Neues system. Conch.-Cab. I. 1769. jag. 191, und besonders die tabellarische Uebersicht in System. Conch.-Cab. III. 1777. 
dritten Favanne'schen Ausgabe der Conchyliologic von Argenville, bei den Herausgebern des KnorR'schen. Werks ${ }^{1}$ ), bei DA CosTA ${ }^{2}$ )], theils als Helix haliotoidea fungiren zu lassen [wie die strengeren älteren Linnaeisten, wie bei V. BOrN ${ }^{3}$ ) und Schröter ${ }^{4}$ ) sowie in der dreizehnten Gielin'schen Ausgabe des Syst. nat. ${ }^{5}$ ), ferner bei Dillwyn ${ }^{6}$ ), Turton ${ }^{7}$ ), WOOD $^{8}$ ) $\left[\right.$ MONTAGU $\left.\left.^{9}\right)\right]$ und in noch mehreren anderen weniger bedeutenden Arbeiten $\left.\left.{ }^{10}\right)\right]$; während endlich noch andere Verfasser sie als besondere, aber meistens doch nicht characterisirte Gattungen hinstellten [MEUSchen ${ }^{11}$ ) (Auriformis), Humpireys ${ }^{12}$ ) (Auris Veneris), BOLTEN $\left.^{13}\right)$, LINCK $\left.{ }^{14}\right)$ (Sinum)].

Alle jene Thierformen (Conchylien) gruppiren sich doch deutlich um H. haliotoidea, L. Dagegen war die H. perspicua den Conchyliologen der Dazeit ganz unbekannt geblieben (vergl. Schröter, l. c.); und nicht viel besser stand es um die Kenntniss der H. neritoidea. Fast gleichzeitig mit den späteren LINNÉ'schen Arbeiten war aber eine mit H. perspicua verwandte Form in die Wissenschaft eingeführt worden, die von STRö: ${ }^{15}$ ) be-

1) Kivore, Vergnüg. des Auges und des Gem. 1761-1772.

T. IV. I. XVII. Fig. 5. BoLTEN giebt diese Figur als sein Sinum fuscum darstellend an; sie scheint noch mit der A. veneris pallens von Homprrexs identisch und mag vielleicht das Cr. Leachii, Pr. darstellen.

T. VI. p. 75., T. 39. Fig. 5 soll Bortex zufolge sein Sinum haliotoideum darstellen.

2) Er. Mennes da Costa, elements of conchology. 1776. pag. 146, 187. Ste (durch Druckfehler 10te) Fam. pl. 3. Fig. 8.

3) Ignat. de Born, ind. rer. natur. mus. Caes. Vindeb. I. Testacea. 1778. pag. 393.

4) Schröter, Einleit. in die Conchylienkenntn. nach Livá. II. 1784. pag. 176.

Als eine Varietät wird hier eine Form von Tranquebar beschrieben, ihm von Spexarer mitgetheilt.

5) Syst. nat. T. I, p. VI (1790), pag. 3362.

Gurmix nimmt hier die Helix haliotoidea auf, wie sie sich bei Scuröter findet; als (var.) $\beta$ kommt noch zu die von Cirennitz (N. syst. Conch.-Cab. X. 1783. Taf. 165. Fig. 1598, 1599) erwähnte H. neritoidea, die hierhin nicht gehört und später den Typus der Gattung Velutina von Buanvilie und Grax bildete. Die Charactere der Gattung Haliotis stehen unverändert, was aber Gaelin nicht verhindert, imnerhalb derselben noch imperforirte Formen, Hal. imperforata, perversa, plicata (1. c. pag. 3690) unterzubringen.

6) Diclwy, a descript. catal. of recent shells. 1817. 1I. pag. 972.

7) T'urton, a general system of nat., by Linnaeus. VI. $\mathbf{1 8 0 4 .}$

S) Woon, index. 182S. pl. 35. F'ig. 187.

9) Montagu, 'Test. 1803. Brit.

10) O. Fr. Müller, zool. Dan. prodr. 1776. pag. 210. No. 2900.

Die von Mürcer hier aufgenommene Helix haliotoidea ist Velutina haliotoidea. In der Fauna groenland. von Fabricios (pag. 390) ist diese letztere als $H$. haliotoidea, L. aufgeführt; wie vom Citate Akoperursak hervorgehend, hat M. nach Fabricios diese Identification aufgenommen.

11) Meuscien, Mus. Gevers. 1786, pagr. 250.

In einer eigenen Unterabtheilung (cfr. Addenda, pag. 657) werden 3 Arten gesondert. Die Synonymie ist sehr unzuverlïssig (vergl. die Citaten wach Gualtierr, auch damit Pmin., Abbild. I).

12) MLs. Calonnianum, 1797. pag. 20.

Auch hier ein Versuch die collective Lrwsésche Art zu theilen (330-332). Auris veneris alba ist vielleicht del Sig. depressus, Pr. oder S. perspectivus, SAr; A. T. pallens (Sinum fuscum, Bortris) ebenso das Cryptostoma Leachii, Pr., und die A. v. pulligera der Sigaret von Amanson.

13) Mus. Boltex. 1798 (ed. 1). ps. 2, p. 14. - ed. II. 1S19. p. 10.

14) Linck, Mus. Rostock. pag. 112 (3 te Abth. 1807).

Die Gattung ist hier characterisirt.

In: Lrcutensterx, das zool. Aus. der Univers. zu Berlin (2 Ausg. 1807. pag. 107) findet sich "Nerita (Helix, Sinum) haliot".

15) Skrifter, som udi det Kjöbenh. Selsk. ere fremlagte og oploste. X. 1770. pag. 10. Tab. V. Fig. 1-4. (vergl. auch die originalen, in del Universitätsbibliothek von Kopenhagen deponirten Handzeichnungen). 
schriebene Thetys absque auriculis, die von O. Fr. MüLLER ${ }^{2}$ ) als Bulla latens aufgenommen wurde, und die, obgleich in den Formverhältnissen des Thieres vielleicht abweichend, in den Schalenverhältnissen an die Lisné'sche Art erimnerte. GMelin hat diese Art ibersehen, und somit blieb diese sowie die verwandte H. perspicua von Linné noch lange fast vollkommen unbekannt, selbst den nordischen Naturforschern. Erst M. SARS ${ }^{2}$ ) hat die B. latens wieder hervorgezogen; die LiNvé'sche Art wurde erst später wieder erkannt und untersucht, falls dieselbe iiberhaupt specifisch noch zu erkennen war. - G. CuviER, der eben seine Molluskenstudien angefangen hatte, lieferte gegen das Ende des Jahrhunderts, dessen Beiträge zur Kenntniss der hier zu behandelnden Thierformen oben revidirt worden sind, eine Untersuchung einiger Weichthiere ${ }^{3}$ ), um als etwas der Wissenschaft Neues - die Unnatürlichkeit einer scharfen Unterscheidung zwischen schalentragenden und nackten Weichthieren (Testacea und Mollusca, L.) darzuthun, eine Wahrheit, die schon lange vorher von O. FR. MÜLLER ${ }^{4}$ ) ausgesprochen vorden war. Unter den von Cuvier beschriebenen Thierformen findet sich eine mit innerer Schale, wie er meinte, vom Senegal stammend und mit dem Sigaret von ADAxson identisch und somit die Helix haliotoidea von Linvé. Die Voraussetzungen, auf denen sich der gegebene Name stützte, waren grundfalsch, hervorgegangen, wie es scheint, aus vernachlässigter oder fahrlässiger Vergleichung mit der Beschreibung und der Figur ADANson's; die eigene Beschreibung CuviER's ist noch dazu so unvollständig und fehlerhaft, dass die Malacologen der nächsten Decennien darin unmöglich die Form vermuthen konnten, womit sie Cuvier später (1817) bekannt machte. ${ }^{5}$ ) Die nähere Verwandtschaft der Form mit H. perspicua, L. („labro nullo") bemerkte Cuvier nicht; die nahestehende Art von STRöM scheint er damals nicht gekannt oder vergessen zu haben. ${ }^{6}$ ) Fast zu gleicher Zeit wurde das Thier als Gattung in der 5 ten der Uebersichtstabellen aufgeführt, die den ersten Theil der Leçons d'anat. comparée begleiten; sie steht hier unter lauter nackten oder nur schwach beschalten Mollusken, zwischen Testacella und Aplysia. Bei seiner Anstellung als Docent der Naturgeschichte der niederen Thiere hatte LA\ARCK seine botanischen Studien mit zoologischen vertauscht und vorzugsweise die Mollusken zu bearbeiten

1) Zool. Dan. Prodr. 177G. pag. 242, No. 2923.

2) Beskriv. og Jagttag. over nogle morkelige eller nye i Havet ved den Bergenske Kryst levende Dyr. Bergen. 1835. pag. 67. [Uebersetzung in Isis. 1S37. pag. 754 (Sigar. Stroemii)].

3) Bull. de la soc. philomat. Oct. 1799. No.31. pag. 32. Observ. nour. sur quelques Mollusques.

4) Verm. terr. et fluv. hist. Vol. II. 1774. Praef. pag. VII, VIII. Limax und Helix finden sich daher in eine grosse Gruppe vereinigt, während sie dagegen Lissé in jenen 2wei Abtheilungen auseinander gehalten hatte.

5) OKEs, Lehrb. d. Zool. I. 1815. pag. 299. Aplysia. Art? Sigaret, H. haliotaideus: Hierher oder zur folgenden oder zu Karsessters's Phyllidia“. Gray (Zoolog. Journ. I. pag. 427) meint, dass Crrier in dem "Bull, des sc." No. 31 wirklich das Thier vom Lasarckschen (Adarsor'schen) Sigaretus beschrieben habe, und macht darauf aufmerksam, dass Covier später (Anat. des moll.) unter demselben Namen ein ganz anderes Thier dargestellt habe.

6) Wenige Jahre nachher (Ann. du MIus. VI. 1805. pag. 416) citirt er denselben Band der Schriften der Kopenhagener Ges. d. Wissenschaften, in seiner Abhandlung: Eolidia, Scyllaea und Glaucus. 
angefangen, mit denen er sich schon früher, theilweise durch den Dänischen Conchyliologen Hrwass beeinflusst, beschäftigt hatte. Kaum einen Monat vor jener kleinen Notiz CUVIER's hatte LAMARCK auch einen Versuch einer Reform der Malacologie publicirt, aber nach einem viel grösseren Maassstabe angelegt. In seinem Prodrome d'une nouvelle classification des coquilles ${ }^{1}$ ) sowio in seinem, nicht lange nachher erschienenen Système ${ }^{2}$ ) finden wir den Artnamen Sigaret von Adanson für eine Gattung Sigaretus angewendet, die auf die Schalencharactere gegrindet ist, die der H. haliotoidea und somit auch der AdANson'schen Art angehören; in seiner letzt erwähnten Arbeit kommt dazu noch eine Beschreibung des Thieres, d. h. er fuigt jenen die von CUviER gegebenen Erläuterungen über ein ganz verschiedenes Thier zu, das dieser Sigaret genannt hatte. Der Sigaretus von LAnARCK ist also die H. haliotoidea, L. = Stomatia, Hrlu, Browne = Catinus (lactis), Klein, Martini; während der Sigaretus von Cuvier dagegen ein ganz verschiedenes 'Thier darstellt, das eine sehr fragile und innere Schale ohne Innenlippe besitzt und somit Formen umfasst, die mit der Helix perspicua von LINNÉ und der Thetys von STröm iibereinstimmen.

Die bei LAMARCK der Schalenbeschreibung angehängte Beschreibung des Thieres - woher dieselbe herrïhrte, konnte nicht Allen klar sein - musste Missdeutungen zulassen, um so mehr als Cuvier das Dasein von Kiemen unter dem Mantel des Thieres wie in der Patella angegeben hatte. Es konnte daher nicht vermieden werden, dass verschiedene Gattungen allmählig gebildet und als neue Thierformen repräsentirend in die Wissenschaft eingetragen wurden, obgleich sie in der That ganz mit den Formen zusammenfielen, dic LamarcK und Cuvier vor sich gehabt hatten.

In dieser Weise kam der bekannte englische Faunist MonTAGU ${ }^{3}$ ) dazu (1811), für cinige Meeresgasteropoden mit innerer Schale die Gattung Lamellaria aufzustellen. Innerhalb der Gattung sonderte er ferner zwei Gruppen, eine mit äusseren Kiemen (L. membranacea, n. sp.; L. plumula, Test. Brit.), eine andere ohne solche (L. tentaculata, n. sp.; L. haliotoidea, Test. Brit.). Für dic erste Gruppe hatte Cuvier ${ }^{4}$ ) schon (1804) die Gattung Pleurobranchus aufgestellt; die zweite ist init dem Sigaret von CUVIER identisch, so wie dieser spiiter bekannt wurde. Es war dem MonTaGU ganz unmöglich, diese Identitït voraussetzen zu können.

Die Aehnlichkeit des von Montagu gegebenen Namens mit der generisehen Benemnung einer Alge (Laminaria, Lamouroux), noch dazu der Umstand, dass der Name Lamellaria sich nicht für die erste und wohl typische Section der Gattung von MonTAGU bewahren liess, scheinen LEACI dazu bewogen zu haben den Namen ganz aufzugeben. Er hat schon etwa 1819 im Britischen Museum und im folgenden Jahre in seiner Synop.

\footnotetext{
1) Mém. de la soc. d'hist. nat. de Paris. I. An VII (1798-1799). pag. 63.

2) Système des anim, sans vertèbres. 1S01. pag. 64.

3) Linnean Transact. XI. 1811. pag. 179.

1) Ann. du Mus. V. 1804. pag. 260.
} 
sis $^{1}$ ) fur die erste Gruppe der MonTAGU'schen Lamellarien die Gattungsnamen Oscanius ${ }^{2}$ ) (L. membranacea) und Cleanthus (L. plumula) angewendet, doch wohl nur als subgenerische Bezcichnungen innerhalb des umfassenden Genus Pleurobranchus von CuviEr; während er die andere, die hier abzuhandelnde Gruppe (mit Ausschluss der irreleitenden Benennung Sigaretus) Marsenia benannte. Als Typus ${ }^{3}$ ) der neuen Gattung sctate er Bulla haliotoidea, MTG. T'est. Br. (= Lamell. haliot., Limn. Tr.'), deren Namen er (auch um neue Irrthiimer auszuschliessen) in (Marsenia) producta änderte. - Eine ganz andere, doch mit den Sigareten ron Cuvier, den Lamellarien (p. p.) von Moxtagu, den Marsenien von LEACH verwandte Thierform meinte etwas später (1S24) BLANyille in einem Thiere von Isle de France zu erkennen, und stellte fïr dasselbe sein Genus Coriocella auf. ${ }^{4}$ ) Diese erwies sich aber als eine Marseniade mit sehr dünner Schale, die an dem von Blainville untersuchten Exemplare ausgefallen war, wie $\mathrm{GRAY}^{5}$ ) und Cuviel. ${ }^{0}$ ) bald bemerkten. Den Namen Sigaretus wollte Blarvville an nahestehende Formen mit deutlich entwickelter innerer Schale übertragen haben; von den zwei, von ihm zu dieser Gruppe citirten, Arten entspricht doch nur die eine den Gattungscharacteren, die andere dagegen (, S. haliotoid., Mar'trin. I. Taf. 16. Fig. 151-154") gehört der Gattung Stomatia, Hill (Cryptostoma, BlaInv.) an. In dem Artikel Sigaret des ein Paar Jahr später erschienenen 49. Bandes der Dict. sc. nat. stehen die Gattungsmerkmale noch ungeändert, nur die Zahl der Arten scheint ziemlich vermelırt, von diesen 8 Arten sind aber wenigstens 6 StonatiaFormen (Blannvile scheint übrigens hier geneigt, die Helix perspicua als einen Pleurobranchus zu betrachten). - Um einen nominellen Gegensatz zu dem kurz vorher aufgestellten Cryptostomus (der übrigens von ihm nur als Synonym zum „Sigaretus, Lik., Sow. " [!] aufgenommen wurde) schuf $\mathbf{M E x K E}^{\top}$ ) später (1830) für die Coriocellen BLAINVILLE's die Benennung Cryptothyra, jetzt also die vierte Benennung für dieselbe generische Gruppe.

Somit sind also für eine und dieselbe Gruppe, die, welche sich um Helix perspicua, L. sammelt, vier (fünf) Gattungsbenennungen entstanden, die Cuvrer'schen Sigarets (1799), die Lamellaria von Moxtagu (1811), die Marsenia von LEACH (1819), die Coriocellen von Blainvile (1824) und die Cryptothyra von Menke (1830). Solches hatte darin seinen

1) W. E. Leach, synopsis of Br. Moll. 1820. teste Grax (Ann. mag. n. h. XX. Oct. 1847); efr. Okex, Isis, 1823. II. pag. 460 (Mus. Paris).

- - , Molluse. Brit, synopsis. ed. Grar. 1852. pag. 26.

2) nec Oscana, Bosc. 1792 (eine parasitische Crustace).

3) Die Angabe von Herranssex (Ind. malacoz. prim. II. pag. 23), dass Bulla latens von Mëlier der Typus der Gattung sein sollte, rührt wohl nur daher, dass diese nordische Art sich mit der Etiquette Marsenia latens in der, von Dr. H. BEck (Mus. Christiani VIII) an die Naturforscher-Versammlung in Fiel 1817 eingesandten Sammlung nordischer Mollusken fand.

4) Dict. sc. nat. T. 32. 1824. pag. 259 . Man. de malacologie. 1825. pag. 466.

5) GRaY, spicil. zoolog. part I. (1828). pag. 4. efr, auch Gray in Proc, zool. soc. 1847. pag. 143.

6) Cuvier, Règne animal. 2 éd. 11l. 1830. pag. 90.

7) MExke, synopsis. éd. 2, 1830. pag. 87. 
Grund, dass es bei der Unvollständigkeit und Fehlerhaftigkeit der ersten Cuvier'schen Untersuchung und Beschreibung dieser Thiere den folgenden Forschern fast unmöglich wurde die 'Thierformen zu erkennen, die Cuvien vor sich gehabt hatte. - Spätere Verfasser (Delle Chiaje, Gould, Mrchaud, Audouin u. s. w.) hatten die Anzahl der Arten der Gruppe vermehrt, sonst - mit Ausnahme von LOvÉN ${ }^{1}$ ) - Nichts zu genauerer Kenntniss derselben beigetragen, eher die Verwirrung dadurch aufrecht erhalten oder wieder erweckt, dass sie diese Formen unter dem Gattungsnamen Sigaretus (LMK.) erwåhnten. Meine 1853 erschienene Monographie ${ }^{2}$ ) klärte endlich diese Fragen und erweiterte die Kenntniss der Gruppe.

Die andere der oben erwähnten drei Gruppen, zahlreicher an Arten und deren Arten viel fruher gekannt sind, hat als Typus die Helix haliotoidea, L. Diese collective Art LinNÉ's hatten schon einige der älteren postlinnaeischen Conchyliologen (MEuscren, Humpurers) in ihre einzelnen, specifisch verschiedenen Theile aufzulösen angefangen. Es war dieselbe Art, die den Typus fuir die Gattungsformen Stomatia und Catinus (lactis) der älteren Verfasser abgegeben hatte; es war in der 'That hierher, dass der Sigaret von ADanson zu bringen wäre, und auf sie fusste der Sigaretus von LaMarck. Wie oben erwïhnt hatte LAMARck seiner Beschreibung der Schale die Angaben Cuvier's über die Formverhältnisse seines Thieres hinzugefiigt; daher konnte BlarviluE ${ }^{3}$ ) in einem hierher gehörenden Gastraeopoden, den er im Britischen Museum vorfand, nicht die Gattung von LAMARCK erkennen, sondern glaubte eime ganz neue vor sich zu haben, die er Cryptostoma nannte. Dieselbe wurde aber doch so hinlänglich von ihm characterisirt, dass die Aehnlichkeit mit dem Thiere von Natica (LAMk.), wie dieses später gekannt wurde, unverkennbar ist. Hinliinglich und ganz richtig waren die von BLAINviLLE gegebenen Charactere doch nicht, besonders war die Angabe von einer ganz inneren Schale wohl dazu geeignet, Missverständnisse zu veranlassen, und mit dem neuen Namen war somit nur die Anzahl der Gattungsnamen vermelırt, aber noch nicht ein genaueres Verständniss geschaffen. Nicht lange nachher machte Eudès Delonchansp ${ }^{4}$ ) in einer Note iiber cinige von ihm lebend beobachtete Meeres-Mollusken auf die Formverhältnisse des Natica-Thieres auf-

1) Index moll. Scandin. occid. habit. 1846. pag. 15.

Oefvers. Vetensk. Ac. Handl. 1S47. pag. 192.

2) R. Beren, Bidr. til en Monogr. af Marseniaderne. 1853. Kgl. Danske Vidensk. Selsk. Skr. 5 R. Naturvidensk, og mathemat. Afdel. III. pag. 243-359. Tab. I-V.

3) ("Encycl. Edin. Suppl. 1818").

Dict. sc. nat. T. XII. 1818. pag. 121; T. XXXII. 1824. pag. 259.

Man, de malac. 1825. pag. 467.

[Cryptostomus, Rang. Man. 1829. pag. 237].

Die Elaterin-Gattung selbigen Namens ron Dejean ist jünger.

4) Bull. des sc. X. 1527. pag. 298. 
merksam; diese skizzenhaften Angaben wurden aber übersehen, und erst durch GuLinING') und fast gleichzeitig durch Fonbes ${ }^{2}$ ) wurde dieso Thierform wirklich bekannt. - Schon GRAY $^{3}$ ) hatte (1825) auf die Schalen-Aehnlichkeit des Cryptostoma mit dem Sigaret von ADANSON und dem Sigaretus von LAMARCK aufmerksam gemacht, sowie auf die wahrscheinlich generische Identität dieser Namen, ferner die bedentenden und auffallenden Verschiedenheiten von den CuviER'schen Sigareten hervorgehoben, zu denen die Helix perspicua von Linné und Bulla haliotoidea von Movtagu und somit ein I'heil der Lamellaria ${ }^{4}$ ) von MoNTagu hinzuführen wären. Später (1828) wies GraY ${ }^{5}$ ) den Cryptostomen und somit den LAMARck'schen Sigareten ihre richtige Stellung unter den Naticiden an, während er gleichzeitig die Coriocella von Blainville als eine Form der Cuvier'schen Sigareten mit (ausgefallener) dünner Schale deutet. Die Nothwendigkeit einer gainzlichen Reform der Gattungsbenennungen scheint damals GRAY noch nicht klar geworden zu sein, desshalb blieben seine sonst so wesentlichen Bemerkungen ohne Einfluss.

Die'nicht lange nach der Publication der Cryptostoma-Gattung erschienene grosse Arbeit LAMARCK's ${ }^{6}$ ), Hist. nat. des anim. s. vert., adoptirte nicht oder vergass die Coriocella. Die Sigareten stehen unverändert wie in den früheren Arbeiten; nur die Anzahl (4) der Arten ist vermehrt, und mit Ausnahme von einer, die der Gattung Vanicoro (Quoy et Gamard, 1832) angehört, sind sie alle wirkliche Stomatien (Cryptostomen). Solches hat aber, wie schon erwähnt, spätere Verfasser (Brown, Fleming, Bouchard, Gould, Forbes, Michlaud, Philimpi, Cantraine, Risso, delle Cinaje u. M.) nicht daran gehindert, unter der Benennung Sigaretus (Lsк.) Thiere zu verzcichnen, die der ganz verschiedenen Marsenia-Gattung angehören; der anderen Conchyliologen nicht zu erwähnen [Brown ${ }^{\top}$ ), Broderip, SowerbY ${ }^{8}$ )], die unter demselben Gattungsnamen Velutinen (u. a. Formen) beschrieben haben. In der neuen Ausgabe des LAmarck'schen Werkes hat DesmaYes ${ }^{9}$ ) die durch QUOY und GAIMARD vollständig gesicherten bedeutenden Unterschiede zwischen Cryptostoma und Marsenia aufgenommen, erwähnt aber weder hier noch anderswo irgend eine Art der letzteren Gattung; oder: eine schon längst bekamnte Gat-

1) Linn. Transact. XVII, pt. I. 1835. pag. 29.

2) Ann. mgz. n. h. VIII. 1835. pag. 68; IX. 1836. pag. 191.

Malac. Monensis. 18338. pag. 29.

3) Zool. Journ. I. 1825. pag. 428 ,

4) Sowohl hier wie früher (1821) in London medical repository schreibt Grar Laminaria.

5) GraY, spicil. zoolog. part I. 1828. pag. 4.

6) T. VI, pt. 2. April 1822. pag. 207.

Die Augenkrankheit Lamarck's hatte eben gegen den Zeitpunkt des Erscheinens dieses Theils des Werkes sich zu vollständiger Blindheil entwickelt, daher die Lücken in seiner Litteraturkenntniss.

Durch Gmadix, Abiddana und Ratuke verleitet hat er unter den Synonymen des Sigar, haliot. auch Bulla velutina, M. aufgenommen, den Typus der Gattung Velutina, Buy. [Enc. Edin. 1819. - Man. de malac. 1825. pag. 468 (= Galericulum, Brown, Illustr. Conch, Gr. Brit. 1827)].

7) Sigar, flexilis, Brown, Illustr. Tab. 4t. Fig, 3-4.

s) Sigar. coriaceus, Brod, and Sow. Zool. Journ. IV.

(1) T. IX, 1843, pag. 7 . 
tung mit melıreren noch länger bekannten $\Lambda$ rten wurde in dieses grosse und umfassende malacologische Werk noch garnicht aufgenommen. Obgleich nun alle Materialien zur vollständigen und endlichen I Lösung der bezüglichen Fragen vorlagen, zeigte sich SwarvsoN ${ }^{1}$ ) noch ausser Stande dieselben zu klären, die rechten Benennungen durchzuführen und den Formen ihre einigermaassen richtige Stellung und gegenseitige Stellung im Systeme anzuweisen. Als Resultat seiner Vergleichungen nimmt er an, dass zwei weit verschiedene Gruppen in eine zusammengeworfen wären; die eine, die der Cryptostomen; die andere, die der Sigareten ron CuviER; und er ist der Meinung, dass die ersten als echte Naticiden scharf von den anderen, deren Namenreichthum er noch mit einem Chelinotus vermehrt, auszusondern wären. Dieses ist im Wesentlichen nur, was schon lange vorher GrAY gelehrt hatte. Wenn aber Swainson die neue Gattung, die er in Velutina, Coriocella und Chelinotus (strictius, mit Sig. T'onganus, Q. et G. als 'Typus) zergliedert hat, als 'Theil der nacrirten, himmelweit verschiedenen Haliotiden unterbringt, dann muss er diese Rückkehr zu dem unrechten, eben verlassenen Weg der alten Conchyliologen verantworten. Viel richtiger hat D'Orbigny die natürlichen Affinitäten dieser letzteren Gruppe aufgefasst; in seiner Voy. dans l'Amér. mérid. $\left.{ }^{2}\right)$ hat er die Cryptostomen als eine Unterabtheilung den Naticiden einverleibt, und von denselben die "Lamellaria, MTG. und die Coriocella" weit entfernt. Solcher Meinung waren nicht ADAMs und Lovell ReEve; in dem malacologischen Theile der Voy. of the Samarang ${ }^{3}$ ) scheinen diese Verfasser die Marsenien und Stomatien in ihre Familie Neritacea zu vereinigen geneigt zu sein. Nachher ist die Gruppe, die übrigens ganz ausserhalb des Bereichs dieser Untersuchung liegt, besonders mit einer grossen Anzahl ron Arten nach und nach bereichert worden.

Auf der Helix neritoidea von LiNxé baute sich endlich nach und nach eine dritte Gruppe auf. Diese Art scheint den Zeitgenossen Lrvwé's ganz unbekannt gewesen zu sein, ist es aber auch später lange geblieben. Auch neue Formen liamen lange nicht $\mathrm{zu}$, die sich um dieselbe gruppiren könnten. In 1815 stellte RAFINESQUE ${ }^{*}$ ) eine Gattung Oxуnов̈ auf, aber so mangelhaft characterisirt, dass es sich schwerlich mit Sicherhcit bestimmen liess, ob damit eine fehlerhaft oder lückenhaft characterisirte Marsenia-Form oder vielleicht eine ganz neue generische vorläge, welch Letzteres, wenn die Kiemenver-

1) Swainson, a treatise on malacology. 1S40. pag. $234,355$.

2) Mollusques. 1835-1843. pag. 400 .

3) Moll. by Adais and Lovell Reeve, 1818. pag. 54.

4) "Spechio delle science o giornale encyclopedico di Sicilia. Palermo. 1814", teste ipso Journ. de phys. 1819. T. 89. pag. 182; erst hier fügte er, nach Erscheinen der Anat. des Moll. von Cuvier, die Bemerkung über die Aehnlichkeit mit Sigaret, Cuv. (cfr, RANG), zu.

Ohne Aenderung ging die Gattung in Dict. sc. nat. [T. 32. 1824. pag. 260 (BLainville)] über, ferner in BuatNville's Manuel (pag. 467) sowic in RANG's Manuel (app. pag. 375). 
hältnisse richtig aufgefasst wären, wohl scheinen könnte; vielleicht beruhten aber diese "branchies marginales striées transversalement" auf einem ähnlichen Irrthum, wie der CUVIER's an seinem Sigaret (s. näher unten); der Mantel war „élargi en deux ailes latérales“, wodurch das 'Thier dem Vanicoro von Quoy und Gamard ähnlich wurde. Vom Mittelmeere war kein Vanicoro bekannt. Die einzige Form von RAFINESQUe, die Oxynoë olivacea, vom Mittelmeer stammend, kann mit der Helix neritoidea, L. nicht identisch sein; iibrigens ist kein Hab. bei Livxé angegeben. Wahrscheinlicher ist es aber, dass diese eine Vanicoro (oder selbst eine Velutina) sei. ${ }^{1}$ ) Jedes Material zu nílierer Bestimmung fehlt, und entscheidend wird die Frage vielleicht nie entschieden werden können. Die Oxynoë von RAfrnesQue, die urspriinglich ganz allgemein ${ }^{2}$ ) für eine Stomatia, HrLu (Cryptostoma, BLAINv.) von den Verfassern angesehen wurde, nur von CourHour ${ }^{3}$ ) für eine Marseniade gehalten, ist eine diesen beiden Gruppen ganz ferne stehende Form. In meiner Monographie der Marseniaden (1. c. pag. 255) hatte ich dieselbe als mit dem Vanicoro von QUOY und Gamard ${ }^{4}$ ) identisch betrachtet. Die später (1839) von GRAY ${ }^{5}$ ) aufgestellte Merria, sowie seine Nioma (1840), sowie ferner noch die Leucotis (1840) von Swainsox ${ }^{6}$ ) und die Narica (1844) von Recluz ${ }^{7}$ ) gehören auch hierher.

Die obengenannten drei LINNÉ'schen Arten wurden somit Typen von drei Gattungsformen. Jede derselben ist mit einer Anzahl von Namen begnadet worden; die Frage ist die, zu entscheiden, welche derselben zu bewahren seien.

Für die erste Gruppe, die der Helix perspicua, liegen also die Benennungen

1) Mehrere nordische Verfasser schienen mit Chersirz (X.pag. 360) anzunehmen, dass die Helix neritoidea, I. auf die meist bekannte nordische Velutina aufgestellt wäre. [Diese nordische Form scheint übrigens erst von OuAfSEN und POVELSEN (Reise gj. Island. II. 1772. pag. 1017. Gen. Olubogaskjel) erwähnt, die dieselbe als Patella neritoidea, L. betrachteten (die eine Crepidula ist). MIULler nahm in seinen Prodromus (2873) aus OLAFsen diese unsichere "Patella testa ovata apice subspirali obtuso" auf, die er aber doch nicht als Patella neritoidea betrachtete; während er nach Autopsie dieselbe Form als Bulla velutina (prodr. 2922) einregistrirte und für Zool. Dan. (III. pag. 32. Tab. 102. Fig. 1-4) abbilden liess; dasselbe Thier war von 0. FABricius (Fauna groenl. pag. 390) als Helix haliotoides, L. beschrieben und figurirt unter diesem. Namen noch ein drittes Mal bei O. Fr. MǗLler (prodr. 2900). MOHR (Forsög til en isl. Naturh. 1786. pag. 138) hat erst diesen Irrthum OLAFSEN's hervorgehoben].

2) So noch von Grax in Proc. 20ol. soc. 1847, pag. 150.

3) Boston Journ. II. Jan. 1838, pag. 90. Tab. 3. Fig. 16.

4) Voy. de l'Astrolabe. Moll. I. 1834. pag. 239. pl. 66 bis. Fig. 20-22.

5) BEECHEY, voy. Zool. 1839. pag. 137.

Später findet sich diese, sowie auch die Nioma-Benennung in den verschiedenen Ausgaben d. Syn. Br. Mus. benutzt. In Proc. zool. soc. (1817. pag. 156) zieht GraY die beiden Namen als Synonymen unter Vanicoro ein. [Dem Nomen-

clator von Agassiz (sowie dem Herrisansen'schen Index) zufolge soll Nioma dagegen eine Trochoide sein. Tragen hieran die weniger stringente Ausdrücke von GRAY „pedal appendages" (cfr. MIerria, 1. c.) die Schuld?]

6) STranson, a treatise on malacology. 1840, pag. 346. $=$ Leucotus, Sow. JUN. Conch. man. ed.2. pag. 172.

7) Teste ${ }_{n} \mathrm{D}^{\prime} \mathrm{ORP}$. Moll. Cub. II. 1811 und Paléontologie franç. II. pag. 170“. RECLUZ, Rev, zool. 1814. pag. 4, 47 (IIonogr.). 
Sigaret, Sigaretus ${ }^{1}$ ) von Cuvier (1799), Lamellaria von Montagu (1811), Marsenia von Leach (1819), Coriocella von Blainville (1824), Cryptothyra von Menke (1830) und Chelinotus von. Swainson (1840) vor. Der Name Sigaret, Sigaretus muss als ursprünglich unberechtigt und dazu irreleitend für diese Gruppe verworfen werden; in diesem Punkte sind die Verfasser auch so zu sagen einig gewesen. Würde man den Namen Lamellaria bewahren, wäre er für die erste der Arten von Montagu oder also für eine Pleurobranchus-Form, Lamellaria wäre dann mit Oscanius oder Cleanthus von LEAcrr identisch. Bei T. BroWN ${ }^{2}$ ) wie in den früheren Arbeiten von $G_{R A Y}{ }^{3}$ ) ist die Benennung Lamellaria ("Laminaria ${ }^{4}{ }^{4}$ ) etwa in dieser Bedeutung bewahrt. Die Benennung Marsenia dagegen, die den Umständen nach durch viele Jahre ausserhalb Englands nur Wenigen bekannt sein konnte ${ }^{5}$, die aber durch OkEN doch schon seit $1829^{6}$ ) in die Wissenschaft eingebürgert war, wird für diese Gruppe anzuwenden sein, wie Solches schon durch WOOD ${ }^{7}$ ), H. BECK ${ }^{8}$ ) und mich ${ }^{9}$ ) geschehen ist. Lovḱn, der friher ${ }^{10}$ ), sowie FÉRUasac ${ }^{11}$ ), Johnston $\left.{ }^{12}\right)$, D'OrbignY ${ }^{13}$ ) und in späteren Jahren GrAY ${ }^{14}$ ) die Benennung Lamellaria, MTG. adoptirte und als Synonymen dazu die anderen Gattungsnamen einzog, hat später ${ }^{15}$ ) den Namen Coriocella, Blainv. für die typischen Formen verwendet, während er für

1) Anat. comp. I. cinquième tableau.

2) T. Brown, illustr. of the conchology of Great Britain and Ireland. 1827.

3) London medical repository. 1821. pag. 232. GRAY, a natural arrangement of mollusca according to their internal structure. Ordo IV. Trachelobranchiata.
a) 1. Sigaret.
b) 3. Velutina.
2. Cryptostoma.
4. Capulus. 5. Stomata. (sic!)

Ordo V. Monopleurobranchiata.

1. Umbrella. 2. Pleurobranchus. 3. Laminaria. (sic!)

Zool. Journ. I, 1S25. pag. 427. GrAY, on the Gen. Sigaretus and Cryptostoma.

An beiden Stellen schreibt GrAY, wahrscheinlich durch einen Irrthum, Laminaria ("MTG.") und meint daher, dass für diese schon lange von LAMouroux fü eine Alge angewendete Benennung eigentlich eine andere zu substituiren wäre. An beiden Stellen scheint er den Namen für Pleurobranchus-Formen anzuwenden wollen. Später bat er (Proc. zool, soc. 1817. pag. 163. No. 325, 326) Laminaria und "Lamellaria B, MTG." als Synonymen unter Pleurobranchus eingezogen, während (fehlerhaft) "Lamellaria A., MTG." als Benennung für die Formen hervorgezogen wird, für die wir hier den Namen Marsenia bewahrt haben wollen.

4) Dieser Name taucht wieder bei Clark (On the Conovulidae etc. Ann. ingz. n. h. 2 S. VI. 1850. pag. 451) auf.

5) Es sollte scheinen, dass die Benennung BuAixvilue bekannt sein musste, der im Brit. Museum mehrere neue Molluskenformen untersucht und daselbst die Gattung Cryptostoma aufgestellt hat (s. oben).

6) Isis. 1823, II. pag. 460 .

7) Ann. and $\mathrm{mgz}$. of nat. hist. IX. 1812. pag. 455, 527.

S) Amtl, Bericht über die 24. Versammlung d. Naturf, u. Aerzte in Kiel. 1846. pag. 116.

9) Bidr. til en Monogr. af Marseniaderne. 1853. 1. c.

10) Ind. moll. 1816. pag. 15.

11) Tableaux systémat. des anim. moll. 1822. pag. XVI.

$$
\begin{aligned}
& \text { 4. Sous-Ordre. Adélodermes, FÉR. }) \quad \text { Gen. 1. Sigaretus, Lar.. ScHw. } \\
& \text { Adélobranches, Dus. II. Fam. Lamellaria, MTo. } \\
& \text { Aplysia, OK. }
\end{aligned}
$$

Die Zusammenstellung des Verfassers kann keine Forderung darauf machen klar zu sein.

12) Ann. mgz. n. h. 1836. pag. 229.

13) Voy. dans l'Amér. mérid. pag. 403.

14) Figures of moll anin. IV. 1850 , pag. 75.

Guide. I. 1857. pag. 27 (und pag. 28: Ermea).

15) Oefvers. Vet. Ak. Handl. 1817. pag. 192. 
eine neue und abweichende den Gattungsnamen Lamellaria bewahrte. Dieses ist sicherlich ein unberechtigtes und ganz unrichtiges Verfahren gewesen, selbst wenn davon abgesehen wird, dass Blatnville ursprünglich diese seine Gattung auf einen fehlerhaften Character baute, und dieselbe sich erst (wie von PHILIPI' ${ }^{1}$ ) geschah) mit der Cuvier'schen Rectification überhaupt anwenden liess. Die Coriocellen von Blatyville sind doch etwas atypische Formen, und diese Benennung ist daher am wenigsten für die ganz typischen anzuwenden. Die Bezeichnung Cryptothyra von MENKE ist als ganz überflissig auszumerzen. Der von Swarnson für cine mit der Coriocella nigra, BLv. wenigstens ganz nahe verwandte Art aufgestellte Chelinotus aber muss den missbrauchten und irreleitenden Coriocella-Namen als generische oder subgenerische Bezeichnung verdrängen.

Fur die andere Gruppe, deren Typus die Helix haliotoidea, L. ist, hatten, wie oben nachgewiesen, erst HILL und Browne (1752) die Gattung Stomatia, spaiter (1753) KLein (und Martini) den Catinus (lactis), Meuschex (1787) die Auriformis und BoLtex (und LINCK) Sinum (1798) aufgestellt; auf derselben oder ähnlichen Eormen fussten ferner Sigaretus, LuK. (1799) und Cryptostoma, BLAINv. (1818). Es liegen kaum Griinde vor die erste dieser Benennungen, die Stomatia, zu verwerfen; HelbulNG's ${ }^{2}$ ) Stomatia ist viel jünger. In seinen späteren Arbeiten hat Griy auch so verfahren (während er für Helbling's Stomatia die Benennung Stomax, MTf. wieder hervorgesucht hat). Von den anderen Bezeichnungen lat man kaum $^{3}$ ) andere als die von LAmarck und von BlatvviLle zu vindiciren versucht. Die erste aber (Sigaretus) haben doch die meisten Verfasser (Brown, Deshayes, Philippi ${ }^{4}$ ), Vax der Hoeven ${ }^{5}$ ) u. MI.) beibehalten wollen, obgleich der Name Stomatia von HILL eine Priorität von mehreren Decennien hat. Uebrigens wird oben hinlänglich gezeigt sein, welche Verwirrung durch diesen Namen hervorgerufen worden ist. Aus ähnlichen Grinden wäre die Benennung Cryptostoma wohl auszumerzen.

Die dritte Gruppe endlich, die mit der Helixneritoidea, L. als Typus, bildet vielleicht die Gruppe der Vanicoriden (1834).

Aus den drei Linvé'schen Arten (619-621), Helix perspicua, haliotoidea und neritoidea wurden somit drei Gattungen, respective. Familien, die Marseniaden, Stomatien und Vanicoriden. Die Unterscheidung der drei Gruppen liegt noch nicht sehr

1) Berichtigung zu Berichtigungen. Sigar. und Lamellaria. WIEgM., Arch. VII, 1. 1841. pag. 343.

En. moll. Sic. II. 1844. pag. 142.

2) Beitr. zur Kenntı. neuer Conchylien. A bhandl, einer Privatgesellsch. in Böhmen. IV. 177S. pag. 124.

3) In einer ${ }_{n}$ Fortegnelse over Biskop Fabricius's efterladte Naturalier“. Kjöbenharn. 1824. pag. 71 (Catinus haliotoideus)

(nach dem MIS. von FABRICrus gedruckt) ist der Name Catinus wieder hervorgezogen worden.

4) Enum. moll. Sic. I. 1836. pag. 165; II. 1844. pag. 142.

Abbild. u. Beschreib. I.

5) Handb. d. Zool. I. pag. 764. 
weit zurïck, Rückfälle in die alte Verwirrung sind aber noch dann und wann (VAN DER HoEver u. A.) vorgekommen. ${ }^{1}$ ) Die untenstehende Untersuchung behandelt ausschliesslich die erste Gruppe, die Marseniaden, zu deren Kenntniss seit meiner Monographie (1853) nur wenige Beiträge zugekommen sind.

1) Auch bei NYst (Mém. des savans etrangers par l'ac. roy. de Bruxelles. XVII. 1845. pag. 437) enthält die „Fam. Sigarets, Cuv." die Gattungen Natica, AdANs, und Sigaretus, Lack. (!) - Die Natice, Natica von AdANson ist wie seine übrigen Gattungen wesentlich nach dem Thiere selbst (cfr. ADANSoN, pag. 82) aufgestellt; von den 4 Arten der Gattung ist le Fossar die erste und dazu die einzigste, deren Thier er hat untersuchen können. BRuguiere (Enc. méth. Hist. nat. des vers. I. 1789. pag. XVI) und nach ihm LAMARCK haben deshalb unrichtig verfahren. indem sie nach der zweiten Art von ADANSON die Gattung la Natice (= Nerita collari ornata, CH. V. Taf. 187. Fig. 1895 a b = Natica collaris, Sow. Catal. Tankerv. pag. 47) aufstellten. Ladurch sind wieder Gray und später PHILIPPI genöthigt worden die Gattung Fossarus zu bilden. [Die Gattung Cyclostrema von Fleming (Brit. anim. 1828, pag. 312) berubt auf einer mit le Fossar congenerischen Art ('Turbo zetlandicus, MTG.), ist also mit Fosșarus von Grax und Philipri identisch, und von Cyclostrema, Marryatt (Linn. Tr. XII. 1817. pag. 338) ganz verschieden]. Es wäre gewiss correcter gewesen, die Benennung Natica auf le Fossar zurückzuführen; Natica, A DANSON wäre somit mit Cyclostrema, Flem. (nec Marryatr) und Fossarus, Gray et Phil. identisch. 


\section{II.}

\section{SYSTEMATISCHER THEIL.}



Fam. MARSENIADAE, (LeAch) BGH.

Marsenia, Leaci (1820). Mollusc. Brit. synopsis. ed. Gray. 1852. pag. 26.

Lamellariacea, Lovén. Oefvers. Vetensk. Ak. Handl. 1847. pag. 192.

Lamellaridae, Gray. Figures of moll. anim. IV. 1850. pag. 75.

fLamellariadae, GrAY. Guide. I. 1857. pag. 27-28.

Velutinidae, GraY.p.p. 1. c. 1857. pag. 46.

Marseniadae, Bergh. Bidr. til en Monogr. af Marseniaderne. l. c. pag. 243-359. Tab. I-V.

(Marseniadae, Troschet. Das Gebiss der Schnecken. I. 1856-63. 'Taf. XVI. Fig. 1-5. IVelutinidae, p. p. 'Troschel. 1. c. p. 167-169. 'Taf. XV. Fïg. 17-19.

Mollusca gastraeopoda, prosobrauchiata (streptoneura, azygobrauchiata). Pallium ampliatum, incrassatum, supra laeve vel nodulosum vel grosse tuberculatum; continuum, testam recondens; vel culmine fissum, testam pro parte detegens. Limbus pallii vel amplus et planus vel magis rotundatus, ultra margines laterales podarii productus; pro siphone antice in pagina inferiore semicanali exaratus cum plica marginali vel emarginatura; in medio lateris dextri limbi interdum semicanalis et plica similes. Testa semper adest, ut plurimum obtecta, interdum partim denudata; tum spiraliter convoluta, paucigyra, calcarea, tenuis, semper absque margarita; apertura ampla, margine columellari simplici arcuato antice vix cum flexurae vel emarginaturae vestigio; tum cornina, scutiformis, absque spira. Cavitas branchialis duabus "branchiis" instructa; altera spuria, antica, minore, foliolis homomallis; altera vera, postica, majore, foliolis secundis.

Caput depressum, antice truncatum. Tentacula quasi ex angulis capitis orta, teretia, basi depressa, vel subcylindrica vel subconica; oculi in tentaculorum basi externa sessiles, quasi ophthalmophoriis brevibus inserti. - Rostrum retractile, sat longum, validum, per rimam oralem (transversalem) exsertile; os internum utrinque lamina mandibulari validiori, cornina armatum. Radula linearis, valida, postice in vaginam libere prominentem, longam et interdum quasi spiraliter involutam continuata. Armatura radulae mire diversa. Dens medianus semper solitarius; margine basali posteriori truncato vel 
bifido; apice recurvato cum acie unicuspide et utrinque denticulata. Dentes pleurales numero varii, semper lateralis internus validus, interdum praeterea uncini duo externi.

Podarium oblongum, antice truncatum, subemarginatum, margine antico sulco exaratum; postice nonnihil acuminatum, apice subrotundatum (operculo lobuloque operculigero nullis).

Animalia pro parte dioecia, pro parte monoecia. - Penis validissimus, pone tentaculum dextrum exsertus, sat compressus; interdum falcatus, apice incurvatus; interdum involutus: sub inertia intra marginem cavitatis branchialis recondendus. - Apertura genitalis foeminina (vulva) verruca perforata intra angulum dextrum fissurae branchialis sita.

Animalia marina, ut plurimum solitaria, segnia; ova in cavitates ascidiis compositis vel spongiis excavatas deponentia. Embryones testa externa provisoria carinis compluribus instructa.

Die äusseren Formverhältnisse der Marseniaden sowie ihr innerer Bau blieben lange wenig gekannt, und dazu war diese Kentniss eigentlich (wahrscheinlich) auf die typischen Formen beschrïnlt, von denen dann kurz nach einander drei anatomische Untersuchungen vorgelegt wurden.

Die älteste, die von CUvier $^{1}$ ) (1817), ist vielleicht weniger genau als irgend eine andere seiner anatomischen Arbeiten. Die specifische Bestimmung dés Thieres, das Cuvier vor sich gehabt hat, ist ohne Untersuchung der anatomirten Indididuen, die wahrscheinlich nicht mehr existiren, kaum möglich. Aus den Worten sciner Abhandlung lässt sich kaum herausfinden, ob die untersuchten Individuen von MATTIIEU und somit von Isle de France herstammten, oder vom Senegal. Aus den frïhesten Bemerkungen iiber diese Thierform von Cuvier in Bull. de la soc. philomat. (vergl. auch Mém. pag. 3) sehen wir, dass die Thierform sich in dem lange vor Cuver gegriindeten Pariser Museum vorfand (,il existait au Mus. d'hist. nat."), wahrscheinlich nicht etiquettirt, und die LocalitatsAngabe von Cuvier wird wahrscheinlich nur eine Conjectur gewesen scin (der Ausdruck "il vient de Senegal" im Gegensatze zu den übrigen Imperfecta ist kaum zurälligg). Später scheint er (Mém. pag. 5) Exemplare von Isle de France vor sich gehabt zu haben. Wemn Gray (Proc. zool. soc. 1847. pag. 143) behauptet, dass Cuvier's Sigaret, authentischen Exemplaren nach, dieselbe Form sei, die Buanvilue als Coriocella nigra beschrieben hat,

1) Cuvier, anat. des moll. - Mém. sur l'Haliotide ou oreille de mer, sur le Sigaret, sur le genre Patella etc. pag. 2-6. 11. I. Fig. 1-S.

Die Mundparthie wird von Cuvier flüchtig als der des Buccinum ähnlich angegeben; die Abbildungen erläutern in dieser Beziehung Nichts oder sind eher ziemlich irreleitend. Die Verdauungsorgane sind im Ganzen ganz fehlerhaft dargestellt, Anus wird selbst links liegend erwähnt und abgebildet. Die Augen werden als am inneren Rande des Grundes der Fühler liegend angeführt. - Im Ganzen findet sich in den die Abhandlung einleitenden Bemerkungen ein Mangel an Scharfheit des Ausdruckes sowie in den -beigefügten zoologisch-kritischen Angaben ein so bedeutender Mangel an Accuratesse, wie sie wohl sonst selten in den Arbeiten von Cuvier rorkommt. 
so ist diese Behauptung von sehr fraglichem Werthe. Als Buainvilue diese letztere zum ersten Male (1824) publicirte, giebt er sie als nicht abgebildet an; die Abhandlung von Cuvier ist aber von Figuren begleitet, und Blalvville wird somit beide Formen als von einander versehieden betrachtet haben, wie sie es, nach Vergleichung der Figuren von Cuvier mit den später publicirten von Blainville (Man. de malac. pl. 42. Fig. 1), in der That vielleicht auch scheinen. Die Beschreibungen sind bei den beiden Verfassem zil unvollständig, um denselben eine Verschiedenheit oder Identität mit Sicherheit entnehmen zu können. Cuvrer giebt ausdrücklich an, dass die Farbe der Individuen "fort

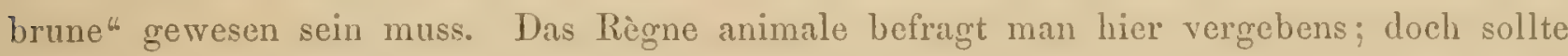
es aus der Aufstellung der Coriocella neben dem Sigaretus (noch dazu mit der beigefiigten Notiz, dass sich eine Schale doch finde) herworzugehen scheinen, dass Cuvien selbst die Form von BLAisvrle untersucht und sie von der von ihm anatomirten vcrschieden gefunden hat. Wenn nicht auf der einen Seite die deutlich ausgeprägte Unzuverliissigkeit der Abhandlung ron Cuvien, sowohl in Betreff des 'Textes wie der Figuren, jeden aus derselben gegrindeten sicheren Schluss verböte; und nicht auf der anderen Seite ein Vorkommen einer ächten Marsenie in jenen tropischen Gegenden jetzt (s. unten) nachgewiesen wïre: so könnte man geneigt sein, jene Form als rom Mittelmeere herstammend zu betrachten (vielleicht als den Sigaretus Adansonii von DELLE ChiAsE). Unmöglich wäre es auch nicht, dass die Fig. 1 und 2 bei Cuvrer eine, die Fig. $3-8$ eine andere Art darstellen; jedenfalls stellt die Fig. 8 wegen des (b!) freien Samenleiters eine ächte Marsenia dar.

Die andere Untersuchung, die von BLAINville ${ }^{\mathrm{I}}$ ) (1827), ist etwas ausführlicher als die vorige. Sie hat ziemlich richtige Angaben von Lage- und Formverhältnissen des Herzens, der Verdauungsorgane, des Nerrensystems; enthält nebenbei aber fehlerhafte Angaben genug. - Die Thiere, an denen Blatsville scine Untersuchung anstellte, rührten von den englischen Kïsten (dem Canale) dureh LEAcr her; BLALNiLle betrachtete sie als eine neue Art, Sigaretus convexus.

- Fast gleichzeitig mit der vorigen (1828) ist endlich die dritte und wohl die beste dieser Untersuchungen, die ron Delle ChIAJE" ${ }^{2}$. Die "Zunge" (d. h. die Raspel), bei Cuvier und bei Blarvilete nur eben genannt, ist in ihrem Detail hier einigermaassen gut beschrieben (und abgebildet) ${ }^{3}$ ). Die harte Mundbekleidung, die Mandibelplatten, werden

1) Dict. sc. natur. T. 49. art. Sigaret (pas. 105).

Buataville reproducirt die ältere Angabe von Cuvier (Bull. soc. philom. 1799. 31. pag. 52) ron Fiemen zwischen Mantel und Fuss und vergleicht ausdrücklich das Verhältniss mit dem der. Patellen; die Darstellung des Mundbaues ist sehr verworren; die homartige Bekleidung im MIundeingange (die Cuvier übersehen hat) scheint BLAINviLte gesehen zu haben, aber nur als starke, der Zunge gehörende Muskelparthien aufgefasst.

2) Mem. sulla storia e notomia degli animali senza vertebre. III. pag. 216. pl. 47. „Fig. 5, 18, 21" (noch aber 10, 11, 19, 20).

3) Die Figur 19 auf pl. 47 bei Delle Criraje stellt die Zungenbewaffnung der "Helix neritoidea" dar; Fig. 10 und 11 die hornartige Bekleidung des Mundes (vergl. pag. 203).

IVas DELLE CHIAJE mit dem "mediano lungo ed acuminato cirro, che ì inserito nel principio del camaletto o sifonc conducente nel cavo branchiale" meint, bleibt aber unverständlich; die Figur erläutert in dieser Beziehung gar nichts. 
als cine cartilaginöse zweilappige Platte beschrieben; ferner das Herz erwähnt; die "appendice ovale" an der Vena branchialis scheint die kleinere falsche Kieme zu sein, daher die Angabe von nur einer Kieme. Hinter dem Anus sollen sich einige eigenthuimliche Driisen finden; die Genitalöffnung (DELLE CrIAJE untersuchte nur ein Weibchen)

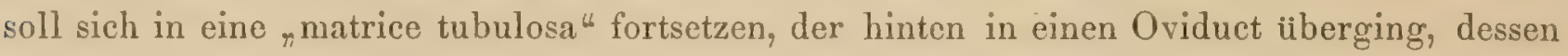
Ursprung wie zwischen den Leberlappen eingesenkt lag; schliesslich berührt er auch das Vorkommen eines Wassergefässsystems. - Die von DELLE CHIAJE untersuchte Form scheint die Mars. neritoidea (s. unten) ${ }^{1}$ ) zu sein.

In dem Reisewerke von Quor und Gamaru ${ }^{2}$ ) wurden noch ganz einzelne anatomische Bemerkungen, diese Gruppen betreffend, publicirt. In 1853 erschien (l. c.) meine grössere monographische Bearbeitung dieser Gruppe, nåmlich der Gattungen Marsenia, Onchidiopsis sowie theilweise auch des Genus Chelyonotus. Derselben folgte später (1857) meine Untersuchung der Marsenina prodita. ${ }^{3}$ ) Danach hat JHERING ${ }^{4}$ ) eine Untersuchung des Centralnervensystems der Marsenia perspicua geliefert, und schliesslich G. O. SARS einige Notizen ïber die Mundtheile der Marsenia latens, der Marsenina prodita und der Onchidiopsis glacialis ${ }^{5}$ ) gebracht. Durch einige Faunisten, besonders DALL und Verrilu, sind endlich einige neue, mehr oder weniger zweifelhafte Arten kurz beschrieben.

Die Marseniaden sind von rundlichem oder ovalem Umrisse, fast halbkugelförmig. Der R iicken (Mantel) eben oder mit mehr oder weniger grossen, kurz-kegelförmigen oder mehr rundlichen Höckerı bedeckt. Er enthält eine Schale, die entweder ganz im Mantel eingeschlossen ist oder in der Mitte in'einer rundlichen oder ovalen Oeffnung theilweișe entblösst liegt (Marscnina). Diese Schale deckt die ganze Kiemenhöhle (Onchidiopsis), aber hüllt meistens noch die ganze obere Eingeweidemasse von oben ein; längs des Randes der weiten Oeffnung ist sie mit einem verdickten, flachen Rande der oberen Eingeweidemasse, der Schalenleiste, inniger verbunden. Die Schale ist entweder schildförmig, ohne Spur von Spiralwindung, dann hornartig (Onchidiopsis); oder fast hornartig, aber mit Andeutung von Spiral (Marseniella); meistens aber spiral gewunden, mit kleiner Spirale von ganz wenigen Windungen, der letzte Umgang sehr weit, die Schale so immer kalkig, aber sehr dünn und sehr zerbrechlich. An der Innenseite der aussersten Windung der Schale findet sich jederseits gewöhnlich eine, doch meistens sehr wenig deutliche Muskelfacette,

1) Es ist kaum verständlich, wie PHilip I (Abbild. I. 1844. Sigaret, pag. 2) die H. neritoidea von DELLE CHIAJE zu seinem Sigaretus haliotoideus, L. hat citiren können; er wird ebensowenig den anatomischen Text durchlesen wie die Figuren durchsehen haben. Die Quelle seines Irrthums ist wohl in den Ausdrücken DELLE CHIAJE's „conchiglia solida, la spira esterna giallicia e la interna perlacea" zu suchen.

2) Voy. de l'Astrol. Moll. I. pag. 218. Atlas, Tab. 66. Fig. 4-8.

3) R. Bergh, Bidr. til en anatom. Unders. af Marsenina prodita (LovéN). Naturh. Foren. vidensk. MIeddel. for 1857. p. 110 122. I'ab. I.

4) Jebinga, vergl. Anat. des Nervensyst. und Phylogenie der Mollusken. 1877. pag. 115-117.

5) G. O. SARS, Bidr. til Kundsk. om Norges arktiske Fauna. I. Moll. reg. arct. Norv. 1878. pag. 150-153. 
eine vordere linke und eine mehr hintere rechte. Das Mantelgebräme ist sehr entwickelt, ringsum vortretend, den Kopf und den Fuss (mit Ausnahme der Spitze des Schwanzes) meistens ganz deckend; meistens ist es abgeplattet, den (oberen) Körper als ein mehr oder weniger breites Gebräme einfassend; seltener ist es dicker, am Rande gerundet, anch an der Unterseite etras abgeplattet (Onchidiopsis, Marseniopsis). Eine eigentliche, stärker vortretende siphonale Bildung fehlt, ist aber durch einen Halbcanal vorne an der Unterseite des Mantelgebrämes ersetzt, welcher den Vorderrand nach oben als eine vortretende Falte umbiegt oder zwischen zwei fingerartigen Verlïngerungen endigt (Chelyonotus). Dieser Halbcanal endet links am Vorderrande der Kiemenspalte, in ihrer linken Ecke. Ausser diesem Inspirationscanal findet sich in einigen Gattungen (Marsenina, Onchidiopsis) noch an der rechten Seite ein vollständig ähnlicher Exspirationscanal, in die rechte Ecke der Kiemenspalte endigend. Die Kiemenh $\ddot{h} \mathrm{le}$ ist weit und gerïlmig, aber niedergedrückt; an ihrer Decke sind die zwei "Kiemen" angeheftet, eine falsche vordere, gefiederte, die an der Wand fast in ihrer ganzen Breite und Länge befestigt ist, und eine wirkliche hintere mit einseitigen Bliittern. Diese letztere, die eigentliche Kieme, ist aus dünnen Blättern gebildet, die, dicht neben einander der Länge nach etwas schräg stehend, von ihrem oberen längeren oder kürzeren, angehefteten Rande schräg nach unten in die Kiemenhöhle hinabragen. Die Blätter sind schmäler oder breiter; in den melır typischen Gruppen (Marsenia, Marseniella, Marseniopsis) mit querstehenden Leisten oder niedrigen secundären Blätterchen an den Flächen der Blätter. Hinter der Kieme findet sich im Dache der Kiemenhöhle entweder eine längere Niere (Marsenina), oder dieselbe ist kleiner, links liegend; ganz links, am linken Ende der Niere zeigt sich der Herzbeutel. Meistens findet sich ein Zwischenraum hinter der Kieme, von weisslichen Secretmassen (der Niere oder der Blätterdrüse) bedeckt. Hinter der Krieme und der Niere zeigt sich endlich in der ganzen Breite der Kiemenhöhle die schmälere oder breitere Blïtterdriise. An der Decke der Kiemenhöhle findet sich ferner mehr median und hinten, oder und meistens links die äussere (branchiale) Oeffnung der Niere (und Blätterdriise). Innerhalb der rechten Ecke der Kiemenspalte springt die Analpapille mehr oder weniger hervor; hinter derselben zeigt sich an den Weibchen der dioecischen Marseniaden die Vulva, und in den mónoecischen (Marsenina, Onchidiopsis) immer die weibliche Geschlechtsöffnung. - Der untere Körper, unterhalb der Kiemenhöhle, viel kleiner als der obere, das Centralnervensystem, den ganzen vorderen Theil des Verdauungssystems und ein grosses Stück des Samenleiters enthaltend. Der Kopf ist ziemlich gross, abgeplattet; vorne abgestutzt, mitunter etwas ausgerandet und jederseits in einen nach vorne gerichteten T'entakel ausgezogen. Die Tentakel von den Seiten des Kopfes ausgehend, am Grunde etwas abgeplattet, sonst kegelförmig oder mehr cylindrisch; die Augen aussen am Grunde der Tentakel sessil oder wie an kurzen Ophthalmophorien sitzend. An der Unterseite des Kopfes findet sich der Aussenmund, meistens rom Vorderende etwas entfernt und damn eine Querspalte bildend; mitunter 
(Marsenina, Onchidiopsis) mehr vorne liegend und dann mehr rundlich. Durch den Aussenmund wird die Schnauze hervorgestuilpt. Der Fuss ist kräftig ${ }^{1}$ ), vom Mantelgebräme mit Ausnahme der Schwanzspitze uiberall iuberragt, an welchem letzteren das Thier sich während des Kriechens doch nicht stiitzt ${ }^{2}$ ); er ist länglich, nach hinten etwas zugespitzt, zugespitzt-gerundet endigend; der Vorderrand mit tiefer Furche und median in derselben die Pore der Fussdrüse, die Fussecken wenig vortretend; der Schwanz nicht kurz. Mitunter (Onchidiopsis) findet sich ein cigenthümlich verdicktes Fussgebräme. - Der Penis ist immer sehr stark, nicht zurỉckziehbar, kann aber während der Ruhe und Inactivität innerhalb des Randes der Kiemenhöhle versteckt werden. Das Organ ist mehr oder weniger zusammengedrückt, meistens planconvex; dem Rande nach gebogen oder etwas eingerollt (Onchidiopsis); am Ende mitunter breiter (Marsenia), mitunter verschmälert (Onchidiopsis). Durch die ganze Länge des Organs verläuft der Samengang, dessen Ende meistens fingéerförmig hervorgestreckt werden kann.

Die Schale der meisten Marseniaden ist, wie erwähnt, verkalkt, aber dünn und spröde, durchscheinend; an der Aussenseite meistens mehr matt, mit mehr oder weniger ausgeprägten Anwachslinien; die Innenseite mehr glatt, von schwachem Seidenschimmer; die musculären Facetten gegen die Seitenränder des letzten Umganges liegend, meistens sehr undeutlich; die Spira ganz klein, der letzte Umgang sehr weit; von der weiten Schalenoffnung ab kann die Innenseite der ganzen Spira übersehen werden. Nur in einer einzigen der untersuchten Formen (Marsenina Dalli) zeigte sich die embryonale Schale als die Spitze der Schale bewalırt; sonst wenigstens nie deutlich. - In den ächten Marsenien ist die Schale fast immer stärker verkalkt, mitunter mit einem ganz dünnen, wie periostrakischen, schwach gelblichen, structurlosen, mitunter äusserst fein der Länge nach faltigem Ueberzuge. In den Chelyonoten, theilweise auch in den Marseniellen und Marseniopsen, (ist dieser Ueberzug an der letzten Windung stärker, während die stärker verkalkte Spira denselben viel schwächer und undeutlicher zeigt. Der letzte Umgang ist hier oft auch viel weniger verkalkt und sticht deshalb gegen die Spira oft stark ab; besteht wie aus einer zïhen gelblichen Cuticula, die an der Innenseite mit einem dünnen, meistens etwas seidenglänzend-verkalkten Lager bedeckt ist, das sich oft von der Cuticula leicht ablösen lïsst; mitunter findet sich das verkalkte Lager nur hinten im Gebiete der Spira, während der ibrige 'Theil der letzten Windung in Cuticula-Zustand verharrt; wenigstens ist ziemlich allgemein der Saum des letzten Umgangs weich. In diesem Zustande von ganz geringer Verkalkung findet sich die Schale besonders in den Marseniellen und

1) Es ist selbstfolglich ganz unrichtig, wenn Forbes und HANLEY, ADAMs, Loveli-ReEve und besonders Keferstein (BRony, Kil. u. Ordn. d. Thierreichs. III. Malacozoa. 1S64. pag. 1057) den Fuss als "die Schale fast ganz verbergend" angeben, und den einhüllenden Mantel als eine Entwicklung des Lobus operculigerus betrachten.

2) Solches scheint dagegen bei Pyrula der Fall zu sein. Vergl. OERsted in: Vidensk. Meddel, fra den naturhist, Foren. i Kjöbenhavn. 1850. pag. 9. 
in den Marseniopsen. In den Onchidiopsen bleibt die Verkalkung ganz aus. Dio Schale bestcht aus einer homogenen organischen Substanz, wie einer Art (Couchiolin-) Cuticula, in welcher und an der Innenseite von welcher die anorganische Substanz, der (kohlensaure) Kalk, abgesetzt wird. Die Verkalkung schreitet von der Spiize der Spira allmählig vorwärts; wie erwähnt; oft nicht den Vorderrand erreichend. Die verkalkte Schale scheint nur aus zwei und zwar undeutlich geschiedenen Lagen gebildet zu sein, deren Elemente fast senkrecht aufeinander stehen (vergl.nỉher unten). Die Elemente scheinen längliche Plättchen oder abgeplatteto Prismen zu sein, die mit den Flächen aufeinander liegen. Die rerkalkten Schalen lösen sich und verschwinden fast vollständig durch Einwirkung von verdünnter Salzsåure oder concentrirter Essigsåure. Die nicht recht verkalkten Schalen hinter]assen, nach einem geringen Aufbrausen, einen nicht unbedeutenden organischen Rest, ebenso und einen noch stärkeren die Onchidiopsis-Schalen. - Die sich der Aussenseite der Schale eng anschliessende Innenseite des Mantels ist von einem flachen Epithele ${ }^{\mathrm{I}}$ ) mit Zellen, die meistens einen Durchmesser bis 0,02-0,025 $\mathrm{mm}$ erreichen, bedeckt; dieselben sind bei den Chelyonoten sehwarz pigmentirt. Die mit der Innenseite der Schale in enger Berührung stehende und dieselbe ganz oder vesentlich erzeugende Oberfläche der oberen Eingeweidemasse und der Kiemenhöhle ist von einem ähnlichen Epithele ïberzogen. An den beiden Flächen fanden sich, diesen mehr als der Schale anklebend, Kalkkrystalle, isolirt oder in Gruppen, und Klumpen von ähnlichen oder, wie es schien, von amorphen kleinen Kalkballen.

Das Centralnervensystem stimmt im Ganzen mit dem der ibrigen azygobranchen streptoneuren Gastraeopoden ${ }^{2}$ ), sich von dem einiger solcher Formen (Cassidaria) wesentlich nur durch die Verkürzung der proximalen Enden der pleuralen (visceralen) Commissur unterscheidend. Jede der Hälften der oberen Ganglienmasse zeigt drei dicht neben- und aufeinander liegende Ganglien; die linke ein cerebrales, ein pleurales und ein meistens auf denselben liegendes supraintestinales (Siphonalganglion, JHEr.); die rechte nebencinander ein cerebrales, ein pleurales und hinter und unter denselben ein subintestinales (Abdominalganglion, JHER.). Die cerebralen Ganglien durch eine ziemlich kurze Commissur verbunden, die gewöhnlichen Nerven sowie dic cerebro-pleurale und cerebro-pedale Connective abgebend. Die pleuralen Ganglien auch die gewöhnlichen Nerven und die pleuro-pedale Connectivo abgebend, das rechte oben und links mit dem supraintestinalen Ganglion verbunden, ferner hinten und unten noch mit dem subintestinalen und dureh dieses mit dem linken pleuralen Ganglion in Verbindung stehend; das linke pleurale Ganglion nach oben mit dem supraintestinalen Ganglion verbunden. Wahrscheinlich (s. unten) ist das subintestinale Ganglion ferner durch eine, in die pleurale

1) Nach Lexdig [Die Hautdecke u. Schale der Gastropoden (Arch. f. Naturg. XXXXII, 1. 1S76). pag. 45] fehlt bei den Limaciden ein eigentliches Epithel an der inneren Fläche der Höhle, in welcher die Schale gebildet wird.

2) Vergl. SPENGEL, die Geruchsorgane u. das Nervensystem der Mollusken. Zeitschr. f. wissensch. Zool. XXXV. 1881. p. 373. Semper, Philippinen. II, II (Bergh, Irgänzungsheft III. Mtarseniaden I). 
(viscerale) Commissur eingeschlossene feine Commissur mit dem supraintestinalen verbunden. Das (also links liegende) supraintestinale Ganglion giebt der Kieme, dem Geruchsorgane und der linken Mantelh:̈̈lfte Nerven. Das (also rechts liegende) subintestinale Ganglion versorgt hauptsåchlich das Verdauungssystem und die rechte Mantelhälfte mit Nerven. Die buccalen Ganglien verhalten sich wie gewöhnlich. Die untere Ganglienmasse, die pedalen Gauglien, dicht am Fusse liegend, durch die cerebralen und pleuralen Connective mit der oberen Masse verbunden; die Connective der rechten Scite aber am öftesten (Chelyonotus, Marsenia, Marseniella, Marseniopsis) ziemlich verkiirzt. Vom rorderen Theile dieser Ganglien hat sich immer je ein kleines rundliches secundirres Ganglion abgelöst, das den vorderen Theil des Fusses mit Nerven rersieht.

Die $\Delta u g e n$ sind, wie erwähnt, an niedrigen Höckern (Ophthalmophorien) aussen am Grunde der 'Tentakeln angebracht. Die Otocysten, in flachen milchweissen, von Bindesubstanz gebildeten Scheiben eingesehlossen, am Rande der F'ussknoten oder weiter ausscrhalb derselben liegend; der $\mathbf{N}$. acusticus steigt durch das cerebro-pedale Connectir an das Gehirnganglion hinanfi); der Otolith gross, kugelrund. Das ror der Kieme wie in einer eigenen Grube liegende und angeheftete, bipinnate Gernchsorgan durch eine feine Falte, durch welche der aus dem supraintestinalen Ganglion stammende. N. olfactorius verläuft, an die Gegend der Schalenleiste befestigt. Das Organ besteht aus einer den Nervenstamm einschliessenden Thachis und aus von derselben entspringenden ziemlich hohen Blittern mit Nervenverbreitung. Die H a u mit Drischen reichlich ausgestattet, besonders der Mantel. Im Vorderende des Fusses median eine kleine Fussdriise, die sich durch die erwihlnte Fusspore öffnet.

Die Marseniaden haben eine a usstiilpbare Schnauze. Der mehr hinten liegende und quere oder mehr vorne sich findende und runde A ussem mud leitet in die M und röhre, die eingestiilpte Schnauze, an deren Boden sich, wenn die Mundröhre vollständig zuriickgestülpt ist, der schmale senkrechte Innen mund, das Vorderende des Schlundkopfes, findet. Wenn nur halb eingestỉlpt, enthält die Mundrühre den Ueberrest der Schnauze als ein Kegel, auch mit dem Innenmunde an der Spitze, mitunter schon in der Mundspalte sichtbar. Wenn vollständig ausgestïlpt, ist die IIundröhre in cine lange cylindrischconische Schnauze umgestaltet mit dem Innenmunde an der Spitze; innerhalb der Schnauze liegt daun der ganze Schlundkopf. Dieser Innenmund ist von einer niedrigen und schmalen Lippenscheibe eingefasst und an der Innenseite mit oben und unten fast zusammenstossenden, ziemlich flachen, horuartigen $\mathbf{M}$ andibelplatten belegt. Diese letzteren sind entweder ziemlich homogene, starke und mit dem vorderen rerdickten Rande hervorragende Organe (Chelyonotus, Marsenia, Marseniella); oder mehr schwache, ziem-

1) Unter den vielen Gattungen, bei welchen IACAZE-Duthiers (Comptes rendus. LXVIII. 186S. pag. SS4, Note) dieses Verhältniss, das Entspringen des N. acusticus aus dem Gehirnganglion, selbst bei pedaler Lage der Otocjsten, gesehen hat, nemut er auch dio Lamellarien. 
lich schmale, aus undeutlich geschiedenen Reihen von Stibchen bestehende Platten Marseniopsis); oder den letzteren etwas ähnliche, aber stärkere, aus regelmässigen Schrägreihen von Elementen zusammengesetzte Bildungen mit zackigem Vorderrande (Marscnina), mitunter auch noch dazu mit einem stärkeren, zusammengesetzten Zacken (Onchidiopsis). Der Schlundkopf ziemlich stark (besonders in den Chelyonoten); der vordere Theil mit den Mandibelplatten etwas nach unten gebogen; am Hinterende jederseits ein eigenthiimlicher "Knorpelfleck", rom Hinterende der Zungenknorpel gebildet, und wie diese Muskelinsertionen dienend; vom Hinterende ragt die ziemlich lange, meistens erst nach unten, dam nach oben gebogene oder etwas spiralig gedrehte Raspelscheide hervor. Die kurze und breite $\mathrm{Zung} \mathrm{e}^{1}$ ) eine sehr verschiedene Bewaffnung zeigend: meistens Fommt neben der medianen Platte jederseits nur eine starke laterale vor; in einigen Gattungen (Marseniopsis, Marsenina, Onchidiopsis) aber noch zwei äussere Haken. Die Anzahl der Zahnplattenreihen ist bei den Marseniaden (wie in der nïchst verwandten Familie) nicht gering, in Allem (an der Zunge und in der langen Scheide) 42-92 betragend, am grössten in den Onchidiopsen (bis 92) und in den Marseniopsen (bis 72). Die medianen Platten zeigen den Hinterrand abgestutzt oder (Chelyonotus, Marsenia, Marseniella) tief gekluftet; der nach oben gebogene Vorderrand hat zu jeder Seite der starken Spitze kleine Dentikel. Die starken Seitenzahnplatten haben meistens den breiten Rücken des Körpers tief gekluftet oder nur seichter ausgehöhlt (Marsenina, Onchidiopsis); während der Verkiirzung der Zunge wird die Spitze des Körpers der Zahnplatte in die Kluft der hinter ihr liegenden Platte eingeschoben. Der starke Haken dieser Platten ist an beiden Riandern gezähnelt, feiner an dem oberen (hinteren). Die zwei äusseren hakenartigen Platten viel schmächtiger, ohne Denticulation des Hakens oder mit ganz wenigen und feinen Ziihnchen.

Eigentliche Speicheldruisen scheinen zu fehlen.

Die Speiseröhre ziemlich kurz und weit, mitunter unten etwas kropfartig erweitert, wach unten, link's oder rechts oder gerade nach hinten hinabsteigend. Vor der Cardia zeigt sich die Speiseröhre in einigen Gattungen (Chelyonotus, Marsenia) mit einem lïngs des rechten 'Theils der Vorderseite des Blättermagens und weiter vorwärts liegenden sackartigen Vormagen (Proventriculus) verbunden. Die Speiseröhre mündet in den unteren Theil der Vorderfläche eines ganz eigenthümlichon Blättermagens ein. Dieses Organ ist haubenförmig, mit mehr oder weniger ausgehöhlter Vorderfäche und gervölbter Hinterseite; die Höhle ist klein, abgeplattet, sich vorne in die Speiseröhre, hinten in das Magenrohr offnend; die Wand ist sehr dick, aus einer nicht grossen $\Lambda$ nahal ron (meistens 10-20) driisigen Dissepimenten gebildet, welche senkrecht auf der Magenwand stehen. Dieser Magen ist mehr oder weniger rou einem dicken Drisenlager eingehiillt, das meistens unten besonders stark entwickelt ist, oft die pedalen Ganglien fast einhüllt und 
sich mitunter noch weiter nach vorne erstreckt. Das Drisenlager repräsentirt vielleicht die Speicheldrisen; mündet aber weder in den Schlundkopf noch in die Mundröhre ein. Aus der Hinterfläche des Blättermagens geht das kurze Magenrolı schräg nach oben durch die dïnne, aber zähe Scheidewand zwischen der unteren und oberen Körperhöhle und durch die Leber, um sich an der vorderen oder unteren Wand des eigentlichen Magens zu öffnen. Dieser letztere ist ziemlich weit, rundlich, zeigt ausser der Cardia mehrere weite Gallenöffnungen und setzt sich fast ohne Grenze in den Darm fort; er sehimmert (wie auch die hintere Strecke des Darmes) an der hinteren Seite der oberen Eingeweidemasse hindurch, ist sonst von der Leber eingeschlossen. Die erste Strecke des Darmes als eine verschmälerte Fortsetzung des Magens sich links erstreckend, und, dicht vor dem Pericardium, knieförmig in die vordere, längs der Vorderseite der Leber rechts verlaufende Strecke umbiegend, welche schliesslich nach vorne umbiegt und an der Analpapille innerhalb der rechten Ecke der Kiemenspalte endigt. - Der Inhalt der Verdauugshöhle war meistens unbestimmbare (hauptsächlich wohl ron Alcyonien und Ascidien stammende) thierische Masse; im Darm zeigte sich derselbe meistens als ovale oder kurz-wurstförmige, weisse oder dunkle festere Kothballen.

Die Leber vom gewöhnlichen Bau ${ }^{1}$ ); von einem Netze von schliesslich weiten Gallengängen durchzogen, deren Endstämme sich durch einige runde Oeffnungen in den eigentlichen Magen ausleeren.

Das Pericardium, das Herz und das arterielle sowic venöse System schienen sich wesentlich wie bei anderen Prosobranchiern zu verhalten.

Die Niere meistens ziemlich klein und links liegend; mitunter grösser, etwas weiter nach hinten verbreitert (Onchidiopsis) oder hinter der Kieme ganz querliegend (Marsenina). Der Bau scheint derselbe wie bei vielen anderen Prosobranchiern. Die Niere offnet sich dureh eine feine Pore in das Pericardium, und durch eine Spalte links (oder hinten) in die Kiemenhöhle.

Die hinter der Kieme und der Niere, am Vorderrande der Leber und theilweise am Darm ruhende Bläitterdrüse (feuillets muqueux, Cuv.; Schleimdrỉse, der Verfasser) auch von gewöhnlichem Baue; sie scheint sich durch dieselbe Spalte wie die Niere in die Kiemenhöhle zu öffinen.

Die meisten Marseniaden sind, wie andere Prosobranchier dioecisch, unisexuell. Die Geschlechtsdrüse, der Hoden oder das Ovarium, bildet die ganze Spitze und den hinteren Theil der letzten Windung der oberen Eingeweidemasse; sie sind beide aus langgestreckten Follikeln gebildet. - Der aus dem Hoden ausgehende Samenleiter bildet ein grosses Knäuel, mit welchem sich die Windungen eines appendiculären rohr-

1) Vergl. Barfurth, über den Bau und die Thätigkeit der Gasteropoden-Leber. Archiv f, mikk. Anat. XXII. 18S3. pag. 473 -524. Taf. XX. 
förmigen prostatischen Organs verwickeln; die Fortsetzung des Samenleiters tritt aus der oberen Eingeweidemasse in die (rechte) Wand der unteren Eingeweidehöhle und verläuft stark geschlängelt in der Wand bis an den Penis, durch welchen sich der Samenleiter bis an eine Oeffnung an oder nahe der Spitze fortsetzt. Nur seltener (Marsenia, Marseniella) tritt der Samenleiter an der Wurzel des Penis aus der Köorperwand frei in die Körperhöhle hinein, wird stärker und legt sich mit mehreren Schlingen iiber den Blättermagen und den Schlundkopf hin, ehe er in den Penis eintritt. Die letzte Strecke des Samenleiters ist in den meisten Gattungen in der Höhle (des Penis) frei und fingerförmig, aus der Oefinung ausstreckbar und kann ganz zuriekgezogen werden. Der Penis, wie oben erwähnt, in den verschiedenen Gattungen theilweise etwas verschieden. - Der aus dem Ovarium entspringende Eileiter öffnet sich in eine grosse, innerhalb der rechten Schalenmuskelfacette liegende Schleim- und Eiveissdriise; diese Drise setzt sich nach vorne in eine ziemlich kurze, aber starke $V$ a gina fort, die sich unterhalb der Analpapille öffnet; dicht oberhalb der Vulva bildet die Vagina ein besonderes, kurzes, dickwandiges Divertikel. In das Hinterende der Schleim- und Eiweissdriise öffnet sich eine Reihe von kleinen Samenblasen.

Unter den Marseniaden kommen aber einige (xattungen vor (Marsenina, Onchidiopsis), die monoecisch, bisexuel, sind, ein Verhältniss, das unter den Prosobranchiern sonst nur von der wenig bekannten Gattung. Valvata angegeben wird. ${ }^{1}$ ) Die Zwitterdriise (Gland. hermaphrodisiaca) zeigt den gewöhnlichen Bau; die Zwitterdriisengänge stehen mit einer sehr eigenthümlichen Nebenzwitterdruse in Verbindung; der aus dieser letzteren hervorgehende gemeinschaftliche Zwitterdrüsengang sich in gewöhnlicher Weise theilend. Der männliche Zweig, der Samenleiter, mit einer rohrartigen, in ein unregelmäissiges Knäuel aufgerollten, den Samenleiter zum grossen Theil einhüllenden Prostata in Verbindung stehend; dam in gewöhnlicher Weise in der Körperwand bis an den Penis verlaufend. Der weibliche Theil, eine Art Vagina, mit einer colossalen Samenb lase, mit einem dickwandigen Vestibularsack und mit der grossen, zweikammerigen Schleim- und Eiweissdrise in Verbindung stehend. Die Vagina öfunet sich mit einer kleinen spaltenartigen Vulva unterhalb und hinter der Analpapille. Wie hier eben kurz geschildert, ist wenigstens das Verhältniss des zusammengesetzten (monoecischen) Geschlechtssystems bei den Onchidiopsen.

Ueber die Ontogenie dieser Gruppe ist bisher nur Weniges bekannt. Die Marseniaden - von den echten Marsenieu (M. perspicua) ist Solches wenigstens durch PEACII, Hennedy ${ }^{2}$ ) und GiarD mit Sicherheit bekannt - fressen sich in zusammengesetzten Ascidien (Leptoclinum maculosum, Polyclinum succineum) rundliche Höhlen aus, in die sie

1) A. Moquin -Tandon, observ, sur l'appareil génital des Talvées. (Mém. de l'acad. sc. Inscript. et Belles-Lettr. de Toulouse. 4 S. XI. 1852. pag. 63). Journ, de conchyl. III. 1852. pag. 244-218. pl. IX. Fig. 3, 4.

2) Zoologist. 1853. pag. 4185 . 
ihre Eier absetzen; die Höhlen verschliessen die Thiere mit besonderen Deckeln, die concentrische Ringe zeigen sollen, welche durch Drehbewegungen der Thiere hervorgebracht sein sollen. Die Onchidiopsen scheinen (s. unten) in einer Halisarcide (und wahrscheinlich noch auf anderem Boden) ähnliche Höhlen mit ziemlich ähnlichen Deckeln (s. unten) zu bilden. Die Bruthöhlen enthalten, wie Giakd (Marsenia) und ich (Onchidiopsis) gesehen haben, cine gewisse Anzahl ron Nahrungseiern, die den Embryonen während der Entwicklung als Futter dienen. Die gröberen Züge der Ontogenie sind durch Giard verfolgt; ihm zufolge ${ }^{1}$ ) kommen (nach einander) zwei provisorische Schalen vor; die erste Larvenschale ist nautiloid, ihr folgt cine andere mehr einfache, mehr Carinaria-Schale :ihnliche. Lange vor GiARD hatte aber Knoms ${ }^{2}$ ) bemerkt, dass die Larvenschale dieser 'Thiere nicht zur Schale des reifen Thieres auswachse, sondern dass sich, umschlossen von der mit mehreren Kielen versehenen nautiloiden Schale, cine neue Schale bildete, die der bleibenden Marsenia-Schale viel mehr ähnlich aussah. Das Thier zieht sich aus der primairen Schale heraus, die verloren geht, und ist nur rom Rudiment der neuen (bleibenden) Schale bedeckt. Ganz ähnliche Beobachtungen hat MACDonald in der Siidsee angestellt, aus denen ${ }^{3}$ ) liervorgeht, dass die Jasonillen MACDONALD's, die Brownien von D'Orbigny und die Calcarellen von Souleyet wahrscheinlich nur Larven von Marsenien oder Marsenia-ihlnnlichen Thieren seien. ${ }^{4}$ ) Eine Larve mit ziemlich ähnlicher, aber vielrippiger primairer Schale, die ich gefunden habe (s. unten), gehört wahrscheinlich einer hocharetischen Onchidiopsis an. ${ }^{5}$ )

Die Marseniaden kommen durch alle Meeresgegenden verbreitet vor, meistens mit besonders ausgeprïigten Typen in den tropischen (Chelyonotus) und in den arctischen (Onchidiopsis) Mecresstrecken. - Was dic Verbreitung der Gruppe in der Zeit betrifft, so scheint sie (Marsenia) erst spiit in der tertiiren Periode aufgetreten zu sein.

Obgleich in Habitus wie im inneren Baue eine ziemlich scharf umschriebene. Gruppe bildend, bieten die Marseniaden doch unter sich bedeutende Unterschiede sowohl im Habitus wie im inneren Baue dar, besonders in der Bewaffnung der Zunge, weshalb die verschiedenen Glieder der Familie auch mehrmals von einander kïnstlich getrennt wor-

1) Grard, sur l'embryologie du Lamellaria perspicua. Comptes rendus. 22 Mrars 1875. pag. 736 (733-739).

2) А. Krinot, über einen neuen mit Wimpersegeln versehenen Gasteropoden. Archir f. Naturg. XIX, 1. 1S5̃3. pag. $223-226$. Taf. XI. Fig. I-II.

A. KroHN, Nachträge zu dem Aufsatz üb. die Echinospira diaphana. Archir f. Naturg. XII, 1. 1\$55, pag. 1-5. Taf. I. Fig. 1-2.

A. Krons, ferncre Nachträge zu dem Aufsatz üb. die Echinospira, nebst Bemerk. üb. eine ihr verwandte Larve. Archiv f. Naturg. XXIII, 1. 1857. pag. 252. Taf. XII.

3) Macdonald, further observ, on the metamorphosis of Gasteropoda. Trans. Linn. soc. XXIII, 1. 1860. pag. 70.

4) Die von M. Sars (Nyt Mgz. f. Naturvidensk. XVII. 1870. pag. 182-186. Tab. YI. Fig. 1-6) beschriebene Colpodaspis pusilla ist trot\% einiger Aelnlichkeiten sicherlich keine Marseniale, viel eher, wie von GW. JEFfrers angenommen, eine junge Cypraea europaea.

5) Sonst scheint eine ähnliche hinfällige Larvenschale bisher nur bei den Cymbulien (von KroHs) nachgerviesen; die Gallertschale des reifen Thieres scheint eine völlige Neubildung zu sein. 
den sind. $\left.{ }^{1}\right)$ Mit Ausnahme der Marseninen, welche in der Jugend wahrseheinlich sich wie andere Mitglieder der Familie verhalten, haben diese Thiere alle einen continuirlichen, geschlossenen, eine innere Schale enthaltenden Mantel; der Rand des letzteren ist entweder gebrïmartig verbreitert oder schmal und mehr gerundet (Onchidiopsis, Marseniopsis); ausser der immer anwesenden vorderen Inspirations-Falte und - Furche haben cinige Gattumgen (Marsenina, Onchidiopsis) noch eine rechte Exspirations-Falte und -Furche. Die Schale ist meistens verkalkt, seltener fast (Marseniella) oder ganz (Onchidiopsis) hornartig. Die Bewaffnung der Zunge ist curios verschieden, und diese Verschiederheit allein ist die kïnstliche Grundlage für die öfter stattgefundene Auflösung der Gruppe gewesen. Während die mehr typischen Formen neben der medianen Platte nur Seitenzahnplatten zeigen (1-I-1), haben andere (Marseniopsis, Marsenina, Onchidiopsis) ausser dieser noch zwei äussere Haken (2-1-I-1-2). Und was nun am aller Befremdesten ist, während die allermeisten Marseniaden wie andere Prosobranchier unisexuel sind, tritt Monoecie in zwei Gattungen (Marsenina, Onchidiopsis) auf.

\section{Conspectus generum:}

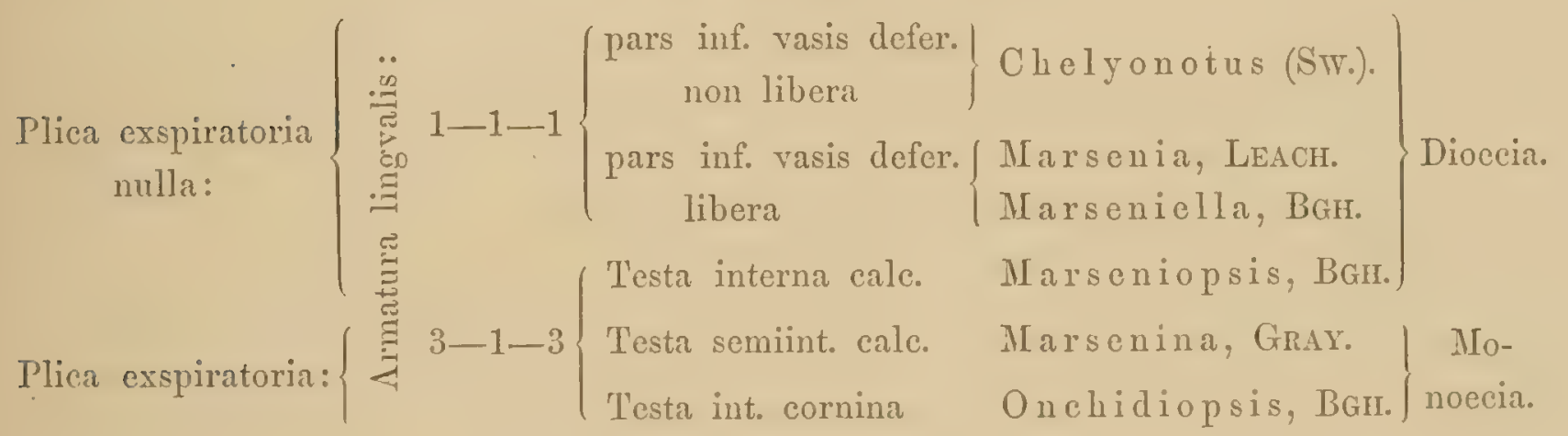

Was nun die systematische Stellung der Gruppe betrifft, so kann diese augenblicklich nicht mit irgend einiger Sicherheit angegeben werden; die wahrseheinlich nächst stehenden Gruppen sind, so wie im Ganzen die Prosobranchier, bisher zu wenig anatomisch untersucht. Jedenfalls stehen sie aber ganz nahe beiden Velutiniden, welche vielleicht nicht einmal als besondere Familie später zu unterscheiden sein werden. Diese letzteren stimmen nach meinen Untersuchungen mit den Marseniaden in der Form des Nervensystems sorvie sonst ziemlich im anatomischen Baue, besonders im Dasein des

1) Trosciel stellt (Das Gebiss der Schnecken. I. 1856-1863. pag. 167, 185) die Marsenien und Chelyonoten neben den Naticaceen, die Onchidiopsen und Marseninen neben den Velutinaceen, wie übrigens sehon ron GraY (Guide. I. 1857. pag. 46) gemacht, welcher die Velutiniden dieselben incorporiren liess.

Der Versuch Gray's (Guide. I. 1857. pag. 27-28) die Familie in drei generische Gruppen zu rertheilen, die Coriocellen, die Lamellarien (mit Lam. tentaculata als Typus) und die Ermeen (mit E. perspicua als Typus), ist so in jeder Beziehung - was Namen, Formulirung und lnhalt betrifit - ganz sinnlos. 
eigenthümlichen Blättermagens; ganz besonders aber schliessen sie sich durch ihren Hermaphroditismus und die Art ihrer Zungenbervaffnung (2-1-I-1-2) den monoecistischen Marseniaden (Marsenina, Onchidiopsis) an. Wäre nicht die Gattung Marseniopsis, die wieder ganz an die ächten Marsenien anknüpft, könnte man wohl (mit Gray u. A.) verleitet sein, jene Gattungen von den anderen Marseniaden zu trennen und mit den Velutiniden zu einer Familie zu vereinigen. Vorläufig wenigstens scheinen aber die Marseniaden so, wie hier aufgefasst, eine einheitliche Familie zu bilden.

\section{Conspectus systematicus.}

\section{Marsenia, LEAcir.}

Marsenia, Leaci. „Synopsis moll. Brit. 1820." OKEN, Isis. 1823, 2. pag. 458. Wood, catal. of shells from Crag. Annals and mgz. n. h. IX. 1842. pag. 528.

LEACH, moll. Brit. synopsis. ed. Gray. 1852.pag. 34-35.

Helix sp., L., Schröter, Gir., I'Urton, Dillwyn, Wood, delle Cimlaje. Thetys, STröM.

Bulla sp., O. Fr. Müller, Pulteney, Mtrg., Matton et Race., Tur'on, Wood, T. BRown etc.

Sigaret, Sigaretus, Cuv., Desh.-Lam., Bowdich, Risso, Blv., Michaud, Flem., Rang, delie Chiaje, Quor et Gam., Bouch.-Chanter., Philippi, Stwangion, Forbes, Gould, Möller, 'l'horpe, Lank. (sec. charact. gener., non secundum sp.)

Lamellaria (sect. b) MITG., Lovín, Gray.

Laminaria, Gray. 1821.

Ermen, GraY. Guide. I. 1857. pag. 28.

Coriocella sp., Blv., Desir. E. m., Philipr.

Cryptothyra, Mre.

Cryptocella, H. et A. AdAMs. The genera of recent moll. I. 1858. pag. 202.

Velutina sp., Mrсr.

Oxynoe, Coutr. (nec. RFQ.).

Animalia dioecia; pallio ampliato, supra continuo, antice sulco et plica inspiratoria. Penis falcatus, apice dilatatus. Lamellae branchiales lateribus plicis transversalibus instructae. - Lamellae mandibulares fortiores structura uniformi (homogena). Dens media- 
nus radulae basi (fere semper) bifidus; dens lateralis magnus dorso fissus, hamo curvato marginibus serrulato. Proventriculus non deest. Pars inferior vasis deferentis in cavitate abdominali pro parte libera.

'Testa interna calcarea, lactea, nonnihil diaphana, laevis, obovata, spirata, anfractibus vix tribus; spira ad $1 / 4$ longitudinis partem sita, prominente, acutiuscula, anfractibus vix duobus; apertura ampla, ovata, patente usque in fundum spirae; columella antice sinu excisa.

Die von LEAcir schon um 1820 aufgestellten (ächten) Marsenien sind nicht sehr gross, haben einen oben geschlossenen Mantel mit breitem Gebräme und (nur) mit einer vorderen, in die linke Ecke der Kiemenspalte leitenden Falte und Furche (an der Unterseite des Mantelgebrïmes). Die ganz eingeschlossene, verkalkte Schale mit kleiner Spira, mit sehr weiter bis in die Spira ubersehbarer Oeffnung und mit einem ziemlich deutlichen Columellar-Sinus. - Die Marsenien haben hohe Iancetförmige Kiemenblätter, die an den Seiten mit $Q$ uerfalten bedeckt sind. Die Mandibelplatten sind stark, aus einer e införmigen (homogenen) hornartigen Masse (nicht aus Stäbchenreihen) gebildet, mit breiter Greif- oder Kauparthie. Die medianen Za h n platten der Zunge im Hinterrande fast immer tief gekluftet; die starken Seitenzahnplatten mit starkem, an beiden Rändern, aber ungleichartig gezïhneltem Haken. Ein grosser Vormagen (Proventriculus) kommt immer vor. Diese Thiere sind getrennt geschlechtlich; der Samenleiter ist in einer grossen Strecke frei und deckt mit seinen Schlingen theilweise den Schlundkopf und den Blättermagen. Der abgeplattete sichelförmige Penis am Ende etwas breiter.

Die ächten Marsenien kommen in allen Meeresgegenden vor, in den tropischen wie in den arctischen. Ueber ihre biologischen Verhältnisse ist bisher wenig bekannt; sie scheinen (wenigstens nach Angaben yon MTG., Fley., RANG, M. SARS) etwas tieferes Wasser und Felsengrund zu lieben; sie scheinen nicht sehr lebhaft zu sein, etwas lichtscheu; sie schwimmen mitunter. Sie scheinen auf animalische Nahrung angewiesen zu sein. Die Ontogenie der typischen Art ist, wie oben angegeben, theilweise, aber unvollstïndig bekannt.

Dieser Gruppe gehören die einzigen bisher bekannten fossilen Marseniaden; die grosse Fragilitit der Schalen wird iberhaupt dem Bewahren derselben grosse Hindernisse in den Weg gestellt haben. Prillup giebt seine Coriocella perspicua als im Basalttuffe von Militelli vorkommend an, sowie im Kalksteine von Palermo; Woon die Marsenia producta als auch in der Crag-Formation vorkommend, von welcher er noch eine andère Art, die M. depressa, hat; subfossil hat Dr. H. Beck die Marsenia latens im "Blaaleer" der gehobenen „Havstokke" bei Bergen gefunden (Lrelu) ').

1) Die von Fischer (Advers. 20ol. 1819. pag. 84. Tab. III. Fig. 1) beschriebene und abgebildete Ploearhia, die eine innere Schale (nuti animal Parmacellae, Sigareti“ $\rightarrow$ ) haben soll, hat kaum einem Mollusken gehört. (Cfr. FerR., Bull, 1826, I. pag. 128). Semper, Philippinen. II, II (hergh, Ergânzungsheft III. Marseniaden, I). 
Eine Reihe von Arton dieser Gruppe ist bisher beschrieben, meistens auf Verschiedenheit in Farbe und auf unbedeutende Variationen in der Form der Schale gegruindet. Die Marsenien sind aber — wie verschiedene andere Gastraeopoden ${ }^{1}$ ) - in ihren Farbenverhältnissen ganz ausserordentlich variabel, und die Formverhältnisse der Schale auch nicht so ganz constant, sie sind alle ,in apicem usque perspicuae“ (LinNÉ); weshalb fast alle diese "Arten" nur mit Reserve angenommen werden können. Um die Frage iiber die Specifität sicher zu beantworten, braucht es eine an Ort und Stelle gemachte Untersuchung einer grösseren Anzahl von Individuen.

1. M. tentaculata (MTG.).

M. atlant. or.

2. M. producta, LEACH.

M. atlant. or.

3. M. perspicua (Linné).

M. mediterr.

4. M. lateus (O. Fr. MüLler).

M. atlant. or. septentr.

5. M. pellucida (Verrill).

M. atlant. occ.

6. M. Stearnsii (DALL).

M. pacific. (Californ.).

7. M. orbiculata (DALL).

M. pacific. (Californ.).

8. M. Rangii, BGIr.

II. antillense.

9. M. minuta (H. ADAns).

II. rubrum.

10. M. gemma, BGI. n. sp.

M. philippin.

11. M. Cabulana, BGH. n. sp.

M. philippin.

12. II. affinis, BGH. n. sp.

M. philippin.

13. M. indecora, BGH. n. sp.

M. philippin.

14. M. is a bellina, BGI. M. sp.

M. philippin.

1) Vergl. MoqunN-Tandon, rech. anatom. sur l'Ombrelle de la Miediterranée. 1870. pag. 15-16 (Ann. des sc. nat. 4 S. XIV. 1570). 
15. M. Diegoensis (DALL). n. sp.

II. pacific.

16. M. oplione (Gray).

II. pacificum (Nov. Zeland.).

17. M. Kerguelenensis (Studer).

II. pacific australe.

18. M. dubia, BGH. n. sp.

II. atlant. or. (Cap Verde).

19. MI. translucida $\left.\left(\mathrm{BLV}_{0}\right)^{1}\right)$.

M. ?

† 20. M. depressa, WooD ${ }^{2}$.

Crag (Sutton).

\section{Mars. tentaculata (MTG.).}

Lamellaria tentaculata, MTG. Linn. 'Tr. XI. 1811. pag. 179. Tab. 12. Fig. 5-6.

Jonst. Loudon, Ann. mgz. 1836. pag. 229. Fig. 2-5.

Lovén, ind. moll. 1846. pag. 109.

Bulla tentaculata. Turton, Conch. Dict. 1819. pag. 25 (e MTG.).

Sigaretus tentaculatus. Fleir., Br. anim. 1828. pag. 360.

Thorpe, Br. mar. conch. 1844. pag. 154.

Thompson, rep. on the fauna of Ireland. 1844. Br. assoc.

f. advanc. of sc. 1843. pag. 258.

Marsenia tentaculata, MTg. R. BERGH, Monogr. 1853. pag. 327.

Lamellaria tentaculata, MTG. Forbes and HANLey, a hist. of Br. Moll. III. 1853. pag. 358 .

Ha b. Oc. atlant. or. septentr.

Diese Form soll am Ruicken gelb sein mit schwefelgelben oder rothen Flecken, noch dazu mit schwarzen Wärzchen und Punkten; eine Varietät soll stärker gelb oder grüngelb sein kömmen und ohne schwarze Abzeichnung. Die Schale soll mehr flach und mehr opak als in der Mars. producta sein.

Die Art ist an den englischen Kïsten, an der west-schwedischen und an der dänischen Küste (Agger-Kanal) gefischt. ${ }^{3}$ )

1) Diese von Budinville (Dict. sc. nat. XLIX, pag. 111) als Sigaretus translucidus aus der Sammlung des Herzogs voN RivouI kurz und unbrauchbar beschriebene Narsenia wird jetzt wohl immer unbestimmbar bleiben.

2) H. et A. AdAus (1. c. pag. 201) haben noch als Namen eine M. antarctica, CouTH., eine M. practenuis, Couru. und eine M. tuberculosa, H. et A. ADAMS.

3) M'ANDREW (Rep. on the marine testac. moll. - Rep. of the Br. assoc. for adranc, of sc. for 1856. pag. 126) giebt sie auch als in Biscayischen Busen (Vigo) und Mittelmeer vorkommend an. 
2. Mars. producta, LEACE.

Bulla haloitoidea. MITG., Test. Br. 1803. ed. Chenu. pag. 92. pl. 3. Fig. 6.

Matt, et RACQ. Linn. 'Tr. VIII. pag. 123.

Turton, conch. dict. pag. 24.

Lamellaria haliotoidea. MFrG., Linn. Tr. XI. pag. 184.

Helix haliotoidea. DiLlw., deser. catal. II. 1817. pag. 973.

Marsenia producta. Leach, Moll. Br. Syn. ed. Gray. 1852. pag. 34.

Sigaretus haliotoideus. Brown, Illustr. 1827. pl. 44. Fig. 1-2.

- convexus. Boucir.-Chanter., Catal. des moll. mar. - du Boulonnais. 1835. pag. 149.

- perspicuus. Forbes, Malac. Monensis. 1838. pag. 29 (excl. synon.).

Clark, Ann. mgz. n. h. 2 S. XI. 1853. pag. 54.

Lamellaria perspicua. Lovén, Ind. moll. 1846. pag. 15 (excl. synon.).

Coriocella perspicua. Lovéx, Oefvers. 1847. pag. 193.

Marsenia producta. Bengh, Monogr. 1. c. 1853. pag. 328.

Lamellaria perspicua, L. ForBes and HANLEY, 1. c. 1853. pag. 355.

var. Mars. complanata. LEACH, 1. c. 1852. pag. 35.

H a b. M. atlant. or. septentr.

Diese Form scheint mit sehr verschiedener Farbenzeichnung aufzutreten. Lovéx giebt sie als grau, schwarzgestreift und gelbgefleckt an; Bouchard-CHAnteraux als grün mit dunkleren Flecken; MONTAGU beschreibt sie als röthlich oder braun, mitunter auch fast weiss.

Die Schale ist, wie oben erwïhnt, meistens weniger flach und weniger opak als in der vorigen Art; Lovén zufolge ist die Schale mit einer ,fascia spirali media nebulosa" ausgestattet, ein individueller Character, der sich auch in anderen Arten zeigen kann (vgl. unten M. zonifera).

Die Verbreitung dieser Form scheint mit der der vorigen zusammenzutreffen. WooD giebt sie als fossil in der Crag-Formation vorkommend an.

Diese Form ist mit der vorigen wahrscheinlich identisch, wie schon von LEACr, CLARK $^{1}$ ) u.A. angenommen. GW. JefFreys zufolge ${ }^{2}$ ) sind die Bulla haliotoidea von MontaGU (die Mars. producta von LEACH) das Weibchen, und die Bulla tentaculata Montagu's (die Mars. complanata von LEAch) das Männehen derselben Art, so, den Angaben Jefreeys's nach, nach seiner Untersuchung der originalen Exemplare MonTAGU's im Brit. Museum (wo ich dieselben in 1873 nicht finden konnte). Ein männliches Individuum hat aber Montagu bei der Beschreibung (1. c.) seiner Bulla haliotoidea ganz deutlich vorgelegen.

1) Ann. mgz, nat. hist. 2 S. XI. 1853. pag. 55.

2) GW. Jeffrers, Brit. conchology. IV. 1867. pag. 235-238. 
Forbes und Hanley (1. c.) sowie Gw. Jefrreys (1. c. pag. 235) betrachten die zwei Formen als noch mit der Mars. perspicua des Mittelmeeres identisch, was wohl auch der Fall sein könnte. Leider habe ich nicht Gelegenheit gehabt, die nördlichen und nordatlantischen Formen dieser ziemlich variablen collectiven Marsenia (perspicua) zu untersuchen.

\section{Mars. perspicua (L.).}

Helix perspicua, L. S. nat. ed. X. 1753. I. pag. 775. No. 620.

Mus. Lud. Ulr. 1764. pag. 673. No. 381.

S. nat. ed. XII. I, 2. 1767. pag. 1250. No. 712.

S. nat. ed. XIII. (GxeL) VI. pag. 3663. No. 151.

Vitrina ampullacen. Christophori et Jan. ex auctor. Pinlmpr (et Pfeiffer).

Sigaretus perspicuus. PHL., en. moll. Sic. I. 1836. pag. 165. 'I'ab. X. Fig. 1 abc.

Marsenia perspicua. R. Bergi, Monogr. 1853. pag. 330.

var. Sigaretus Kindelaninus, Mrchaud. „Bull. Soc. Linn. de Bourdeaux. II. 1828. pag.

119. Tab. adnexa, Fig. 1-2". Ferr., Bull. univ. sc. nat.

XVII. 1829. pag. 308.

Velutina Kindelanina. Micr. et Potiez, catal. de Douai. I. 1838. pag. 508.

Marsenia Kindelanina (Mice.). R. Bergir, Monogr. I. c. pag. 333. Tab. V. Fig. 6. var. Sigaretus stomatellus. Risso, hist. nat. de l'Eur. mérid. IV. 1827. pag. 252. Tab. X.

Fig. 152.

Sigaret. RANG, manuel. 'I'ab. V. Fig. 4, 5, 6.

Marsenia stomatella (Risso). R. Bergi, Monogr. 1. c. 1853. pag. 333. T'ab. V. Fig. 7, 7\%.

var. Sigar. Audouini, CAntr. Diagn. 1835. pag. 15. - Nouv. Mém. de l'ac. royale de Brux. XIII. 1840. pl. IV. Fig. 1, 2.

Mars. Audouini (CANTr.). Bergr, Monogr. pag. 334.

var. Mars. zonifera, BGr. Bergir, Monogr. pag. 335. 'l'ab. V. Fig. 8.

var. Helix neritoidea. Delle Crinje, Memorie. III. 1828. pag. 215, 226. Tav. 47. Fig. 5

$(10,111,8,19,20,21)$.

Sigaretus neritoideus. DELle ChIAJE, descr. e not. II. 1841. pag. 111. - V. pag. 84.

- VI. 1841. Tav. 79. Fig. 5, 18, 21.

Mars. neritoidea (Delle Chidje). Bergh, Monogr. pag. 336. 'I'ab. V. Fig. 9.

var. Sigaretus Adansonii. Delle Chraje, Mem. III. 1828. Tav. 47. Fig. 3, 4.

Helix haliotoidea, Sigareto. velle ChidJe, Mem. IV. 1829. pag. 203.

Sigaretus haliotoideus. DELLE CHAJE, descr. e not. II. 1841. pag. 111. - V. pag. 84.

Mars. Adansonii. BerGi, Monogr. 1853. pag. 337. 
var. Sigaretus flavus. Delle Chraje, Mem. V. 'Tav. 77. Fig. 10.

Delle Chitaje, Deser. e not. II. pag. 111. - V. pag. 85. - VI. 1841. Tav. 69. Fig. 10. - VII. Tav. 104 a. Fig. 3-5.

Mars. flava (Delle Chide). Bergh, Monogr. 1853. pag. 338.

var. Lamellaria Kleciachi. Brusina, contrib. pella fauna dei moll. Dalmat. 1866. pag. 35.

Hab. M. mediterraneum.

Animal colore magnopere ludens.

T'esta ambitu oblique-obovate-subelliptico, supra sat convexa, infra planata, anfractibus paucis, fere $2 \frac{1}{2}$, rapide evolutis; diaphana, nitida, alba, incrementis confertis inaequalibus subtiliter striata. - Dim.: long. : lat. : alt. $=1: 0,7: 0,35$. Ang. apicalis c. 112. Pond. 40 milligr. (dim. long., lat., alt. $=12,9$ et $5 \frac{1}{2} \mathrm{~mm}$.). - Spira brevis, lateralis, margini postico testae approximata, prominens, convexa, apico vix acutiusculo, fere digyra, basi altitudinem ter saltem superans; partem quintam totius diam. longit. testae occupans similique spatio a margine testae postico remota; parte nucleali obtusiuscula, sub lente subrugato-striata (linea impressa irregulari simul distincta); reliqua spirae parte turgidius-convexa, sutura simplici filiformi ab anfractu ultimo defensa. Ultimus anfractus ambitu obovato, antice parum dilatatus, nothaeo medio turgidior, suturam versus et labrum sensim minus convexe descendens, ad latus sin. rotundate incurvatus; plagulis incrementi, oculo nudo inspectis inaequalibus, interdum plicaeformibus; lineis spiralibus 3, suturae subparallelis, ab illaque parum remotis, 2 approximatis magis conspicuis, a margine labri versus mediam testam tendentibus. Apertura ampla, ovalis, in spiram usque patula (long.: lat. $=3: 4$ ); pariete int. aperturae striis subtilioribus concolore, nitido. Margo columellaris tenuis, simplex, leviter arcuatus cum flexura leviori in marginem anteriorem abiens. Labium tenue, simplex, arcuatum.

Periostracum tenuissimum, nitidum, pallide flavescens.

Diese Art wurde zuerst, aber ohne Angabe von Heimath, in der X. Ausgabe des Systema naturae aufgestellt, wurde dann etwas genawer im Mus. Lud. Ulriccae beschrieben und ging so, nur mit beigefügter Heimathsangabe "Nare mediterraneum ", in die XII. Ausgabe des Systems über.

Sie scheint ganz bedeutend in Farbenverhältnissen zu variiren. Phudppr hat sie zinnoberroth gesehen, oben mit einem grösseren violetten Flecken jederseits und überall mit kleinen grauen Flecken besprengt; er hat sie aber auch mehr oder weniger hoch orangenfarbig mit zerstreuten weissen Flecken gesehen, oder mäusegrau mit mehr dunkelgrauen Fleckchen; oder graugelb oder endlich ganz gelb. G. Moguin-T'Andon sah sie')

1) Moquin-Tandon, rech. anatom. sur l'Ombrelle de la Mediterranée. 1870, pag. 15-16. (Ann. des sc. nat. 5 S. XIV. 1S70). 
von milch- und schmutzig Weiss bis Violett und Orangegelb variiren. RANG meint ${ }^{1}$ ), dass sie während ihres Lebens 3-4 mal Farbe ändern. Zwei von mir (s. näher unten) in Trieste und Napoli untersuchte Individuen waren hauptsïchlich griulichweiss mit dunkleren Punkten. Auch die Schale dieser Form ist nicht immer von absoluter Formconstanz, mitunter ein wenig länger oder kïirzer, ein wenig mehr oder weniger gewölbt, die Spira ein wenig mehr oder weniger vortretend.

Die Art scheint fast überall an den Kiisten des Mittelmeeres vorzukommen, und an einigen Stellen in Menge. Sie ist an den suidspanischen Ki uisten, an den Balearen (M'ANDrEv), an dem Frankreich bespülenden Theile des Mittelmeeres (Pedit, Moguin-I'Andon, Vayssière, BerGi), ringsum an den italienischen Küsten, auch in der Adria (SANdri, Bergir), und bei Algerien (Weinkauff) gefischt. Philippi giebt sie als fossil im Basalttuffe und im "Kalkstein vorkommend" an.

Es muss vorlïufig dahingestellt bleiben, ob diese Form des Mittelmeeres wirklich von der atlantischen verschieden sei. Sie wird es aber kaum sein, wie schon vor Jahrzehnten von Forbes (1838), theilweise von LovéN (1846) u. A. angenommen, und wie in neuester Zeit auch von Conchyliologen wie WennkAUfF $^{2}$ ), Gw. Jeffreys u. A. ${ }^{3}$ ) In meinen schalengläubigen Tagen (1853) habe ich die Form des Mittelmeeres nicht allein von der (oder denen) des atlantischen Occans verschieden angesehen, sondern noch die verschicdenen, von den Verfassern gebrachten Spielarten von jener als wirklich differente Arten angesehen. Und das sind in der That alle jene absolut nicht, oder höchstens vielleicht nur eine einzige, der Sigar. Norelli von DELLE CHIAJE, welchen doch SCACCII und nach ihm PiIllipr auch nur als eine Varietät der jetzigen Art betrachten.

\section{Mars. Morelli (delie ChiaJe).}

Sigaretus Morelli. delle ChidJe, Memorie. V. 'Tav. 62. F'ig. 1-4.

Sigar. Morelli. delle Chuaje, descriz. e notomia degli an. invert. della Sic. citer. II. 1841. pag. 111. - V. pag. 85. - VI. 1841. Tar. 54. Fig. 6. - VII. 'Tav. 106. Fig. 1-3.

Mars. - Bergir, Monogr. 1853. pag. 338.

Den Angaben Delle CirnJE's zufolge ist diese Form am Rücken olne Knoten, cinfarbig, blutroth bis kastanienbraun, und diese Charactere bot auch ein von mir untersuchtes Individuum (s. unten) dar.

1) FÉrussac, Bull, des sc, XIX, Oct. 1829. pag. 147.

2) WEInkauff, die Conchylien des Mittelmeeres. II. 1868. pag. 258.

3) LeSLIE and HerdiaN, the invertebrate fauna of the Firth of Forth. 1881. pag. 95 ("Iamellaria perspicua, I."). 


\section{t. Mars. latens (Mǘr..).}

Thetys auriculis nullis, margine antico fisso prominulo. STrön, Skr. som udi det Kíjöbenh. Selsk. ere fremlagte og oploste. X. 1770. pag. 10. Tab. V. Fig. 1-4.

Bulla latens. O. Fr. MÜLler, Prodr. zool. Dan. 1776. pag. 242. No. 2923.

Sigaretus Stroemii. SARS, Beskr. og Jagttag. 1835. pag. 67 (Isis. 1837. pag. 754). Marsenia latens. Beck, Amtl. Ber. über die 24. Versamml. der Naturf. u. Aerzte in Kiel. 1846. pag. 116. No. 45.

Lamellaria latens. Lovén, Index molluse. 1846. pag. 15.

Marsenia latens. Bergh, Monogr. 1. c. 1853. pag. 325-326. 'Tab. V. Fig. 1-4.

Lamellaria latens, Müller. G. O. SARs, Bidrag til Kundsk. om Norges arktiske Fauna. I. Moll. reg. aret. Norvegiae. 1878. pag. 150. Tab. 12. Fig. 4 a-e; Tab. V. Fig. 6 a, 6 b.

Animal nonnihil depressum, dorso sublaevi. Color paginae superioris brunneus, fuscato sparsim maculatus; paginae inferioris albescens.

Testa subrotunde-ovalis, repanda, striis evanidis; spira laterali nonnihil depressa, ad tertiam longitudinis partem sita.

Ha b. M. atlant. or. septentr.

Diese schon von STröm und für seine Zeit (1770) ganz gut beschriebene und abgebildete Form ist von den skandinavischen Faunisten öfter erwähnt. Sie kommt an der nördlichen Westkiiste von Norwegen (Bergen, Lofoten, Finmarken) ziemlich sparsam vor. Die Form ist von mir (s. unten) genauer untersucht worden.

Die Schale war bei dem von mir untersuchten $20 \mathrm{~mm}$ langen Individuum von einer Länge von $13 \mathrm{~mm}$, bei einer Breite bis 9,5 und einer Höhe von $4 \mathrm{~mm}$; kalkweiss, ziemlich stark abgeplattet; die Spira klein, wenig vortretend, die letzte Windung sehr weit.

H. BECK zufolge (vergl. meine $\lambda$ Ionogr. pag. 326) kommt sie nicht selten im „Blanleer" der gehobenen "Havstokke" in der Nähe von Bergen vor (LyelL).

\section{Mars. pellucida (VerRiLL).}

Lamellaria pellucida, Verrill. Notice of a remarkable marine fauna occupying the outer banks off the southern coast of New-England. Amer. journ. of seience. XX. 1880. pag. 395.

- - V. Catalogue of marine mollusca. Trans. of the Connecticut acad. V, 2. 1882. pag. 518. Pl. LVHI. Fig. 4, 5, 5a. 
Lamellaria pellucida, $V$. Notice of recent addit. to the marine invertebrata of the northeastern coast of America. Proc. Un. St. Nat. Mus. III. 1880, pag. 372.

Ha b. M. atlant. occid.

Color e luteo-brunneus, obscurius maculatus. Testa ut in Marsenia perspicua. Dentes mediani radulae postice truncati (non bifidi).

Diese distincte Form des westatlantischen Oceans ist in den iiusseren Formverhältnissen der oder den Varietäten der M. perspicua (des Mittelmeeres), die einen nicht knotigen Mantel zeigen, ähnlich. Auch die Farbe ist gelblichbraun oder braun, nach VERRILL bald heller, bald dunkler.

Die Schale der zwei Individuen, die ich untersucht habe (s. unten), war im Ganzen der der M. perspicua ziemlich ähnlich, $13 \mathrm{~mm}$ lang, bei einer Breite bis 10 und ciner Höhe bis $6 \mathrm{~mm}$, aber kürzer, mehr gewölbt und mehr pellucid; die Antvachsstreifen ziemlich stark.

Die medianen Zahmplatten unterscheiden sich, wie schon von VerriLl bemerkt, auffallend von denen anderer bekannten Marsenien, indem sic hinten nicht gekluftet, sondern einfach abgestutzt sind.

Var. Gouldii, Verrill.

Lamell. pellucida, var. Gouldii, Vernill. 1. c. 1882. pag. 518. Pl. LVIII. Fig. 3.

Diese Form soll sich nach Verrill von der typischen durch kürzeren, höheren und breiteren Mantel unterscheiden, welcher fernerhin weicher, dicker. und am Riicken mehr oder weniger lnotig sein soll; der Penis soll noch dazu vou anderer Form sein, mehr löffelförmig und mit grösserer und anders geformter Papille am Rande (wie auch in der rohen Zeichnung sichtbar). Die Schale soll kiurzer und breiter sein, die Spira niedriger, die Sutur weniger tief und die letzte Vindung mehr gewölbt. Verrill bemerkt selbst, dass diese und die obige Form untereinander vorkommen, ferner, dass sich auch Zwischenformen rorzufinden seheinen.

Die ron mir (s. unten) untersuchten Individuen waren zwar in der allgemeinen Gestalt von der typischen Form etwas abweichend, nicht aber mehr knotig als diese (s. unten), und die (leider mehr oder weniger beschädigten) Schalen schienen kaum in den zwei Formen wesentlich verschieden. Bei dem Fehlen eines mäinnlichen Exemplars der typischen Form konnte ich die von Verrill prätendirte Verschiedenlieit in der Gestalt des Penis nicht constatiren. 


\section{Mars. Steaimsii (Datr).}

Lamellaria Stearnsii. DALL, descr. of sixty new forms of Moll. from the W. coast of North America ete. Amer. Journ. of conchology. VII, 2. 1871. pag. 122. Pl. 15. Fig. 6.

Ha b. M. pacific. (Californ.).

Von dieser Form ist nur die Schale bekannt, die ziemlich klein war ("lat..26, long..2, alt. 12 in." $)$; sie ist rein weiss, rundlich, etwas abgeplattet, mit drei Windungen; die Spira wenig vortretend, die Oeffinung sehr weit und rundlich, die Zuwachslinien scheinen wenig vortretend, die Innenseite schimmernd (polished). - Eine mir von DALL freundschaftlich geschickte Schale war $9 \mathrm{~mm}$ lang bei einer Breite bis 7 und einer Höhe bis $3,6 \mathrm{~mm}$, kalkweiss, ziemlich abgeplattet; die Spira nicht vortretend, klein; der hinter der Columella an der Unterseite liegende Theil der letzten Windung ziemlich schmal.

\section{Mars. orbiculata $\left(\mathrm{D}_{\Delta L L}\right)$.}

Lamellaria (? Stearnsii, var.) orbiculata, DALl. 1. c. pag. 122. Pl. 15. Fig. 2, 3.

Ha b. M. pacific. (Californ.).

Diese Form ist auch nur durch die Schale bekannt, welche, DALL zufolge, etwas breiter als die vorige ist, und nur 21/2 Windungen haben soll; die Windungen sollen mehr gewölbt sein; die Spira relativ grösser und melır vortretend, die Sutur tiefer, die weite Oeffnung schräge, die Columella dicker. - Diesen Angaben entsprach auch ganz cine mir von DALL freundlich geschickte Schale. Sie war (schwach bläulich)-milchweiss, mehr gewölbt, $9 \mathrm{~mm}$ lang bei einer Breite von 7,4 und einer Höhe bis etwa $4 \mathrm{~mm}$; die Spira mehr vortretend, grösser, rundlich-papillenartig; die Anwachsstreifen schwach; die Schalenöflnung rund; die Innenseite glinzend, wie polirt; der hinter der Columella liegende 'Theil der letzten Windung etwas breiter.

\section{Hars. Rangii, BGH.}

Sp. affinis Sigg. Kindelaninus, Mren. Férussac, Bull. un. se. nat. XVII. 1829. pag. 309.

Mars. Rangii. Bergi, Monogr. 1853. pag. 334.

Ha b. Mare antillense (St. Thomas).

Wie oben bemerkt, erwähnt RANG eine Form aus dem Antillenmeer. In den sonst so reichen westindischen Sammlungen Kopenhagens (HORNBECK, RrsE) finden sich keine Marsenia-Schalen. 
9. Mars. minuta (H. Adars).

Lamellaria minuta. H. AD. - R. M'Andrew, rep. on the testaceous moll. obtained during a Dredging-excurs. in the Gulf of Suez in - 1869. Republished with addit. and correct. by A. H. Cooke. II. Ann. mgz. nat. hist. 5 S. XVI. 1885. pag. 38.

Hab. Mare rubrum.

Diese ist die einzige bisher aus dem Rothen Meere erwähnte Art ${ }^{1}$ ) und uber dieselbe ist bis jetzt eigentlich gar nichts bekannt.

10. Mars. gemma, BaH. n. sp.

Marsenia gemma, BGH. Malacolog. Unters. (SEMper, Philipp. II, II) IX. Heft. 1875. Taf. XLI. Fig. 7.

Ha b. M. philippinense.

Diese lebend schön gefärbte Art zeigt den Rücken am Mantelgebräme hell grauviolett, die Gegend der Sehale roth und am Mantelgebräme ahnliche rothe Flecken; der ganze Mantel ist noch dazu mit weissen Punkten übersiet, besonders an der Mitte dicht gedrängt und noch dazu ein schönes griechisches Kreuz bildend; die Innenseite der Athemröhre scheint violettgrau gewesen zu sein.

Die Schale war $8,3 \mathrm{~mm}$ lang bei einer Breite vorn von 6 und einer Höhe bis $3,2 \mathrm{~mm}$, ziemlich pellucid, sehwach milchweiss; die Spira wie gewöhnlich; die Anwachsstreifen ziemlich stark.

Die Form ist unten anatomisch untersucht.

11. Mars. cabulana, Ban. n. sp.

Ha b. MI. philippin.

Diese neue, vielleicht etwas zweifelhafte Art, die unten genauer untersucht worden ist, scheint wenigstens durch ihre Schale von den anderen philippinischen Arten verschieden.

Diese S chale war (schwach gelblich) kalkweis; 10,5 mm lang bei einer Breite vorne ron 8 und einer Höhe von $5,9 \mathrm{~mm}$; die Spira wie gewöhnlich, die Anwachsstreifen ziemlich

1) Durch die Freundlichkeit des rerstorbenen Prof. Peters in Berlin hatte ich kurz wach dem Tode von Ehrenberg Gelegenheit im Sommer 1876 in Berlin seine auf die Evertebraten des rothen lieeres bezüglichen MSS. durchzusehen. Im "III. Theile" derselben (Fasc. XXVIIr. pag. 2) findet sich als die Gattung "Creusa" bildend (nebenbei steht mit Bleistift Deridobranchus ocellatus geschrieben) ein wahrscheinlich Marsenia-artiges Thier, in drei colorirten Figuren dargestellt; hierhin scheint cine "von HearRici" im Berliner Museum herrührende Marsenia zu gehören. 
stark; an der letzten, ziemlich gewölbten Windung mehrere mit dem Umgange parallele Furchen, unter denen zwei stärliere.

12. Mars. affinis, Ban. n. sp.

Ha b. M. philippin.

Auch diese Form scheint specifisch ziemlich zweifelhaft zu sein, auch der anatomischen Untersuchung nach (s. unten).

Die Schale ist der der Mars. cabulana etwas ähnlich, aber etwas weniger gewölbt und olne die Furchen der letzten Windung; die Länge 9,5 $\mathrm{mm}$ bei einer Breite bis 5 und einer Höhe bis $3,8 \mathrm{~mm}$. - In zwei Individuen, die doch hierher zu gehören schienen, war die Schale von etwas anderer Beschafienheit, milchweiss, mehr gewölbt, etwas kiirzer.

13. Mars. indecora, Barr. n. sp.

Ha b. M. philippin.

Diese durch die Form der Mandibelplatten und der Zahuplatten von den anderen philippinischen Marsenien ganz verschiedene Art (s. unten) scheint auch in der Schalenform von denselben etwas abzuweichen.

Die Schale ist milchweisslich, ziemlich pellucid, ziemlich kurz und hoch; $6,5 \mathrm{~mm}$ lang bei einer Breite bis 5,1 und einer Höhe bis $4 \mathrm{~mm}$; die Zuwachsstreifen von mittelmässiger Stiirke.

\section{Mars. isabellina, BGH. n. sp.}

Marscnia isabellina, BgH. Malacolog. Unters. (Semper, Philipp. II, II). Heft IX. 1875. 'Taf. XLl. Fig. 8.

H a b. M. philippin.

Die Farbe des lebenden Thieres ist an der oberen Seite dunkel isabella, mit ziemlich zahlreichen, nicht ganz feinen, weissen Fleckchen und mit weissem Mantelrande. Einer Abbildung SEmper's (des Entdeckers aller dieser philippinischen Arten) zufolge, ist die Schale ziemlich niedrig, sonst von gervöhnlichen Formverhältnissen.

Uebrigens sind nur die Mundtheile (Mandibelplatten und Raspel) dieser Art bekannt (s. unten).

\section{Mars. Diegoënsis (DaLL).}

Lamellaria Diegoensis, Datu. MIS.

Hab. Mare pacificum (Californ.).

Diese Form scheint sich schon durch dunklere, schwirzliche Farbe von anderen bisher bekannten Marsenien zu unterscheiden. 
Die Schale war durchscheinend, (schwach bläulich-) kalkweiss, etwa $13 \mathrm{~mm}$ lang, bei einer Breite bis 9,5 und einer Höhe ron $7 \mathrm{~mm}$; die Spira klein, etwas abgeplattet; der letzte Umfang sehr gervölbt, im Torderrande gar nicht rerkalkt, mit schwachen Anwachslinien; die Unterseite stark concar.

\section{Mars. ophione (Gras).}

Lamellaria ophione, Gr. Proc. zool. soc. 1849. pag. 169.

Marsenia ophione. BErgm, Monogr. 1853. pag. 339.

Hab. M. pacificum (Auckland, New-Zealand).

Unter obigem Namen hat Grar eine unbrauchbare Dingnose einer MIarsenia (oder Marsenina?) geliefert, iiber welche später Nichts bekannt worden ist. H. und A. ADAMS (1. c. pag. 203) citiren sie zu ihrer Coriocella.

\section{Jars. Kierguelenensis (STUDER).}

Lamellaria Kerguelensis. STUdER, die Fauna von Kerguelensland. Arch. für Naturg. XXXXV, 1. 1879. pag. 128.

Hab. M. pacific. (Ins. Kerguelen).

Ueber diese ron STUDER zwischen Florideen gefischte Art ist weiter nichts bekannt, als dass sie "roth" ist; einer mir zugegaugenen brieflichen Mittheilung STUDER's zufolge wurde uur ein einziges Individuum gefangen, das dem Berliner Museum übergeben sein soll, wo ich aber dasselbe nicht habe finden können.

\section{S. Mars. dubia, BGH. n. sp.}

Ha b. M. atlant. or. (Cap Terde).

Während der Challenger-Expedition wurde bei St. Tincent, Cap Verde, ein winziges Individuum einer Marsenia gefischt, die kaum mit der M. perspicua identisch war (s. unten).

Die Schale kaum wesentlich von der der M. perspicua verschieden, die letzte Windung doch von ungemöhulicher Grösse.

\section{† 19. Iars. depressa, Wood.}

II. depressa, Wood. Ann. mgz. n. h. IX. 1842. pag. 528. Pl. V. Fig. 8, 9.

- - Mormis, brit. fossils. 1843. pag. 150.

Die Schale scheint sich durch kürzere und mehr rundliche, sowie auch niedergedrückte Form, ferner durch andere Beschaffenheit der Lippen der weiten Oeffnung ron der auch fossil rorkommenden M. producta (s. oben) zu unterscheiden.

Die Art ist erst aus der Crag-Formation bei Sutton bekannt. 


\section{Chelyonotus, (Swarvs.) Bergir.}

Chelinotus (rectius Chelyonotus), Swainson. Treatise of malacology. 1840. pag. 355. Chelyonotus. Bergir, Monogr. 1853. pag. $3 \pm 0$.

Sigaretus sp., Quoy et Gamird.

Coriocella, Brainville. Dict. sc. nat. XXXII. 1824. pag. 259.

Man. de malac. 1825. pag. 466.

Enc. méth. Hist. nat. des vers, cont. Desh. II.

- - Rang, Menke, Cuv., Sw., Sow., Gray.

Animalia dioccia, Marseniis propriis similia, sed plica respiratoria producta apice interdum bifida. Lamellac branchiales lateribus ut in Marseniis propriis plicis transversalibus instructae, sed humiliores. - Lamellae mandibulares et armatura lingvalis fere ut in Marseniis. Proventriculus ut in Marseniis non deest. - Vas deferens in cavitate abdominali non liberum, sed in paricte abdominali omnino inclusum.

l'esta interna, fere omnino ut in Marseniis, sed magis calcarea.

Firr die Form dieser Abtheilung, welche erst bekannt wurde, die Coriocella nigra, bildete Blanville die Gattung Coriocella. Dieselbe war damals aber nur durch ein mutilirtes Individuum repräisentirt, und der angegebene Hauptcharakter, das Fehlen einer Schale, falsch. Der Gattungsname ist deshalb entweder ganz verworfen worden oder als Synonym in die Marsenia aufgegangen, oder noch, wie von Lovév (s. oben), für die typischen Marsenien angewendet. In meiner fríheren Monographie habe ich daher ganz die Bezeichnung Coriocella (selbst nach der durch Cuv. und GrAy geschehenen Rectification) gestrichen und die von Swarson eingeführte Bezeichnung Chelyonotus (Chelinotus) angewendet, obgleich Swassson eigentlich die beiden Gattungen nebeneinander stellt, die Coriocellen mit dem C. nigra als Typ., die Chelinoten mit dem Sigaretus tonganus, welche aber absolut congenerisch sind.

Die Chelyonoten sind fast uur sehr grosse Marsenien, mit mehr vorwärts ausgezogener Einathmungsfalte, deren Ende oft gekluftet ist. Die Schale fast ganz wie in den ächten Marsenien, nur dicker und mehr verkalkt. Die Kiemenblätter niedriger als in den Marsenien, aber mit Querfalten wie in diesen. Die Mundtheile (Mandibelplatten, Zungenbervaffnumg) wesentlich ganz wie in den Marsenien. Ein grosser Vormagen kommt auch immer vor. Auch die Chelyonoten sind getrennt geschlechtlich; der untere Theil des Samenleiters ist aber nicht theilweise frei, sondern in der Körperwand ganz eingeschlossen.

Die Gruppe enthilt, wie bisher bekannt, nur wenige Arten, alle aus tropischen 
und subtropischen Meeresgegenden stammend. Sie scheinen hier und da mitunter massenweise vorzukommen, wie mir z. B. für die Palauinseln von KUBARY mitgetheilt wurde.

1. Chelyon. Semperi, BGH.

M. philippin.

2. Chelyon. tonganus (Quor et Gams.).

M. indicum.

3. Chelyon. tuberosus (Stunpson).

M. chinense.

4. Chelyon.? punctatus (STIMPson).

M. chinense.

1. Ch. Semperi, Bergi, n. sp.

Chelyonotus Semperi, Barr. Malacolog. Unters. (SEMrer, Philipp. II, II). Heft IX. 1ミ75. T'af. XLI. Fig. 9.

Ha b. M. philippin.

Color corporis aterrimus, velutino submicans; pagina superiore lineis coeruleis arcuatim et reticulatim dispositis ornatus.

Dorsum proprium tuberculis grossioribus quinque, quincunce dispositis institutum.

Testa fere ovalis, trigyra, supra convexa, infra levissime excavata, pellucida, spira nitide alba, anfractu ultimo cornino-albescenti striis incrementi subtilius ornato; periostraco tenuiori, sordide flavescenti. (Dimens. long.: lat. : alt: $=1: 0,714: 0,428$ ) Spira lateralis pone medium sita, obliqua, parva, acutiuscula, basi circiter 1/3 diam. transv. min. testae occupans, altitudine basi triplo latior; anfractibus 2 convexiusculis laerigatis; apiculo nucleali ipso cum 1/4 diam. longitud. margine posteriore distat. Ultimus anfractus ambitus fere ovalis, nothaeo convexus, ventro levissime excaratus. Sutura parum profunda. Apertura ampla, obovata, peritremate simplici; long.: lat. $=1: 0,77$; paries internus aperturae laevis, nitidus, lineis incrementi pellucentibus. Labium columellare postice plaunlatum cum margine columellari tenui postice breviter reflexo, sinu columellari subobsoleto.

Diese, die grösste der bekannten Marseniaden, lebend eine Länge bis $7,5 \mathrm{~cm}$ crreichend, scheint schon in der Farbenzeichnung von der folgenden Art verschieden. Sie ist sammtschwarz mit lineären blauen Zeichnungen; diese bilden am Grunde des centralen Rückenknotens, sowie am Grunde der vier mehr peripherischen Knoten, abgebrochene kurze Bogen, die einigermaassen concentrisch geordnet sind; am Vorderende des Körpers kommen quergestellte und schräge Bogen vor; am breiteren Hinterricken bilden sie ein 
weitmaschiges Netz; das Hinterende des Riickens, die Unterseite des Mantels, der Kopf, sowie der Fuss cinfach schwarz, nur die Spitze der Tentakel ist gelblich.

Die Mitte des Ruickens, der eigentliche Rücken, ist stärker gewölbt; vor der Mitte desselben erhebt sich ein grosser $K$ noten und um denselben stehen, zwei vorn und zwei hinten, etwa dem Umkreise der Schale entsprechend, etwa in gleichgrossen Abstïnden, vier ähnliche.

Die Schale ist im Ganzen der der Marsenien ähnlich, aber stïrker und meistens stïrker verkalkt; an Höhe etwas variabel, sowie an Grösse der Spira. Bei einzelnen Individuen war das immer sehr diunne Periostracum sehr ausgeprägt; bei einigen war die Verkalkung an der letzten Windung wenig vorgeschritten oder wenigstens am Rande nicht complet, das Kalklager dann deutlich an der Innenseite des hornartigen (cuticularen) Lagers. Die Länge der grössten von mir untersuchten Exemplare betrug $20,5 \mathrm{~mm}$ bei einer Breite bis 16,5 und einer Höhe bis $9 \mathrm{~mm}$.

Die Zungenzahnplatten dieser 'Thierform schienen nicht ganz mit denen der folgenden iibereinzustimmen (s. näher unten).

\section{Ch. tonganus (Quox et Gamard).}

Sigar. tonganus, Q. et GAn. Voy. de l'Astrolabe. Zool. II, 1 partie. 1832. pag. 217. Pl. 66. Fig. 4-8.

Chelinotus tonganus. Sivainson, treat. 1840 . pag. 355.

Chelyonotus - Bergh, Monogr. pag. 342. Tab. V B. Fig. 1.

Color corporis aterrimus, velutino submicans; radix podarii e brunneo rubra.

Dorsum, verrucis majoribus applanatis obtectum et nodis majoribus compluribus.

'I'esta fere ut in specie praecedente.

Hab. M. indicum, pacificum.

Diese der vorigen sehr nahestehende Form zeigt dieselbe dunkel sammtschwarze Farbe, aber die blauen Abzeichnungen fehlen, und die Wurzel des Fusses ist braunroth. Die Schale unterscheidet sich kaum wesentlich oder constant von der obigen; ein von mir friher untersuchtes Exemplar hatte eine Lainge von 28 bei einer Breite von 20 und einer Höhe von $12 \mathrm{~mm}$.

Diese Thierform ist von Quoy und Ganmard (im stillen Ocean und) bei Isle de France, auf Sandboden gefischt.

Val. mauritiana, Bตн.

Sigar. tonganus var. („Sigaret de Maurice"). QuoY et GAIn., 1. c. pag. 219. Pl. 66 bis. Fig. 9 (testa). 
Chelyonotus mauritianus, Bergir. Monogr. 1853. pag. 343. Tab. VB. Fig. 2.

Lamellaria nigra (BlaInv.). Moebius, Beitr. zur Meeresfauna d. Insel Mauritius und Seychellen. Martens, Mollusken. 1880. pag. 275.

Coriocella nigra, Blatnv. Man. de malacol. 1825. pag. 466. Pl. 12. Fig. 1.

- - Guerin-Cuvier, iconogr. Moll. Pl. 15. Fig. 12, 12 a.

- - Gray, Zool. of Cpt. Beecher's roy. Moll. 1839. pag. 193. (excl.

synon.) (testa fere membranacea, viridula).

Chelyonotus niger. BERGH, Monogr. pag. "34t.

Sigaret, Cuv. Riègne an. ed. 1. 1817. II. pag. 445. Pl. XI. Fig. 4.

ed. 2. 1830. III. (pag. 90) Pl. XIV. Fig. 4. (nec anat. des moll.!).

Chelyonotus Cuvieri, BGr. Monogr. pag. $3 \pm 4$.

Ha b. M. indicum (Ins, Maurit.).

Das Thier soll dem typischen (Chel. tonganus) ganz ahnlich sein. Die Schale ist aber, Quor und Gamarn zufolge, etwas kürzer und mehr rundlich, aber besonders höher und zwar mit stärkerer Spira. Ich habe friher eine wahrscheinlich hierher gehörende Schale untersucht, die eine Länge von 26,5 bei einer Breite von 18,5 und einer Höhe von $15,5 \mathrm{~mm}$ hatte, und deren apicaler Winkel nur $108^{\circ}$ betrug; Mosius sah Exemplare von einer Länge bis $36 \mathrm{~mm}$ bei einer Breite und Höhe von 25. Die 2 von mir untersuchten Individuen aus dem Meere von St. Mauritius, die von Moebius gefischt worden sind und von ihm zu dieser 'Thierform hingezogen wurden, zeigten beide eine solche besonders hohe Schale, die bei einer Lüinge von 20-21 und einer Breite von 14-16 eine Höhe von 9-10,5 mm hatten. Die Grösse der Spira, sowie der Erhiirtungsgrad und die Dicke der Schale variirten nicht unbedeutend.

\section{Var. Berghi, Desh.}

Marsenia Berghi. Desinayes, conchyliol. de l'île de Réunion (Bourbon). 1863. pag. 77-78. Pl. 1X. Fig. 18-20.

Lamellaria Berghi, Desir. Moebius (1. c. MaItens). 1880. pag. 275. Taf. XXI. Fig. 9.

? Cryptostoma nigrum, Dufo. Obs. sur les moll. - des îles Séchelles. Ann. se. n. 2. S. XIV. 1840. pag. 201.

Ha b. M. africano-indic. (Bourbon).

Diese von DesinaYes aufgestellte Form, von welcher nur die Schale bekannt ist, wolche aber auch ron MoEBrus (wesshalb?) als besondere Art aufgenommen worden ist, Semper, Philippinen. II, II (Bergh, Ergänzungsheft III. Marseniaden I). 
scheint in der Schalenform auch nicht wesentlich von den vorigen "Arten "verschieden. DesIAyes zufolge ist die Schale durchschimmernd, glinzend weiss; die Länge betrug $20 \mathrm{~mm}$ bei einer Breite bis 16; die Dicke der Schale sich bis zu $0,8 \mathrm{~mm}$ belaufend.

3. Ch. tuberosus (Stimpson).

Coriocella tuberosa, Strmpson. Descr. of some of the new marine Invertebrata from the Chinese and Japan. seas. Proc. of the ac. of nat. se. of Philadelphia. VII. 1856. pag. 379.

Hab. M. chinense.

Diese Form ist lebend, Stmpson zufolge, bis $2^{\prime \prime}$ lang, "blass braun, an der. Unterseite mit schwefelgelben Filecken" (pale brownish, spotted beneath with sulphur yellow). Der Rücken ist mit zahlreichen unregelmässigen Höckerchen bedeckt, unter welchen vier stärkere emporragen. Ueber die Schale ist Nichts bekannt.

Es muss vorläufig dahin gestellt bleiben, ob diese Form von dem Ch. Semperi wirklich verschieden sei.

\section{Ch. ? punctatus (Strupson).}

Coriocella punctata, Stumpson. 1. c. pag. 379.

Hab. M. Chinense (Ousima).

Diese Form soll hyalin mit schneeweissen Punkten (flake-white) sein; der Ruicken mehr eben; die ubrige "Besehreibung. von STInIson ist ganz unbrauchbar. Vielleicht stellt sie nur eine Marsenia vor.

\section{Marseniella, Bergir. N. Gen.}

Animalia dioecia, Marseniis propriis similia. Lamellae branchiales ut in Marseniis; ita quoque lamellae mandibulares et armatura lingralis. Proventriculus deest. Pars inferior vasis deferentis in cavitate abdominali ut in Marseniis libera.

Testa fere cornina; spira minuta, anfractus ultimus maximus postice solutus.

Im Aeusseren unterscheiden sich die Marseniellen nur wenig von den ichten Marsenien; sie sind aber doch etwas mehr abgeplattet, besonders der eigentliche Rücken, und etrvas mehr länglich. Die Schale ist fast hornartig; die Spira ganz klein; die letzte Windung sehr gross und weit, hinten von der Spira ganz gelöst. In imneren Baue stimmen die Marseniellen fast vollständig mit den Marsenien; sie sind 
dioecisch, die Mandibelplatten und die Zungenbewaffnung wie bei jenen, und der untere Theil des Samenleiters auch frei; der Vormagen fehlt aber und dio Form des Penis ist vielleicht etwas abweichend.

Von der Gattung ist bisher nur die untenstehende neue hochnordische Art bekannt.

Mars. borealis, B $\mathrm{Gr}$. ๖. sp.

Hab. M. arcticum or.

Von dieser auffallenden 'Thierform habe ich ein einzelnes, bei Florö in der Niahe von Bergen gefischtes, $22 \mathrm{~mm}$ langes Individuum genauer (s. unten) untersucht.

Die Form war von der der typischen Marsenien etwas abweichend, etwas mehr abgeplattet und mehr länglich; der Rücken uberall grob- und feinknotig. Die Sehale etwa $13 \mathrm{~mm}$ lang bei einer Breite bis 10 und einer Höhe bis etwa $5 \mathrm{~mm}$; selır diun, hell horngelblich, hornartig mit an der Innenseite zerstreuten schwachen Kalkablagerungen an der Spira, welehe ganz kurz ist; der letzte Umgang sehr weit, hinten von der Spira gelöst, und die dimne Randparthie hier nach hinten spitz ausgezogen.

Im inneren Baue stimmte diese Thierform wesentlich mit der typischen Marsenia (s. unten).

IV. Marseniopsis, BGr. N. Gen.

Animalia dioccia, forma generali corporis Onchidiopsidibus similia, corpore ita quasi sphaeroideo, quasi inflato, sed solummodo plica et semicanali inspiratoria antica; os externum subanticum. - Lamina mandibularis utrinque minor, angusta. Armatura lingvalis fere ut in Marseninis et in Onchidiopsidibus $(2-1-1-1-2)$.

Testa interna, calcarea, ut in Marseniis.

Die Marseniopsen bilden ein ganz merkwürdiges Uebergangsglied zwischen den dielinen und androgynen (Marsenina, Onchidiopsis) Marseniaden und zeigen ganz deutlich, wie alle diese Formen von cinander nicht gesehieden werden kömmen, sondern in eine Familie zusammengehören. Sie haben die allgemeinen Formverhailtnisse der On chidiopsen, den halbkugelförmigen, wie aufgeblasenen Oberkörper mit dem dicken, wulstigen Mantelrande; auch der A ussenmund liegt mehr mach vorne. Es fehlt ilunen aber die rechte Athmungsalte und - halbkanal (Expirationskanal), und die Kiemenblätter sind etwa wie bei den Marsenien. Die Mandibelplatten sind schmäler und im Ganzen kleiner als bei anderen Marseniaden. Die Zungenbewaffnung ist der der androgynen Maseniaden ganz ähnlich; ausserlalb der Seitenzahmplatten kommen somit zwei hakenförmige Zahnplatten vor. Die Marseniopsen sind getrennt 
geschlechtlich und stimmen im Baue der Geschlechtsorgane zunächst mit den Chelyonoten, der untere Theil des Samenleiters ist somit auch nicht frei in der unteren Körperhöhle; auch die Form des Penis stimmt wohl zunächst mit der des Organs der ächten Marsenien. Die-Schale ist im Ganzen der der achten Marsenien seh" ähnlich, aber mehr gewölbt.

Von der Gattung sind bisher nur die Zwei untenstehenden neuen Arten aus der Südsee ${ }^{1}$ ) bekannt.

1. Mars. pacifica, BGIr. n. sp.

M. pacificum.

2. Mars. Murrayi, BGri. n. sp.

M. pacificum.

1. Hars. pacifica, BGH. n. sp.

Hab. M. pacificum (Ins. Kerguelen).

Von dieser Form habe ich ein einzelnes und zwar weibliches Individuum, bei Kerguelen-island von der Challenger-Expedition gefischt, zur Untersuchung gehabt. Dieselbe wird in den Reports der Challenger-Expedition beschrieben werden.

Die Schale des $18 \mathrm{~mm}$ langen Thieres war $15 \mathrm{~mm}$ lang bei einer Breite bis 12 und einer Höhe bis $10 \mathrm{~mm}$; die Spira klein, mit zwei Windungen; der letzte Umgang sehr gross und sehr gewölbt; die Schale war dünn, kalkweiss, mit sehr schwachen Anwachsstreifen.

Für den imeren Bau wird auf den unten gegebenen Auszug meiner Untersuchung hingewiesen.

\section{ฆ. Mars. Murrayi, Barr. n. sp}

Hab. M. pacificum (Ins. Marion).

Auch von dieser Form habe ich nur ein einziges, auch von der Challenger-Expedition herrủhrendes Individuum zur Untersuchuug gehabt, aber ein männliches, so dass die zwei Untersuchungen trotz dem beschränkten Material einander ergainzen.

Das auch $18 \mathrm{~mm}$ lange Thier zeigte cine $\mathrm{Seh}$ ale, die der der vorigen ziemlich. ähnlich schien; ${ }^{2}$ ) die Länge betrug $13,5 \mathrm{~mm}$ bei einer Breite bis 10,5 und einer Höhe bis $8 \mathrm{~mm}$; sie war ganz dün, aber liart und spröde.

Wahrseheinlich differirt diese Form schon in den Farbenverhïlnissen von der vorigen und ebenso in der Beschaffenheit der Zungenbewaffnung (s. unten).

1) Einer von mir in 1873 im Brit. MIuseum aufgenommenen Notiz zufolge fand sich daselbst ein Individumm einer Thierform, das, in "Sholl-Bay, Strait of Magellan" gefischt, vielleicht hierhin gehören könnte.

2) An dem untersuchten Individum war der Mantel gespalten, und die Schale fand sich, wahrscheinlich durch einen Versuch dieselbe zu entfernen, in Stückchen zersprungen, die Stücke aber noch zusammenhängend. 


\section{Marsenina, Gray.}

Marsenina, Grar. Figgs. of moll. anim. IV. 1850. pag. 76. — Guide. I. 1857. pag. 46. Lamellaria sp., Lovén. Ind. moll. 1847. pag. 15.

Lamellaria, Lovén. Oefversigt. Vetensk. Ac. Handl. 1847. pag. 192.

Oithonella, Mörcr. Naturh. Foren. vidensk. Meddel. f. 1856. pag. 119.

Marsenina, Gr. Bergh, Monogr. 1853. pag. 349-351.

Bergh, Bidr. til en anat. Unders. af Marsenina prodita (Lovév). Naturh. Foren. vidensk. Meddel. f. 1857. pag. 110-122. Tiab. I.

- - G. O. SArs. Moll. leg. aret. Norv. 1878. pag. 151.

Animalia monoecia, Marseniis propriis similia, sed fissura pallii submediana, partem testae denudatam relinquente. Praeter semicanalem anteriorem (inspiratoriam) semicanalis dextra (expiratoria) adest. - Lamellae mandibulares fortiores e seriebus baculorum breviorum compositae. Armatura lingvalis ut in Onehidiopsibus; praeter dentes laterales utrinque duo uncinati $(2-1-1-1-2)$.

Testa semi-interna (dorso plus minusve denudata), calcarea, illi Marseniarum non dissimilis.

Der erst von LovéN entdeckte Typus dieser Gattung wurde vom Entdecker auch zu einem Genus erhoben, welchem er aber wenig glicklich den Gattungsnamen Lamellaria verlich (während er die typischen Marsenien Coriocella benannte). Gray änderte den Gattungsnamen in Marsenina.

Die Marseninen sind schon im Aeusseren von den ächten Marsenien, deren allgemeine Kö r perform sie sonst haben, leieht unterscheidbar; erstens durch den medianen Längsehlitz des $R$ ückens, in welchem die Schale mehr oder weniger entblösst liegt;') damn dureh die an der reehten Seite des Mantelgebrïmes stehende Expirationsfalte und -Halbkanal. Die Kiemenblitter olme Querfalten der Seitenflächen. Der Aussenmund und der Penis sind denen der ächten Marsenien ziemlich ähnlich. - Im inneren Baue dagegen stimmen die Marseninen mit den Onchidiopsen und sind wie diese hermaphroditisch. Die Mandibelplatten stark, aus Reihen von kurzen Stïbchen zusammengesetzt (aber ohne vurragenden Zahn am Vorderrande). Ausser den Seitenzahnplatten zeigt die Zungenbewaffnung zwei äussere hakenförmige Zahnplatten.

Die Marseninen sind, insoweit bisher bekannt, auf die kalten Meeresgegenden beschränkt, und daselbst nur durch einige wenige Arten vertreten.

1) Nur in der MIars. Dalli ist die Schale vom Mantel rollständigst eingehüllt, und jede Spur ron دantelspalte am Rücken fehlt. 
1. M. prodita (Lovéx).

I. atlanticum.

2. M. glabra (Coutur.).

II. atlanticum oce.

3. II. ampla, Verrill.

M. atlantic. occid.

4. M. grocnlandica (MöLLER).

M. grönland.

5. M. rhombica (DALL).

II. pacific. (Calif.).

6. MI. Dall i, B G H. n. sp.

M. pacific. bor.

\section{Marsenina prodita (LovÉn).}

Lamellaria prodita, Lovén. Index moll. 1847. pag. 15.

- - Lovén. Oefvers. Vet. Ae. Handl. 1847. pag. 192. 'I'ab. IV.

- - Lovén. M. SARS, Beretn. om en i Sommeren 1849 foret. zoolog. Reise i Lofoten og Finmarken. 1851. pag. 65.

Marsenina prodita (LovéN). R. BERGI, Bidr. til en anat. Unders. of Marsenina prodita (Lovén). Naturh. Foren. vidensk. Meddel. for 1857. pag. 110-122. Tavle 1.

- - Lovén. G. O. SARs, moll. reg. arct. Norv. 1878. pag. 151.

Tab. 12. Fig. 5 a-c; Tab. V. Fig. 7 a, 7 b.

- - Verrill, notice of recent addit. 11. 1. c. 1881. pag. 373.

- - Verrill, catal. of marine moll. 1. c. V, 2. 1882. pag. 518. Pl. XLII. Fig. 2, 2 a.

Color pallii rufescens, fusco maculatus. Pallium subverrucosum, fissura longitudinali submediana (centrali) minori forma et magnitudine variabili.

'Testa non multum fragilis, albida, oblongo-ovata, spira distincte prominenti.

Ha b. M. atlant. or. areticum (Fimmark.) et occid. septentr.

Diese erst von LovéN (1847) aufgestellte Art wurde kurz nachlher (1849) von demselben, wie erwihnt, von den iichten Marsenien, die er Coriocella benannte, unter dem Namen Lamellaria prodita abgesondert. M. SARs lieferte ein paar Jahre später einige Notizen iiber das 'Thier; und ich einige anatomische Data; G. O. SARs hat vor einigen Jahren noch einige gute Abbildungen dazu gefügt. 
Die Lainge dieser Thiere beträgt im Leben wenigstens bis $24 \mathrm{~mm}$ bei einer Breite bis fast 21 und einer Höhe bis 9. Die Farbe der Riickenseite ist dem älteren SARS zufolge hellgelb oder orangegelb, theils einfarbig, theils mit mehr oder weniger zahlreichen, kleinen, graubraunen, unregelmïsigen oder rundlichen Fleckchen versehen; mitunter ist der Rücken auch grauweiss oder fast schwarz dureh dichtstehende sehr kleme dunkle Punkte gefärbt; — die Unterseite des Mantelgebräimes so wie der Kopf mit den 'T'entakeln und der Fuss hellgelb, orangegelb oder grauweiss, immer aber ist die untere Seite des Thieres heller als die obere. Der juingere Sans giebt die Farbe der oberen Seite als meistens rothbriunlich, braun gefleckt an.

Die Schale, ron welcher ich friiher ${ }^{1}$ ) eine sehr detaillirte Untersuchung und Iicschreibung gegeben habe, war in den jetzt von mir untersuchten (s. unten) Individuen 13,5-15 mm lang bei einer Breite bis 10-10,5 und eincr Höhe bis $6-6,5 \mathrm{~mm}$. Sic war cin wenig länger als die Marsenien-Schalen, mehr opak als meistens diese, kalkweiss, matt; die nucleale Windung sehr klein und wenig vortretend, die letzte Windung schr gross mit fast ganz ovaler Schalenöffinung.

Für die innere Untersuchung der Art muss unten nachgesehen werden.

\section{Marsenina glabra (Coutr.).}

Oxynoe glabra, Coutiour. Bost. Journ. II. 1838. pag. 90. Tab. 3. Fig. 16.

Marsenia glabra (Couti.). BerGi, Monogr. 1853. pag. 326.

Marsenina micromphala, BaII. BergIr, Monogr. 1853. pag. 350. 'Tab. IV B. Figg. $1-3$.

Oithonella micromphala. Mörcr, l. c. 1857. pag. 79.

Marsenina micromphala, BGH. BERGH, l. c. 1857. pag. 121.

BaIf. G. O. Sars, I. c. 1878. pag. 151. 'Tab. 21. Fig. $10 \mathrm{a}-\mathrm{d}$.

Marsenina glabra. Vernill, Catal. 1. c. 1882. pag. 517. pl. XliI. Fig. 1, 1a, 4. Verrill, notice. l. c. 1881. pag. 373.

Color pallii albidus, maculis fuscis symmetricis. Palliun laevius, parum repandum, fissura mediana (contrali) majori maximam partem testae denudatam relinquente.

'T'esta tenuior, magis pellucida, nitidula, spira minus prominenti.

Ha b. Oc. atlant. or. et occid.

Den nordamerikanischen Faunisten zufolge ist die ron mir und von G. O. SARS beschriebene Art mit der lier und da an der nordamerikanischen Küuste sehr lıäufig rorkommenden Marsenina glabra identisch, was wohl in der That anch möglich sein könnte.

1) Vergl. meine Untersuchung der Mars, prodita. 1. c. pag. 111-115. 
SArs zufolge (dessen Angaben sich aber vielleicht nur auf todte und in Alkohol bewahrte Individuen beziehen) scheint das Thier von anderer Farbenzeichnung als die vorige Form. Was aber diese Form ganz besonders characterisiren sollte, ist die grosse Oeffnung des Mantelruckens, welche fast die ganze Schale entblösst zum Vorschein kommen lïisst.

Von der Schale habe ich friher ${ }^{1}$ ) eine sehr eingehende Beschreibung geliefert. Sie ist dünner als bei der vorigen Form, daher mehr durchscheinend; sie ist mehr glänzend, mit noch weniger hervorragender Spira.

Für den inneren Bau muss auf die unten liommende Untersuchung verwiesen werden.

\section{Marsenina ampla, Verrild.}

Marsenina ampla. Verrilu, catal. 1. c. 1882. pag. 518. pl. XLII. Fig. 3, 3a. - - Verrill, notice. l. c. 1881. pag. 374.

Ha b. M. atlant. occ. septentr.

Diese den gelieferten Abbildungen nach ziemlich ausgeprägte Form scheint nur durch die Schale bekannt. Diese letztere, von einer Länge von 11 bei einer Breite bis $8 \mathrm{~mm}$, ist "weiss, opak und zeigt die nucleale Windung ganz ungewöhnlich klein und eingesenkt, die letzte Windung ist im Verhältniss zu jener colossal, „fast die ganze Schale bildend".

\section{Marseniua groenläudica (MöLLER).}

Sigaretus? groenlandicus. MöLlen, ind. moll. Groenl. 1842. pag. 10.

Marsenia groenlandica (Möller). BergI, Monogr. pag. 99. 'Tab. V. Fig. 12.

Marsenina groenlandica (MöLLER). BERGH, 1. c. 1857. pag. 121. Fig. 7.

Marsenina groenlandica. G. O. SARs, l. c. pag. 152. Tab. 21. Fig. 11 a-c.

Ha b. M. areticum.

Diese ziemlich zweifelhafte, mit der M. glabra vielleicht identische Form, ist nur ans dem grönländischen Meere und vielleicht von der Kiiste von Finnmarken (Vardö) bekannt.

Das T'hier ist, MöLler zufolge, oben weiss, durchscheinend; an der hinteren Schalengegend ein braunrother, ron dichtstehenden Punkten gebildeter Bogen und an der vorderen jederseits ein ähnlich gefiirbter Fleck (welehe ich als von den durehsehimmernden Eingerveiden hervorgebracht betrachte). Die Beschreibung der Schale, wie bei MöLLER, liefert keine brauchbaren Charactere. 
Das Originalexemplar von MöLLER ist verloren gegangen. Ein vom grönlindischen Forscher HoLBöLL spåter gefischtes Individuum, welches dieser Art angehören soll (vergl. 1. c. 1857. pag. 121), zeigt den Mantel bis iiber den Schalenrand hinaus zurückgezugen (1. c. Fig: 7). Weder ich noch SARS haben das Thier untersuchen können, und die von ihm wie ron mir erwähnten Charactere der Schale haben kaum irgend einen specifischen Werth.

\section{Marsenina rhombica (D $\triangle L L)$.}

Lamellaria rhombica, DALL. Deser. of sixty new forms of Moll. from the Westcoast of North-America etc. Amer. journ. of conchol. VII, 2. 1871. pag. 122. pl. 15. Hig. 4, 5.

Hab. M. pacific. (Californ.).

Der Californische Faunist StEarns hat Dall einige an Ort und Stelle iiber diese Form aufgenommene Notizen geschickt. Denselben zufolge liegt auch beim lebenden, T'hiere immer ein Theil der Schale entblösst und dasselbe ist somit eine Marsenina; auch die Expirationsröhre scheint in der albernen Beschreibung erwähnt. Das Thier ist wenn lebend, weiss, durchscheinend mit bläulichem Schimmer („looking like a lump of mucus"i).

Die Schale ist, Dall zufolge, weiss, etwas gewölbt, mit drei Windungen; die Spira ganz klein, nicht vortretend; die Schalenöffnung subquadratisch; die Aussenseite der Schale eben. Eine mir von DALL freundlich geschickte Schale war 12,5 mm lang bei einer Breite bis 9 und einer Höhe bis $5,8 \mathrm{~mm}$; die Farbe war (gelblich-) weiss, matt; sie war ziemlich dick und hart; die Spira klein, wenig vortretend; die Anwachsstreifen ziemlich stark, auch an der matt gläizenden Innenseite deutlich; die Oeffnung kurz gerundet-eckig-eiförmig-oval.

Die Larvenschalen (Echinospira) ron dieser Art (oder der Marsenia Stearnsii) wurden von StEanns im Januar 1866 (mit drei Kielen) haiufig an der Meereskiiste bei Monterey (Californien) gesehen.

\section{Marsenina Dalli, BqH. n. sp.}

Hab. M. pacific. boreale (Unalashka):

Diese Form unterscheidet sich von allen anderen bekannten Marseninen durch das Fehlen einer medianen Mantelspalte; sonst ist sie ganz und gar eine Marsenina, und das Fehlen jenes Characters würde kaum genuigen, um für dieselbe eine nene generische Gruppe zu bilden. Wahrscheinlich haben alle Marseninen, wenn jung, eine gesellossene Mantelhöhle. 
Das einzige von DALL bei Unalashka im September 1874 aus einer Tiefe von 60 Faden auf Schlamm- und Steingrund gefischte, männliche Individuum war lebend gelblich-weiss. In Alkohol bewahrt war dasselbe etwa $17 \mathrm{~mm}$ lang bei einer Breite bis 13 und einer Höhe bis $8 \mathrm{~mm}$. Die Formverhältnisse wie in anderen Marseninen. Der Rüken mit zahlreichen rundlichen $K$ noten von einem Durchmesser bis $1-1,5 \mathrm{~mm}$.

Die schöne, ziemlich dünne Schale matt milchweiss mit schwachem Seidenschimmer; $14 \mathrm{~mm}$ lang bei einer Breite bis 9,5 und einer Höhe bis 6,5 mm, im Ganzen der der M. rhombica z. B. etwas ähnlich; die Nucleus-Parthie aber ganz eigenthümlich (wie. ich sie in keiner anderen Marseniade gesehen habe), wie der embryonalen nautiloiden Schale aihnlich, aber fast ganz ohne Rippen oder nur mit Andeutung von (absorbirten?) solchen; die Spira der Schale im Ganzen klein; die Schalenöffinung weit, kurz-eiförmig.

Fuir den inneren Bau des 'Thieres muss unten nachgesehen werden.

\section{Onchidiopsis, BECK, BErGH.}

Onchidiopsis, BEck. Catal. mus. regii Hafn. 1830 (ined.).

Bergi, Monogr. 1. c. 1853. pag. 345-348. T'ab. II-III.

Onchidiopsis, Bergh. G. O. Sars, Moll. reg. arct. Norv. 1878. pag. 153.

Animalia monoecia, pallio sphacroideo quasi inflato; practer plicam et semicanalem anteriorem (inspiratoriam) plica et semicanalis dextra (expiratoria) adsunt. Os subanticum. Penis compressus, quasi alatus, quasi convolutus, apice cylindrico obtuso. - Lamellae mandibulares ut in Marseninis, sed prominentia dentiformi marginis anterioris instructae. Armatura lingralis ut in Marseninis (2-1-I-1-2).

'Testa interna cornina, scutiformis, non spirata.

Ueber diese characteristische Gattung sind seit meiner Arbeit (1853) fast nur durch G. O. SARS (1878) einige Notizen bekannt geworden.

Die Onchidiopsen sind schon im Aeusseren durch ihre fast kugelförmige a ufgeblasene Gestalt leicht kenntlich; sie erimnern oberflächlich an die Form der Onchidien, woher der (durch H. BECK) wenig gliicklich gewählte Name. Sie zeigen somit dieselben Formverhailtnisse wie die Marseniopsen, sind aber nicht rie diese auf die der Inspiration dienende Falte und Halbkanal beschränkt, sondern haben, wie die Marseninen, noch eine rechtsseitige Expirations-Falte und Halbkanal. Der Aussenmund liegt nach vorne an der Unterseite des Kopfes; der Penis ist von dem anderer Marseniaden etwas verschieden, zusammengedruickt und etwas eingerollt, aber mit cylindrischem abgestutztem Ende. Die Kiemenbliitter etwa wie bei den Marseninen, ohne Querfalten der Seitenflächen. - Im imeren Bau stimmen die Onchidiopsen mit den 
Marseninen und sind wie diese hermaphroditisch. Die Mandibelplatten wie bei den Marseninen aus Reihen von kurzen Stäbchen zusammengesetzt, aber noch $m$ it einem starken vorspringenden Zahne unten am Vorderrande. Die Zungenbewaffnung fast ganz wie bei den Marseninen, mit zwei hakenartigen Platten ausserhalb der Seitenzahuplatten.

Die Onchidiopsen scheinen auf die arktischen Meeresgegenden beschrankt zu sein.

1. O. groenlandica, BGH.

II. arcticum (atlant., pacific.).

2. O. glacialis (M. SARS).

M. arcticum (atlant.).

\section{0. groenlandica, Bgr.}

Gasteropus No. 6. Möllekr, index moll. Groenl. 1842. pag. 24.

Onchidiopsis groenlandica, BGI. Monogr., 1. c. 1853. pag. 346. Tab. II.

? - Reinhardti, BECK. Mörcr, faunula moll. Isl. 1868. pag. 25 (Vidensk. Meddel. fra deu naturhistor. Foren. i Kjöbenhavn f. 1868. 1869. pag. 209). ${ }^{1}$ )

- groenlandica, BerGi. W. Leche, Oefvers. öfver de af Svenska expedit. til Noraja Semlja och Jenissei 1875 och 1876 insamlade Hafs-Moll. 1878. pag. 46 (Kgl. Svenska Vetensk. Akad. Handl. XVI. No. 2).

Coriocella carnea, Kröyer. Amtl. Ber. iib. die 24. Vers. d. Naturf. u. Aerzte in Kiel. 1846. pag. 115. No. 10.

Onchidiopsis carnea (Kr.). Bergr, Monogr. pag. 347. Tab. III, IV.

? juv. = Coriocella recondita, Kr. 1. c. No. 11. Bergir, l. c. pag. 347. Tab. IV. Fig. 1-4.

Organon olfactorium basi aterrimum. Uncini interni armaturae lingvalis hamo edentulo.

Testa depressa, medio parum convexa, fere scutiformis; postcrius subtruncata; latcribus deflexis subparallelis, subrectis; margine antico convexo; tenuissima, fere membranacea, pallide cornina; plicis incrementi inaequalibus, nucleo subconcentricis, fere hippocrepidiformibus, striolisque incrementi subaequalibus, caeterum sublacvis. Diamet. longit. $25 \mathrm{~mm}$, diam. transv. max. $16 \mathrm{~mm}$, altitudo maxima $6,5 \mathrm{~mm}$; pondus 130 milligr. - Nucleus obsoletus subposticus; testa ad utrumque latus inde dilatata medio culmine paullum elevato convexiuscula; in medio e lateribus quasi subcompressa; margine sinistro autice late emarginata, margine dextro medio quoque sed minus profunde, unde plagae

1) Mrörch giebt an, dass sich „im Pariser Museum unter dem Namen von Doris ein colossales Exemplar dieser Thiertorm,

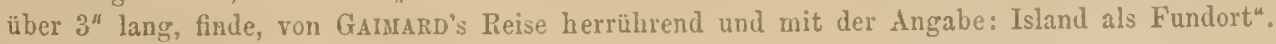


incrementi ad latus sinistrum magis divergunt, ad latus dextrum magis subito deflectuntur. E centro nucleali antrorsum versus striolae impressae nonnullae plus minusve obsoletae irradiant. Superficies testae subsericeo-micans. Apertura maxima amplissima. Margo testae simplex, subacutus. Paries internus aperturae pliculis pellucentibus fere aequalis, nitidus, concolor; vertigia impressionum muscularium vix ulla.

Hab. M. arcticum.

Die von Ḱnörer nur als Museumsname aufgestellte Coriocella carnea betrachtete ich früher (1853) als ron der Onchidiopsis groenlandica specifisch rerschieden, was sie kaum ist. Wegen dieser Unsicherheit, ferner weil der Name O. groenlandica schon eingebürgert ist und weil endlich diese reinen Museumsnamen ohne gelieferte Beschreibung eigentlich keine wissenschaftliche Berechtigung haben, habe ich diese meine fruhere ArtBezeichnung der von Krnöyer vorgezogen.

Von der Onchidiopsis-Gattung scheinen vorläufig zwei Formen vorzuliegen, die (weuigstens wemn in Alkohol bervahrt) im Acusseren einander ganz ähneln, welche aber im Inneren constante Unterscheidungsmerkmale darzubicten scheinen. Die Schale der jetzigen Art ist hinten breiter; vor Allem aber ist das Gexuchsorgan am Grunde schwarz oder sammtschwarz, und die inneren Haken der'Zungenbewaffnung am Aussenrande nicht gezähnelt; auch die Kiemenblätter scheinen von ctwas eigenthimlicher Form.

G. O. SarS u. A. haben die zwei Formen sowie ich Anfangs auch mit einander vermischt. Weder beim älteren noch beim jüngeren SARS finden sich Angaben, die erlauben würden zu bestimmen, welche von den hier angenommenen Arten ihnen vorgelegen hat. Als nun (s. weiter unten) ein von mir untersuchtes, von M. SARs selbst herrihrendes Individuum der "Lamellaria glacialis" nicht die obigen Charactere darbot, wïhrend die von mir friiher (1853) untersuchte Onchidiopsis groenlandica (carnea) die tiefschwarze Farbe der Gegend des Geruchsorgans żeigte, so habe ich die eben genannte specifische Bezeichnung für diese Form bewahrt.

Ueber diese Art, wenn lebeud, ist, so zu sagen, Nichts bekannt. Die Notizen Ḱnöyer's über Coriocella carnea, die mir zu Verfügung gestanden haben, erwähnen nur (vergl. meine Monogr. pag. 347), dass dieselbe von schöner Zinnober-Orangenfarbe und die Farbe in den jüngeren Individuen lebhafter sei als in den ailteren. Das Thier wïre ferner sehr weich und liönnte in contrabirtem Zustande eine Actinia simuliren.

Die Schale war in dem grössten, von mir untersuchten, etwa $6 \mathrm{Cm}$ langen Individuum 4,2 Cm lang bei ciner Breite bis 3,1 und einer Höhe bis etwa 1,5 Cm; sie war von hell horngelber Farbe. Sie ist düm, hinten am diunsten, hornig-membranartig, (etwas elastisch-) biegsam. Sic ist etwas niedergedruickt, unregelmässig schildfürmig, von der Mitte ab nach allen Seiten abfallend, am stärksten hinten. Sie ist in den zwei hin- 
teren Dritteln breiter, mehr gleichmässig gewölbt; vorne schmäler, an der rechten Seite mehr gewölbt, an der linken mehr abgeplattet. Der Hinterrand ist zienlich gerade; links geht er schneller gerundet in den gerade laufenden, an der Mitte etwas ansgeschweiften linken Seitenrand ïber; rechts geht er breiter gerundet in den convexen, vor der Mitte etwas ausgeschweiften rechten Seitenrand iber; der Vorderrand convex. Der linke Rand hinten tiefer stehend, nach rorne sich erhebend; der rechte mehr hinabtretend, besonders hinten. Der Kern der Schale (Nucleus) undeutlich, unbedeutend vorspringend, ein wenig links vor dem Hinterrande liegend; die ungleichmässigen, sehr deutlichen, aber kaum vortretenden, sich nach vorne allmïhlig verlängeruden Anwachsstreifen mit dem Kerne einigermaassen parallel; vom Hinterrande der Schale erstreckt sich zu jeder Seite der Kermparthie nach rorne bis an die Gegend der Ausschweifung des Seitenrandes eine seichte Einsenkung. Die obere sowie die untere Seite seidenartig glïnzend, die erstere an der Mitte ein wenig weisslich, die letztere ohne (deutliche) Spur von MIuskel-Eindrïcken. Der Schalenrand ringsum ziemlich scharf, vorne mehr horizontalliegend, sonst hinabstehend.

Die Art ist hoch-arktisch, im nördlichsten atlantischen und im Eismeere (Grönland), selbst bis Franklin-Pierce-Bay ${ }^{1}$ ), von Dinischen, Sehwedischen, Euglisehen und Holliindischen Naturforschern gefischt. Ein Individuum wurde von DALL in Kiyska-Harbor an den Aleut.-Inseln (Alashka) gefischt (s.unten).

Ð. 0. glacialis (MI. SARS).

Lamellaria glacialis, M. SARs. Beretn. om en i Sommeren 1849 foretagen zoologisk Reise i Lofoten og Finmarken. 1851. pag. 65 N N Jt Magaz. f. Naturvidensk. VI. 1851).

Onchidiopsis glacialis (M. SARS). G. O. SARS, moll. reg. aret. Norv. 187s. pag. 153. Tab. 12. Fig. 6 a-c.

Pallium cinereum, fusco maculatum, subverrucosum et nodosum. - Organon olfactorium basi incolor. Uncini interni armaturae lingualis latere externo denticulati.

T'esta ut in specie praccedenti, sed postice minus lata.

Hab. M. arcticum.

Im Christiania-Museum habe ich eine vom älteren SArS selbst gefischte Onchidiopse bekommen. Dieses Individuum hatte kein schwares Geruchsorgan und zeigte denticulirte innere Haken an der Zunge. Deshalb habe ich den ron SArS gegebenen Namen für diese Thierform angewendet.

1) Vergl. E. A. Surre, on the mollusea collected during the aretic expedition of 1S75-1S76. Ann. mgz. n. h. 5 S. XX. 1877. pag. 140. 
Ursprünglich wurde die von M. SARS als Lamellaria glacialis bezeichnete Form bei Hammersfest und Havősund (1849) aus einer Tiefe von 30-40 Faden (mit Marsenina prodita zusammen) gefischt, auf Felsengrund zwischen $\Lambda$ scidien kricchend. Später ist dieses Thier auch von G. O. SARS an den Kuisten von Finmarken, bei Vardö und auch in einer Tiefe von 40-50 Faden, gefischt. Es wird als ziemlich selten rorkommend von den bciden SARS angegeben. Diese Thierform ist ferner von der Holländischen arktischen Expedition (Varna), von der Dänischen Djimphna-Expedition (s. unten) und in dem Nordgrönländischen Meere gefischt. Sie ist wie die vorige eine ganz arktische Form.

Das lebende Thier ist, den beiden SArs zufolge, am Riicken von grauer Farbe, hier mit ziemlich sparsam zerstreuten dunkelbraunen Flecken; der ältere SARS erwähnt noch dazu zahlreiche gelbe Punkte. (Die Farbe der übrigen Körpertheile ist nicht erwïhnt). - Dem vom jüngeren SARS (1. c. Fig. 6 a) der von ihm gelieferten Abbildung zugefügten Maassstabe zufolge erreicht das Thier eine Länge von vollen $22,5 \mathrm{~mm}$ (wïhrend der 'Text nur $16 \mathrm{~mm}$ angiebt). Diese Figur, die dem lebenden Thiere nach, wie es scheint, aufgenommen ist, zeigt den Kopf und das Vorderende des Fusses vor dem Mantel stark vorspringend, ebenso das etwas gerundete Hinterende des Fusses; der Mantel ist ziemlich gewölbt, dick, mit dicken gerundeten Rändern, oben etwas knotig.

Für genaueres Detail der äusseren Formverhältnisse und für den inneren Bau wird die folgende anatomische Abtheilung zu consultiren sein. 


\section{III.}

ANATOMISCHE ABTHEILUNG. 



\section{I.}

Chelyonotus, (Sivains.) Bergir.

Anatomisch unterscheiden sich die Chelyonoten von den so nahestehenden ächten Marsenien wesentlich nur dadurcli, dass die untere Strecke des Samenleiters seiner ganzen Liinge nach in der Körperwand eingeschlossen ist und nicht mit freilicgenden Schlingen in die untere Körperhöhle eintritt.

\section{Ch. Semperi, Barr. n. sp.}

Ha b. M. philippinense.

Diese, im Ganzen wohl die grösste der bekannten Marseniaden, von der noch dazu eine grössere Anzahl von Individuen zu meiner Verfügung gestanden hat, habe ich fiir die typische Untersuchung benutzt. Auf dieselbe als Typus werden, anatomisch die verschiedenen anderen untersuchten Formen der Marseniaden bezogen.

Taf. XLI. Fig. 9; Taf. M, N, O, P; Taf. Q. Fig. 1-5.

Von diescm in Formverhältnissen so ausgeprïigten Thiere hat SEMPER an verschicdenen Punkten des philippinischen Meeres nach und nach im Ganzen 16 Individuen eingesammelt und mitgebracht, von welchen sieben Männchen waren. SEMPER hat dem lebenden Thiere nach eine Abbildung (l. c. Fig. 9) ${ }^{1}$ ) gemacht; sonst fehlen Notizen.

Das lebende Thier ist, der erwähnten Zeichnung zufolge, bis 7,5 Cm. lang bei einer Breite bis 2,5 Cm., die Höhe der Ruickenfortsätze hat bis 1,5 Cm. betragen. Die F a r b e ist, wie oben erwiihnt, sammtschwarz, am Rücken mit blauen lineiren Zeichnungen; diese bilden am Grunde des centralen Knotens an der Nitte des Riickens sowie am Grunde der vier mehr peripherischen Rückenknoten kurze Bogen, dic einigermaassen concentrisch georduet sind; am Vorderende des Körpers kommen quergestellte und schräge Bogen vor, am breiteren Hinterrücken bilden sie ein weitmaschiges Netz, auf den Rückenknoten abgebrochene Querlinien und Bogen; das Finterende des Rückens, die Unterseite des Mantels,

I) Das Thier, das bei der Zeichnung vorgelegen hat, war im Januar 1862 bei Burias gefischt. Semper, Philippinen. II, II (Bergli, Erginnzungsheft III. Jiarseniaden I). 
der Kopf sowie der Fuss einfach schwarz; die Spitze der (sonst schwarzen) 'l'entakel fast immer gelblich.

An den in Alcohol bewahrten Individuen zeigt sich die Farbe (wo die Oberfäche der Haut nicht abgerieben ist) fast cinfarbig kohlenschwarz, mitunter mit bläulichem Anfluge; die fünf Knnoten des Riickens waren mitunter von bläulichgrauen Linien eingefasst. Einzelne Individuen waren, wahrscheinlich in der angedeuteten Weise, ganz wachsweisslich geworden. - Die Länge dieser Individuen variirte von 3-6,5 Cm. An zwei 6-6,5 Cm. langen Individuen betrug die Körperbreite 3,3-3,5 und die Höhe (bis an die Spitze des centralen Ḱnotens) volle 3-2,5 Cm.; die Breite des Nantelgebräms an den Seiten 1,4-1,8, hinten 2,8-3,4 Cm.; die Höhe der Riickenknoten 7-11 mm; die Fusslinge war 2,7-3,8 Cm. bei ciner Breite bis $1-1,5 \mathrm{Cm}$; die Länge der T'entakel war 3,5-4, die des (ausgestreckten) Penis $11 \mathrm{~mm}$. Bei einem 4,2 Cm. langen Individuum betrugen dieselben Maasse 2,4-1,5; - 0,8-2,2; - 0,7;-1,4-0,6 Cm.; 3 und $\mathrm{S}$ mm.

Der Umriss des lebenden Thieres war tast kurz-spindelförmig (l. c. Fig. 9); bei den in Alcohol getödteten Individuen lïnglich-oval; die Form meistens stark verdreht, und das Mantelgebräme nach unten geschlagen, die Ränder desselben der medianen Läingslinie nach einander oft beriihrend und somit F'uss und Kopf ganz deckend. Die ('I'af. MI. Fig. 1) ziemlich gewölbte Rückenseite des Thieres ist in der Nitte mehr gewölbt; dieser Theil, der eigentliche Rücken, ist von dem mehr flachen Rücken- oder Mantelgebräme umgeben. Die ganze Rückenseite ist ziemlich eben, ziemlich weich, durch ziemlich zahlreiche verzweigte und anastomosirende Furchen in grössere und kleinere, unregelmässige, etwas gewölbte Fielder getheilt. Auf der Centralparthie des eigentlichen Rückens erhebt sich ein grosser Kínoten, und um denselben stehen, zwei vorne und zwei hinten, etwa dem Umkreise der Sehale entsprechend, in gleichgrossen Abstïnden vier ähnliche. Diese Knoten treten am lebenden wie am todten 'I'hiere sehr deutlich hervor, waren alle bei jenem wie bei diesem ron derselben Grösse; im Leben scheinen sie doch (vergl. I. c. Fig. 9) höher und am oberen Ende etwas geschwollen gewesen zu sein; bei den todten Individuen waren es hohe, gerundete, auch ron Furchen durchzogene Hügel, deren Höhe nur so gross oder selbst ein wenig geringer als der Durchsehnitt am Fusse der Huigel war. Ausserhalb dieses eigentlichen Rückens ist ein schwacher, von der Peripherie der Schale hervorgebrachter Vorsprung mitunter sichtbar, jedenfalls fiihlbar. Das Mantelgebräme gegen den ziemlich scharfen, aber nicht duinnen, geraden oder undeutlich rundzackigen Mantelrand langsam schräge abfallend. Der vordere Theil des Mantelgebrïmes kiirzer als der hintere und schmäler, wesentlich zur Bildung der Athemfurche verwendet. Diese letztere wird dadurch gebildet, dass der fast mittlere (ein wenig mehr links liegende) Theil der Unterseite des Mantelgebrämes seiner ganzen Lïnge nach schwach, aber breit ausgepfliigt ist, die Furche ist von mehr oder weniger vortretenden Rändern begrenzt, welche also etwas rom :iusseren Raude des Mantelgebräimes entfernt liegen; das Vorderende jener Ränder mehr oder weniger zipfelartig vortretend. Wenn die Riinder des Mantels sich zusammenrollen, 
der rechte den linken oder umgekehrt deckend, wird die Furche in ein Athemrohr (Iaf. M. Fig. 2) mit seiner rundlichen Oeffnung an der Spitze umgebildet; hinten endet die Athemfurche, am Eingange in die Kiemenhöhle (dicht an der Spitze des Geruchsorgans), mit ciner sehr schwachen (gebogenen) Querleiste. Das Mantelgebräme wird von der Athemfurclie ab nach hinten allmïhlig breiter; der hinter dem eigentlichen Rücken liegende (Taf. M. Hig. 1a) Theil des Mantelgebrämes somit länger und breiter, als der vor jenem gelegene. Die Unterseite des Mantelgebrämes eben, nach Abreibung der schwarzen Farbe mitunter eine deutlich durchschimmernde radiäre sowie auch circuläre Streifung zeigend. Der innerste T'heil der Unterseite, dem Fusse zunïchst, der gewölbten Unterseite der letzten Windung der Schale entsprechend, mehr oder weniger deutlich die gewöhnliche der Schale entsprechende gebogen-radiäre Streifung darbietend. - Der Kopf nicht gross, abgeplattet (Taf. M. Fig. 3; Taf. O. Fig. 1, 2); vorne in die zwei, an ihrer Wurzel vereinigten, abgeplattet-kegelförmigen Tentakel verlïngert; am Grunde derselben aussen ein vorspringender Höcker mit dem Auge. Unter dem von dem Grunde der Tentakel gebildeten Dache die quere Mundspalte (Taf. O. Fig. 1), meistens von, der mehr oder weniger zurückgezogenen Schnauze gefuillt (Taf. Ir. Fig. 3; Taf. O. Fig. 2a). I)ie obere Seite des Kopfes setzt sich in das convexe (immer fein und dicht schriaggefurchte) Genick fort, das die Kiemonspalte nach unten begrenzt und sich nach hinten in die Kiemenhöhle hinein rerlängert, indem es den Boden derselben bildet. Von der rechten ('I'af. O. Fig. 2 b) Scite des Genickes geht bei den Männchen der starke Penis aus, welcher in der Ruhe nach hinten und oben gebogen ist und meistens mit fast seiner hinteren Hiilfte in dem vordes en rechten Theile der Kiemenhöhle verborgen liegt. Das Kinn (die untere Gegend hinter dem Aussenmunde) ist ziemlich kurz (Taf. O. Fig. 1 a) und geht in den Fuss ïber. Dieser letztere ist, wie der untere Körper im Ganzen, klein im Verhailtnisse zu der mächtigen Entwicklung des Mantels. Der Fuss ist nu durch einen nicht sehr um. fangreichen Stiel mit dem Körper verbunden (Taf. M. Fig. 28); wïhrend er ringsum stark vorspringt. 1)er Fuss ist durchgehends fast ron derselben Breite, vorme ein wenig breiter, mit ein wenig vorspringenden Fussecken; der vordere unter und vor dem Kimne des Kopfes vorspringende Fusstheil (Taf. M. Fig. 4) Lat fast $1 / 3$ der Länge des Schwanzes; der Vorderrand ist gerundet, zweilippig, mit einer Furche des nicht ganz bis an das Ende der Fussecken reichenden oberen Lippenrandes. Zwisehen den zwei Lippen median eine ganz feine Fusspore. An den Seiten springt der Fuss auch stark hervor. Der Schwanz beträgt meistens gegen dic Hälfte der Länge des Fusses, ist nach hinten etwas verschmälert, hinten gerundet endigend; die obere Seite hat einen (I'af. M. Fig. 9) schwachen Rückenkicl.

Die Kiemenspalte hat die ganze Breite des Genickes, sich ron dem einen an den anderen dicken Muskelbauch erstreckend, der zur Bildung der Muskelfacetten hinaufsteigt, rechts also etwas weiter nach hinten gehend (Taf. M. Fig. 5, 6); sio ist niedrig, von ihrer Mitte nach den Seiten allmählig enger, und leitet in die Kiemenhühle. Der 
grösste Diameter dieser letzteren maass an zwei der grössten Individuen (schräge) in die Quere (in gerader Linie) 19-20 mm, bei einer Länge von 14-15 mm und einer Höhe von 6-6,5 mm. Etwa an der Mitte der Kiemenspalte ragt mitunter die Spitze der Kieme hervor, im rechten Winkel beim Weibchen mitunter die Vulva und an der linken Seite derselben die kleinere Analöffnung (Taf. M. Fig. 6). Die Höhle trat links etwas weiter zuriick als rechts, war am Hinterende gerundet. Der Boden der Kiemenhöhle war von der gerundeten Fortsetzung des Genickes gebildet. An der Decke der Höhle zeigte sich (Fig. 5, 6) links innerhalb der Kiemenspalte in einer länglichen Strecke die Pericardialhöhle hindurchschimmernd, hinter derselben und rechts die Niere, und vor der letzteren, von dem Pericardium durch den linken Schalenmuskel geschieden, das doppelfiederige Geruchsorgan; hinter dem letzteren und dem Pericardium erstreckt sich in einem grossen Bogen (Taf. Q. Fig. 2aa) die Kieme, deren linkes Ende die Niere von unten fast ganz deckt; den Boden der Kiemenhöhle bildet (vergl. 'Iaf. Q. Fig. 15) mehr oben der schräge Vorderrand der Blïtterdriise, unten der Vorderrand der selıwarzen Leber. $\Lambda$ m Boden der Kiemenhöhle oder eigentlich an ihrer oberen Wand ganz links und hinten (T'af. O. Fig. 12; vergl. T'af. Q. Fig. 15) findet sich, von den iussersten Kiemenblättern mehr oder weniger bedeckt, dic schlaffe, bis $0,75 \mathrm{~mm}$ weite Nierenspalte, die in die Niere (und in die Ilöhle der Bliitterdriise) leitet. Am rechten Ende des Bodens der Kiemenhöhle, dicht am aufsteigenden rechten Schalenmuskel fand sich (zrvei Mal deutlich) eine feine, wahrscheinlich in die Blïtterdruse fülırende Pore (vergl. Taf. Q. Fig. 15). Längs der (rechten Seite der) obcren Wand verläuft der Darm, dessen Oeffnung ('l'af. M. Fig. 5, 6) (Anus) sich dicht innerhalb der Kiemenspalte findet; längs des Darmes erstreckt sich bei dem Weibuhen (Fig. 6) der dicke Eileiter, dessen Oeffnung, eine grosse Vulva, sich dicht vor dem Anus und meistens an seiner rechten Scite findet (Taf. M. Fig. 7a).

Der vordere Theil des Genickes ist bis an die Kiemenspalte schwarz und zeigt (nach Abschaben des Pigments) ein der Liinge und der Quere nach gehendes Muskellager: die Wand ist aber dick, und die im Kopfe liegenden 'Theile schimmern nicht hindurel. IIinter der Kiemenspalte verschwindet die schwarze Farbe; die Wand wird viel diuner und zeigt die gewöhnlichen Längsfasern, statt der Querfasern treten aber allmählig schrïge auf, die in die Richtung von dem linken nach dem rechten Muskelbauche der Muskelfacetten verlaufen. In dieser Strecke schimmern dam die undentlichen Kontouren des Schlundkopfes und der Speiseröhre hindurch, viel dentlicher aber die Windungen der Raspelscheide, aber wieder mehr undeutlich der Halbkugel- oder Kugel-förmige gelbliche Drïsenmagen.

Die sehr dicke $\mathrm{H}$ a ut des Riickens (Mantel) hatte an einem der grössten Individuen oben gegen die Mitte eine Dicke von 4, mehr seitwärts von nur etwa 2 nm; Durchschnitte der Rückenhöcker zeigten eine Dicke bis $10 \mathrm{~mm}$; die Dicke des Mantelgebrämes 
an seinem Grunde 6, an der Mitte der Breite etwa $3 \mathrm{~mm}$; die Dicke der Wand der Athemfurche meistens $3 \mathrm{~mm}$. Die Haut des Rückens weich anzufühlen, abcr zähe. Die Gegend der peripherischen, besonders der rechten hinteren, Riickenknoten ist an der Inmenseite (durch die Schale und jener durch die Spitze derselben) oft mehr oder weniger ausgehöhlt (eingedrickt). - Vom (Cylinder-)Epithele der Haut zeigten sich nur sehr unbedentende Ueberreste; an der Oberfläche fanden sich dagegen zahlreiche runde Drüsen-Oeffnungen. Unter dem Epithele folgt ein dünnes, ein- oder zweischichtiges Lager von kleinen, rundlichen, schwärzlichen oder schwarzbraunen Zellen, deren Farbe hauptsächlich von dem grossen farbigen Kerne herríhrte. Aelinliche Pigmentzellen kamen noch in dem ganzen oberen Lager der Haut zerstreut ror, fehlten dagegen fast vollständig in der 'Tiefe derselben. Das obere Hautlager bestand hauptsiachlich aus senkrecht und schrïg hinaufsteigenden Fasern und Faserbiindeln, die oft bogenförmig anastomosirend rundliche und mehr längliche, dichtstehende, mitunter zusammen eine Wachswaben-ähnliche Structur vortäuschende (lacunäire) Råume umschrieben. Zwischen diesen Räumen steigen zahlreiche verzweigte Nerveniste empor. Der ibrige Theil der Haut bestand aus stark und dicht verfilzten, in den verschiedensten Richtungen verlaufenden Fasern und Faserbiundeln; kleinere Zellen und Kerne kamen nur sparsam vor; hier und da zeigten sich an Durchschnitten lacunäre Räume (Gefiasse) sowie aufsteigende Nerven. Die Haut brauste nur wenig mit Essigsäure. - Die glatte, die Innenseite der Rückenhaut, und die Aussenseite der Schale bekleidende Faserhaut ist von der Haut selbst schwer zu lösen, besteht aus einander meistens rechtwinkelig kreuzenden Fasern und Faserbündeln; hier tritt Pigment wieder ein wenig stärker auf, meistens längliche Striche und Fleckehen bildend, theils als freies Pigment, theils an Zellen gebunden. Ein flaches Epithel kommt hier vor. - Die Haut am übrigen Körper vom gewöhnlichen Baue.

Nach Entfernung des Mantels liegt die Schale ganz entblösst. Dieselbe stimmt, wie oben beschrieben, fast vollstindig mit der anderer Chelyonoten und überhaupt der meisten Marseniaden. Die Facetten an der Innenseite fuir die Muskelinsertionen sehr undeutlich, besonders die linke.

Nach Wegnahme der Schale zeigt sich die die Schale tragende und absetzende Fläche von einer dünnen Membran gebildet, die hinten die Geschlechtsdrüse, die Leber und den Magen u. s. w. überzieht, während sie vorne das Dach der Kiemenhöhle bildet; die unterliegenden Eingeweide schimmern alle mohr oder weniger deutlich lindurch. Diese Membran war aus einander in allen Richtungen kreuzenden Faserehen und Bïndeh ron solchen gebildet; an der Oberfläche auch ein flaches Epithel (und mitunter cine äusserst feine, mitunter ganz fein strcifige Cuticula). Der verdickte, matt-tweisse Rand ist unten wie von ciner etwas dickeren, helleren und weicheren Lippe eingefasst, die die Kiemenspalte nach oben begrenzt. Der Rand besteht aus dicht gedrängten, parallelen, mit dem Rande parallel laufenden Faseru; die obere Seite ist mit einem schönen feinzelligen Epithele überzogen. In der dem Rande nüichstliegenden Parthie der erwähnten 
Membran verlaufen die Faserchen der Länge nach, d. h. senkrecht auf die Richtung der Fasern des Randes; diese Strecke zeigt noch an der Oberflïche eine äusserst feine und eigenthümliche quergehende Wellenzeichnung. Das Material erlaubte kaum eine genauere Bestimmung des Baues der Membran und des Randes. In der Membran, besonders abrr in dem Rande wurden zahlreiche, verzweigte und in den Theilungsstellen oft Zellen enthaltende Nerven gesehen. Länggs des Randes kamen sehr oft gelbe, klumpige, verkalkte Körper einzeln oder in grösseren oder kleineren Haufen liegend vor; sie erreichten einen Durchmesser bis wenigstens $0,04 \mathrm{~mm}$. Die sich dem Rande anschliessende Lippe ist von etwas lockerem Baue, aus einander kreuzenden Fasern und Faserziigen gebildet, mit eingestreuten kleinen Zellen und von einigen Gefässen durchzogen.

Durch die erwähte dinne, die Schale tragende Membranschimmern die Eingeweide sehr deutlich hindurch ('Taf. M. Fig. 5, 6). An der oberen Seite zeigt sich die ganze Spitzo der Eingeweidemasse oder die Spitze selbst und die linke Seite der folgenden Windung derselben von der oberen Parthie der schwach röthlichgelben, gelben oder gelbgranen Geschlechtsdrủse eingenommen, welche meistens ringsum oder wenigstens rechts von der grauen, braungrauen oder (besonders bei dem Männchen) schwarzen Leber ganz umgeben und dadurch von der unteren Parthie dieser Drüse geschieden ist, die eine Strecke der convexen Seite der letzten Windung der Eingeweidemasse iiberzieht, von der Gegend vor der Stelle ab, wo diese Windung in die Spitze einzubiegen anfingt. Häufig zeigen sich die zwei Parthien der Geschlechtsdrüse auch viel mehr zusammenfliessend. Oben in der tiefen Columellar-Furche der letzten Windung zeigen sich die Stammäste des Geschlechtsdrü unganges, welcher letztere damn, bei dem Weibchen weniger entwickelt, bei dem Minnchen ein grosses flaches Trnäuel bildend, längs der Columelli (oberhalb der rechten Muskelfacette) hinabsteigt. Weiter nach unten sind dic Verhältnisse nun bei den Männchen und Weibchen etwas verschieden, - Bei dem Weibchen (Fig. 6) zeigt sich ein Bogen von (meistens 15-18) kleinen, runden oder lïnglichen, bräunlichen oder gelblichen und schwarzgerandeten oder ganz schwarzen Säckchen (Samenblasen), die durch eine graue Linie von dem vorne liegenden Organe geschieden sind. Dieses letztere Organ, die Schleim- und Eiweissdrüse, fïllt durch seine gelbliche Farbe in die Augen; ihr oberes Ende ist nach rechts gebogen und geht in den Eierstockgang über; sonst bildet das Organ ein mit der Columella paralleles, oben etwas breiteres Band, dessen rechte Hïlfte etwas mehr brïunlich, die linke mehr gelblich ist; das Organ endet in der Gegend der rechten Muskelfacette. Weiter nach unten sieht man undeutlich das Organ sich in die Vagina fortsetzen, die, mit dem deutlicher durchschimmernden Rectum parallel laufend, sich in die mehr deutlich durchscheinende Vulva neben dem und meistens ausserhalb des Anus öffnet. Dem linken Rande und theilweise dem oberen Ende der Schleim- und Eiweissdrüse und dem Orarium schliesst sich die hïbsche, (schwach grimlich-) graue Blätterdru ü e mit ihren langen, halbfiederigen oder einfach fiederigen Lappen an und an ihrer linken vorderen 
Ecke mehr oder weniger deutlich das erste Darmknie (Fig. 5 c). - Bei dem Männchen erstreckt sich diese letztere Drüse, die also grösser ist, nach hinten und rechts bis an den Hoden und an den Darm; hinten und an der linken Seite zeigt sich meistens ein Theil der (schwarzen) Leber. - Weiter nach vorne sind die Verhältnisse in beiden Geschlechtern dieselben. Mit dem Darmende und dem Vorderrande der Schleimdrise parallel beschreibt die grosse Kieme einen schrägen Bogen; am linken (oberen) Ende derselben schimmert vor dem ersten Darmknie die ovale, gelblichweisse oder gelblichbraune Niere mit ihren kleinen Läppehen hindurch, und vor derselben das fast ebenso grosse oder ein wenig grössere, meistens etwas mehr bräunliche, doppelfiederige Geruchsorgan, sich links (und hinten) fast an die linke Muskelfacette lehnend (Fig. 5 b, 6 b). An der linken Seite und hinter dieser letzteren zeigt sich ein grösserer oder kleinerer Theil des Herzbeutels mit dem mehr oder weniger deutlich durchschimmerndem Herzen. - Von der Unterseite betrachtet zeigt sich ganz oben gegen die Spitze die grane oder schwarze Leber durchschimmernd mit sammt ihren Venen; mehr rechts schimmerten der Magen und die erste Strecke des Darmes hindurch, nach hinten und rechts peripherisch von einem nach oben sich verschmäleruden Leberstreifen umgeben; mehr vorne zeigt sich oft links eine kleine Strecke der Nicre.

Die Wand des Genickes zeigt sich von dem gewöhnlichen Epithele iiberzogen und sonst von den besprochenen Muskellagern gebildet, die sich leicht von einander lösen lassen.

Die Eingeweide wie in anderen, "Pectinibranchiern" in zwei Massen gesondert. Die hintere und obere, wie gewöhnlich ganz in die Schale eingeschlossen, von der Geschlechtsdrüse, der Leber und einem Theile der Verdaumgsorgane (zweitem Magen, hinterer Strecke des Darmes) gebildet. Die vordere und untere auf dem Fusse ruhend, aus der vorderen Strecke der Verdauungsorgane mit ihren Nebenorganen und dem Centralnervensystem bestehend; rechts läuft bei den Männchen neben und in der Körperwand der Ausfihhrungsgang des Hodens, der Samenleiter (während bei den Weibchen der Ausfiuhrungsgang des Eierstockes, nachdem derselbe die Schleim- und Eiweissdrüse verlassen hat, längs des Rectums an der oberen Wand der Kiemenhöhle verläuft). Die beiden Eingeweidemassen sind von einander durch eine verduinnte Fortsetzung des Bodens der Kiemenhöhle ganz gesondert, und stehen (ausser durch Nerven und Gefässe) nur durch dic Riöhre in Verbindung, die vom Drüsenmagen an den zweiten Magen heraufsteigt. Die untere Lingeweidehöhle zeigt das gewöhnliche, hinter dem Centralnervensysteme und dem zweiten Kropfe stehende Dissepiment; vor demselben liegt der Schlundkopf mit seinen Appendices, hinter demselben der Drïsenmagen, welcher durch kurze Gefässe und Bindesubstanzbiinder an die Körperwand geheftet ist.

Wenn diese (untere) Eingerveidehöhle exriscerirt (Taf. M. Fig. 2S) ist, zeigt sich der Boden derselben ausgehöhlt, besonders in der Mitte vertieft. Etra die hintere Hälfte wird von starken Muskelbändern begrenzt, die der Länge naclı bogenförmig 
verlaufen und einander zum Theile kreuzen; in der Mitte findet sich eine spaltförmige grössere Oeffnung und mehrere kleine, durch welche das Blut des Fusses sich in die Körperhöhle ergiesst. Vor jener Oeffnung zeigen sich starke sehnenartige, quergehende, freie Muskelbänder, und in der Tiefe zwischen denselben wieder Oeffnungen, die sich in den Fuss hinein fortsetzen, und durch cine von welchen auch die Art. pediaea hineintritt; seitwärts werden die Wände von einer Fortsetzung der oben erwähnten bogenförmigen Muskelbånder gebildet, die vorne sich verdicken und mehr (Fig. $28 \mathrm{~d}$ ) oder weniger frei werdend ein starkes Muskelpolster bilden, dessen kräftige Fascikel an die Schnauze verlaufen. Vom Boden entspringt, innerhalb des Muskelpolsters (Fig. 28), jederseits der starke II. retractor bulbi. Ausserhalb des erwähnten Muskelpolsters steigen die sehr kräftigen armartigen Schal enmuskel empor, der linke (nach vorne [Taf. N. Fig. 24a] das Pericardium begrenzend) mehr nach vorne (Fig. 28 a b) liegend, als der rechte (Fig. 28 c); sie bestehen aus starken, mehr oder weniger deutlich geschiedenen Fascikeln ('Taf. N. Fig. 27a), die sich nach unten bis in das unterste Lager des Fusses verfolgen lassen. Das obere Ende der Muskeln, die Muskelfacetten (Taf. M. Fig. 5, 6), sind bräunlich, eben, an der Oberfliche wie etwas netzartige Bildungen (Fig. 28b) wegen der Fascikeln zeigend; sie sind meistens von ovaler oder eiförmiger Gestalt, mitunter an den Enden mehr zugespitzt, mitunter mehr eckig (Taf. M. Fig. 5a); die rechte ist oft etwas (Taf. M. Ïig. 5, 6) stärker als die linke; an den grössten Individuen betrug die Läinge der grössten, dèr rechten Facette $5,75-7 \mathrm{~mm}$ bei einer Breite von $1,5-2 \mathrm{~mm}$, während die entsprechenden Maasse der linken 5 und 1,5-2,5 mm betrugen. Vom Grunde des rechten Schalenmuskels lösst sich hinten ('laf. N. Fig. 27 b) ein kurzer, aber starker M. retractor vulvae.

Diese (untere) Eingeweidehöhle, wahrscheinlich der Uoberrest der primären Leibeshöhle, ist, wenigstens oben, von einem dünnen, von Bindesubstanz gebildeten Pseudo-Peritonaeum ïberzogen, das (im Gegensatzo zu dem die secundäre Leibeshöhle bildenden Pericardium) ohne Epithel scheint. ${ }^{1}$ )

Es gliickte nur durch Untersuchung einer grösseren Anzahl von (16) Individuen die anatomischen Verhältnisse innerhalb des verhältnissmässig kleinen eigentlichen Körpers zu bestimmen.

Die cinzelnen Theile des Centralnervensystems sind theilweise genau mit einander durch Bindesubstanz verbunden und in solche gehüllt; diese Kapsel setzt sich, mehrere Nerven an ihrem Grunde gemeinschaftlich einhüllend, weit hinaus auf dieselben fort und ferner als ein besonderer Strang hinaus bis zu der Körperwand. Hieraus folgt die nicht geringe Schwierigkeit, die Beschaffenheit der einzelnen Ganglien zu bestimmen

1) Vergl. auch: Grobbex, morpholog. Studien über den Harn- u. Geschlechtsapparat sowie die Leibeshöhle der Cephalopoden. Arb. d. zoolog. Instituts zu Wien. V, 2. 1884. (Separat pag. 38, 67-70) 
und dem Verlauf der Nerven zu folgen. In der Bindesubstanz kamen, oft massenhaft, runde und ovale, gelbliche und farblose, mehrschichtige, erhärtete Körper von einem Durchmesser bis $0,06 \mathrm{~mm}$ vor; sowie andere ganz erhärtete und fast zerfallende (Taf. N. Fig. 31). - Das Centralnervensystem liegt ziemlich weit nach hinten und tief, umfasst die Speiseröhre und die Aorta zwischen dem ersten und zweiten Kropfe. Es besteht aus einer oberen, in die Quere gespannten, jederseits ans drei kleineren Ganglien gebildeten Abtheilung, und einer länglichen unteren, aus 2 grösseren Ganglien zusammengesetzt. Die untere Abtheilung liegt ganz schief gegen die obere, weil dic Connective der einen (rechten) Seite viel kiirzer als die der anderen sind. Die obere Ganglienmasse besteht aus zwei wenig abgeplatteten, unsymmetrischen, in der Mittellinie zusammenstossenden, meistens schräg- oder querovalen Hälften, von denen jede wieder aus drei Ganglien zusammengesetzt ist. Diese Ganglien finden sich aber (im Tode?) in den verschiedenen Individuen in der verschiedensten Weise unter cinander verschoben. Am Constantesten ist die Lage des (rechten) subintestinalen Ganglions ganz unten, danach die des (linken) supraintestinalen oben (und vorn) (vergl. 'Taf. O. Fig. 3 ; 'Taf. P. Fig. 1-4). Die linke Parthie der oberen Ganglionmasse zeigt meistens hinten (Fig. 3 b) das gewöhnlich ei- oder birnförmige (linke) pleurale Ganglion, das nach aussen zwei oder drei Nerven und noch die pleurale Commissur abgiebt; ron den Nerren gingen der vordere oder die zwei vorderen an die Wand des Pericardiums und an das hintere Ende der Kieme; der letztere, der N. branchialis, längs des Basalrandes der Kieme verlaufend; der hintere und stirkere Nerv, der N. pallialis sin., durchbohrt die Wand der unteren Körperhöhle, um sich in der linken Hälfte des Man. tels zu verbreiten. Vor, seltener (Fig. 1a) innerhalb dieses pleuralen Ganglions folgt das meistens ein wenig kleinere (Fig. 3a) cerebrale Ganglion, sich durch eine kurze Commissur mit dem entsprechenden rechten und nach unten und hinten mit dem äusseren Theile des gleichseitigen pleuralen Ganglions verbindend, nach aussen wenigstens 5-6 Nerven abgebend an die Schnauze (die Mundröhre), an den Schlundkopf, an den T'entakel und das Auge (Nn. rostrales, Nn. labiales, Nn. bulbi phar., N. tentacularis, N. ophtalmicus); der äusserste ist meistens der stïrkste, theilt sich und verbreitert sich in die Schnauze. Vor dem cerebralen Ganglion (Fig. 3d), seltener oberhalb (Fig. $2 \mathrm{~d}$ ) oder unterhalb desselben ('Taf. P. Fig. 3d) liegt endlich das supraintestinale, das gar keine Verbindung mit dem cerebralen hat, dagegen durch ein schmäleres oder breiteres Connectiv mit dem gleichscitigen pleuralen und durch ein mehr oder wenigrer kurzes mit dem rechten pleuralen Ganglion verbunden ist; das Ganglion giebt nach aussen einen sehr starken Nerven, den N. olfactorius, ab, welcher in der Gegend der linken Ecke der Kiemenspalte in die Körperwand cintritt und in einer, dem vorspringenden Vorderrande der Vertiefung für das Geruchsorgan begleitenden, Lacune bis an das Dissepiment verläuft, das von jenem Rande (Taf. Q. Fig. 2b) an die Nitte des Geruchsorgans hinübertritt; der Nerv biegt hier nach innen, verläuft durch den freien Rand des Dissepiments an die Axe des Organs (s. weiter unten). Der andere vom Ganglion ausgehende Nerv steigt längss der Vorderseite des Blättermagens 
empor, und verläuft längs des Seitenrandes der oberen Seite nach hinten. - Die rechte Parthie der oberen Ganglienmasse zeigt hinten, aussen und unten das mehr oder weniger senkrecht stehende, kurz-sichelförmige subintestinale Ganglion ('I'af. O. Fig. 3c; Taf. P. Fig. 1 c, 2c, 3c, 4c), das nach innen durch die pleurale Commissur mit dem linken pleuralen Ganglion in Verbindung steht, nach oben stielartig mit dem iusseren Theile des gleichseitigen pleuralen Ganglions verbunden ist; es giebt nach aussen einen selır starken Nerven ab, welcher, meistens mit dem grossen Nerven des pleuralen Ganglions in eine gemeinschaftliche Hülle eingeschlossen, an die Körperwand verläuft, nach hinten biegt, längs des Blättermagens verläuft, und mit einem diunnen Ast oder mehreren in die hintere Eingerweidemasse hineintritt. Vor und oberhalb dieses Ganglions liegt das ple urale etwa von ähnlicher Form und Grösse wie das entsprechende linke; es ist ausser mit dem supra- und subintestinalen mit dem gleichseitigen cerebralen Ganglion verbunden; es giebt nach aussen einen starken Nerven ab, welcher hinter dem aufsteigenden (rechten) Schalenmuskel die Körperwand durchbohrt und als N. pallialis dexter die rechte Mantelhälfte zu versorgen scheint; von dem Nerven geht ein Zweig über den unteren Theil des Rectum und der Vagina, diesen Organen und dem Samenleiter Aeste sendend (wahrscheinlich ein besonderer, innerhalb einer gemeinschaftlichen Hiille mit dem anderen eingeschlossener Nerv). Vor oder hinter dem (Fig. 1a) letzteren Ganglion findet sich das cerebrale Ganglion, links mit dem entsprechenden linken, ferner mit dem gleichseitigen pleuralen durch kurzes Connectiv verbunden; es giebt wie das linke nach vorne und aussen etwa $\&$ Nerven ab an dieselben Organe wie oben, noch dazu an den Penis. Die Gehirnknoten sind ziemlich leicht von den pleuralen und dem supraintestinalen zu lösen; sie sind meistens die am wenigsten pigmentirten, wïhrend die anderen Ińnoten meistens reichlicher mit zerstreutem Pigment versehen sind. - Schief unterhalb der oberen liegt die untere Ganglienmasse (Fig. 3e), die pedalen Ganglien, schief, weil die cerebro- und pleuro-pedalen Connective der rechten Seite viel kürzer als die der linken Seite sind. Die Ganglien sind oft in ihrer Lage durch Faserbänder befestigt, die quer iiber die Gauglien von der einen an die andere Seite der Körperhöhle verlaufen. Die pedalen Ganglien sind in ihrer Hülle mehr oder weniger stark pigmentirt, besonders an beiden Enden und zwar am meisten am hinteren ('laf. P. Fig. 5, 6). Sie sind mehr oder weniger ausgeprïgt 8 -förmig (Fig. 5), meistens dieker im vorderen Ende, wenn dasselbe nicht, wie aber fast immer, in einen fast gesonderten Knoten (Fig. 5) entwickelt ist, der aber sehr oft (Fig. 3; 4,6) von der Unterseite ausgeht und somit nicht von oben sichtbar ist; sie sind nur wenig abgeplattet; die obere Seite ist mitunter etwas concav und dio untere convex, mitunter ist auch das Umgekehrte der Fall, und die obcre Seite von der Mitte nach vorn und nach hinten abfallend. Die beiden Ganglien sind im vorderen Drittel mit cinander fast unmittelbar verbunden; in dieser Gegend ist das rechte Ganglion etwas armförmig ausgezogen (Fig. 5, 6), was damit in Verbindung steht, dass die hier ausgehenden, dicht neben einander liegenden cerebro- und pleuropedalen Connective nur zwischen 
der Hïlfte und dem Drittel der linksseitigen Connective betragen; aus dem rorderen Ende der Ganglien gehen 3-4, aus dem hinteren auch drei Nerven, und neben den Connectiven noch ein oder zwei Nerven; alle diese Nerven scheinen den Fuss zu versorgen, sind geschlängelt und in lose Bindesubstanz gehủllt. Die pleurale Commissur ist nicht weit, nicht dünn (Fig. 3;3,4), zwischen dem linken pleuralen und dem subintestinalen Ganglion ausgespannt; eine Fortsetzung der Commissur weiter hinauf in das rechte pleurale Ganglion konnte nicht.nachgerviesen werden; die Commissur gab keine Nerven ab. Die Commissur zeigte sich bei mehreren Individuen theil weise doppelt (Fig.1), aber nur in cinem Falle gliickte es einen Theil desselben durch das linke Pleuralganglion hinauf zum Supraintestinalganglion zu verfolgen. Die buccalen Gauglien hinten am Pharyux liegend (Taf. M. Fig. 10), rundlich, durch eine ziemlich lange Commissur verbunden (Fig. 3 f: 'l'af. P. Fig. 7); die Ganglien geben nach hinten und unten das cerebro-buccale Connectiv ab; damn nach vorn und aussen einen Nerven an den oberen Theil des Schlundkopfes, ferner $2(-3)$ an die Speiseröhre; und am Grunde der Commissur geht endlich (jederseits) ein Nerv aus, der längs der Seite oder an der Unterseite der Speiseröhre an die den Blättermagen einhiullende Drüsenmasse verläuft und in dieselbe eindringt.

Die A ugen treten, wie oben erwähnt (Taf. O. Fig. 1, 2), an besonderen Höckern, verkürzten Ophthalmophorien, aussen am Grunde der Tentakel auf. Sie sind nicht klein, fast kugelrund und lassen sich mit Ausnahme des vorderen Endes ziemlich leicht ausschiilen. Die die Vorderfïche iiberziehende Epidermis diinn, mitunter leicht berstend (in der Art, dass das Organ ein ,offenes Auge" simuliren kanu). Hinter der Cornea schimmert die ('laf. N. Fig. 1) runde Pupille deutlich hindurch; hinter derselben liegt die kugelrunde, dunkelgelbe Linse; das Pigment sehwarz. Der (Fig. 1 a) gesonderte Nervus opticus steigt meistens ziemlich geschlängelt an das Auge hinauf. - Es glückte nie den ('Taf. O. Fig. 3, 4a) N. acusticus direct vom Gehirnganglion an die Otocyste zu verfolgen. Die Ohrblas e liegt in einer rundlichen, weisslichen Scheibe unter und ausserhalb des (Fig. 4 b) Fussknotens (Fig. $3 \mathrm{gg}$ ), welche lose an die Muskulatur des Fusses befestigt ist. Die Ohrblase selbst (Fig. 4) war kugelrund; in den grossen Individuen vou einem Durchmesser ron $0,2-0,22 \mathrm{~mm}$, bei einer Grösse des fast farblosen oder schwach gelblichen, stark lichtbrechenden, radiäir streifigen, kugelförmigen Otolithens von $0,12 \mathrm{~mm}$; bei den kleimeren Individuen maass die Ohrblase im Durchmesser etwa $0,12 \mathrm{~mm}$, bei einem Diam. des Otolithen von beiläufig $0,088 \mathrm{~mm}$. - In den Tentakeln trat die Längsmuskulatur besonders stark auf; ein oder zwei Nn. tentaculares konnten bis an die Spitze verfolgt werden.

Das an die Decke der Kiemenhöhle angelöthete, federförmige Geruchsorgan schimmert mit seiner Rhachis und seinen Blättern mehr oder weniger braungran deutlich hindurch (Taf. M. Fig. 5, 6), hinter der Kieme und der Niere den grössten T'heil der Coneavitüt des Kiemenbogens füllend (Taf.Q. Fig. 2); links stittzt das Organ sich an die Muskelfacette, vorne an den inneren Mantelrand. Das sehr schrigge liegende Organ (Fig. 5, 6) mass an den grössten Individuen an Länge $10 \mathrm{~mm}$ bei einer fast durchgehenden Breite 
von $4,5-5 \mathrm{~mm}$. Von der unteren Seite betrachtet (Taf. Q. Fig. 2) zeigt sich das Organ in eine ovale Vertiefung hinter dem Mantelrande eingesenkt, die etwa die Tiefe des Pericardiums $(4-5 \mathrm{~mm})$ hatte. Der vordere Rand dieser Vertiefung springt stärker nach unten hin vor, ist schräg und breiter, somit nach hinten (innen) etwas vortretend in der Weise, dass derselbe mitunter den vorderen Rand des Organs von unten deckt, besonders springt er an der Mitte (wegen des schräge an die Muskelfacette aufsteigenden Schalenmuskels) ror. Dieser vordere Rand geht an beiden Enden bogenartig in den hinteren über, am linken (hinteren) Ende verbreitet sich der Rand mitunter zu einer kleinen schrägen (das Pericardium deckenden) Fläche (Fig. 2). Der hintere Rand, vom Basalrande der Kieme, der Kiemensichel, gebildet, ist viel niedriger als der vordere. Von etwa der Mitte der vorderen Wand dieser Vertiefung (und in den erwathnten Vorsprung des vorderen Randes iibergehend) springt ein dünnes, im freien Rande wegen des eingeschlossenen Nerven verdicktes, querstehendes, senkrechtes Dissepiment hervor, in eins der Bliitter des Geruchsorgans übergehend (Fig. 2 b). Sonst ist die Vertiefung rings um die Anleftung des Organs ganz eben. Das Geruelısorgan ist in der grössten Ausdehnung seiner oberen Seite angeheftet; nur die Enden ein wenig frei, so wie das äussere Ende der Blätter. Das Organ ist von elliptischer Form, an Länge etwas variabel, mèistens ziemlich abgeplattet, mitunter der Länge nach an der Axe ziemlich vertieft, mit schwächerer oder stärkerer schlangenartiger Krümmung derselben. Die Zahl der Blätter jederseits meistens 40-60 betragend; sie sind, wenn schlaft, dreieckig mit gerundeter Spitze (T'af. Q. Fig. 4 b), in den grössten Individuen von einer Höhe bis $2,25 \mathrm{~mm}$, diun, (meistens mit gegen 10) feinen, in einander guirlandenartig übergehenden Querfalten an den Flächen (Taf. Q. Fig. 10). Unter dem Axenstrange verläuft, schon unter der Loupe sichtbar, eine ziemlich weite Lacune ('Taf. Q. Fig. 4). Auch in den Blättern des Organs schienen lacunäre Röhren vorzukommen. Der der Länge nach in jedem Blatte verlaufende Nervenzweig lässt sich bis in die Axe des Geruchsorgans verfolgen. Dieser, wie meistens schon unter der Loupe sichtbar (T'af. Q. Fig. 4a), an den meisten Stellen (aber mehr oder weniger deutlich) aus zwei uber einander liegenden ungleichgrossen Theilen bestehende, gelbe Axenstrang giebt also von seinen Seiten so viel Nerven ab, wie Blätter da sind. An mit Picrocarmin gefïrbten Schnittserien des Organs zeigten sich dieselben Structur-Verhältnisse wie bei den ïchten Marsenien (s. unten). - Die sich in die feine Fusspore öftnende Fussdriise klein und übrigens von ähnlichem Baue wie bei anderen Marseniaden.

Die interstitielle Bindesubstanz scheint hauptsächlich, wie bei anderen Pectinibranchiern, theils aus einem Netze von sternartigen, anastomosirenden Zellen, in mehr oder weniger reichlicher homogener Intercellulärsubstanz liegend, gebildet; theils aus grösseren stern- oder spindelförmigen Zellen mit fibrillïren Ausläufern; theils endlich zeigen sich hier und da die grossen, von Brock ${ }^{1}$ ) Plasmazellen genannten, Bildungen. 
Treisrunde oder ovale Durchbrechungen oder Löcher in der Bindesubstanz (Circulationslïcken) ${ }^{1}$ ) kamen überall håufig vor.

Die einstülpbare Schnauze ist mitunter ganz zuríckgrezogen, es kommt dann hinten an der Unterseite des Kópfes eine quere Mundspalte mit wenig wulstigen Lippen (Taf. O. Fig. 1) vor. Meistens ist die Schnauze aber mehr oder weniger aus der (Taf. M. Fig. 3; Taf. O. Fig. 2a) Mundspalte herrorgestiilpt, und dieselbe zeigte sich dann bei den grossen Individuen ron $8-\$, 5 \mathrm{~mm}$ Länge, dick, cylindrisch oder kurz-kegelförmig, mit dem runden oder ovalen, mehr oder weniger zusammengezogenen Innenmunde an der Spitze oder meistens unterhalb derselben. Mitunter ist dieser letztere Mund (mit dem Schlundkopfe) in eine Vertiefung an der Spitze der Schnauze zurückgezogen (Taf. M. Fig. 3). Die dickwandige Schnauze (Rostrum) zeigt innerhalb eines dünneren Kreislagers ein mit ihren dicken Buindeln an der Innenseite stark rorspringendes Längslager, welches eine Fortsetzung ist von mehreren, meistens 4-5, mitunter mehrköpfigen, sehr starken Muskelsträngen (Mm. rostrales proprii s. retractores rostri), die von dem Fusse und von der Ruickenseite ausgehen, mit jenem wie mit dieser in fast der ganzen Lïnge ihres Ursprunges verwachsen. Kurze, der Länge nach und schräg laufende Muskelbänder heften ferner den (Xrund der Schnauze genauer an das Genick, den Kinn und den Fuss (T'af. M. Fig. $12 \mathrm{ab}$ ) ( $1 \mathrm{Im}$. nucho-, mento- und pedi-rostrales). Zwischen der Schnauze und dem innerhalb derselben liegenden Schlundkopfe bleibt ein kleiner Zwischenraum, eine Fortsctzung der grossen Kopf-Lacune; schräg durch denselben erstrecken sich an den Seiten noch mehrere (meistens 3), meistens mehrköpfige Muskelbänder (Mm. rostro-labiales), so wie längs der inneren Wand die verschiedenen $\mathrm{Mm}$. bulbo-rostrales, darunter der starke, vom bläulichen Knorpelflecken entspringende, fäicherartig verbreitete bulbo-rostralis inf. (Taf. M. Fig. 12). Bei eingestiulpter Schnauze zeigt sich dieselbe oben durch die schmale Lippenscheibe mit dem zwischen den freien Mandibelrändern liegenden Innenmunde begrenzt. Die Lichtung der Schnauze ist rundlich, hinten weiter, mitunter hier im Durchmesser bis $6 \mathrm{~mm}$ messend; die Wiande derselben, wenu sie eingestulpt ist, dick, die tiefschwarze Innenseite dann mit ziemlich zahlreichen, starken Längsfalten. Die radiär- und dunkelstreifige schmale Lip p.enscheibe iiber dem gebogenen Schneiderand der beiden Mandibelplatten (Taf. M. Fig. 11 a) schnürlochartig zúsammengezogen oder denselben melır oder weniger und zwar meistens ganz entblösst lassend; mitunter traten diese braunen Ränder selbst 2-2,25 $\mathrm{mm}$ in die Nundröhre hinein. Der Inuenmund, die Oeffnung des Schlundkopfes in die Mundröhre, dem gemäss enger oder weiter, wesentlich von dem Rande der Mandibelplatten gebildet, somit elliptisch, oben etwas weiter (Taf. N. Fig. 19).

Der Schlundk opf ist (Taf. M. Fig. 10-12) gross und ziemlich plump, an den erwähnten zwei Individuen an Länge $9-9,25 \mathrm{~mm}$ bei einer Breite hinten bis 7 und bei

1) BRock, Unters. üb. die interstitiellen Bindesubstanzen d. Moll. Zeitschr, f, wissensch. Zoologie. XXXIX, 1883. pag. 21, 32. 
einer Höhe bis 5-5,5 mm messend; der Umfang des Organs gerundet, ein wenig niedergedruckt; vorn ist der Schlundkopf etwas schmächtiger und etwas zusammengedriickt so wie etwas nach unten gebogen (Fig. 12). Der Schlundkopf besteht nämlich aus zwei Abtheilungen; einer vorderen (Fig. $12 \mathrm{f}$; Fig. $10 \mathrm{~b}$ ) schmäleren, viel kürzeren und im Ganzen viel kleineren; und einer hinteren (Fig. 12 g; Fig. $10 \mathrm{c}$ ), die zum grössten Theile von der Zunge und ihrer Muskulatur gebildet ist. Die vordere Abtheilung kurz abgestutzt-kegelförmig, etwas zusammengedriickt, meistens oben etwas schmäler; sie ist aus Irreisfasern (Fig. 11) gebildet (M. circularis bulbi), welche an der oberen Seite schwächer entwickelt sind, weshalb die Mandibelplatten hier bräunlich durchsehimmern (Fig. 12). Die hintere Abtheilung springt ringsum iiber die vordere hervor, von derselben durch eine starke obere und eine viel weniger deutliche untere Furche geschieden. Die obere Seite (Fig. 10) etwas gewölbt, hinten ein wenig breiter, vorne gerundet, hinten mehr abgestutzt; vorne an derselben die weite Oeftnung des Pharynx. Die obere Seite ist von zwei ganz dünnen Nuskellagern gebildet, dem M. longitudinalis sup. (der an dem mittleren Theile fast fehlt) und einem M. transv. post. superficialis, beide respective aus dem Hinterende und dem oberen Rande des zu erwihnenden Sehnenfleckes entspringend. Nach Wegnahme dieser Muskellager liegt ein zwischen den Mm. lingvales proprii ausgespanuter M. transversus post. profundus entblösst, unter diesem findet sich das Raspeldach. Die Seitenflächen dieser hinteren Abtheilung sind (Fig. 12) etwas abgeplattet, nach vorne und nach unten schräg einwärts abfallend, unten und hinten mit gerundeten Ecken vortretend. An der Aussenseite dieser letzteren unten (Fig. $11 \mathrm{cc}$ ), ein länglicher, meistens schräger, bläulicher Sehnen-oder Knorpelfleck (das freiliegende hintere untere Ende des Zungenknorpels). Von diesem Knorpelflecken entspringt unten der fächerförmige M. bulbo-rostralis inf., und nebenbei inserirt sich der starke M. retractor bulbi (Fig. 12d; Fig. 2S), der (der Stellung der Schnauze nach, nach voru oder hinten) an den Fuss geht; vom Vorderrande des Fleckens gehen schräge, respective nach oben und nach unten, der M. lateralis sup. und inf.; am oberen Rande heften sich die erwähnten Mm. longitudinalis sup. und M. transv. post. superficialis; vom ganzen hinteren Umfang entspringt der M. lingvalis proprius. Nach Wegnahme des M. bulbo-rostralis inf. liegen an der Seitenfläche des Schlundkopfes entblösst der starke II. lateralis sup. und der etwas schwächere II. lateralis inf.; beide gehen (Fig. 11) vom Vorderrande des Knorpelfleckens aus und divergiren stark von einander; der erste geht nach oben, bildet den vorspringenden Vorderrand der hinteren Abtheilung des Schlundkopfes und verwebt sich oben in der Mittellinie mit dem entsprechenden Muskel der anderen Seite, indem er oben auch schräge Fascikel iiber die vordere Abtheilung des Schlundkopfes schickt (Fig. 12); der andere kiirzere geht schriig nach unten und inmen, und heftet sich an und mischt sich mit der Oberfläche des M. circularis, indem er sich in der Mittellinie mit dem entsprechenden anderen Muskel kreuzt (Fig. 11); in dem hinten durch Zusammenstossen der beiden Muskel gebildeten Winkel tritt die Art. lingvalis ein. In dem dreieckigen Zwischenraum 
zwischen dem M. lateralis sup. und inf. zeigen sich schrig ron der Winkelspitze nach oben (Fig. 11, 12) aufsteigende Fasern, die sich vorn an den M. circularis anschliessen; zwischen beiden Muskeln tritt der stärkste N. bulbi phar. sehräg nach oben hinein. Die schmälere Unterseite (Fig. 11) vorn convex, aus zwei Parthien bestehend, einer vorderen (Fig. 11 a) von dem M. circularis, und einer hinteren (Fig. 11 b) von den schriigen, hinten zusammenstossenden M. laterales inff. gebildet; im Winkel kamen oft noch quere Fascikel des M. circularis bulbi zum Vorscheine (Fig. 11). Hinter dieser Strecke folgt dann eine Einsenkung zwischen den hier gesässartigen Hintertheilen des Schlundkopfes. Das Hinterende des Schlundkopfes ist ziemlich hoch, gerundet, nach unten und vorne abfallend, in der Mitte eingesenkt; aus der Einsenkung tritt die lange, aufgerollte Raspelscheide (Fig. 11) hervor. - Die vordere Abtheilung des Schlundkopfes ist an der Innenseite von den Mandibelplatten bekleidet, und ihr vorderer Rand passt in den Falz der Aussenseite derselben hinein. Nach Wegnalıme der Platten sieht man die Innenseite von zwei seitlichen, oben und unten einander berührenden F a cetten eingenommen, die in Form vollständig dem hinteren Theile der Mandibelplatten entsprechen; die Facetten haben, wie erwähnt, vorn eine dem Falze entsprechende, vortretende Kante; sie sind von schönem Epithele bekleidet. Die starken Mandibelplatten (Taf. N. Fig. 16-19) hatten bei drei in dieser Beziehung genauer untersuchten Individuen eine Länge von 4-5 $\mathrm{mm}$ bei einer Höhe bis etwa $3 \mathrm{~mm}$. Jede Platte ist ein der Länge wie der Höhe (Fig. 19) nach gebogenes festes Blatt, etwas dicker in der vorderen Hälfte (Fig. 19) und längs der Mitte der Höhe des Blattes; die Dicke doch kaum etwa 0,25 mm übersteigend, gegen den hinteren Rand allmählig verschmächtigt. Etwa an der Mitte des oberen Randes sind beide Platten durch eine Art von Sehloss (Fig. 17-19) und hinter demselben durch eine starke weissliche Cuticula (Fig. 1S) verbunden; am unteren Rande sind die Platten am etwa entsprechenden, selten vorspringenden Punkte (Fig. 17) durch eine feine Cuticula an einander gelibthet. Das Vorderende jeder Platte ist dem der anderen ziemlich stark genähert (Fig. 19); zwischen den beiden Vorderrändern findet sich der oben weitere, nach unten verschmälerte (Fig. 19) Innenmund. Hinten treten die Platten weit, bis $3-4 \mathrm{~mm}$ aus einander (Fig. 18). Die Platten bestelen aus einem vorderen, dickeren, bräunlichen, in die (Taf. M. Fig. 10a) Schnauze (Mundröhre) frei hineinragenden Theil und einem hinteren, der ein wenig grösser als der vordere ist. Dieser vordere Theil ist an der Aussenseite durch einen von oben nach unten gehenden, fast geraden oder wenig gebogenen, nicht tiefen Falz (Fig. 16-19) von dem hinteren geschieden; an der Innenseite geht der vordere Theil iiber eine wenig bemerkbare gerundete Kíante, die dem Falze entspricht, in den hinteren ibler; der Vorderrand (Fig. 16, 17) ist abgestutzt, nicht scharf, geht gerundet-winkelig in den dunkleren, mehr geraden, an der Ecke etwas abgestutzten oberen und in den helleren, mehr gerundeten, diunneren unteren liaud uber; der obere Rand ist, wie erwähnt, in der Gegend.(Fig. 18) des Falzes mit dem des anderen Kiefers verbunden. Der hintere Theil ist, wie auch erwähnt, etwas grösser als der vordere, oben 
meistens etwas kiirzer, nach dem Rand zu (und zwar besonders nach der hinteren unteren Ecke) allmählig verduinnt; der freie Rand ist oben schwach gebogen oder etwas winkelig; unten mehr gerade (Fig. 16, 17); die Flächen glatt, die Innenseite (Fig. 18) die mit dem Rande parallel laufenden Zuwachsstreifen deutlicher als die Aussenseite zeigend. Die Farbe des vorderen Theils der Kieferplatten an der Aussenseite gelbbraun oder braungelb; der hintere Theil zeigt die Aussenseite innerhalb der bräunlichen oder braunen, mitunter auch, besonders oben und unten, schwarzbraunen Randparthie aber fast immer schön grün, besonders längs der Mitte. Die Innenseite der Platten ist an dem rorderen Theile braungelb oder schmutzig horngelb, an dem hinteren heller. Die Platten sind von dichtem Baue; unter dem Mikroskope an der Oberfliche mehr oder weniger deutlich eine Zusammensetzung aus langen, diinneren und dickeren Säulchen, die von deutlich geschichtetem Baue sind, zeigend (Taf. N. Fig. 21). - Die Masse der hinteren Abtheilung des Schlundkopfes ist wesentlich von der sehr starken Zunge gebildet.

Die Zunge ('Taf. N. Fig. 2) ist gross und breit, aber mit der Unterseite und den Seitenflächen fast bis an die Spitze angeheftet, welche zwischen den Kieferplatten liegt, die, besonders an der oberen Seite, noch mehr nach hinten treten; die Farbe ist gelblich, gräulich oder schwärzlich. Dio Raspelfurche (Fig. 3) etwas vertieft, nicht breit; (an den in Alcohol bewahrten Individuen) von einer weissen schmalen Kante (Fig. 2; Taf. O. Fig. 5 aa) eingefasst; innerhalb derselben zeigen sich die braunen oder braunschwarzen Grundstiicke der Seitenzahnplatten (Fig. 2), von denen sich dann die stark schillernden horngelben Hakenparthien nach innen schriig erheben; in der Mittellinie zeigt sich, mitunter undeutlich (Fig. 5), die Reihe der medianen Platten; die Spitze des Hakens oder der ganze Haken der rechten Zahnplatten deckte meistens die entsprechenden 'T'heile der linksseitigen Platten ('Taf. O. Fig. 5). Der hinterste Theil der Raspel (in einer Länge von 7-9 Zahnplattenreihen) von dem in Grösse etwas variablen, platten, dünnen, vorn abgestutzten Raspelda c he (Taf. N. Fig. 2, 5) bedeckt, das am Rande und hinten mehr gelblich und etwas verdickt war. In der Raspel kamen bei 16 in dieser Beziehung untersuchten Individuen 7-9-13 Zahnplatten reihen vor, unter dem Raspeldache ferner 5-6-7-9 und in der langen Raspelscheide $40,54,61,62,54,53,52,52,64,72,46,48,49,50,50,64$ entwickelte und $7(-9)$ mehr oder weniger unvollendete Reihen; die Gesammtzahl derselben somit $64,76,87,86,80,81,65,74,87,72,70,75,73,74,67,91$. Die vordersten (Taf. O. Fig. 5) Reihen der Zunge waren fast immer mehr oder weniger incomplet; von der vordersten fanden sich mitunter nur die mehr oder weniger abgebrochenen Seitenzahnplatten oder (Fig. 5 c) nur die (abgenutzte) mediane Platte vor, und in den folgenden (3-6) war der Haken der lateralen (Fig. 5) noch immer abgebrochen oder wenigstens stark abgenutzt. Die Breite der medianen P latten ('Taf. N. Fig. 6-13) betrug an zwei grossen, in dieser Beziehung untersuchten Individuen hinten in der Raspelscheide 0,49-0,53 mm. Die Farbe der medianen Platten ziemlich hell-horngelb; der Grundtheil der lateralen Platten rothbraun oder ganz dunkelbraun, der Haken mehr horngelb; der in die Raspelscheide ein- 
geschlossene Theil der Raspel-Fortsetzung dunkler. Die medianen sind ziemlich düne Platten, die mit ihrer hinteren Strecke in die Cuticula übergehen (Fig. 6, 7), während sie sonst derselben platt anliegen oder sich (Fig. 7,9) wenigstens nur wenig (vorne) von ihr erheben; sie sind mehr oder weniger asymmetriseh, besonders im hinteren Theile, die linke Seite immer stärker entwickelt (Fig. 6-12). Die obere Seite des eigentlichen Zahnkörpers fällt von der Mitte nach den Seitenrändern ab (Fig. 6); dieselben sind fast parallel, ein wenig ausgekerbt; der hintere Rand ziemlich tief ausgeschnitten, der mit der Cuticula verwachsene Theil viel heller (Fig. 6, 7). Der nach oben gekrummte, breite (Fig. 6) Hakentheil der Quere (Taf. N. Fig. 7) und besonders (Taf. N. Fig. 9) der Lïnge nach gebogen, meistens ziemlich stark zugespitzt (vielleicht besonders bei den Weibchen [Fig. 6, 7]), seltener mehr gerundet (Fig. 11, 12); der Schneiderand unbedeutend umgeschlagen,. meistens mit 5-7 ziemlich schwachen, aber spitzen Dentikeln (Fig. 6-9). Die lateralen Platten (Taf. M. Fig. 17-20; Taf. N. Fig. 14, 15) stehen einander gegenuiber, doch etwas schrïge und sind in der Weise nach innen gedreht, dass sie sich mit dem Haken gegenseitig iber die mediane Platte kreuzen (Taf. O. Fig. 5). Vorne an der Zunge Kommen die Mittelzahnplatten meistens ziemlich deutlich zwischen den Seitenzahnplatten zum Vorschein (Taf. O. Fig. 5 c); weiter nach hinten werden sie von den letzteren fast gauz verdeckt. Der Grundtheil dieser Platten ist stark, dick, subparallelogrammatisch, mit dickeren Seitenparthien (Taf. N. Fig. 15); von diesem Grundtheil erhebt sich der starke, etwas gebogene, schief abgeplattete Haken (Fig. 18; 14). Dieser Haken ist etwa in seiner unteren Hälfte im Rücken tief gekluftet, das hintere Ende der Kluft gerundet; die obere Wand der Kluft breiter (T'af. N. Fig. 14), als die untere (Taf. M. Fig. 18) und das Aussehen der Zahnplatten somit etwas versehieden, je nachdem sie vou oben oder von unten betrachtet werden (vergl. Fig. 18 u. 14); die Spitze des Grundtheils der vorne liegenden Zahnplatte tritt mehr oder weniger tief in die Kluft hinein (Fig. 18; 14); lïngs der Unterfläche (Hinterfläche) des Hakens setzt sich das Hinterende des Grundtheils als ein starker Kiel fast bis an die Hakenspitze fort; die hintere (obere) Parthie des Hakens (Taf. M. Fig. 19) ist viel schmäler als die vordere (untere) und trägt am Rande meistens 20-25, seltener bis 30, oder (besonders bei den Männchen) 15-20, von der Hakenspitze nach hinten zu an Grösse allmählig ein wenig zunehmenden, mehr oder weniger spitzen Dentikel; die vordere (untere) Parthie des Hakens (Fig. 19) ist breiter, gegen den Rand dïnner, hier etwas nach (Fig. 18) unten umgeschlagen und in meistens $5-7$ Dentikel entwickelt, die grösser als die des anderen Randes sind. Abnormitäten sowohl der medianen (Taf. M. Fig. 21; Taf. N. Fig. 12) wie der lateralen ('T'af. M. Fig. 17, 20) Platten kamen dann und wann vor. - Die lange Raspels cheide hatte an 5 genauer in dieser Beziehung untersuchten grösseren Individuen eine Lïnge von $2,5-3 \mathrm{Cm}$ bei einer fast durchgehenden Breite von 1,1-1,2 mm; nur das hinterste Ende war etwas breiter, wie geschwollen (Taf. M. Fig. 10 d, 11 c). Die Scheide war etwas abgeplattet-biconvex, meistens der Flaiche nach am Hinterende des Schlundkopfes in den verschiedensten Stellungen (Fig. 10, 11), in 
meistens 2-3 Windurigen aufgerollt, welche durch lose Bindesubstanz locker an einander befestigt waren; nur am Hinterende der Scheide war die Befestigung inniger, jederseits noch durch die Ausbreitung einer dünnen Membran verstärkt, die (vom Ende der Scheide ab) sich nach vorne mit einem Muskel verbindet, der jederseits von der hinteren-oberen Seite des Schlundkopfes (vom Grunde des Pharynx ab) bogenartig hinabsteigt (von einer mehr oder weniger gefensterten Fortsetzung der erwähnten Membran eine Strecke begleitet, sowie von einer Arterie); beide bleiben unten isolirt oder vereinigen sich und verlieren sich schliesslich in den Fuss (Taf. M. Fig. 12 e) (M. retractor bulbi secundarius). Die Raspelseheide zeigt innerhalb eines diinnen längslaufenden Faserlagers unten ein ziemlich bohes Epithel mit Cuticula und den derselben gehörenden Zahnplattenreihen und oben zwischen den Zahmplatten die gewöhnlichen kleineren Zellen; ganz hinten, am Ende der Raspelscheide, die gewöhnlichen grossen Pulpenzellen. - Nach Wegnahme der Raspel liegt die Tragmembran derselben (Taf. N. Fig. 3) entblösst und ist also wie. jene nicht breit; sie setzt sich jederseits als obere Wand der Zunge fort und geht in die sonstige Bekleidung der Mundhöhle über, sich vorne am Vorderende der Zungenknorpel anheftend. Die Tragmembran ist in der vorderen Hälfte der Raspelgegend sehr dünn und lässt die Zungenhöhle durchschimmern (Fig. 3) mit sammt dem Vorderende der Zungenknorpel (dem linken meistens iiber den rechten klappend) und dem der Innenseite desselben gehörenden M. applanator superficialis; weiter nach hinten ist die 'Tragmembran (wegen der in der Mittellinie einander berïhrenden Mm. tensores meŕbranae radularis postt.) undurchsichtig, bräunlich (Fig. 3). Die Tragmembran besteht aus einer iusserst feinfaserigen Grundlage, die an der oberen Seite von einem grosszelligen Epithel bekleidet ist, an der unteren (wenigstens in der vorderen Strecke) noch von einem ganz kleinzelligen; in mehr als der hinteren Hälfte heften sich die Fascikel der Mm. tensores radulae postt., ganz vorne die $\mathbf{M m}$. tensores radulae antt. Nach Spaltung der 'Tragmembran liegt die ziemlich kleine, durch die mächtigen Zungenknorpel eingeschrïnkte Zungenhöhle offen, aber nur das Vorderende und zum Theil der untere Rand von jenen erseheinen mit der weissen Farbe der Knorpel, welche letztere sonst von Muskeln bedeckt sind, jeder vorne von den Mm. applanatores lingrae, hinten von dem grossen M. lingralis. Die sogenannten Zungenknorpel (Taf. M. Fig. 13-16), welche ihren Namen dem makroskopischen Aussehen, nicht dem mikroskopischen Baue verdanken, sind mächtige, bei zwei grossen Individuen 6,25-6,75 $\mathrm{mm}$ lange, 2,5-2 $\mathrm{mm}$ breite und 3-2,75 $\mathrm{mm}$ hohe, weisse (nur an der freien Endfläche bläuliche) Körper ('laf. M. Fig. $11 \mathrm{cc}$ ), die den grössten Theil des ganzen Schlundkopfes ausmachen. Diese Körper sind länglich, etwas zusammengedrückt (Fig. 16), in etwas mehr als dem vorderen Drittel etwas geschwollen, aber ganz vorne und unten wieder schmäler; nach hinten zu sind sic etwas verschmächtigt, mit schrïger, entblösst liegender Facette endigend (Fig. 13 b, 14 b). Die Innenseite ist convex, längs des Unterrandes etwas ausgehöhlt (Fig. 15); die Aussenseite (Fig. 13), der Innenseite entsprechend, concav, besonders in der unteren Hälfte; längs des unteren Randes oder 
wenigstens mit demselben parallel verläuft, fast der ganzen Länge nach, eine feine Leiste (Fig. 14) fur Insertion der Mm. constrictores lingvae. Der obere Rand ist ziemlich dick, gerundet, in der vorderen Hälfte ziemlich stark convex, in der hinteren fast gerade; der untere Rand fast gerade, dünn, meistens nach innen (Fig. 15) etwas umgeschlagen (dem II. applanator superfic. als Anheftungsleiste dienend). Das etwas nach innen gebogene Vorderende zusammengedrickt; das Hinterende schräg von oben nach unten und vorn so wie von hinten und innen nach vorn und aussen abgestutat mit einer länglichen, planen, freiliegenden (Fig. 13 b, 14b) Facette endigend. Die Farbe des Knorpels weiss, nur die Endfacette bläulich. Die Knorpel sind etwas durchseheinend, an der Oberfläche uiberall cine feine netzartige Bildung zeigend (Fig. 13-15); sie sind sehr resistent, etwas zusammendruickbar, elastisch, fast von knorpelartiger Consistenz; die von denselben entspringenden oder denselben ganz zugehörenden Muskel sind mit ihren Fascikeln sehr fest an die Oberfläche befestigt. Diese Muskel sind die folgenden: Von dem hinteren Ende und dem oberen Rande der Endfacette entspringen der M. longitudinalis sup. und der M. transversus post. superficialis; vom Vorderrande gehen schrïig, respective nach oben und nach unten, der M. lateralis sup. und inf; vom Unterrande der fächerförmige M. bulbo-rostralis inf. und der starke M. retractor bulbi (Fig. 12). Vom inneren Theile des Hinterendes entspringt ferner der M. tensor radulae post., welcher (T’af. N. Fig. 3) mit gesonderten Fascikeln nach oben steigt und sich an der Unterseite der Tragmembran der Raspel befestigt; der etwas keilförmige, hinten breitere, vorne cinen scharfen Rand bildende Muskel ist unten durch eine Spalte von dem entsprechenden geschieden, sonst liegen sie platt aneinander. Dicht oberhalb dieses Muskels und an der Aussenseite desselben und fernerhin fast rings um den Rand derselben (Fig. 3 aa) entspringt der starke M. lingvalis proprius, weleher mit seinen aufsteigenden Bündeln eine hinten und unten dicke, nach oben allmählig. diinnere Haube um den grössten 'Theil des Knorpels bildet und nach vorne in die seitliche Fortsetzung der Tragmembran übergeht. Von diesem Muskel theilweise gedeckt findet sich an der Innenseite des Knorpels der vom Unterrande entspringende, flache, ziemlich dünne M. applanator superficialis, welcher etwas schräg nach oben hinaufsteigt, um auch in die Tragmembran über zu gehen (Fig. 3). Unter diesem Muskel oder doch zum grössten Theile von demselben bedeckt liegt der auch diinne M. applanator profundus, schrig nach hinten hinaufsteigend und sich neben dem vorigen anheftend. An der Aussenseite des Knorpels, von dem M. lateralis sup. (mitunter auch von einem Theile des MI. lingvalis) bedeckt, zeigt sich der die Concavität der Scite iiberbrückende (Fig. 13c) starke M. dilatator lingvae, welcher an der Facette entspringend sich hinter dem dickeren Vorderende des Knorpels anheftet. Ausserhalb und oberhalb des unteren Randes des Knorpels entspringt vorn der quergehende (mit sammt dem folgenden Muskel den Boden der Zungenhöhle bildende), an entsprechender Stelle des anderen Kinorpels inserirte M. constrictor lingvae ant. (Taf. N. Fig. 4). Ein wenig mehr nach oben und sich weiter nach hinten erstreckend findet sich dio Insertion des sonst ganz :ahnlich verlaufenden M. con- 
strictor lingrae post. (Fig. 4). In eine mediane Spalte hinter dem letzteren Muskel tritt der von der Hinterseite des Schlundkopfes entspringende paarige oder (Fig. 4 b) unpaarige (dann gegabelte) M. tensor lingvae inf., welcher sich, in mehrere Fascikel aufgelöst, an der Unterseite jenes Muskels anheftet. Die Unterseite der Seitentheile jener Constrictoren ist mit den unterliegenden Mm. lateralis inf. und circularis verwachsen; in der grössten Strecke bleibt zwischen jenen und diesen ein kleiner, mit der erwähnten Spalte communicirender Raum. - Geschnitten zeigt sich der "Knorpel" auch von fast knorpelartiger Härte; unter der Loupe präsentiren sich die Längs- und Querschnitte noch heller als die Oberfläche des Knorpels; die helle Grundsubstanz zeigt sich (Fig. 16) von weissen netzartig einauder kreuzenden, meistens horizontal und senkrecht verlaufenden Fasern durchzogen (T'af. N. Fig. 22). An ungefärbten sowie mit Pikrocarmin geftirbten (etwa 0,02 mm dicken) Schnitten zeigte sich die (schwach gefärbte) Grundsubstanz (Fig. 23) fast homogen, äusserst feinstreifig, von (stark gefïrbten) breiten und schmalen, vielfach anastomosirenden faserigen Blättern und Wänden ${ }^{1}$ ) durchzogen; hier und da kamen Körnergruppen sowie ganz ausnahmsweise einzelne Korne vor; die an der Obertäche des "Kinorpels" sich inserirenden MIuskel verweben sich mit den Blättern. - Die Zungenhöhle ist, wie erwähut, klein, zwischen den Zungenknorpeln eingeengt (Taf. N. Fig. 4); oben verbreitet sic sich seitwärts unter der 'Tragmembran und unter dem M. lingvalis; hinten öffnet sich die Arteria lingvalis durch die erwihnte Spalte in die Höhle hinein.

Die II undhöhle ist klein. Die obere Wand dün; vom Pharynx ab erstreckt sich median (Taf. M. Fig. 10) längs derselben bis an die Verbindnng der beiden Mandibelplatten eine seichte, aber nicht ganz schmale Furche, die mitunter am Rando schwarz oder schwärzlich pigmentirt war.

Als Speicheldrüsen sind vielleicht zwei, durch mehr gelbliche Farbe ausgrezeichnete flache Massen zu betrachten, die, meistens in der Mittellinie zusammenfliessend, die Seiten der oberen Fläche oder die gainze obere Seite und den vorderen oberen Rand des grauen Drüsenmagens decken, mitunter sich am oberen-hinteren T'heil des Schlundkopfes verbreitend: mitunter hüllen sie auch den Druisenmagren fast vollstiundig ein. Sic sind ron sehr langgestreckten, sehr ïstigen Drüsenlappen gebildet (Taf. O. Fig. 6). Die Ausführungsgiinge glückte es nicht nachzuweisen; öffnen die Driisen sich in den Drüsenmagen?

Die weite Speiseröhre etwa an der Mitte des Schlundkopfes entspringend, mit weiter Pharynx-Oeffnung (Taf. M. Fig. 10) sich links mehr oder weniger nach vorne über den Schlundkopf hinlegend und an der linken Seite desselben hinabsteigend; meistens

1) Claparìde (Anat. u. Entwicklungsgesch. der Neritina fuviat. J. MüLuER, Arch. 1857. pag. 157) dentet wohl mit Unrecht "die netzförmig geschlungenen Fasern - als die Wandungen der - Knorpelzellen". 
eine kleine Erweiterung, den (Taf. P. Fig. 8b) ersten Kropf, bildend; dann horizontal liegend, vom Centralnervensystem umfasst und, meisten fast median, oberhalb des unteren Randes des Driisenmagens eintretend. Nur in einem Falle (von den 16) stieg die Speiseröhre fast in der Mittellinie, die Raspelscheide links schiebend, hinab. Unmittelbar vor dem Eintreten der Speiseröhre in jenen Magen, dicht vor der Cardia, muindet der grosse, querliegende zweite Kropf ein ('Taf. O. Fig. 10; Taf. P. Fig. 8c). Die Speiseröhre maass bei einem der grössten Individuen $13 \mathrm{~mm}$ an Lïnge bei einem Durchmesser bis $3 \mathrm{~mm}$; die Imenseite (Fig. 10;8) mit feinen Längsfalten ausgestattet, die auch den ersten Kropf durchzogen. Der zweite Kropf (Fig. 10, 11;8c,9c) breiter als die Vorderseite des Drüisonmagens, mehr oder weniger iiber die Seiten desselben hervortretend, besonders rechts (Fig. 8 c, 9 c), mitunter schob das rechte Ende sich an der rechten Seite des Schlundkopfes etwas nach vorne hervor. Der Kropf war durch Bindesubstanzstränge, besonders an seinen Enden, locker befestigt. Die Form dieses Sackes war sehr variabel (vergl. Fig. 10, 11); der Hals, durch den er sich in die Speiseröhre öffnet, kurz (Fig. 10;9); die Wände dünn, die Innenseite mit netzbildenden Falten, doch mit Vorberschen der circulären; die Höhle war leer oder hatte nur einen sparsamen Inhalt gewöhnlicher Art. Der durch kurze Bånder ringsum angeheftete Blätter-oder Driisenmagen war selten fast kugelförmig, an der Vorderseite etwas abgeplattet und ein wenig ausgehöhlt; meistens war derselbe halbkugelförmig, an der Vorderseite abgeplattet und mehr oder weniger, mitunter stark ausgehöhlt (theilweise der Ráspelscheide angepasst), unten ein wenig abgeplattet (Taf. P. Fig. $8 \mathrm{~d}, 9 \mathrm{~d})$. Der Durchmesser betrug an einem der grössten Individuen $8 \mathrm{~mm}$. Die Oberflächo des Magens zeigte iberall, nach Wegnahme des mehr gelblichen SpeicheldruisenLagers, besonders deutlich an der oberen Seite, mehr oder weniger klar die dem Magen gehörenden Scheidervände durschschimmern (Fig. 8 d, 9 d). Unten an der Vorderseite öffnet sich, wie erwähnt, die Speiseröhre; von der oberen Seite geht links und hinten ein kurzes, ziemlich weites Rohr (Fig. Se, 9 e) als die Fortsetzung an den eigentlichen Magen (T'af. P. Fig. 10a) ab. Durchselınitte dieses Magens zeigen die Wände desselben sehr dick und von eigenthümlich-blätterigem ('Taf. O. Fig. 7) Baue; seine (leere) Höhle abgeplattet, klein, sich nach oben in die erwähnte ziemlich weite Röhre (Taf. P. Fig. 8 e, 9e) fortsetzend, die an der oberen Seite stärker ausgeprägt, schrïg nach rechts aufsteigt, in die obere Eingerveidemasse eintritt und von Lebermasse eingeschlossen sich in den eigentlichen Magen öffnet. Die dicken Wände dieses Magens bestehen aus dichtstehenden, von der äusseren an die innere Wand sich erstreckenden Blättern (Fig. 7), die in Anzahl an verschiedenen Individuen ziemlich wechseln, (oben) kaum mehr als 17-19 betragen. Die Blätter sind ziemlich dick, nur an der. inneren Anheftung mitunter dinner; an beiden Seiten mit mehr oder weniger hervortretenden, mit mehr und weniger dicht gedrängten, hauptsächlich der Länge nach und schräg gehenden Falten bedeckt, welche in der verschiedensten Weise getheilt, gebogen und gewunden sind (Taf. O. Fig. 8). Die Falten scheinen von drüsigem Baue zu sein (Fig. 9). Ihr Secret sammelt sich wahrscheinlich zwischen den Blättern 
und ergiesst sich nach und nach in die kleine Höhle des Nagens. Die (innere) Wand des Magens selbst schien fast eben oder nur mit feinen Längsfalten versehen, mit zahlreichen Oeffnungen und Spalten ausgestattet zu sein. Der schräg nach oben und rechts vom Magen aufsteigende Gang (bei den grössten Individuen bis $5 \mathrm{~mm}$ lang) ziemlich weit; mit feinen Längsfalten der Innenseite (Taf. P. Fig. Se, 9e); er öffnet sich in den untersten Theil des eigentlichen Magens. Dieser letztere ist, wie erwähnt, hinten an der Unterseite der letzten Windung der hinteren Eingeweidemasse leicht bemerkbar. Er ist ziemlich geräumig, fast kugel- oder halbkugelförmig ('Taf. P. Fig. 10 e) oder mehr länglich; an zwei grösseren Individuen 5,5-6 $\mathrm{mm}$ an Länge bei einem Durchmesser von 3,5-4 mm messend; er ist von Lebermasse meistens ringsum umgeben, seltener beruhrt er rechts und oben unmittelbar die Geschlechtsdruise. Seine hintere Wand ist eben und dünner, fast ebenso die untere; dagegen der Boden rechts, theilweise die obere und hauptsiichlich die vordere Wand dicker, von concentrischen Falten durchzogen, die von anderen ausstrahlenden grekreuzt wurden ('Taf. P. Fig. 10), welche mitunter besonders stark waren. An der unteren Wand findet sich immer eine runde weite Crypte, die rechts zwei Gallenoffnungen zeigt und sich nach unten und links noch in den Gang (Fig. 10a) fortsetzt, welcher in den Blättermagen einmündet; meistens kommt aber noch eine besondere Gallenoffnung (Fig. 10) vor. Der Magen setzt sich ïber eine leichte Einschnürung (Fig. 10) nach oben und links in den Darm fort, welcher im Pylorus-Theile sich (Fig. 10) weiter allmählig verschmälert, indem er, auch aussen durchschimmernd, längs der hinteren unteren Seite der grossen Eingeweidewindung verläuft, immer von Lebermasse nach vorne und unten begrenzt (Taf. M. Fig. 5 c; Taf. O.Fig. 12 b; Taf. P. Fig.10d). Der Darm bildet dann sein erstes Knie zwischen der Blätterdrüse und der Niere (Taf. M. Fig. 5 c), schwingt dann an die vordere (obere) Seite der Leber hinüber und verlïuft ('Taf. P. Fig. 11a), erst nach oben und hinten aufsteigend, in einer oder zwei Biegungen an dem Vorderrand der Leber, immer in einer mehr oder weniger tiefen Furche derselben eingesenkt (Fig. 10, 11). Der Darm bildet sein zweites Kinie, setzt sich längs der rechten Seite der oberen Wand der Kiemenhöhle fort, und öffnet sich etwa in der Mitte der Länge dieser Parthie (Fig. 11 b). Meistens schimmert dieses Rectum mit dem Anus (Taf. M. Fig. 7 b, 8 b) deutlich durch die obere Wand der Kiemenhöhle hindurch (Taf. M. Fig. 5, 6); mitunter bis zu einer Weite von $3 \mathrm{~mm}$ durch kugelförmige, durch gegenseitigen Druck oft facettirte, gelblichweisse, etwas bröckelige Körper erweitert, die einen Durchmesser von 1,5-3 mm hatten und aus den unten zu erwähnenden Partikeln bestandeu. Seltener schimmert der Darm in seiner ganzen Länge, wegen seines weisslichen Inhalts hindurch.

Die Verdaungshöhle zeigt fast immer, besonders die Speiseröhre und der eigentliche Magen, einen weisslichen, meistens zerbröckelten Inhalt; mitunter kamen als solcher auch grössere kugelförmige oder kurz-wurstförmige, weissliche Körper von eincr Länge bis 9 und einem Durchmesser bis $4 \mathrm{~mm}$ vor. Diese wie der ubrige Inhalt zeigte immer eine Unmasse von drusenartigen krystallinischen Körpern (von einem Diam. bis 
0,05 mm) (T'af. M. Fig. 22-24) und grössere, längliche (bis 0,25 mm lange), gelbliche Körper (Fig. 25), die vielleicht von einer Alcyonide herstammten. Seltener war der Inhalt unbestimmbare thierische Masse mit feinen Algen, Diatomeen, Polythalamien und Cnidae vermischt. ${ }^{1}$ )

Die Leber (Taf. P. Fig. 10, 11) von melir oder weniger dunkelschwarzer oder (besonders bei den Weibchen) dunkelgrauer Farbe; fast an Breite und Höhe der letzten Windung der Schale entsprechend. Die vordere Hälfte der oberen Seite (Taf. M. Fig. 5, 6) fast ganz von der Blåtterdrise bedeckt, die auch den Vorderrand mit Ausnahme des unteren Theils bedeckt, welcher am Hintergrunde der Kiemenhöhle erscheint (Taf. Q. Fig. 15): hinten verlingert die Leber sich nur ein wenig in die vorletzte Windung der Schale hinein (Taf. M. Fig. 27), wo sie verschmächtigt gerundet endigt, mit der Geschlechtsdrüse innig. verbunden, die sich noch eine Strecke ïber die Oberfliiche des hinteren Theils der Leber fortsetzt. Der Hinterrand der Leber trägt eine tiefe, breite Furche für den Magen und für die erste Strecke des Darmes ('l'af. M. Fig. 5; Taf. P. Fig. 10), und ist mit diesen Organen innig verbunden; die vordere-obere Seite zeigt eine etwas weniger breite Furche fiir die Darmschlinge (Taf. P. Fig. 11). Die ganze freie Fläche der Leber zeigt zahlreiche oberflächliche Venen und spaltenartige Vertiefungen für Fortsetzungen der letzteren. Die Leber sonst in gewöhnlicher Weise aus Läppchen zusammengesetzt und vom gewöhnlichen Baue. - Ihr Secret ergiesst die Leber, wie oben erwähnt, dureh 2-3 Gallenöffinungen (Taf. P. Fig. 10) in den Magen und in die Pylorus-Parthie des Darmes; die kurzen Gallengänge komnten, sich wieder und wieder in kurze Zweige theilend, eine Strecke in die Leber hinein verfolgt werden.

Das Pericardium liegt, wie erwälnt, links (Taf. M. Fig. 5 b) am Rande der letzten Windung, wo die obere in die untere Fläche umbiegt, ausserhalb der linken Muskelfacette und der Niere, wo das Herz auch meistens mehr oder weniger deutlich hindurchsehimmert. An der Oberfliche prïsentirt sich das Organ von etwa derselben Grösse wie die Niere, in den gro̊ssten Individuen von einer Länge von $8,5-9,5 \mathrm{~mm}$ bei einer Höhe und Breite bis $4,5-5 \mathrm{~mm}$; die beiden Enden des Herzbeutels sind etwas verschmälert (Taf. N. Fig. 24; Taf. O. Fig. 12 aa). Die Imnenseite desselben glatt; rechts schimmert (Fig. 12) die Niere hindurch, und hier zeigt sich nach vorne oder seltener nach hinten dic (T'af. N. Fig. 24b) selten recht deutliche pericardio-renale Pore. Das (Fig. 24) H erz gross; der braungraue Ventrikel (Taf. N. Fig. 24; Taf. O. Fig. 13 e), wenn schlaff, 4-4,5 mm lang; die Atrialklappen nicht klein, auch nach unten in die Vorkammer vorspringend (T'af. N. Fig. 25; Taf. O. Fig. 13 b), mit ausgeprägten Querfasern; die Aortaklappen (Taf. N. Fig. 26) gross, selbst bis fast $2 \mathrm{~mm}$ lang bei einer Höho bis beiläufig $1 \mathrm{~mm}$. Der ganz (Fig. 21) kurze Aorta-Stamm in der Ecke, dicht an dem ersten Knie des Darmes sich in die Aorta ant. s. cephalica und die Aorta post. s. hepatica theilend. Die Aorta cephalica tritt in die untere Eingeweidehöhle hinein, geht schräg nach rechts und unten zwischen

1) Bei einem Individuum hatte ein harter, kalkartiger Körper von $2,2 \mathrm{~mm}$ Diam. den Darm durchbrochen und fand sich ausserhalb desselben hinter der rechten Miuskelfacette eingekapselt. 
dem Drüsenmagen und dem zweiten Kropf, dem Drüsenmagen einen Ast schickend, geht unter dem Kropfe durch den grossen Nervenring (mit der Speiserölre), giebt dem Penis einen Ast, ferner eine starke, vor den pedalen Ganglien absteigende Art. pediaea, die durch die vordere Spalte am Boden der Eingeveidehöhle eintritt, und verläuft an den unteren Theil des Hinterendes des Schlundkopfes, wo sie sich dicht an der Wurzel der Raspelscheide theilt. Der eine kiirzere Ast steigt an der linken Seite der Schlinge der Raspelscheide empor, sich wicder in einen an die Raspelpulpe gehenden und in einen anderen. nach vorme an die obere Seite des Schlundkopfes verlaufenden Zweig theilend. Der andere, längere Ast geht nach rorne und gabelt sich in der Gegend des hinteren Randes der $\mathrm{Im}$. Iaterales inff. Die beiden Zweige gehen divergirend nach vorne unterhalb der Mm. bulbo-rostrales, schrïg iiber den Mr. circularis an die Mundröhre; die an der Gabelungsstelle entspringende Art. lingvalis scheint sich in die Zungenhöhle zu öffnen. Die A orta hepatica scheint gleich einen längs der vorderen Strecke des Darmes nach hinten aufsteigenden Ast abzugeben und übrigens von dem ersten Darmknie an der hinteren Strecke des Darmes zu folgen, indem sie der Leber und den Geschlechtsorganen mehrere Zweige giebt. - Das ans den Theilen, die von der Aorta cephalica versorgt werden, zuriickkehreude Blut (Haemolymphe), das ans dem Kopf ${ }^{1}$ ) mit den Tentakeln, aus der vorderen Strecke der. Terdauungsorgane und aus dem Fusse, sammelt sich in die vordere Eingeweidehöhle und umspült die in derselben liegenden Organe; am Boden der Höhle finden sich mehrere, besonders (Taf. M. Fig. 28) eine grössere Oeffinung, durch welche das in den Fuss eintretende Blut zuriekkchrt. Hinten steht dieser grosse untere Visceral-Blutraum wahrscheinlich in der Gegend des Durelitretens des BlättermagenRohres mit dem oberen (oder einem der oberen) Visceral-Blutraume in Verbindung. Diese grosse untere Lacume oder Blutraum ist durch das oben erwähnte, hinter dem Centralnervensystem und dem zweiten Kropfe stehende, mehr oder weniger senkreehte, und verschiedentlich gebogene Dissepiment wieder in eine vordere und eine hintere $\Lambda \mathrm{b}$ theilung geschieden. In diesen unteren Blutraum scheint theilweise noch die Haemolymphe aus dem grossen circumpallialen Sinus einzutreten, welcher, hinten an der Unterseite des Darmes und des Magens verlaufend, das Blut aus dem ganzen Mantel und aus den lacunären Simus der oberen Eingeweidemasse empfängt. Der ziemlich weite circumpalliale Sinus zeigt iiberall an seiner. Wand Oeffnungen, durch die sich das Blut aus dem Mantel in denselben ergiesst. ${ }^{2}$ ) In denselben entleert sich ferner, an der Wurzel der Kieme, ein Venenstamm, welcher in zwei getheilt ron der Gegend der Niere herkommt und innerhalb der (linken) Muskelfacette längs des äusseren und vorderen Randes des Geruchsorgans nach vorne verläuft. Diese Venenstämme stehen wahrscheinlich

1) Durch die ganze Breite des Kopfes erstreckt sich oben ein niedriger, ron kurzen unregelmässigen Trabekeln durchzogener lacunärer Hohlraum, oder ein medianer und mehrere'laterale.

2) Auf Durchschnitten des Sipho zeigen sich, etwas uach oben zu, zwei Sammelcanäle, der Länge nach gehend; in den Tentakeln finden sich zwei ähnliche. 
nach hinten mit denen der Leber und der Geschlechtsorgane in Verbindung. In den Sinus circumpallialis entleert sich ferner ein lïngs des ganzen inneren Randes der Spirale absteigendes Gefiss oder rohrartige Lacune, die unten innerhalb des rechten Schalenmuskels, bei dem Weibchen zwisehen diesem und der Schleimdruse verlïuft und weiter nach unten längs der Vagina. Am vorderen Grunde der Kieme ist dann das Vas afferens branchiae ${ }^{\prime}$ (Art. branchialis) gebildet, welches, längs des Kiemensichel-Randes verlaufend, jedem Kiemenblatte einen, dem einen Rande entlang bis an die Spitze aufsteigenden Ast schickt. Långs des entgegenstehenden Randes der Kiemenblätter steigt das riickfuihrendé Gefäss an die Kiemensichel herab (Taf. Q. Fig. 11); allmählig bildet sich dann das schliesslich in die Vorkammer des Herzens einmündende Vas efferens branchiae (Vena branchialis).

Die Ki emenhöhle, wie oben eriähnt, niedrig, aber tief, rechts ein wenig tiefer als links (Taf. M. Fig. 5, 6); liings des rechten Randes verläuft der Darm (und bei dem Weibchen die Vagina), am linken Ende findet sich der Herzbeutel. Der schwach gewölbte untere Boden von der Fortsetzung des Genickes nach hinten gebildet; an dem etwas stïrker gewölbten Dache die grosse Kieme und zur linken Seite derselben hinten die die Niere, vorne das Geruchsorgan; der hintere Boden der Höhle vom etwas abgeplatteten Vorderrande (Taf. O. Fig. 12 d) der Blätterdrüse, unten vom mehr gerundeten Vorderrande (Fig. 12 c) der Leber gebildet; am linken Ende der Bliitterdruise und der Leber, wo diese an die Niere und den Herzbentel stossen, die branchiale (äussere) Nierenöffnung (Fig. 12). Die Kiemenspalte (mit den Schalenmuskeln) an der rechten Seite weiter nach ('Tat. M. Fig. 5, 6) hinten tretend. - Die obere Wand der Kiemenhöhle ist in zwei Hälften getheilt, von denen die vordere ein wenig kleiner als die hintere ist, durch eine mit (T'af. Q. Fig. 2 aa) dem Hinterrande, fast parallele, wenig, besonders wenig an dem vorderen (rechten) Ende, vorspringende (Kiemen-) Sichel begrenzt, von deren freienı Rande die Kiemenblätter parallel nach unten und hinten ausgehen; links wird die Sichel (Fig. 2e) etwas höher und breiter, schliesst sich an den linken aufsteigenden Schalenmuskel an und geht in die untere Wand des Herzbeutels über. Während die Kieme mit der Sichel fast überall dureh das Dach der Kiemenhöhle durchschimmert, ist dieser linke Theil (Taf. M. Fig. 5, 6) von oben durch die Niere ganz verdeckt. Die Kieme ist also gross; die Chorda des Bogens in den zwei grössten Individuen 15-16 mm betragend, die Höhe der Blätter von etwa 0,12 bis $9-10,5 \mathrm{~mm}$ steigend. Die Kieme hat ihre grösste Höhe etwa an oder ein wenig vor der Mitte; die Höhe sinkt dann gegen die Enden zu, wo sie ganz unbedeutend ist. Die Zahl der Blätter in der Kieme betrug bei den grössten Individuen etwa 160-200. Die (Taf. P. Fig. 13; Taf. Q. Fig. 3) Kiemenblätter schwertförmig, etwas zugespitzt, am Ende gerundet; etwas gebogen; mit vorderem convexen,

1) Vergl. Kollacans, der Kreislauf des Blutes bei den Lamellibranchien, den Aplysien und den Cephalopoden. Zeitschrift für wissensch. Zool. XVI. 1875. pag. 91.

Semper, Philippinen. II, II (Bergh, Ergänzungsheft III. Marseniaden l). 
hinterem conearen Rande; der Grund der Blätter mit dem Kiiemendache verwachsen (Taf. P. Fig. 13), und die Länge dieser angehefteten Strecke relativ grösser an den kleineren Blättern (Fig. 13; Fig. 3). Diese, die Kiemenblätter anheftenden Fältchen bilden mit ihrem hinteren Ende eine auch mit dem Hinterrande der Kiemenhöhle parallele, durch das Kiemendach durchschimmernde (wie aus Punkten bestehende) feine Linie (Taf. M. Fig. 5, 6). Der hintere Rand der Kiemenbliitter ist etwas dicker und etwas steifer, ist ron einem hellen, durch die ganze Höhe des Blattes aufsteigenden Strang gestützt, der structurlos oder höchstens ron feinstreifigem Character ist. Die Seiten der Kiemenblätter wie aus zwei Abtheilungen bestehend, einer hinteren glatten und einer vorderen mit dichtstehenden ${ }^{1}$ ) Fiiltchen und Blitterchen (Taf. Q. Fig. 3). Die glatte Strecke ist mit zahlreichen sternartigen, unbedeutend vorspringenden, bräunlich-griiulichen Punkten bedeckt, die aus kleinen Zellen und von ausstrahlenden Fäden und feinsten Fältchen gebildet sind; die Falten und der hintere Rand der Blätter auch bräunlichgrau. Längs der Ränder der Blätter verlaiuft je ein Gefiiss, das sich respective in ein rolhrartiges und in ein spaltenartiges grösseres am Grunde des Blattes und in der Anheftungsleiste vorhandenes Gefäss entleert ('I'af. P. Fig. 13).

Nach Wegnahme der Schale zeigt sich (Taf. M. Fig. 5, 6), wie schon oben erwähnt, die mehr oder weniger gelblichweisse oder gelbliche Niere deutlich durch die Decke der Kiemenhöhle, an welche sie angeheftet ist, durchschimmern; sie liegt hinter dem Geruchsorgane, an der rechten Seite des Pericardiums. Sie ist von ovaler (Fig. 6) oder dreickkiger (Fig. 5) Form, bei den grössten Individuen ron 8-9 mm Länge bei einer Breite bis 5,5-6 $\mathrm{mm}$; die Dicke ist ziemlich geringe, nur bis etwa $2,5-3 \mathrm{~mm}$; sie erscheint, von oben betrachtet, als aus einer Menge ron ziemlich dichtstehenden (Taf. P. Fig. 12 b), mitunter auch ficherartig oder federartig (Fig. 5) geordneten Laippchen zusammengesetzt. An der Unterseite wird die Niere in ihrer hinteren Parthie vollständig rom linken-hinteren Ende der Kieme bedeckt, während die vordere Parthie durch die Innenseite des Herzbeutels (nach Eröfthung desselben) durchschimmert (Taf. O. Fig. 12 a b). Die am hinteren Ende des Organs liegende feine spaltenförmige oder rundliche branchiale oder äussere Nierenspalte (Taf. O. Fig. 12), vom linken Ende der Kieme bedeckt, ̈̈ffnet sich in die Kiemenhöhle. In das Pericardium öffnet sich (Taf. N. Fig. 24b) die Niere durch die feine reno-pericardiale Pore $\left.{ }^{2}\right)$. Die Liappchen der Niere hangen ziemlich fest an den dieselbe umfassenden Wänden; an der Oberfliche verlaufen mehrere, auch oben durchschimmernde Gefïsse; längs einer Strecke der unteren Wand

1) Williass (On the mechanism of aquatic respir. -- in invertebr. anim. Ann. maz. n. h. 2 S. XVII. 1856. pag. 33. pl. V. Fig. 3) hat schon in der Littorina littorea Fültchen an den Seiten der Kiemenblätter nachgewiesen.

$\because$ SPENGer hat schon (Die Geruchsorgane und das Nervensystem der Mollusken. Zeitschr. f. wissenseh. Zoologie. XXV. 1S81. pag. 348 Note 3) bei rerschiedenen Prosobranchiern (Dolium, Cassis, Cassidaria, Murex) einen grossen Renopericardialporus gefunden, so wie auch Béla Haller (Zur Kenntn. d. Muriciden. I. 1882. [Denkschr. d. mathem. naturwiss. Classe der k. k. Acad. d. Wissensch. XLV] Taf. I. Fig. anm) an dem MLurex trunculus einen solchen gesehen hat. 
verlaufen die Kiemengefässe. Eine eigentliche Höhle innerhalb der wie gewölnnlich schwammigen Niere scheint nur in der Nähe der Nierenspalte vorzukommen, aber mehrere rohrartige Hohlri̊ume erstrecken sich durch die Länge derselben. Der Bau der Niere schien der gewöhnliche zu sein. - Das Secret der Niere scheint in der Kiemenhöhle sich mit dem der Blätterdrüse zu vermischen (s. unten).

Die gräuliche, gelblichgräuliche oder meistens schwach grünlichgraue Bliitterdriise, die nach Wegnahme der Schale (Taf. M. Fig. 5, 6) sich ror der Geschlechtsdrise und der Leber, hinter der Kieme und der Niere präisentirt, variirt etwas an Grüsse, hauptsächlich je nach der Grösse der Geschlechtsdriise, und ist im Ganzen vielleicht etwas (Fig. 5) grösser bei dem Männchen. Sie stösst bei dem Weibehen reehts an die Schleim- und Eiweissdrise, bei dem Niinnehen an das Rectum; links grenzt sie an dic Leber, an die vordere Strecke des Darms und ganz links an das erste Darmknie; die Drise ruht mit ihrer Unterfliche an der Leber, von welcher sie sich in Zusammenhang und ziemlich leieht lüsen lässt. Die Drüse ist beim Weibchen weniger breit als beim Männchen; sie ist einigermaassen nierenförmig (Taf. P. Fig. 12 a), beim Weibchen der Form nach lïngs oder schräg (Taf. M. Fig. 6), beim Männchen quer liegend (Fig. 5). Bei den grössten (männlichen) Lndividuen betrug die Länge etwa $14 \mathrm{~mm}$ bei einer Breite bis 7 und ciner Dicke bis $3 \mathrm{~mm}$. Die Driise besteht, wie besonders an der oberen Fläche deutlich, aus der Länge nach gehenden (Fig. 5, 6; Fig. 12), melıx oder weniger deutlich ausgeprägt-einfach-federförmigen Lappen, die bis an den Vorderrand reichen, und aus kleineren, die sich am Hinterrande zwischen den Grund der anderen einschieben. Das Organ nimmt von hinten nach vorn an Dicke zu und bildet mit seinem ziemlich dicken Vorderrand, wie es sich beim Spaltèn ('T'af. O. Fig. 12 d) der Kiemenhöhle zeigt, den oberen Theil des niedrigen hinteren Bodens (Fundus) derselben; es ruht auch hier an dem (schwarzen) Vorderrand der Leber (Fig. 12c), von welchem die Drise mitunter dureh eine lange feine Spalte geschieden scheint, die durch die dieselbe schliessende Fortsetzung der Wrand der Kiemenhöhle durchschimmert. (In dieser selbigen Wand findet sich vielleicht eine ziemlich feine spaltenartige Oeffnung (vergl. Taf. Q. Fig. 15), die in den erwaihnten kleinen Raum zwischen dem Vorderende der Leber und der Blätterdruise leitet.) Die Driise scheint fernerhin sich mit der Niere gemeinschaftlich durch die oben erwaihnte branchiale Oeftnung (Taf. O. Fig. 12) in die Kiemenhöhle zu öffnen. In der Kiemenhöhle, besonders ganz hinten, zwischen der Decke der Kiemenhöhle und der Kieme und an den Kiemenblättern klebend, zeigen sich immer gelblichweisse und weisse, mehr oder weniger trockene, immer aber sehr spröde, kleinere und grössere, ziemlich dünne Schuppchen; mitunter quellen solche schon bei Druck an der Decke der Kiemenhöhle aus der Kiemenspalte reichlich hervor; mitunter schimmern sie, massenweise am Boden (Fundus) der Kiemenhöhle angesammelt, als ein mehr oder weniger breiter, bogenartiger Streifen schon von oben hindurch. Die mikrochemische Untersuchung zeigte diese Massen aus Mucin, einem Albuminstoff und aus alkalischen Erdarten (besonders Kalk) bestehend; Xanthin schien 
auch vorzukommen, aber keine Spur von Murexid-Reaction (waren die harnsauren Salze im Alcohol aufgelöst und weggeschwemmt?). Die mikroskopische Untersuchung erwies diese Massen als amorph und granulirt, ohne Krystalle. ${ }^{1}$ )

Die Geschlechtsdrüse nimmt die (Taf. M. Fig. 5, 6; Taf. P. Fig. 14a) ganze obere Spitze der oberen Eingeweidemasse und theilweise noch die hintere Parthie der letzten Windung ein; die Grösse ist etwas variabel, vielleicht im Ganzen ein wenig geringer beim Männchen; mitunter erstreckt sich die Drüse, die Leber ganz deckend, bis an den Magen und den Darm. Sie ist von gelblicher, seltener röthlichgelber, bråunlicher oder selbst (besonders beim Männchen) von brỉunlichgrauer oder fast gräulicher Farbe; der oberste (spirale) Theil fast immer heller (mitunter röthlichgelb), als der übrige. Meistens ist die Drỉse an der Oberfläche ganz zusammenhängend, unten und hinten von der schwarzen Leber eingefasst (Fig. 5, 6); mitunter (besonders bei dem Weibchen) schiebt sich die letztere von der rechten Seite her in die Druise hinein (Fig. 5, 6), mitunter ist dieses Verhältniss weiter entwickelt bis zu vollståndiger Trennung der Drüse in zwei Theile (Fig. 6). Als ein Lager von $1,5-3,5 \mathrm{~mm}$ Dicke bekleidet die Drüse überall die Leber. und ruht an derselben in der Weise, dass an Querschnitten der Spitze (Spira) näher bei oder an der Wurzel derselben die Leber von der Geschlechtsdrủse eingefasst erscheint (Taf. M. Fig. 27). Die Oberfläche der Driise zeigt (Fig. 5, 6, 26) ganz feine, mitunter facettenartig abgeplattete Körnchen, die oberen Enden der Follikel der Drüse. Genauer untersucht zeigt sich dieselbe in (Taf. O. Fig. 14, 15) gewöhnlicher Weise gebaut, aus langgestreckten, gruppenweise vereinigten Follikeln gebildet, die im T'estis vielleicht ein wenig länger als im Ovarium sind. Im Ovarium kamen meistens grosse oogene Zellen vor, im Testis Zoospermien gewöhnlicher Art. - In den zwei Geschlechtern verhalten sich die iibrigen Theile des Geschlechtsapparats verschieden.

Der an der Spiralseite der äussersteu Windung des Thieres (unterhalb und vor dem Ovarium) durchschimmernde Eierstocksgang entspringt aus der Drüse mit wenigen, sich schnell vereinigenden Gängen (Taf. P. Fig. 14b), ist ziemlich kurz (in den grossen Individuen bis $2,5 \mathrm{~mm}$ lang) und geht etwas dicker in die Schleim- und Eiweissdrise iiber. Diese letztere ist abgeplattet, langgestreckt, bei den grossen Individuen bis $12 \mathrm{~mm}$ lang, bei einer Breite oben bis $6 \mathrm{~mm}$ und einer Dicke bis 1,5 mm; das Organ ist von gelblicher Farbe, in der rechten Hälfte (so wie mitunter auch am Hinterende und selbst längs des linken Randes) meistens stärker gelblich, in der übrigen Strecke heller und mitunter gräulichweiss; die Oberfläche äusserst fein granulirt. Das Organ liegt an der Oberfläche der hinteren Eingeweidemasse hinter und innerhalb der Kiemenhöhle in der Nähe des inneren Randes derselben; längs seines linken Randes (Taf. M.

1) Es waltet noch viel Unsicheres in der morphologischen und physiologischen Deutung der grossen Excretionsorgane der Gastraeopoden ob. Bei Cyclostoma elegans konnte BARFurTH (Die Excretionsorgane von Cyclostoma elegans. Zool. Anz. VII. 1854. 178. pag. 474) in den Producten der (morphologisch) eigentlichen Niere keine Harnsäure nachweisen, dagegen in denen der sogenannten Concrementdrüse. 
Fig. 6) von der gräulichen Blïtterdruise begleitet, welche auch mit einem dimen Lager einen grossen oder den grössten Theil der Unterseite des Organs bekleidet, welches aber sich leicht von jenem lösen lässt. Das obere Ende des Organs (Fig. 6; Fig. 14 c) ist abgerundet, rechts sich in eine kurze und breite Verlängerung fortsetzend, welche in den Eicrstocksgang übergeht; nach unten verschmälert sich die Schleimdruise ein wenig und geht allmählig in die Vagina iiber. Oberhalb des Eierstocksganges mindet mitunter ein dünner Gang in die Schleim- und Eiweissdruise ein (Taf. O. Fig. 16 bb), welcher dem. Rande der Druise folgt und eine ganze Reihe von Samenblasen aufnimmt, wenn nämlich dieselben nicht unmittelbar in die Drüse einmünden. Die Wände der sich quer durch die ganze Länge der Schleimdrüse erstreckenden flachen Höhle sind dick, perpendiculär streifig (Taf. O. Fig. 18), nur unten etwas dünner; an der Wand der Höhle ist die Grenze zwischen der dunkleren und der lelleren Parthie auch angedeutet, mitunter durch eine Längsfurche. Die streifige Beschaffenheit riihrt von den (bis fast 0,7 mm) langen, starken, einfachen oder getheilten, auf die Höhle senkrecht stehenden Drüsen her (Taf. O. Fig. 19), welche schwach gelblich sind, etwas stiirker in den Randparthien, und aus um die Axe schräg und dicht gestellten langgestreckten Zellen zusammengesetzt (Fig. 19; Taf. P. Fig. 16). Die Höhle war immer leer. Jene, meistens in Vertiefungen der Schleimdrüse ruhenden Samenblasen treten unter der Loupe als ein schwarzer Bogen am hinteren Ende des Uterus hervor (Taf. M. Fig. 6), aus (11-18) kleinen, runden (Taf. O. Fig. 16 aa) oder länglichen ('Taf. P. Fig. 14 b, 15) Säckchen bestehend, die bei den grössten Individuen eine Länge bis $3,5 \mathrm{~mm}$ erreichten, und in einer einzelnen oder durch Verschiebung doppelten (vergl. Taf. Q. Fig. 17) Reihe gestellt sind. Die Säckchen haben eine kohlschwarze Hülle (Táf. P. Fig. 15), eine Auskleidung von schönem Plattenepithel und einen gelblichen oder rothgelblichen Inhalt, aus Zoospermien gebildet; wenn die Blasen stark ausgespannt sind, zeigt sich (Fig. 16) der Rand kohlschwarz, und der Inhalt sehimmert gelblich hindurch. Die an dem unteren Ende der Schleimdriise ('I'af. P. Fig. 14e) abgehende Vagina ist durch kurze Bindesubstanz (Taf. M. Fig. 7 a, 8 a) innig an das Rectum geheftet, gerade laufend oder etwas gebogen, ausgestreckt bei den grössten Individuen bis $9 \mathrm{~mm}$ lang bei einem Durchmesser bis $1 \mathrm{~mm}$; sie ist cylindrisch, nach unten meistens etwas verschmälert, in der untersten Strecke bis an die Vulva stark (bis zu einem Diam. von $2,75 \mathrm{~mm}$ ) erweitert; diese letztere Strecke hat starke Längsfalten und ist von einer gelblichen Cuticula überzogen, die sich nach oben allmählig verdünnt; die Längsmuskulatur der Vagina ist vortretend stark. Oberhalb des Endes der Vagina ('Taf. P. Fig. 14f) bildet dieselbe ein kurzes dickes Diverticulum nach vorue, auch mit starken Falten der Innenseite.

Der S a menleiter entspringt (vergl. Tat. R. Fig. 8a), in älnnlicher Weise wie der Eierstocksgang aus dem Eierstock, aus dem Hoden, wird dicker und bildet an der abgeplatteten Columellarseite der letzten Windung der Lingeweidemasse ein grosses, abgeplattetes Knäuel, das (vergl. Fig. 8 b) bei den grössten Individuen eine Länge bis 8 , 
bei einer Breite bis $5-5,5$ und einer Dicke (oben) bis $3 \mathrm{~mm}$ hatte; das Knäuel zeigt mehr oder weniger deutlich eine Zusammensetzung aus zwei Abtheilungen, von welchen die kleinere vordere von den Windungen eines langen rohrförmigen Divertikels gebildet wird, das sich in den Samenleiter dicht vor seinem Austreten aus der hinteren Eingeweidemasse öffnet (vergl. Fig. 8c). Die unten aus dem Knäuel austretende Fortsetzung des Samenleiters etwas dicker, von einem Durchmesser bis etwa $0,75 \mathrm{~mm}$, und durch den iibrigen Verlauf fast dieselbe Dicke bewahrend. Entwirrt maass jener gewundene Theil des Samenleiters und seines Divertikels wenigstens etwa $35 \mathrm{Cm}$. Der Samenleiter steigt dann hinter dem rechten Schalenmuskel hinab, indem er die obere Eingeweidemasse verlässt, kreuzt den letzteren Muskel an seiner Imnenseite und wird am Vorderrande desselben von dem der unteren Eingeweidehöhle zunächst liegenden diunnen Quermuskellager bedeckt. Unter diesem verläuft der Gang nun schlangenartig längs den starken Muskelbiindeln der Körperseiten an den Penis, um (Taf. O. Fig. 2 c) in denselben einzutreten; stark geschlängelt und lose befestigt setzt sich der Samenleiter, von einem Nerven begleitet, durch eimen besonderen (fast bis an die Spitze ausgeprägten) Canal (T'af. O. Fig. 2 b) bis an das Ende des Penis fort, wo er immer noch aus einer ovalen Vertiefung (bei den grössten Individuen bis $1,5-2,5 \mathrm{~mm}$ ) als ein langgestreckter spitzer Kegel (Fig. $2 \mathrm{~b}^{\prime}$ ) mit Oeffnung an der Spitze hervorragt. Ausgestreckt maass der im Penis eingeschlossene 'Theil des Samenleiters etwa $5 \mathrm{Cm}$ bei einem fast durchgehenden Diam. von $0,5-1 \mathrm{~mm}$. Der maichtige Penis bildet ein stark zusammengedriicktes, der Kante nach gebogenes, stark sichelförmiges (Fig. 2b) Organ, biconvex oder mit convexer Aussen- und fast planer Innenseite (Taf. N. Fig. 30), fast ron durchgehends derselben Breite (Höhe), nur am Grunde mitunter etwas weniger stark (Fig. 2); aus der Vertiefung an der Spitze (Taf. N. Fig. 29) ragt, wie erwähnt, das weissliche Ende des Samenleiters kegelfürmig hervor, oder (T'af. N. Fig. 28) der Penis setzt sich, wem vollstindig ausgestreckt, an der Unterseite in die Spitze fort, während die Oberseite ein Halbdach iiber diese bildet. Ausgrestreckt maass der Penis der grössten Individuen etwa $2 \mathrm{Cm}$ bei einer Höhe bis $4-5 \mathrm{~mm}$ und einer Dicke bis $2 \mathrm{~mm}$. An Durchschnitten des Penis (Fig. 30) zeigen sich ausser dem Samenleiter-Canal ein Nerv und mehrere Gefiiss-Lichtungen, darunter zwei besonders grosse.

2. Ch. touganus (Quoy et Gain.), var. Berghi, Desh.

H a b. M. africano-indicum (Bourbon).

'Taf. Q. Fig. 6.

Voin dieser Form hat Prof. Möblus am 24. September 1874 an Fouquets-Riff (Mauritius) zwei ungleich grosse, ein grösseres männliches, ein kleineres weibliches, Individuen gefischt, dic mir, in Alcohol bewahrt, freundlich zur Verfügung gestellt wurden; das cine (männliche) war schon der Schale beraubt. 
Der von Möbius dem leb"enden Thiere nach aufgenommenen Abbildung zufolge scheint dasselbe in den allgemeinen Formverhailmissen mit dem Chel. Semperi iibereinzustimmen. Den mir freundlich geliehenen wenigen Notizen von Mößuss zufolge ist der "Mantel flachwarzig"; nauf dem Rücken drei grosse dicke Papillen, von denen die vordere höher als die hintere"; "die Fühler walzenförmig, nach der Spitze etwas verdünnt; der Fuss ungefähr halb so breit wie der Körper, vorne mit kleinen Ecklappen, hinten abgerundet". Dic Farbe durchgehends tief schwarz; der Fuss etwas heller, mehr briunlichschwarz; die Spitze der Fühler mit weissen Punkten; die Augen vorn und innen von weissen Punkten umgeben.

Die in Alcohol bewahrten Individuen stimmten in den Farbverhälnissen ganz mit den oben untersuchten. Die Läng e des grösseren Individuums belief sich zu $6 \mathrm{Cm}$ bei einer Breite bis 3,5 und einer Höhe bis $2 \mathrm{Cm}$; die Länge des Fusses war 2,8 bei einer Breite bis $1,3 \mathrm{Cm}$; die Breite des seitlichen Fussgebrämes $4 \mathrm{~mm}$; die Länge des Schwanzes $11 \mathrm{~mm}$; die Länge der Tentakel $5 \mathrm{~mm}$; die Breite der (15' mm langen) Athemfurche vorn 5,5 mm; die Länge des (ausgestreckten) Penis $17 \mathrm{~mm}$ bei einer Breite bis 3. Die Länge des anderen Individums betrug $4 \mathrm{Cm}$ bei einer Breite bis 2,5 und einer Höhe bis 1,4 Cm; die Länge des Fusses 17 bei einer Breite bis $8 \mathrm{~mm}$; die Länge der 'T'entakel $4 \mathrm{~mm}$.

Die Form verhïltnisse des Thieres wie oben, nur waren die grossen Rückenknoten kaum oder nicht sichtbar (während sie an den oben untersuchten 16 Individuen [des Chel. Semperi] immer stark vortraten), und dann höchstens eine Andeutung von einem (doch giebt MöBIUs deren drei an, wihhend in seiner Figur nur einer deutlich hervortritt).

Das Centralnervensystem ganz wie oben, die Lage der Ganglien zu cinander wie bei der vorigen Art. - Die Otocysten (Fig. 6) zeigten sich unter der Loupe als glänzend kalkweisse Punkte asymmetrisch und weit von einander am Fusse befestigt, seitwïrts zwischen und unter den starken queren Trabekeln am Boden der (unteren) Körperhöhle. Die Ohrblasen waren auch jede in eine kleine scheibenartige Capsel von kernhaltiger Bindesubstanz eingesehlossen, und durch central convergirende feine Bindesubstanzfiden (vergl. Taf. Q. Fig. 9) befestigt. Die Otocysten maassen (bei dem grossen Individuum) etwa $0,28 \mathrm{~mm}$ bei einem Durchmesser des unter der Loupe glänzend weissen, unter dem Mikroskope gelben Otoliths von $0,1 \mathrm{~mm}$. Die Anzahl der Blaitter des Gieruchsorgans vielleicht grösser als bei der typischen Form (etwa 70), und die Blätter höher.

Der Schlundkopf maass bei dem grössten Individuum an Lïnge $10 \mathrm{~mm}$ bei einer Breite (hinten) bis 8 und einer Höhe bis $5 \mathrm{~mm}$; die Formverhälnisse desselben vollständig wie oben. Die Kieferplatten auch ganz ron den gewöhnlichen Formverhältnissen, aber stärker; die Luinge $4 \mathrm{~mm}$ betragend bei ciner Höhe bis 3,5 ; die Farbe dunkler, die hintere Parthie fast ganz braun, die vordere gegen den Rand hin mit grinlichem Anfluge. - Die Zunge $7 \mathrm{~mm}$ lang, von Form- und Bauverhiiltnissen ganz wie 
oben; die stark aufgerollte Raspelscheide ausgestreckt $3,5 \mathrm{Cm}$ lang bei einer fast durchgehenden Breite von $1,5 \mathrm{~mm}$, ihre Verhältnisse ganz wie oben. Die Raspel vorn etwa $2 \mathrm{~mm}$ breit, hinten nur 1,1; der kalkweisse Rand gegen die dunkel mahagonybraunen Grundstücke der Seitenzahnplatten stark abstechend, die Platten der Raspel sonst schön und kräftig horngelb. In der langen Raspelscheide wiederholten sich (durchschimmernd) dieselben Farbenverhältnisse, nur etwas gedämpft. In der Raspel kamen 9 und weiter unter dem Raspeldache 8 Zahnplattenreihen vor; in der Scheide 59 entwickelte und 10 mehr oder weniger unreife; ${ }^{1}$ ) die Gesammtzahl derselben somit 86 . In dem kleineren Individuum fanden sich an der Zunge $16(9+7)$, in der Raspelscheide $57(49+8)$ oder im Ganzen 73 Zahnplattenreihen. Die Seitenzahuplatten denen der typischen Form ganz ähnlich; nur ist der untere (vordere) Rand am inneren Ende anderer Art, nicht schräg, sondern abgestutzt und mit einer grösseren Anzahl von Dentikeln, meistens 15-17; der obere (hintere) Rand mit meistens 20-30 Dentikeln. Die medianen'Platten kaum constant vou denen der typischen Art verschieden, mitunter nur an der einen Seite gezähnelt. Die Breite der medianen Platten bis $0,56 \mathrm{~mm}$ betragend, die Länge der lateralen bis 1,1 mm. Die Farbe der Platten wie in der typischen Form, nur war das Grundstiick der Seitenzahnplatten dunkler.

Die Speiseröhre legt sich längs der linken Seite des Schlundkopfes bis an die Mundröhre hin, und ist mit einigen Bindesubstanz-Fascikeln an dieselbe befestigt; ausgestreckt etwa $17 \mathrm{~mm}$ lang bei einer Breite bis $4 \mathrm{~mm}$; fast farblos; der hinterste Theil vor dem Nervenschlundringe knieartig als erster Kropf erweitert. Der zweite Krop f von gewöhnlicher Form, auch fast farblos, $9 \mathrm{~mm}$ lang bei einer Höhe bis 3,5 mm. Der Blättermagen von gewöhnlichen Formverhälitnissen, an der Vorderseite stark ausgehöhlt, grau; die Länge $7 \mathrm{~mm}$ bei einer Breite bis 10 und einer Höhe bis $7 \mathrm{~mm}$; die Anzahl der Blätter 15; die Höhle wie gewöhnlich; das Pylorus-Rohr $5 \mathrm{~mm}$ lang. Der eigentliche Magen wie gewöhnlich; $10 \mathrm{~mm}$ lang bei einer Höhe von 6,5 und einer Breite von $6 \mathrm{~mm}$; die Imnenseite mit starken Längsfalten; die besondere Gallenöffnung nur halb so weit wie die Cardia-Oeffinung. Der Darm wie gewoohnlich. $\left.{ }^{2}\right)$ - Der Inhalt der Verdauugshöhle eine dicke, graue, weissgesprenkelte, schlammartige Masse, hauptsächlich aus, den oben erwähnten ähnlichen, Körperchen bestehend, unter welchen einzelne Diatomeen und Kieselspiclen. - Die tiefschwarze Leber wie gewöhnlich.

Die querliegende, subparallelogrammatische gräulichgelbe Niere und die bräunliche Blätterdrüse schienen sich ganz wie gewönlich zu verhalten.

Der Hoden gelbbraun, ganz wie oben; in den Liappchen wirklich, wie es schien, zwei Arten von Zoospermien. Das vom Samengange gebildete Kínảuel 8,5 mm lang

1) An den vier ältesten entwickelten Reihen nach den 10 war das Grundstück noch nicht ganz fertig, hatte noch nicht die dunkle Farbe ganz angenommen.

2) Die ubeu gegebenen Maasse beziehen sich auf das grösste der Individuen. 
bei einem Durchmesser hinten von beiliufig $7 \mathrm{~mm}$, etwas zusammengedriickt, kurz-kegelförmig, hinten breiter, vorn schmiler, wie in zwei Abtheilungen geschieden, von denen die vordere kleiner ist. Das bråunliche Knnäuel aus dicht geschlungenen. Windungen gebildet; der Gang von seinem Ursprunge ab an Dieke allmählig etwas zunelimend; dicht vor dem Austreten aus der oberen Eingerveidehöhle nimmt der Samengang auch das lange Divertikel auf, dessen Windungen die erwiihnte vordere Abtheilung des Kniuels bilden. An der Imnenseite des Schalenmuskels tritt der Samengang, wie gewölnlich, in die Seitenwand der unteren Eingeweidehöhle ein und verlïuft, geschlïngelt und etwas mehr diinnwandig, in derselben bis an den Penis. Dieser letztere zwar von gewolnlicher Form; die Spitze aber eine unmittelbare fingerförmige weisse Fortsetzung desselben bildend, von ciner Länge ron etwa 2,1 mm. - Der Eierstock nicht gross, graubraun, vom obigen Baue; in den Läppchen grosse oogene Zellen. Der Eierstockgang wie oben. Am linteren Rande der Schleimdrüse zeigen sich die in einem Bogen stehenden Samenblasen; die Anzahl derselben war aber geringer als oben, nur acht; sie waren kleiner, bis $1,5 \mathrm{~mm}$ lang; birn- und kurz-spindelförmig, gelbbraun und ohne schwarze Hülle; der Inhalt, wie gewöhnlich, Samen. Die Schleim- und Eiweissdriise $8,5 \mathrm{~mm}$ lang bei einer durehgehenden Breite von $3 \mathrm{~nm}$; die hintere Strecke, fast die Hälfte, gelblich, der Ueberrest bräunlich; die Verhältnisse und der Bau des Organs wie oben. Die Vagina fast $4 \mathrm{~mm}$ lang, stark; unten auch das gewöhnliche, aber nach hinten und innen sehende, etiva $1,4 \mathrm{~mm}$ holıe Divertikel.

Der anatomischen Untersuchung nach konnte es fast scheinen, als ob hier eine selbststïndige Art vorliege. Die Zahuplatten sind etwas anderer Form, so wie vielleicht auch andere Unterschiede da sind, was aber bei den beschränkten Materiale und der nicht geringen Latitude der Variabilität der Organe sich nicht bestimmen liess. Auch im Aeusseren, in der Beschaffenheit der Ruickenknoten, und in der Schale scheinen Verschiedenheiten nachgewiesen werden zu können. 



\section{DIE}

\section{A R S E N I A D E N.}

EINE

SYSTEMATISCHE MIONOGRAPHIE

VUx

\section{$D^{R}$ RUD. BERGH.}

C. W. KREIDEL'S VERLAG. 1887. 



\section{II.}

\section{Marsenia, LEACH.}

Anatomisch unterscheiden sich die Marsenien von den Chelyonoten wesentlich nur dadurch, dass die untere Strecke des Samenleiters am Grunde des Penis frei in die untere Körperhöhle eintritt und sich mit mehreren Schlingen uiber den Schlundkopf und andere Eingeweide hinlegt.

\section{Mars. perspicua (L.).}

Ha b. M. mediterranenm.

Taf. P. Fig. 17-22; Taf. Q. Fig. 7-18; Taf. R. Fig. 1-9; Taf. V. Fig. 1-5; Taf. F. Fig. 1-7.

Von dieser Art habe ich lebend zwei (ein weibliches und ein månnliches) Individuen untersuchen können, beide im Mai 1880, das eine in der Station von 'I'riest, das andere in der von Neapel. Beide waren einander wesentlich ziemlich ähnlich.

Die Länge betrug bei dem Individuum aus Triest $26 \mathrm{~mm}$ bei einer Breite bis 18,5 und einer Höhe bis $9,5 \mathrm{~mm}$; in dem anderen Individuum beliefen sich die entsprechenden Maasse auf 39, 35 und $22 \mathrm{~mm}$, die Länge des Fusses war in diesem letzteren Individuum 25 bei einer Breite bis $17 \mathrm{~mm}$, die Länge des Athemrohres (an der Unterseite) 11, die Länge der 'T'entakel $8 \mathrm{~mm}$. Die Ma asse wurden während des Kriechens der Thiere genommen. - Die Farbe des Ruickens des Triester Individuums versehwimmend und unregelmässig streifig-weisslich, nur auf der Nitte hell und schwach grinlich-briiunlichgrau (wegen einer Menge von glatten gräulichen Fleckchen), sonst iiberall äusserst fein weisslich granulirt. An dem anderen Individuum war die ganze Rückenseite hell gräulich-weiss mit zahlreich zerstreuten feinen schwarzen Punkten. Die Unterseite des breiten Mantels immer weiss. Der Kopf mit den Tentakeln immer weisslich, unter der Loupe mehr oder weniger deutlich sehr fein gelblichweiss punktirt, besonders an der Unterseite des Kopfes und an der oberen Seite der T'entakel; die Umgegend des Aussenmundes fast hell schwefelgelb in dem Neapolitaner Individuum; in dem anderen schwärzlich, sowie auch das Genick. Die Kiemenspalte schwar\%, und die Unterseite des Athemrohres fein und unregelmässig schwarz geringelt. Der Fuss oben gräulich, am Rande 
fein radiat schwarz gestrichelt, die Fussfurche schwärzlich; die Fusssohle weiss oder, besonders vorne, sehr schwach gelb, an dem. Neapolitaner Individuum unter der Loupe (sowie auch die obere Seite des Fusses und der obere 'Theil des Mantelrandes) ganz fein gelblichweiss punktirt, sowie auch ein kurzer medianer gelblicher Längsstreifen. - An der Unterseite des Kopfes schimmerto linten der Schlundkopf graubräunlich hindurch; am vorderen Theile der Fusssohle ein gelbliches, und an der Hitte des Ruickens ein violettgraues Eingeweide; innen an der Unterseite des Mantels schimmert die Leber grau hindurch.

Die Form des lebenden, in Consistenz etwas knorpelartigen 'Thieres ziemlich hoch, nach oben etwas zugespitzt, und gestreckt-halbkugelfürmig. Der Ruicken ist mit kurzen und starken Kegelchen (bei dem grössten Individuum) von einer Höhe bis 2 und einem Durehmesser am Grunde von 1-2 mm mehr oder weniger bedeckt, unter welchen auch kleinere vorkommen; mitunter waren dieselben alle in concentrischen Bogen mehr oder weniger deutlich geordnet; durch die Achse der grössten Ḧ̈ckerehen und aller Kegel schinmerte eine axiale weisse Säule hindurch. Die $\Lambda$ themröhre von einer Höhe und einer Breite von etwa $3 \mathrm{~mm}$; mehr eben als der Ruicken, am Ende eingerollt. Die 'I'entakel fingerförmig, ziemlich schlank. Die Unterseite des Mantelgebrämes glatt, ganz immen in gewöhnlicher Weise radiat und schräg streifig (Taf. R. Fig. 1). Die Fussfurche stark.

Das ziemlich lebhafte 'Thier kroeh mit einer Schnelligkeit von 5,5 ('Triest) bis S Cm. (Neapel) in der Minute. Die l'entakel wurden während des Krriechens sehr lebhaft bewegt, wie suchend nach vorne und unten gerichtet; die Athemröhre war nach vorne und oben gestreckt. Wenn irritirt kugeln sich die Thiere, falten den Fuss der Liinge nach fast ganz zusammen und schlagen den Mantel fast bis an die Fussrainder hinab, oder selbst weiter hinab bis zu rollständigem Bedecken des Fusses; dazu ziehen sich die Kegelchen des Rückens mehr oder weniger vollständig ein, und der Riucken wird ebener, nur mehr oder weniger groblnotig (fast wie in den in Alcohol bervahrten Individuen). Es gliickte nicht, während des Lebens das Geschlecht der. Individuen zu bestimmen; das kleinere war aber weiblicher, das grössere männlicher Natur.

Die erwähnten Individuen zogen sich, in Alcohol bewahrt, beziehungsweise auf cine Länge von 25 (Triest) bis $33 \mathrm{~mm}$ (Neapel) zusammen, bei einer Breite (bei ausgeschlagenem Mantel) von beziehungsweise 17-28 und einer Höhe von $10-17 \mathrm{~mm}$. Die Läinge des Fusses in dem grössten Individuum $18 \mathrm{~mm}$ bei einer Breite von 9, die Läinge des Schwanzes $9 \mathrm{~mm}$; die Lïnge des Athemrohres $9,5 \mathrm{~mm}$ bei einer Breite bis $4 \mathrm{~mm}$, die der Tentakel $4 \mathrm{~mm}$. Die $\mathrm{F}$ arbe war durchscheinend gräulich-weisslich; an der Riickenseite mit ziemlich zahlreich zerstreuten weisslichen Knötehen, sowie mit grauen und schwärzlichen Punkten. Am Grunde des Fusses sehimmerte innen an der Unterseite des Mantelgebrämes, die daselbst die eradiirenden weissen ('I'af. I. Fig. 1) Streifen sehr 
ausgeprägt zeigte, die Leber gräulich hindurch. Die Athemfurche gräulich; das Genick und die Seiten des Halses schwärzlich, ebenso die Innenseite der Schnauze, ihr Boden aber weisslich; die Fussfurche oben meistens bräunlich, sonst schwärzlich. - Die Form wie oben; die Rückenseite fast glatt, mit wenig vorspringenden (weisslichen) Kn̈ötehen. Die äusseren Formverhältnisse übrigens wie in den Chelyonoten; die Spitze der Kieme und des Geruchsorgans oft in die Kiemenspalte vortretend. Die Innenseite der Rïckenhaut (des Mantels) auch sich iiberall genau an die Schale anschmiegend, grau pigmentirt, mitunter mit dunkleren Punkten und Fleckehen oder mit querbogenähnlichen Strichen; an derselben hier und da kleinste weisse Klümpchen, mit Essigsäure brausend. - Die (weibliche) Schale $19 \mathrm{~mm}$ lang bei ciner Breite von 14,25 und einer Höhe von $8,5 \mathrm{~mm}$ ('laf. V. Fig. 1-3).

Dann habe ich noch fün andere, in Alcohol bewahrte Individuen aus Messina. (M. SARS) und dem Marseille-Busen (VAYSsIł̀RE) untersuchen können; endlich noch 9 aus dem Golfe von Neapel. Die Individuen waren alle von etwa derselben Grösse wie oben oder etwas kleiner. In Allem habe ich in Beziehung auf Form und Geschlecht (iusscrlich) 26 Individuen von Mars. perspicua untersucht, von denen 10 männlich, 16 weiblich waren. Anatomisch sind 16 Individuen untersucht worden.

Nach Wegnahme der Schale zeigten sich die Eingeweide in den gewöhnlichen Lageverhältnissen durchschimmernd; die Muskelfacetten wie gewöhnlich, die rechte grösser und mehr länglich. Der Eierstock meistens dottergelb, der Hoden etwas heller; die Leber schwarz; die Farbenverhältnisse der anderen Organe wie in den Chelyonoten. - Nach Spaltung der Decke der Kiemenhöhle schimmerten die Eingeweide der unteren Körperhöhle in denselben Lageverhältnissen und fast ganz wie in den Chelyonoten durch den Boden derselben; beim Männchen schienen die Windungen des Samenleiters besonders stark durch und konnten bis zu ihrem Ursprunge an der Innenscite des (rechten) Schalenmuskels meistens sehr deutlich verfolgt werden. - Nach Spaltung des Bodens zcigten diese Eingeweide an und für sich und in ihren gegenseitigen Verhältnissen eine aufallende Aehnlichkeit mit denen der erwähnten Gruppe.

Das Centralnervensystem ('Taf. R. Fig. 2) (fast olne Pigment, sonst) dem der Chelyonoten sehr ähnlich, die Lage der einzelnen Ganglien aber fast constant. Die linke Hiilfte der (Taf. Q. Fig. 7; Taf. R. Fig. 2 a) o beren Ganglienmasse zeigte unten und vorne das cercbrale Ganglion (Fig. 7 a; Fig. 2 a) mit wenigstens 6 Nerven; hinter derselben, also auch unten, aber mehr hinten, das, einen dicken Nerven abgebende, kaum kleinere pleurale (Fig. 7 b; Fig. 2b); an der Vereinigungsstelle dieser zwei Ganglien ruht das zivei dicke Nerven abgebende supraintestinale Ganglion (Fig. 7 d; Fig. 2c). Die durch ziemlich kurze Commissur mit der linken verbundene rechte Hälfte zeigte unten und rorne auch das 6-8 Nerven abgebende cerebrale Ganglion; hinter (mitunter theilweise auf) demselben ruht das etwas kleinere, einen starken Nerven abgebende pleurale; unter dem letzteren mehr oder weniger senkrecht stehend, durch einen kurzen Stiel mit dem- 
sclben verbunden, das einen dicken Nerven abgebende infraintestinale Ganglion (Fig. 2 d), durch eine mittelgrosse Commissur mit dem linken pleuralen Ganglion (Fig. 2 b) verbunden. Die von den verschiedenen Ganglien abgehenden Nerven verhalten sich wic bei Chelyonotus. Die sich auch in der oben beschriebenen Lage zu der oberen Ganglienmasse befindende untere, die pedalen Ganglien, waren jedes ron wenig ausgeprägter 8-Zahl-Form; wohl immer war auch hier der vorderste Theil knotenartig abgeschnürt, kurzstielig (Taf. R. Fig. 2e); mitunter fand sich diese secundäre Ganglienbildung nach unten gebogen und war somit von oben nicht oder kaum sichtbar (Taf. Q. Fig. S); der vordere Theil der Iussknoten immer etwas dicker, und der armartige Fortsatz des rechten Ganglions (Fig. 8 a, $2 \mathrm{f}$ ) auch ganz wie in den Chelyonoten. Der innerste der drei vom Hinterende abgehenden Nerven kounte, mit der Mittellinie fast parallel laufend, bis an das Hinterende der Körperhöhle, oberflächlich im Fusse verlaufend, verfolgt werden; der ausscrhalb des vorigen sich erstreckende versorgte den mittleren Theil des Fusses; der kürzeste äussere sich vor dem Verbreitungsbezirke des letzteren und ausserhalb desselben ausbreitend. Diese Nervenstïmme wurden in ähnlicher Weise wie die Fussknoten durch quergehende Faserstrïnge in ihrer Lage gehalten. 1)ie meistens zwei, ein (vorderer) stïrkerer und ein dünnerer, von der Seite des Ganglions ausgehenden Nerven versorgen die Seitenwände der Körperhöhle. Vom Vorderende der Fussknoten gehen 3-4 Nerven fuir den allervordersten 'Theil des Fusses aus. Die buccalen Ganglien ('l'af. R. Fig. 2 g) ganz wie bei den Chelyonoten. - Der Bau der grüsseren Ganglien der gewöhnliche. In der Rindensubstanz nach aussen grössere, nach innen kleinere Zellen; die Marksubstanz von einem filzähnlichen Gewirr von Primitivfibrillen gebildet.

Die Ophtalmophorien mit den A ugen ganz wie oben, somit auch die schon aussen als weisser Punkt auf schwarzem Boden durchschimmernde Linse ('Taf. R. Fig. 3). Die Otocysten durch einen dünen Nerven mit dem vorderen oder mittleren Theile der Fussknoten, der Gegend des cerebro-pedalen Connectivs, verbunden (Taf. Q. Fig. 9; 'Taf. R. Fig. $2 \mathrm{hh}$ ); sie sind weisslich, kugelrund, (in dem grössten Individuum) von etwa $0,16 \mathrm{~mm}$ Diam. mit einem runden Otolithen vou etwa $0,06 \mathrm{~mm}$ Durchmesser. ${ }^{1}$ ) - Das Geruchsorgan fast vollständig wie bei den Chelyonoten, relativ von etwa derselben Grösse, und in ganz ähnlicher Weise situirt; die Zahl der Blätter (jederseits) etwa 32-35, ihre Form- und anderen Verhältnisse wie in der eben erwähnten Gruppe, ebenso das faltenartige Dissepiment. Die sich von aussen ('Iaf. Q. Fig. 10) mehr oder weniger gegen die Achse an den beiden Seiten der Blätter erstreckenden, guirlandenartig ineinander iibergehenden Querfalten gelblich. Obgleich im Ganzen derartige feinere Untersuchungen ausserhalb des Planes dieser Arbeit liegen, wurde dieses Geruchsorgan doch genauer histologisch untersucht, an Thieren nimlich, die durch die Freundlichkeit des Dr. PAUL

1) Die ausstrahlenden (Muskel-) Fasern der Ohrscheiben erinnern auch an die von YuNG (VoGT et YuNG, traité d'anat. comp. prat. 7 livr. 1884. pag. 493. Fig. 250 e) gelieferte Abbildung der Otocysten von Arenicola piscatorum. 
MAYer (in der Station von Neapel) erst mit Sublimat behandelt, dann in Alcohol bewahrt waren. Aus der Untersuchung der an solchem Material hergestellten, mit Pikrocarmin gefärbten Schnittserien scheint dann Folgendes hervorzugehen: Lie Blätter zeigen an beiden Seiten senkrechte Falten, die unten (Taf. E. Fig. 1, 2) mehr oder weniger tief gekluftet und wie durch einen, aus der Kluft ausgehenden schmalen Stiel an den Grund des Blattes befestigt sind; oben enden die Blätter gerundet ('Taf. E. Fig. 3, 4). Selten verbinden sich die Falten miteinander; die Anzahl derselben betrug an den grösseren Blättern meistens etwa 25-30. Die Falten sind (wie das iibrige Blatt) von kleinen (also jetzt rothen) Epithelzellen mit einer diinnen Basalmembran und Wimperhaaren (Fig. 3, 4) iiberzogen; au denșelben kommen aber noch Gruppen von gelblichen Zellen vor, die sich sonst kaum von den ubrigen unterscheiden und keine besondere Wimperhaare tragen (Fig. $4^{* * *}$ ); ron den letzteren gelblichen Zellengruppen kommt oft eine unten univeit vom Stiele vor (Fig. $4^{\text {*** }}$ ), meistens aber noch höher hinauf $2-3$; wahrscheinlich gehören sie den oben erwähnten gelblichen Festons an. Durch die Achse der Falten scheint ein einfacher oder zusammengesetzter Strang aufzusteigen und eine von verzweigten Fädchen durchsponnene Höhle, die sich hier und da lacunenartig erweitert (Fig. 5); danu und wann schienen auch durchschnittene Nerven sich zu zeigen (Fig. 5). Durch die Rhachis des Geruchsorgans und dieselbe hauptsächlich bildend (Taf. Q. Fig. 4a; Taf. E. Fig. 1a) verlief der nicht dünne N. olfactorius. Derselbe ist von einer dinnen Scheide umgeben, die von kleinen, in einem oder wenigen Lagern liegenden Zellen gebildet ist, die mitunter kurze Ausläufer zwischen den Nervenfasern einschieben. Der Nerv bestand hauptsiichlich aus längslaufenden Nervenfasern, welche aber in mehrere grössere Portionen vertheilt schienen, unter denen besonders eine untere hervortrat (vergl. 'Taf. Q. Fig. 4 a). Die vou dem Nervenstamme abgehenden Zweige, einer für jedes Blatt, scheinen (Iaf. E. Fig. 2a) ganz denselben Bau zu zeigen; die Veråstelung derselben zu verfolgen glückte niemals. Unterhalb des Nervenstammes ('laf. E. Fig. 1 b; vergl. I'af. Q. Fig. 4) findet sich eine grosse, meistens dreieckige Lacune (Vene), die mit feineren Hollrïumen am Grunde der Blätter und in denselben in Verbindung steht (Fig. 1).

Der quere Aussenmund und die Schnauze ganz wie bei den Chelyonoten, ebenso die ganz schmale Lippenscheibe mit dem Innenmunde ('laf. Q. Fig. 12). Die Mm. rostrales proprii, die $\mathrm{Mm}$. nucho-, mento- und pedi-rostrales wie oben, ferner die Mm. rostro-labiales und bulbo-labiales ${ }^{1}$ ). - Der Schlundkopf in dem grössten Individuum ron einer Länge ron $5 \mathrm{~mm}$ bei einer Breite bis 3,5 und einer Höhe bis $3 \mathrm{~mm}$. Die Formverhältnisse desselben fast ganz wie bei den Chelyonoten; auch hier bestelit der Schlundkopf aus einer vorderen und einer hinteren Abtheilung. Die vordere ist auch wesentlichst von dem M. circularis bulbi gebildet. Die hintere hinten und unten den gewöhnlichen Sehnen-oder Knorpelfleck zeigend, welcher gräulich ist und gegen die

1) Vergl. Taf. X. Fig. 13 (Onchidiopsis groenlandica). 
gelblichweisse Miuskulatur contrastirt; an demselben heften sich auch der M. bulbo-rostralis inf. und der starke M. retractor bulbi an; von ihm entspringen ferner auch die MIm. lateralis sup. und inf., die $\mathbf{M m}$. Iongitudinalis sup. und transversus post. superficialis der oberen Seite, und vom ganzen hinteren Umfange der M. lingvalis proprius; der Verlauf und die Verhältnisse dieser Muskel sind fast ganz wie oben beschrieben. Die (Taf. P. Fig. 17) Mandibelplatten waren bei dem oben erwähnten grössten Individuum von ciner Länge von 2,2 bei einer Höhe bis $1,5 \mathrm{~mm}$. Die Platten in gewöhnlicher Weise mit cinander verbunden. Der Fal\% der Aussenseite wie gewöhnlich, aber etwas mehr nach vorne liegend; der vordere Theil der Platte daher relativ etwas kleiner als bei den Chelyonoten; der obere und untere Rand der Platte schräge, das Vorderende daher etwas zugespitzt (Taf. P. Fig. 17). Die Farbe der Mandibelplatten ist horngelb mit gräulichem Anfluge; der vordere Theil dunkler, streifig, mitunter weisslich scheckig (aber wenig mit Säuren brausend). - Die Zunge wie der ibrige Sehlundkopf gelblichweiss oder weiss, von den oben bei den Chelyonoten geschilderten Formverhältnissen; die Raspelfurche auch wie oben, mit der gewöhnlichen (hier weissen) Kante; die Raspel gelblich, auch hier deckte wenigstens die Spitze des Hakens der rechten Zahnplatten meistens die der linksseitigen; das Raspeldach wie bei den Chelyonoten. In der freien, ziemlich hellen Raspel') kamen bei dem erwähnten grossen Individuum 14 Zahnplattenreihen vor, und unter dem (etwa $1 / 3$ der Raspel deckenden) Raspeldache noch 5; weiter nach hinten in der Raspelseheide noch 25 entwickelte und 6-7 mehr oder weniger unentwickelte Reihen; die Gesammtzahl derselben somit 51. In den siebzehn iibrigen Individuen kamen an der Zunge $21(8+13), 20(13+7), 19(10+9), 17(10+7)(6$ Indiv. $), 16$ (2 Indiv.), $15(8+7)(3$ Indiv. $), 14$ (3 Indiv.) und 13 Plattenreihen ror; weiter nach hinten $54(48+6)$, $42,41,40(33+7), 39$ (2 Indiv.), 38 (2 Indiv.), 37, $36(30+6$ oder $29+7)$ (2 Indiv.), $35,34(28+6)(2$ Indiv $), 32,30(24+6)$ und $29(23+6)$. Die Gesammtzahl der Reihen in Allem 74, 61, 56 (2 Indiv.), 55 (3 Indiv.), 53 (2 Indiv.), 52 (3 Indiv.), 51, 50, 46, 45 und 42. Die Männchen und Weibchen schienen, was diese Verhältnisse betrifft, mit einander iibereinzustimmen. Die Breite der medianen Platten betrug bis $0,22 \mathrm{~mm}$ in dem grössten Individuum; die Länge der lateralen bis $0,4 \mathrm{~mm}$. Die Farbe der Platten horngelb, mehr oder weniger hell; die der medianen sehr hell; der Grundtheil der lateralen von der dunkelsten Farbe. Die Platten der nächsthintersten Strecke der Raspelscheide (die jünsten der entwickelten Platten) im Ganzen die dunkelsten. Die medianen Platten (I'af. P. Fig. 18-21) in Formverhältnissen mit denen der Chelyonoten ganz übercinstimmend, nur symmetrisch oder fast symmetrisch (mit dem linken Beine ein wenig länger); der. Schneiderand umgeschlagen, mit $2-5$ geraden oder gebogenen, spitzen Dentikeln zu jeder Seite der ziemlich starken Spitze (Fig. 21). Die (Taf. P. Fig. 22; 'Taf. Q. Fig. 13; Taf. R. Fig. 4) lateralen Platten von ganz derselben Form wie bei den Che-

1) Die Zungenbewaffnung findet sich bei TroscueL (Das Gebiss der Schnecken. I. 1856-1S63. pag. 1S6. Taf. XVI. Fig. 3, 3a, 3b) ganz gut dargestellt. 
lyonoten; der hintere (obere) Schneiderand des Hakens (Taf. Q. Fig. 13) meistens mit 10-12, seltener 6-8 (Taf. P. Fig. 22) feinen Dentikeln, nicht selten ist die Denticulation (durch Verschmelzung oder Fehlen von Zähnchen) sehr unregelmässig; der vordere (untere) Ilakenrand (Fig. 22;4) mit 3-5 kurzen, dickeren, etwas gebogenen Dentikeln. Die abgeplattet weissgerandete Raspelscheide und ihre Verhälnisse wie oben beschrieben. Die Platten der Männchen kaum constant heller als die der Weibchen, und der Haken kaum constant kuirzer und stårker. Der Bau der Zunge wesentlich wie bei den Chelyonoten; die Mm. tensores membr. radularis postt. und antt. wie oben. Die Zungenhöhle wie oben, und ebenso die Formverhältnisse der durchscheinenden Zungenknorpel, deren Länge bei dem grössten Individuum $3,2 \mathrm{~mm}$ betrug bei einer Breite bis 1,1 und einer Höhe bis etwa 1,5 mm. Die Oberfläche der Ḱnorpel unter der Loupe ganz fein netzartig; die Consistenz desselben wie gewöhnlich; am blossliegenden hinteren Ende des Kinorpels die gewöhnlichen Muskelaussprünge; der M. lingvalis proprius, die $\mathbf{I m}$. applanator supcrficialis und profundus, der M. dilatator lingvae, die $\mathbf{M m}$. constrictor. lingvae ant. und post. und der M. tensor lingvae inf. auch fast ganz wie oben beschrieben. Schnitte des Knorpels ergaben einen dem der Chelyonoten vollständig ähnlichen Bau. - Die Mundhöhle wie oben.

Die als solche etwas zweifelhaften, oben so genannten Speicheldrüen auch, als meistens überall in eine zusammenhängende Masse übergehende Lappen, die Unterseite, die Seiten und den grössten Theil der Vorderfäche (Taf. R. Fig. 5, 6) des Blättermagens iberziehend, die Cardia- und die Pylorus-Gegend desselben meistens ganz einhiillend (T'af. R. Fig. 6); mitunter überzog die Drüse vorzüglich die ganze obere Seite und das Hinterende. Dünnere Läppchen und Lappen deckten den grössten Theil des übrigen Magens (Fig. 5). Die Farbe der Drise weisslich, bleigrau oder rothbraun. Der Bau (Taf. R. Fig. 5) der Drise wie oben. Ausführungsginge wurden nicht nachgewiesen.

Die weissliche oder gelblichweisse Speiseröhre ganz wie oben, bei dem grössten Individuum fast $5 \mathrm{~mm}$ lang, auch meistens eine kleine Erweiterung (den ersten Kropt) bildend; wie gerwöhnlich links an dem Blättermagen hinabsteigend, vor dem Eintreten in denselben den ganz kurzen Gang des zweiten Kropfes aufnehmend. Dieser letztere ebenso variabel an Form. wie bei den Chelyonoten, weisslich, grau oder schwarzgrau ('Taf. R. Fig. 5 a) in dem Weibchen, in den (3) Männchen weisslich; von ganz ähnlichen Lageverhältnissen; in dem grössten Individuum $7 \mathrm{~mm}$ lang bei einer Dicke bis $2 \mathrm{~mm}$. Der Blätter-oder Drüsenmagen bei dem grössten Individuum 5 mm lang bei einer Breite bis $6,5 \mathrm{~mm}$ und einer Höhe bis 4,5 mm, fast halbkugelförmig oder wegen der Aushöhlung der Vorderseite (Taf. R. Fig. 6) haubenförmig; weisslich oder schmutzig braungrau bis schwarzgrau (dann stark gegen die Speicheldriisen abstechend) bei den Weibchen; meistens weisslich, seltener gräulich bei den Männchen. In der Cardia (Fig. 6) wie in dem Pylorus (Fig. 5 b) starke Längsfalten; die Magenhöhle klein (T’af. R. Fig. 7 a b); die Wände ganz wie bei den Chelyonoten, dick, die obere auch viel dicker (Fig. 7); die Anzahl der Blätter knum oder wenig geringer (meistens etwa 15, seltener bis 20), der Bau derselben 
wie oben (Fig. 7). Die kurze Pylorus-Röhre (Fig. $5 \mathrm{~b}, 7 \mathrm{~b}$ ) nach oben und rechts aufsteigend, sich in den untersten rechten Theil des eigentlichen Magens öffnend. Dieser ('Taf. Q. Fig. 14a) letztere weniger weit und weniger vom Darme abgegrenzt als bei den Chelyonoten; die Wände des Magens melr eben; neben der Cardia findet sich die auch runde und fast eben so weite Gallenöffnung (Fig. 14). Der Darm (Fig. 14b) wie bei den Chelyonoten und ebenso sein Verlauf; nur ist der iber die Leber hinstreichende Bogen kiirzer, und der ganze Darm deshalb ein wenig kiirzer; das Rectum wie oben.Der Inhalt der Verda ungshöhle unbestimmbare thierische Masse, mit feinen Algen, Diatomeen und Cnidae vermischt; an den Wänden des Magens und der ersten Strecke des Darmes batte der Inhalt meistens einen kalkähnlichen Ueberzug mehr oder weniger abgesetzt.

Die Leber schwarzgrau oder (beim Männchen) braungrau, vielleicht im Ganzen etwas kleiner als bei den Chelyonoten, besonders hinten nicht oder weniger tief in die Geschlechtsdrüse eindringend; die Formverhältnisse der Leber wie oben.

Das Pericardium wie oben; in dem grössten Individuum etwa $5,5 \mathrm{~mm}$ lang bei einer Höhe bis $2,5 \mathrm{~mm}$; die pericardiaco-renale Pore vorne und oben, neben dem mehr vorderen Theile der Vorkammer liegend. Das Herz und die gesehenen Theile des Gefässsystems wie bei den Chelyonoten; die Kammer bei dem grössten Individuum $2 \mathrm{~mm}$ lang.

Die Kieme von ganz ähnlichen Form- und Lageverhältnissen wie oben; die Chorda des Bogens bei dem grössten Individuum etwa $9 \mathrm{~mm}$ messend, die Länge der gro̊ssten Blätter $5 \mathrm{~mm}$. Die Blätter (Taf. Q. Fig. 11) schienen sich im Ganzen wie oben zu verhalten.

Die Niere ('laf. V. Fig. 4) in denselben Lageverhältnissen wie oben; weisslich oder gelblichweiss; länglich-dreieckig, meistens doch ein wenig mehr langgestreckt als bei den Chelyonoten, mit gerundeten Ecken; die Länge bei dem grössten Individuum 5,5 mm betragend bei einer Breite bis 1,5-2 mm und einer Dicke bis 1,5. Die Läppchen der Driise hauptsächlich der Lainge nach gehend, theilweise halbfiederig; in Anzahl meistens 6, von denen die (zıvei) äussersten linken viel kiurzer.

Die Blätterdrủse grau oder grünlich- oder braungrau, beim Männchen heller und mehr gelblich; dreieckig; im Ganzen etwas kleiner und düner als bei den Chelyonoten; beim Weibchen unmittelbar an den Eierstock grenzend; beim Männchen an dem Hoden, an der Leber und dem quergehenden Darme ruhend; die Breite beim grössten (weiblichen) Individuum 10,5 $\mathrm{mm}$ betragend bei einer Länge von 9,5 mm. Der federartige Bau aussen im Ganzen weniger ausgeprägt, deutlichst gegen den Vorderrand; der blätterige innere Bau dagegen sehr oft stark ausgeprägt. Die spaltenartige Oeffnung der Driise ('Taf. Q. Fig. 15a) in die Kiemenhöhle ganz wie oben. In der Kiemenhöhle fanden sich, besonders hinten, ähnliche weissliche Massen wie bei den Chelyonoten, aus dem Secrete der Drise gebildet; die chemische Untersuchung derselben ergab vollständig dieselben Resultate wie oben. 
Die Verhältnisse der Geschlechtsdrise wie bei den Chelyonoten, nur war dicselbe im Ganzen grösser, die Leber fast gar nicht in dieselbe eintretend; hinten sich bis an den Magen, vorne an die Blätterdrise erstreckend; gelblich, die Farbe stärker bei dem Weibchen. Die Gonoblasten wie oben. - Der grosse Eicrstock wie oben, gelblich oder rothbraun. Der Eierstockgang weiter als bei den Chelyonoten, sich in gervöhmlicher Weise in die Schleim- und Eiweissdrise öfnend. Diese letztere wie bei den Chelyonoten; in dem grössten Individuum $9 \mathrm{~mm}$ lang bei einer Breite bis 4,5 und einer Dicke von $2,5 \mathrm{~mm}$; die rechte Hälfte gelblich, mehr grobkörnig; die linke weniger grobkïrnig, etras mehr grelblich oder auch mehr weisslich als die rechte, und der hinterste Theil meistens weiss oder rothgelb und äusserst feinkörnig; zwischen der rechten und der linken Hialfte oft wie ein helleres schmales Band, von der durchschimmernden Höhle herrihrend. Die Höhle und der Bau des Organs wie bei den Chelyonoten. - Durch den hinteren Rand der Schleimdriise öfnen sich durch einen oder durch zwei, nicht lange gemeinschaftliche Giinge die dicht aneinander gedrängten weisslichen oder gelblichen Samentaschen. Dieselben ruhen (nicht an der Schleimdrüse, sondern) an dem Eierstock, von dem sie durch ihre Farbe abstechen; sie finden sich meistens auch in Anzahl von 11-20, rundlich, birn- oder zugespitzt sackförmig (Taf. Q. Fig. 16, 17), im Ganzen vielleicht relativ ein wenig kleiner als bei den Chelyonoten; auch von Samen strotzend. - Die von dem unteren Ende der Schleimdrüse ausgehende Vagina (Taf. Q. Fig. 18a) bei dem grössten Individuum etwa 4,5 mm lang bei einem Durchmesser bis $1 \mathrm{~mm}$; der Verlauf und die iibrigen Verhältnisse derselben wie oben; das Diverticulum oberhalb der Vulva stärker (Fig. 18c) als bei den Chelyonoten, bei jenem Individuum fast $2 \mathrm{~mm}$ vorragend, mit starken Liingsfalten der Innenseite; die Vulva (Fig. 18b) wie oben.

Der Hoden meistens von ein wenig hellerer Farbe als der Eierstock, gelblichweiss, seltener rothbraun; auch kaum viel kleiner, vom gewöhnlichen Baue, mit Zoospermien gewöhnlicher Art. ${ }^{\text {}}$ ) Der Samenleiter (Taf. R. Fig. Sade) in ähnlicher Weise wie bei den Chelyonoten entspringend und verlaufend. Das grosse Tinäuel der Windungen desselben vorne und rechts an der Unterseite des Hodens liegend; der kleinere hinterste Theil des Knäuels von viel dünneren und dichter liegenden Vindungen gebildet, die meistens auch stïrker gefürbt waren; allmählig werden die Windungen dann dicker und liegen mehr lose aneinander; die verschmälerte Fortsetzung des Samenleiters tritt dann hinter der MIuskelfacette hervor und rerbindet sich mit der Prostata. Die Windungen des Knaiuels lassen sich leicht entwirren, und messen in Allem wenigstens 10-12 Cm.; die Farbe war bei weisslicher Farbe des Hodens meistens kalkweiss, bei rothbrauner dagegen rothgelblich; sehr oft schimmert der Samenleiter fast in seiner ganzen Länge deutlich durch die Wand der Körperhöhle. Die Prostata ein kleines aufgerolltes Knäuel

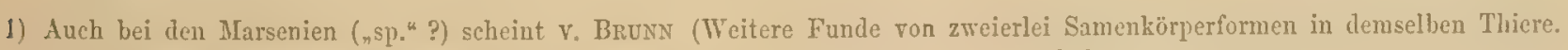
Zoolog. Anz. VII, 178. 188t. pag. 546) zwei Formen ron Zoospermien gesehen zu haben. 
bildend, dessen Windungen mitunter mit denen des Samenleiters verwickelt waren ('Taf. R. Fig. 8 bc); sie waren meistens weisslich, dünnwandig. Die dünne Fortsetzung des Samenleiters nicht wie bei den Chelyonoten in der Scitenwand der Körperhöhle verlaufend, sondern liöchstens nur von einigen gelösten Fascikeln des Schalenmuskels am Austreten aus der oberen Eingeweidemasse gedeckt; dann gleich frei (Fig. $8 \mathrm{~d}$ ) und in der unteren Körperhöhle seine langen Windungen (Taf. R. Fig. 8e) zur rechten Seite des Schlundkopfes und hinter demselben hinlegend, meistens auch die Raspelscheide unfassend. Diese freie Strecke hatte (bei drei Individuen von etwa 2-2,5 Cm. Lainge) ausgerollt eine Länge von etwa $3-3,5 \mathrm{Cm}$. bei einem fast durchgehenden Diameter von etwa $0,5-0,6 \mathrm{~mm}$; bei einem anderen (vierten) Individuum (von ähnlicher Grösse) betrug die Länge der freien Strecke 4,5 Cm., von welchen der eine etwa mittlere Centimeter rothbraun (wegen dunkeln Pigments der äusseren Hülle) war. In dieser Strecke war der Gang auch derber im Gegensatz zu seiner etwas weicheren Beschaffenheit im ganzen oberen Krnäuel. Der Gang verdiinnt sich nur unbedeutend, wenn in den Penis eintretend und geschlängelt denselben durchlaufend bis an und weiter durch die spitze Kegel hinter dem Ende, welche meistens mehr oder weniger aus einer runden Oeffnung hervortritt ('Taf. V. Fig. 5). Die Formverhältnisse und der Bau des Penis (Taf, R. Fig. $S \mathrm{fg}$ ) ganz wie früher beschrieben; die Länge desselben bei den erwähnten drei Individuen, wenn ausgestreckt, etwa $8-10 \mathrm{~mm}$ betragend, bei einer Breite bis 2,2-3 $\mathrm{mm}$; die vortretende Spitze des Samenleiters mitunter ganz klein ('Taf. R. Fig. 8), mitunter von bedeutender Lainge, bis etwa $5 \mathrm{~mm}$ messend (Taf. Ir. Fig. 9 a).

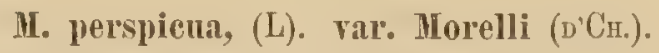

M. Morelli, (D'Crr.) BGH.

Taf. R. Fig. 10--11.

Von dieser Form (s. näher oben) habe ich Mitte Mai 1880 in der Station von Neapel cin (männliches) Individuum lebend zur Untersuchung gehabt. Dasselbe hatte, wenn kriechend, eine Länge von 2,5 Cm. bei einer Breite bis 2,1 und einer Höhe bis $1 \mathrm{Cm}$.; die Länge der Tentakel $3 \mathrm{~mm}$. Die F a r b e roth-orangeroth, unter der Loupe eine Menge von ganz feinen bräunlichen Punkten zeigend; der Kopf mit den Tentakeln mehr gelblich; der Fuss viel heller, besonders die untere Seite; unter der Loupe an der Oberseite des Fusses, besonders vorne, eime Menge von äusserst feinen gelblichweissen Punkten; ähnliche Punkte kamen auch am Mantelrande vor. An der Unterseite des Körpers schimmerte die Schale durch die eradiirende Streifung violet hindurch. Der Riicken ganz eben; die Athemröhre nach oben gebogen.

Das in Alcohol bewahrte Individuum latte noch eine Länge von $2,5 \mathrm{Cm}$. bei einer Breite bis $2 \mathrm{Cm}$. und einer Höhe bis $9 \mathrm{~mm}$. Die F a r be durchgehends (schwach gelblich-) weiss; die Furche des Vorderrandes des Fusses (oder wenigstens die obere Lippe 
derselben) schwarzgrau. Die F ormverhältnisse ganz wie oben; der Rücken ganz eben. - Die Schalenseite des Mantels nur mit zerstreuten granen Punkten und kleinen Ringen. - Nach Wegnahme der Schale schimmerten die Eingeweide in der bei der typischen Form beschriebenen Weise hindurch.

Das Centralnervensystem schien sich wie oben zu verhalten. - Der Schluudkopf von etwa $3,5 \mathrm{~mm}$ Länge, von gewöhnlichen Formverhältnissen. Die Kieferplatten (Fig. 10) schienen sich ganz wie oben zu verhalten, waren nur vorne etwas mehr gerundet, etwa 1,5 mm lang (Fig. 10). An der Zunge kamen im Ganzen 18 Zahnplattenreihen vor; in der Raspelscheide (dic ein wenig kürzer als gewöhnlich war) $24(18+6)$, die Gesammtzahl der Reihen somit 42. Die Platten, die lateralen wie die medianen, wie oben beschrieben, nur ziemlich hell; der hintere Rand der Seiten-Zahnplatten mit 13-20 Dentikeln, der vordere (wie es schien constant) mit 5 gebogenen Zacken. Dic Breite der medianen Platten hinten an der Zunge 0,18; die Länge der lateralen daselbst 0,26 mm.

Die Speiseröhre olıne deutliche Erweiterung (ersten Kropf). Der (zweite) Kropf weisslich, sonst wie gewöhnlich; der Blättermagen auch weisslich, halbkugelförmig, an der Vorderseite ausgehöhlt, von gewöhnlichem Baue; das ïberziehende Drüsenlager gelb. Der eigentliche Magen und der Darm wie gewöhnlich. Die Leber gelblich.

Die Blätterdriise und die Niere heller wie gewöhnlich.

Der Hoden gelb, der Bau der gewöhnliche; die Zoospermien wie gewöhnlich. Das Knäuel des Samenleiters (Fig. 11 b) kleiner als gewöhnlich, der Verlauf des Ganges (Fig. 11 ad) sonst wie gewöhnlich; ebenso, wie es schien, das Divertikel desselben (Fig. 11 e). Der Penis wie gewöhnlich, ausgestreckt etwa $10 \mathrm{~mm}$ lang bei einer Breite bis 2,5 ; das spitze Ende des Samenleiters wie gewöhnlich vortretend.

\section{I. perspicua (L.). var. dubia, Barr.}

Mars. dubia. Bergir, Rep. on the Marseniadac. - The Zool. of the Voyage of H. M. S. Challenger. Vol. XV. Part XLI. 1886. pag. 16-18. pl. I. Fig. $1-6$.

Hab. M. atlant. occ. (Cap Verde).

Von dieser als specifisch etwas zwcifelhaften Form wurde während der ChallengerExpedition (am 28. Juli 1873) bei St. Vincent, Cap Verde, ein einzelnes, männliches Individuum gefischt, für dessen Untersuchung auf obige Stelle hingewiesen werden muss.

Die Länge des Individuums betrug nur 4,5 mm. Die Formverhältnisse wie die der M. perspicua. Die Schale wie oben erwähnt.

Die Mandibelplatten fast wie in der Mars. perspicua, ebenso die Zahnplatten der Zunge; die Anzahl der Zahnplattenreihen 44, von denen 11 an der Zunge; die medianen Platten vielleicht etwas liinger als in jener Art. - Die iibrigen Eingerweide schienen sich 
ganz typisch zu verhalten. Der Penis vielleicht von anderer Form, und das freie Ende des Samenleiters ganz ungewöhnlich mächtig.

Diese Form reprïsentirt wahrscheinlich nur eine Localvarietiit der typischen Art.

\section{Mars. latens (O, Fro MüLuER).}

Hab. M. atlant. septentr.

Taf. Q. Fig. 19-20; Taf. R. Fig. 12-20; Taf. S. Fig. 5.

Von dieser Art ${ }^{1}$ ) lag ein einziges, weibliches Individuum vor, bei Solsvig in der Nähe von Bergen gefischt und nir im August 1884 von Herrn Prof. ColletT geschenkt. Dasselbe war in Alcohol gut bewahrt.

Die Länge ${ }^{2}$ ) betrug $20 \mathrm{~mm}$ bei einer Breite bis 15,5 und einer Höhe bis $6 \mathrm{~mm}$, die Tiefe der Spalte des Mantelrandes zur $\Lambda$ themfurche $2 \mathrm{~mm}$. Die F a r b e gelb-rveisslich; am Ruicken, besonders am Mantelrande, zerstreute weissliche Punkte; die Schale nur undeutlich durehschimmernd, viel deutlicher die vom Zenith radiat ausstrahlende cutane (oder subcutane) muskuläre Streifung; die Streifung der Unterseite des Mantelgebräimes (oberhalb des Schwanzes) wie gewöhnlich. - Die Form etwas abgeplattet. Die obere Seite fast eben, die erwähnten weisslichen Punkte sehr wenig vortretend. Die ziemlich breite, gegen hinten allmählig breitere Athemfurche vorne in den erwähnten submedianen Ausschnitt des Mantelrandes iibergehend. Die Tentakel kaum kürzer als gewöhnlich. Die Schalenseite des Mantels grauscheckic. - Die Schale ist oben beschrieben worden. - Nach Wegnahme der Schale zeigten sich die Eingeweide in gewöhnlichen Lageverhailtnissen; am Vorderrande der Blätterdruise, den freien Theil der Kiemenblätter deckend, ein aus kurzen, der Länge nach gehenden Streifchen gebildetes, kalkweisses, von den Secreten gebildetes Band. Dureh den Boden der Kiemenhöhle schimmerte in gewöhnlicher Weise der Schlundkopf.

Das Centralnervensystem vollständig wie bei der M. perspicua. Die Oto cysten auch hier durch den kalkweissen Otolithen leicht auffallend. Das Geruchsorgan jederseits mit etwa 40 Bliittern.

Der Schlundkopf $3 \mathrm{~mm}$ lang bei einer Breite auch bis 3 und einer Hôhe bis 2,2 mm; die Formverhältnisse ganz wie gewöhnlich ('l'af. R. Fig. 12); die horngelben Mandibelplatten 1,4 mm lang, von der gewöhnlichen Form (Fig. 13). An der Zunge $18(8+10)$ Zahnplattenreihen, weiter nach hinten in der Raspelscheide $53(46+7)$, die Gesammtzahl derselben somit 71. Die Farbe der Platten horngelb; die Länge der me-

1) Der in der vorigen Abtheilung (pag. 168) gegebenen Literatur ist noch hinzuzufügen:

Lamellaria latens, Müller. Aurivillius, Hafsevertebr. frin Nordligsta Tromsö Amt och Vestfinmarken. pag. 31. K. Svenska Yet.-Ak. Handl. XI. 1886. No. 4.

2) Die Länge dieser Thierform wirl von G. O. SARS (1. c. pag. 150) zu $12 \mathrm{~mm}$ angegeben. 
dianen bis 0,16 , die Breite bis $0,14 \mathrm{~mm}$; die Länge der lateralen bis $0,26 \mathrm{~mm}$. Die medianen Platten (Taf. R. Fig. 14-16, 18; Taf. S. Fig. 5) von gewöhnlicher Form, vorne etwas enger; die Spitze kurz, oft unregelmässig fein denticulirt (Fig. 14-16, 18); zu jeder Seite der Spitze 4-5 kleine Dentikel, mitunter fast versehwindend klein. Die Seitenzahnplatten ('Taf. Q. Fig. 19, 20 ; Taf. R. Fig. 17, 19) von gewöhnlicher Form; am umgeschlagenen Vorderrande des Hakens $4-5$ gerundete oder mehr spitze Dentikel; am Hinterrande cine geringe Anzahl von (meistens 5-7) kurzen Dentikeln.

Die weissliche Speiseröhre wio gewöhnlich; der vordere Kropf klein. Der zweite Kropf gross, lang, grauschwarz. Der Blättermagen $3,75 \mathrm{~mm}$ lang bei einer Breite bis $3,5 \mathrm{~mm}$, schrvarz; an den Seiten sowie vome an der oberen Fliiche von dem gelblichen Drüsenlager bedeckt; das Pylorusrohr stieg mehr schräge nach links als gewöhnlich empor. Der eigentliche Magen rechts an den Eierstock und ganz hinten unterhalb dieses an die Leber stossend; liings des oberen Randes vom Eierstock begleitet; sonst wie gewöhnlich. Der Darm ganz wie gerwöhnlich. Im Magen und im Darme unbestimmbare thierische Masse. - Die Leber gross, brïunlich schwarz.

Die Niere klein, weisslich, in die Quere gestreckt-dreieckig. Die Blätterdrise (der Grösse des Eierstockes entsprechend) klein, grau.

Der Eierstock ungewöhnlich gross, fast die Hälfte des letzten Schalenumganges einnehmend, schmutzig röthlichgelb; in den Läppehen grosse oogene Zellen. Die Samentaschen wie gewöhnlich am oberen Rande der Schleimdrise, kalkweiss, in Anzahl 6, sich durch 3 Gänge in die Höhle der Schleimdrüse öffnend; von Samen strotzend (T'af. R. Fig. $20 \mathrm{~b}$ b). Die Schleimdruse stark gekrummt, schmutzig gelb, die rechte Hälfte dunkler als die linke, und der hinterste Theil der letzteren weisslich (Fig. 20a). Die Vagina wie gewöhnlich, der untere Theil sehr dickwandig; das Divertikel ungewöhnlich stark, sehr dickwandig, mit feinen Längsfalten der Innenseite der Höhle.

\section{Mars. pellucida (VerrilL).}

II a b. M. atlant. occid.

$$
\text { Taf. S. Fig. 14-23. }
$$

Von dieser Art habe ich zwei, weibliche Individuen zu untersuchen gehabt, von Verrill bei Newport in 1880 aus einer Tiefe von 115 Faden heraufgefiseht und mir von ihn in 1883 freundlich geschickt.

Von den in Alcohol bewahrten Individuen hatte das grösste eine Länge ${ }^{1}$ ) von 16 bei einer Breite bis 13 und einer Höhe bis etwa $9 \mathrm{~mm}$; die Länge des Fusses 9,5 mm bei einer Breite bis 6,5; die Breite des Mantelgebrïmes 3,25, die Länge der T'entakel 2,5 mm. Die Länge des kleineren Individuums $12 \mathrm{~mm}$; die anderen Maasse den oben-

1) Verrilit giebt die Länge des lebenden Thieres zu $12-16 \mathrm{~mm}$ an. 
stehenden fast relativ entsprechend. - Die Farbe war durchgehends gelblichweiss; der Rücken mit zerstreuten weissen Knötchen und mil zerstreuten (leicht abstossbaren) braungrauen Fleckchen. ${ }^{1}$ )

Die Form verhältnisse wie gewöhnlich. Bei dem grossen Individuum war der Rücken mit weissen Knötchen bedeckt, bei dem kleineren fast ganz eben (wie von VerriLI als typisch angegeben). Die Siphonalfalte fast genau über dem linken 'T'entakel liegend. Die Mantelstreifung rings um die Fusswurzel wie gewöhnlich.-Die Schalenseite des Mantels gräulich. Durch die Schale schimmerten ungewöhnlich deutlich der grosse Eierstock gelb hindurch, vor demselben schwach grünlichweiss die Blätterdriise, vor dieser rothgrau die den freien Theil der Kiemenblätter deckenden Secretmassen und (mehr rechts) die gelbe Schleimdruise; vor jener etwas heller rothgrau die Kieme und vor dieser gelblich das Geruchsorgan; ganz rechts schimmert das Rectum schwarz hindurch. Die Muskelfacetten sehr stark. - Durch den Boden der Kiemenhöhle schimmern die Eingeweide in gewöhnlicher Art.

Das Centra In ervens ystem wesentlich ganz wie bei der typischen Art; das supraintestinale Ganglion das kleinste. Die pedalen Ganglien (Fig. 14) an der Mitte stark eingeschnürt. - Die Otocysten (wegen des Otoliths) als kalkweisse Punkte am (Fig. 14bb) Aussenrande der Fussknoten oder hinter denselben sichtbar, von beiläufig 0,2 mm Diam., mit dem Otolithen von 0,1 mm Durchmesser. Das Geruchsorgan jederseits mit etwa 35 hohen Blïttern.

Der Schlundkopf kurz, bei dem grössten Individuum an Länge 2,5 mm bei einer Breite bis 2,25 und einer Höhe von 2,2 mm messend; sonst von gewöhnlichen Bauverhältnissen. Die Mandibelplatten (Fig. 15) 1,3 mm lang, ziemlich diinn, hell horngelb, dunkler am Vorderrande; der Falz der Aussenseite sehr schwach. Die Zunge von gewöhnlicher Form, mit 16 Zabnplaltenreihen der Raspel; weiter nach hinten in der hellgelben Raspelscheide $46(40+6)$ Reihen; die Gesammtzahl derselben somit 62. Bei dem kleineren Individuum kamen an der Zunge 14, in der Scheide 31, oder im Ganzen 45 Zahnplattenreihen vor. Die Mittelzahnplatten bis $0,14 \mathrm{~mm}$ breit; die Seitenzahnplatten bis $0,24 \mathrm{~mm}$ lang. Die medianen Platten fast farblos, die lateralen horngelb. Die medianen P latten (Fig. 16-18) ziemlich kurz, breit, am Hinterrande nicht gekluftet; an jeder Seite des gerade hinauf (Fig. 17) gebogenen Hakens 5-7 Dentikel. Die lateralen Platten (Fig. 19, 20) mit breitem Haken (Fig. 19); am hinteren Rande desselben 7-10, am vorderen 5-7 meist gröbere Dentikel.

Die Speiseröh re wie gewöhnlich, hinten (Fig. 21 a) ein wenig kropfartig erweitert; durch ihre ganze Länge zieht sich eine starke gelbe Falte. Der zweite (Fig. 22 b) Kropf gross, sich weit nach rechts, vorn und oben erstreckend, weiss; sich oberhalb der Speise-

1) -Animal yellowish brown mottled with darker, broad elliptical, swollen, without tubercles on the back" (sic!). VerriLL, 1. c. 1880 . pag. 395 . 
röhre in den Blättermagen öffnend; die Höhle leer. Der weisse B liittexmagen (Fig. 22c) von etwa $5 \mathrm{~mm}$ Breite bei einer Länge bis 3 und einer Höhe bis $4,5 \mathrm{~mm}$; die Zahl der dicken Blätter etwa 10. Das diesem Magen gehörende Drüsenlager ockergelb, eine untere und eine rechte-obere Masse bildend. Der sich weit rechts erstreckende eigentliche If gen lang und schmal; seine Wände fast obne Fạlten. Der wegen seines schwarzgrauen Inhaltes dunkel durchschimmernde Uarm wie geröhnlich verlaufend. Der Inhalt der Verdauungshöhle unbestimmbare thierische Masse, mit Sandlïrnern und Diatomeen gemischt. Die grosse Leber gelb.

Das Herz und die Niere wie gewöhnlich. Die Kiemenblätter ziemlich spitz (Fig. 23).

Der grosse gelbe Eierstock (mehr rein gelb als die Leber) mit grossen oogenen Zellen. Die Samentaschen ganz atrophisch, ihre Anzahl konnte nicht bestimmt werden. Die gelblichweisse Schleimdrüs e klein, 3,5 mm lang bei einer Breite bis $1,6 \mathrm{~mm}$, wie gewöhnlich aus zwei Hälften bestehend; die Vagina kurz, ihr Diverticulum wie gewöhnlich.

Diese Form unterscheidet sich durch die nicht gekluftete Grundplatte der medianen Zahnplatten von den obenstehenden Arten.

\section{Var. Gouldii, VerRiLl.}

Ha b. M. atlant. occid.

Taf. S. Fig. $2 t-34$.

Von dieser Varietät lagen zwei fast gleich grosse Individuen vor, 1881 bei „Narthas Vineyard" aus einer Tiefe von 224-458 Faden von Professor Verrill gefischt und mir von demselben 1883 geschenkt; das eine war männlichen, das andere weiblichen Geschlechts.

Von den in Alcohol bewàhrten Individuen maass das grösste, das männliche, etra $17 \mathrm{~mm}$ an Läng $\mathrm{e}^{1}$ ) bei einer Breite bis 13 und einer Höhe bis 8,5 mm; die Länge des Fusses $11 \mathrm{~mm}$ bei einer Breite (vorne) bis $9 \mathrm{~mm}$; die Breite des Mantelgebrämes 4,5, die Länge der T'entakel $4 \mathrm{~mm}$. Die Farbe des Mantels weisslich mit stärker weissen zerstreuten Knötchen des Rïckens; am Rüicken, besonders aber am Mantelgebräme, zerstreute graue Flecken; der Fuss gelblich ${ }^{2}$ ), am Rande einzelne schwarze Flecken.

Die F or m verhältnisse die gewöhnlichen; nur war (bei beiden Individuen) das Mantelgebräme ungewöhnlich dïnn und vom ủbrigen Mantel fast gradwinkelig abstehend, sowie die Fussecken ungewöhnlich (etwa $2 \mathrm{~mm}$ ) vortretend. In dem männlichen Individuum war der Stirnrand fein zackig (Fig. 24).

Die Schale deutlich durchschimmernd.

1) Die Länge eines in Alcohol bewahrten Individuums wird von VerriLl (1. c.) zu 1 s bei einer Breite bis 12 und einer Höhe bis $10 \mathrm{~mm}$ angegeben.

2 VerriLl giebt die Farbe als blassgelb oder gelblichweiss an, mit braun, schneeweiss (flake-white) und gelb gefleckt (blotched or specked). 
Nach Spaltung des Mantels zeigte sich die Schalenseite desselben farblos; die Eingewẹide schimmerten mit ungewöhnlicher Deutlichkeit durch die ganz dünne Schale (rurgl. Fig. 25).

Die Lageverhältnisse der Organe ganz wie gewöhnlich.

Das Centralnervensystem wie oben; das rechte supraintestino-pleurale Connectiv nur ganz ungewöhnlich lang. Die Otocysten wie oben; das Geruchsorgan jederseits mit etwa 45 Blättern; die Falten an den Seiten desselben ungewöhnlich ausgeprägt (Fig. 31).

Der Schlundkopf wie oben; der Kaurand der schmutzig grünlichgelben Mandibelplatten (in beiden Individuen) zufällig (durch Bruch?) von etwas anderer Form (Fig. 26). In der Raspel kamen in dem mimnlichen Individuum 19 Zahnplattenreihen vor, in der (Fig. 34) hellen Raspelscheide $29(23+6)$, die Gesammtzahl derselben somit 45. In dem weiblichen Individuum fanden sich an der Zunge auch $19(12+7)$, in der Raspel 33, oder im Ganzen 52 Zahnplattenreihen. Die Breite der medianen Platten bis etwa 0,167 mm betragend, die Länge der lateralen bis $0,29 \mathrm{~mm}$; die Farbe der letzteren sehr hell horngelb, die der ersten kaum heller. Die Zahnplatten im Ganzen wie in der vorigen Form; die Dentikel (Fig. 27, 28) der medianen vielleicht im Ganzen etwas feiner, und der Haken der lateralen (Fig. 29,30) vielleicht etwas lïnger; die Zahl der Dentikel im Ganzen eben so inconstant wie oben.

Die Speiseröhre wie oben, somit auch die erwähnte Falte, die aber hier heller war. Der zweite Kropf wie oben. Der Blättermagen weiss oder gräulich $(q)$, sowie auch das deckende Drisenlager, welches sich sonst wie oben verhielt; zwei lange Drüsenläppchen dieses Lagers vereinigen sich zu einem (Fig.33) Stamm, welcher durch das Loch am Hinterende der unteren Eingeweidehöhle (Fig. 33 a) eintritt und sich fast durch die ganze Liinge des Schwanzes ungetheilt fortsetzt. - Der eigentliche Magen (Fig. 25b) wie oben; seine Cardia weit rechts, weit von der Gallenöffnung liegend. Der Darm wie gervöhnlich. - Der graue und griunlichgraue Inhalt des eigentlichen Nagens und des Darmes sehr reichlich, ganz von derselben Art wie oben. - Die hellgriinlichgraue Leber gross, bis an die Spitze der Spira aufsteigend (Fig. 25).

Das Balkenwerk der weissen Blät ter dri i s e sehr ausgeprägt (Fig. 25 c). Die Niere wie gerwöhlich.

Der weisse Hoden nicht ganz an die Spitze der Spira reichend, dem Anscheine nach aus zwei Theilen bestehend (Fig. 25a), die aber zwischen den Windungen der Spira ineinander ibergehen; der Bau der gewölunliche; in den Laippehen die (zwei? Arten von) Zoospermien. Der Samenleiter an der unteren Seite der grösseren Parthie des Hodens ein flaches Kñiuel von ziemlich dicken Windungen bildend, zu dessen Bildung aber auch das aufgerollte grosse Divertikel (Prostata) beitrïgt, welches mehr vorne (an der Seite des Rectums) in den Samenleiter iibergeht. Die festere (mehr muskulöse) Fortsetzung des Samenleiters verläuft, von einem MLuskellager bedeckt, längs der (rechten) Seite der unteren Körperhöhle, wird dann in gewöhnlicher Weise frei, bildet cin Paar lange Schlingen (an 
der rechten Seite des Schlundkopfes liegend) und dringt in den P en is ein. Dieser letztere (Fig. 32) etwa $8 \mathrm{~mm}$ lang bei einer Breite bis 2, im Ganzen ziemlich abgeplattet (bis zur Bildung eines Gebrämes längs des oberen Randes), längs der unteren (inneren) Seite etwas concav; etwas hinter dem gerundeten Ende (als eine Abnormität?) ein auch etwas abgeplatteter und concaver dreieckiger Fortsatz, an dessen Spitze sich der hinaufschlängelnde Samengang offnet (Fig. 32 a).

Der gräulich-gelbliche Eierstock von ganz ähnlicher Verbreitung und Grösse wie der Hoden oder wenigstens nicht grösser; in den Läppchen grosse ongene Zellen. Die Samentaschen weisslich, leer, länglich, wie atrophisch, hinten an der Unterseite der Schleimdruse liegend. Die weisse und kalkweisse Schleimdrïse $4 \mathrm{~mm}$ lang bei einer Breite bis 2,2 und einer Dicke bis $1,5 \mathrm{~mm}$; sonst wie gewöhnlich, nur vorne breiter.

\section{Mars. gemma, Bøн. n. sp.}

$\mathrm{Ha}$ b. M. philippinense.

Taf. XLI. Fig. 7; Taf. S. Fig. 10; Taf. T. Fig. 5-S.

Von dieser mit Namen (Malacol. Unters. IX. Heft. 1875. Taf. XLI. Fig. 7) schon vor mehr als einem Jahrzehnte veröffentlichten schönen Art wurde von SEMPER in 1859 bei Panglao auf Sandboden in einer Tiefe von 3 Faden ein einzelnes, männliches Individuum gefischt. SEMPER zeichnete das Thier dem Leben nach, hat sonst keine Notizen über dasselbe gemacht.

Das lebende Thier hat eine Länge von $21 \mathrm{~mm}$ bei einer Breite bis 17 gehabt. Die Farbe (1. c. Fig. 7) des Rückens ist am Mantelgebräme hellgrauviolett gewesen, die Gegend der Schale roth, und am Mantelgebrämo ähnliche rothe F'lecken; das Ganze ist mit weissen Punkten ibersået, die besonders an der Mitte dicht gedrängt stehen und noch dazu ein schönes griechisches Kreuz bilden; die Innenseite der Athemröhre scheint violettgrau gewesen zu sein.

Das in A l cohol bewahrte Individuum hatte eine Länge von $15 \mathrm{~mm}$ bei einer Breite bis 12 und einer Höhe bis $5,6 \mathrm{~mm}$. Die Farbe durchgehends gelblichweiss, die Schale ziemlich stark weisslich durchschimmernd; das Genick braungrau. Die Formverbältnisse wie in der typischen Form (M. perspicua).

Die Innenseite des Mantels farblos. Nach Wegnahme der Schale zeigten sich die Eingeweide in gewöhnlichen Lageverhältnissen durchschimmernd; alle sehr blass; längs des Vorderrandes der Blätterdrüse schimmerte ein kalkweisses breites Band, die Kiemenblätter theilweise deckend, hindurch, von den Secret-Concrementen gebildet. - Durch das Genick schimmerten die Eingeweide wie bei der Marsenia perspicua, die Windungen des Samenleiters zeigten sich schon hier kurzer, als bei der typischen Art.

Das Centralnervensystem fast ganz wie bei der typischen Marsenia; die cerebropleuralen Ganglien aber grösser; an den Fussknoten war auch der vordere Theil knoten- 
artig abgeschniirt. - Die schwarzen $\mathrm{Augen}$ verhältnissmässig gross. Die Ohrblasen als kalkweisse Punkte seitwärts zwischen und unter den Trabekeln am Grunde der (unteren) Körperhöhle liegend; von einem Durchmesser von etwa $0,16 \mathrm{~mm}$ bei einem Diameter des gelblichen, radiär streifigen, kugelförmigen Otolithen von beiläufig 0,08 mm. Das gelbliche Geruchsorgan jederseits mit etwa 40 Blättern.

Die Länge des Schlundkopfes $2 \mathrm{~mm}$, die Formverhältnisse desselben die gewöhnlichen. Die Mandibelplatten wie gewöhnlich; die hinteren zwei Drittel grünlich; das vordere horngelb, $1 \mathrm{~mm}$ lang (Taf. T. Fig. 5); der Hinterrand des vorderen (Kau-) Stückes an dem Falz eigenthümlich zackig (Fig. 6a). Die Zunge im Ganzen mit $18(9+9)$ Zahnplattenreihen; in der langen, ausgestreckt 4,5 mm messenden, in gewöhnlicher Weise aufgerollten Raspelscheide 33 entwickelte und 9 jüngere Reihen; die Gesammtzahl derselben somit 60. Die Breite der medianen Platten bis 0,14 ; die Länge der lateralen bis $0,25 \mathrm{~mm}$ betragend. Die Platten ziemlich stark horngelb, besonders die seitlichen. Die medianen Platten (Fig. 7) mit meistens 4 Dentikeln zu jeder Seite der Spitze. Die lateralen mit 12-20 Dentikeln des hinteren Randes, mit meistens 4 groben des vorderen (Fig. 8).

Die Speiseröhre wie gewöhnlich, ihre Erweiterung mehr nach vorne liegend. Der farblose (zweite) Kropf wie gewöhnlich. Der Blättermagen von gewöhnlicher Form; 2,4 mm breit bei einer Länge von 1,6 mm, gelblichweiss; die Zahl der Blätter etwa 20; das überziehende Drúsenlager ziemlich gelblich. Der eigentliche Magen wie gewöhnlich, ebenso der Darm. Die Leber gelblich.

Die Blätterdrüse fast weisslich, vielleicht kleiner als gewöhnlich. Die weissliche Niere wie aus 4 schräg gehenden kurzzackigen Bändern gebildet.

Der hellgelbliche Hoden vorn gewöhnlichen Bau; auch hier schienen zwei Arten von Zoospermien vorzukommen. Das gelbe Knåuel der Windungen des Samenganges etwa $2 \mathrm{~mm}$ lang; dicht vor seinem Austreten aus der oberen Körpermasse nimmt er auch ein, aber wie es schien, nicht langes (prostatisches) Divertikel auf. In der hinteren Strecke seines Verlaufes in der unteren Körperhöhle ist der Gang dinnwandig, an die Körperwand befestigt; er wird dann mehr dickwandig und liegt mit seiner langen schlinge hinter dem Schlundkopf; diese untere Strecke des Samenganges hat eine Länge von etwa $12 \mathrm{~mm}$ bei einem Durchmesser des Ganges von beiläufig 0,25 mm. Der Penis maass ausgestreckt (Taf. S. Fig. 10) etwa $6 \mathrm{~mm}$ bei einer. Breite bis 1,3 mm; die Form desselben (zufällig?) etwas abweichend; die weisse Spitze des Samenganges etwa $2 \mathrm{~mm}$ vortretend (Fig. 10a).

\section{M. Cabulana, BGH. n. sp.}

H a b. M. philippin.

$$
\text { Taf. S. Fig. 11-13; Taf. T. Fig. 1-4. }
$$

Von dieser Form lag nur ein einziges, weibliches, in Alcohol bewahrtes Individuum vor, ohne Notizen; von SEMPer bei Cabulan vor Bohol aus einer Tiefe von 15 Fadeu 1859 gefischt. 
Das in Alcohol bewahrte Individuum hatte eine Läng e von $18 \mathrm{~mm}$ bei einer Breite bis 14,5 und einer Höhe bis $7 \mathrm{~mm}$. Die Farbe war gelblich mit nicht sehr reichlich zerstreuten schwarzen Punkten, Strichen und Ringen am Ruicken. Die Schale (Taf. T. Fig. 1) deutlich durchschimmernd.

Die Lageverhältnisse der Organe zeigten sich nach Wegnahme der Schale sowie nach Spaltung der Decke der unteren Eingeweidehöhle wie gewöhnlich.

Das Centralnervensystem wie oben, ebenso die stark seitwårts liegenden Ohrblasen mit ihrem stark kalkweissen Otolithen ron 0,08 mm Diam.; das Geruchsorgan wie gewöhnlich, jederseits mit etwa 40 Blättern.

Der Schlundkopf $2,8 \mathrm{~mm}$ lang, blass, ganz wie gewöhnlich. Die Kieferplatten (Taf. T. Fig. 2) etwa 1,5 mm lang, gelblich; der Vorderrand kürzer als bei den vorigen Arten. An der Zunge fanden sich $18(9+9)$ Zahnplattenreihen, in der langen Raspelscheide $28(21+7)$, die Gesammtzahl derselben somit 46 ; in den Reihen deckte die Spitze der rechten Seitenplatten die der linken. Die Farbe der Platten horngelb; die Breite der medianen Platten bis 0,14 ; die Länge der Seitenzahnplatten bis gegen $0,25 \mathrm{~mm}$. Die (Taf. S. Fig. 12, 13) medianen Platten mit 5-6 Dentikeln zu jeder Seite der gebogenen Spitze; die Beine etwas ungleich. Die lateralen Platten (Fig. 11) mit meistens 12-15 Dentikeln des hinteren und 5-6 des vorderen Randes des Hakens (Taf. T. Fig. 3, 4).

Die Speiseröhre wie gewöhnlich, mit kleinem Kropfe. Der zweite Kropf wie gewöhnlich; der Blättermagen $3 \mathrm{~mm}$ lang und breit, an der Vorderseite applanirt und etwas ausgehöhlt, der Bau wie gewöhnlich; der eigentliche Magen und der Darm wie gewöhnlich. Der Darm und theilweise der Magen waren von kleinen, weisslichen, ovalen Seybala erfullt, die aus unbestimmbarer thierischer Masse bestand, in welcher eine Masse von Cnidae und schönen grösseren und kleineren Diatomeen. - Die L eber hell gelblich.

Die Blätterdrüse wie gewöhnlich. Die Niere schien aus 6 der Länge nach gehenden zackigen Drüsenmassen gebildet.

In den Läppchen des gelblichen Eierstockes grosse oogene Zellen. Die Samentaschen waren von sehr winziger Grösse. Der hinterste-linke Theil der Schleim drüse durch seine weissliche Farbe gegen den ibrigen Theil contrastirend; die Vagina sowie ihr Divertikel wie gewöhnlich.

6. M. affinis, BGH. n. sp.

H a b. M. philippin.

Taf. R. Fig. 21-23; Taf. T. Fig. 18-23.

Von dieser Form haben drei, weibliche Individuen vorgelegen, von SEMPER 1859 im Canale von Lapinig gefischt. Zwei Individuen waren einander fast in allen Verhältnissen ganz ähnlich, das dritte kleiner.

Die zwei Individuen waren etwa $13 \mathrm{~mm}$ lang. Sie waren von schmutziggelblicher 
Farbe; am Riicken unregelmässige schwärzliche Fleckchen zerstreut sowie rundliche rothbraune Fleckchen; der vordere Theil des Genickes schwarz oder braunschwarz. Am dritten (9 mm langen) Individuum fanden sich nur die rothbraunen Flechehen, dagegen schien das Schwarze verschwunden. Die ('Taf. T. Fig. 18) kalkweisse Schale stark durchschimmernd; die Schalenseite des Mantels stark schwarzfleckig. Nach Wegnahme der Schale (und schon vorher) zeichnete sich der Eierstock mit stark ausgeprägter gelbrother Farbe aus; vor der Blätterdrise in dem einen Individuum auch ein breiter, vom angesammelten Secrete herrührender weisser Streifen.

Das Centralnervensystem wie gewöhnlich; die (wegen des Otolithen) kalkweissen Otocysten sehr deutlich.

Der Schlundkopf $2 \mathrm{~mm}$ lang; die Mandibelplatten ('I'af. R. Fig. 21) wie oben. An der Zunge $17(9+8), 17(9+8)$ und 19 Zahnplattenreihen; weiter nach hinten (in der Raspelscheide) fanden sich deren $45(37+8), 40(33+7)$ und $30(23+7)$; die Gesammtzahl der Reihen somit 62, 57 und 49. Die Breite der vorderen medianen Platten 0,1, der hinteren 0,12 mm; die Länge der vorderen Seitenplatten 0,16, der hinteren 0,18 mm. An dem Sehneiderande der medianen Platten (Taf. T'. Fig. 19, 20) 3-4 Dentikel zu jeder Seite der Spitze; am hinteren Rande (Taf. 'T. Fig. 21, 22) der lateralen 8-15, am vorderen 4 (selten 3 oder 5) ('Taf. R. Fig. 22, 23). - Der weissliche Blättermagen wie gewöhnlich, ringsum mit Ausnahme der Vorderseite vom ockergelben Drüsenlager überzogen. Die Leber hell. - Die Niere aus 6-7 am hinteren Ende zerklüfteten Drüsenbändern gebildet.

In den Läppchen des Eierstockes nur wenige grosse oogene Zellen. Die S a me ntaschen (Taf. T. Fig. 23) in Anzahl zwischen 8 und 12 variirend, weisslich, leer, zum grossen Theil ganz zusammengefallen. Die linke Hälfte der Schleimdrüs e hellgelb, linten am hellsten; die rechte dunkelbraungelb.

Die Art unterscheidet sich in der Beschaffenheit der Schale von der vorigen; wahrscheinlich auch in der Farbe des Rückens sowie vielleicht in Beziehung auf Farbe des Eierstockes und der den Blättermagen überziehenden (übrigens, wie es scheint, in Farbe selır wandelbaren) Druise.

Derselben Art gehörten wahrscheinlich auch zwei von SEMPER, gleichfalls 1859, bei Cebú und im Canale von Lapinig aus einer Tiefe von 10 Faden gefischte Individuen, das eine weiblich, das andere männlich.

Das grössere weibliche war etwa $15 \mathrm{~mm} \mathrm{lang}$ bei einer Breite bis 12 und einer Höhe bis $7 \mathrm{~mm}$; das kleinere männliche maass $7,5-6,5$ und $3,5 \mathrm{~mm}$. Die Farbe wie oben, die Schalengegend aber fast aschengrau; die Unterseite des Mantels mit zerstreuten schwarzgrauen Punkten; das Vorderende des Fusses oben schwarz, grau punktirt.

Die Otocysten wie oben. Die Mandibelplatten wie oben. Die Zung e mit $15(10+5)$ und $17(10+7)$, die Raspelscheide mit $55(45+10)$ und $47(40+7)$ Zahnplattenreihen; die 
Gesammtzahl derselben somit 70 und 64. Die Breite der medianen Zahnplatten in dem grossen Individuum bis 0,14 , die Länge der lateralen bis $0,26 \mathrm{~mm}$ betragend. Im Blättermagen etwa 16 Septa. Die Leber graubraun. - Die Niere mit etwa 8 Bändern. - Dio Samentaschen wie oben, oder noch mehr atrophisch. Das Knäuel der Windungen des Samenleiters wie oben, die untere Strecke desselben viel kürzer und weniger geschlungen als gewöhnlich. Der $3,5 \mathrm{~mm}$ lange $\mathrm{Penis}$ wie gewöhnlich.

H a b. M. philippin.

\%. Mars. indecora, BGн. n。 sp.

Taf. T. Fig 9-17.

Von dieser Form hat Semper 1859 bei Pandanon aus einer Tiefe von etwa 30 Faden ein einzelnes, männliches Individuum gefischt. Notizen über dasselbe fehlen.

Dasselbe maass, in Alcohol bewahrt, an Länge $12 \mathrm{~mm}$ bei einer Breite bis 9,5 und einer Höhe bis $6 \mathrm{~mm}$; die Länge des Fusses betrug $8 \mathrm{~mm}$ bei einer Breite bis 4,1 mm, der Schwanz 3,5 mm lang; die Länge des Penis $4 \mathrm{~mm}$ bei einer Breite bis 1,5, die Spitze des Samenganges noch 1,4 mm hervorragend. Die F arbe schmutzig gelblichweiss; die äusserste Hälfte der Tentakel gelb. Der Kopf war weniger als bei anderen untersuchten Arten abgeplattet. Die (Fig. 9) Schalenseite des Mantels ohne Schwarz.

Die cerebralen und pleuralen Ganglien im Vergleiche mit dem supra- und infraintestinalen ungewöhnlich gross; die pedalen (Fig. 10) kurz, an der oberen Seite des Vorderendes die gewöhnliche abgeschnürte Parthie. Die Otocysten auswärts hinter den Ganglien liegend, von 0,14 mm Durchmesser; wegen des kalkweissen, in Diam. etwa $0,09 \mathrm{~mm}$ haltenden Otoliths unter der Loupe in die Augen fallend (Fig. 10 bb, 11).

Der Schlundkopf wie gewöhnlich. Die Mandibelplatten von ungewöhnlicher, langgestreckter Form, an Länge etwa $1,22 \mathrm{~mm}$ messend bei einer Höhe bis $0,56 \mathrm{~mm}$; gelblich, der hintere Theil mit griunlichem Schimmer (Fig. 12). An der Zunge 15 Zahnplattenreihen; in der nicht recht langen Raspelscheide 24 entwickelte und 6 jüngere Reihen, die Gesammtzahl derselben somit 45. Die Farbe der Platten stark gelb. Die Breite der medianen Platten 0,068 bei einer Länge von 0,075 und einer Höhe von $0,06 \mathrm{~mm}$; die Länge der Seitenzahnplatten 0,14 mm. Die medianen Platten (Fig. 13, 14) mit 4 Dentikeln zu jeder Seite der gebogenen Spitze. Die lateralen Platten mit meistens 8-12 Dentikeln des hinteren und mit 4 ungewöhnlich spitzen und starken des vorderen Randes (Fig. 15, 16).

An der Speiseröhre kaum eine Erweiterung; der zweite Kropf dagegen stark entwickelt, weisslich. Der Blättermagen weisslich, an der oberen Seite und am Hinterende von graugelbem Drüsenlager iiberzogen. Die hellbraungraue Leber gross. - Die weissliche Niere von 7-8 kürzeren, längeren und wieder kürzeren Drüsenziigen gebildet.

Der kleine von weissen Follikeln gebildete $\mathrm{Hoden}$ ringsum von der Leber eingefasst; in den Follikeln, wie es schien, auch zwei Arten von Zoospermien. Die das 
ctwa 1,5 mm lange Knäuel bildenden Windungen des Samenganges hinten sehr dünn, vorne dicker (Fig. 17 a); die Fortsetzung des Ganges auch in der ersten Strecke längs der Scitenwand der Körperhöhle mehr dünnwandig, dann an der rechten Seite des Schlundkopfes mehrere Schlingen bildend (Fig. 17 b) und in den Penis (Fig. 17 c) eintretend; jener Theil des Samenganges ausgestreckt etwa $12 \mathrm{~mm}$ messend.

Durch die Form der Mandibelplatten sowie vielleicht der Zahnplatten, vielleicht auch durch die Eorm der Schale unterscheidet sich diese Art von den anderen bisher bekannten Marsenien.

\section{II. isabellina, BGI. n. sp.}

II a b. M. philippinense.

Taf. XLI. Fig. 8; Taf. Q. Fig. 21; Taf. S. Fig. 6-9.

Von dicser schon 1875 von mir mit Namen veröffentlichten Form hat SEMPER bei Zamboanga in einer liefe von 2-3 Fäden am 17. October 1859 ein männliches Individuum gefischt, das am Morgen des dritten Tages schon gestorben und halb in Verwesung war und das verloren ging, uber welches doch neben der nach dem lebenden Thiere aufgenommenen Abbildung noch Notizen vorliegen, sowie ein Priparat der Mundtheile.

Die Länge des lebenden 'Thieres hat sich, SExper zufolge, zu etwa $10 \mathrm{~mm}$ belaufen. Die F a rbe ist, der Zeichnung (l. c.) zufolge, an der Oberseite dunkel-isabell gewesen mit ziemlich zahlreichen nicht ganz feinen weissen Fleckchen und mit weissem Mantelrande. SEMper hat das Thier an der Oberfliche des Wassers schwimmen gesehen.

Semper hat noch die ziemlich flache Schale abgebildet und die "Ohrblase mit cinfachem sehr grossem Otolithen".

Die Mandibelplatten sind horngelb, von gewöhnlichen Formverhältnissen, der Vorderrand nur ziemlich stark ausgerandet. An der Zunge kamen 10 Zahnplattenreihen vor und in der langen Raspelscheide 53 entwickelte und 7 jüngere Reihen; die Gesammtzahl derselben somit 70. Die Zahnplatten von horngelber Farbe; die Breite der medianen bis $0,04 \mathrm{~mm}$ betragend, die Länge der lateralen bis $0,08 \mathrm{~mm}$. Die medianen Platten mit stark vortretender Spitze und jederseits drei Dentikeln, mit ziemlich stark gespreizten Beinen (Fig. 6 a, 7, 8a). Die Seitenzahnplatten mit 4-5 groben Dentikeln des vorderen, mit 6-7, mitunter auch bis 12-15 feinen des hinteren Randes (Fig. 21; Fig. 6 bb, 8 bb, 9).

\section{II. Diegoënsis (DALL).}

Ha b. M. pacific. (Californ.).

Taf. T. Fig. $24-32$.

Von der Art lag mir nur ein einziges, männliches Individuum vor, mir 1884 freundlich von Herrn W. H. DALL (Washington) geschenkt. 
Die Länge des in Alcohol bewahrten Individuums (dessen Schale schon oben beschrieben worden ist) betrug beiläufig 16 bei einer Breite bis 12 und einer Höhe bis $9 \mathrm{~mm}$; die Länge des Fusses 14 bei einer fast durchgehenden Breite bis 8 , aber vorne bis $12 \mathrm{~mm}$; die.Länge des Schwanzes $7,5 \mathrm{~mm}$; die Breite des Mantelgebrämes bis $5 \mathrm{~mm}$; die Länge der Tentakel 2,5, die des (ausgestreckten) Penis $10 \mathrm{~mm}$. Dio F a r be des Rückens schwarz und grauschwarz, ebenso die der oberen Seite des Fusses, während der Schwanz sowie das Genick sammtschwarz sind; die Unterseite des Mantelgebrämes schwarzgrau; die niedrigen Seiten schwach-gelblichweiss, ebenso der Penis, der Boden der Kiemenhöhle und die Fusssohlc.

Die Formverhältnisse schienen fast die gewöhnlichen. Der Rücken war etwas knotig uneben; das Mantelgebräme ziemlich breit, wellenförmig, ziemlich dünn; die Athemröhre etwas links liegend und nicht tief; eine eradiirende Streifung an der Unterseite des Mantelgebrämes, rings um den Fuss, war kaum sichtbar. Der Kopf wie gewöhnlich, die Tentakel ziemlich kurz; durch die. Nundspalte war an dem untersuchten Individuum die (den Schlundkopf enthaltende) Schnauze (Mundröhre) ganz ausgestulpt, 4,5 mm lang bei einer Breite von 3,5 und einer Höhe von $2,75 \mathrm{~mm}$; an der Spitze zeigte sich der von den braungelben Mandibelplatten eingefasste Innenmund. Der Fuss kräftig, vorne mit stark ausgezogenen Ecken, die Furche des Vorderrandes sehr ausgeprågt; der Schwanz stark. - Die Länge der Schale 13,25 mm bei einer Breite bis 9,5 und einer Höhe bis $7 \mathrm{~mm}$ (s. oben). Die Schalenseite des Mantels schwarzgrau.

Nach Wegnahme der Schale zeigen sich die Theile der oberen Eingeweidemasse in den gewöhnlichen Lageverhältnissen durchschimmernd. Die Spitze der Kieme sowie die Analöffnung präsentiren sich rechts, den Rand der eigentlichen Kiemenspalte ein wenig überragend.

Das Centralnervensystem fast wie gewöhnlich; nur waren die cerebralen Ganglien ungewöhnlich gross und das infraintestinale kleiner; die durch starke, die Fussknoten kreuzende (quergehende) Muskelfasern an den Fuss innig befestigten pedalen Ganglien von gewöhnlicher 8-Zabl-Form, vorne dicker; an der Unterseite eine Andeutung von der secundären Ganglienbildung.

Das Geruchsorgan wie bei verwandten Arten, jederseits mit etwa 40 Blättern.

Der weissliche Schlundkopf etwa $5 \mathrm{~mm}$ lang bei einer Breite bis 3 und einer Höhe bis 2,5 mm; die gräulichen Knorpelflecken wie gewöhnlich; die Muskeln der Oberfläche wie oben beschrieben. Die (Fig. 24, 25) Mandibelplatten horngelb in der freien Parthie, sonst gelblich und gelblichgrün; etwa $2 \mathrm{~mm}$ lang bei einer Höhe bis $1,5 \mathrm{~mm}$; der freie Theil bis $0,55 \mathrm{~mm}$ breit, von mehreren (5) mit dem freien Rande parallelen Linien durchzogen. Die Zunge von gervöhnlicher Form, an derselben $15(9+6)$ Zahnplattenreihen, von denen die 6-7 vordersten mehr oder weniger beschïdigt; in der $10,5 \mathrm{~mm}$ langen, am Ende in gewöhnlicher Art geschwollenen, links aufgerollten Raspel- 
scheido 40 entwickelte und 6 jüngere Reihen; die Gesammtzahl derselben somit 61. Der Bau der Zunge vollständig wie bei der typischen Art; das Raspeldach auch so. Die Zahnplatten gelblich; die Länge der lateralen bis 0,38 , die der médianen bis $0,28 \mathrm{~mm}$. Die medianen (Fig. 26, 27) Platten von gewöhnlicher Form, an jeder Seite des Schneiderandes 4-6 Dentikel; ganz unregelmässige Formen kamen auch vor (Fig. 27). Die lateralen Platten auch wie gewöhnlich; am oberen Rande des Hakens 12-15 kleine, am unteren 3-5 starke Dentikel (Fig. 28, 29).

Die weissliche Speiseröhre etwa $5 \mathrm{~mm}$ lang und, wie gewöhnlich, auch hinten an der rechten Seite erweitert (erster Kropf); ganz hinten mündet in dieselbe der auch weissliche (zweite) Kropf. Der Blättermagen $3,5 \mathrm{~mm}$ lang bei einer Breite bis 3,5 und einer Höhe bis $4 \mathrm{~mm}$, braungrau, aber nur an der rechten Seite oben entblösst, sonst ringsum von dem starken gelblichen Drüsenlager eingehüllt; der blätterige Bau der Wand wie gewöhnlich. Der eigentliche Magen mit der weiten Cardia-Oeffnung und der Gallenöffnung nebeneinander, die Wände waren meistens mit einem kalkweissen Praecipitate überzogen; der Darm ganz wie gewöhnlich, fast am Vorderrand der Leber verlaufend. - Der Inhalt der Verdauungshöhle unbestimmbare thierische Masse, worin mehrere Stücke von Hydroid-Polypen-Stämmen sowie eine Masse von den von den Chelyonoten (vergl. 'Taf. M. Fig. 24, 24) bekannten Körperchen (s. oben). - Die Le ber braungrau.

Die Kiemenblätter mit ziemlich schwachen Querfalten; eine Unmasse (Fig. 30) von Zellen mit concentrischen Verdickungen und von einem Diam. bis $0,05 \mathrm{~mm}$ zeigend. Das Pericardium mit dem Herzen wie gewöhnlich, vorne die feine pericardio-renale Oeffnung. Die Niere und die Blätterdruise wie gewöhnlich.

Der gelblichweisse Hode wie gewöhnlich, die Spira ganz von demselben gebildet; in den Läppchen kleine Zellen und Zoospermien. Der Samenleiter an gewöhnlicher Stello sein sehr grosses (bei einer Höhe von 2,5 und einer Dicke bis 1,5 mm, etwa $3,5 \mathrm{~mm}$ langes) Knäuel von erst ganz feinen, dann allmählig dickeren Windungen bildend; dicht hinter der Muskelfacette nimmt er sein sehr langes, unregelmässig aufgerolltes, in die Bildung des Knäuels eingehendes Divertikel auf. Die Fortsetzung des Samenleiters fein geschlängelt in der Körperwand bis an die Gegend des Penis verlaufend, dann diese verlassend, frei und etwas dicker werdend und in mehreren Schlingen sich iber das Centralnervensystem und den Blättermagen linlegend; diese freie Strecke des Samenleiters etwa $22 \mathrm{~mm}$ lang bei einem fast durchgehenden Durchmesser von beiläufig $0,4 \mathrm{~mm}$. Der Penis wie bei anderen Marsenien biconvex, planconvex und concav-convex, gebogen, in der letzteren Hälfte etwas breiter, bis $3,5 \mathrm{~mm}$ breit, mit ovaler Oeffnung fast am Rande hinter der Spitze (Fig. 31 a); hinter der Oeffnung lag das Ende des Samenganges zurükgebogen (Fig, 32 a). 


\section{III.}

Marseniella, BGIr. N. gen.

Im Aeusseren unterscheiden die Marseniellen sich nur wenig von den ächten Marsenien; sie sind aber doch etwas mehr abgeplattet, besonders der eigentliche Ruicken, und etwas mehr länglich. Die Schale ist fast ganz hornartig; die Spira ganz klein; die letzte Windung sehr gross und weit, hinten von der Spira ganz gelöst. Im inneren Baue stimmen die Marsenicllen vollstïndig mit den typischen Marsenion, nur fehlt der Vormagen (zweiter Kropf) vollstiindig. Auch der Penis ist vielleicht von etwas anderer Form.

Von der Gattung ist bisher nur die untenstehende neue, hochnordische Art bekannt.

II. borealis, BGI. n. sp.

Ha b. M. atlant. septentr.

Taf. U. Fig. 1-2; Taf. V. Fig. 6-8; Taf. X. Fig. 1-6.

Von dieser merkwiirdigen 'Thierform hat mir ein einziges, männliches Individuum vorgelegen, mir von Herrn Museumsdircetor R. CoLLETT, als bei Florö unweit von Bergen mit Velutina haliotoidea zusammen gefischt, geschenkt.

Das in Alcohol gut bewahrte Individuum hatte eine Länge von $22 \mathrm{~mm}$ bei einer Breite bis 15 und einer Hühe bis fast $11 \mathrm{~mm}$; die Länge des Fusses 16,5 bei einer fast durchgehenden Breite von $7,5 \mathrm{~mm}$, die Länge des Schwanzes $8 \mathrm{~mm}$; die Breite des Mantelgebrämes bis $5,5 \mathrm{~mm}$; die Länge der Tentakel $3,5 \mathrm{~mm}$, die des Penis $8 \mathrm{~mm}$. - Die Farbo des Thieres war durchgehends schmutziggelb, am Rücken zerstreute kleine hellere Punkte und noch dazu einzelne schwärzliche verschwommene Flecken.

Die Form von der der ächten Marsenien etwas abweichend, etwas mehr abgeplattet und mehr länglich. Der Rücken überall grob- und feinknotig; die (Ein-) Athmungs-Falte und Furche wie gewöhnlich; das Mantelgebräme ziemlich breit, die eradiirende Streifung hinten an der Unterseite wie bei den typischen Marsenien; die Mundspalte wie bei diesen letzteren etwas nach hinten an der Unterseite des Kopfes liegend, (die Schnauze fast $2 \mathrm{~mm}$ hervorgestülpt). Die Fusspore wie gewöhnlich.

Der Mantel im Ganzen dicker als bei den Marsenien. - Die Schale (Tat. A. Fig. 1, 己) ist oben (pag. 179) beschrieben.

Nach Wegnahme der Schale zeigten sich die Lageverhältnisse der oberen Eingeweide ganz typisch; hinten der grosse, hellgraubräunliche, ziemlich grob eckig-körnige, die Spira und die hintere Hälfte der oberen Eingerweidemasse bildende Hoden; vor der Spira 
die groben opak-gelblichweissen Windungen des Samenganges; vor den beiden letzteren Organen die (ganz schwach griunlich-) graue Blätterdrüse (Taf. V. Fig. 8a), vor dieser schimmerten kürzere und liingere, ungetheilte oder gebrochene, kalkweisse Secretmassen (Fig. 8 b) durch das Dach der Kiemenhöhle, und ganz links zeighte sich die schrägstreifige, schwach gelblichweissliche Niere; vor den Secretmassen die (Grundstiucke der gebogenen) (Fig. Sc) Kieme (Taf. X. Fig. 3); vor dieser das schräigliegende, ziemlich grosse, schmutzigbräunlich-gelbliche Geruchsorgan. Die Schalenleiste ziemlich (meistens $1-1,1 \mathrm{~mm}$ ) breit; die braunen Muskelfacetten der Schale an gewöhnlicher Stelle, stark (2,4 mm lang). Hinten schimmerten an der Unterseite der oberen Eingeweidemasse der Magen und der Anfangstheil des Darmes sotvie vor und hinter denselben ein kleiner Theil der gelben Leber hindurch.

Die Organe der unteren Eingeweidemasse fanden sich in den bei den Marsenien gewöhnlichen Lageverhältnissen.

Das Centralnervensystem ganz wie bei den typischen Marsenien; die Ganglien alle deutlich geschieden, das supraintestinale das kleinste; das rechte cerebro- und pleuropedale Connectiv in gervöhnlicher Weise verkïrzt; die pedalen Ganglien von gewöhnlicher Kegelform; die secundären kurzstieligen Ganglien vorne an der unteren Seite und somit von oben ab gar nicht sichtbar.

Die milchweissen, die Otocysten enthaltenden Seheiben an der Aussenwand der Körperhöhle in der Höhe der Mitte der Fussknoten angelöthet, von etwa 0,25 mm Durchmesser. Die kugelrunden Otocysten in Diam. beiläufig 0,15 $\mathrm{mm}$ haltend, mit einem kugelrunden Otolithen von $0,055 \mathrm{~mm}$ Durchmesser. Das Geruchsorgan mit der gewöhnlichen Falte, (jederseits) mit etwa 30 hohen Blättern.

Der Schlundkopf 3,5 mm lang bei einer Breite bis 3 und einer Höhe bis $2,5 \mathrm{~mm}$; die nach oben aufgerollte Raspelscheide wenigstens noch einmal so lang wie der Schlundkopf; die Formverhälinisse des letzteren ganz wie bei den typischen Marsenien; die starken Knorpelfacetten dreieckig, bräunlich, die Raspelscheide ganz wie bei den Marsenien. Die Mandibelplatten (Taf. V. Fig. 7) hell horngelb, etwas dunkler in der vorderen Hälfte, etwa 1,5 mm lang, vorne ziemlich niedrig, der Kaurand etwas ausgeschweift. Die Zunge wie gerwöhnlich; in der dunkel horngelben Raspel 16 Zahnplattenreihen, von denen die 2-3 vordersten mehr oder weniger beschädigt; in der Raspelscheide 34 entwickelte und 6 jügere Reihen; die Gesammtzahl derselben somit 56. Die Zahnplatten horngelb, die Breite der jüngsten medianen etwa 0,16, die Länge der entsprechenden Seitenzahnplatten beiläufig $0,29 \mathrm{~mm}$. Die Platten von gewöhnlicher Form; am Schneiderande der medianen jederseits meistens 5-7 feine Dentikel (Taf. U. Fig. 1), der Untersehied in der Länge der Beine unbedeutend; nach hinten zu kamen öfter etwas abnorme Platten vor (Taf. V.Fig.6); am oberen (hinteren) Schneiderande der Seitenzahnplatten meistens 10-15 winzige Dentikel, mitunter auch eine geringere Anzahl, an dem unteren (vorderen) Rande $4-5$ stärkere 
(Taf. X. Fig. 5, 6). Die Zungenknorpel vorne milchweiss, hinten mehr gelblich, übrigens ganz wie gewöhnlich.

Die Speis eröhre links hinabsteigend, nach hinten etwas weiter; keine Spur eines Vormagens. Der Blättermagen gelblich, von gewöhnlicher Form, mit etwa 10 Blättern; das überziehende Drisenlager gelb. Der eigentliche Magen und der Darm wie gewöhnlich. Die Leber gelb.

Die Niere mit 4-5 Federn, von gewöhnlicher Form, so auch die Blïtterdrüse. Die Kiemenblätter ungewöhnlich (bis $3,75 \mathrm{~mm}$ ) hoch und schmal (Taf. X. Fig. 3), sonst wie geivöhnlich.

Der Hoden gross, die Lïppchen ziemlich gross, mit den gewöhnlichen Zoospermien. Der Samenleiter das gewöhnliche Knäuel bildend, das eckig-kugelrund war und von etwa 3,5 mm Durchmesser; aus dem Vorderende geht der eigentliche Samenleiter aus, welcher gleich ein gewundenes Divertikel aufnimmt, nach einem freien Verlauf von $4 \mathrm{~mm}$ in gewöhnlicher Weise in die Körperwand eindringt und aus derselben wieder austritt, dann mehrere lange, in Allem $23 \mathrm{~mm}$ lange Schlingen über den Blättermagen und den Schlundkopf hinlegt und in den Penis eintritt; der Samengang ist in dieser Strecke von einem durchgehenden Diam. von 0,5 mm. Der (T'af. U. Fig. 2) Pen is $7 \mathrm{~mm}$ lang bei einer Breite bis 3, etwas abgeplattet, besonders am Ende, dessen Rand von einer Furche aufgenommen war, dem ausgestreckten Ende des Samenleiters entsprechend, welches spitz zulaufend (Fig. 2a) etwa halb so lang wie der Penis war.

\section{IV.}

Marseniopsis, BGir. N. gen.

Die Marseniopsen bilden, wie früher erwähnt, cin Uebergangsglied zwischen den diclinen und androgynen (Marseniua, Onchidiopsis) Marseniaden. Sie haben die allgemeinen Formverhältnisse der Onchidiopsen, den halbkugelförmigen, wie aufgeblasenen Oberkörper mit dem dicken wulstigen Mantelrande; auch der Aussenmund liegt mehr nach vorne; es fehlt ihnen aber die rechte Athmungsfalte und -Halbkanal (Exspirationsfurche), und die Kiemenblätter sind etra wie bei den Marsenien. Die Kieferplatten sind schmäler und im Ganzen kleiner als bei anderen Marseniaden. Die Zungen bewaffnung ist der der androgynen Marseniaden ganz ähnlich; ausserhalb der Seitenzahnplatten kommen somit zwei hakenförmige Zahnplatten vor. Die Marseniopsen sind getrennt geschlechtlich und stimmen im Baue der Geschlechtsorgane zunächst mit den Chelyonoten, der untere Theil des Samenleiters ist somit auch nicht frei in der unteren Körperhöhle, auch die Form des Penis stimmt wohl zunächst mit der des Organs der ächten Marsenien. Die Schale ist im Ganzen der der ächten Marsenien sehr ähnlich, aber mehr gewölbt. 
Von der Gattung sind bisker nur die untenstehenden Arten aus der Sïdsee bekannt:

1. M. pacifica, BGH. n. sp.

Rep. on the Marseniadae. Voy. of H. M. S. Challenger. l. c. 1886. pag. 19-22. pl. I. Fig. 7-27.

2. M. Murrayi, BGI. n. sp.

1. c. 1856 . pag. $23-24$. pl. 1. Fig. $28-38$.

3. M. Wilsoni (E. A. Sirtir).

Lamellaria Wilsoni. E. A. Surte, descr. of a new sp. of Lamellaria from South Australia. Ann. mgz. n. h. 5 S. XVIII. Oct. 1886. pag. 270-271. w. figg.

M. austr. (Port Phillip Bay).

1. Marseniopsis pacifica, $B \mathrm{GH}_{\mathrm{H}}$ ‥ sp.

Ha b. M. australe (ins. Kerguelen).

Taf. Y. Fig. 23; Taf. Z. Fig. 1-5; Taf. A. Fig. 6-9.

Von dieser Form lag nur ein einziges, weibliches Individuum vor, während der Challenger-Expedition in 1873 in der Nähe der Kerguelen-Insel gefischt.

Das Individuum war $18 \mathrm{~mm}$ lang, röthlichgelb, der Rücken mit groben gerundeten Kuötchen wie bei den Onchidiopsen bedeckt; für näheres Detail muss hier auf die im englischen "Report" gelieferte Untersuchung hingewiesen werden, für die der Schale (Taf. E. Fig. 6) ebenso.

Das Centralnervensystem, die Tentakel ('Taf. Z. Fig. 1) und die Otocysten wie gewöhnlich. - Der Schlundkopf (Taf. E. Fig. 7) von gewöhnlicher Form und von gewöhnlichem Baue; die Kieferplatten ('T'af. Z. Fig. 2 bb) horngelb, schmal, beiläufig $0,6 \mathrm{~mm}$ lang, aus dicht gedrängten Stäbchen gebildet. Die Zunge wie gervöhnlich; in der Raspel 20 Reihen von Zahnplatten, die Anzahl derselben im Ganzen 55. Die medianen Zahnplatten (Taf. Z. Fig. 3; 'Taf. E. Fig. 8a) mit 4-5 Dentikeln an jeder Seite der Spitze. Die lateralen Zahnplatten (Taf. E. Fig. 8 bb) zeigen am oberen-hinteren Rande des Hakens 6-12, mitunter doch nur 4-5 Dentikel; am unteren-vorderen Rande 4-5 gröbere. Die beiden hakenförmigen Aussenplatten (Taf. Z. Fig. 4ab; Taf. E. Fig. Sc) olne Dentikel.

I) Se Speiseröhre hinten kropfartig erweitert, ein zweiter (eigentlicher) Ḱropf fehlt absolut. Der Blättermagen wie gewölmlich halbkugelförmig; die Zahl der Blïtter schien nur etwa 10 zu betragen; das überziehende Druisenlager weiss. - Die Niere (Taf. Y. Fig. 23) wie gewöhnlich; die pericardiaco-renale Oeffnung (Fig. 23 a) sehr deutlich. Die Kiemenblätter an Zahl etwa 75 betragend, mit ähnlichen Falten an den Seiten wie bei den ichten Marsenien (Taf. E. Fig. 9). - Der Eierstock und der Oviduct wie 
gewöhnlich; die (4) Samenblasen (Taf. Z. Fig. 5b) kalkweiss. Die Schleim- und Eiweissdrise wie gewöhnlich (Fig. 5 a); ebenso die Vagina, ihr Divertikel sehr stark. ${ }^{2}$ )

\section{Marseniopsis Murrayi, Ban. ก. sp.}

Ha b. M. australe (ins. Marion).

Taf. Y. Fig. 22; Taf. Z. Fig. 6; Taf. E. Fig. 10, 11.

Von der Art lag auch nur ein einzelnes, aber männliches Individuum ror, während der Challenger-Expedition in der Nähe von der Marion-Insel gefischt.

Das in Alcohol bewahrte Individuum war $18 \mathrm{~mm}$ lang, von (gräulich-) rothbrauner Farbe; der Riicken war mit etwas abgeplatteten runden Knoten bedeckt.

Im inneren Baue stimmt diese Form wesentlich mit der vorigen. Der Schlundkopf wie oben; die Mandibelplatten 0,75 mm lang, im Baue (Fig. 22) mit denen der vorigen Art stimmend. In der Raspel 24 Zahnplattenreihen; die Gesammtzahl derselben 72. Die medianen Platten (Taf. E. Fig. 10-11) jederseits mit 6-8 Dentikeln am Schneiderande; die lateralen schlanker, fast ohne Dentikel am oberen Rande des Hakens. - Der Hoden, der Samenleiter und sein prostatisches Divertikel fast wie bei den Chelyonoten. Der Pen is (Taf. Z. Fig. 6) in Form auch einigermaassen mit dem dieser Gruppe iibereinstimmend.

\section{V.}

\section{Marsenilla, Gray.}

Die Marseninen sind schon im Aeusseren von den ächten Marsenien, deren allgemeine Körperform sie sonst haben, leicht unterscheidbar; erstens durch den medianen Längssehlitz des Rückens, in welchem die Schale mehr oder weniger entblösst liegt ${ }^{2}$ ); dann dureh die an der rechten Seite des Mantelgebrämes stehende Exspirationsfalte und IIalbkanal. Die Kiemenbläter ohne Querfalten der Seitentächen. Der Aussenmund und der Penis sind denen der ächten Maxsenien ziemlich ähnlich. - Im inneren Baue stimmen die Marseninen dagegen mit den Onchidiopsen und sind wie diese hermaphroditisch. Die Mandibelplatten sind stark, aus Reihen von kurzen Stïbchen zusammengesetzt (aber ohne vorragenden Zahn am Vorderrande). Ausser den Seitenzahnplatten zeigt die Zungen bewaffnung zwei äussere hakenförmige Zahnplatten. Fin Vormagen fehlt. Das Geschlechtssystem im Ganzen sowie der Penis wesentlich mit denen der Onchidiopsen iibereinstimmend.

1) Für näheres Detail der anatomischen Untersuchung dieser und der folgenden Art muss anf den citirten Report hingewiesen werden; demselben sind auch die hierhin gehörenden Figuren entlelınt.

2) Nur in der Mars. Dalli ist die Schale rom Mantel rollständigst eingehüllt, und jede Spur von MIantelspalte am Rücken fehlt. Vielleicht bricht die Schale erst in einem gewissen Alter des Thieres durch. 


\section{Marsenina prodita, LơÉn.}

H a b. Oc. atlant. or. septentr. et occident, arctic.

Taf. T. Fig. 33-34; Taf. U. Fig. 4-26.

Von dieser aretischen Art habe ich 10 Individuen zur Untersuchung gehabt, alle in Havösund (beim Nordeap) von M. SARS gefischt, der sie (1. c.) als mit Ascidia mentula und Leptoclinum clavatum in einer Tiefe von 30-50 Fäden sehr allgemein vorkommend erwaihnt. Die mir von Herrn Museums-Inspector R. Colletr freundlich gegebenen, in Alcohol bewahrten Individuen waren leider alle ziemlich stark erhärtet. Neun davon waren alle fast von derselben Grösse und Form, und es wurden alle (10) anatomisch untersucht.

M. SARs giebt die Farbe des Rickens beim lebenden Thiere als hellgelb oder orangegelb an mit mehr oder weniger zahlreich zerstreuten graubraunen Fleckchen oder ohne solche; oder der Riicken ist grauweiss ohne Fleckchen oder mit dunkeln Punkten, die mitunter ganz dichtstehend denselben fast schwarz färben. Die Unterseite des Mantelgebrämes, der Kopf und der Fuss immer heller als der Rücken, grauweiss, hellgelb oder orangegelb. G. O. SARs erwälhnt den Mantel als röthlich braunfleckig ( rufescens, fusco maculatum"). - Den beiden SARs zufolge ist der Riicken knotig, um die Mantelspalte nämlich mit mehreren (10-16) ziemlich grossen conischen Knoten, wie auch von G. O. SARS (1. c. Fig. 5 a) dargestellt. Der ältere SARS scheint uibrigens Individuen ohne Mantelspalte gesehen zu haben, bei welchen der Mantel in der Gegend der Sehale nur "sehr dün" war. - G. O. SARs hat Individuen von einer Länge bis $24 \mathrm{~mm}$ gesehen.

Die in Alcohol bewahrten Individuen erreichten eine Lainge bis $21 \mathrm{~mm}$ bei einer Breite bis 18 und einer Höhe bis $8 \mathrm{~mm}$; die Lünge des Fusses 12 bei einer Breite bis 6,5 mm; die Breite des Mantelgebrämes (an der oberen Seite) bis 5,5 mm; die Liange der (dorsalen) Mantelspalte $1-7 \mathrm{~mm}$ bei einer Breite bis $3-5 \mathrm{~mm}$; die Länge der 'Tentakel 3,5 mm. Nur ein Individuum war grösser, bis $27 \mathrm{~mm}$ lang bei einer Breite voll 18 und einer Höhe von $8 \mathrm{~mm}$; die Länge der Mantelspalte betrug hier 10 bei einer Breite bis $5 \mathrm{~mm}$. - Die Farbe der Rückenseite weiss oder weisslich, mitunter ganz schwach röthlich in der hinten der Schale entsprechenden Strecke (wegen der Geschlechtsdrüise); die Unterseite des Mantelgebrämes (schwach gelblich-) weiss, der Kopf und der Fuss gelblich.

Die Form verhältnisse wesentlich wie bei den Marsenien. Am Riicken hier und da, besonders aber in der Umgegend der Ruickenspalte, im Ganzen aber sparsam zerstreute (weisse) Knötchen. Die dorsale Mantelspalte in Form und Breite schr wechselnd, länglich, an den Enden gerundet oder zugespitzt; der ebene Rand derselben liegt mit der Schale in Berührung, lässt sich aber von derselben leicht aufheben, sowie der im Ganzen gegen die Spalte hin kaum wesentlich diinnere Mantel sich bis an den Schalenrand und hinten bis an den Grund von der unterliegenden Schale leicht abheben 
liisst. Das Mantelgebrime breit, gegen den freien Rand allmihlig verdünnt, hinauf- und hinabgebogen. $\Lambda \mathrm{m}$ Vorderrande zeigt sich submedian, d. h. etwas melı links, cine durch wenigstens die halbe Breite des Mantelgebrämes reichende Spalte, deren hinterer Rand nach oben gebogen ist ${ }^{1}$ ); dieser Einschnitt setzt sich an der Unterseite des Mantelgebrimes in den gewöhnlichen, an der linken Ecke der Kiemenspalte endigenden Halbkanal (Inspirations-Canal) fort. An der Mitte der rechten Seite des Mantelgebrämes oder ein wenig mehr nach vorne findet sich eine der vorigen ganz ähnliche oder noch tiefere Spalte, von deren meistens nach oben geschlagenen Rindern der hintere grösser ist und meistens den vorderen deckt; die Spalte sich wie oben in einen ähnliehen, im Granzen vielleicht ein wenig breiteren Halbkanal fortsetzend, welcher in die rechte Ecke der Kiemenspalte ïbergeht (Exspirations-Canal). Innen an der Unterseite des hinteren Theils des Mantelgebrämes die gewölnnliche eradiirende Streifung. Die Kicmenspalte wie gewöhnlich; rechts ragt die Spitze der Kieme meistens in dieselbe hervor, in der Mitte mitunter auch die Spitze des Geruchsorgans. Der Kopf mit den Tentakeln (und den Augen) sowie dem Aussenmunde wie bei der Marsenia, ebenso der Fuss mit dem Schwanze; in der Furche des Vorderrandes die Fusspore.

Die Immen (Schalen-) seite des Mantels farblos. Nach Entfernung der Schale zeigten sich die einzelnen Theile der oberen Eingeweidemasse in denselben Lageverhältnissen wie bei der Marsenia; hinten die grosse gelbe (Fig. 20a, 21a) Geschlechtsdrủse, vor derselben erstreckt sich in einem grossen Bogen die lange, von der linken nach der rechten Seite hin verschmälerte, weissliche, wie ganz fein und dicht gefensterte Blätterdrüse (Fig. 20 b); vor derselben findet sich ganz rechts die gelblich-weissliche und weissliche, gebogene, mit der am rechten Rande liegenden, lïngsgehenden, halbmondförmigen Muskelfacette parallele Schleim- und Eiweissdrüse (Fig. 20d) mit der winzigen Prostata an ihrem Hinterrande durchschimmernd; an der linken Seite der erwähnten Drüsemmasse die nach links verschmïlerte, von längsgehenden Lappen gebildete, gelblichweisse Niere (Fig. 20c); in der linken Ecke endlich das Pericardium. Vor allen den letzteren Organen die sich ziemlich quer iber das Dach der Kiemenhöhle erstreckende Kíeme; vor dieser das Geruchsorgan, sich links an die, auch etwas gebogene quergehende Muskelfacette anlehnend. Am Hinterrande der oberen Eingeweidemasse schimmern der Magen und der Darm hindurch, mach oben und rechts hauptsiichlich voll der Leber und der gelben Geschlechtsdrise, nach unten von der gelblichweissen Leber eingefasst. Innerhalb der rechten Ecke der Kiemenspalte der Anus, und mehr nach unten und hinten die Vulva, am Hinterende des Schalenmuskels (Taf. U. Fig. 26 a c). Ganz links an der Berihrungsstelle ron Niere und Blätterdriise die spaltenartige äussere Nierenöfinung. - Die Lageverhältnisse der Organe der unteren Körperhöhle wie bei den Marsenien.

1) Vergl. G. 0. SARS, 1. c. Fig. 5a; R. Bergh, 1. c. Fig. 1, 2.

2) Vergl. R. BERGH, 1. c. Fig. 1. 
Das Centralnervensystem (Fig. 5) nach links verschoben, wesentlich wie bei den Marsenien; die Ganglien vielleicht von mehr unbeständiger Grösse; das subintestinale Ganglion (Fig. 5 d) schien im Ganzen etwas kleiner; die cerebro- und pleuropedalen Connective (Fig. $5 \mathrm{gg}$ ) nicht kurz, die der rechten Seite kaum küirzer; die pedalen Ganglien fast (Fig. 5f) ganz wie oben, ziemlich kurz, immer mit einer gestielten (Iig. $5 \mathrm{f}^{\prime}$ ) secundären Ganglienbildung am Vorderende; die buccalen Ganglien (Fig. $5 \mathrm{~h}$ ) ganz wie obeu.

Die Tentakel sowie die Augen wie oben. Am Aussenrande der Fussknoten oder melır nach aussen die, die kugelrunden, kalkweissen Ohrblasen enthaltenden milchweissen Scheiben (Fig. 5ii), von einem Durchmesser von etwa $0,28 \mathrm{~mm}$; die Otocyste selbst von etwa $0,16-0,2 \mathrm{~mm}$ Durchmesser; der Otolith sehr blass, von beiläufig 0,08-0,1 mm Diam. Das Geruchsorgan auch wie oben; die an den Vorderrand tretende kleine Falte findet sich mehr links, etwa am Anfange des letzten (linken) Viertels; in dem Organ (jederseits) etra 25 starke Bliitter. Die Rückenhaut mit der gewöhnlichen Masse ron kleinen und kleinsten sack- und flaschenförmigen Drüsen.

Die quere Mundspalte, die Schnauze (Fig. 11, 12) mit dem Innenmunde wie bei den ächten Marsenien. Der Schlundkopf auch (Fig. 12c) wesentlich wie bei den letzteren; die Länge desselben 3,5 mm bei einer Breite bis 3,5 und einer Höhe bis 2,5 mm. Die Formverhältnisse wie oben, der vorderste (Fig. 12) Theil (mit den Mandibelplatten) nach unten stehend; die Knorpelflecke wie gewöhnlich; die Muskulatur, insoweit sie beurtheilt werden konnte, ebenso, somit auch die zwei- oder dreiküpfigen starken Mm. retractor. bulbi; die ziemlich lange (noch etwa ein halbes Mal so lange wie der Schlundkopf), am Ende knopfartig geschwollene Raspelscheide meistens rechts, seltener links geschlagen, mehr oder weniger spiralartig eingerollt und meistens auf der Kante stehend. Innerhalb der den Rand der Mandibelplatten einfassenden, ganz selımalen Lippenscheibe der ganz enge, senkrechte, ziemlich lange Innenmund (Fig. 12), von den Mandibelplatten eingefasst, die die Lippenseheibe kaum überragen. Diese letzteren bekleiden die innere Wand des zusammengedrückten Vorderendes des Schlundkopfes und zeigen ihren ganz feinzackigen Vorderrand in der Mundspalte; sie sind oben durch eine dickere (Fig. 6 a) Cuticula verbunden, unten durch eine dïnnere und sind hier weniger einander genähert. Die Platten (Fig. 6), von bis 1,2-1,6 mm grösstem Diam., sind von länglich-subquadratischer Form, der untere Rand länger als der obere; sie sind von horngelber Farbe, nur im Hinterrande farblos; dünn, aber ziemlich stark. Der Bau wie bei den Onchidiopsen (s. unten); sie sind, wie früher von mir ${ }^{1}$ ) dargestellt, von etwa 35 bis 45 ziemlich geraden, nur unten (Fig. 6) etwas gebogenen, parallelen Schrägfurchen durchzogen, die durch die reihegeordneten, zu der Richtung der Furchen schräge stehenden Stäbchen hervorgebracht werden; oben sind die Reihen mehr verwischt. Die Stäb-

1) Vergl. 1. c. pag. 117-118. Fig. 14, 15. 
chen erreichen eine Länge bis etwa $0,05 \mathrm{~mm}$, sind leicht gebogen und zeigen an der Aussenseite das Hinterende etwas geschwollen und (Fig. 9) rortretend, weshalb die erwähnten Linien an dieser Seite sich wie ausgepflügt zeigen; gegen den Hinterrand (Fig. 8) der Mandibelplatten hin werden die Stïbehen blasser und kleiner, und die Querlinien noch undeutlicher; gegen den Unterrand verschwinden diese Structurverhältnisse ganz. Der (immer beschiidigte) Vorderrand der Mandibelplatten ist, dieser Structur gemiiss, (Fig. 6, 7) unregelmïssig feinzackig, die Zahl der Zacken meistens gegen 20; die 6-9 vordersten Reihen scheinen an der Aussenseite frei (nicht an die Matrix angeheftet), aber weder da noch an der die Mandibelplatten tragenden Facette findet sich eine Spur ciner Falz-Bildung. - Die Zung e wie gewöhnlich; in der freien gelblichen, von dem gewöhnlichen Rande eingefassten Raspel kamen in den 8 untersuchten ${ }^{\text {) }}$ Individuen 8-14 Zahnplattenreihen vor und unter dern Raspeldache 7-10; weiter nach hinten in der Raspelscheide 30-38 entwickelte und (5-) 6 mehr oder weniger unfertige Reihen; die Gesammtzahl derselben somit 51, 53, 5t, 57, 62, 59, 53 und 48. Die Platten sind von gelber oder gelblicher Farbe; die Breite der medianen bis $0,13 \mathrm{~mm}$ betragend; die Lünge der grossen Seitenplatten 0,18, der zwei iusseren respective 0,16 und $0,14 \mathrm{~mm}$. Die medianen Platten (Taf. T. Fig. 33 ; Taf. U. Fig. 13 a, 14, 15) vorne breiter, hinten viel schmailer; die vorne stark convexen Seitenräinder am hinteren Drittel wie eingeschniirt; der Vorderrand (Fig. 15) stark nach oben gebogen, mit starkem spitz zulaufendem Haken und an jeder Seite desselben meistens 2-3 Dentikeln; seltener kamen deren einer oder gar keiner vor. Die (Fig. 16 a, 17 a, 18 a, 19) grosse Seitenplatte war von der gewöhnlichen Form, im Vorderende eigenthümlich ausgepflügt; am Grunde des Hakens unten (vorne) 1-2 stärkere, oben (hinten) zwei schwächere Dentikel. Die beiden ïusseren Platten (Taf. U. Fig. 13 c, 16 bc, 17 bc, 18 bc) auch im Rücken der Länge nach ausgepfliigt, die obere (innere) Flïche somit einen längs jedes Randes schwach flügelartig entwickelten Kiel bildend; die äusserste Platte kürzer ('Taf. T. Fig. 34); die innerste dieser Platten am Innenrande des Hakens mit einem, seltener mit zwei spitzen Dentikeln (Fig. 16 b), seltener (Fig. 16 c) war solches mit der äusseren der Fall. - Der Bau der Zunge wesentlich wie bei den Marsenien, soweit derselbe beurtheilt werden konnte; die MIm. lingvalis propr., die (hier sehr schwachen) Mm. applanator superficialis und profundus, dilatator lingvae, constrictor lingvae ant. und post. schienen sich wie oben zu verhalten. Dic Zungenkuorpel mehr zusammengedruckt. ${ }^{2}$ )

Die zweifelhaften Speicheldrü en weisslich oder schwach gelblichweiss, ganz wie bei den Marsenien, besonders an dem Fusse stark verbreitert.

Die Speiseröhre meistens links hinabsteigend, ziemlich kurz, sehr weit, am hinteren Ende mitunter (rechts) erweitert; die Innenseite mit starken Lïingsfalten und

1) In dem einen Individuum fehlte der Schlundkopf mit einem Theile der Speiseröhre vollständig (ausgefressen, abgebissen?). Ein ganz ähnliches Verhältniss habe ich an einem Individum der Amphorina molios gesehen; vergl. meine: Beiträge zur Kenntn. d. Aeolidiaden. VIII. pag. 38 (Verh. d. k. k. bot. Ges. in W'ien. XXXV. 1SSə̆. pag. 40).

2) Vergl, 1. c. 1S57. Fig. 23, 24. 
Runzeln, besonders der unteren Seite. Keine Spur von Kropf. Der Blätter-oder Druisen-Magen etwa 5,5 mm lang bei einer Breite bis 3 und einer Höhe bis 2,5 mm, haubenförmig, an der Vorderseite ausgehöhlt, ron ähnlicher Farbe wie das überziehende (Speichel-?) Drïsenlager; die Höhle wie gewöhnlich klein, die Wand mit etwa 15-20 ziemlich dicken Blättern; die Pylorusröhre etwas nach links gerichtet, in den eigentlichen Magen etwa in der Lingsaxe des Körpers eintretend. Dieser letztere ziemlich klein, sonst wie gewöhnlich, mit feinen Längsfältchen; die Cardia ziemlich weit, die dicht nebenbei liegende Gallenöfinung kleiner. Der Darm in der ersten Strecke ganz wie oben und in gewöhnlicher Weise sein Knie bildend, dann längs des Vorderrandes der Leber am unteren-vorderen Rande der Zwitterdruise bis an die Mitte desselben verlaufend, dann frei hervortretend, schrïg mach vorne biegend und in dem Dache der Kiemenhöhle längs der linken-unteren Seite der (fraglichen) Prostata verlaufend, dicht am Ende zusammengeschnürt und mit einer mitunter nach unten umgebogenen Papille am Ende (Fig. 26 a) vor jener endigend. - In der Verdauungshöhle unbestimmbare, thierische Masse, oft grössere weisse Ballen bildend; bei einem Individuum ragte ein $6 \mathrm{~mm}$ langer, etwa $0,6 \mathrm{~mm}$ breiter, weisser, knotiger Kothballen aus dem Anus hervor.

Die Leber gräulichweiss punktirt, wie gewöhnlich an dem Hinterrande der oberen Eingeweidemasse entblösst, hier mit einer tiefen Furche für den Magen und die erste Strecke des Darmes; dieselben schimmern somit hier hindurch als ein glatter, einfarbig weisser Streifen, oben von einem schmäleren, rechts und unten von einem breiteren Lebersaume eingefasst. - Der Bau der gerwöhnliche fein- und stark verzweigt-lappige.

Das Pericardium wie oben; bei einem Individuum glaubte ich die pericardiorenale Oeffnung zu sehen. - Die Kieme wie erwihnt, mehr querliegend; die Kiemenblïtter ziemlich senkrecht stehend, bis $4,5 \mathrm{~mm}$ hoch, mit ziemlich kurzer Grundfläche, ohne Querfalten, aber mit mehr oder weniger ausgeprïigter Spitze; sonst von gewöhnlichem Baue (Fig. 4). - Die (Fig. 20e) Niere lang und schmal, sich, wie erwähnt, hinter der Kieme vom Pericardiun bis an die Schleim- und Eiweissdruise erstreckend, mitunter links den Herzbeutel fast vollstïndig deckend, in der Art, dass nur ein kleiner Theil des Herzens undeutlich durehschimmert. Die Niere deckte einen grossen Theil der Blaitterdruse und war an dieselbe innig angeheftet. Die weissen Secretmassen hinten an der Decke der Kiemenhöhle wie gewöhnlich. - Die Blättexdriise aber (Fig. 24, 25) nur zum Theil hinter der Nicre entblösst (Fig. 20 b); sonst von oben von dieser bedeckt; die Blätter, besonders links, gross, einander schräg deckend, bis $2 \mathrm{~mm}$ lang bei einer Höhe bis 1,75 (Fig. 24). Die erwähnte Spalte links am Dache der Kiemenhöhle wahrscheinlich (wie bei den Onchidiopsen) sowohl der Niere wie der Bliitterdrüse gehörend.

Die grosse dottergelbe Zwitterdrü e die ganze Spira (deren Spitze immer mehr weisslich ist) einnehmend, die Leber von oben deckend; sie ist wie bei den Onchidiopsen wie aus zwei Lagern gebildet, einem oberen gelben ovarialen und einem unteren abstechend weissen testicularen (Taf. U. Fig. $20 \mathrm{a}, 21 \mathrm{a}$ ). In den Ovarialfollikeln grössere 
und kleinere Eier und Unmassen von Fettropfen; in den 'Testicular-Parthien Zoospermien. Die Hodenparthie dick, kurz und kurzistig, sich ohne Grenze in die dicken Ausfiuhrungsgïnge fortsetzend, die, nach vorme und unten hinabsteigend, sich allmählich rereinigen und mehrere Staimme bilden, die sich oberhalb des Darmes nach rechts erstrecken: Es glückte nicht (bei dem erhärteten Zustande der Eingeweide) die Verhältnisse des Genitalsystems zu eruiren. Der Samengang (Fig. 2́2a) schien mit ciner, ein am hinteren Ende und an der linken Seite der Schleim- und Eiwcissdrüse liegendes, längliches Kuauel bildenden, Prostata in Verbindung zu stehen (Taf. U. Fig. 22a); setzt sich dam ziemlich gestreckt lïngs der Aussenseite des (rechten) Schalenmuskels (Taf. U. Fig. $26 \mathrm{~b}$ ) fort, wird diinner, wieder dicker und mehr muskulös in der Strecke, wo er stark geschlängelt, in der Körperwand eingeschlossen, bis an den Pen is verliuft (Fig. 22 d). Dieser letztere (Fig. 23) ist etwas linger als die T'entakel, ziemlich abgeplattet, besonders an der inneren Seite, gestreckt zungenförmig, am Ende gerundet, meistens mehr oder weniger geknickt oder gedreht; dureh denselben verlïuft bis an das Ende median die Fortsetzung des Samenganges (Fig. $23 \mathrm{ef}$ ). Die weisse und gelblichweisse, etwas gebogene Schleim- und Eiweissdrüse (Taf. U. Fig. 20 d) am rechten Rande des letzten Umganges der oberen Eingerveidemasse liegend; diese Masse liatte cine Lünge von 5,25-6,5 bei einer Breite bis 2,8-4 und einer Dicke bis 2,5-3 $\mathrm{mm}$; rechts stiutzte sie sich an den rechten Schalenmuskel und seine Facette, im Granzen der Biegung der letzteren folgend; die obere Seite zeigte immerhalb einer Art Gebräimes meistens eine kleinere rechte und eine grössere linke Parthie, die meistens mehr weisslich war'; am Hinterende der letzteren kommt oft eine gelbe Strecke vor (Fig. 20). Der Bau des Organs schien wesentlich derselbe wie bei den Onchidiopsen (s. unten) zu sein; es schienen zwei abgreplattete Höhlen vorzukommen, die vorne miteinander communiciren, eine obere kleinere und eine viel grössere untere. Die dicken Winde des Organs von hohen, senkrecht auf die Wand stehenden Drischenzellen gebildet. Das Vestibulum genitale (Figु. 26c) iusserst kurz; vielleicht fand sich auch hier, wie bei den Onchidiopsen (s. unten), ein besonderer Vestibularsack. - Obgleich das Genitalsystem im Ganzen wahrscheinlich mit dem der Onchidiopsen iibereinstimmt, scheinen doch recht bedeutende Unterselicde in der Beschaffenheit desselben zwischen den Marseninen und den Onchidiopsen vorhanden zu sein.

\section{\%. Marsenina glabra (Courr.).}

Marsenina micromphala, BGr. C. Aurivillius, arktiska Hafsmollusker. Vega-Expedit. vetensk. Jakttag. IV. 1885. pag. 332.

Hab. Oc. atlant. septentr:

Taf. U. Fig. 27-28; Taf. V. Fig. 7-S.

Von dieser Form, die sich vielleicht schliesslich doch nur als eine Varietä der typischen Art herausstellen wird, habe ich durch die Freundlichkeit des Herrn Inspector 
Collet' 3 Individuen untersuchen können, die alle in der Nähe der Küuste von Finmarken ('l'romsö) gefischt waren.

Das lebende Thier scheint G. O. SArs zufolge etwas über $7-8 \mathrm{~mm}$ an Länge zu messen; die Farbe des Rückens (Mantels) ist weiss mit zerstreuten ysymmetrischen bramen (fuscis) Flecken". Der Mantel ist mehr glatt als bei der vorigen Art, fast nur ein Gebräme auf dem Schalenrande bildend und selbst uur unvollständig die Spira deckend. - Die in Alcohol bewahrten Individuen hatten eine Länge von 7-9 mm. Die Farbe war hellschmutzig gelblichweiss, mit zerstreuten dunkelgrauen Punkten und Fleckehen am Rücken. Die Formverhältnisse ganz wie bei der vorigen Art, nur war die Riickenspalte des Mantels viel grösser, und der Mantel bildete (wie von mir und G. O. SARS bildlich dargestellt) fast nur ein Gebraime um die Schale und auf der Randparthie und der Spira derselben. Die Schale (s. näher oben) ist dünner und mehr durchsichtig als die der vorigen Art, mehr weiss, kürzer, und die Spira niedriger.

Das Centralnervensystem und die (bis $0,3 \mathrm{~mm}$ breiten) milchweissen Ohrscheiben wie oben; die Otocysten von 0,168 mm Diam. mit kugelrundem, immer dunkel horngelbem Otolithen von beiläufig $0,08 \mathrm{~mm}$ Durchmesser. Das Geruchsorgan (jederseits) mit etwa 20-25 Blättern. Der Schlundkopf mit den Mandibelplatten wie oben. Die Zunge mit 18, 20 und 23 Zahnplattenreihen; weiter nach hinten 21, 27 und 26 entwickelte und 6 jüngere Reihen; die Gesammtzahl derselben somit 45, 53 und 55. Die Breite der :iltesten medianen Platten etwa 0,075, die der jüngsten beiläufig $0,09 \mathrm{~mm}$. Die Platten hell horngelb, die äusseren fast farblos. Die Form der (Fig. 27) medianen Platten wie oben; die Denticulation aber sehr variabel, bald kam jederseits nur ein Zähnchen vor, bald deren 4-5. Die Seitenzahmplatten nur mit einem Dentikel jederseits (Fig. 27 b). Der innere Haken (Fig, $27 \mathrm{c}, 28$ ) mit einem Dentikel der inneren Seite und mit einem (weiter nach unten) an der äussern. Der äussere Haken (Fig. $27 d, 28$ ) mit einem Dentikel der inneren Seite.

Die kurze, weite Speiseröhre links oder gerade nach hinten hinabsteigend. Der Blättermagen selbst gräulich. Die äussere (branchiale) Oefłnung der Niere und Blätterdrise wie oben. Die Ǩieme aus beiläufig 50 (Fig. 7) Blättern gebildet, die sich kaum wesentlich von denen der vorigen Art untersehieden. Die Generationsorgane (Fig. 8) mit sammt dem Penis wie oben.

\section{Marsenina Dalli, BGн, n. sp.}

Ha b. M. pacific. bor. (Unalashka).

$$
\text { Taf. V. Fig. 9-21. }
$$

Von dieser Form lag, wie oben erwähnt, nur ein einziges, männliches Individuum ror, von DALL bei Unalashka (Aleuten-Insel) im September 1874 aus einer 'Tiefe von 60 Faden und auf Schlamm- und Steingrund gefischt. 
Der Notiz, der einzigen, von DALL zufolge, ist das lebende Thier gelblichweiss (yellowish-white). - Das in Alcohol ganz gut be wa hre Individuum war etwa $17 \mathrm{~mm}$ lang bei einer Breite bis 13 und einer Höhe bis $8 \mathrm{~mm}$. Die Farbe des Riickens selbst eigentlich durchschimmernd-weisslich, aber durch die gelben Kunoten desselben fast verdrängt; der Kiopf und der iibrige Körper sonst gelblich. Die Form verhältnisse im Ganzen wie sonst bei den Marseninen. Der Rücken mit zahlreichen rundlichen Knnoten, meistens von einem Durchmesser ron 1-1,5 mm, bedeckt; unter denselben kamen, besonders gegen den Rand hin, kleinere vor. Das Mantelgebräime nicht breit; die Inspirationsfalte etwas links liegend; die Exspirationsfurche breiter als die der Inspiration dienende; die etwa an der Mitte der rechten Seite liegende Falte selur stark, auf den Ruicken hinauftretend. Der Mantel ist in der ganzen Ausdehnung der Schale ganz diinn, aber oben iiberall geschlossen, ohne Spur einer medianen Spalte. Die ausstrahlenden Streifen an der Unterseite des Mantels und um den Fussrand wie gewöhnlich. Der ganze Kopf, der Penis und der Fuss wie bei der typischen Marsenina.

Die schöne Schale (Fig. 9, 10), wie oben erwähnt, $14 \mathrm{~mm}$ lang bei einer Breite bis 9,5 und einer Höhe bis 6,5 mm, im Ganzen der der Mars. rhombica z. B. ähnlich; die Nucleus-Parthie aber ganz eigenthumlich (wie ich sie in keiner anderen Marseniade gesehen habe), wie der embryonalen nautiloiden Schale aihnlich, aber fast ganz ohne Rippen oder nur mit Andeutung von (absorbirten?) solchen (Fig. 11).

Nach Wegnahme der Schale fanden sich die unterliegenden Eingeweide in den gewöhnlichen Lageverhăltnissen. Die Zwitterdruise gross, gelbbraun mit weisslicher Spitze; die Blätterdrüse ein ziemlich schmales, sich hinter der Schleim- und Eiweissdrüse an die rechte Muskelfacette erstreckendes gelbliches Band bildend; die gelbe Schleim- und Eiweissdriise fast so lang wie die Muskelfacette; die Niere gelblich, klein, dreieckig; die Kieme und das Geruchsorgan wie gewöhnlich. An der Hinterseite der oberen Eingerveidemasse schimmerten der Magen und der Anfang des Darmes als ein schmaler, heller, ringsum von der gelben Leber eingefasster Streifen hindurch. Die Muskelfacetten lang und schmal; die rechte $\mathrm{S}$-förmig gebogen, in gerader Linie $4,5 \mathrm{~mm}$ messend; die linke kaum kiirzer, einen starken Bogen bildend. - Auch die Organe der unteren Eingerveidemasse in gewöhnlicher Art durchschimmernd.

Das Centralnervensystem wie bei anderen Marseninen, der obere T'heil sehr abgeplattet; das Ganglion supraintestinale ein wenig kleiner als bei der typischen Form. Die pedalen Ganglien kurz und dick; die vordere secundäre Ganglienbildung wie bei der typischen Form.

Die Ophtalmophorien ungewöhnlich stark am Grunde der $(4,5 \mathrm{~mm})$ langen Tentakel vortretend. Die Otolithen als kalkweisse Punkte sich am Aussenrande der pedalen Ganglien prỉsentirend; die Otocysten von etwa $0,18 \mathrm{~mm}$. Durchmesser, in die geröhnlichen Scheiben eingeschlossen; der Otolith blass, stark lichtbrechend, von bei- 
liufig 0,09 mm Diam. Das ,4,2 mm lange Geruchsorgan wie gewöhnlich, mit .28 Blätterparren. Die Knoten des Rückens mit dicht gedrångten Drüsenöffnungen.

Der querovale Aussenmund stark nach vorne liegend. Der Schlundkopf von gewöhnlicher Form, das Vorderende stark nach unten gebogen; etwa 2,5 mm lang bei einer Breite bis $3 \mathrm{~mm}$. Die brïunlichgelben Mandibelplatten etwas $\mathrm{S}$-förmig gebogen, $1,7 \mathrm{~mm}$ lang bei einer Breite von $0,9 \mathrm{~mm}$, wescntlich wie bei der typischen Art; mit etwa 32 Reihen von Stäbchen, der Vorderrand in gewöhnlicher Art feinzackig. Die Zunge mit ihren Knorpeln wie gewöhnlich; in der gelben Raspel 18 Zahnplattenreihen; in der $3,5 \mathrm{~mm}$ langen, rechts aufgerollten, röthlich mahagonybraunen Raspelseheide $2 \pm$ entwickelte und 8 jüngere Reihen; die Gesammtzahl derselben somit 50. Die Länge der ailtesten medianen Zahnplatten betrug 0,12 bei einer Breite bis $0,11 \mathrm{~mm}$, die der juingsten 0,14 bei einer Breite bis fast $0,12 \mathrm{~mm}$. Die medianen Platten vorne und hinten fast von derselben Breite, die Seitenrïnder etwas weniger ausgerandet als bei der typischen Art (Fig. 15-17); der Haken gross, stark gebogen, mit 1-3. spitzen Dentikeln am Grunde (Fig. 15), meistens einem inneren grösseren und einem kleineren. Die Seitenzahnplatten wesentlich von derselben Form wie bei der typischen Art; am inneren (oberen) Rande nur ein einziger, aber starker und spitzer Dentikel (Fig. 18, 21 aa) und gar keiner am unteren. Die äusseren Platten wie gewöhnlich (Fig. 19, 20, 21 b c); der innere mit einem kleinen spitzen Dentikel am inneren Rande des Hakens (Fig. 19, 21 b); der aiussere ohne Dentikel (Fig. 20, $21 \mathrm{c}$ ).

Die Speis eröhre wie bei der Mars. prodita. Der Blättermagen breit, gräulichweiss, mit etwa 20 Blättern der Wand; fast vollstiindig vom dicken gelben Drüsenlager eingehüllt, das sich an der unteren Wand der Körperhöhle weit nach vorne erstreckt, die pedalen Ganglien fast einhüllend. Der eigentliche Magen und der Darm zeigen sich am Hinterrande der oberen Eingeweidemasse als ein hellerer, von der gelblichen Leber oben und unten eingefasster, schmaler Streifen; der Magen und der Darm sonst wio bei der typischen Art.

Die Leber hell gelblich, sonst wie gewöhnlich. - Die (Fig. 12-14) Kiemenblätter wie bei der Mars. prodita, im Ganzen ein wenig niedriger; auch die Niere und die Blätterdrůse wie gewöhnlich, wie es schien.

Die gelbbraune Zwitterdrüse ganz ungewöhnlich gross, die ganze Spira und fast die hintere Hiilfte des grossen letzten Schalenumgangs einnehmend; der Bau wie oben; im äusseren Lager nur kleine oogene Zellen, im inneren Zoospermien. Der 2,2 mm lange Penis in Form- und Grössenverhältnissen mit dem der typischen Art übereinstimmend. Die Schleim- und Eiweissdruse, in so weit bestimmt werden konnte, auch wie bei der Mars. prodita. - Das diurftige, noch dazu ziemlich erhärtete Material erlaubte keine genauere Bestimmung der Organisation des Genitalapparats. 
VI.

Onchidiopsis, BGH.

Die in den äusseren Formverhältnissen und inder Schalenbildung von den Marseninen so verschiedenen Onchidiopsen unterscheiden sich aber im inneren Baue rerhäItnissmaissig wenig von denselben, hauptsäehlich nur durch eine eigenthïmliche Zahnbildung am Vorderrande der Mandibelplatten (welche auch bei den Velutiniden [Taf. E. Fig. 13, 14] vorkommt).

\section{0. groenlandica, Barr.}

Ha b. M. arcticum.

Taf. T. Fig. 35-36; Taf. U. Fig. 3; Taf. V. Fig. 22-24; Taf. X. Fig. 9-27; Taf. Y. Fig. 1-18; Taf. Z. Fig. 7 -22.

Durch die Freundlichkeit des Herrn H. FrIELE in Bergen habe ich (Febr. 1885) zwei grosse und fast gleichgrosse Individuen dieser Art bekommen, die aus dem Magen ron Dorschen ausgenommen waren, welche in der Nähe von Spitzbergen gefischt waren; dem Conservationszustande nach schienen sie soeben verschluckt. Dieselben hatten, in Alcohol bewahrt, eine $L$ änge von etwa $6 \mathrm{Cm}$. bei einer Breite bis 4,25 und einer Höhe bis beiläufig $3 \mathrm{Cm}$; die Länge des Fusses 4 bei einer Breite bis 2,5 Cm., die Länge des Schwanzes 18-20 mm; die Breite des Mantels um den Fiss an den Seiten 12-14, hinten bis $24 \mathrm{~mm}$; die Länge der Tentakel 12, des ausgestreckten schlaffen Penis $22 \mathrm{~mm}$. - Die Farbe des Riuckens durchgehends scheckig bräunlichgrau, die Unterseite des Mantelgebrämes sowie der Kopf und der Penis gelblichweiss; die obere Seite des F'usses dunkel und schmutzig bräunlichgrau oder schwärzlichgrau, um die mediane Parthie des Schwanzes gelblichweiss; die Fusssohle hell schmutziggelblich.

Der obere Körper fast kugelförmig, wie etwas aufgeblasen, die obere Seite mit ziemlich grossen, auch oft wie etwas aufgeblasenen Knoten bedeckt; der gerundete Rand zeigt vorne, etwas links eine nicht tiefe Ausrandung ${ }^{1}$ ), die sich an der Unterseite des Mantelgebrämes gerade nach hinten in die linke Ecke der Kiemenspalte fortsetzt; diese Athemfurche rorne $4-3 \mathrm{~mm}$, uibrigens meistens $2 \mathrm{~mm}$ breit. Vor der Mitte des rechten Mantelrandes eine ähnliche Ausrandung, die in eine der Inspirationsfurche ganz ähnliche Exspirationsfurche übergeht, welche in die Quere gehend sich in die rechte Ecke der Kiemenspalte verliert. Die (mit dem Kopfe und dem Fusse in Beriihrung liegende) Cnterseite des Mantels abgeplattet, eben. Der Kopf fast ganz wie bei den Chelyonoten, somit auch die Tentakel mit den Augenhöckern, welche die schwarzen Augen stark durchschimmern lassen; der Aussenmund mehr vorne als bei den Marseninen liegend.

1) Die Athemfalten fehlen in der Figur (1. c. Fig. 6a) von G. O. Sars. 
Der Pen is von dem der anderen Gruppen abweichend (s. unten). Der Fus im Ganzen grösser als bei den Chelyonoten, sonst wesentlich wie bei denselben. Der Vorderrand wie gewöhnlich tief zweilippig, und die obere Lippe auch mit Andeutung einer Furche; median findet sich (Taf. Y. Fig. 6) zwischen den zwei Lippen die dreieckig-rundliche, etwa $0,5 \mathrm{~mm}$ in Diam. haltende Oeffnung der Fussdriise. Der Schwanz auch stark (vergl. T'af. Y. Fig. 20), nach hinten ein wenig zugespitzt, gerundet endigend. Die breite Randparthie des Fusses von den Fussecken ab sehr stark gerunzelt und vom iibrigen Fusse vortretend (Taf. X. Fig. 9 d, Taf. Y. Fig. 20), was besonders am Schwanze auffällt, der somit eine flachere mediane Parthie zeigt, von einem breiten Gebrime eingefasst. - Am Grunde des Fusses, an der Unterseite des Mantels, nur eine schwache Andeutung der bei den iichten Marsenien so ausgeprighten eradirenden Streifung. - Die Kiemenspalte von einer Breite von etwa 11 bei einer Höhe bis $2 \mathrm{~mm}$; die Länge der Kiemenhöhle etwa $2 \mathrm{Cm}$. Innerhalb der rechten Ecke der Kiemenspalte (Taf. Y. Fig. 7 a), unterhalb des (Fig. 7 c) Rectums, eine feine, moistens etwas gebogene Spalte, die weibliche ge nitale Oeffnung (T'af. Y. Fig. 7 d). Hinten und etwas links an der Decke der KiemenLöhle die Nierenspalte (Taf. V. Fig. 30 c, 31). Der Boden (untere Wand) der Kiemenhöhle, die mehr gerundete Fortsetzung des mehr abgeplatteten Genickes, ziemlich stark bogenartig schriggestreift.

Durch die Rückenbedeckungen, die aus einem oberen dickeren und einem unteren dünneren Lager bestehen, konnte die Schale nicht deutlich gefühlt werden; dieselben waren relativ dicker als bei den hartschaligen Marseniaden; unten an den Stiten etras düner. Die Innenseite des Mantels bis an die Gegend des Uebergangs des oberen Körpers in die niedrigen Seiten nicht angelöthet, nur an die Schale und an die Eingeweidemasse dicht anliegend; unten bildet sie eine kleine Falte, die sich am Vorderende der Leber dicht hinter jeder Muskelfacette mit der oberen Eingerveidemasse verbindet. Die Imnenseite zeigte sich ganz glatt, höchstens mit feinen bogenartigen Linien und hier und da etwas schwärzlich pigmentirt. Die grössere vordere Hälfte der oberen Eingeweidemasse (Taf. X. Fig. 9 a) von der ziemlich durchsichtigen Schale gedeckt, hinter der letzteren liegt die gelbliche Geschlechtsdriise entblösst (Fig. 9 b). Die hornartige, liell horngelbe, schöne Schale wie oben (pag. 188-189; 'Taf. Z. Fig. 7-9) beschrieben; sie lässt sich leicht von der unterliegenden Fläche lösen, am wenigsten leicht von der Randparthie derselben. Nach Wegnabme der Schale zeigt sich die entblösste Strecke ringsum von der wenig vortretenden, ungleich $(1,5--2,5 \mathrm{~mm})$ breiten weisslichen Leiste eingefasst, welche in ihrer grössten Länge dem Schalenrande entspricht (Taf. X. Fig. 9) und meistens aus 2-3 Bündern zusammengesetzt scheint; nur hinten uberragt die Schale in einer kleinen (doch bis fast $7 \mathrm{~mm}$ breiten) Strecke ${ }^{1}$ ) diese Leiste. Wo die Schalenmuskeln an die Oberfläche

1) Alle die oben gegebenen und unten vorkommenden Maasse beziehen sich auf die oben erwähnten zwei grossen Individuen. Bei der Beschreibung der Organe ist aber hier und da auch auf die kleineren unten zu erwähnenden Individuen Rücksicht genommen. 
treten, bilden sie an und dicht innerhalb der Schalenleiste eine, mitunter ctwas mehr gelbliche Andeutung einer MIuskelfacette, eine rechte etwas breitere und etwas halbmondförmige, eine linke etwas längere und schmälere (ausserhalb des Geruchsorgans). Innerhalb der Leiste schimmern die Eingeweide hindurch; in der vorderen Iralfte die dem Dache der Kiemenhöhle gehörenden Organe; ganz vorne (und ein venig links) auf schwarzem Boden das Geruchsorgan, hinter demselben die grosse bogenartige Kieme, und ganz rechts der liingslautende schwarzgraue Darm; hinter der Kieme ganz links der Herzbeutel, neben diesem die etwas mehr als die anderen Organe der Kiemenhöhle gelblich grefarbte Niere, linter dieser die Blätterdrise. Die gerundete hinter der Schale liegende Eingeweidemasse wird zum allergrössten Theil von der (röthlichbraun-) gelben Geschlechtsdrüse gebildet, dic unten in einem grossen Bogen bis an die Sehalenleiste von der schwarzgrauen, 6-16 mm breiten Leber eingefasst ist; an der rechten Seite in der grössten Strecke noch die auch an die Leiste stossende, $14 \mathrm{~mm}$ Iange, $9 \mathrm{~mm}$ breite gelblichweisse Schleim- und Eiweissdriise (Fig. 9).

In der unteren Eingeweidehöhle lagen die Organe ganz wie bei anderen Gruppen der Marseniaden; sie schimmerten kaum irgendwo deutlich bindurch, oder höchstens nur ein Theil der Raspelscheide.

Das Centralner.vensystem ('Taf. Y. F.ig. 1) ganz wie bei den Marseninen, und ebenso, insoweit solches bestimmt werden konnte, die Nervenvertheilung. Die Ganglien der oberen Nervenmasse mitunter (bei einigen der kleineren Individuen) ziemlich stark unter einander yerschoben. Die cerebro-pleurale Ganglienmasse (Fig. 1 aa bb) zeigte, besonders die linksseitige, eine deutliche Grenze zwischen den zwei Abtheilungen; aus den Gehirnknoten gingen wenigstens je 8 Nerven aus. Die cerebro- und pleuro-pedalen Connective meistens ein wenig länger an der linken, seltener (Fig. 1) an der rechten Seite. Vom Hinterende der (Taf. X. Fig. 10; T'af. Y. Fig. 1e) (kïrzeren oder lïngeren) Fussknoten gehen die drei starken gewöhnlichen Nerven aus, von welchen jederseits ein $\mathrm{N}$. pediaeus longus fast an das Schwanzende verfolgt werden konnte; vom Vorderende ein und von der unteren Seite 6 stïrkere und 2 diume Nerven. Die secundäre Ganglienbildung der Fussknoten (Fig. 10 a; Fig. 1f) stark, meistens am Vorderende, mitunter an der unteren oder an der oberen Seite, kurzgestielt, selten fast sessil; von diesen Ganglien gehen auch 4-5 Nerven nach vorne aus. Die gastro-oesophagalen Ganglien wie gewöhnlich.

Die Tentakel mit den Augen wie bei anderen Marseniaden. Die Otocysten an der Aussenseite der Fussknoten oder unterhalb derselben sich unter der Loupe in grossen, runden, milehweissen Scheiben ('Taf. X. Fig. 10 b) prisentirend, die durch lange Bindesubstanzfäden quer über die obere Seite der Fussknoten mit einander verbunden und durch kürzere an die nächsten Umgebungen geheftet sind. Mitunter fanden sich die Scheiben rit den Fussknoten zusammen von der gelben Magendrisenmasse eingeschlossen. In diesen, hauptsächlich aus lockerer zelliger Bindesubstanz gebildeten, Scheiben liegen nun die rundlichen eigentlichen Otocysten (Fig. $11 \mathrm{~b}$ ), meistens etwa 0,5 $\mathrm{mm}$ in Diam. haltend; 
die zellige Wand derselben ziemlich dick, mit einem dickeren Hügel. Der grosse, (Fig. 11 b) kugclrunde Otolith gelblich, von etwa 0,14 mm Durchmesser, mitunter mit ausgeprägtem Kern. In einem Individuum (Taf. X. Fig. 10c) gliuckte es (mit vollständiger Sicherheit) den N. acusticus, frei längs des Fussknotens verlaufend, bis in das cerebro-pedale Connectiv zu verfolgen. - Das mitunter breitere, mitunter schmälere (dann gegen die Enden etwas zugespitzte) Geruchsorgan der Richtung der Kieme gemäss etwas halbmondförmig gebogen, sich mit seinen weissen Blatträndern gegen den fast sammtschwarzen Boden schön pråsentirend, an Länge (in gerader Linie) $10 \mathrm{~mm}$ messend bei einer Breite bis 4; die Höhe der Blätter bis $2,25 \mathrm{~mm}$ betragend; die etwa an die Mitte des Vorderxandes ibertretende Falte wie gewöhnlich. Die Zahl der Blïtter (jederseits) meistens etwa 40-45, mitunter 50; die Blätter am Rande weiss, sonst (wie der unterliegende Boden) mehr oder weniger schwarz, besonders an dem iusseren Rande. Der Bau des ganzen Organs schien sonst der gewöhnliche zu sein.

Die Mundspalte, wie bei den Marseninen, mehr nach vorne an der Unterseite des Kopfes liegend; die stark muskulöse Mundröhre (die Schnauze) zurückgezogen $14 \mathrm{~mm}$ lang bei einem Durchmesser von 4 (vorne bis 7,5$) \mathrm{mm}$; dieselbe (sowie der etwa $5 \mathrm{~mm}$ lange Ueberrest der Schnauze) mit dem Aussenmunde wie gewöhnlich (Taf. X. Fig. 12). Die Retractoren der Mundröhre und der Schnauze (Fig.13) wie gervöhnlich - Der Schlundkopf ${ }^{1}$ ) 5,5 mm lang bei einer Breite bis 5,25 und einer Höhe bis $4 \mathrm{~mm}$; die Raspelscheide nach unten und ein wenig links stehend (Fig. 13), nur $5 \mathrm{~mm}$ lang, in der letzten Strecke röthlich, in gewöhnlicher Weise am Ende geschwollen und hier an der Vorderseite abgeplattet; an jeder Seite der gewöhnliche, der Scheide gehörende Zaum; an jeder Seite der Austrittsstelle der Raspelscheide ein ziemlich starker (Fig. 13) Retractor; an der Unterseite des Schlundkopfes heftet sich wie gewöhnlich mit zwei starken Schwänzen der grosse M. retractor bulbi (Fig. 13). Die gräuliche Ḱnorpelfacette hinten an jeder Seite der Unterflache des Schlundkopfes relativ kleiner als bei den Marsenien; die Muskulatur desselben aber wesentlich wie bei diesen; dasselbe schien mit der Zunge der Fall zu sein, welche aber doch die "Zungenknorpel "s schwïcher, dünner, fast flügelartig und mehr plattliegend zeigte; die unten zwischen den Knorpeln liegenden Muskeln (Mm. constrict. lingv. ant. und post.) daher breiter; der Bau der Zungenknorpel ganz wie oben ${ }^{2}$ ); auch das Raspeldach wie gewöhnlich. Der wie gewöhnlich nach unten gebogene vordere t'heil des Schlundkopfes in gewöhnlicher Weise mit den flachen Mandibelplatten bewaffnet; zwischen den Rändern derselben der senkrechte, schmale Innenmund; neben dem Grunde des freien Theils der Mandibelplatten eine Andeutung einer Lippenscheibe. Die Mandibelplatten sind schillernd horngeld, nur im hinteren und unteren Rande farblos; die Länge (von oben nach unten) 4 bei einer fast durchgehenden Breite von $2,5 \mathrm{~mm}$; sie sind ziemlich

1) Aus dem anderen Individuum war schon (in Bergen) der ganze Mundapparat mit sorgfältiger Schonung der übrigen Eingeweide wegrenommen.

2) Vergl. auch die citirte Monographie 1ag. 296. Tab. III. Fig. 23. 
platt, cin wenig gedreht-gebogen, an der Aussenseite oben convex, unten concar. Dic Form ist (Taf. X. Fig. 14) gestreckt-oval; der diunne Hinterrand fast gerade; der dickere Vorderrand convex, unten, etwa am Anfange des letzten Fünftels, mit einer vortretenden, schräge nach unten gerichteten Spitze (Fig. 14b), die das vordere Ende einer schräge ïber die Aussenseite verlaufenden, ger undeten Leiste bildet; der kürzere obere und untere Rand gerundet, der untere doch mehr abgestutzt. Die Mandibelplatten sind an den Flächen eben, doch von feinen, ein wenig gervundenen, von oben und vorn nach unten und hinten verlaufenden Linien durchzogen, welche der Reiheordnung der die Platten zusammensetzenden Elementen entsprechen; von solchen Reihen kamen untén beiläufig 42 vor, oberhalb der Mitte etwa 70, ganz oben war die Anzahl bedeutend grösser, liess sich aber wegen der Kleinheit und Verschobenheit der Elemente nicht bestimmen. Die Reihen aus (Fig. 15-17) wenigen Lagern von dicht gedrängten, der Länge nach ein wenig gebogenen, von vorne (Fig. 15) nach hinten (Fig. 17) an Lïnge allmählig ein wenig bis zu der von etwa $0,08 \mathrm{~mm}$ zunehmenden, hinten ( $\mathrm{F} i \mathrm{~g}$. 17) ein wenig dickeren Stäbchen zusammengesetzt, die fast senkrecht an der Richtung der Linien stehen (Fig. 15, 16). In der"Randparthie des oberen Viertels etwa waren die Elemente kleiner, mehr unregelmäissig und weniger geordnet; dasselbe war auch in der untersten Randparthie der Fall. Dieser Bau der Mandibelplatten bedingt die durch das Abnutzen des Vorderrandes hervorgebrachte Dentikel-Bildung an demselben (Fig. 14-16); von solchen Dentikeln kamen an den beiden Platten 40-45 vor (und ausserdem war der grosse Zahn wi 15 ) von b.-6 Reihen gebildet); am oberen Viertel sowie ganz unten war der Rand wegen der Klcinbeit der Elemente nur schwach und unregelmåssig zackig. Die beiden Mandibelplatten waren oben einander etwas mehr genähert als unten, hier durch eine diinne, fust farblose Cuticula rerbunden; oben durch eine dicke und horngelbe, welche wie eine Fortsetzung der Plattenmasse bildet; die Hinterränder standen von einander mehr entfernt als die Vorderränder. Die vordersten etwa $\%$ der Mandibelplatten (Fig. 14) ragen frei hervor, der übrige T'heil war an die Wand des vorderen Theils der Mundhöhle geheftet; es fand sich aber kein Falz, nur eine etwas erhabene Linie (Fig. 14) bezeichnete die Anheftung. - Die (ziemlich stark contrahirte) Z ung e ron gewöhnlicher breiter Form, ${ }^{1}$ ) an der Unterseite ein starker medianer Längskamm. In der schillernden gelben Raspel 24 Zahnplattenreihen und noch 6 unter dem Raspeldache; die 9 ersten Reihen mehr oder weniger beschädigt (T'af. V. Fig. 23), die zwei vordersten selbst ohne mediane Platten; in der nicht langen (Fig. 13) Raspelscheide 32 entwickelte und 6 jiingere Reihen, die Gesammtzahl derselben somit 68 . Die Zahnplatten von hell horngelber Farbe; die Breite der allesten medianen betrug 0,25, der jüngsten entwickelten $0,26 \mathrm{~mm}$; die Höhe der iussersten Platte $0,28 \mathrm{~mm}$. Die medianen Platten (Taf. U. Fig. 3; Taf. V. Fig. 22; 'Taf. X. Fig. 18; Taf. Y. Fig.' 2 a, 3 a) ron gewühnlicher Grundform; die Grundplatte wappenschildförmig, ein wenig breiter als 
lang, und vorne etwas breiter, die obere Seite etwas convex, die untere etwas ausgehöhlt (Fig. 3, 22); der Iakentheil ist fast rechtwinkelig hinaufgebogen, mit 6-S Dentikeln zu jeder Seite des Hakens und mitunter (Fig. 22) mit feinen Zähnchen am Haken selbst. Die Seitenzahnplatten sind wesentlich ron derselben Grundform wie die medianen, aber asymmetrisch (Taf. X. Fig. 19; Taf. Y. Fig. 2bb, 3b); die Grundplatte schief, mit sehr schrigem Innenrande, die obere Seite etwas convex, die untere etwas concav, besonders rorne (Fig. 19); der auch fast rechtwinkelig linaufgebogene Hakentheil (Fig, 19) spitzt sich allmählig stark zu; am Grunde desselben (Fig. 19) aussen meistens 7 - , selbst 9 Dentikel; innen meisteus 4-5, seltener 6-7. Die zwei äusseren, hakenartigen Platten sind einander (Taf. 'T. Fig. 35, 36; Taf. X. Fig. 20, 21, 23; Taf. Y. Fig. 2 c c) ziemlich :̈hnlich, zeigen ein kleines, an der Unterseite etwas ausgehöhltes Grundstiick, von welchem der dünne, etwas gebogene Haken steil emporsteigt; die Grundplatte der inneren dieser Platten (Taf. 'T. Fig. 35; Taf. X. Fig. 20; 'Taf. Y. Fig. 2) ist grösser, und ihr Haken ein wenig mehr gebogen, unten etwas knieartig, glattrandig oder ganz ausnalımsweise mit Andeutung eines Dentikels (Taf. T. Fig. 35).

Die Speiseröhre ist lang (an Länge $10 \mathrm{~mm}$ messend bei einem fast durchgehenden Durchmesser von $2 \mathrm{~mm}$ ) (T'af. X. Fig. 13), meistens über die linke Seite des Schlundkopfes hinabsteigend, vor dem Durchtreten durch den Nervenring an der rechten oder unteren Seite etwas erweitert. Die Inmenseite mit sehr feinen Längsfältchen und einer starken, die cisin in die lfvene Höhle des Blättermagens hinein fortsetzt. - Der graue blätermagen an und fự sich 10-12 mm breit, bei einer Höhe von 9,5-10 und einer Lïnge (an der Mitte) ron $5 \mathrm{~mm}$; cr ist von der gewöhnlichen Haubenform, unten in der Mittellinie et:sas vertieft; unten und etwa in der Mitte der Vorderseite tritt die Speiseröhre ein; aus der Hinterseite, unter der Mitte und ein wenig an der linken Seite der Mittellinie tritt das (1,5-2 $\mathrm{mm}$ im Diam. haltende) Magenrohr aus. Der Bau der Wand der gewöhnliche, die Zahl der Blåtter etwa 12-15. Das bekleidende Drisenlager bis $3 \mathrm{~mm}$ dick, gelblichweiss; hauptsächlich die Seiten, den oberen Rand und die Unterscite des Magens iberzichend, mitunter die vordere und die obere Seite ganz entblösst lassend, sich nach hinten bis unter die Leber, nach vorne bis unter die Fussknoten und den Schlundkopf hin fortsetzend; der Bau der gewöhnliche. Das Magenrohr 2-3 mm lang, schräge nach oben und rechts aufsteigend und sich durch eine (5-6 mm lange) spaltenartige Oeffnung in den eigentlichen $\mathrm{Magen}$ öffnend. Dieser letztere tritt nirgends an die Oberfläche und reicht viel weniger als bei anderen Marseniaden rechts, indem der Magengrund sich etwa in der Mittellinie des Thieres oder nur wenig zur rechten Seite desselben findet. Dieser Magen ist von der griingrauen Leber ringsum eingeschlossen, vorne (und rechts) stösst er fast an den grossen runden Nebenhoden, vor ibm liegt oben ein Theil der vorderen Strecke des Darmes. Der Magen war im Ganzen ziemlich wechselnd in Form, bald kiirzer und weiter, bald länger; er war in dem einen Individuum etwa $15 \mathrm{~mm}$ lang, bei einer Höhe von fast 10 und einer 'Tiefe von etwa $6 \mathrm{~mm}$; die Wand 
mit feinen Längsalten, unten die weite Cardia; oberhalb derselben und links die Gallenoffnung entweder als eine weite Vertiefung mit mehreren Oefinungen oder als zwei, seltencr drei oder mehreren Löcher neben einander; der Pylorus fast so weit wie die Cardia, aber mehr rund. Mitunter ist der Magen durch eine senkrechte Falte in zwei Abtheilungen geschieden, in der rechten liegt dann eine Gallenöffnung, in der linken die anderen sowie unten die Cardia. Die erste Strecke des Darmes kurz; derselbe bildet damn in gewöhnlicher Weise ein spitzwinkeliges Ḱnie (die etwas zusammengedriickte Lichtung des Darmes schimmert hier [hinter dem Pericardium] griulich hindurch) und rerliiuft unter dem oberen Rande der Blätterdriise längs des oberen Randes der Geschlechtsdrise in einer Furche der Leber oberhalb des Niveaus des Magens; der Darm biegt daun nach rorne, steigt liings der linken Seite des erwähnten Nebenhodens, an der Prostata und an der Samenblase ruhend, ferner längs der linken Seite der Schleim- und Eiweissdrïse hinab und endet (Taf. Y. Fig. 7 c) an gewöhnlicher Stelle. Die Innenseite des Darmes mit feinen Längsfalten. - Der reichliche, meistens knollige Inhalt des Verdauungscanals war ganz unbestimmbare weissliche oder gräuliche thierische Masse.

Die gringraue Leber hinten unterhalb der Geschlechtsdriise an der Oberfäche der oberen Eingerveidemasse entblüsst ('laf. X. Fig. 9 c), ebenso an den Seiten derselben, an der rechten schimmern noch hier die an den Nebenhoden hinuber tretenden Lappen der Geschlechtsdriise undeutlich hindurch (Fig. 9); sonst ist die Leber von der Geschlechtsdriise bedeckt; vorue stïsst sic an den Nebenholuss, umhüllt denselben mehr oder weniger, dringt zwischen den Theilen der vorderen Genitalnasse sowio zwischen dieser und dem Darme ein. Die Dicke der Leber war unten und etwas links in der Nähe des Pylorus etwa $6 \mathrm{~mm}$, sonst ist sie diinner. Die verästelten Gallengänge ziemlich (bis 1,2 mm) weit, wie an Durchsehnitten der Leber iiberall deutlich, von einer nicht ganz dünnen Membran ausgekleidet, weshalb sie sich auch ziemlich leicht ausdessiciren lassen.

Das Pericardium ziemlich gross, etwa $11 \mathrm{~mm}$ lang bei einer Höhe und Tiefe von $6 \mathrm{~mm}$, gerundet kurz pyramidal nit der Spitze nach innen (und hinten); hinten an den Darn und an die Leber grenzend, nach unten an die Leber, nach oben an die Niere, nach vorne an die Wand der Kiemenhöhle, nach aussen (links) frei liegend. Die pericardio-renale Oeffnung schien sich vorne, hinter der Aortawurzel zu finden. Die Länge der (zusammengezogenen) Herz kammer 6-6,5 mm; die atrio-ventriculären und die AortaKlappen sehr schön entrvickelt. Die Aorta ant. quer iiber den Blättermagen hinziehend. - Die Kieme etwa wie gewöhnlich; die Blätter aber kürzer und höher (Taf. Y. Fig. 4, 5) (besonders [Fig. 5, 7b] die den Enden der Kieme gehürenden), bis etwa $11 \mathrm{~mm}$ lang bei einer Höhe bis $7 \mathrm{~mm}$, und noch an etwa der Mitte des oberen Randes eine kurze nach hinten gerichtete Spitze tragend (Fig. 4, 5), keine Audeutung von Lamellen an den Seiten der Blïtter; die Anzahl der Blätter in der Krieme etwa gegen 300.

Die Niere meistens einigermaassen von gerundet-viereckiger Form, etwa $11 \mathrm{~mm}$ breit bei einer Länge von 9 und einer Dicke von $1-2 \mathrm{~mm}$, von gervöhnlicher blass 
gelblichweisser Farbe und wie sonst die länglichen, undeutlich fiederigen, der Länge nach gehenden Lappen zeigend. An einigen Individuen war die Form gerundet-dreieckig, die Spitze nach links gebogen, die Grundlinie vorne; oder die Form noch mehr länglich. An zwei der kleineren Individuen (s. unten) wurde eine innere, pericardio-renale Oeffnung vielleicht gesehen. An der gegen die Kiemenhöhle kehrenden Fläche (vergl. 'Taf. V. Fig. 31 a), mehr vorne oder mehr hinten, aber dicht neben der Blätterdruise, war eine äussere, branchio-renale, spaltenartige Oeffnung sehr deutlich (vergl. Taf. V. Fig. 30a). Diese Oeffnung geht in eine ziemlich schmale Höhle ein, deren dünne Seitenwände äusserst feine und zierliche Fältchen zeigt, während gröbere und verzweigte an der unteren Wand vorkommen; links öffnet sich in diese Höhle durch ein oder mehrere Löcher die Niere (Fig. 30 c), rechts durch eine Spalte (Fig. 30 b) die Blätterdrüse. Der Bau der Niere der gewöhnliche.

Die weissliche Blätterdrise breit, halbmondförmig, rechts breiter, sich bis an die Schalenleiste (Taf. X. Fig. 9) erstreckend; nach hinten an dem vorderen Rande der Zwitterdrise und an der Leber angeheftet, an die letztere theilweise auch nach unten. Die Blätter ziemlich stark, hier und da unmittelbar oder durch ganz kurze Scheidewände mit einander verbunden. Die gegen unten weiteren (interlamellaren) Räume sich durch die erwähnte Spalte in die besprochene kleine Kammer und durch diese in die Kiemenhöhle öffnend (vergl. Taf. V. Fig. 30 b).

Dic mediane Oeffnung im vorder.an ('Taf. Y. Fig.6) Fussrande leitet in einen ziemlich kurzen, von nicht reichlichem Drüsengewebe umgebenen Kanal; diese Fussdruise scheint jederseits "von ciner Vene oder Lacune begleitet und scheint jederseits einen besonderen Nerven zu empfangen. Das (Taf. X. Fig. 9 d) wulstige, viel gefurchte Randgebräme des Fusses, das in Wasser stark quillt und dasselbe sehr schleimig macht, von einem etwa $0,10 \mathrm{~mm}$ hohen Epithele bekleidet; das Epithel des Schwanzrückens fester und niedriger.

Die Zwitterdri so (Gland. hermaphrodisiaca) von lebhaft schmutziggelber Farbe, den grössten 'Theil der hixteren Hälfte der oberen Eingeweidemasse ïberziehend (Taf. X. Fig. 9 b); hier $30-31 \mathrm{~mm}$ breit bei einer Länge von $26-27$; hinten bis $6,5-7 \mathrm{~mm}$ dick, vorne an der rechten Seite an Dicke nur $3 \mathrm{~mm}$ messend; in ihrer grössten Ausdehnung ist die Druise an die Leber innig geheftet. Sie zeigt sich überall wie aus zwei Lagern bestehend, einem viel dickeren, gelben oberen und einem dinnen, abstechend weissen unteren; unterhalb des letzteren kommen hier und da, in die Leber mehr oder weniger eindringend, noch kurze gelbe Lappen vor; das gelbe Lager und die gelbe Lappen sind von den Ovarial-Follikeln gebildet, die Testicular-Theile dagegen sind weiss. Genauer betrachtet zeigt sich die Geschlechtsdruise aus den gewöhnlichen langen, mehrmals dichotomirten oder etwas mehr unregelmiissig verzweigten und Knospen tragenden, meistens senkrechtstehenden Lappen (I'af. X. Fig. 27) gebildet, deren meistens viel lïngerer, gelber oberer Theil (Fig. 27) den gewöhnlichen ovarialen Bau (Fig. 25) zeigt, während der kïrzere 
weisse untere Zoospermien enthält ('’af. Y. Fig. S b). Von ctwa der Mitte der Breite der Gland. hermapbrodisiaca, oberhalb der Mitte der Liinge derselben (oberhalb des eigentlichen Magens) schiesst ein kurzes und breites Fascikel (Fig. 14a) von Zwitterdrüsen-Lappen (ron etwa $3 \mathrm{~mm}$ Diam.) schrigge durch die Leber an dic Nebenzwitterdrise über, und durchbohrt die Hinterflïche derselben. Dieses eigenthümliche, in reichliche lose Bindesubstanz gehüllte Organ, das vorläufig als Nebenzwitterdrüse (Taf. Y. Fig. 9 a, 14) bezeichnet werden kann, liegt etwas rechts und oben in der oberen Eingeweidemasse, vor dem Magengrunde und etwas rechts, auch an der Vorderseite von einigen fest anhängenden Leberlappen iiberzogen. ${ }^{1}$ ) Das Organ ist ziemlich halbkugelförmig, an der vorderen Seite etwas abgeplattet und an der Mitte nabelartig vertieft; die Breite betrug in den zwei Individuen $13 \mathrm{~mm}$ bei einer Höhe bis 14 und 15 und einer Länge von 13 und $15 \mathrm{~mm}$. Die Nebenzwitterdrüse war von weisser Farbe; mit ebener Oberfläche, welche aber überall eine Unmasse you, mitunter kalkweissen, geschlungenen Windungen zeigte (Fig. 9 a), die wenigstens zum allergrössten Theile sich in dic Zwitterdriisenlappen des erwähnten Fascikels fortsetzen. An Durchschnitten durch die Achse des Organs zeigt sich das Innere (Fig. 14) eine kleine grauwandige Höhle bildend, welche ringsum kurze Aeste ausschickt und gegen diese convergiren von allen Seiten die das Organ bildenden langen, dünnen, kalkweissen Schläuche ('laf. X. Fig.'26). Diese letzteren theilen sich von innen nach aussen dichotomisch oder unregelmaissig und die Aeste tragen oft kürzere oder längere Knospen und Zweige (Fig. 26), ihr oberes Ende ist, oft an der Oberfläche des Organs gebogen und schlängelt sich hier mehr oder weniger (Fig. 9a). Die Wände der Schläuche sind dünn; der Inhalt Zoospermien, mit zerstreuten oder in grösseren oder kleineren Gruppen gesammelten, runden und ovalen, bis $0,05 \mathrm{~mm}$ langen, gelblichen, wie fein querstreifigen Körperchen vermischt (Fig. 26 aa); einzelne, meistens kleinere Eier kamen auch vor. In der Gegend des hinteren Pols der Höhle des Nebenhodens sind die Uebergänge der ( Geschlechtsdrüsen-Follikel besonders (Fig. 9a, 14a) ausgeprägt; aus dem vorderen nabelartigen Pole tritt der nur dicht am Anfange ganz dünnwandige Zwitterdrisengang (Fig. 9, 14 b; Taf. Z. Fig. 12a). Dieser letztere ist in der ersten, freien Strecke stark geschlängelt (Fig. 14b); er schlängelt sich dann weiter theils an der Oberflïche eines grossen Knäuels, theils durch die Tiefe desselben (Fig. 15 b) bis an den hintersten 'Theil der Vagina (in der Naihe des Samenblasenganges), die er dann gleich wieder als Samengang veriässt (Fig. $15 \mathrm{~d}, 16 \mathrm{~d}$ ): oder also das Verhältniss ist so aufaufassen, dass sich der Zwitterdrüsengang in einen weiblichen Ast (Oviduct, Vagina) und in einen männlichen (Samengang) theilt. Die letzte Strecke des ziemlich dünnwandigen Zwitterdruisenganges zeigt zahlreiche feine Längsfalten; die runde Oeffnung in den weiblichen Gang liegt dicht an der runden Oeffnung des Samenganges. Die erste Strecke des Samenganges ist so

1) Dieses Anhängen der Leberlappen und ihr Eindringen zwischen den einzelnen Theilen des Ausführungsapparats der Geschlechtsdrüse erschwert bedeutend die Untersuchung ron jenen. 
dick wie der Zwitterdrisengang, nimmt durch meistens zwei bis drei (oder mehrere) Stämme die Prostata auf (Fig. 15 c, 16 c); wird dann dünner, verlaiuft unterhalb der weiblichen (Fig. $7 \mathrm{~d}, 9 \mathrm{~d}, 15 \mathrm{~g}$ ) Genitalöffnung längs des aufsteigenden Schalenmuskels, dann in gerwöhnlicher Weise in der Körperwand ('I'af. Y. Fig. 18 ca) an die Wurzel des Penis. Die Länge des Samenganges von den Nebenhoden ab bis an das Eintreten in die Körperwand beträgt etwa 3,5 C'm. Der Pen is war immer ('Taf. Y. Fig. 18; T'af. Z. Fig. 12 de, 13) etwas eingerollt; etwas abgeplattet, biconvex oder planconvex, an dem einen Rande etwas fliigelartig entwickelt, oben mit einem ziemlich kurzen, fast cylindrischen Fortsatze mit gerundetabgestutztem Ende, dessen Rand kaum hervorsprang, die subcentrale Oeffinung hier kaum muter der Loupe sichtbar. Die Länge des ausgestreckten Organs 12-13 mm bei einer Breite bis 6. Dem gefluigelten Rande mehr genähert steigt der dünne Samengang durch das Organ bis an die Mitte der Endfacette hinauf; an Durchschnitten zeigen sich ferner mehrere Gefässöffnungen sowie ein N. penis. Die Prostata ist (Taf. Y. Fig. 9; Taf. Z. Fig. $12 \mathrm{~b}$ ) ein weissliches, ovales Organ von rundlichem Umrisse, $8-8,5 \mathrm{~mm}$ lang bei einem Durchmesser von 5-5,5 $\mathrm{mm}$; es besteht aus einer Menge von an der Oberfläche des Organs (Fig. 9) kriechenden, ungetheilten sowie kurzästigen und mit (T'af. Z. Fig. 14) Ausstulpungen versehenen, cylindrischen Röhren (Fig. 15b), die, durch lockere Bindesubstanz an cinander gelöthet, die dickere Wand einer kleinen Höhle (einer oder mehrerer weiteren Röhren) im Inmeren des Organs bedecken und mit derselben communiciren. Das Organ öffnet sich oben und aussen in den Samengang (Fig. 15c, 16 c) durch ein Rohr oder durch mehrere. Die Wand der Röhren ziemlich dünn, weich, mit ziemlich niedrigen Zellen ausgekleidet.

Die Vagina (weiblicher Ausfuhrungsgang) (Taf. Y. Fig. 9, 10 b, 15f, 16f) kräftig, ziemlich dickwandig, etwa $5,75 \mathrm{~mm}$ lang, etwas gebogen; hinten nimmt er von oben her den Zwitterdriisengang auf, von unten her den kurzen Gang der (Fig. 9, 15, 16) Samenblase (oder biegt, so zu sagen, in denselben um); weiter nach vorne giebt er den Samengang (Fig. 15, 16) ab) und öfnet sich mit zicmlich feiner Oeffnung (Fig. 17) links und hinten innerhalb der Vulva, dicht an dem Vestibular-Sack, der Oeffnung der Schleim- und Eiweissdrise gegeniuber. Von der Oeffnung des Zwitterdrisenganges ab erstreckt sich durch die ganze Lainge der Vagina (Fig. 17 b) an der oberen Wand eine ziemlich hohe Falte; neben dieser kommen feinere Längsfalten vor. Die Höhle war leer. Die grosse, unterhalb der Vagina liegende Samenblase (Fig. 9, 15e, 16e) 10-11 mm lang bei einer Höhe von 6,5-7 und einer Breite von $5 \mathrm{~mm}$, sackförmig, ein wenig zusammengedrüekt, von weisslicher Farbe; die Wand diunn; der dicht zusammengeballte Inhalt in langen, geschlängelten, dicht gedräingten Schnuren (Fig. 9) gelagert. Dicht an der Oeffinung der Vagina öfnet (Fig. 9, 15) sich der runde, ungestielte Vestibular-Sack in das ganz kurze Vestibulum genitale (Fig. 17). Dieser Sack hatte eine Länge von 6 bei einem Durchmesser ron $2 \mathrm{~mm}$; die Wand dick, in den unteren $2 / 3$ mit starken Längsfalten (Fig. $17 \mathrm{a}$ ); der Boden des Sackes mehr dünnwandig; die Höhle war leer. Rechts öf̈net sich endlich 
durch eine kleine (Fig. $17 \mathrm{c}$ ) gebogene Spalte die grosse Sch leim-und Eiweissdrise. Dieses in eine dünne, aber zähe, und in den Furchen fast anhängende Albuginea gehiillte Organ (Taf. Y. Fig. 9-13) von einer Lïnge von 12-15 bei einer Breite von 9-10 und einer Dicke ron $3,5-4,5 \mathrm{~mm}$; die Farbe weisslich, die ringslaufende Randparthie streifig gelbweiss; die rechte (untere) II:ilfte der oberen Seite körnig- und die linke streifig-kalkweiss; die untere Seite fein körnig schmutzig gelblichweiss. Die Form des Organs eckigeiförmig, hinten etwas breiter; es ist abgeplattet, biconvex, die untere Seite ('I'af. X. Fig. 24) etwas mehr gewölbt als die obere, besonders hinten (Taf. X. Fig. 24). Das Organ zeigt eine unregelmïssig radiär-streifige Randparthie, die, in der letzten Strecke ('laf. Y. Fig. 11 b, $13 \mathrm{~b})$ weiter und mehr glatt, sich in die Spalte rechts im Vestibulum offnet; an der Unterseite ist diese Randparthie weniger ausgeprägt. Innerhalb der Randparthie zeigt die obere Seite eine rechte (untere) mehr vortretende und mehr ebene und eine linke (obere) melir querstreifige Parthie; die untere (linke) Seite zeigt eine sehr starke Querfurche und mehrere weniger starke quere und schräge Furchen. Die oben erwähnte Spalte in dem Vestibulum leitet gleich oben nach hinten in die tiefere Höhle der grossen Drüscnmasse und in den Randkanal, nach unten (rechts) in die oberfächliche Höhle des Organs. Wenn die letztc (obere) Strecke der Randparthie geöffnet wird, zeigen sich innerhalb derselben (Fig. 24 a) die zwei etwas wulstigen, aber dicht an einander schliessenden Randlippen der tieferen Iöhle; vorne, in der Niihe der äusseren Spalte, weichen die Lippen etwas auseinander, wodurch der flache Randkanal sich also in die erwähnte Höhle (Fig. 24a) öffnet; in der Gegend des hinteren Endes der Drisenmasse versehwinden diese Lippen, und die dickere obere Wand des Organs geht allmählig in die diunnere untere iiber. Die (Fig. 24) tiefe, untere Höhle ist abgeplattet, stark gebogen wegen der nach allen Richtungen convexen Decke; die untere Wand der Höhle ist nicht dick, eben, aber mit starken, schon an der äusseren Seite ausgeprägten, schrägen Falten; die stärkste (Fig. 12) setzt sich an das Vorderende der Höhle fort, geht durch die in die obere Höhle leitende Oeff̈nung und läuft in dem Vorderende der Decke derselben aus. Die obere Wand (Fig. 12aa) der unteren Höhle ist mehr eben, doch mit starken, besonders gegen die Ränder hin vortretenden Furchen und Falten. Die obere Höhle (Fig. 13) ist viel kleiner als die untere, durch das an der oberen Seite der ganzen Driisenmasse so ausgeprägte Randgebräme (Fig. 11 a, 13 a) begrenzt; sie ist niedrig; die untere Wand mit einer starken links liegenden Falte, von welcher kalkweisse Querfalten ausgehen (Fig. 13); die obere Wand mit Querfalten, auch von :ihnlicher Farbe. Der Bau ist der gewoohnliche; das Organ wesentlich aus hohen, senkrecht stehenden Driisenzellen gebildet.

Wie oben erwähnt, soll die M. perspicua in zusammengesetzten Ascidien sich eine Höhle für ihren Laich graben. Knöyen fand ${ }^{1}$ ) eine ganz kleine Onchidiopsis (O. recon-

1) Vergl. meine Monographie, pag. 317-348.

Semper, Philippinen. II, Ir (Bergh, Ergänzungsheft IV. Marseniaden II). 
dita, KRöYkr, wahrscheinlich ganz junge [3,5 mm lange] Individuen der typischen Onchidiopse) in den Bedeckungen einer Ascidia gelatinosa. ${ }^{2}$ ) Von Herrn KIELSEN ist vor Jahren (1849) mit drei Onchidiopsen zusammen eine etwas lederartige, rundlich-eckige, braungelbe $\mathrm{Hal}$ is arcide dem Museum von Kopenhagen geschickt worden, in welchem sich eine nicht geringe Anzahl von Höhlen mit Molluskenlarven fanden. Das Spongiar hatte (Taf. Z. Fig. 15) eine Länge von $28 \mathrm{~mm}$ bei einer Höhe von 25 und einer Breite bis $18 \mathrm{~mm}$; an der Oberfläche derselben eine Anzahl (etwa 25) von weissen, runden und ovalen, flachen Scheiben (Deckel) (Taf. V. Fig. 24) ron einem Durchmesser bis etwa 2 mm. Diese Deckel oder Scheiben ${ }^{2}$ ) deckten runde und ovale Höhlen von einem Durchmesser bis $7 \mathrm{~mm}$, deren Inhalt mitunter bräunlich hindurchschimmerte; beim Eröffnen derselben entleerte sich eine Wolke von kleinen bräunlichen Körpern (den Larven). Die Scheiben waren hornartig (Taf. V. Fig. 24), ziemlich scharf begrenzt, aber zeigten an der oberen Seite dichtstehende, oben und unten zusammenstossende, concentrische Halbbogen. Die Larven waren von etwas ungleicher Grösse; unter denselben kamen unentwickelte Eier (Nahrungseier) ziemlich zahlreich vor. Die Larven ${ }^{3}$ ) (Taf.Z.Fig. 16-19) von dem gewöhnlichen Baue, die Cilien des Wimpersegels sehr lang, das Operkel wie gewöhnlich. Die (primaire) (Fig. 16-22) ganz wasserhelle Schale von einem grössten Durchmesser bis $0,6 \mathrm{~mm}$. Sie war sehr schön; wie einfach zusammengebogen, eine halbe Windung bildend; die Miindung einigermaassen halbmondförmig mit kaum dickerer, nach aussen etwas umgeschlagener Lippe; die letztere in der Mittellinie ausgeschnitten (Fig. 17, 18), und mit zahlreichen Spitzen, die sich längs der ganzen Aussenseite -der Schale als niedrige Rippen fortsetzen (Fig. 17, 21), die Rippen meistens mit etwas wellenartig verlaufendem Rande (Fig. 21). Es wurden keine Individuen mit secundärer, bleibender Schale innerhalb der primären gesehen (im Gegensatze zu den bei den ächten Marsenien [s. oben] gesehenen Verhältnissen); und es wurden keine anderen leeren Schalen als solche'der eben beschriebenen Beschaffenheit gefunden.

Unter den durch die holländische Expedition (WILLEM BARENTSz) zurückgebrachten Mollusken fanden sich ferner 10 mittelgrosse Individuen dieser Art, die am 6. August 1882 an $69^{\circ}$ und $73^{\circ} 5^{\prime} \mathrm{n} . \mathrm{Br} ., 54^{\circ} 34^{\prime}$ und $52^{\circ} 14^{\prime}$ w. L. gefischt waren.

Diese in Alcohol bewahrten Individuen waren alle ziemlich stark contrahirt, ron fast derselben Grösse, an Länge 25-30-32 mm messend bei einer Breite von 20_25-28

1) Koren und DANiet,SSEN haben (Nyt Mgz. f. Naturvidensk. V, 3. 1847. pag. 260) auch Eikapseln eines Gasteropoden im Iantel einer Ascidie gefunden; ebenso StEENstrup, welcher aber (Forhandl. v. skandinav. Naturf. femte Miöde 1847.1849. pag. 956) meinte, dass die Eierkapseln nur durch Wachsthum des Mantels in denselben eingeschlossen worden sind, nicht rom Mutterthiere in denselben eingebracht.

2) Lis wäre von Interesse diese Deckel chemisch zu untersuchen. Vergl. KrukenberG, fortgesetzte Unters. üb. die Skeletine. Ztschr, f. Biol. XXII. N. F. VI. 1SS5. pag. 246. Taf. I.

3) Unter denselben kam auch eine geringe Anzahl ron Nematoden vor, etwa 5-6 Mal so lang wie der grösste Durchmesser der Tarvenschale. 
und einer Höhe von 17-21-23 mm; die Länge des Fusses 20_23 bei einer Breite bis 10-13 mm, die des Schwanzes 8-10 mm. Die Farbe war braungrau; die Unterseite des Mantelgebrämes sowle die Fusssohle und der Kopf gelblich; die obere Seite des Fusses grau, schwarzgrau oder violettgrau, die mediane Parthie des Schwanzriickens braungelb. Die F orm verhäitnisse wie oben. - Sieben der Individuen wurden anatomisch untersucht.

Der Mantel ganz wie oben. Die Schale etwas diunner, etwas blasser und hinten etwas weniger breit; an den beiden Seitenrändern trat immer, den Gegenden der MLuskelfacetten entsprechend, eine Faltenbildung auf (Taf. Z. Fig. 7, 8). Die Länge der Schale betrug in 5 in dieser Beziehung untersuchten Individuen 23-26 $\mathrm{mm}$ bei einer Breite von (14) $15-17 \mathrm{~mm}$.

Das Nervensystem wie oben. Die Otocysten ron einem Durchmesser von beiläufig $0,48-0,50$ bei einem Diam. des Otolithen von $0,12-0,2 \mathrm{~mm}$. Das Geruchsorgan (jederseits) mit 40-42 Blättern, iibrigens wie oben.

Die ganz zurückgezogene Mundröhre an Länge 11 bei einem Durchmesser von $3,5 \mathrm{~mm}$ messend. An einem Individum waren die Mundtheile $9 \mathrm{~mm}$ lang bei einem Durchmesser von fast $4 \mathrm{~mm}$ hervorgestiilpt (Taf. X. Fig. 12). - Die Länge des Schlundkop fes 3-3,5 mm; die der Raspelscheide 3,5-4 mm; die Mandibelplatten ganz wie oben, etwa 2,5-3 mm lang bei einer Höhe von beiläufig $1,5-1,6$; von Linien wurden unten 23-26, oben etwa 30-40 gezählt. An der Zunge kamen $32(25+7), 32,24,26,26$, 27 und 33 Kahmplattenreihen vor; in der Scheide $60(54+6), 44,67,52,43,47$ und 43 Reihen; die Gesammtzahl derselben war somit 92, 76,91, 78,69, 74, 76. Die Breite der vordersten medianen Platten betrug 0,21, die der jüngsten etwa 0,25 mm. Die Form der Platten ganz wie oben; die medianen zeigen jederseits meistens 6 Dentikel und meistens noch ganz feine Zähuchen an dem Haken; die Seitenzahnplatten meistens mit 5-7 Dentikeln jederseits.

Die Speiseröhre 9-10 mm lang bei einer Breite von 1,5-2 mm. Der Blïtermagen mit sammt seinem drüsigen Ueberzuge $10-10,5 \mathrm{~mm}$ breit bei einer Höhe von 6-6,5 und an der Mitte von einer Länge von 4-5 mm; die Zahl der Blätter 12-15. Der eigentliche Magen und der Darm wie oben.

Die Kiemenblätter, die Niere und die Blïtterdrise wie oben.

Die Geschlechtsdrüse fast ganz wie obeu, bis $6 \mathrm{~mm}$ dick; in den langen Driisenlappen entwickelte Zoospermien. Die ibrigen Theile des Genitalapparats relativ kleiner als in den obigen Individuen, aber sonst wie in diesen. Der Penis mehr oder weniger cingerollt, die cylindrische Spitze länger oder kürzer.

Unter den von der holländischen Expedition gefischten Onchidiopsen fand sich endlich auch ein einzelnes kleineres Individuum, das aber den Character der typischen Form, den sammtschwarzen Grund des Goruchsorgans so ausgepriigt 
wie gewőhnlich zeigte. Dasselbe war an $51^{\circ} 26^{\prime} 23^{\prime \prime} \mathrm{L}$. und $73^{\circ} 57^{\prime} 30^{\prime \prime} \mathrm{Br}$. aus einer Tiefe von 135 Faden (Temper. des Wassers 0,9 C.) hinaufgezogen.

Die Länge des in Alcohol bervahrten Individuums betrug $16 \mathrm{~mm}$ bei einer Breite bis 11 und einer Höhe bis $10 \mathrm{~mm}$. Die Farbenverhältnisse wie gewöhnlich.

Der Schlundkopf wie gewöhnlich; die Mandibelplatten auch, die Anzahl der Dentikel des Vorderrandes etwa 30. An der Zunge 17 Zahnplattenreihen; in der Raspelscheide 46 entwickelte und 6 jüngere, die Gesammtzahl der Reihen somit 69. Die Zahnplatten wie gewöhnlich; die medianen Platten etwas irregulair denticulirt; meistens jederseits 5 Dentikel zeigend; die Breite der jüngsten entwickelten medianen Platten 0,135 mm betragend. - Die Speiseröhre an der rechten Seite des Schlundkopfes hinabsteigend; der Blättermagen dunkel (blaiulich-) grau, mit gelbem Drisenlager. Die Leber graubraun.

Die gelbweisse Geschlechtsdrüse ohne entwickelte Zoospermien. Die vordere Abtheilung des Genitalapparats wenig entwickelt. Der Penis klein, kaum $1 \mathrm{~mm}$ hoch, fast cylindrisch, kaum geflügelt, mit gebogener Spitze.

\section{0. groenlandica, $\mathrm{B}_{\mathrm{GH}}$, var, pacifica.}

Ha b. M. pacif. bor.

Taf. F. Fig. 18, 22; T'af. Y. Fig. 19; Taf. Z. Fig. 23.

Im nördlichen stillen Ocean, in Kyska Harbour (Aleutischen Inseln), hat IV. H. DALL ein einziges Individuum dieser Form gefischt.

Dasselbe hatte, in Alcohol bewahrt, eine $\mathrm{L}$ iin $\mathrm{g}$ e von $3,2 \mathrm{Cm}$. bei einer Breite bis 2,2 und einer Höhe bis 1,9 Cm.; die Länge des Fusses 25 bei einer Breite bis $10 \mathrm{~mm}$, die Liange des Schwanzes $11 \mathrm{~mm}$; die Länge der T'entakel $4 \mathrm{~mm}$. Die Farbe schmutziggelblich. - Die Schale $24 \mathrm{~mm}$ lang bei einer Breite von $17 \mathrm{~mm}$, in jeder Beziehung sonst wie oben beschrieben.

Die Formverhältnisse wie oben; nach Spaltung des Mantels und Wegnahme der Schale zeigten sich die Eingeweide etwas blasser als oben erwähnt.

Das Centralnervensystem wie oben. Die rundlichen flachen, weisslichen Ohrscheiben am Aussenrande der Pedalganglien, von etwa $0,57 \mathrm{~mm}$ Durchmesser; die in denselben liegenden $\mathrm{Otocysten}$ von beiläufig $0,3 \mathrm{~mm}$ Diam., mit sehwach gelblichem Otolith von $0,16 \mathrm{~mm}$ Durehmesser. Das Geruchsorgan wie oben, etwa $7 \mathrm{~mm}$ lang bei einer Breite bis 2,75 und einer Höhe bis $1,75 \mathrm{~mm}$, gegen den schwarzen Grund auch stark contrastirend, mit ctwa 35 Bliattern.

Die ganz zuriickgezogene Schnauze (Mundröhre) $7 \mathrm{~mm}$ lang bei einer Breite (hinten) bis $3,5 \mathrm{~mm}$. Der Schlundkopf $3,5 \mathrm{~mm}$ lang bei einer Breite ron auch 3,5 und einer Höhe von 2,5; die Form wie oben; die hier 3,5 $\mathrm{mm}$ lange Raspelscheide an der linken Seite des Hinterendes des Schlundkopfs aufsteigend. Die Mandibelplatten wie oben, schillend horngelb, ron etwa 2,75 mm Länge bei einer Breite bis 1,5 mm; 
die Dicke der Platten bis $0,3 \mathrm{~mm}$ betragend; der Bau der gewöhnliche, die Anzahl der Stäbchenreihen unten etwa 33, an der Mitte beiläufig 50; die Anzahl der deutlichen Dentikel des Vorderrandes etwa 30 ; etwa $1 / 3$ der Breite der Mandibelplatte ragte als Kaurand frei vor der Lippenscheibe hervor. Die Zung e wie gewöhnlich; in der Raspel 26 Zahnplattenreihen, von welchen die 11 vor dem Raspeldache liegend und alle mehr oder weniger abgenutzt, in der Raspelscheide 46 entwickelte und 6 juingere Reihen; die Gesammtzahl derselben somit 78. Die Breite der vordersten medianen Platten betrug etwa 0,16, die der hintersten beiläufig $0,18 \mathrm{~mm}$; die Höhe der äussersten Haken fast durehgehends $0,16 \mathrm{~mm}$. Die Farbe der Zahnplatten wie oben. Die medianen Platten (Fig. 18) ganz wie oben, so auch ihr Kaurand. Die lateralen Platten ganz wie in der typischen Form; die Zähnelung der Ränder des Hakens wie oben. Die ii usseren Haken auch wic oben; der äussere Rand des inneren aber (wie in der O. glacialis) mit meistens 3 -4, mitunter mit mehreren (selbst bis 9) feinen Dentikeln (Fig. 22 aa; 19 aa); es kamen aber auch einzelne (wie es schien, nicht beschaidigte) innere Haken ohme Dentikel vor.

Die Speiseröhre ziemlich weit, bis $6,5 \mathrm{~mm}$ lang bei einem fast durchgehenden Durchmesser von $2 \mathrm{~mm}$. Der gräulichweisse Blättermagen von der gewöhnlichen Haubenform, etwa $6 \mathrm{~mm}$ lang bei einer Breite von 5 und einer Höhe von $3 \mathrm{~mm}$; die Zahl der Blätter der Wand etwa 12-13. Das den Magen iiberziehende Driisenlager sehr stark, besonders unten, bis 2 mm dick, ockergelb. Das Magenrohr fast $2 \mathrm{~mm}$ lang. Der eigentliche Magen schien sich wie in der typischen Form zu verhalten, und ebenso der Darm.

Die Leber gelbbraun, kaum in Farbe an der Aussenseite der oberen Eingeweidemasse von der Zwitterdriise unterscheidbar; an Schnitten war die Farbe mehr gräulich im Gegensatz zu der mehr gelben der Gland. hermaphrodisiaca; der Bau sonst wie oben.

Die Niere gelblichweiss, etwa $9,5 \mathrm{~mm}$ breit bei einer Länge (von vorne nach hinten) bis 3,5 und einer Dicke bis $2,25 \mathrm{~mm}$; die pericardio-renale Oeffnung ziemlich nach vorne im Herzbeutel; die branchiale Spalte wie oben. - Die Blätterdüse weisslich, $14 \mathrm{~mm}$ breit bei einer Läinge (von vorne nach hinten) von $9.5 \mathrm{~mm}$; ihre eine Hälfte vor, die andere hinter der Schalenleiste liegend; die Dicke bis $2 \mathrm{~mm}$ betragend; der Bau wie oben. - Die Kieme in gerader Linie $13 \mathrm{~mm}$ messend; die Liinge der Grundlinie der Blätter bis $4,5 \mathrm{~mm}$ steigend, ihre Höhe bis $3 \mathrm{~mm}$; die Anzahl der Bliitter etwa 200, ihre Form wie oben.

Die Z witterdruse in der Oberfläche schmutzig ockergelb; ein Untersehied zwischen dem ovarialen und testicularen Lager viel weniger deutlich vortretend, besonders weil das letztere viel schwächer war; in der Driise iberhaupt kaum reife Gonoblasten. Die oben sogenannte Nebenzwitterdrüse länglich-oval, der Länge nach etwas gebogen, etwa $8 \mathrm{~mm}$ lang bei einer Breite bis 3,5 und einer Höhe bis $4 \mathrm{~mm}$; auch an der Oberfläche dichte kalkweisse, in einander geschlungene Windungen zeigend; an Durchschnitten prïsentiren sich die Röhren gegen den Nabel convergirend; dieser letztere an der etwas aus. 
gehohlten Vorderseite liegend, schlitzartig; im Nabel verlief eine Anzahl von ziemlich dünnwandigen Sammelgängen, die sich allmählich zu dem Ausführungsgange vereinigten, dem Zwitterdrüsengange. Die Röhren der Drüse von Samen strotzend. Der oben sogenannte Zwitterdris is ng ng ganz wie in der typischen Form, sich theils an der Oberflïche der Prostata schlängelnd, theils durch dieselbe; sich theilend, der weibliche Ast sich in die Vagina offnend, der männliche sich als Samengang fortsetzend. Dieser letztere durch einen kurzen Gang die Prostata aufnehmend. Diese letztere zusammengedrickt, von ovalem Umrisse; etwa $6 \mathrm{~mm}$ lang bei einer Höhe bis 3 und einer Dicke bis $2 \mathrm{~mm}$; der Bau schien sonst der gewöhnliche. Der Samengang setzt sich in gewöhnlicher Weise an den Penis fort. Dieser letztere (Taf. Z. Fig. 23) war von etwas abweichender Form, stark gedreht, in der unteren etwas breiteren Hälfte zusammengedriiekt, in der oberen fast cylindrisch, ausgestreckt etwa $1 \mathrm{Cm}$. lang bei einem Durchmesser bis 2,5 mm. Der Samenleiter Konnte bis an die feine Oeffnung an der Spitze des Penis verfolgt werden. Die Vagina, weiblicher Ausführungsgang, wie oben, sehr stark, gebogen, ausgestreckt bis $6,5 \mathrm{~mm}$ lang bei einem fast durchgehenden Diam. bis $2 \mathrm{~mm}$; die Falten der Innenseite im Ganzen stark, besonders traten zwei solche hervor. Die Höhle mit Samen und Detritus gefullt. Die S a meublase unterhalb der Vagina liegend, zusammengedrickt, von ovalem Umrisse und etwa $3,5 \mathrm{~mm}$ Länge, von schwach röthlicher Farbe, kurzstielig; der Inhalt als lange, geschlängclte, dicht gedrïngte, aus Zoospermien gebildete Schnuren durehschimmernd. Der Vestibular-Sack klein. Die Schleim-und Eiweissdrise von etwa derselben Form wie oben, beiläufig 9,5 $\mathrm{mm}$ lang bei einer Breite bis 8 und einer Dicke bis $4 \mathrm{~mm}$; die obere Seite weisslich und links gelblichweiss; die untere bräunlich, nur links und vorne gelblichweiss; das radiat-streifige der oberen Seite rechts sehr stark ausgeprïgt. Der innere Bau wie oben; die stark gyraten Wände der oberen Höhle weiss; die ziemlich ebenen Wände der unteren Höhle bräunlichgelb, nur ganz vorne auch weiss. Der Bau wie geröhnlich.

Trotz Abweichungen vou den typischen Verhältnissen stellt diese Form doch wohl nur eine Varietat der Onchidiopsis groenlandica dar, welehe also circumpolar in ihrem Vorkommen scheint.

Ha b. M. arcticum.

2. O. glacialis (MI. SARS).

Taf. V. Fig. 25-32; Taf. X. Fig. 28; Taf. Y. Fig. 20-21; Taf. Z. Fig. 24.

Von der Art ${ }^{1}$ ), habe ich melhere (in Allem 5) Individuen untersucht, besonders ein colossales, von Herrn Museumsinspector Livinsex 1877 in der Nähe von Egedesminde.(Nord-Grönland) gefischtes Individuum; Notizen über dasselbe fehlen leider.

1) Der in der vorigen Altheilung (pag. 189) gegebenen Literatur ist noch hinzuzufügen:

Onchidiopsis glacialis, M. SARS. Aurivillius, Hafserertebr. från Nordligsta Tromsö Amt och Vestfinmarken. pag. 32. Taf. I. Fig. S. - K. Srenska Vet.-Akad. Handl. XI. 1S86. Nr. 4. 
Dasselbe hatte eine Länge von $6,5 \mathrm{Cm}$. bei einer Breite von 4 und einer Höhe auch von $4 \mathrm{Cm}$; das Mantelgebräme mass (bis an die Fusswurzel) ringsum fast durchgehends 12-13 mm an Breite, nur war die Inspirationsfurche etwa $15 \mathrm{~mm}$ lang bei einer Breite bis $4 \mathrm{~mm}$, an der Exspirationsfurche betrugen die entsprechenden Maasse 10 und $3,5 \mathrm{~mm}$; die Länge des Fusses war 3,5 Cm. bei einer Breite (vorne) bis $18 \mathrm{~mm}$, von denen jederseits $2 \mathrm{~mm}$ auf die vortretenden Fussecken kamen; die Länge des Schwanzes $15 \mathrm{~mm}$, die Breite des Fussgebrämes bis $4 \mathrm{~mm}$; die Länge der (zusammengezogenen) Tentakel 7 , die Breite der Kiemenspalte $9 \mathrm{~mm}$. - Die Farbe des Mantels braungrau mit sparsam zerstreuten dunkleren Fleckehen; die Unterseite des Mantelgebrämes durchscheinend (grinlich-) weisslich; Kopf und Fuss gelb mit schwarzgrauem Fussgebräme, der Schwanzrücken graubraun. - Der weiche Mantel fein und unregelmässig knotig.

Die allgemeinen Formverhältnisse und die einzelnen äusseren Theile wie in der vorigen $\Lambda$ rt. Der Mantel 2-5, hinten selbst $13 \mathrm{~mm}$ dick; an der inneren Hälfte der Unterseite ganz dünn, fast membranartig.

Die Schale $44 \mathrm{~mm}$ lang bei einer Breite bis 25 ; kaum hinten breiter und übrigens ganz wie in den kleineren Individuen der O. groenlandica (s. oben), mit ähnlicher Faltenbildung der Seitenränder.

Die Schalenleiste etwa $2 \mathrm{~mm}$ breit. Die Kiemenspalte und die Kiemenhöhle mit der weiblichen Genitalöftnung und der Nierenspalte (Taf. V. Fig. 30 a) wie in der vorigen Art. Die obere Eingeweidemasse $37 \mathrm{~mm}$ lang bei einer Breite von 23 und einer Höhe von $22 \mathrm{~mm}$. - Durch die obere Wand der Kiemenhöhle schimmerten die gewöhnlichen Eingeweide hindurch, das Geruchsorgan aber nicht schwarz.

Das Centralnervensystem ganz wie oben; die oberen Ganglien alle von ziemlich ähnlicher Grösse, von cinem zwischen 1,4 und 1,6 mm schwankenden grössten Durchmesser; das subintestinale schien das grösste zu sein; die Länge der eigentlichen Fussknoten (ohne die vorderen secundären Ganglien) etwa 2,3 mm. An der oberen Seite der Prostata hinten ein flaches, gerundetes Ganglion von beiläufig $0,75 \mathrm{~mm}$ Diam. mit einem eintretenden und zwei austretenden Nerven. - Die Otocyste in der gewöhnlichen weissen Scheibe aussen an der Mitte der Fussknoten, von etwa 0,45 mm Diam.; der Otolith in Durchmesser $0,16 \mathrm{~mm}$ messend. Das Geruchsorgan $10 \mathrm{~mm}$ lang bei einer Breite bis $4,5 \mathrm{~mm}$, gelblichweiss; die Anzahl der Blätter etwa 45; die Blätter wie oben (Taf. Z. Fig. 24).

Die ganz zurückgezogene Sclmauze und M undröhre etwa $12,5 \mathrm{~mm}$ lang bei einer Weite hinten bis $7 \mathrm{~mm}$. - Der Schlundkopf 4,5 mm lang bei einer Breite bis 5 und einer Höhe bis $4 \mathrm{~mm}$; die Raspelscheide nur 3,5 mm lang, gerade nach hinten und oben stehend, am Ende ein wenig rechts gekrimmt; die Knorpelfacetten klein und undeutlich. Am Grunde des freien Theils der Mandibelplatten eine schmale Lippenscheibe. Die Mandibelplatten von einem grössten Durchmesser von 4,5 mm, der andere etrva 2,25, die Dicke bis $0,4 \mathrm{~mm}$; sie sind braungelb; die Form wie oben, am Vorderrande 23-25 irre- 
gulaire Dentikel; unten wurden 32, nach oben etwa 42 Linien gezäblt. In der braungelben Raspel $29(24+5)$ Zahnplattenreihen; in der Raspelscheide 21 entwickelte und 7 jüngere Reihen; die Gesammtzahl derselben somit 57. Die medianen Platten ziemlich unregelmässig denticulirt, die Zahl der Dentikel jederseits 7-12; die Breite der ältesten Platte 0,29 mm. Am Aussenrande der Seitenzahnplatten meistens 8-9 Dentikel. Der Haken der inneren hakenartigen Platte mit 3-4 (selten 5-6) kleinen und spitzen Dentikeln ('Taf. X. Fig. 28).

Die Speis eröh re rechts hinabsteigend, $11 \mathrm{~mm}$ lang bei einem fast durchgehenden Diam. von $1,5 \mathrm{~mm}$; neben ganz feinen Längsfalten eine etwa $1 \mathrm{~mm}$ hohe. Der Blättermagen brîunlichgrau; (ohne Driisenlager) $10 \mathrm{~mm}$ breit bei einer Höhe von 8 und einer Liange von beiläufig $4 \mathrm{~mm}$; die Zahl der Blïtter etwa 15. Das überziehende Drüsenlager gelblich, bis $3 \mathrm{~mm}$ dick. Der $\mathrm{Magen}$ etwa 10,5 lang bei einer Höhe bis 9,5 und einer Tiefe von $8 \mathrm{~mm}$. Die an der Vorderseite der oberen Eingeweidemasse verlaufende Strecke des Darmes $33 \mathrm{~mm}$ lang bei einem fast durchgehenden Durchmesser von $3 \mathrm{~mm}$; die der hinteren Seite etwa $8 \mathrm{~mm}$ lang; die letzte Strecke des Darmes (Rectum) mit stärkeren Längsfalten. - Die Leber an der Aussenseite braungrau, an Schnitten schmutzig gringelb; sich mit ihren Fortsetzungen zwischen den einzelnen Organen des Genitalsystems einschicbend und mit denselben durch Bindesubstanz innig verbunden; die Leber an der Unterseite der Eingeweidemasse an Länge 15, an Breite $23 \mathrm{~mm}$ messend; an Schnitten der Leber zeigten sich die Gallengäuge von einem Durchmesser bis $1,2 \mathrm{~mm}$.

Das Pericardium $12 \mathrm{~mm}$ lang bei einer Höhe bis $9 \mathrm{~mm}$. - Die Niere (Taf. V. Fig. 31) $15 \mathrm{~mm}$ lang, oben 3, unten $8,5 \mathrm{~mm}$ breit; halbmondartig gebogen, oben (hinten) gerundet, vorne abgestutzt; die pericardiale Oeffnung wurde nicht gesehen, die Spalte in die (laf. V. Fig. 30c) Kiemenhöhle sehr deutlich. - Die Kieme etwa wie oben, die Blätter aber von etwas anderer Form (I'af. V. Fig. 25-27). - Die Blitterdrüse sich an die Schalenleiste erstreckend, nur links dieselbe ein wenig überschreitend, von den unterliegenden Organen leicht lösbar (T'af. V. Fig. 30 b, 32); in gerader Linie $26 \mathrm{~mm}$ lang bei einer Breite links von 6, rechts ron $12 \mathrm{~mm}$, bis $3,5 \mathrm{~mm}$ dick.

Die Zwitterdruise röthlichgelb, an der rechten Seite weiter nach vorne als an der linken tretend; in gerader Linie an Länge bis $20 \mathrm{~mm}$ messend, die Dicke des Drüsenlagers bis 5-6 mm; der Bau der Drüse vollständig wie oben. Der Nebenhoden auch ziemlich balbkugelförmig, rechts wegen der Eiweiss-Schleimdrüse facettirt, mit der nabelförmigen Vertiefung der etwas abgeplatteten Vorderseite; etwa $14 \mathrm{~mm}$ breit bei einer Liinge von 9 und einer Höhe von $12 \mathrm{~mm}$; graugelb; der Bau vollstindig wie oben. Der Anfangs auch korkzieherïhnlich gewundene $Z$ witterdrüsengang sich ganz wie oben verhaltend, sich in den männlichen und weiblichen Ast theilend. Der Samengang sich auch ganz wie oben verhaltend, unterhalb der Vulva in die Körperwand eintretend und an den Penis verlaufend. Die Prostata auch ein ovales gerundetes Organ bildend, von einer Lïnge von 8 bei einer Höhe von 5 und einer Breite von $3 \mathrm{~mm}$; der Bau wie oben. 
Der Penis ('laf. V. Fig. 29) etwas schlanker als in der vorigen Art und mit kuirzerem Fligel; etwa $10 \mathrm{~mm}$ lang bei einer Breite bis 2,5. Die (6 mm lange) Vagina und die Vulva wie oben; die Samenblase 7,5 lang bei einer Höhe von 5,5 und einer Breite von $4 \mathrm{~mm}$, gelblich, der Inhalt auch in starken Schniiren gelagert. Der VestibularSack 7,6 mm lang bei einer Höhe und Breite von 4 und 3 ; ganz wie oben. Die Schleimund Eiweissdrise $13 \mathrm{~mm}$ lang bei einer Breite von 10 und einer Dicke bis $4 \mathrm{~mm}$; die Randparthie gelblichweiss, die obere Seite hell gelblich, die untere körnig braungelb und gelb, nach oben mehr bräunlich (mil einem grösseren weissen Flecken).

Als von M. SARS in der Nähe von Hammersfest gefischt und von demselben als Onchidiopsis glacialis etikettirt, wurde mir (s.oben) von Herrn Museumsinspector R. CoLletT (im September 1884) aus dem Christiania-Museum ein Individuum geschenkt, welches auch dieser Art gehörte. Unter den von der holländischen Expedition (Varna) aus der Karen-Zee (1882_-83) gefischten Nudibranchien fand sich ferner noch ein Individuum. Ein drittes endlich rührt von der dänischen Djimphna-Expedition her, aus einer Tiefe von 46 Faden am 7. August 1883 im Meere von Karah gefischt.

Das erst erwähnte Individuum latte eine Länge von 13 bei einer Breite bis 10,5 und einer Höhe bis $9 \mathrm{~mm}$; die Länge des Fusses war 9,5 bei einer Breite bis 4,5, die Liinge des. Schwanzes $3 \mathrm{~mm}$; die Breite des Mantelgebrämes $3,5 \mathrm{~mm}$. Das andere Individuum war grösser, $27 \mathrm{~mm}$ lang bei einer Breite bis 20 und einer Höhe bis $17 \mathrm{~mm}$ : die Länge des Fusses war 18 bei einer Breite bis, 9 mm, die Breite des Mantelgebrämes beiläufig $8,5 \mathrm{~mm}$. Das dritte war $17 \mathrm{~mm}$ lang bei einer Breite von 14 und einer Höhe von 12. - Die Farbe des ersteren Individuums war weiss, mit einzelnen mehr kalkweissen Punkten am Rücken; die des anderen oben gräulich; die des dritten dunkler, etwa wie in den typischen Individuen.

Die Schale des ersteren Individuums maass an Länge $9 \mathrm{~mm}$ bei einer Breite bis 8,75; die des anderen und dritten 21 und 16 bei einer Breite bis 13 und $10 \mathrm{~mm}$; die Schale schien auch hinten weniger breit als in den typischen Individuen.

In dem grösseren Individuum maass die ganz. zurückgezogene Schnauze $5 \mathrm{~mm}$ bei einem Durchmesser von 4; der fast kugelrunde Schlundkopf hatte einen Diam. von $3,5 \mathrm{~mm}$, die Raspelscheide 3,5 mm lang. Die Mandibelplatten wie gervöhnlich; oben wurden in den drei Individuen 35, 40 und 26, unten 29-32.- 28 Reihen gezïhlt; am Vorderrande 35 und 40 deutliche Zacken (ausser dem grossen). Die Zunge mit starkem Liingskamm der Unterseite; in der Raspel 20, 25 und 19 Plattenreihen (von denen die 4-9 vordersten beschädigt, die allervordersten auch incomplet); in der Raspelscheide 27, 40 und 40 entwickelte und 6 jüngere Reihen, die Gesammtzahl derselben somit 53, 71 und 65. Die medianen Platten jederseits mit 5-6, mitunter mit 3-4 und einigen kleinen Dentikeln (im Ganzen etwas irregulair); oder mit 6-7. Die Seitenzahnplatten (Taf. X. Fig. 28) zeigten am Aussenrande meistens nur 4 Dentikel. An allen Individuen zeigte Semper, Philippinen. II, II (Bergh, Ergänzungsheft IV. Marseniaden II). 
die innerste Aussenplatte an der Aussenseite des Hakens (l'af. X. Fig. 28) z wei, seltener nur einen oder 3-4 winzigen Dentikel. Die Breite der ältesten medianen Platten war in den kleineren Individuen etwa 0,08 und $0,167 \mathrm{~mm}$, die der juingsten 0,14 und 0,195. - Die Speiseröhre immer rechts hinabsteigend, in dem grossen Individuum $11 \mathrm{~mm}$ lang bei einem Durchmesser von 2. Der Blättermagen selbst (ohne das Drisenlager) in dem grossen Individuum $6,5 \mathrm{~mm}$ breit bei einer Höhe von 5 und einer Lüinge (an der Mitte) von 3,5 mm, braungrau, mit 13-15 Blättern. Dieser Magen von dem gewöhnlichen Drüsenlager überzogen, das eine (an der Unterseite) $1-2 \mathrm{~mm}$ dicke weissgelbe Haube bildete. Die grosse Leber heller und mehr gelblich als die Geschlechtsdriise.

Das Geruchsorgan in den kleineren Individuen mit $45-50$ und 35 ziemlich hohen Blättern, in dem grösseren mit 32; die Falte wie gewöhnlich. Die Otocyste in dem mittelgrossen Individuum von 0,3, der Otolith von 0,10 mm Diam. - Die Kieme nur mit 80-100 Blättern. Die Niere gelblichweiss, schön fiederig. Die Anwachsstreifen der Schale prägten sich ungewöhnlich stark an der Oberfläche der etwas gelblichen Bl atterdrise.

Dio gelblichweisse Geschlechtsdruse ohne entwickelte Zoospermien und weniger weit als gewöhnlich hinter die Schalenleiste reichend. Der Pen is ganz klein,.nur bis $1 \mathrm{~mm}$ hoch, nicht cingerollt, kaum geflügelt ('Taf. V. Fig. 29).

Endlich habe ich ein noch kleineres, nur $10 \mathrm{~mm}$ langes Individuum untersucht, das ich unter Individuen von Marsenina micromphala vorfand, die an der Küste von Finmarken ('Tromsö) gefischt waren.

Die Mundorgane waren ganz vollständig, bis zu einer Länge von 2,5 $\mathrm{mm}$ hervorgestiulpt mit dem Innenmunde und den dunkeln Rïndern der Mandibelplatten am Ende. Diese ziemlich dunkeln Platten mit etwa 30 Zacken an dem Rande. Au der Zunge 20 Zahnplattenreihen, in der Raspelscheide 37, die Gesammtzahl der Reihen somit 57. Die Breite der vordersten medianen Platte beiläufig $0,058 \mathrm{~mm}$. Die Platten waren sonst alle wie gewöhnnlich. 


\section{A DDENDA:}

Der pag. 175 gegebenen Liste der bisher bekannten Arten von Chelyonoten wäre noch hinzuzufïgen der

Chelyonotus patagonicus (E. A. Surrñ).

Peronia sp., Cunningiram. Nat. hist. straits of Magellan. 1871. pag. 75. Wig. 1; pag. 449 .

- - C. Notes etc. Trans. Linn. soc. XXVII, 1871. pag. 484. pl. LVIII. Fig. $4 a,{ }^{\prime}$.

Lamellaria patagonica, E. A. Surre. Account of the zoolog. collect. ete. Proc. zool. soc. 1881. pag. 32. pl. IV. Fig. 9, 9 a, 9 b.

Ha b. M. pacific. (fret. Magellan.).

Diese Form wurde von Herm Cunvinginas in seiner gewöhnlichen schlechtesten Dilettanten-Manier als cine Peronia (!!) zuerst erwähnt und "beschrieben ". Diesem Herrn zufolge ist „der Mantel von schmutzig gelber Farbe, mit Linien und Flecken von ,vandyke" Braun; die Unterseite ringsum den Fuss mit hell farbigen Striehen". Die Beschreibung wird mit zwei, an die Zeiten von ALIROVANDI erinnernden Zeichnungen erläutert.

E. A. Suitri erkannte doch in der Figur von Cunvivgriam leicht eine "Lamellaria und hat Notizen úiber die Form des Thieres, die Mandibelplatten und die Raspel geliefert, noch dazu eine Beschreibung der stark gewölbten (globose) Schale, die einen grössten Diam. ron $25 \mathrm{~mm}$ hatte und sonst der anderer Chelyonoten ähnlich aussieht. 



\section{Register zu Supplementheft I-IV des II. Bandes. Nachträge und Ergänzungen.}

\begin{tabular}{|c|c|c|c|}
\hline & & & \\
\hline leolididae . . . . . . & 80 & Chromodoris, Ald. et Hanc. & $\begin{array}{ll}1 & 14-27 \\
1 & 81-85\end{array}$ \\
\hline & 172 & coccinea (Forbes) & $100-1$ \\
\hline ammis, Bgn. n. sp. & $1245-247$ & coerulea, Risso & $83-$ \\
\hline var. alba Bgh. (s. Jolnnstoni, Ald & & cornigerum, Adams, Bgh. & \\
\hline et Hanc.) . . . . . & . $119-125$ & Coryphella, Gray & \\
\hline $\begin{array}{l}\text { albopustulosa (Pease) } \\
\text { ampla, Verrill. }\end{array}$ & $\begin{array}{r}82 \\
184\end{array}$ & crucis (Oersted) & 42 \\
\hline Archidoris, Bgh. . & $33-35$ & ID. & \\
\hline arrogans, Boh, var? & $\begin{array}{l}86-94 \\
58-60\end{array}$ & Dalli, Bgh. n. sp. & $18 \%-1$ \\
\hline (1) & 0 & debilis (Pease) & $10-$ \\
\hline $\operatorname{cog} \operatorname{cossa} \cdot \cdot \cdot \cdot \cdot \cdot$ & $1-7$ & decora (Pease) & $25-$ \\
\hline Asteronotus, Ehrenbg. . . & . $\quad 67-74$ & depressa, Wood . . . . & \\
\hline $\begin{array}{l}\text { atromaculata, Bgh. n. sp. } \\
\text { atypha, Bgh. n. sp. }\end{array}$ & $\begin{array}{r}45-46 \\
125-128\end{array}$ & desmoparypha, Bgh. n. sp. & $51-$ \\
\hline & & Dictyodoris, Bgh. n. gen. . & 75 - \\
\hline BE. & & Diegoënsis (Dall.) & \\
\hline $\begin{array}{l}\text { bella (Pease) } \\
\text { rar. Berghi, Desh. (s. tonganus } \\
\text { Quoy et Gaim.) }\end{array}$ & $\begin{array}{r}79 \\
177-178 \\
222-224\end{array}$ & Discodoris, Bgh. & $\cdot\left\{\begin{array}{c}47- \\
108-1\end{array}\right.$ \\
\hline bertrana, Bgh. & $67-71$ & Dorididae . & $14-1$ \\
\hline borealis Bgh. n. sp. & $\left\{\begin{array}{r}179 \\
251-253\end{array}\right.$ & Dorididae . . . . & $81-1$ \\
\hline brevicaudatum, Abr. & 28 & $\begin{array}{l}\text { Dorididae Cryptobranchi } \\
\text { Doriopsidae . }\end{array}$ & $\begin{array}{l}14- \\
9-\end{array}$ \\
\hline C. & & Doriopsis, Pease . . . . & \\
\hline Cabulana Bgh. n. sp. & $\begin{array}{l}1 \\
244-245\end{array}$ & var. dubia, Bgh. (s. perspicua L. & ) $237-2$ \\
\hline calcedonicum, Fischer & 28 & E. & \\
\hline cardinalis. Bgh. n. sp. & $23-25$ & & $1-$ \\
\hline Ceratosoma, Ald. et Hanc. & $28-31$ & Elysia (Risso) attt. & - \\
\hline Chelyonotus (Swains.), Bgh.。 & $\left\{\begin{array}{r}174-178 \\
193-224 \\
\mid \begin{array}{rl}285\end{array}\end{array}\right.$ & $\begin{array}{l}\text { Elysiadae . . . . . } \\
\text { eurychlamys, Bgh. var. . }\end{array}$ & $\begin{array}{rr}1 & 1--4 \\
\cdot & 79-8 ! \\
i(1) & 1 ; 2\end{array}$ \\
\hline
\end{tabular}




\section{G.}

gemma, Bgh. n. sp.... . . $\left\{\begin{array}{r}171 \\ 243-244\end{array}\right.$

glabra (Couth.) .

| $183-184$

glacialis (MI. Sars)

1 $261-262$

| $189-190$

280-284

var.' Gouldii Verill. (s. pellueida 169

Verill. . . . . . 241-242

gracillimum. S., Bgh. . . . . 28

gracilis (Rapp.) . . . . . . 15-17

grisea, Bgh. n. sp. . . . . . 11-1:;

groenlandica, Möller (Marsenina) · 184-185

groenlandica, Bgh. (Onchidiopsis) $\left\{\begin{array}{l}187-189 \\ 265-278\end{array}\right.$

groenlandica, Bgh., var. pacifica . 278-280

\section{패.}

Hexabranchus, Ehrenb. . . . . 32

Hoplodoris, Bgh. n. gen. . . . 51-56

I.

Ianuarii, Bgh. . . . . . . . 37-40 var. Iheringi (s. luteo-rosea Rapp.) 19 imperialis, Pease . . . . . 25 indecora, Bgh. (Discodoris) . . 108-112

indecoriarsenia). 172 indocora, Bgt. (Hatsedia) ' 247 -248 inornata, Pease . . . . 21-23 Johnstoni (Ald. et Hane.) . . . 114-118 Johnstoni, A. et $H$., var. alba, Bgh. $\quad 119-125$

Jorunna, Bgh. n. gen. . . . . . 113-128 isabellina, Bgh. в. sp. . . . . 172

\section{IK.}

Kerguelensis (Studer)

var. lactea (s. viridis, NItg.) . . 3-4 latens (Müller) . . . . . $\left\{\begin{array}{r}168 \\ 238-239\end{array}\right.$

var. lineata (s. prismatica, Pease) 26

luteo-rosea (Rapp) . . . . 17-18

luteo-rosea, R., var. Iheringi . . 19

\section{ㅍ.}

mabilla, Bgh. n. sp.

$71-74$

marginata (Pease) marmorata, Bgh. n. sp. . . . s si- 92

marmorata, Bgh. var. . . . . 92— 94

Marsenia, Leach

( $160-173$

225-250

Marseniadae, (Leach), Bgh. . . . . . 147-190

Marseniella, Bgh. n. gen. . . . $\left\{\begin{array}{r}78-179 \\ 251-253\end{array}\right.$

Marsenina, Gray . . . . . $\mid \begin{aligned} & 181-186 \\ & 255-26\end{aligned}$

Marseniopsis, Bgh. n.'gen. . . . 179-180

var. mauritiana, Bgh. (s. tonganus

Qu. et Gaim.) . . . . . 176-177

minuta (H. Adams) . . . . . 171

Morelli (delle Chiaje) . . . . 167

var. Morelli, d. Ch. (s. perspicua L.) 236-237

Murrayi, Bgh. n. sp. . . . . 180. 255

\section{(1).}

oblongum, Abr. . . . . . 28

ocelligera, Bgh. п. sp. . . . . 95-98

Onchidiopsis, Beck, Bgh. . . . $\left\{\begin{array}{l}186-190 \\ 265-284\end{array}\right.$

ophione, Gray . . . . . . . 173

orbiculata (Dall) . . . . . . . 179

ornata (Pease) . . . . . . . 79-80

\section{P.}

pacifica, Bgh. n. sp.

130

var.

parrula, Pease . . . . . . 80

patagonicus (E. A. Smith) . . 285

Peasei, Bgh. . . . . . . . 20

pellucida (Verrill.) . . . . \{ $168-169$

pellucida (Ver.), var. Gouldii, (Ver.) \} 169

Peltodoris, Bgh. n. gen. . . . . 41-46

perspicillata, Bgh. n. sp. . . . 104-107

$165-167$

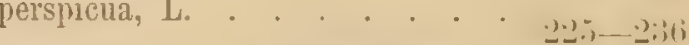

perspicua, L., var. dubia, Bgh. . 237-238 var. Morelli (d. Ch.) . ㄹ:

Phyllidia (Cuv.), Boh.

Phyllidiadae

picta, Pease

8

4

73

80


Plakobranchidae . . . . . . . $\quad 5-7$

Plakobranchus, van Hass. . . . . 5-7

Platydoris, Bgh. . . . . . . $\quad 57-66$

polyomma, Bgh. n. sp. . . . . 29-31

\section{Porostomata}

$8-23$

prodita, Lovén . . . . . . $\left\{\begin{array}{l}182-183 \\ 256-261\end{array}\right.$

producta, Leach . . . . . . 164

propinquata (Pease) . . . . . 81—82

pulchellus, Pease . . . . . . 32

punctatus (Stimpson) . . . 178

\section{IB.}

Rangii, Bgh. . . . . . . 170

rhombica (Dall.) . . . . . . 185

Rostanga, Bgh. . . . . . . 99-107

Rudolphi, Bgh. n. sp. . . . . 19-21

\section{s.}

Semperi, Bgh. в. sp. . . . . 175-176

Semperi, Bgh. 1. sp. . . . . 193-222

Schmelziana (Garr.), Bgh. . . . $\quad 47-50$

sp.
Stearnsii (Dall.) . . . .

170

Staurodoris, Boh - $36-40$

\section{II.}

tentaculata (MItg.) . . . . . 163

tenue, Abr. . . . . . . 28

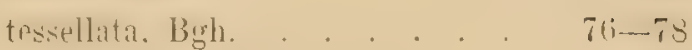

tonganus (Quoy et Gaim.) . . . 176

tonganus (Quoy et Gaim.), var. 177-17S

Berghi, Desh. . . . . . 1222-224

tonganus (Qnoy et Gaim.), var.

mauritiana, Bgh. . . . 176-177

trilobatum, Gray . . . . . 28

tuberculata (Cuv.) . . . . $34-35$

tuberosus Stimpson . . . . 178

varicosa, Lmck., var. . . . 8

variegata, Bgh. n. sp. . . . 63-66

variegatus, Pease . . . . . $5-7$

vibrata (Pease) . . . . 26-27

vicina, Bgh. n. sp. . . . . . 62-63

villafranca (Risso) . . . 14-15. 83

viridis (Mtg.) . . . . . . . $1-3$

viridis (Mtg.), var. lactea . . . 3-4 




\section{Tafel A.}

\section{PELTODORIS CRUCIS (OERSTED).}

Fig. 1. Von der oberen Seite.

Fig. 2. Von der unteren Seite.

Originalzeichnungen von Prof. OERs Ex in natürlicher Grösse.

\section{DORIOPSIS GRISEA, BGI.}

Fig. 3. Von der oberen Seite.

Fig. 4. Von der unteren Seite.

Fig. 5. Rhinophor.

Fig. 6. Kiemenblatt.

\section{PLATYDORIS VARIEGATA, BGH,}

Fig. 7. Von der oberen Seite.

Fig. \&. Von der unteren Seite.

Fig. 9. Kiemenblatt.

Fig. 10. Rhinophor.

CHROMODORIS RUDOLPHI, BGH.

Fig. 11. Von der oberen Seite.

Fig. 12. Von der unteren Seite.

Fig. 13. Rhinophor.

Fig. 14. Kiemenblatt.

\section{DISCODORIS SCHMELTZIANA (GARR.).}

Fig. 15. Von der oberen Seite.

Fig. 16. Von der unteren Seite.

Fig. 17. Kiomenblatt.

Fig. 18. Rhinophor.

Fig. 19. Analpapille.

Fig. 3-19 nach den dem Museum Goderrroy geschickten Originalzeichnungen von Garretr (PEase). 

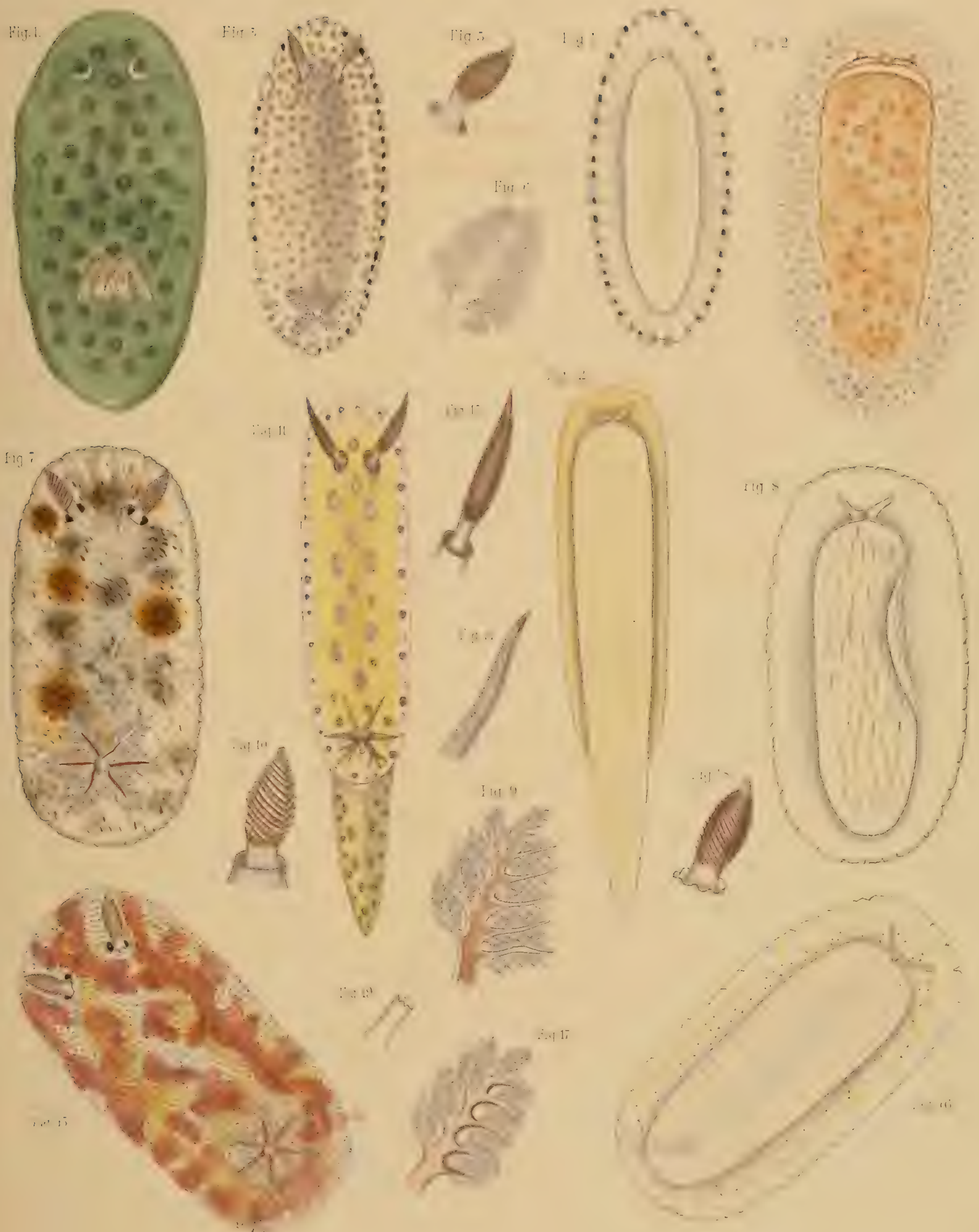



\section{Tafel B.}

\section{CHROMODORIS IMPERIALIS (PEASE).}

Fig. 1. Von der oberen Seite.

Fig. 2. Von der unteren Seite.

Fig. 3. Rhinophor.

Fig. 4. Kiemenblatt.

\section{CHROMOD. DECORA (PEASE).}

Fig. 5. Von der oberen Seite.

Fig. 6. Von der unteren Seite.

Fig. 7. Rhinophor.

Fig. S. Kiemenblatt.

CERATOSOMA POLYOMMA, BGH.

Fig. 9. Das Thier schräge von der Seite.

$$
\text { CHRONOD. PEASEI, BGH. }
$$

Fig. 10. Von der oberen Seite.

Fig. 11. Von der unteren Seite.

Fig. 12. Rhinophor.

Fig. 13. Kiemenblatt.

\section{HEXABRANCHUS PULCHELLUS (PEASE).}

Fig. 14. Von der oberen Seite.

Fig. 15. Von der unteren Seite.

Fig. 16. Rhinophor.

Fig. 17. Kiemenblatt.

CHROMOD. VIBRATA (PEASE).

Fig. 18. Von der oberen Seite.

Fig. 19. Von der unteren Seite.

Fig. 20. Rhinophor.

Fig. 21. 'Kiemenblatt.

Chromod. marginata (Pease).

Fig. 22. Von der oberen Seite.

Fig. 23. Von der unteren Seite. 


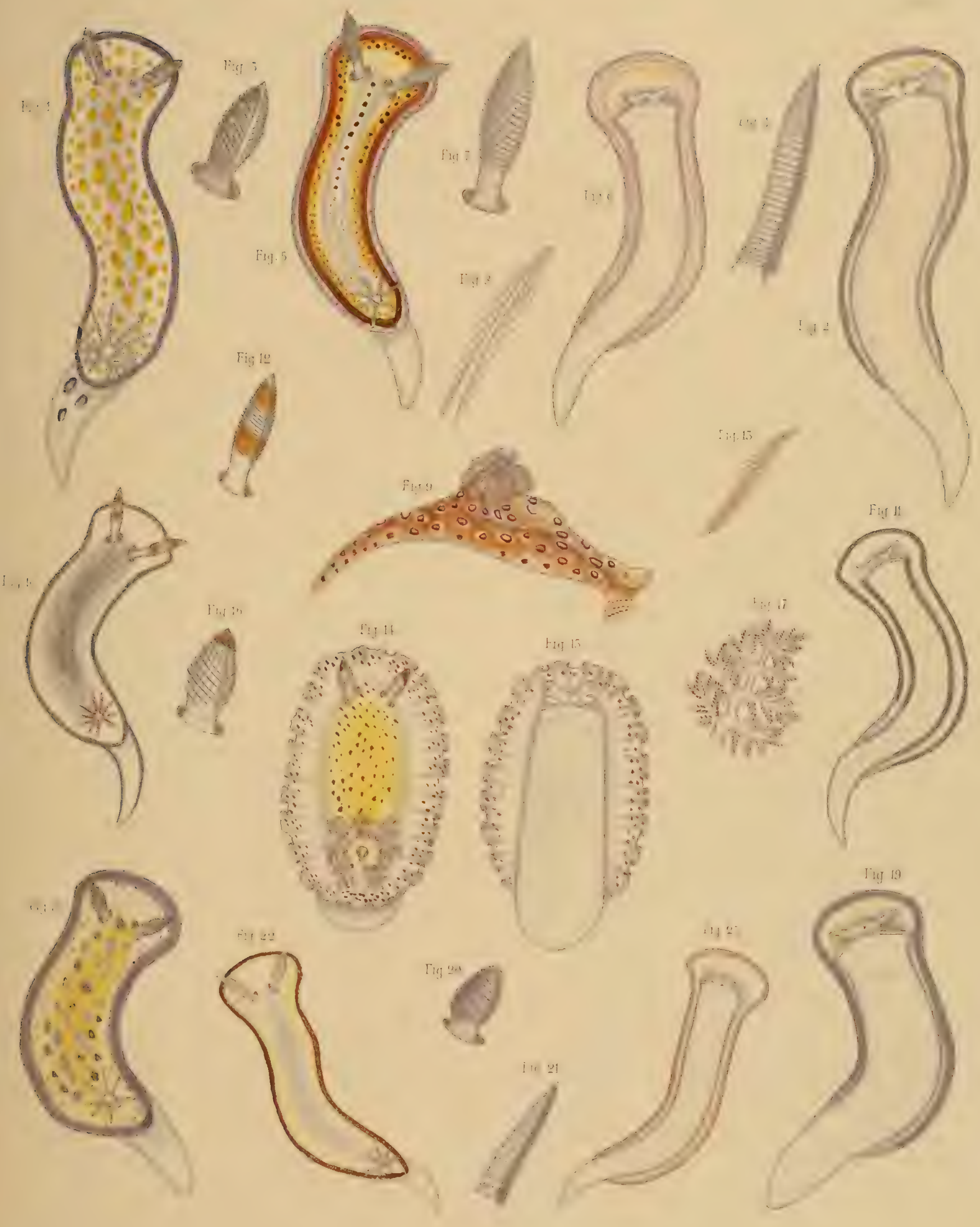





\section{Tafel C.}

\section{CHROMODORIS RUDOLPHI, BGH.}

Fig. 1. Das Centralnervensystem, von oben, mit Cam. Iuc. gezeichnet (Vergr. 100). aa cerebro-viscerale Ganglien mit Augen und von der Unterseite durchschimmernden Ohrblasen; 6 proximale Riechknoten; $c c$ pedale Ganglien; $d$ Commiss. subcerebro-viscero-pediaea; $e$ Comm. cerebro-buccalis; $f$ Comm. interbuccalis; gg Ganglia gastro-oesophagalia.

Fig. 2. Lippenscheibe (Lippenplatte) mit Mundspalte, mit Cam. luc. gezeichnet (Vergx. 100); $\boldsymbol{a}$ oben.

\section{CHROMOD. CARDINALIS, BGH.}

Fig. 3. Centralnervensystem von oben, mit Cam. luc. gezeichnet (Vergr. 100). Bezeichnungen wie oben.

Fig. 4. a Spermatotheke; $b$ Spermatocyste; $c$ uteriner Gang der Spermatotheke; $d$ vaginaler Gang an die Vagina; $\boldsymbol{e}$ Samengang (an den Penis).

\section{HOPLODORIS DESMOPARYPHA, BGH.}

Fig. 5. au Ganglia buccalia, b Gangl: gastro-oesophagale; mit Cam. Iuc. gezeichnet (Vergr. 55).

Fig. 6. Elemente der Lippenplatte, mit Cam. luc. gezeichnet (Vergr. 750).

Fig. 7. Oberes Ende einer der Bricken (Scheiben) der Innenseite des Penis (Pracputium), mit Cam. luc. gezeichnet (Vergr. 350).

Fig. 8. Ende des Stachels (hasta amatoria), mit Cam. luc. gezeichnet (Vergr, 100). $a$ Spitze desselben; $b$ bis an die Spitze aufsteigender Stacheldrüsengang.

Fig. 9. Zellen aus dem erwälnnten Stachel, mit Cam. luc. gezeichnet (Vergr. 350).

\section{ASTERON. MABILLA, BGH.}

Fig. 10. a Speiseröhre; $b$ Magen (mit eingesenkter oberer Wand), hinter demselben links die Gallenblase; $\boldsymbol{c}$ Darm; $\boldsymbol{d}$ linkes, $\boldsymbol{e}$ rechtes Vorderende der Leber.

\section{DICTYODORIS TESSELLA'TA, BGI.}

Fig. 11. Acusserster Theil einer Zahnplattenreihe mit 7 Platten; $\boldsymbol{a}$ äusserste Platte.

Fig. 12. Sechs äussere Platten einer anderen Reihe; $\boldsymbol{a}$ äusserste.

Fig. 11-12 mit Cam. luc. gezeichnet (Vergr. 750).

\section{S'TAURODORIS JANUARIT, BGI.}

Fig. 13. Aussenmund mit a

Fig. 14. Rhinophorgegend mit Schutzpapillen und a Rhinophor.

Fig. 15. Kiemengegend mit zurückgezogener Kieme und zusammengebogenen KiemenPallisaden.

Fig. 16. Stiick des Kỉemenhöhlenrandes, mit grösseren und kleineren Tuberkeln ausserhalb desselben.

Fig. 17. Analgegend mit Analpapille, Nierenpore und Kiemenkrause; $\boldsymbol{a}$ Kiemenblatt.

Fig. 18, 18. Riickentuberkel.

Fig. 19. Stiick eines Rhinophorblattes, mit Cam. luc. gezcichnet (Vergr. 350).

Fig. 20. Commissuren des Centralnervensystems;

a Comm. subcerebro-visceralis, $b \mathrm{~N}$. genitalis, $c$ Comm. pediaea.

Fig. 21. Stiick zweier Zahnplattenreihen, $\boldsymbol{a} 24$ te Zahnplatte (von innen).

Fig. 22. Doppelzalmplatte.

Fig. 23. $\boldsymbol{~}$ S Spermatotheke; $\boldsymbol{b}$ Spermatocyste; $\boldsymbol{c}$ uteriner Gang der Spermatotheke; $\boldsymbol{d}$ raginaler Gang, e Vagina. 


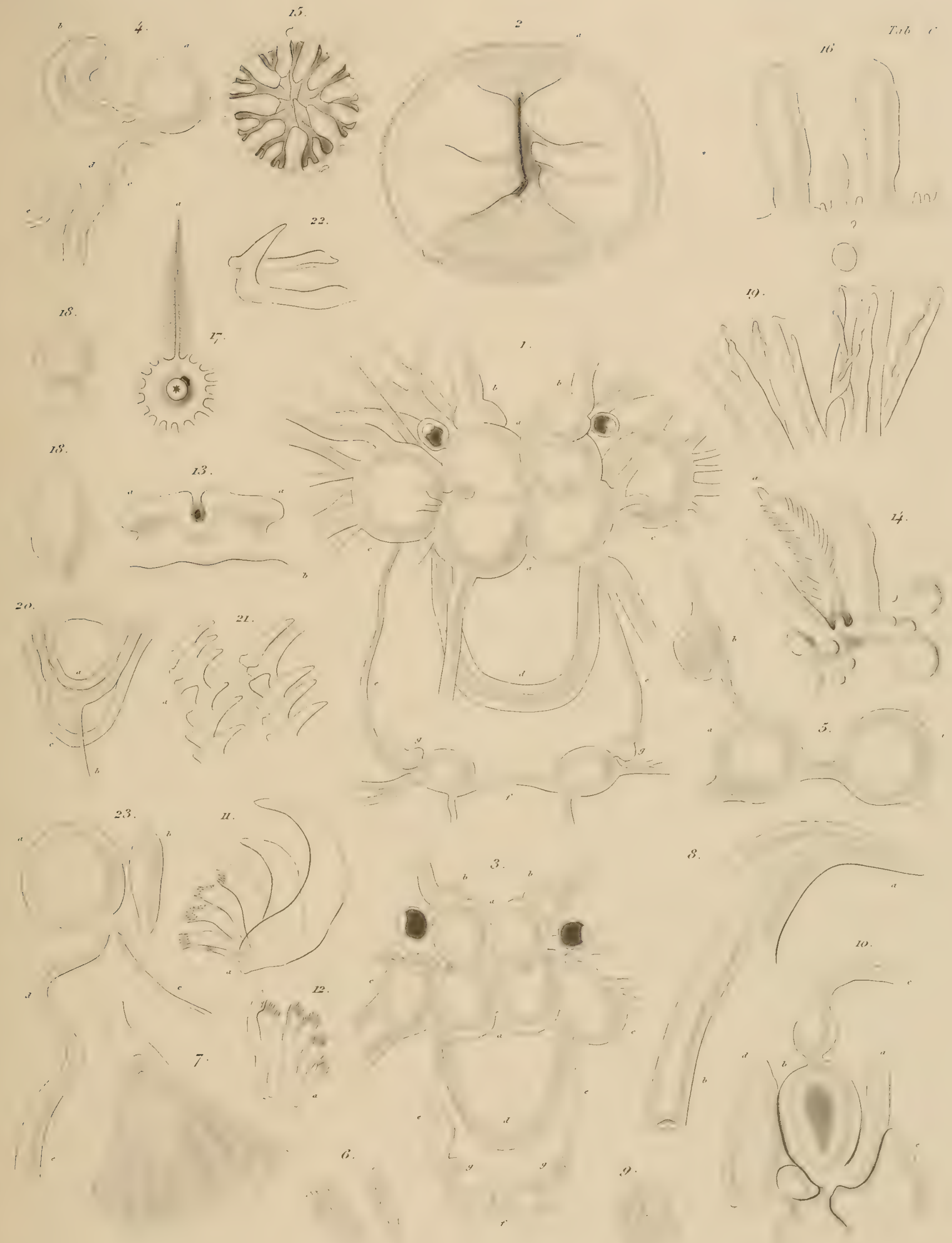






\section{Tafel D.}

Fig. 1. Elemente der Lippenplatte.

\section{CIIROMOD. RUDOLPHI, BGII.}

Fin. 2. Aus der Mitte der Raspel, Spitzen von 4-5 Zahnplatten, a $a$ der medianen, $b b$ der ersten lateralen.

Fiщ. 3. $\quad \boldsymbol{a}$ erste Seitenzahnplatten von der rechten, $b$ ihnliche von der linken Seite, $c$ zweite Seitenzahnplatte.

Fị. 4. Eine der grössten Zahnplatten.

Fin. 5. Mitte einer Zahmplattenreihe von der Unterseite.

Fig. 6. Acusseres Ende yon zwei Zahnplatienreihen mit 4 und 7 Zahnplatten; $\boldsymbol{a}$ äusserste.

ling. 7. Zwvei iusserste Zahmplatten.

Fig. 1-7 mit Cam. luc. gezeichnet (Vergr. 750).

CHROMOD. CARDINALIS, BGH.

Fin. \&. Elemente der Lippenplatte, von der Seite.

Fin. 9. Aehnliche von der Fliche.

Fị. 10. Nitte der Raspel mit Stuick von 5 Zahnplattenreihen. ac Verdickungen der Rhachis, $b b$ erste Seitenzahnplatten.

Fin. 11. Erste Seitenzahnplatte.

Fig. 12. Aeusserster Theil einer Zahnplattenreihe mit 7 Platten; “ äusserste Platte.

Fig. 13. Drei iusserste Seitenzahmplatien, von der Innenseite.

Fir. 14. Zwei äusserste Seitenzahnplatten, schief von der Hinterseite. Fig. 8-14 mit Cam. luc. gezeichnet (Vergr. 750).

Fig. 15. Spikel der IIaut, mit Cam. luc. gezeichnet.

\section{CHROMOD. INORNA'TA, PEASE.}

Fig. 16. Ganglia buccalia und gastro-oesophagalia;

a Speicheldrüsengang, $b$ Vorderende der Speicheldrüse; mit Cam. luc. gezeichnet (Vergr. 100).

Fig. 17. Elemente der Lippenplatte.

Fig. 18. Aus der Mitte der Raspel.

a $a$ innerste Seitenzahnplatten, zwischen denselben Verdickungen der Rhachis.

Fig. 19. Erste Seitenzahmplatten zweier Reihen, von der Seite.

Fig. 20. A A usserer Theil dreier Zahnplattenreihen, mit 6, 6 und 4 Zahnplatten; an äusserste. Fig. 16-20 mit Cam. luc. gezeichnet (Vergr. 750).

Fig. 21. a hervorgestreckte Glans penis, b Samenleiter; mit Cam. luc. gezeichnet (Vergr. 100). STAURODORIS JANUARI, BGH.

Fig. 22. Spikel aus der Hülle des Nervensystems, mit Cam. lue. gezeichnet (Vergr. 350). CERATOSOMA POLYOMNA, BGH.

Fig. 23. Das Thier von der Riickenseite.

Originalskizze in etwa natürlicher Grösse von KuBary. Der Rückenfortsatz (mit umgebogenen Händern) stark gegen oben geschlagen.

Fig. 2-t. Zwei der grössten Zahmplatten, mit Cam. luc. gezeichnet (Vergr. 750).

Fig. 25. Aeusseres Einde ron zwei Zahuplattenreihen mit je 8 Zahnplatten. ua ïusserste Platten; mit Cam. Inc. gezeichnet (Vergr. 350).

Fig. 26. Aeusserste Zahnplatte dreier Reihen, mit Cam. luc. gezeichnet (Vergr. 750).

DORIOPSIS IDEBILIS, BGH.

Fig. 27. Senkrechter Längsdurehschnitt der hinteren Eingeweidemasse (Leber).

Fig. 2s. Hervorgestreckte Glans penis, a Spitze; mit Cam. luc. gezeichnet (Vergr. 750).

Fig. 29. Chitinisirte Auskleidung der Vagina, a unteres Ende; mit Cam. luc. gez. (Vergr. 350). PLAKOBRANCHUS VARIEGATUS, Pease.

Fig. 30. $\quad$ a äusseres Ende des cerebro-visceralen und $b$ des pedalen Ganglions, $c$ Ohrblase; mit Cam. luc. gezeichnet (Vergr. 350).

Fig. 31. Vorderende der Raspel, mit Cam. luc. gezeichnet (Vergr. 750). a Zahnplatte der Zungenspitze, $b$ vorderste Platte der oberen und $c$ der unteren Reihe.

Fig. 32. Glans penis mit $\boldsymbol{a}$ Stachel, b Samenleiter; mit Cam. luc. gezeichnet (Vergr. 100). Fig. 33. Spitze des Stachels, mit Cam. Iuc. gezeichnet (Vergr. 350). 


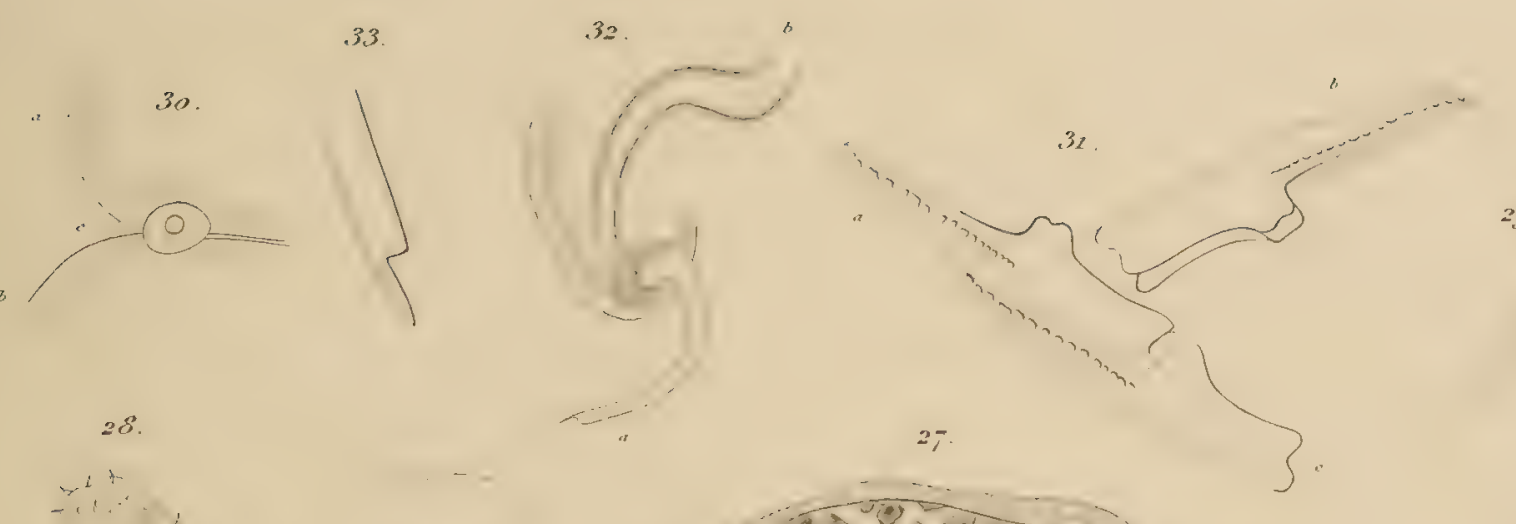

Titi, II

$-x^{2}$
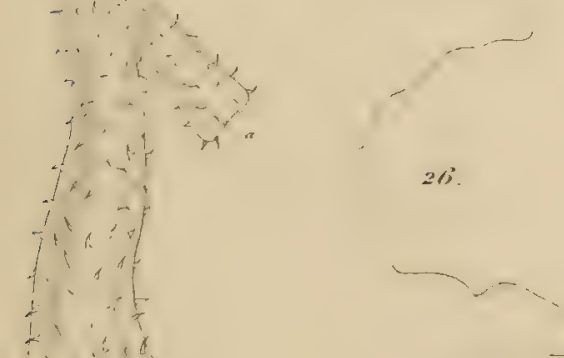

$2 \pi$

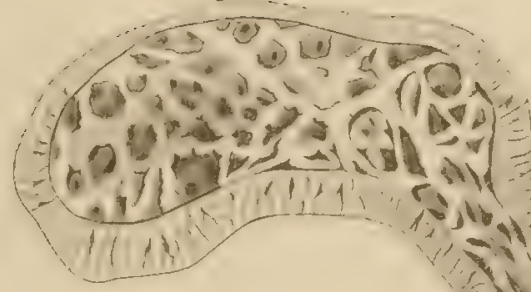

$(f), 21$
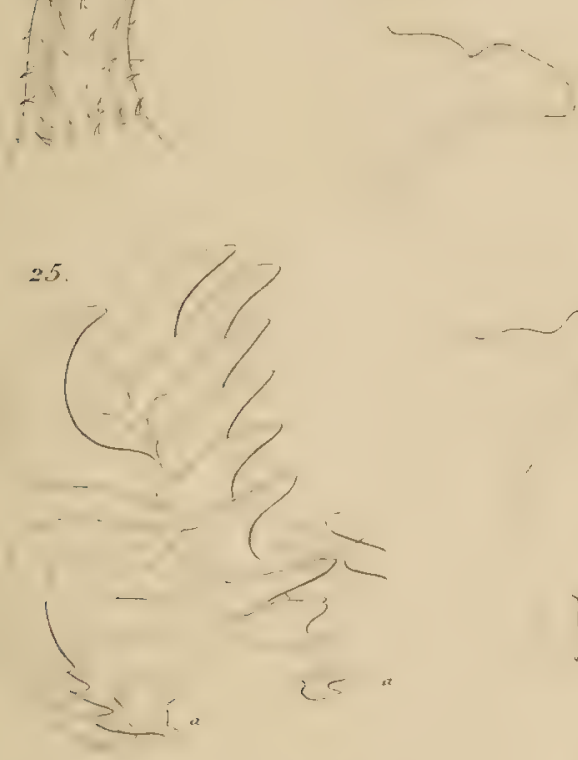

11

$\therefore 0^{2}$
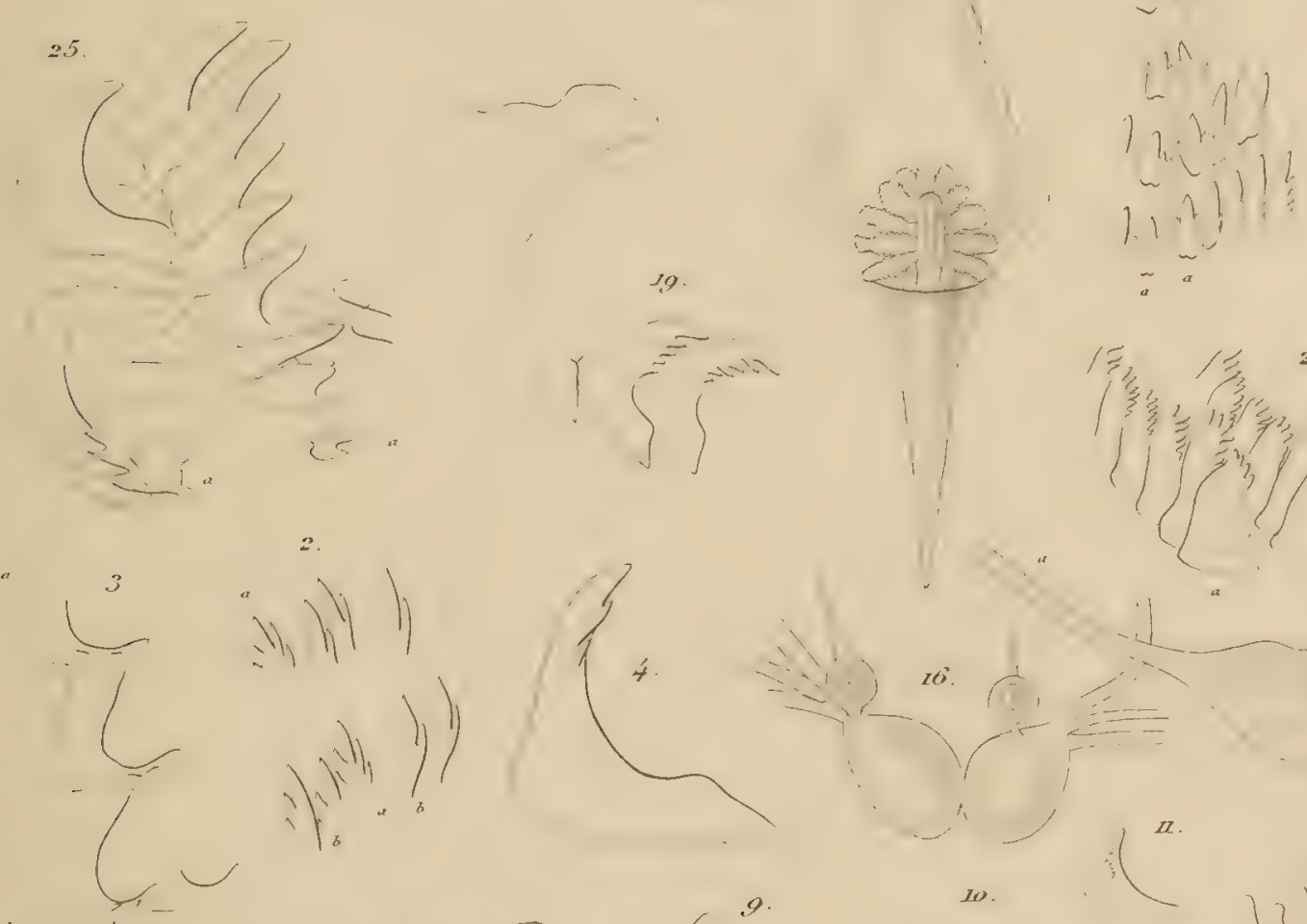

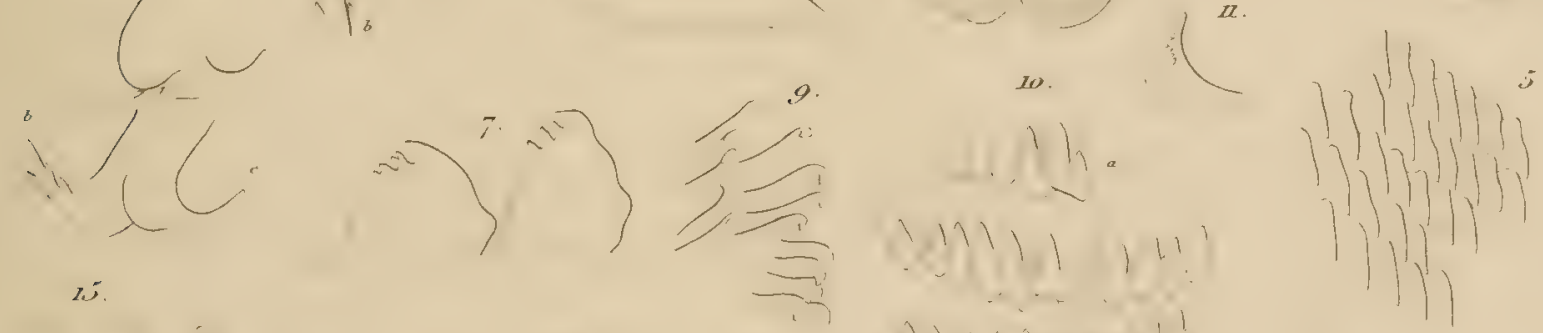
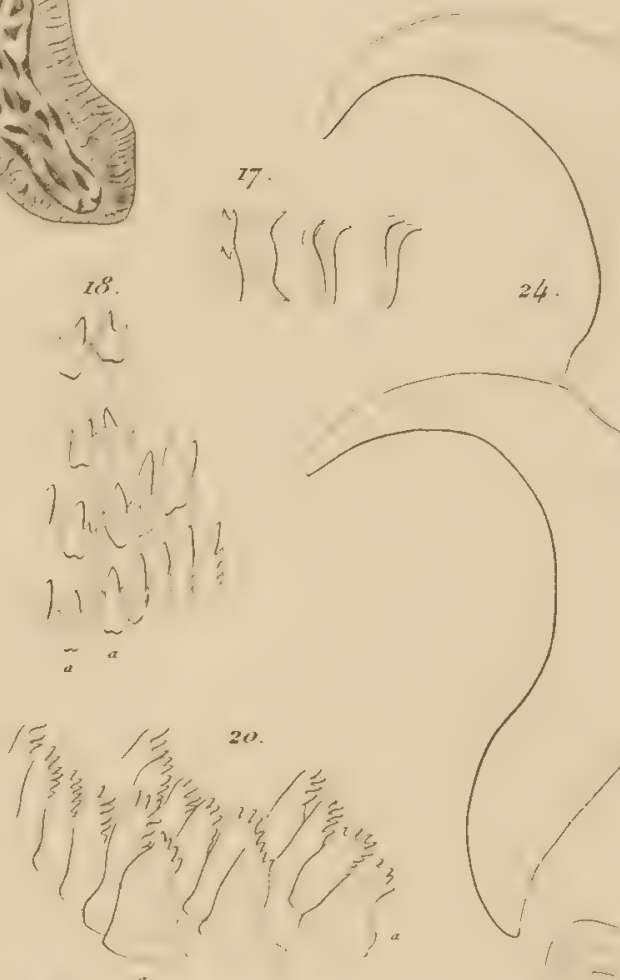




\section{Tafel E.}

\section{(GONIODORIS CASTANEA, AlD. et HANC. ${ }^{1}$ )}

Fig. 1. Glans penis, mit Cam. luc. gezeichnet (Vergr. 750).

Fig. 2. Seitenzahnplatten, mit Cam. luc. gezeichnet (Vergr. 350).

\section{PLATYYDORIS ARROGANS, BGH. var.}

Fig. 3. Innerste Zahnplatte.

Fig. 4. Platte aus der Mitte einer Reihe.

Fig. 5. Acusserster Theil zweier Zahnplattenreihen mit 3 und 7 Platten; $\boldsymbol{a} \boldsymbol{a}$ äusserste. Fig. 3-5 mit Cam. luc. gezeichnet (Vergr. 350).

Fig. 6. a Spermatotheke, $b c$ uteriner Gang, $\boldsymbol{d}$ Spermotocyste, $\boldsymbol{e}$ Gang derselben, $\boldsymbol{f}$ vaginaler Gang der Spermatotheke, y Vagina mit durchschimmernden Falten, h Vestibulum.

Fig. 7. Stiick der Innenseite der Vagina, mit ihrer Cuticula.

Fig. 8. Stïck der Imenseite des Penis (Praeputium) mit ihren Bricken.

Fig. 9. Oberes Ende des Praeputiums mit vorspringender Glans.

Fig. 7-9 mit Cam. luc. gezeichnet (Vergr. 100).

PLA'TYD. EURYCHLAMYS, Bgr. var.

Fig. 10. Spikel aus der Hülle des Centralnervensystems.

Fig. 11. Aeusserster Theil zweier Zahnplattenreihen mit 3 und 7 Platten; an äusserste.

\section{PLATYDORIS VARIEGATA, BGH.}

Fig. 12. a Ganglia buccalia, bb Ganglia gastro-oesophagalia, mit Cam. luc. gezeichnet (Vergr. 100).

Fig. 13. Aus der Mitte der Raspel; a a $\boldsymbol{a}$ innerste Zahnplatten linker, bb rechter Seite.

Fig. 14. Ausserster Theil zweier Zahnplattenreihen mit je 4 Platten; a a iusserste Platte. Fig. 13-14 mit Cam. luc. gezeichnet (Vergr. 350).

Fig. 15. Hinteres Ende der $\boldsymbol{a}$ rechten und $\boldsymbol{b}$ linken Speicheldrise, mit Cam, luc. gezeichnet (Vergr, 55).

\section{PLATYDORIS VICINA, BGH.}

Fig. 16. Aus der Mitte der Raspel; $\boldsymbol{a}$ innerste Zahnplatte linker, $\boldsymbol{b}$ rechter Seite.

Fig. 17. Zahnplatte aus dem äusseren Drittel dreier nach einander folgenden Reihen.

Fig. 18. Aeusseres Ende einer Zahnplattenreihe, mit 7 Platten; $\boldsymbol{a}$ äusserste.

Fig. 19. Aeusseres Ende einer Zahnplattenreihe mit 8 Platten, von der Unterseite.

Fig. 16-19 mit Cam. luc. gezeichnet (Vergr. 350).

Fig. 20, 20. Aus der (Bricken-) Bekleidung des (Praeputiums des) Penis. a vorne; mit Cam. luc. gezeichnet (Vergr. 100).

Fig. 21. Oberes Ende einer Bricke (Scheibe), mit Cam. luc. gezeichnet (Vergr. 350).

PLATYD. VARIEGATA, BGH.

Fig. 22. Stiick der Innenseite des (Praeputiums des) Penis mit ihren Bricken, mit Cam. luc. gezeichnet (Vergr. 100).

Fig. 23. Spitze einer der erwähnten Bricken, mit Cam. luc. gezeichnet (Vergr. 350).

1) Vgl. R. Brrar, die Gattung Goniodoris, Forb. Malakozool. Bl. N. F. I. 18s0. p. 133, 135 . 

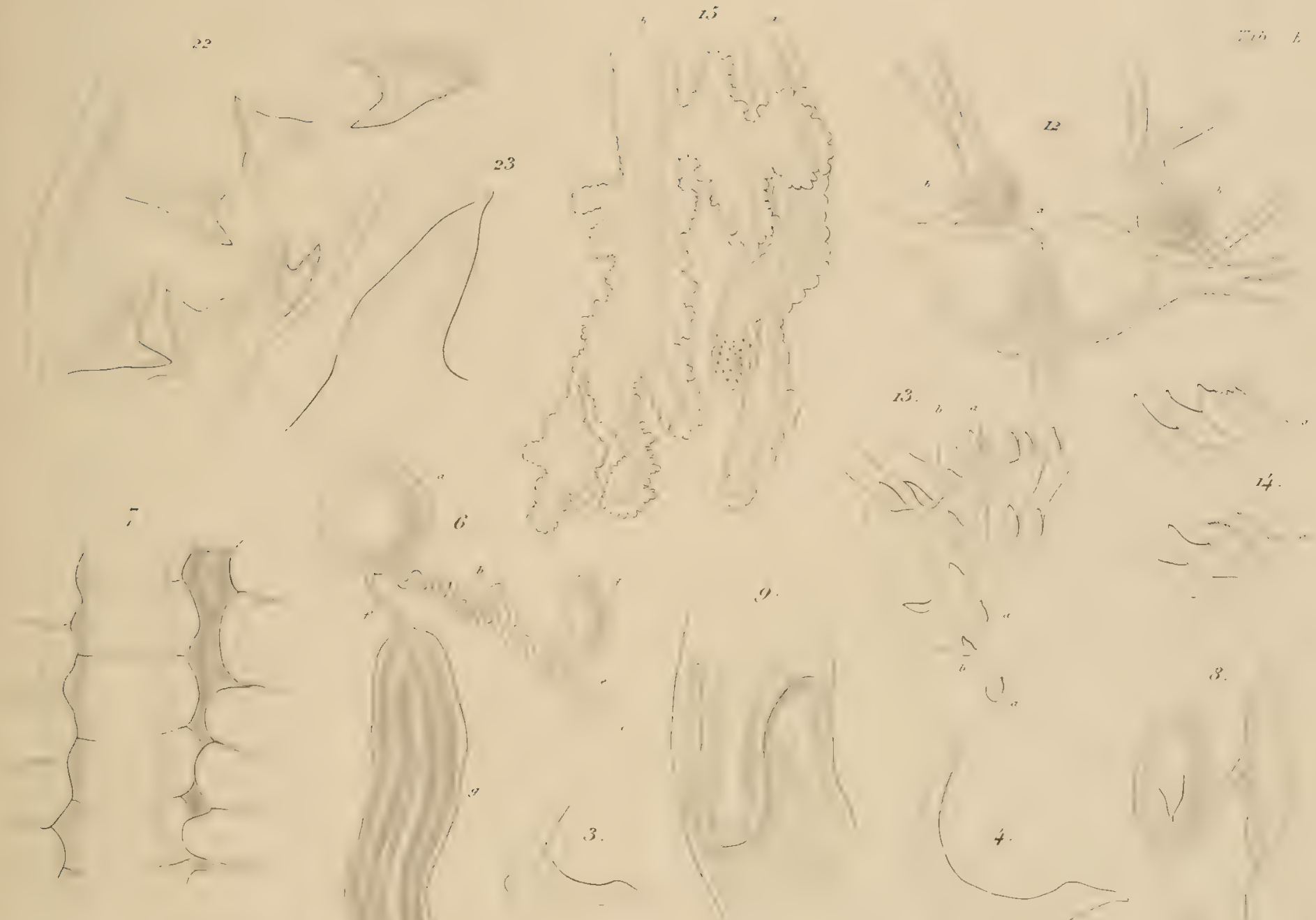

(a) $59 y$
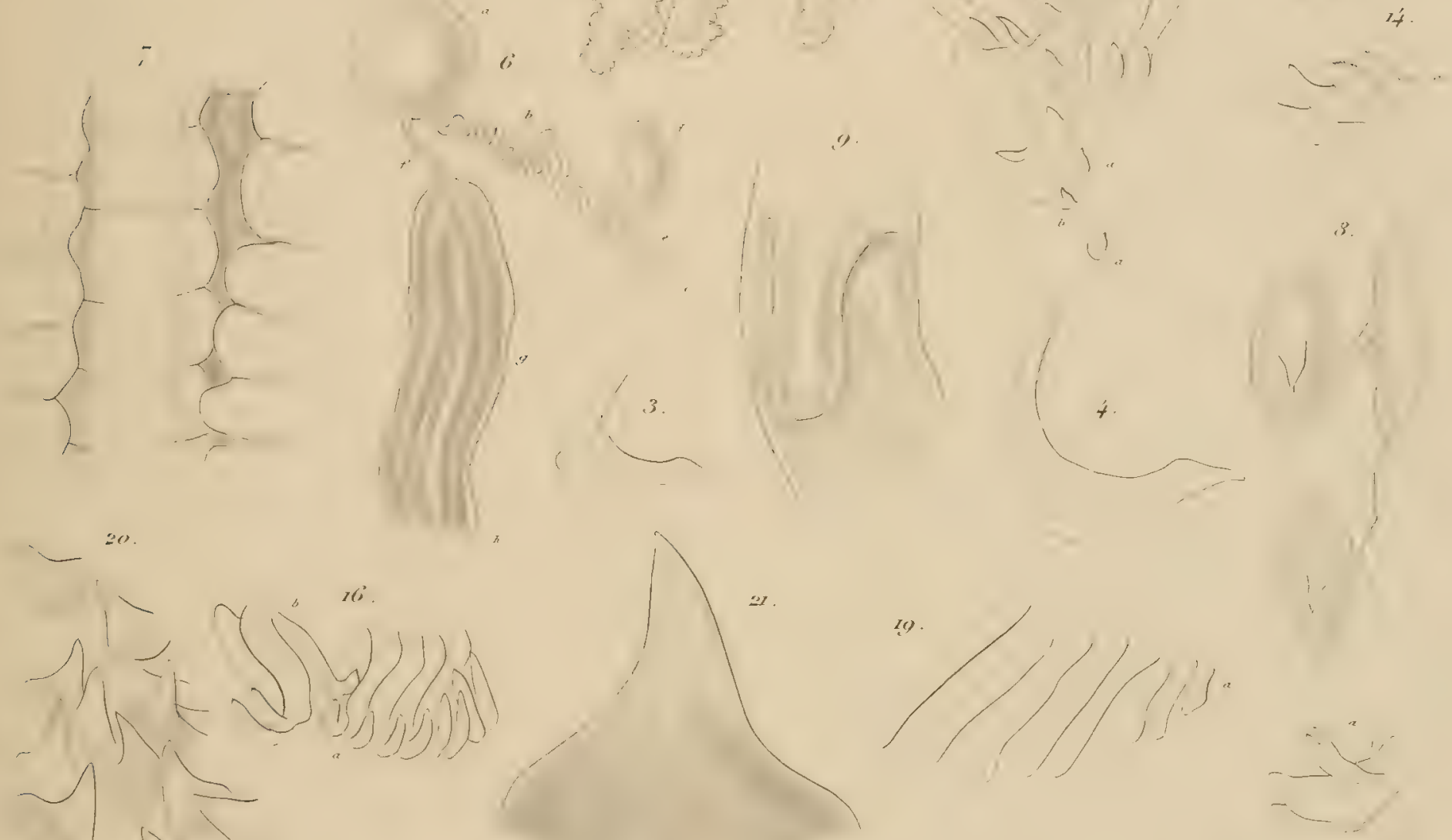

the
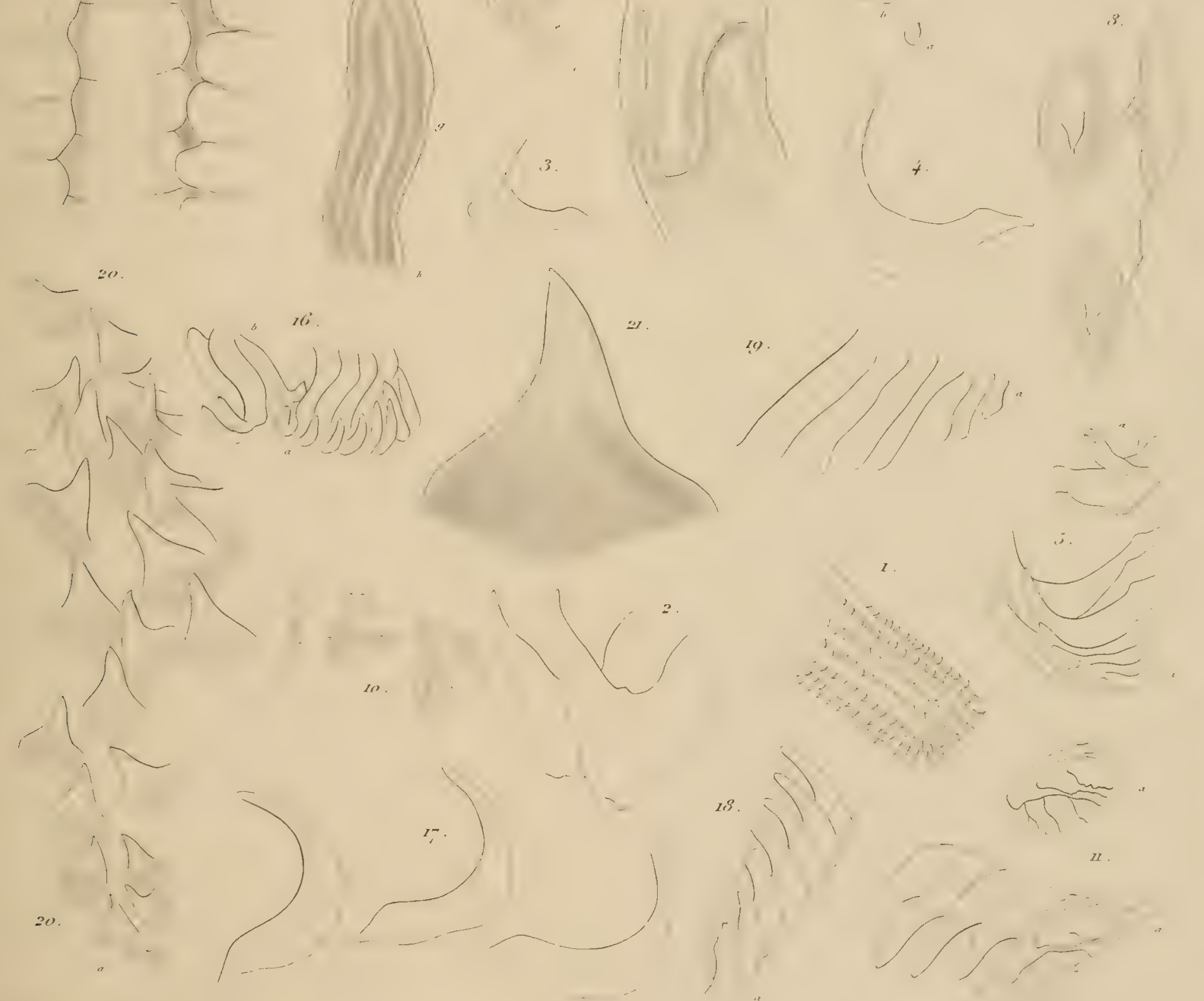



\section{Tafel F.}

\section{IIOPLODORIS DESHOPARYPUA, BGH.}

Fig. 1. Innerster Theil von drei Zahmplattenreihen; $a$ innerste, $b$ zweite Platte.

Fi... ?. Zahnplatten aus der Mitte zweier Reihen; a von der Seite, b sehräge von oben. Fig. 1-2 mit Cam. lnc. gezeichnet (Vergr. 350).

Fin. :S. Innerste Zahmplatte, schriig ron oben.

Fig. 4. Aeusserster Theil zweier Reihen mit 2 und 3 Platten, von der Seite. aa äusserste, $b 6$ nächstäusserste Platten.

Fig. 3-4 mit Cam. luc. gezeichnet (Vergr. 750).

Fig. 5. a Spermatotheke, b vaginaler Gang, $c$ Vagina, dd uteriner Gang, $e$ Spermatocyste, $f$ Stacheldruise, /) Ausfuihrungsgang derselben, h Stachelsack.

Fig. 6. Durchschnitt durch die Liingsachse der Stacheldrüse, um die Verzweigung des a Ausführungsganges im Inneren zu zeigen.

Fin. 7. a Prostata, b Samenleiter, $c$ Penis (Praeputium).

Fin. S. Stiick der Innenscite des Penis (Praeputium), mit Cam. luc. gezeichnet (Vergr. 55). a Vertiefungen zwischen den Bricken (Scheiben) (nach Ausfallen von solchen).

Fig.. 9. Stiick der Innenseite des Penis (Praeputium), mit Cam. luc. gezeichnet (Vergr. 100).

Fig. 10. Querdurchschnitt des Penis (P'raeputium), mit meistens der Höhe nach durchschnittenen Bricken, mit Cam. luc. gezeichnet (Verg. 55).

[ïy. 11. "Ende des vaginalen (xanges der Spermatotheke am oberen Énde der Vagina, $b$ unteres Ende der letzteren, $\boldsymbol{c}$ Einmüundungsïfinung des Stachelsackes mit aus derselben in die Vagina hineintretenden Stachel.

Fiæ. 12. Stachel (hasta amatoria), von der Seite.

Fin. 13. Derselbe, von der Bauchseite.

Fin. 14. Derselbe, von der Rỉckenseite.

Fin. 15. Spitze des Stachels, von der Riickenseite, mit seiner Oeffnung $\boldsymbol{a}$; mit Cam. luc. gezeichnet (Vergr. 350).

Fin. 16. Nöppehen der Haut, mit Cam. Iuc. gezeichnet (Vergr. 350).

Fin. 17. Tentakel, $\boldsymbol{a}$ Spitze.

Fig. 18. Stück des Randes der Analrölıre, mit Cam. Iuc. gezeichnet (Vergr. 55).

\section{PLATYDORIS VARIEGATA, BGIr.}

Fin. 19. Stiick der Lippenplatte, mit Cam. lue. gezeichnet (Vergr. 750).

Fig. :). Aeusserster Theil dreier Zahnplattenreihen mit 5-8 Platten. aaa insserste Platten, mit Cam. luc. gezeichnet (Vergr. 350).

Fig. 21. Senkrechter Längsschnitt am oberen Ende des eingestiilpten Pracputium penis. a Samenleiter, $b$ Hōhle des Praeputium; mit Cam. luc. gezeichnet (Vergr. 100).

\section{DIC'I'YODORIS TESSELLATA, BGII.}

Fiي.. ‥2. Das Hinterende des Thieres, von der Rückenseite, mit halbgeöffneter Kiemenspalte (mit Kieme und Analpapille).

Fiğ, 2:3. Durchschimmernde (3) mediane sternförmige Figuren zwischen den Rhinophorien und der Kieme. 


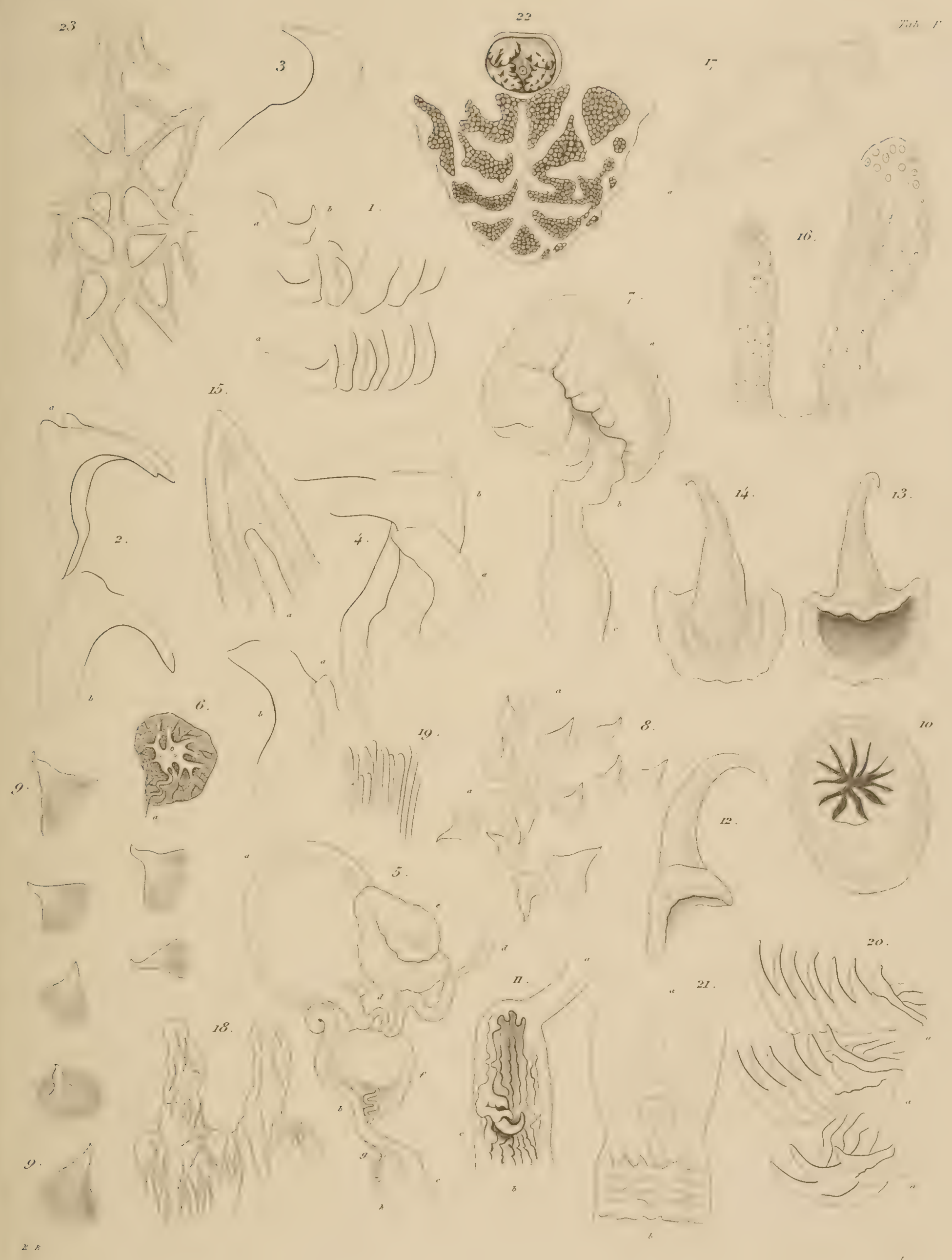






\section{Tafel G.}

Fig. 1. Das Thicr, von oben.

Fig. 2. Dasselbe, von unten.

Fig. 3. Das Thier, von oben.

CHROMODORIS PICTA (PEASE).

Fig. 4. Dasselbe, von unten.

Fig. 5. Kiemenblatt.

CHROMODORIS ALBOPUSTULOSA (PEASE).

Fig. 6. Das Thier, von oben.

Fig. 7. Dasselbe, von unten.

DORIS (Gen. ?) SETOSA, PEASE.

(Vgl. Peise. Proc. zool. soc. XXVIII. 1860, p. 26)

Fig. 8. Das 'Thier, von oben.

Fig. 9. Dasselbe, von unten.

DORIS (Gen.?) NUCLEOLA, PEASE.

(Vgl, PEase. Proc. zool. soc. XXVIII. 1S60. p. 29)

Fig. 10. Das 'Thier, von oben.

Fig. 11. Dasselbe, von unten.

DORIS (Gen.?) ECHINATA, PeAse.

(Vgl, Pease. Proc zool. soc. XXVIII. 1560. p. 27)

Fig. 12. Das Thier, von oben.

Fig. 13. Dasselbe, von unten.

Fig. 14. Ein Rhinophor.

Fig. 15. Eins der Rückenhöckerchen.

NEMBROTILA KUBARYANA, BGIr.

Vgl, R. Bergh, Beitr. zu einer Monogr. 'd. Polyceraden. Ir. Verh. d. k. k. zool. bot. Ges. in Wien. XXX. 1850. p. 655-663.

Fig. 16. a das 'Thier, von der Seite; $b$ dasselbe, ron der Unterseite.

CORYPHELLA? PARVULA (PEASE).

Fig. 17. Das 'Thier, von oben.

\section{ELYSIA BELLA (PEASE).}

Fig. 18. Das Thier, von der Seite.

ELTSIA ORNATA (PEASE).

Fig. 19. Das Thier, von der Seite.

ELYSIA, sp.

Fig. 20. Das Thier, von der Seite. 

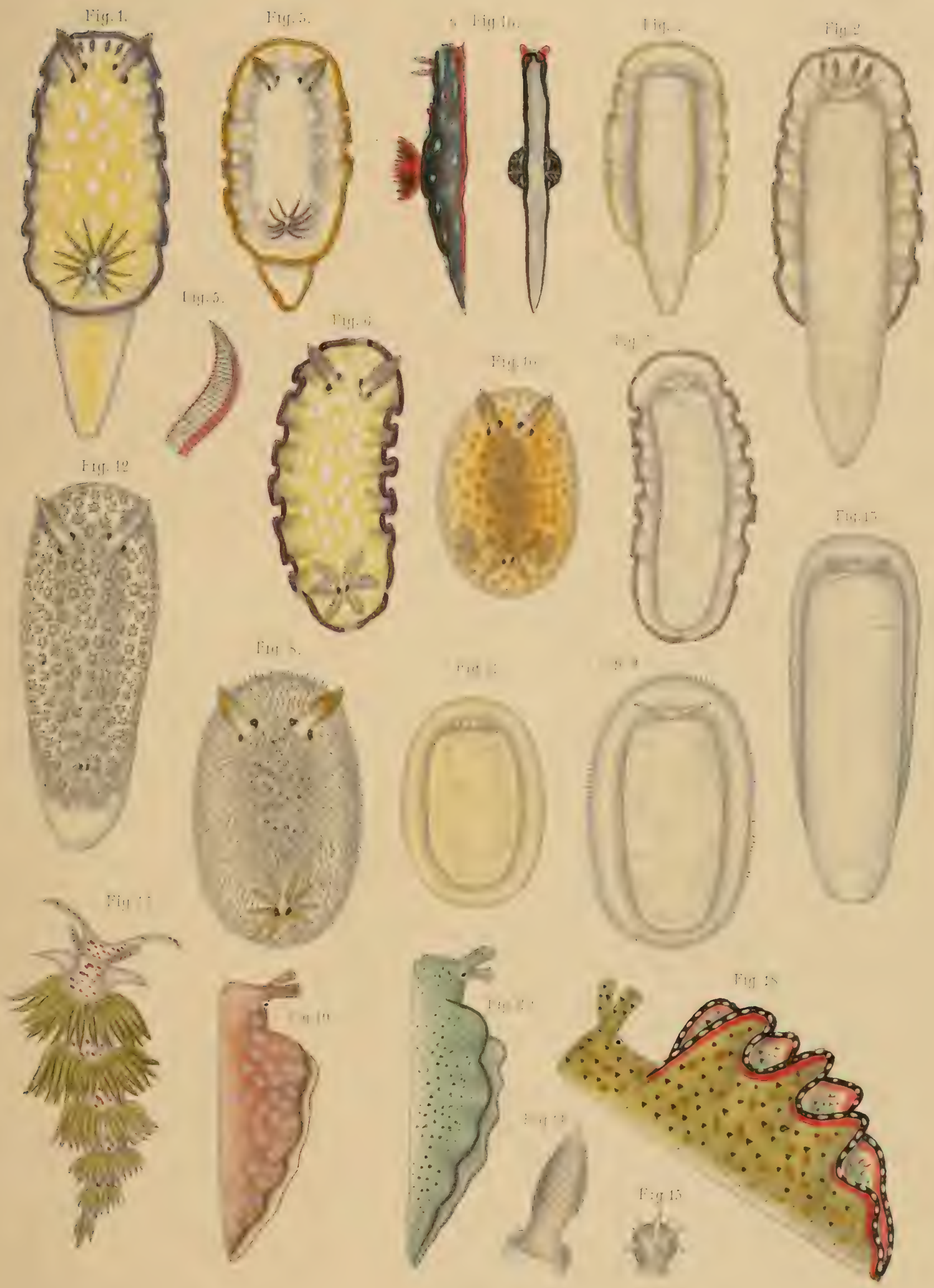




\section{Tafel H.}

\section{ARCHIDORIS MARMORATA, BGI.}

Fig. 1. Grosses Ruicken-Tuberkel, von kleineren umgeben, daneben mittelgrosse; von der Seite.

Fig. 2. Aus der Rhachis der Raspel; aa innerste Zahnplatten.

Fi@. 3. Zwei der grössten Zahnplatten, von der Seite.

Fig. 4. Aeusserster Theil einer Zahnplattenreihe mit 4 Zahnplatten; a äusserste Platte. Fig. 2-4 mit Cam. luc. gezeichnet (Vergr. 200).

Fig. 5. Achte Zahnplatte (von innen ab), von der Seite.

Fig. 6. Aeusserste Zahnplatte, von der Seite.

Fig. 5-6 mit Cam. luc. gezeichnet (Vergr. 350).

Fig. 7. Stück des Speicheldriisenganges, mit Cam. luc. gezeichnet (Vergr. 55).

Fin. 8.8. Hinteres Ende ciner Speicheldriise, mit Cam. luc. gezeichnet (Vergr 55).

Fig. 9. $a$ Spermatotheke, $b$ vaginaler Gang, $c$ Vagina; $d$ vestibulo-vaginale Drüse, $e$ ibr Gang; $f$ uteriner Gang, .g Spermatocyste; $h$ Ampulle des Zwitterdrüsenganges, $i$ männlicher Zweig (an die Prostata), 7 weiblicher Zweig an die Eiweissdrüse, sich bei $l$ mit dem uterinen Gange verbindend.

Fig. 10. a Ampulle des Zwitterdrüsenganges, $b$ männlicher Ziveig, $c$ Prostata, $l$ Samengang; $c$ weiblicher Zweig.

\section{STAURODORIS OCELLIGERA, BGH.}

Fig. 11. Stiick der Haut, mit einem Tuberkel.

Fig. 12. Fine der Rhinophorklappen, a Spikel.

Fig. 11-12 mit Cam. lne. gezeichnet (Vergr. 100).

Fig. 13. Spikel der Haut.

Fig. 14. Centralnervensystem, mit Cam. luc. gezcichnet (Vergr. 100);

aa cerebro-viscerale Ganglien mit proximalen Riechknoten, Augen und durchschimmernden Ohrblasen; $b b$ pedale Ganglien, $c$ die grosse Commissur; $d$ buccale, ee gastro-oesophagale Ganglien.

Fig. 15. Ohrblase, mit Cam. luc. gezeichnet (Vergr. 350).

Fin. 16. Rhachis-Parthie von zwei Zahnplattenreihen mit 3-4 Zahnplatten; an-aa innerste.

Fig. 17. Imnerster Theil von 3 Zalmplattenreihen mit je 5 Platten; aa innerste Platte.

Fir. 18. Innerste Zalnuplatte, von der Seite.

Fin. 19. Zahmplatten aus der Mitte ciner Reihe.

Fig. 20. Acusserster Theil dreier Reihen mit 2-6 Platten.

Fig. 16-20 mit Cam. luc. gezeichnet (Vergr. 750).

Fiي. 21. Theil des Verdaumgsapparats, rou der Unterseite;

$a$ Speiseröhre, $b$ Magen, $c$ Gallengang, $d$ Darm, $e$ Gallenblase.

\section{ROS'IANGA COCCINEA (FORBES).}

Fig. 22. Haut-'Tuberkel, von der Seite.

Fig. 23. Zwei kleinere :ilnnliche, von der Seite.

Fig. 2t. Achnliches, von oben.

Fig. 22-24 mit Cam. luc. gezeichnet (Vergr. 350).

Fir. 25. Querstiick des ganzen Greifringes; a vorne.

Tig. 26. Einzelne Elemente desselben.

Fic. 27. Innerster Theil einer Zahnplattenreihe mit 8 Zahnplatten; $a$ erste, $b$ achte.

Fir. 24. Drei innerste Zahnplatten, schräge von hinten; a erste.

Fiي. -29. Innerster Theil einer der hintersten (juingsten) Zahnplattenreihen mit 11 Zahnplatten; $a$ erste, $b$ elfte.

Fig. 30. Vier Zahmplatten aus der Mitte einer Reihe, schräg gesehen.

Fin. 31. Zwei ähnliche, ron der Seite.

Fig. 3". Aeusserster Theil einer Reihe, mit 6 Zahmplatten, a ausserste Platte.

Fig. 25-32 mit Cam. luc. gezeichnet (Vergr. 750). 


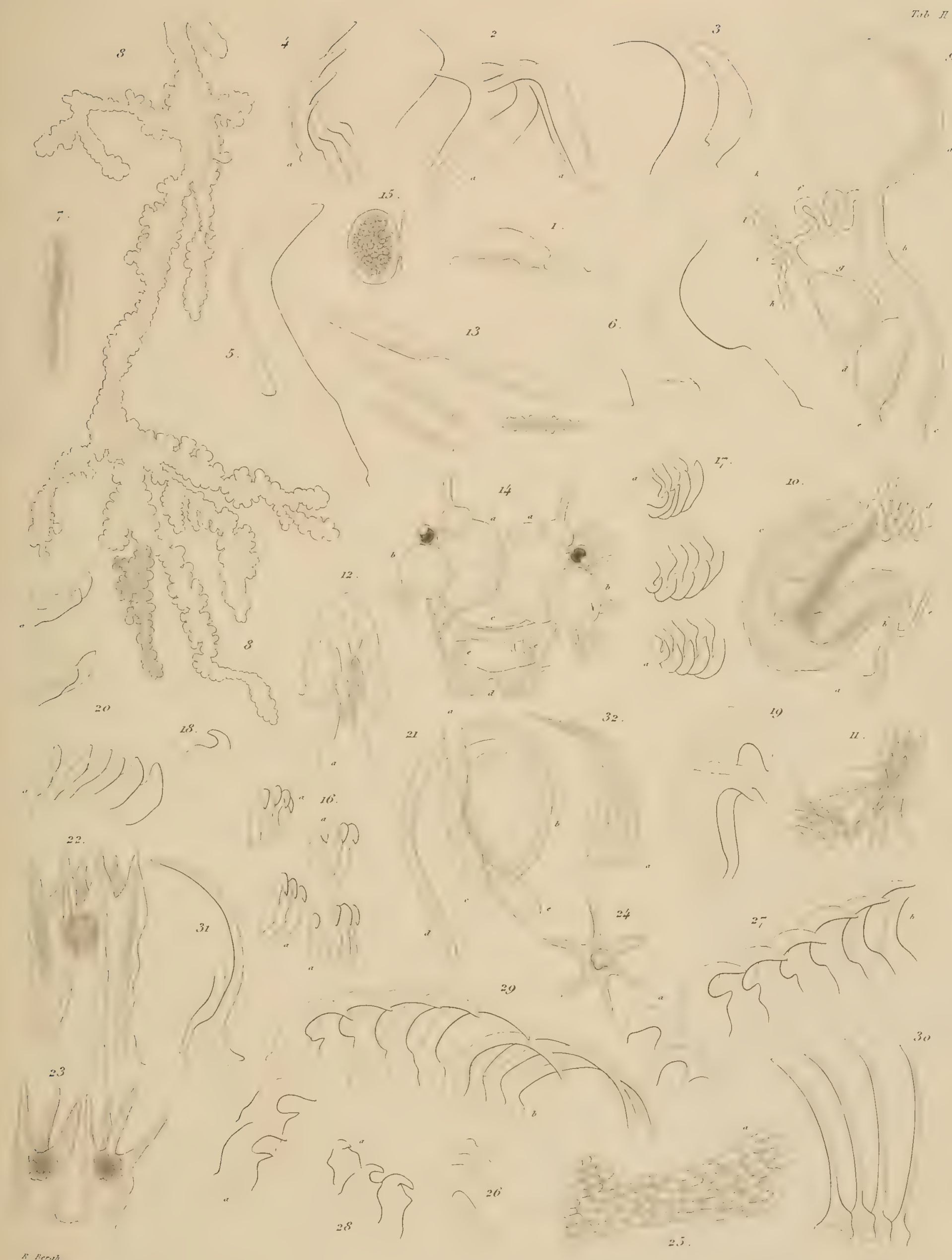



, 


\section{Tafel J.}

ROSTANGA PERSPICILLATA, BGIr.

Fig. 1. Centralnervensystem, mit Cam. luc. gezeichnet (Vergr. 100);

a cerebro-viscerale Ganglien mit proximalen Riechknoten, mit den Augen und den durchschimmernden Ohrblasen, $z$ die grosse gemeinschaftliche Commissur, cc pedale Ganglien, $d$ buccale und gastro-oesophagale Ganglien.

Fị. 2. Ruickenwärzchen, mit Cam. luc. gezeichnet (Vergr. 350).

Fin. 3. Stiick der Lippenplatte, a hinterster Theil.

Fin. 4. Elemente derselben.

Fig, 5. Innerste Seitenzahnplatte.

Fin. 6. Eine der folgenden Platten.

Fig. 7. Stiick des inneren Theils einer Reihe mit 4 Platten in verschiedenen Stellungen.

Fin. $\therefore$ Aehnliches mit 9 Platten.

Fin. !. Vier der grössten Platten des åusseren Theils einer Reihe.

Fir. 10. Zwei äusserste Platten.

Fig. 3-14 mit Cam. Inc. gezeichnet (Vergr. 750).

Fig. 11. Stiick der Thachis-Parthic eines anderen Individuums;

$a$ Rhachis, $b$ innerste Zahnplatte linker Seite (von fünf Reihen), o innerste Zahnplatte rechter Seite (von vier Reihen), $d$ zwei folgende 'Zahnplatten dreier Reihen.

Fin. 12. (Drei und eine) innere Zahmplatten zweier Reihen von oben (so wie die zwei folgenden Figuren von demselben Individuum wie Fig. 11).

Fị. 13. Grösste Zahnplatte der ïusseren IIälfte einer Reihe.

Fin. 14. Zahmplatte rom iussersten Theile zweier Reilen.

Fig. 15. Partlie der vorderen Genitalmasse, mit Cam. luc. gezeichnet (Vergr. 100);

a Ende des prostatischen Theils des Samenleiters, $b$ muskulöser Theil desselben; $c$ Penis (Praeputium mit der Glans), $d$ S'permatotheke, e vaginaler Gang, $f$ Viagina mit ihrer Ansfüterung, " V Vestibulum, $h$ uteriner Gang, $i$ Spermatocyste.

\section{ROSTANGA COCCINEA (FoRBES).}

Fị. 16. Das Centralnervensystem, von oben, mit Cam. luc. gezeichnet (Vergr. 55); ab Ganglia cerebro-visceralia mit den Riechknoten, den Augen und den durchschimmernden Glrblasen,

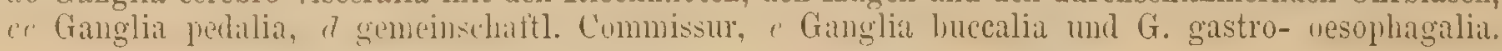

$$
\text { JORUNNA JOHNSTONI (A, et H.), var. alba. }
$$

Fin. 17. Zwei der inneren Zahnplatten.

Fị. 1․ Eine der grössten Zahnplatten.

Fin. 19. Aeusserster 'Theil zweier Zahnplattenreihen mit je 3 Platten, aa äusserste.

Fii:. 20. Aeusserster Theil einer Zahmplattenreihe eines anderen Individuums, mit 5 Platten, a äusserste. - Fig. 17-20 mit Cam. luc. gezeichnet (Vergr. 350).

Fi!: -21. Stachelapparat, mit Cam. luc. gezeichnet (Vergr. 100);

$a$ Stacheldrüsengang, $b$ Matrix-Papille des Stachels, $c$ Spitze des Stachels.

\section{JORUNNA ATYPHA, BGI.}

Fi.... 2.2. Vorderende des Kürpers, ron der Unterseite (Aussenmund, T'entakel).

Fir. 2:.) Innerster Theil einer Zahnplattenreihe nit 6 Platten, a immerste.

Fin. -2t. Eine der grössten Zahmplatten.

Fig. 25. Aeusseres Ende von zwei Zahnplattenreitien mit 4 und 6 Platten, an äusserste. Fig. 23-25 mit Cam. luc. gezeichnet (Vergr. 750).

\section{DISCODORIS INDECORA, BGH.}

Fì. 26. 'T'nentakel von der Unterseite.

Fin. 27. Stiick eines Rhinophorblattes, mit Cam. luc. gezeichnet (Vergr. 350).

Fin. 28. Spikel der Haut.

Fiiv. 2!). Lippenscheibe, von vorne, mit Vorderrand der Lippenplatte.

Fig. 30. Stiick der Rhachisparthie mit dem innersten Theile von zwei Reihen; $a$ die glatte Rhachis, $l b-b$ innerste Zahnplatten.

Fï. 31. Eine der inneren Kahmplatten.

Fin. 3:. Aeusseres Ėnde einer Zahnplattenreihe mit 6 Platten, a äusserste.

Fị. 3i. Dic $(a)$ dritte und vierte, und $(b)$ vierte und fünfte äusserste Zahnplatte zweier Reihen. Fig. 30-33 mit Cam. luc. gezeichnet (Vergr. 350). 


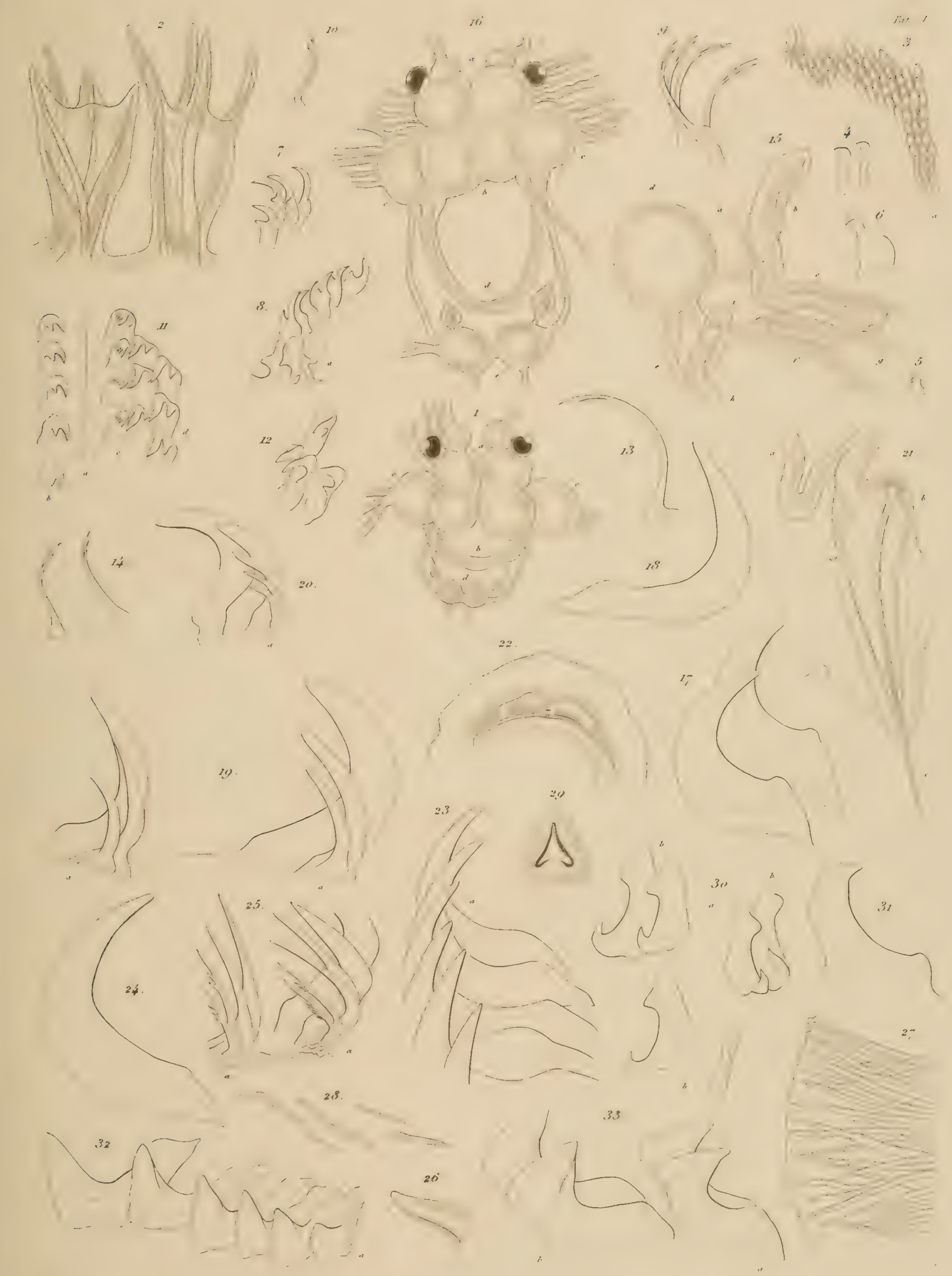






\section{Tafel K.}

Fig. 1. Stück der Lippenbervaftinung, a hinterster Theil.

\section{CIROMODORIS COERULEA (RISSO).}

Fig. 2. Elemente derselben von der Seite.

Fig. 3. Spitzen der vordersten Elemente.

Fig. 4. Vorderste Elemente, von oben, ron der Seite und schief.

Fig. 5. Stück der Mittelparthie der Raspel, von oben; a mediane falsche Platten, $b b$ erste Seitenzahnplatte beider Seiten.

Fig. 6. Erste (inmerste) Seitenzahuplatte, von oben.

Fig. 7. Zwei Seitenzahmplatten, von der äusseren und von der inneren Seite.

Fig. 8. Aeusseres Ende einer Zahnplattenreihe mit 4 Platten; a äusserste.

\section{CHROMODORIS VILLAFRANCA (RISSO).}

Fig. 9. Stück der Mitte der Raspel ; a mediane falsche Platten, $b$ erste Seitenzahnplatten.

Fig. 10. Aeusseres Ende zweier Zahnplattenreihen mit 5 und 6 Platten; a äusserste.

Fig. 1-10 mit Cam. lucida gezeichnet (Vergr. 750).

\section{I)ISCODORIS INDECORA, BGH.}

Fig. 11. Centralnervensystem, mit Cam. luc. ron oben gezcichnet (Vergr. 55); a cerebro - viscerale Ganglien mit Augen und durchschimmernden Ohrblasen, bb pedale Ganglien, $c$ gemeinschaftliche Commissur, $d$ proximale Riechknoten, ce buccale Ganglien, if gastro-oesophagale Ganglien.

Fig. 12. at die (in mehrere Stücke zerfallene) Lippenplatte, $c$ Vorderrand der Mundspalte; mit Cam, luc. gezeichnet (Vergr. 55).

Fig. 13. Stück der Lippenplatte.

Fig. 14. Mittelgrosse Elemente derselben.

Fig. 15. Gtösste Flemente derselben.

Fig. 16. Grosse Zahnplatte zweier Reihen.

Fig. 17. Zahnplatte, von der Seite.

Fig. 1s. Innerste Zahmplatte, von der Seite.

Fig. 13-1S mit Cam. luc. gezeiclmet (Vermr. 350).

Fig. 19. a Speiseröhre, $b$ Magen, $c$ erste Strecke des Darmes, d Darmknie, e naeh hinten gehender Theil des Darmes, * Gallenblase. Von der Unterseite.

\section{JORUNNA JOHNSTONI (A. et H.).}

Fig. o. Stück der Rückenhaut mit ihren Pap̧illen, von der Seite; mit Cam. luc. gezeichnet (Vergr. 100).

Firg. 21. Einzelne Rückenpapille mit Cam. luc. gezeichnet (Vergr. 350).

Fig. 2.2. Stark erhärtete Spikel der Haut.

Fig. 2:3. Fältchen der Cuticula unten an der Lippenscheibe.

Fig. 202-03 mit Cam. luc. gezeichnet (Vergr. 350).

Fig. 24. a Rhachisparthie der Raspel mit jhren Falten, mit Cam. lnic. gezeichnet (Vergr. 100).

Fig. 20. Zahnplatte aus der Mitte einer Reihe, ron der Seite.

Fig. 21. Aeusserster Theil einer Zahnplattemeihe mit 4 Platten, a äusserste.

Fig. 27. Zwei innerste Zalinplatten, a innerste.

Fig. 2. Aeusserster Theil zweier Zahuplattenreihen, mit 4 und 6 Platten; an ïusserste Platte.

JORUNNA JOINTSTONI (A. et H.), var. alba.

Fig. 29. a Theil der Rhachis-Parthie mit ihren gebogenen Falten, $b$ innerste Zahnplatten zweier Reihen, mit Cam. luc. gezeichnet (Vergr. 100).

Fin. : : I. Innerste Zahnplatte zweier Reilen, mit Cam. luc. gezeichnet (Vergr. 350).

Fì. 31. a Speiseröhre, $b$ HIagen, c Darm, d Gallengang.

Fig. 3:. Die rordere Genitalmasse, ron der Hinterseite; a Ampulle des Zwitterdrüsenganges, darüber und sich wach rechts erstreckend die Prostata; $b$ prostatischer Theil des Eamenleiters; $c$ weissliche, $d$ röthliche (chocoladefarbige) P'arthie der Schleimdrüse, $c$ Nebenstacheldrüse (?), f Genitalpapille.

Fir. 33. $f$ Oeffuung des $c$ Stachelsackes, dd Retractoren desselben, $c$ Stachelbentel, $b$ Stacheldrüsengang, $a$ Gang der Nehenstacheldriise.

Fir. 3). a Stacheldrüsengang, $b$ Grund des Stachelbentels mit Matrix-Papille des Stachels, cc Grund des Stachelsackes, a Nebenstacheldrüsengang (?), $e$ Boden des Stachelsackes mit Oeffinung des Stachelheutels.

Fiq. 35. a Prostatischer, $b$ musknlöser Theil des Samenleiter's, c Penis (Praeputium).

Fig. 3i. a Spermatothelre, $b$ vaginaler Ausführumgsgang, $c$ Vagina, dd uteriner Gang, e Spermatocyste. 


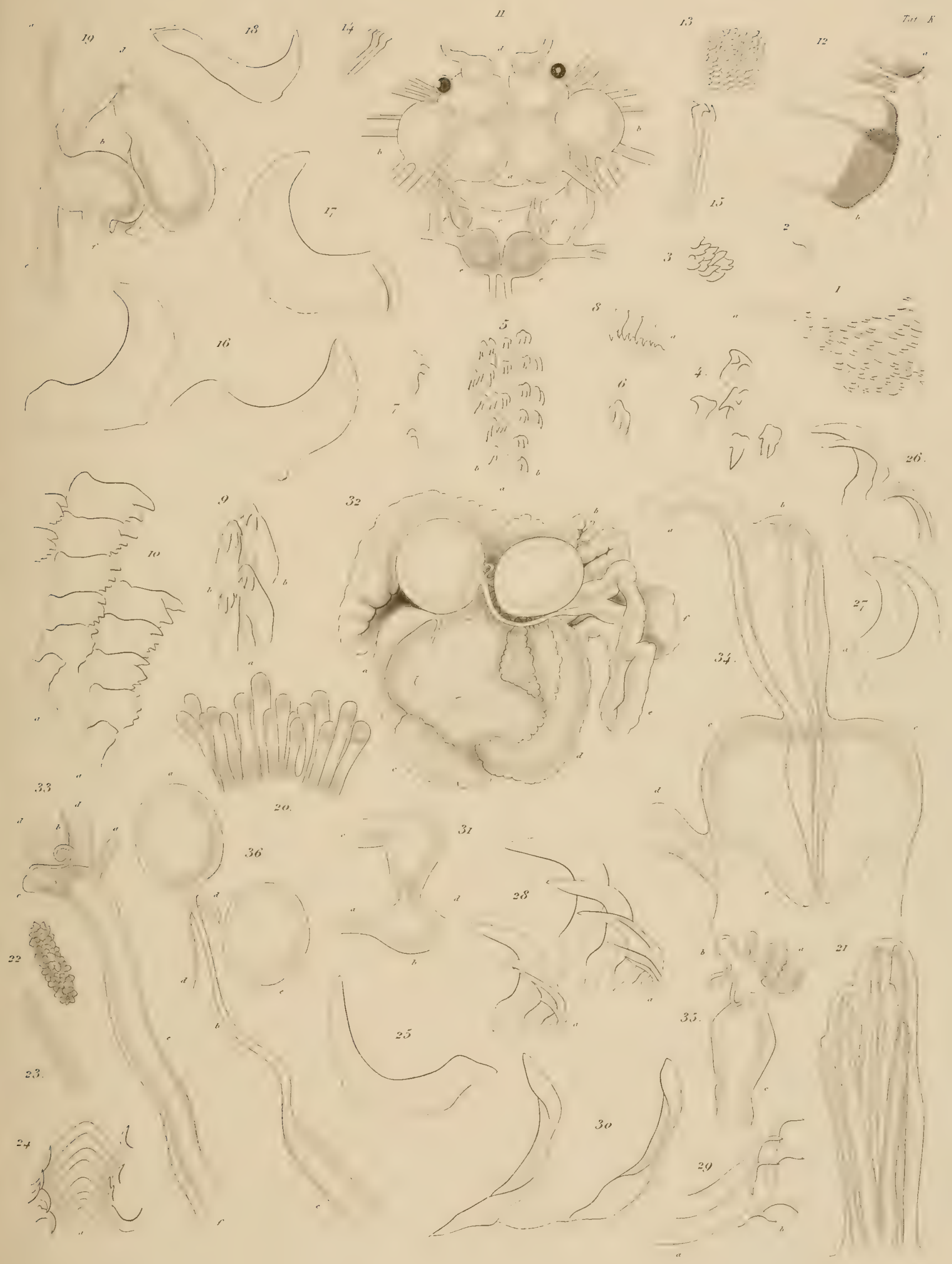






\section{Tafel L.}

\section{ACANTIIODORIS PILOSA (MÜLL.).}

(Vgl. R. Bergr, on the nudibr. gasteropod moll. of the North Pacific. oc. (DALL, scient. results of the explor. of Alaska. I. art. VI) II. 1880 . p. $240-246$.

Fig. 1. a Hinterende des Mantelgebrämes mit seinen Spikeln, $b$ Spikel-Bogen vor der Kiemengegend.

Fig. 2. Mittlerer Theil des Fusses, a Fussgebräme mit seinen Spikeln.

Fig. 1-2 Präparate von kleineren Individuen aus der Nordsee, mit Cam. Iuc. gezeichnet (Vergr. 55).

Fig. 3. Spikeln aus der Haut, mit Cam. Inc. grezeichnet (Vergr. 350).

Hig. 4. Vorderende des Schlundkopfes, mit Cam. luc. gezeichnet (Vergr. 200);

"Munkialte, b die zwei lancetformigen Blätter nnten am Eingange, "c schwarzes Pigment an der Peripherie der Lipnenscheibe, dd- - dl der Greifring.

Fig. 5. Unteres Ende der Mundspalte, mit Cam. Iuc, gezeichnet (Vergr. 350);

a die lancetförmigen Blätter, $6 \succ$ unterer Theil des Greifringes, cc pigmentirte Häkchen desselben und Pigment.

Fig. 4-5 auch von Individuen aus der Nordsee.

TRITONIA HOMBERGI, Cuv.

Fig. 6. Die Mandibel, von der: Vorderseite, mit Can. luc. gezeichnet (Vergr. 55); (t) proc. masticatorii.

Fig. 7. Oberer (vorderer) 'I'heil des gezähnelten Kraurandes; a oben.

Fig. 8. Nittlerer Theil des geziihnelten Kaurandes; $a$ oben.

Fig. 7-8 mit Cam. luc. gezeichnet (Vergr. 5̃5).

Fig. 9. Elemente des letzteren, mit Cam. lne. gezeichnet (Vergr. 350).

Fig. 10. Oberes Ende der Mandibel, schief ron oben rom Vorderrande, a Schloss; mit Cam. luc. gezeichnet. (Die Mandibel ziemlich weit von cinander geöffnet [rgl. Fig. 12]).

Fin. 11. Stark zusammengezogener Schlundkopf, ron oben, mit Cam. luc. gezeichnet; a durchschimmernder Rand der Mandibel; hinter der Pharynx-Oeffnung die Ganglia bucealia und gastro-oesophagalia; linter denselben schimmert die Raspelscheide hindurch.

Fig. 12. Schlundkopf rom Vorderende mit erveiterter Mundötfinung und in derselben innerhalb der Kieferrïinder die Zunge mit der Raspel; mit Cam. luc. gezeichnet; a oben.

Fig. 13. Aus der Bindesubstanz, mit Cam. luc. gezcichnet.

Fig. 14. Zwei grösste Seitenzahmplatten.

Fig. 15. Grundfïche von zwei Seitenzahnplatten, ron der Unterseite.

Fig. 16. 26te Seitenzahmplatte.

Fig. 17. Zweite (a) bis vicrte Seitenzahmplatte.

Fig. 18. Sechs iiusserste Seitenzahnplatten, a iusserste.

Fig. 14-18 mit Cam. luc. gezeichnet (Vergr. 350).

Fig. 19. Senkrechter Durchschnitt durch den hintersten Theil der Raspelpulpe, mit Cam. luc. gezeichnet.

\section{TRITONIA PLEBELA, JOHNSTON:}

Fig. 20. Vom mittleren Theile des Kaurandes, a Vorderrand.

Fig. 21. Von der Mitte der Raspel, von oben; a mediane Platten, 66 erste Seitenzahnplatten.

Fin. a. a erste, $b$ zweite Seitenzahnplatten, von der Seite.

Fig. 23. Innerster 'Theil von. einer Zahnplattenreihe mit 7 Zahnplatten; $a$ erste, $b$ siebente.

Fig. 24. Aeusserster Theil von zwei Zahnplattenreihen mit 4-5 (5-6) Zahnplatten; a a Doppelzahnplatten, $\zeta$ äusserste Platten.

Fig. 20- $2 \pm$ mit Cam. luc. gezeichnet (Vergr. 750). 


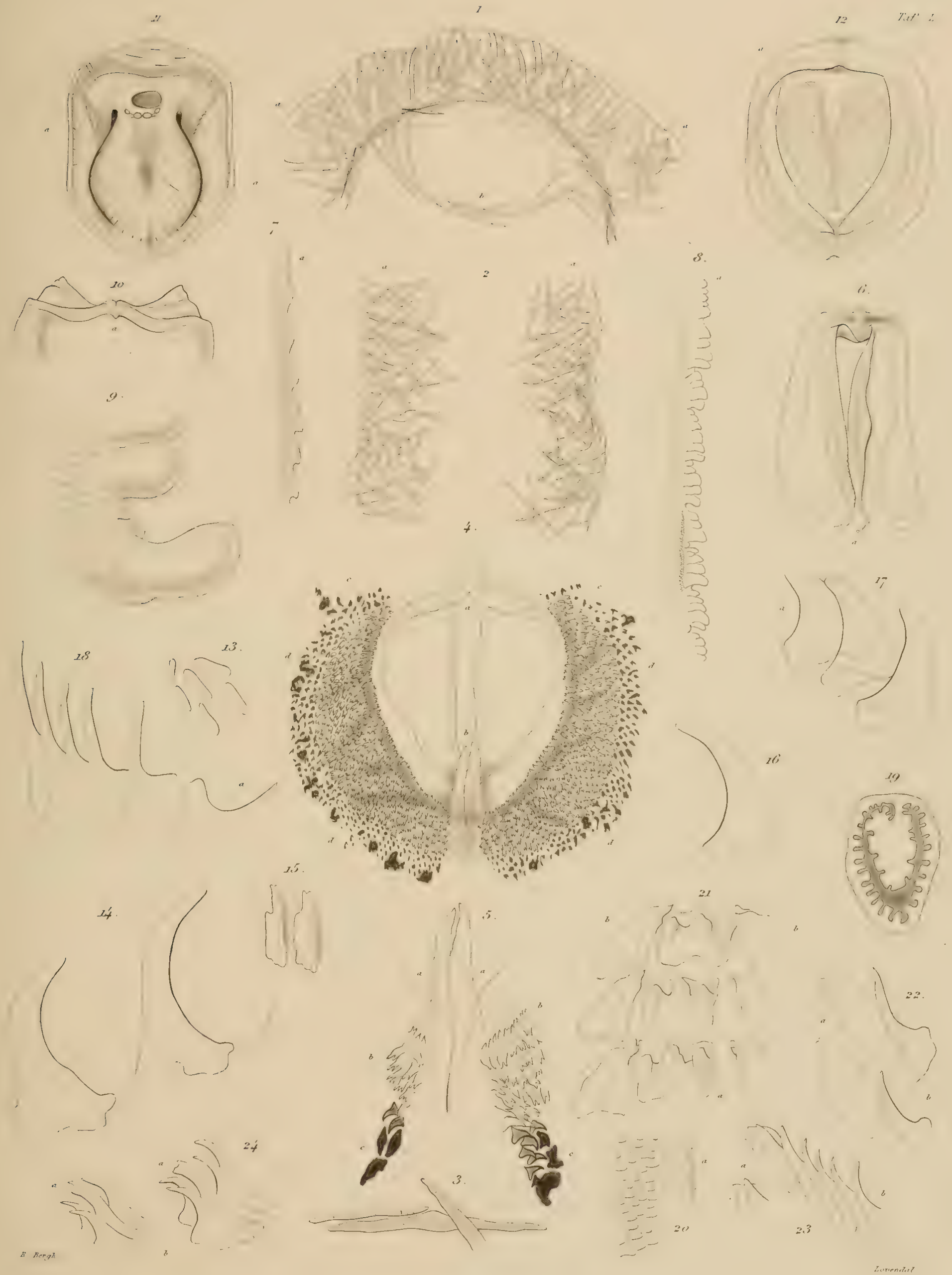





\section{Tafel M. \\ CILLTONOTUS SEMPERT, BGI.}

Fig. 1. Das Thier von der Seite; a Hinterende. $1 / 1$.

Fis. 2. Vorderende des Athemrohres, zusammengerollt.

Fig. 3. Kopf von der Unterseite, mit Tentakeln und der durch den Aussenmund halb rorgestreckten Schnauze.

Fig. 4. Senkrechter Längsdurchschnitt durch das Vorderende des Fusses; $a$ untere Lippe.

Fig. i. Die obere Eingeweidemasse, nach Wegnahme der Schale, beim UI ännchen;

hinten Hoden, rechts und links an die (hier schwarz gezeichnete) Leber stossend; hinter dem Hoden der obere Theil des Magens durchschimmernd; For dem Hoden und der Leber die Blätterdrüse und längs ihres rechten Randes der Darm und weiter rechts $(\alpha)$ die rechte Muskelfacette; vor der Blätterdrüse die lange Kieme und an ihrem hinteren-linken Ende die Niere; hinter der letateren das Darmknie $(c)$ und ror derselben das Geruchsorgan, an der linken Seite von diesem die linke Muskelfacette (b) und dann links und mehr hinten ein Theil des Herzbeutels; dem ganzen Vorderrand entlang die Schalenleiste.

Fig. 6. Die obere Eingeweidemasse, nach Wegnahme der Schale, beim Weibchen;

hinten der Eierstock, vor demselben die gebogene Reihe der Samenblasen, vor derselben die geborene Schleim- und Eiweissdrủse, vor welcher die Vagina und der Darm durchschimmern; rechts $(\alpha)$ die rechte Muskelfacette; an der linken Seite des Eierstocks, der Samenblasen und der Schleim- und Eiweissdrüse die Blätterdrüse, vor der letzteren die Kieme und die Niere; vor diesen das Geruchsorgan und die (b) linke Mnskelfacette.

Fig. 7. $a$ Vulva, $b$ Rectum, $c$ Vorderrand der Kiemenspalte.

Fig. 8. $a$ und $b$ wie in Fig. 7 ; von einem anderen Individuum und mehr von vorne her.

Fig. 9. Senkrechter querer Durchschnitt am Grunde des Schwanzes, mit medianem Blut-Sinus.

Fig. 10. Schlundkopf, von oben;

a Vorderende der Mandibelplatten, $b$ die Mn. bullı-rostrales, $c$ Theil des M. lateralis sup. An der Mitte der Pharynx, hinter demselben die buccalen Ganglien; jederseits der M. Iongitudinalis sup. und unter demselben der MI, transv, post. superficialis, $d$ die Raspelscheide.

Fig. 11. Schlundkopf, von unten;

a Vorderende des Schlundkopfes mit zurückgezogenem Innenmunde, hinter demselben der M. circularis, hinter diesem M. lateralis sup. und inferior; weiter nach hinten $d$ die MIm. retractores bulbi, und an jeder Seite $c c$ die Mm. lingv. proprii mit den Knorpelfacetten.

Fig. 12. Schlundkopf, von der Seite;

a Mm. mento-rostrales, $b \mathrm{Mm}$. pedo-rostrales, $e$ eingestülpte Schnauze, $d \mathbf{M}$ retractor bulbi, e M. retractor bulbi secundarius; $f$ vorderer Theil des Schlundkopfes (mit durchschimmernden Mandibelplatten und) mit z.wei langen $\mathrm{Mm}$. bulbo-rostrales obliqui, vorne vom fächerförmigen M. bulbo-rostralis inferior gedeckt; $g$ hinterer Theil des Schlundkopfes, $h$ Raspelscheide. Die rechte Knorpelfacette sehr deutlieh.

Fig. 13. Zungenknorpel, von der Aussenseite; $a$ rorderes, $b$ hinteres Eude (mit Facette); $c$ M. dilatator lingrae.

Fir. 14. Derselbe, nach Wegnahme des M. dilatator lingrae; $a$ und $b$ wie oben.

Fig. 15. Aehnlicher, von der Innenseite; $a$ und $b$ wie oben.

Fig. 16. Senkrechter Querdurchschnitt desselben, $a$ unterer Rand.

Fig. 17. Irreguläre Seitenzahnplatte, vom Vorderrande; $a$ vorderer land; mit Cam. luc. gezeichnet (Vergr. 350).

Fig. 18. Zwei rechtsseitige Seitenzahnplatten, schräg von der hinteren und linken Seite;

$a$ Rand der Raspelfurche.

Fiig. 19. Haken einer Seitenzahnplatte, von der Hinterseite; $a$ hinterer (oberer) liand.

Fig. 20. Abnorme Seitenzahnplatte, von hinten.

Fig. 21. Zwei abnorme mediane Platten, von der oberen Seite. Fig. 18-21 mit Cam. luc. gezeichnet (Vergr. 100).

Kig. 22. Aus dem Mageninhalte.

Fig. 2:3. Drusenartiger Körper, aus demselben.

lig. 24, 24. Andere, aus demselben.

Fig. 25. Spikelartiger Körper einer Alcyonide (?).

Fig. 22-25 mit Cam, luc. gezeichnet (Vergr. 350).

Fir. 26. Durchschnittenes oberes Ende der oberen Eingeweidenasse (Hoden).

Fig. 27. Durchschnitt der vorletzten Windung (Leber, vom Hoden umgeben).

Fig. 28. Boden der unteren Fingeweidehöhle (obere Seite des Fusses);

a linker Schalenmuskel mit $b$ entsprechender MIuskelfacette, $c$ rechter Schalenmuskel, $d$ Muskelpolster (Mruskeln für die Schnauze), und innerhalb desselben der M. retractor bulbi. 

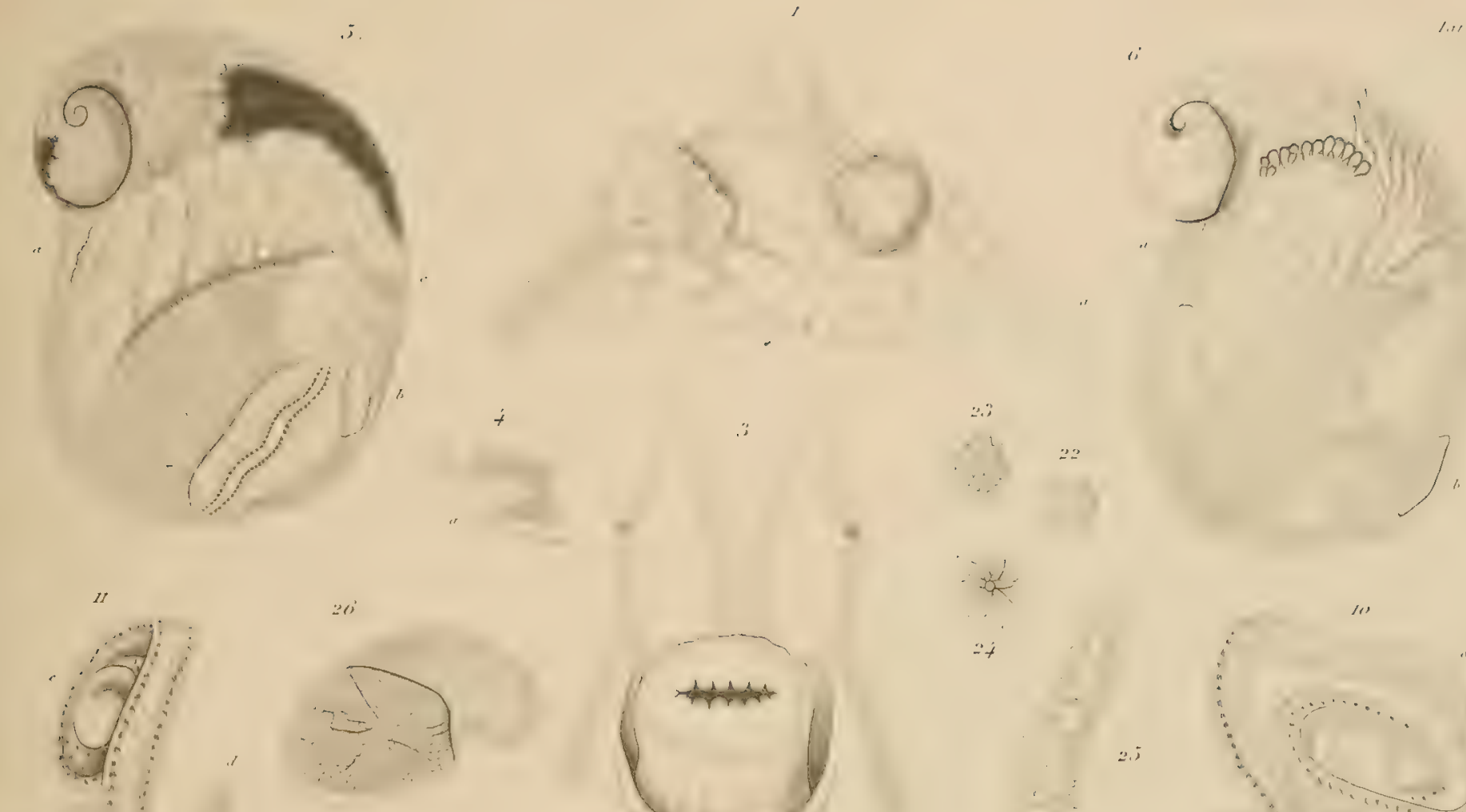

-
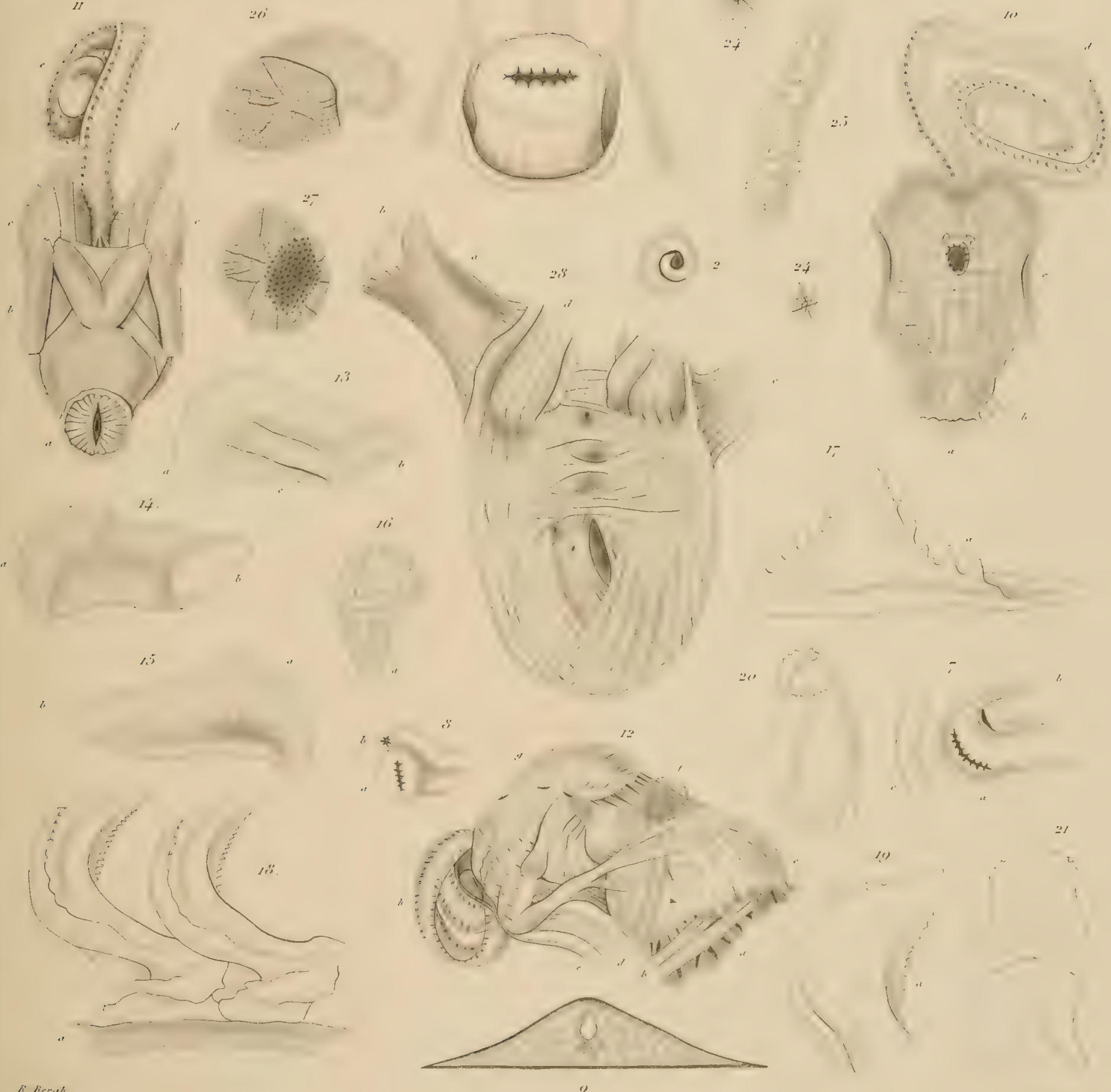




\section{Tafel N.}

\section{CHELTONOTUS, SEMPERI, BGH.}

Fin. 1. Das Auge, mit Cam. luc, gezeichnet (Vergr. 350); $a$ N. opticus.

Fig. ‥ Zumge mit Raspel, hinter derselben Raspeldach; aa Mm. lingrales proprii.

Fin. 3. Zunge nach Entfernung der Raspel; a wie oben.

Fig. 4. Boden der Zungenhöhle mit den $\mathbf{M m}$. constrictor lingvae ant. und post. zwischen den aa Zungenknorpeln, $b$ aI. tensor lingvae inferior.

Fin. 5. Senkrechter Durchschnitt des Vorderendes des Raspeldaches.

Fig. 6. Mittlere /ahnplatte, von oben; von einem weiblichen Individuum.

Fig. $\ulcorner .7$. Aehuliche, schief ron der Unterseite.

Fig. 8. Aehnliche eines männlichen Individuums.

Fig. 9. Aehnliche eines anderen mïnnlichen Individuums, von der Seite.

Fig. 6-9 mit Cam. luc. gezeichnet (Vergr. 200).

Fig. 10,11. Reihe von drei medianen Zahnplatten.

Fig. 12. Reilı von zwei (abgenutzten) medianen Zahnplatten.

Fig. 10-12 mit Cam. luc. gezeichnet (Vergr. 100).

Fị. 13. Schneiderand einer abnormen medianen Zahnplatte, mit Cam. luc. gezeichnet (Vergr. 350).

Fig. 14. Zwei linksseitige Seitenzahnplatten, schief von der oberen und linken Seite, mit Cam. luc. gezeichnet (Vergr. 100); $a$ Rand der Raspelfurche.

Fis. 15. Grundstück einer Seitenzahnplatte, mit Cam. Iue. gezeichnet (Vergr. 100).

Fig. 11: Die Mandibelplatten, von der Seite.

Fig. 17. Aelnnliche eines anderen Individums.

Fig. 1s. Aehnliche, von oben her.

Fig. 19. Aehnliche, von vorne und oben.

Fig. 20. Vorderrand einer abnormen P'latte.

Fig. 16-20 mit Cam. luc. gezeichnet.

Fì. 21. Elemente der Mandibelplatten, mit Cam. luc. gezeichnet (Vergr.. 350).

Fig. 2.2. Stück des Zungenknorpels, mit Cam. luc. gezeichnet (Vergr. 200).

Fig. 2:;. Aehnliches von einer Länge von $0,02 \mathrm{~mm}$, mit Cam. luc. gezeichnet (Vergr. 350).

Fig. 24. Das ron der Aussenseite geôffnete Pericardium mit Herzen; $a$ linker Schalenmuskel, $b$ pericardiorenale Oeffinung.

Fig. … Atrio-ventriculäre Klappen, a Vorkammer.

Fig. 2fi. Aorta-Klappen, 6 Mal vergrössert.

Fig. 27 . a rechter Schalenmuskel, von der Innenseite, $b$ Ursprung des M. retractor vulvae, c Vagina, d Vulva.

Fig. 2.9. Penis-Ende mit ganz ausgestrecktem Ende des Samenleiters.

Fig. 2!?. Aehnliches eines anderen Individuums, weniger vorgestreckt.

Fig. : :1. Querer Durchschnitt des Körpers des Penis.

Fìg. :31. Körperchen aus der das CentraInervensystem einhüllenden Bindesubstanz, mit Cam. luc. gezeichnet (Vergr. 350). 


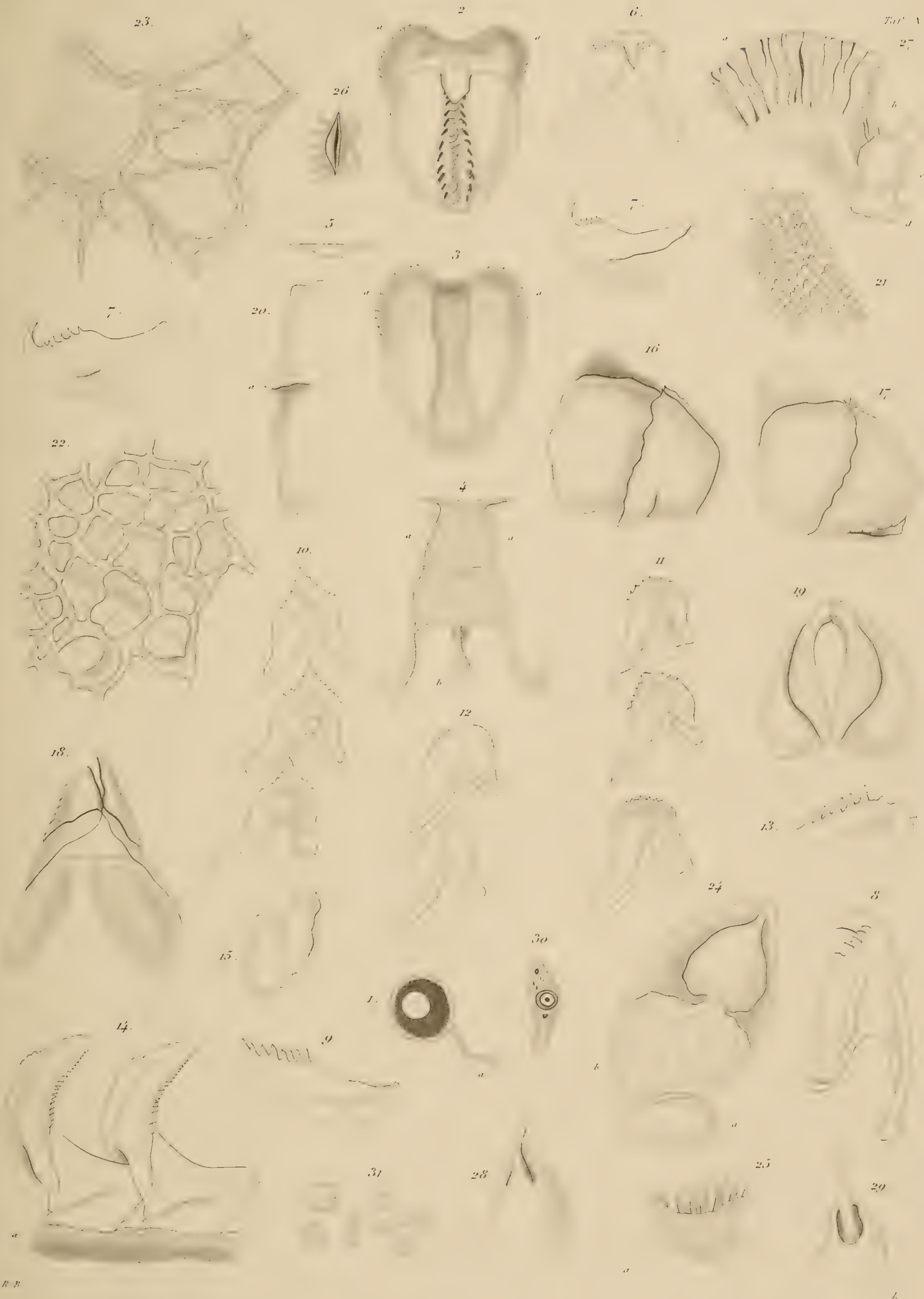





$$
\text { - }
$$




\section{Tafel 0.}

\section{CHELYONOTUS SEMPERI, BGH.}

Fig. 1. Tiopf von der Unterseite mit I'entakeln, Ophthalmophorien und Aussenmund; $a$ Grund des Kopfes (Kinn), am Frusse.

Fig. 2. Kiopf und Vorderende des Körpers

mit $a$ der hervorgestülpten Schnauze und $b$ (der Länge nach horizontal durchgeschnittenem) Penis mit Samenleiter-Kanal und Samenleiter, dessen Ende $b$ frei hervorragt; $c$ Verlauf des Samenleiters in der Körperwand.

Fin. 3. Centralnervensystem, von oben;

$a a$ cerebrale, $b b$ pleurale Ganglien; $c$ subintestinales, $d$ supraintestinales Ganglion; $e$ pedale Ganglien, $f$ buccale Ganglien, $g g$ Otocysten.

Fị. 4. Gehörapparat, mit Cam. luc. gezeichnet;

$a \mathrm{~N}$. acusticus, $b$ Scheibe mit Otocyste (mit Otolith).

Fig. 5. Abgenutztes Vorderende der Raspel, mit Cam. luc. gezeichnet (Vergr. 100); a a dunkle Randparthie der Raspel, $b$ Vorderende derselben, $c$ mediane Zahnplatte, $d$ rorderste unbeschädigte Seitenzahnplatten (die tiefer liegenden medianen sind überhaupt nicht gezeichnet).

Fig. 6. Stiick von der den Blättermagen einhüllenden Drüsenmasse (Speicheldruisen?), mit Cam. luc. gezeichnet (Vergr. 55).

Fị. 7. Senkrecht der Länge nach durchgesehnittener Blättermagen, mit der engen Höhle und den dicken blïtterigen Wänden; $a$ Vorderseite.

Fị. s. Stiick von einem der Blätter, von der Flïche gesehen.

Fig. !). Stuick einer der Falten eines Blattes, mit Cam. luc. gezeichnet (Vergr. 350).

Fin. 10. (Zweiter) Kropf, von der Vorderseite;

a Einmündung in die Speiseröhre.

Fig. 11. Aehnlicher eines anderen Individuums, von der Hinterseite;

$a$ wie oben.

Fig. 12. $a$ a nach oben geschlagene Wand des Pericardiums mit durchschimmernder Niere und $b$ durchschimmerndem Darmknie; $c$ Vorderrand der Leber, $d$ Vorderrand der Blätterdrüse, an ihrem äusseren Ende die branchiale, äussere Oeffnung der Niere (und der Blätterdriise). Von aussen her gesehen.

Jig. 13. a Vorkammer des Herzens, $b$ atrio-ventriculäre Klappen, c Kammer.

Fig. 14. Hodenlappen-Parthie.

Fig. 15. Hodenlappen, mit Cam. luc. gezeichnet (Vergr. 55).

Fig. 16. aa Samenblasen mit bb gemeinschaftlichem Gange; mit Cam. luc. gezeichnet (Vergr. 55).

Fig. 17. Abweichende Samenblase.

Fig.. 18. Senkrechter Durchschnitt der Schleim- und Eiweissdriise; $a$ untere Seite.

Iiig. 19. Vom senkrechten Durchschnitte der Schleim- und Eiweissdrüse, mit Cam. luc. gezeichnet (Vergr. 100). 


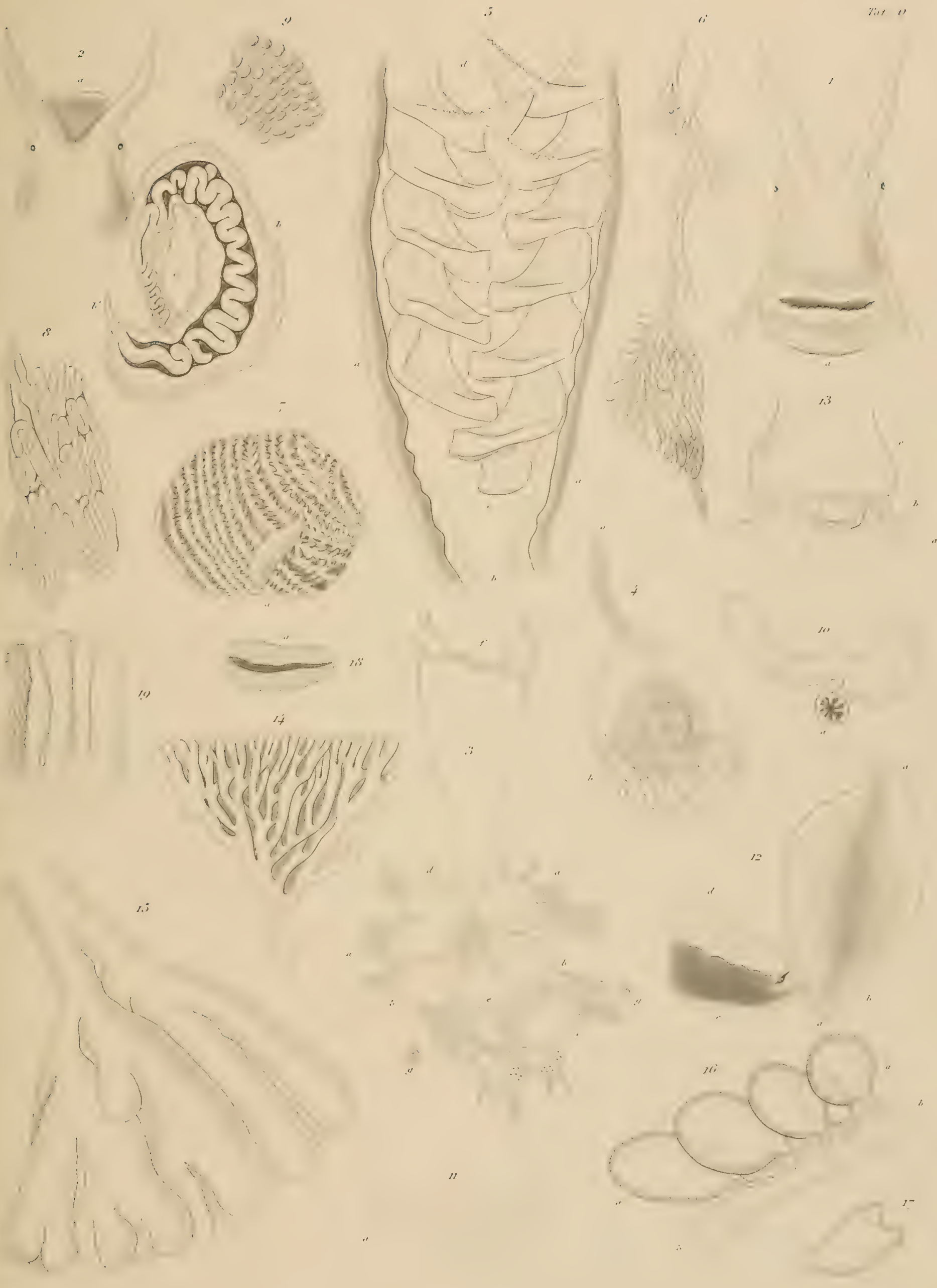





\section{Tafel P.}

\section{CHELYONOTUS SEMPERI, BGH.}

Fir. 1. Centralnerrensystem, ron oben, mit Cam. lue. gezcichnet (Vergr. 55); a Ganglia cerebralia, b6 G. plenralia, $c$ G. subintestinale, $d$ G. supraintestinale, of Connectiva cerebro- und plenropedalia.

Fig. 2: Aehnliches, von der Unterseite, mit Cam. luc. gezeichnet (Vergr. 55); $a, b b, c, d$ wie oben, $c f$ die Commissur zwischen dem subintestinalen und dem linken pleuralen Ganglion.

Fig. 3. Aelnnliches, von der oberen Seite; Bezeichnungen wie oben.

Fig. 4. Aehnliches, auch ron oben; $a, b b, c, d$ wie oben, $e$ Fussknoten.

Fig. 5. Gauglia pedalia, von oben, mit Cam. luc. gezeichnet (Vergr. 55); $a$ secundaire Ganglien am Vorderende, $b b$ Connective an das cerebrale und pleurale Ganglion.

Fig. 6. Aehnliche eines anderen Individuums, anch mit Cam. luc. gezeichnet (Vergr. 55); $b b$ wie in Fig. 5 , die secundüren Ganglien nicht sichtbar, weil an der Unterseite liegend.

Fin. - †. Buccale Ganglien, mit Cam. luc. gezeichnet (Vergr. 55); a cerebrale Connectire.

Fig. 8. $a$ Speiserölure, $b$ kropfartige Erweiterung derselben; $c$ zweiter Kropf, $d$ Blïttermagen, $e$ Röhre an den eigentlichen Magen aufsteigend.

Fig. 9. Aehnliche Organe eines anderen Individuums, mehr schräge gesehen; $a$ linteres Ende der Speiseröhre; $c, d, c$ wie obell.

Fig. 10. Obere Hingeweidemasse, ron hinten; der Magen und Darm geöffnet (Hinterseite weggenommen): a die Communicationsröhre mit dem Blättermagen und ilıre runde Oeffnung, links neben derselbeu die Oeffinung des Gallenganges; $c$ der Magen, sich in den Darm fortsetzend, welcher bei $d$ an die Vorderseite der Eingeweidemasse umbiegt; ef oberer Theil der Leber, $b g$ unterer.

Fig. 11. Dieselbe Eingeweidemasse, von vorne; $a$ (Fortsetzung von $d$ in Fig. 10) der Darm; eine grosse Schlinge bildend ${ }^{\circ}$ und in $b$ die Analpapille endigend; $c$ oberer, $d$ unterer Theil der Leber; $\epsilon$ Geschlechtsdrüse.

Fig. 12. a Blätterdrüse, $b$ Niere.

Fig. 13. Stück der Decke der Kriemenhöhle mit einem (kleinen) angehefteten Kiemenblatte.

Fig. 14. Das weibliche Genitalsystem; a der Eierstock, b Lierstockgang, cc Schleim- und Eiweissdrüse, $d$ Reihe ron Samenblasen; $c$ Vagina, $f$ Diverticulum derselben; $g$ Vulva mit an dieselle himabsteigendem Nerv.

Fig. 15. Reihe von Samenblasen, mit Cam. Inc. gezeichnet (Vergr. 55).

Fig. 16. Aus der Wand der Schleim- und Eiweissdrüse, mit Cam. lue. gezeichnet (Vergr. 350).

\section{MARSENIA PERSPICUA (L.).}

Fig. 17. Mandibelplatten, von oben, mit Cam. lue gezeichnet (Vergr. 55).

Fig. 18. Mediane Zahnplatte, mit Cam. luc. gezeichnet (Vergr. 200).

Fig. 19. Mediane Zahnplatte, anch von der oberen Seite.

Fig. 20. Aehnliche, schief von oben.

Fig. 21. Schneiderand einer ähnlichen.

Fig. 22. Hakenparthie einer Seitenzahnplatte, schief ron der Hinterseite.

Fig. 19-2.2 mit Can. luc. gezeichnet (Vergr. 350). 

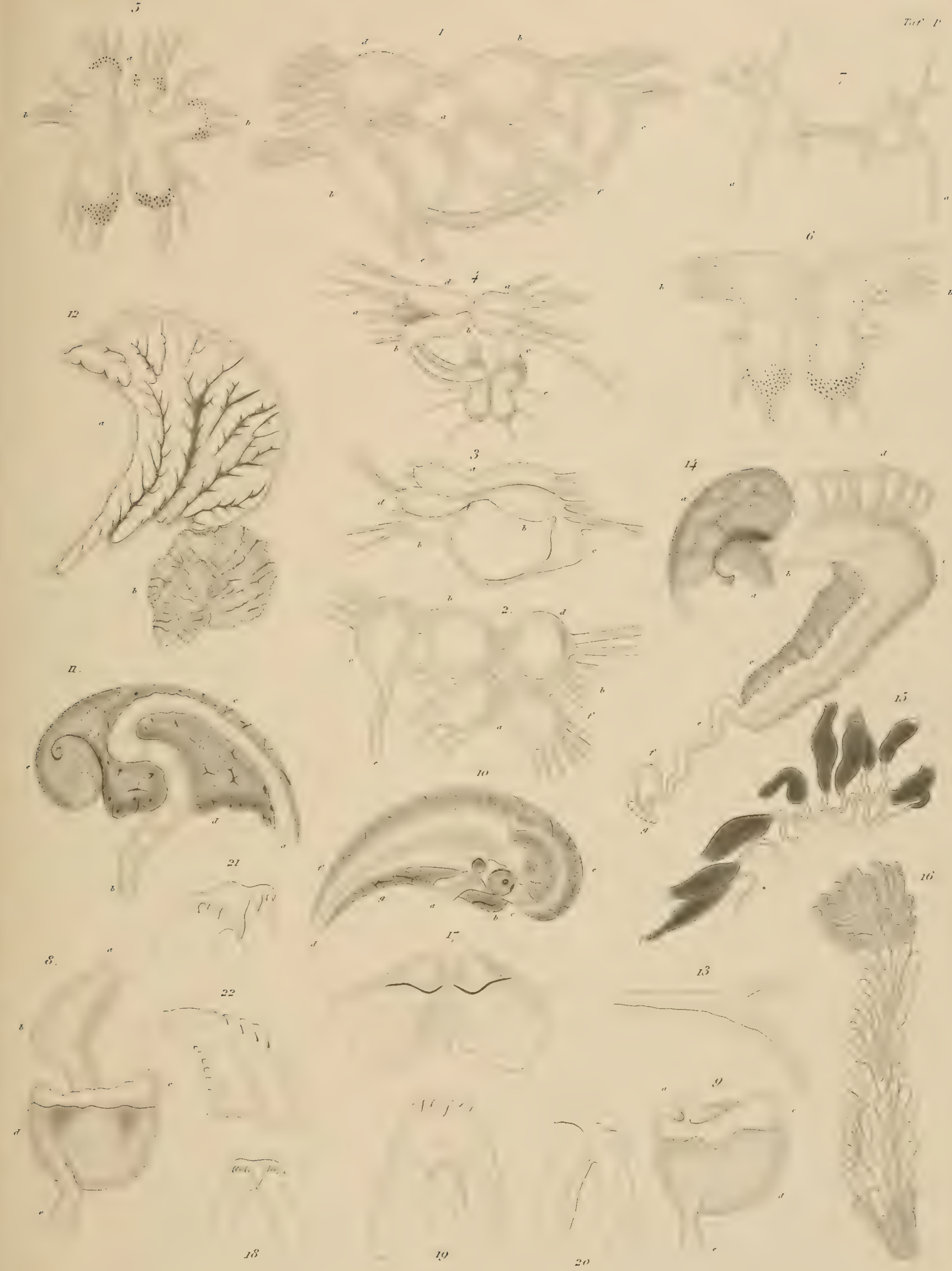



\section{Tafel Q.}

\section{CHELYONOTUS SEMPERI, BGIr.}

Fig. 1. Spitze der Spira der Schale.

Fig. 2. Decke der Kiemenhöhle, ron der Unterseite, mit a der Kieme und dem vor derselben liegenden Geruchsorgane mit $b$ seiner Verbindungsfalte mit der Schalenleiste, $c$ durchschnittener linker Schalenmuskel.

Fig. 3. Kleineres Kiemenblatt, mit Cam. lue. gezeichnet (Vergr. 55), a Grund, b Spitze desselben.

Fig. 4. Senkrechter Querdurchschnitt durch das Gemchsorgan, mit Cam. luc. gezeichnet (Vergr. 55); $a$ axialer Strang mit Hauptnerren, unter demselben Gefüsslichtung; an der einen Seite $(b)$ zwei Blätter.

Fig. 5. Unregelmässige mediane Platte, mit Cam. luc. gezeichnet (Vergr. 350).

\section{CHELYONOTUS TONGANUS (Q. et G.), VAR. BERGHI.}

Fig. 6. Tom Fussganglion; a Commissur zwischen den beiden Ganglien, $b$ das abgeschnürte secundaire Ganglion am Vorderende, c Ohrscheibe mit Otocyste und N. acusticus.

\section{MARSENIA PERSPICUA (L.).}

Fig. 7. Linke cerebro-pleurale Ganglienmasse, ron oben, mit Cam. luc. gezeichnet (Vergr. 55); $a$ cerebrales, $b$ pleurales Gangliou; $d$ pleuro-supraintestinales Connectiv, $d$ pleuro-subintestinales Connectiv.

Fig. 8. Fusshnoten, von oben, mit Cam. Iuc. gezeichnet (Vergr. 55); a rechtes cereloro- und pleuro-pedales Connectiv.

Fig. 9. Ohrscheibe mit Otocyste und Otolith, mit Cam. Inc. gezeichnet (Vergr. 350); a N. acusticus.

Fig. 10. Spitze eines Blattes des Geruchsorgans, mit Cam. luc. gezeichnet (Vergr. 100).

Fig. 11. Ein Kiemenblatt, mit Cam. lue. gezeichnet (Vergr. 100).

lig. 12. Oberes Ende der eingestülpten Schnauze, von der Unterseite.

Fig. 13. Seitenzabnplatten, ron oben; mit Cam. lue. gezeichnet (Vergr. 200).

Fig. 14. Vordere Wand des a eigentlichen Magens mit Cardia und Gallenöffnung und $b$ des Anfangs des Darmes.

Fig. 15. Hintere Wand (Boden) der Kiemenhöhle (Blätterdrïse und unten Leber); aa oberel Rand; links gemeinschaftliche Oeffnung der Niere und der Blätterdrüse, rechts (abnorme?) wahrscheinlich in die Blätterdrüse führende Pore, $b$ Rand des aufsteigenden rechten Schalenmuskels.

Fig. 16. Samenblasen mit $a$ gemeinschaftlichem Ausführungsgange.

Fig. 17. Aehnliche eines anderen Individuums, $a$ wie oben.

Fig. 18. a Vagina, b Vulva, c Divertikel der Vagina.

\section{MARSENIA LA'IENS (MÜLLER).}

Fig. 19. Seitenzahnplatte, von oben.

Fig. 20. Spitze der Seitenzahuplatte, ron unten.

Fig. 19-20 mit Cam. luc. gezeichnet (Vergr. 350).

\section{MARSENIA ISABELLINA, BGH.}

Fig. 21. Spitze einer Seitenzahnplatte, ron unten; mit Cam. luc. gezeichnet (Vergr. 750). 
3.
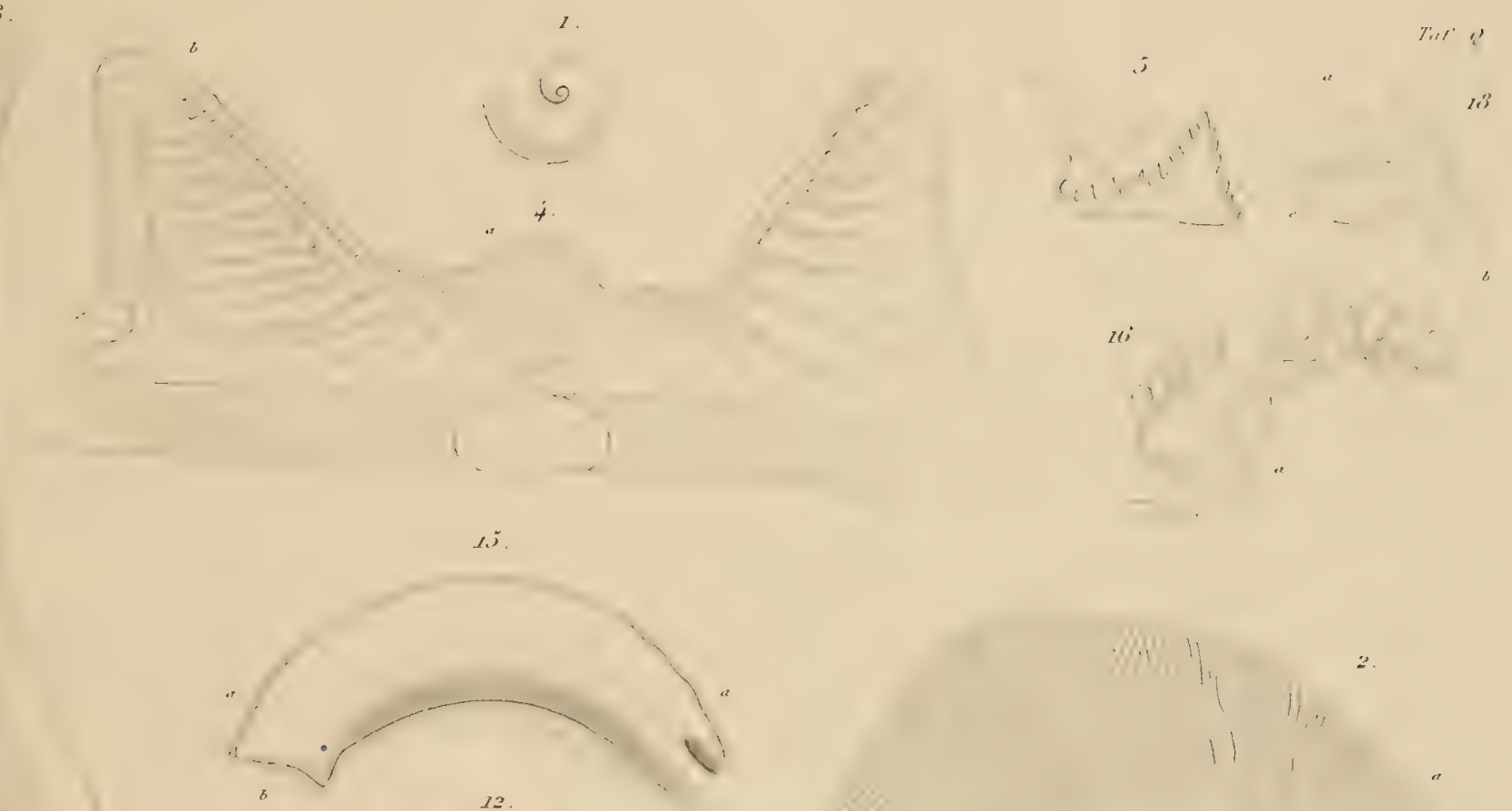

11

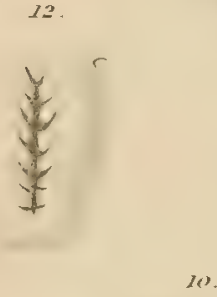

i
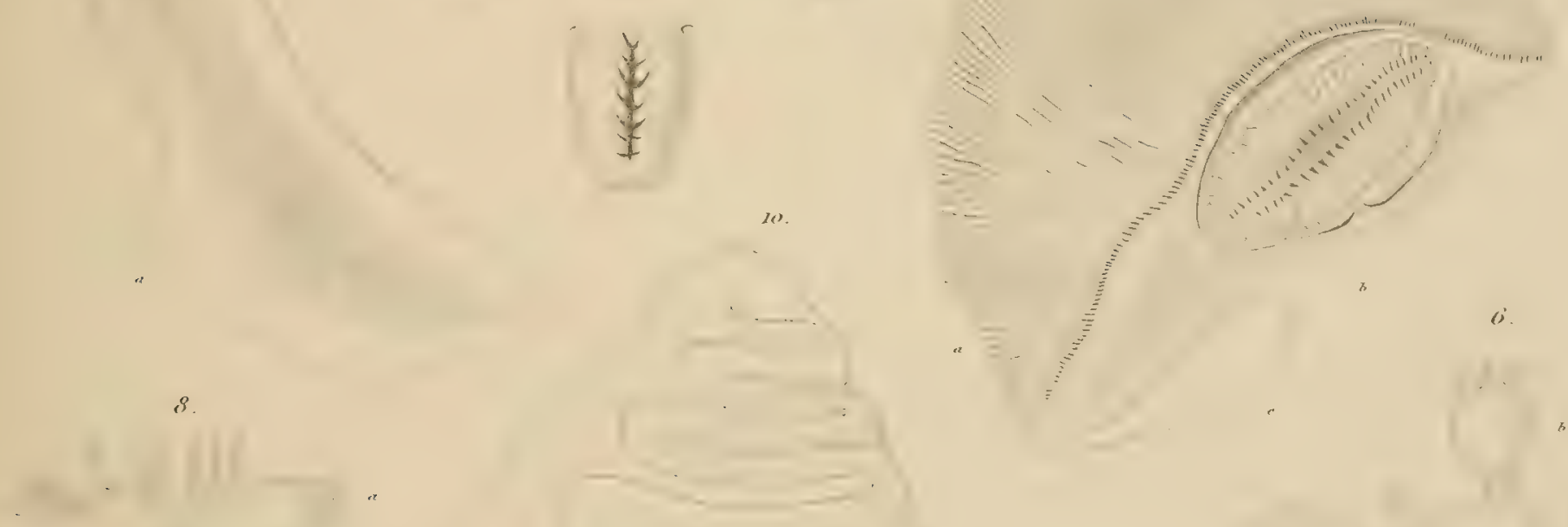

L'́
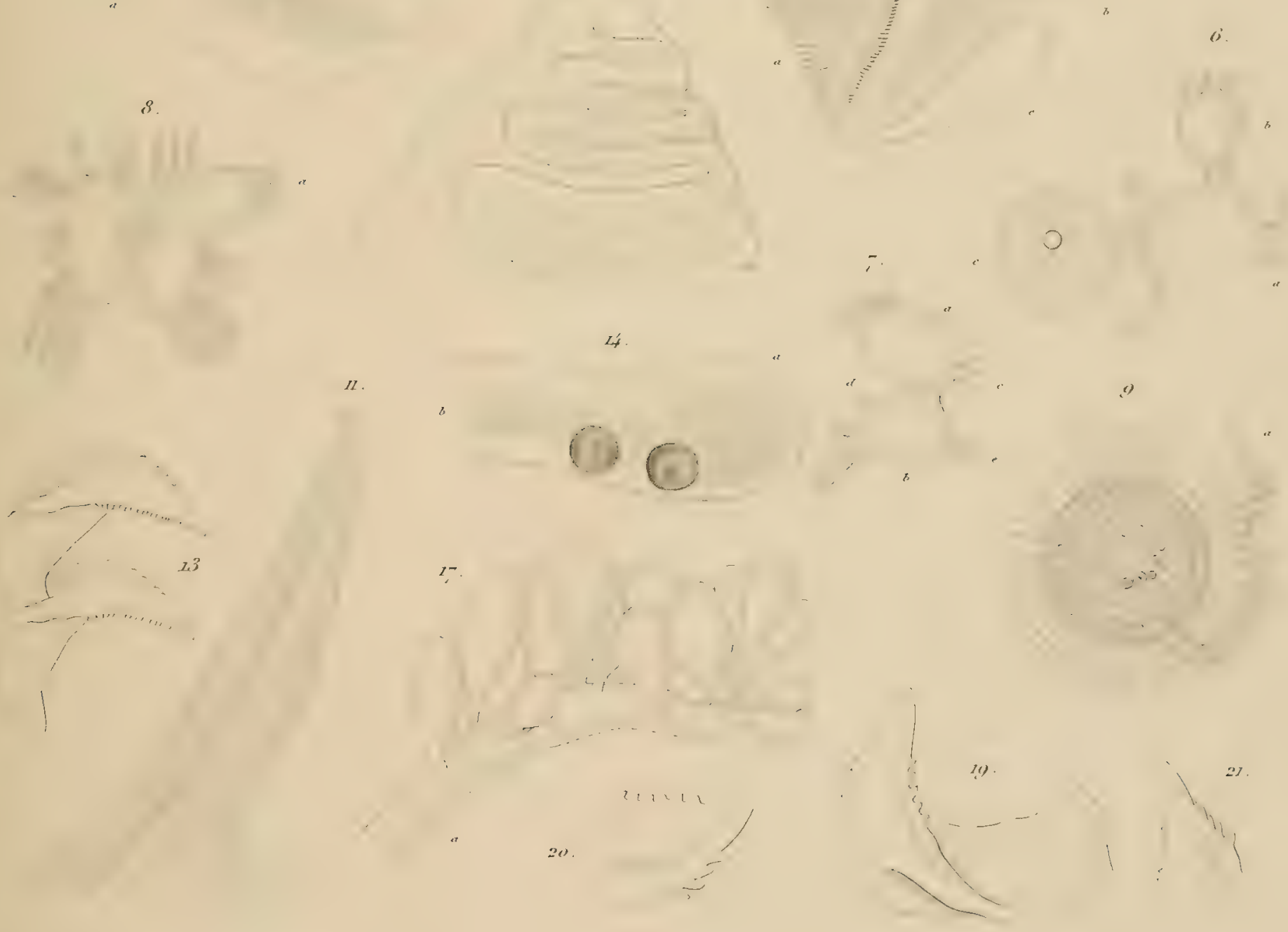



\section{Tafel R.}

\section{MARSENIA PERSPICUA (L.).}

Fig. 1. Mantel, von der Unterseite, $a$ Uebergangsstelle des Mantels in die Wurzel des Fusses, $b b$ Mantelgebräme.

Firg. 2. Das Centralnervensystem, von oben, mit Cam. luc. gezeichnet (Vergr. 55); a cerebrale Gauglien, $b b$ pleurale; $c$ supraintestinales, $d$ infraintestinales Ganglion; $e$ pedale Ganglien; $f$ kurze rechte (überschnittene) cerebro-pedale und pleuro-pedale Connective, $f^{1}$ lange ähnliche der linken Seite; $g$ buccale Ganglien, $h / h$ Otocysten.

Fig. 3. Ange mit a N. opticus.

Fig. 4. Zwei Seitenzahnplatten, von der Unterseite, mit Cam. luc. gezeichnet (Vergr. 200).

Fig. 5. Blättermagen mit dem ihn überziehenden Drüsenlager, von der rechten Seite; $a$ Vorderende des (zweiten) Kropfes, $b$ an den eigentlichen Magen aufsteigendes Robr.

Fig. 6. Der Blättermagen, vom Vorderende, rechts Cardia (Ende der Speiseröhre).

Fig. 7. Längsdurchschnitt des Blättermagens, $a$ Ende der Speiseröhre, $b$ an den eigentlichen Magen aufsteigendes Rohr.

Fig. 8. $a$ Samengang (aus dem Hoden entspringend), $b$ Knăuel desselben und der Prostata, $c$ Ende der Prostata, $d$ Knie des Samenganges an dem (rechten) Schalenmuskel, $e$ in der (unteren) Körperhöhle freiliegende Schlingen des Samenganges; $f g$ Penis, vor dem Ende desselben frei hervortretende Spitze des Samenganges.

Fig. 9. Ende des Penis mit $a$ weit vortretender freier Spitze des Samenganges.

\section{MARSENIA PERSPICUA, VAR. MORELLI (D'CH.).}

Fig. 10. Ilandibelplatten (auseinander geschlagen), von oben, mit Cam. lue. gezeichnet (Vergr. 55).

Fig. 11. $a$ Samengang, $b$ Knäuel desselben, $c$ Prostata, $d$ Fortsetzung des Samenganges.

\section{MARSENIA LA'IENS (O. Fr. MÜLLER).}

Fig. 12. Vorderende des Schlundkopfes mit a Lippenscheibe, die Mandibelplatten einfassend; median der Innenmund.

Fig. 13. Die Mandibelplatten (wie in Fig. 10), mit Cam. lnc. gezeichnet (Vergr. 55).

Fig. 14. Mediane Zahnplatte, von oben.

Fig. 15. Aehnliche, schief von oben.

Fig. 16. Aehnliche, vom Aussenrande.

Fig. 17. Hakenspitze einer Seitenzahnplatte, von oben.

Fig. 14-17 mit Cam. luc. gezeichnet (Vergr. 750).

Fig. 18. Drei mediane Zahnplatten, von oben.

Fig. 19. Grundstück von drei Seitenzahuplatten, von der Unterseite.

Fig. 18-19 mit Cam. luc. gezeichnet (Vergr. 350).

Fig. 20. $a$ Schleim- und Eiweissdrüse, $b 6$ Samenblasen.

\section{MARS. AFFINIS, BGH.}

Fig. 21. Linke Mandibelplatte, von oben; mit Cam. luc. gezeichnet (Vergr. 100).

Fig. 2.2. Seitenzahnplatte, von oben.

Fig. ㄴ.23. Aehnliche, schräge von der Unterseite.

Fig. 22-23 mit Cam. luc, gezeichnet (Vergr. 350). 

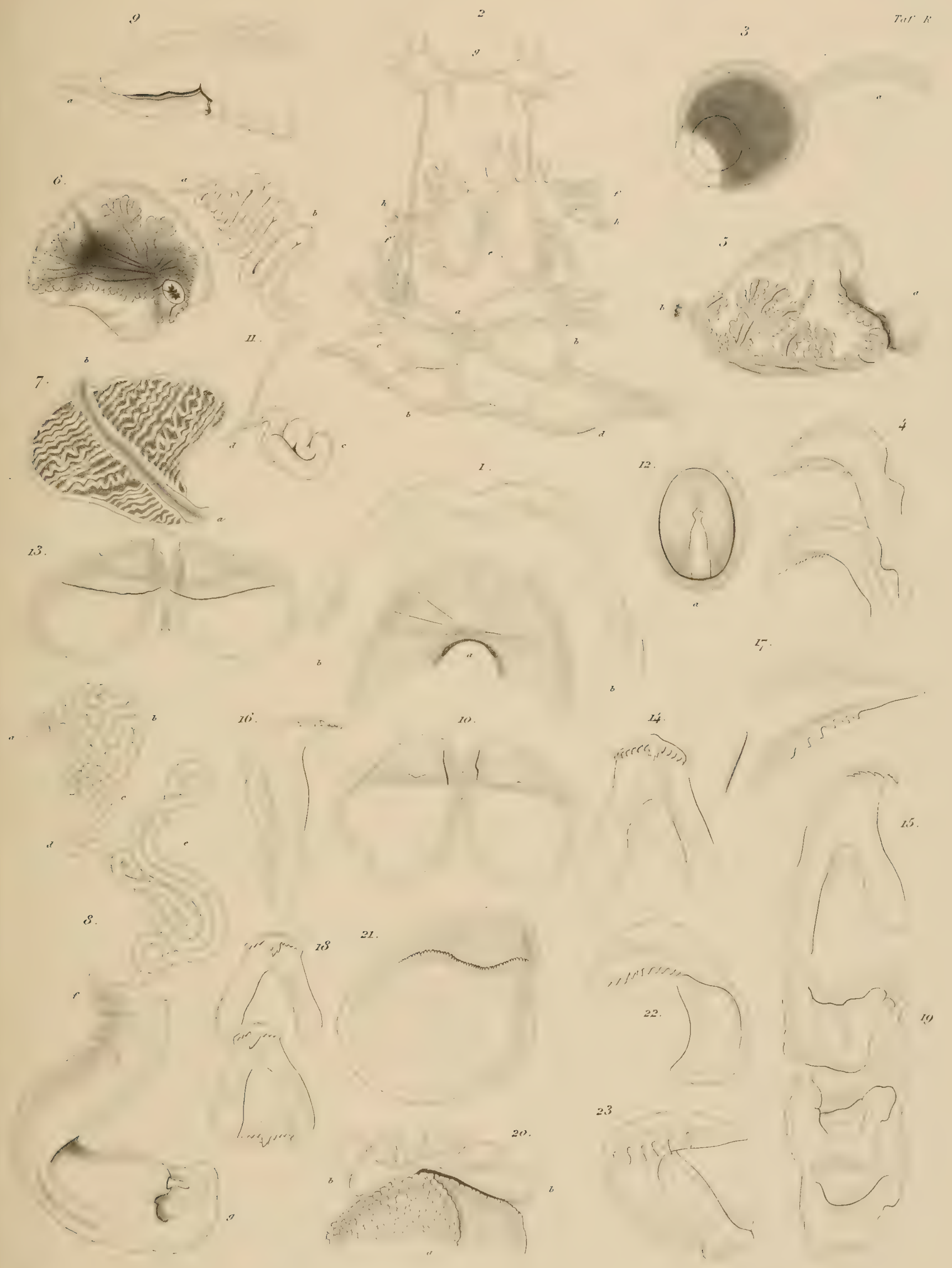




\section{Tafel S.}

\section{CHELYONOTUS TONGANUS (Q. et Gr.), VAR. BERGHI, DESH.}

Fis. 1. Abnorme mediane Zahnplatten.

Fig. 2. Seitenzahnplatten, von der unteren Seite.

Fig. 3. Aehnliche, mehr schief.

Fig. 1-3 mit Cam. gezeichnet (Vergr. 100).

Figr. 4. Ende des Penis mit $a$ fingerförmigem Ende des Samenleiters.

MARSENIA LATENS (O. Fr. MüLLer).

Fig. 5. Zwei mediane Zahnplatten, von oben; mit Cam. gezeichnet (Vergr. 350).

\section{MARS. ISABELLINA, BGI.}

Fis. 6. Stück der Raspel, von der Unterseite; $a$ mediane, bb laterale Platten.

Fin. 7. Eine mediane Platte, schief von der oberen Seite.

Fig. 8. Stück der Raspel, von der oberen Seite; $a$ mediane, $b b$ laterale Platten; cc umgeschlagener Rana der Raspel.

Fis.. Seitenzahnplatte, von oben.

Fig. 6-9 mit Cam. gezeichnet (Vergr. 750).

MARS. GEMMA, BGI.

Fir. 10. Ende des Penis mit a vorgestrecktem Ende des Samenleiters.

MARS. CABULANA, BGir.

Fis. 11. Haken einer Seitenzahnplatte, ron der Unterseite.

Fig. 12, 13. Mediane Zahnplatten.

Fig. 11-13 mit Cam. gezeichnet (Vergr. 350).

\section{MARS. PELLUCIDA (Verrili).}

Tis. 14. Die pedalen Ganglien, mit Cam. gezeichnet (Vergr. 55); an die secundairen Ganglien am Vorderende, $b b$ Otocysten.

Fin. 15. Die aus einander geschlagenen Mandibelplatten, mit Cam. gezeichnet (Vergr. 100); $a$ Vorderrand oben.

Fis: 16. Mediane Platte, von oben.

Fing. 17. Aehnliche, von der Seite.

Fic. 18. Aehuliche, vou hinten (Haken).

Fig. 1!!. '/wei Seitenzahnlatten, von oben.

Fig. 20. Eine Seitenzahnplatte, schief von unten.

Fig. 14-18 init Cam. gezeichnet (Vergr. 350).

Fis. ㄴ. Sipeiseröhre, $a$ Erweiterung derselben.

Fis. '2.) a linterster I'heil der Speiseröhre, $b$ (zweiter) Kropf, c Blaittermagen.

Fin. :2:. Spitze eines Kiemenblattes, mit Cam. gezeichmet (Vergr. 55).

\section{MARS. PELLUCIDA, VAR. GOULDII (Verrill).}

Fị. 24. Vorderende des Kopfes (beim Mrännchen).

Fig. 25. Hinterer Theil der letzten Windung der oberen Eingerveidemasse; $a$ Geschlechtsdrüse, $b$ durchschimmernder Magen, $c$ Balkenwerk der Blätterdrüse.

Fis. 2n. Vorderende der Mandibelplatten (oben), mit Cam. gezeichnet (Vergr. 55).

Fig. 27. Mediane Zahnplatte, vou oben.

Fig. 2.. Zwei ähnliche, von der Unterseite.

Fig. 2!). Eine Seitenzahnplatte, von oben.

Fic. 30. Grundstiick einer solchen, von unten.

Fig. 27-30 mit Cam. gezeichnet (Vergr. 350).

Fic. :1. Ende eines Blattes des Geruchsorgans, mit Cam. gezeichnet (Vergr. 100).

Fin. ::2. Penis, von der Unterseite (nach vorne geschlagen); $a$ fingerformiges Ende des Samenganges.

Fis.: :3:). Zwei sich hinten $(b)$ vereinigende Speicheldrüsenläppchen, die sich durch $a$ Oeffnung am Hinterende der unteren Eingeweidehöhle in den Schwanz hinein median fortsetzen.

Fin. : $t$. Hinteres Ende der Raspelscheide. 



\section{Tafel T. \\ MARSENIA CABULANA, BGi.}

Fig. 1. Die Schale, ron oben.

Fig. 2. Rechte Mandibelplatte, yon aussen, a oberel Rand; mit Cam. gezeichnet (Vergr. 100).

Fig. 3. Grundstück von drei Seitenzahnplatten, von der Unterseite.

Fig. 4. Zwei Seitenzahnplatten, von oben.

Fig. 3-4 mit Cam. gezeichnet (Vergr. 350).

MARS. GEMMA, BGH.

Fig. 5. Rechte Mandibelplatte, von aussen, a oberer Rand; mit Cam. gezeichnet (Vergr. 100).

Fig. 6. a Hinteramd des rorderen Theils iler Mandilelplatte; mit C'an. gezeichnet (Vergr. :3i)

Fig. 7. Mediane Zahnplatte, von oben.

Fig. 8. Laterale Zahnplatte, von oben.

Fig. 7-8 mit Cam. gezeichnet (Vergr. 750).

Fig. 9. Die Sclale, von oben.

MARS. INDECORA, BGr.

Fig. 10. Die pedalen Ganglien mit der secundären Ganglienbildung, von oben; ac cerebro- und pleuropedale Connective, $b 6$ Otocysten.

Fig. 11. Otocyste mit Otolith, mit Cam. gezeichnet.

Fig. 1:. Linke Nandibelplatte, von aussen, a Vorderrand; mit Cam. gezeichnet.

Fi心. 13. Zwei mediane Zahnplatten, von oben.

Fin. 14. Eine älnnliche, ganz von der Seite.

Fig. 15. Seitenzalınplatte, ron oben.

Fig. 16. Abgebrochene Spitze einer Seitenzahnplatte, ron hinten (oben).

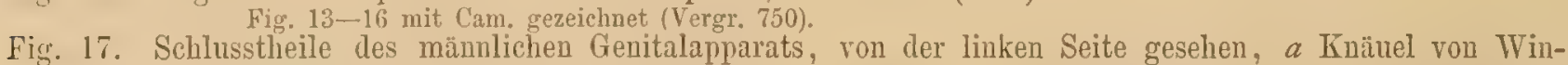
dungen des Samenganges, $b$ Schlingen desselben an der rechten Seite des Schlundkopfes; $c$ Penis, $d$ freies Ende des Samenleiters.

Fic. 18. Schale, von oben.

\section{MARS. AFFINIS, BGH.}

Fig. 1!. Mediane Zahnplatte, von oben.

Fis. '

Fis. 21. Laterale Platten (rechter Seite), von oben.

Fig. 2.. Abgebrochene Spitze einer Seitenzahmplatte, von hinten. Fig. 19-22 mit Cam. gezeichuet (Vergr. 350).

Fig. 2:3. Reihe der Samentaschen, mit Cam. gezeichnet (Vergr. 100).

MARS. DIEGOENSIS, Bgit.

Fi̊r. 24. Vorderende des Schlundkopfs, von der Seite (Mandibelplatten), nach Wegnalıme der a Mundröhre, $b$ freier vorderer Rand der Mandibelplatte (verkehrt gezeichnet, mit dem oberen Rande unten).

Fig. 2:. Vorderende des Schlundkopfs mit Mundspalte, von vorn ab; a oben.

Fis. 26. Zwei mediane Platten, schrige ron oben.

Fic. $-\overline{-}$. Abgebrochene Spitze einer solchen (etwas abnormen), ron hintell.

Fic. 2r. Laterale Zahnplatte, ron oben.

Fig. 2?. Abgebrochene Spitze einer solchen, ron hinten. Fig. 26-29 mit Cam. gezeichnet (Vergr. 750).

Fig. 30. Körperchen vom Stück eines Kiemeublattes, mit Cam. gezeichnet.

Fig. :1. Ende des Penis, mit a der Oeff́nung für Durchtreten des Endes des Samenleiters.

Fiğ. : Aehnliches mit der geöffueten Höhle für das fingerförmige Ende des Samenleiters; $a$ wie oben.

\section{MARSENINA PRODITA (Lovén).}

Fin. :3:: Mediane Zahnplatten, von der Unterseite.

Fin. 34. Aensserste laterale Zahnplatten ron der Aussenseite; a Rand der eigentlichen Raspel.

\section{ONCHIDIOPSIS GROENLANDICA, BGH.}

Fic: 35. Zwei äusserste laterale Zahnplatten, von der Innenseite.

Fic: :ii. Aensserste laterale Zahmplatte, schrïge von der Unterseite. Fig. 33-36 mit Cam. gezeichnet (Vergr. 350). 

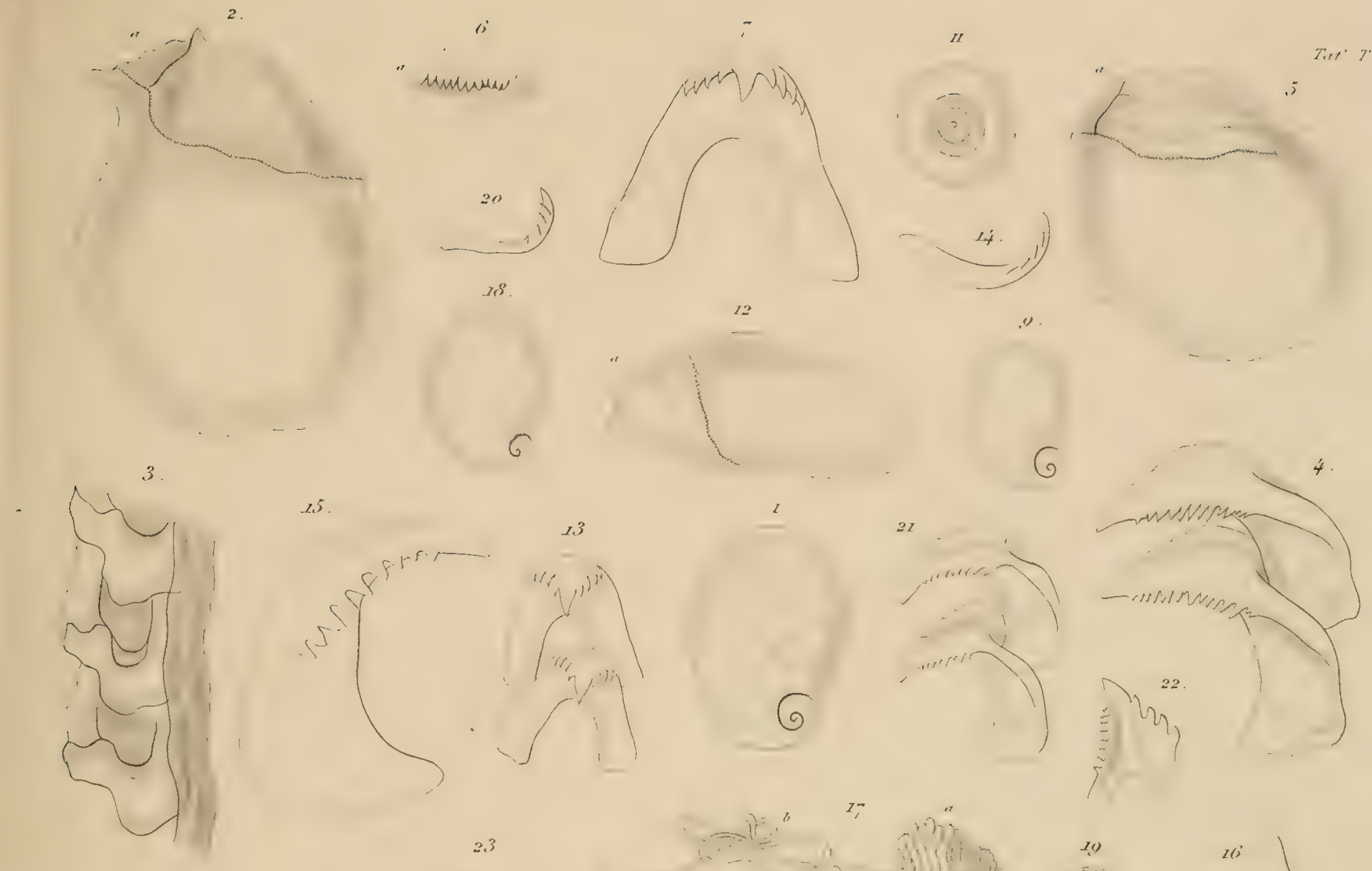

6
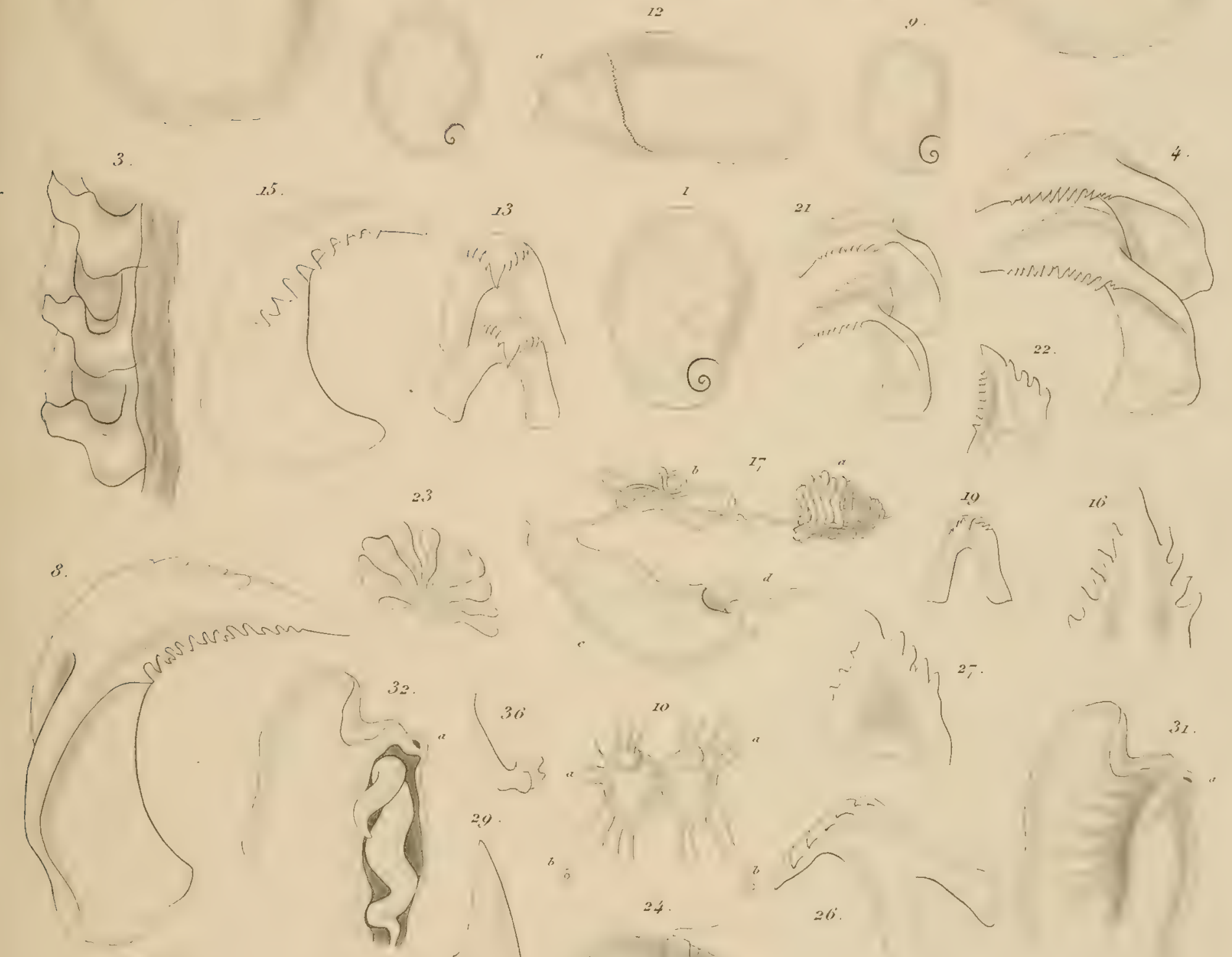

6
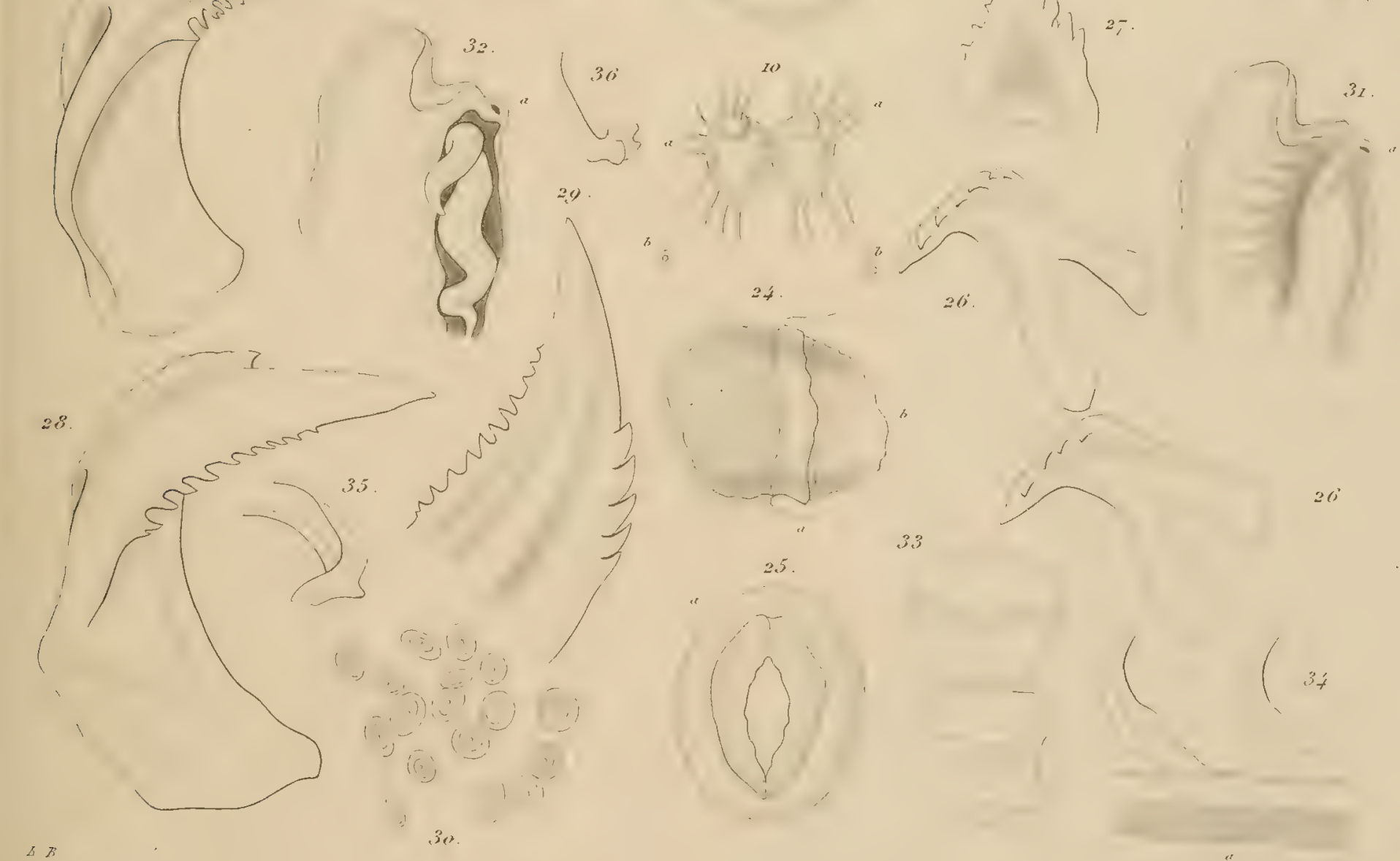




\section{Tafel U.}

\section{MARSENIELLA BOREALIS, BGH.}

Fig. 1. Mediane Zahmplatte, schief von oben; mit Cam. gezeichnet (Vergr. 350).

Fig. 2. Penis, mit a berausgestrecktem Ende des Samenganges.

\section{ONCHIDIOPSIS GROENLANDICA, BGH.}

Fig. 3. Mediane Zahuplatte, von hinteu, mit Cam. gezeichnet (Vergr. 350).

\section{MARSENINA PRODITA (LOVEN).}

Fig. 4. Lins der kleineren Kiemenblätter, mit Cam. gezeichnet (Vergr. 55); $a$ Grund.

Fig. 5. Centralnervensystem, von oben, mit Cam. gezeichnet (Vergr. 55); a cerebrale, bb pleurale Ganglien ; $c$ supraintestinales, $d$ subintestinales Ganglion; $c$ Commissura (Connect.) magna (subintestiuopleuralis); $f$ pedale Ganglien, $f^{\prime}$ abgeschnürter vorderer Theil derselben; so Connectiva cerebro- und plemo-pedalia; $/$ Ganglia buccalia; $i i$ Ohrscheiben mit Otocysten.

Fig. 6. Mandibelplatten, von der Innenseite, mit Cam. gezeichnet (Vergr. 55); $a$ verbindende Cuticula oben.

Fig. 7. Vom Vorderrande der Mandibelplatte, von der Innenseite.

Fig. 8. Vom Hinterrande der Mandibelplatte, von der Innenseite; $a$ linten.

Fig. !. Elemente der Mandibelplatte, vom Rande.

Fig. 10. '/ellen, einer Reihe der Elemente der Mandibelplatte entsprechend. Fig. $7-10$ mit Cam. gezeichnet (Vergr. 350).

Fig. 11. ac Vorderster Theil der Mundröhre (geöffnet) bei zurückgezogenem Schlundkopfe, ron der Unterseite; innen Ueberrest der Schnauze.

Fig. 12. aa äusserer Theil der (geöftineten) Mundröhre (Schnauze) bei zurückgezogenem Schlundkopfe; $b b$ innerer Theil, die Lippenscheibe mit den Mandibelplatten einschliessend; $c$ Vorderende des zurïckgezogenen Schlundkopfes.

Fig. 13. a mediane, $b$ laterale Platte, $c$ zwei äussere Haken, $d$ ungebogener Rand der Raspel; ron oben.

Fig. 14. Mediane Platte, von oben.

Fig. 15. Aehnliche, von der Seite.

Fig. 16. a laterale Platte, $b c$ änssere Haken; rou oben.

Fig. 17. $a, b, c$ wie in Fig. 16, in mehr schiefer Stellung.

Fig. 18. $a, b, c$ wie in Fig. 16 und 17, aber von der Unterseite.

Fig. 19. Laterale Platte, schief von der Vorderseite.

Fig. 13-19 mit Cam. gezeichnet (Vergr. 350).

Fig. 20. Hinterende der Eingeweidemasse, $a$ Zwitterdrüse, $b$ Blätterdrüse, $c$ Niere; $d$ Schalenleiste, innerhalb derselben die Muskelfacette, dann die Schleim- und Eiweissdrüse, hinter denselben sehimmert die winzige Prostata hindurch.

Fig. 21. a ovariale, $b$ testiculare Parthie der Zwitterdrüse; $c$ ovariale Parthie, durchgeschnitten.

Fig. 22. a prostatisches Knäuel des Samenganges, $b$ gestreckt verlaufender muskulöser Theil desselben, $c$ geschlängelte f'ortsetzung bis an $d$ das Ende des Ganges am Uebergange in den Penis.

Fig. 23. Penis; bei $e$ schliesst sich das Ende des Samenganges $d$ in Fig. 22 an; $f$ Oeffuung des Samenganges an der Spitze des P'enis.

Fig. 2.2-23 mit Cam. gezeichnet (Vergr. 55).

Fig. 24. Die Blätterdriise.

Fig. 25. Stück des Hintereudes der Blätterdrüse, mit Cam. gezeichnet (Vergr. 100); $a$ hinten.

Fig. 26. a Rectum, b quergeschnittener Samenleiter, c Vulva, $d$ quergeschnittener Schalenmuskel.

\section{MARSENINA GLABRA (COUTH.).}

Fig. 27. a mediane, $b$ laterile Platte, $c d$ ämssere Haken; von der unteren Seite.

Fig. 28. Die zwei äusseren Halien.

Fig. 27--20 mit Cam. gezeichet (Tergr. 350). 





\section{Tafel V.}

Fig. 1. Schalenstructur.

\section{MARSENIA PERSPICUA (L.).}

Fig. 2. Von der Oberflizche der Schale.

Fig. 3. Epithel ron der Innenseite des Mantels.

Fig. 1-3 mit Cam. lue, gezeichnet (Vergr. 350).

Fig. 4. Die Niere, von oben; $a$ Vorderrand.

Fig. 5. Ende des Penis mit geöftneter Höhle desselben und a Deffinung derselben, in der Höhle das zurückgezogene Ende des Samenleiters.

\section{MARSENIELLA BOREALIS, BGI.}

Fig. (i. Irreguläre mediane Zahnplatte, von der Unterseite; mit Cam. gezeichnet (Tergr. 55).

Fig. 7. Mandibelplatten, aus einander geschlagen, von oben (aussen); mit Cam. luc. gezeichnet (Vergr. 55).

Fig. \&. Stück des Daches der Kïemenhöhle, mit durchschimmernden Organen; a Blätterdrüse, $b$ Secret' massen, $c$ Kiemenblătter.

lïg. !. Die Schale, von oben.

\section{MARSENINA DALLI, BGII.}

Jig. 11. Dieselbe, ron unten.

Fig. 11. Die Nuclealparthie, von oben.

Fig. 12. Kiemenblatt.

Fig. 13. 14. Kiemenblitter.

Fig. 12-14 mit Cam. gezeichnet (Vergr. 100).

Fig. 1.. Mediane Zahnplatte, von oben.

Fig. 16. Andere, von oben.

Fị. 17. Zwei mediane Platten, von der Seite.

Fig. 18. 'Zwei laterale Platten, von der Invenseite.

Fig. 1!. Die äusseren Haken, von der Innenseite; a vortretender Rand der Raspel.

Fig. ㄴ. Aeusserer Haken.

Fig. 21. a $a$ laterale Platten; $b$ innerer, $c$ üusserer Haken; von der Innenseite.

Fig. 15-21 mit Cam. gezeichnet (Vergr. 350).

\section{ONCHIDIOPSIS GROENLANDICA, BGH.}

Iir. 22. Mediane 'Zahnplatte, von vorne ab; mit Cam. gezeichnet (Vergr. 200).

Fin. ․:. Abgenutzte äusserste Platten, mit Cam. gezeichnet (Vergr. 350).

Fig. ㅂ. Operkel ron einer der Fierhöhlen (vgl. Taf. Z. Fig. 15), mit Cam. gezeichnet (Vergr. 55).

\section{ONCHIDIOPSIS GLACIALIS (M. SARS).}

Fïg. 2... Kleineres Kiemenblatt.

Fin. 21;. Spitze eines grossen Kiemenblattes.

Fig. ㄱ. Ganz kileines Kiemenblatt.

Fin. 28. Querdurehsehnitt der Fussdruise.

Fig. 25-28 mit Cam. gezeichnet (Vergr. 55).

Fig. : 2 ?. Penis; $a$ Grund desselben.

Fig. : (1). $a$ untere Lippe der branchio-renalen Oeffnung, $b$ Oeffinung in die Blätterdrüse, $c$ Oeftnung in die Niere.

Fig. :.1. Niere, von der Unterseite; $a a$ in der Kiemenhöhle entblösster Theil.

Fig. ::2. Von der Blitterdrüse, mit Cam. gezeichnet (Vergr. 350). 


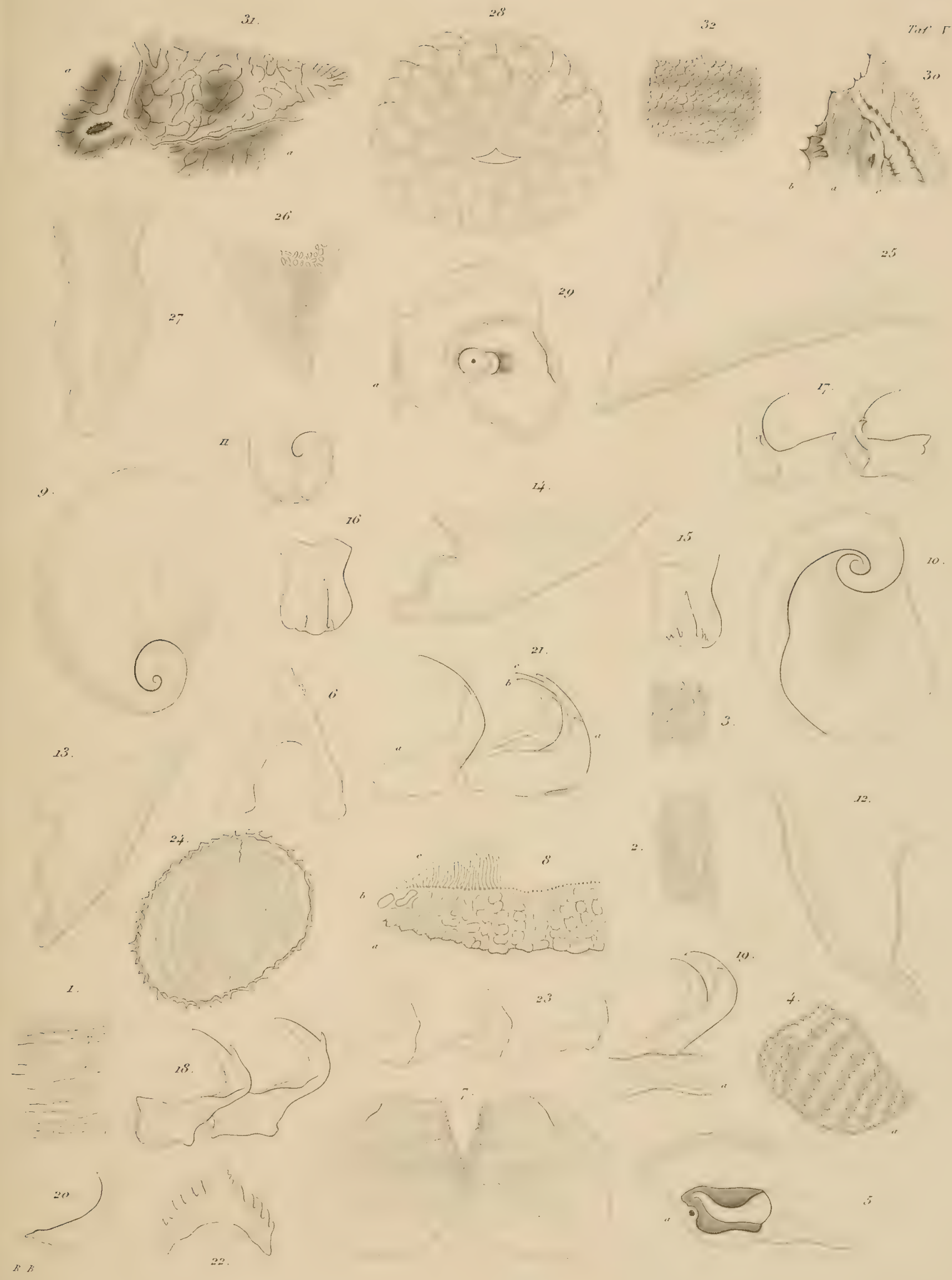






\section{Tafel $\mathbf{X}$.}

\section{MARSENIELLA BOREALIS, BGH.}

Fis. 1. Die Schale, ron oben.

Figr. 2. Dieselbe, von unten.

Fig. 3. Ein Kiemenblatt, mit Cam. gezeichnet (Verg1. 55).

Fig. 4. Mediane Zahmplatte, von oben.

Fig. 5. Spitze einer lateralen Platte, von unten.

Fic. 6. Zwei laterale Platten, von oben.

Fig. 4-fi mit Cam. luc. gezeichnet (Vergr. 350).

Fig. 7. Zwei Kiemenblatter.

\section{MARSENINA GLABRA (COUTH.).}

Fị.. ․ Zwitterdrüsenläppchen, a Ausführungsgang.

Fig. 7--8 mit Cam. gezeichnet (Vergr. 55).

\section{ONCHIDIOPSIS GROENLANDICA, BGI.}

Fis. !. Obere Eingeweidemasse (von der rechten Seite) nach Wegnahme der Rïckenbedeckungen (cc) und der Schale; $a$ Gegend der Schale (Kiemenhöhle u. s. w.), hinter derselben die Schleim- und Eiweissdrüse, daun die Leber; $b$ Gegend der Geschlechtsdrüse; $c$ F'uss mit seinem eigenthümlichen Gebräme.

Fig. 10. Linkes Fussganglion, von oben; mit $a$ dem secundären vorderen Ganglion; $b$ Otocysten-Platte und Otocyste mit dem in $c$ das cerebro-pedale Connectiv übergehenden Nerven.

Fig. 11. a N. acusticus, b Otocyste; mit Cam. gezeichnet (Vergr. 100).

Fig. 12. Eingestülpte Mundröhre, mit ihrer durch $a$ den eingeschlossenen Schlundkopf gebildeten Erweiterung.

Fing. 1:i. Dieselbe geöffnet, und die obere Wand weggenommen; hinten Speiseröhre, Mm. retractores bulbi und Raspelscheide; daun a Schlundkopf mit seinen Muskeln, den durchschimmernden Mandibelplatten und den Retractoren der Mundröhre (Schnauze).

Fig. 14. Ijinke Mandibelplatte, von der Aussenseite, mit Cam. gezeichnet; $a$ unterer Rand, $b$ vorspringende Spitze.

Fig. 15. Die vorspringende Spitze (Fig. 14b), stärker, vergrössert.

Fig. 16. Vom Vorderrande.

Fig. 17. Vom Hinterrande.

Fig. 15-17 mit Cam. gezeichnet (Vergr. 200).

Fig. 1․ Mediane Zahnplatten (von der pacifischen Varietät), von oben; mit Cam. gezeichnet (Vergr. 350).

Fig. 1!). Eine (linke) Seitenzahnplatte, von hinten.

Fig. 21. Innerste Ausseuplatte von drei Zahnplattenreihen.

Fig. 21. Aeusserste Aussenplatte dreier Reiluen.

Fig. 19-21 mit Cam. gezeichnet (Vergr. 200).

Fig. 2.). Die hakenförmigen Aussenplatten (der pacifischen Varietï) zweier Reihen, von aussen; ac die innere.

Fig. 2:3. Die Aussemplatten, vom Vorderrande.

Fig. 22-23 mit Cam. gezeichnet (Vergr. 350).

Fig. 24. Senkrechter Querschnitt der Schleim- und Eiweissdrüse; mit oberer kleinerer, unterer weiterer Hỏhle; a Randkanal, sich in die untere Höhle öfinend.

Fin. 2:. Von einem ovarialen Follikel eines Zwitterdrüsenläppchens, mit Cam. gezeichnet (Vergr. 350).

Fì. ㄱ․ Schläuche der Nebenzwitterdrüse; aa eigenthümliche Körperchen; mit Cam. gezeichnet.

Fig. 27. Zwitterdrüsen-Läpnehen.

ONCHID. GLACIALIS (M: SARS).

Fis. 25. Zwei Seitenzahmplatten rechter Seite, von oben; mit Cam. gezeichnet (Vergr. 200). 


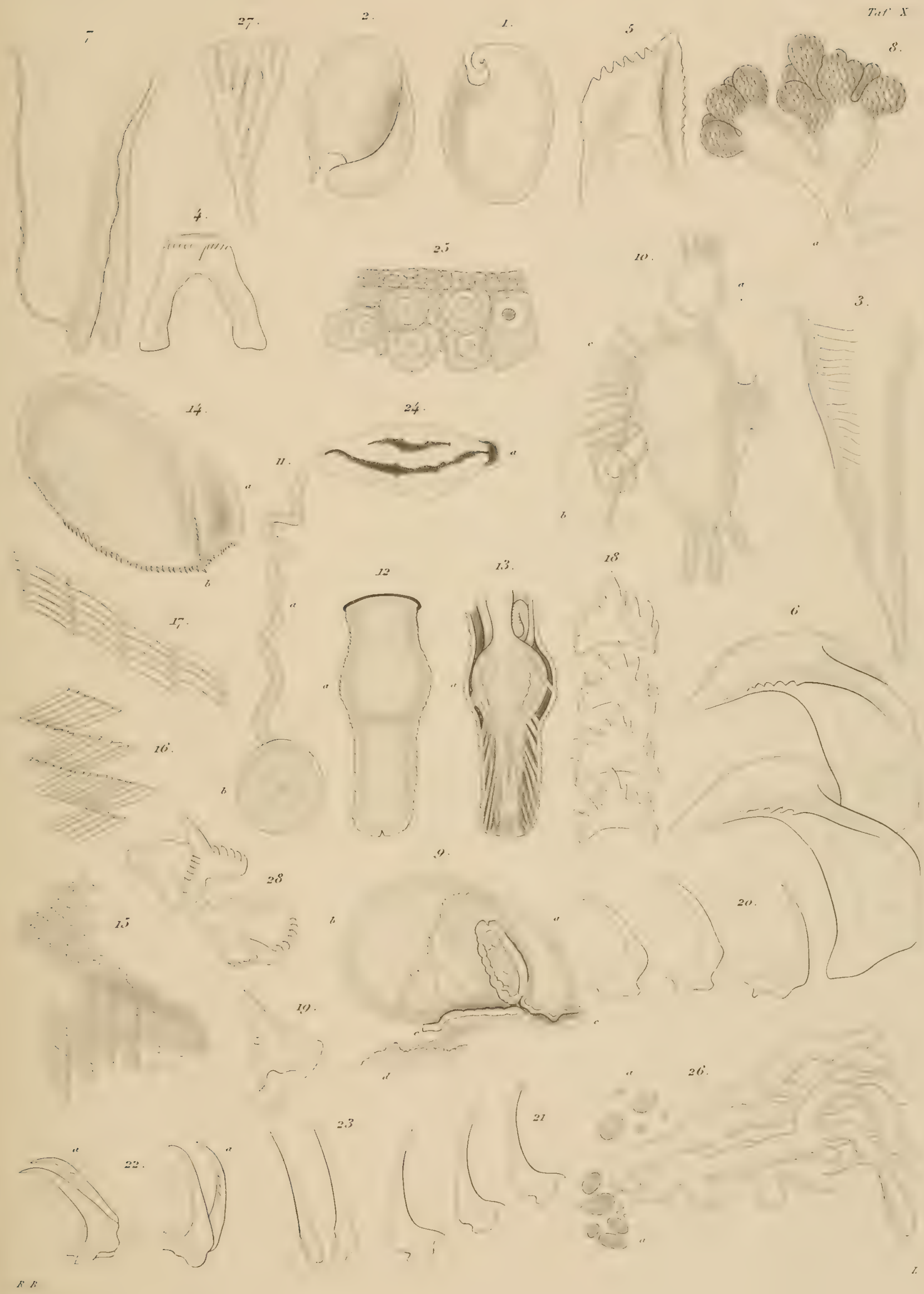






\section{Tafel $\mathbf{Y}$.}

\section{ONCHIDIOPSIS GROENLANDICA, BGH.}

Fig. 1. Das Centralnervensystem, ron oben; $a a$ Ganglia cerebralia, $b b$ G. pleuralia, $c$ G. supraintestinale, $d$ G. subintestinale, $e$ Ganglia pedalia, $f$ G. pedalia succenturiata.

Fir. 2. Theil der Raspel, von der Unterseite; a mediane Zahnplatten, $b b$ laterale; $c c$ äussere Haken; $d d$ Aussenrand der Raspel.

Fig. 3. Stück der Raspel, von oben; $a$ mediane, $b$ laterale Platten.

Fig. 2-3 mit Cam. luc. gezeichnet (Vergr. 200).

Fig. 4. Blatt aus der Mitte der Kieme; $3 / 1$.

Fig. 5. Blatt vom äussersten Theil der Kieme; $7 / 1$.

Fin. (i. Vorderrand des Fusses, mit Fusspore.

Fig. 7. a Rand der Kiemenspalte, $b$ Ende der Kieme, c Rectum, $d$ weibliche genitale Oeffnung.

Fig. 8. Läppchen der Zwitterdrüse, mit Cam. gezeichnet (Vergr. 100); a ovarialer, $b$ testicularer Theil.

Fig. ?. Vordere Genitalmasse, von der inneren (linken) Seite; $a$ Nebenzwitterdrüse; $b b$ Schleim- und Eiweissdrüse mit den an derselben ruhenden Vestibularsack (oben), Prostata und Samenblase (unten); $c$ Samengang über die Vagina verlaufend, $d$ Vulva.

Fig. 10. Schleim- und Fiweissdrüse (wie in Fig. 9) (Nebenzwitterdrïse, Prostata und Samenblase weggenommen); $a$ Vulva, sich in $b$ Vagina fortsetzend, oberhalb derselben Vestibularsack.

Fig. 11. Schleim- und Eiweissdrïse, von der rechten Seite; $a$ rechter, $b$ linker Rand; $c$ Vulva.

Fig. 12. Die unterste Höhle der Schleim- und Eirweissdrüse, von oben; a die zurïckgeschlagene obere Wand derselben, die starke Falte der unteren Wand und die Oeffnung in die obere Höhle dentlich.

Fig. 1:. Die geöffnete obere Höhle der Schleim- und Eiweissdrüse; $a, b, c$ wie in Fig. 12.

Fig. 14. Senkrechter Durchschnitt der Nebenzwitterdrüse; $a$ Ausfübrungsgänge der Zwitterdrüse, $b$ Ausführungsgang der Nebenzwitterdrüse.

Fig. 15. a Theil der Prostata, $b$ Ausführungsgang der Nebenzwitterdrüse, $c$ Ausführungsgänge der Prostata, $d$ Samenleiter, $e$ Samenblase; $f$ Vagina, oberhalb derselben der Vestibularsack; $g$ Vulva.

Fig. 16. Nach Wegnahme von Prostata und Vestibularsack; $b, c, d, e, f$ wie in Fig. 15.

Fig. 17. Senkrechter Längsdurchschnitt; a Vestibularsack, $b$ Vagina, $c$ Oeffnung der Vagina und der Schleimdrüse in das Vestibulum.

Fig. 18. Penis, mit Cam. gezeichnet (Vergr. 100); a Samenleiter.

ONCH. GROENLANDICA, BgI., VAR. PACIFICA.

Fig. 19. a Die zwei (äusseren) Haken zweier Reihen, b Rand der Raspel; mit Cam. gezeichnet (Vergr. 350).

\section{ONCHIDIOPSIS GLACIALIS, M. SARS.}

Fị. 20. Schwanz; a Hinterende der unteren Eingeweidehöhle.

Fig. 21. Lüppchen der Fussdrüse (rergl. Taf. V. Fig. 28), mit Cam. gezeichnet (Vergr. 350); $a$ Ausführungsgang.

MARSENIOPSIS MURRAYI, BGI.

Fig. 2.3. Querer Durchschnitt der ganzen Mandibelplatte, mit Cam. gezeichnet (Vergr. 350); $a$ hinterster, b vorderster Theil.

MARSENIOPSIS PACIFICA, BGH.

Fig. :-:. Niere, von der Unterseite; a pericardiaco-renale Oeffinung. 


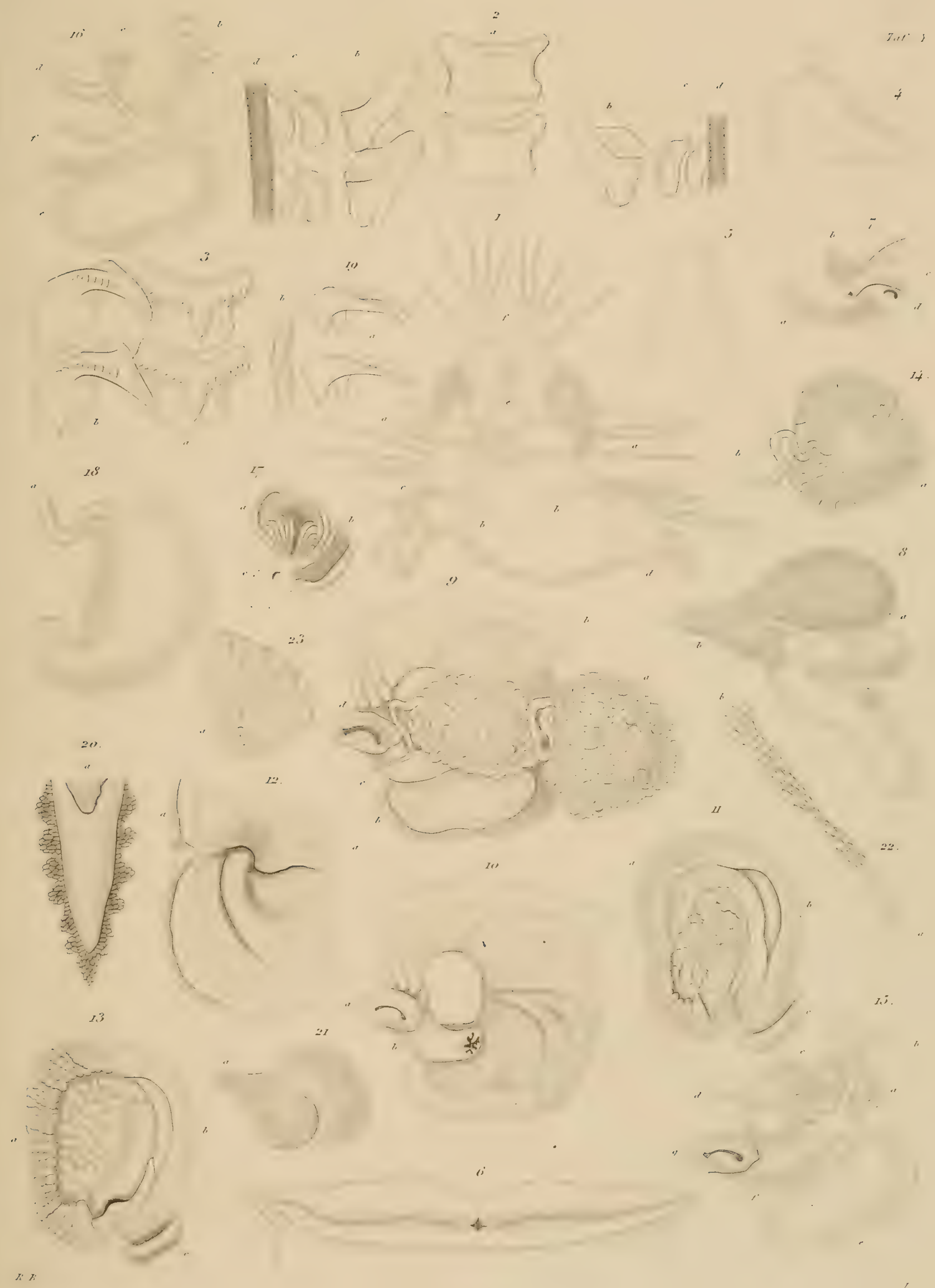






\section{Tafel Z.}

\section{MARSENIOPSIS PACIFICA, BGH.}

Fig. 1. Der Kopf, von der Unterseite mit Tentakeln und Aussenmunde.

Fig. 2. a Vorderrand der Lippenscheibe, bb Kieferplatten.

Fig. 3. Zwei mittlere Zahnplatten.

Fig. 4. a a innere, bb äussere Haken; c Leiste der liaspel. Fig. 3-4 mit Cam. gezeichnet (Vergr. 350).

Fig. 5. a Schleimdriise, $b$ Samenblasen.

MARSENIOPSIS MURRAYI, BgIr.

Fig. 6. Penis, a Grund desselben, $b$ Oeffuung des Samenleiters.

\section{ONCHIDLOPSIS GROENLANDICA, BGH.}

Fig. 7. Die Schale, ron oben. $1 / 1$.

Fig. 8. Jieselbe, vom Rande. $1 / 1$.

Fig. 9. Aehnliche eines anderen Individuums, von oben. 1/1.

Fig. 10. Spitze eines Kiemenblattes, mit Cam. gezcichnet (Vergr. 55).

Fig. 11. a Fussknoten, $b$ secundäre Ganglienbildung, $c$ Ohrscheibe mit Otocyste und

Otolith, $d N$. acusticus an das cerebro-pedale Connectiv geliend; mit Cam. gezeichnet (Vergr. 55̃).

Fig. 12. a Zwitterdrüsengang, b Prostata, $c$ Samengang; d Grund des Penis, $c$ Spitze desselben.

Hig. 13. Penis, ausgefaltet; a Grund, $b$ Spitze.

Fig. 14. Von der Prostata.

Fi.ig. 15. Spongiarium mit Bruthöhlen. $1 / 1$.

Fig. 16. Larve mit Schale, Segel, Fuss und Deckel.

Fig. 17. Larve, von der Hinterseite.

Fig. 18. Achnliche, von vorn.

Fig. 19. Jingere ähnliche, schief von der Scite.

Fig. 20. Schale, von der Seite.

Fig. 21. Aebnliche.

Fig. 16-21 mit Cam. gezeichnet (Vergr. 200).

Fig. 22. Stuck des Schalenrandes, mit Cam. gezeichnet (Vergr. 350).

ONCHID. GROENLANDICA, BGII. VAR. PACIFICA.

Fig. 23. P'enis; a lirund dessclben, $b$ Spitzè.

\section{ONCHIDIOPSIS GLACIALIS (M. SAIS).}

Fig. 24. Querschnitt durch das Geruchsorgan, mit Cam. gezeichnet (Vergr. 55). 

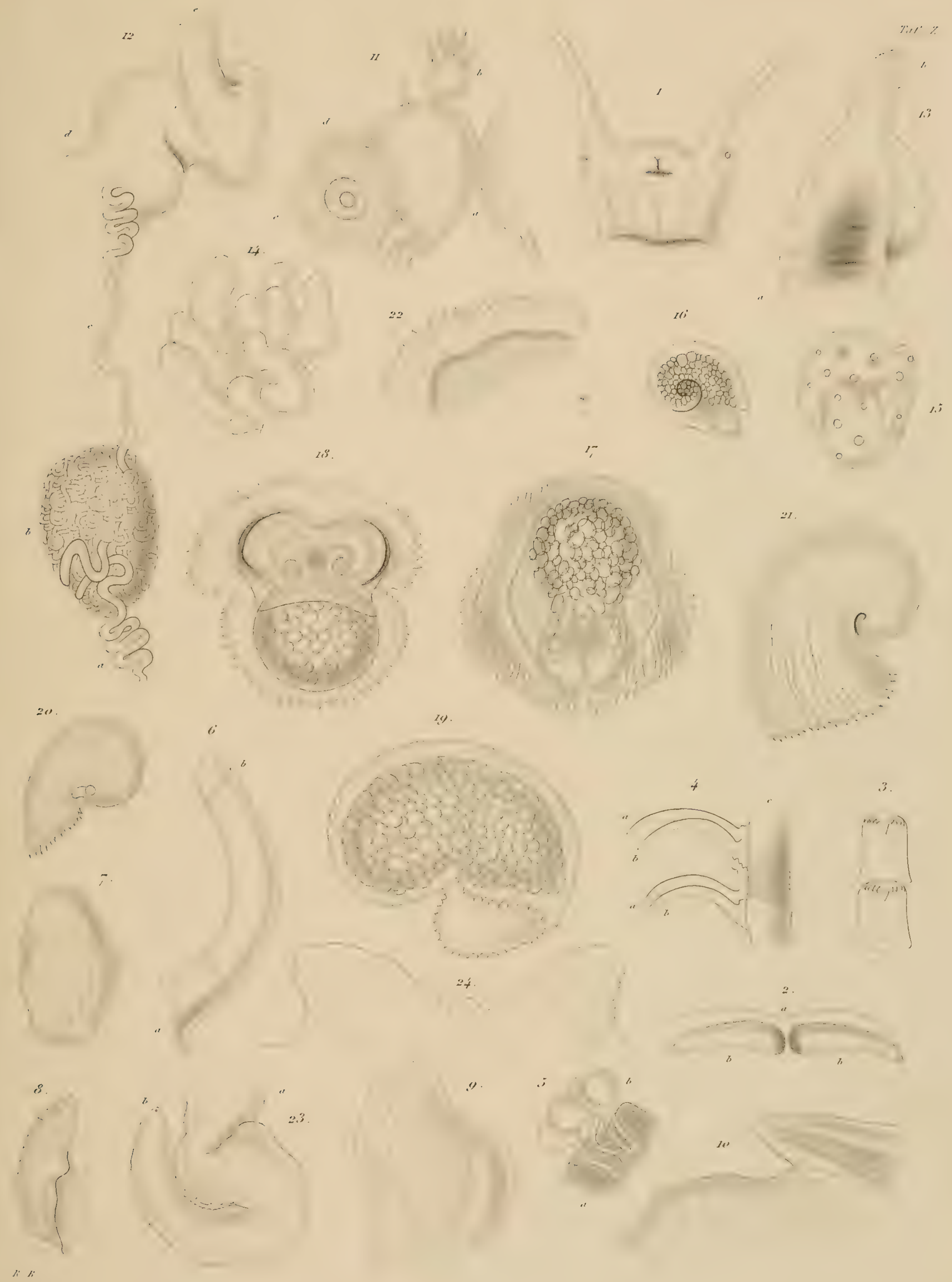




\section{'Tifel E.}

\section{MARSENIA PERSPICUA (L.).}

Fin. 1. Querschnitt eines Blattes des Geruchsorgans;

$a$ Gegend des quer durchschnittenen N. olfactorius, $b$ Gegend der lacunenartigen Höhle.

Fin. 2. Achnliches Stiick; $a$ der Lünge nach gescimittener Nervenzweig.

Fig. 1-2 mit ('am. gezeichnet (Vergr. 100).

Fig. ¿. Unterster Theil der Falten der Blätter (vergl. Fig. 1), mit ihrer Wimperbekleidung.

lig. 1. Achnlicher 'Theil;

** gelbliche (wimperlose) Zellengruppen.

Fig. 万. Oberes Ende ciner Falte (vergl. Fig. 1).

Fig. 3-5 mit Cam. gezeichnet (Vergr. 350).

\section{MALSENIOPSIS PACIFICA, BGGI.}

Fir.. (i. Die Schale, von der Seite. $\%$.

Fin. T. Schlundkopf, ron der Seite; $a$ Schname, $b$ Knorpelfteck, $c$ M. lateralis inf., $d$ Raspelscheide, $e$ Oesophagus.

Fin.. S. Stiick der Raspel mit drei Plattenreihen, von oben; mit Cam. gezeichnet (Vergr. 350); a $a$ mediane Platten, $b b$ laterale, $c$ äusserer Haken, $d$ ïussere Leiste der Raspel.

Fiي. 9. Kiemenblatt, mit Cam. gezeichnet (Vergr. 55);

$a$ Grumd.

\section{MARENIOPSIS MURRAYI, BGI.}

Fin. 10. Mediane Platte, ron der Scite.

Fin. 11. Mediane Platte, von oben.

Fig. 10-11 mit Cinn. gezeichnet (Vergr. 350).

\section{VELUTINA LAEVIGATA (PENN.).}

lï. 12. Tiemenblatt, mit Cam. luc. gezeichnet (Vergr. 55).

Fi... 13. Kieferplatte, mit Cam. gezeichnet (Vergr. 100);

a oberes Zwischenstiick, o Dentikel.

Fin. 1.. Der Dentikel (Fig. 13 b), mit Cam. gezeichnet (Vergr. 350).

Fi... 15. Stick der Raspel mit drei l'lattenreihen, von der Unterseite;

$a$ melliane, $b b$ laterale Platten; $c c$ iussere Haken, dd umgeschlagener Rand der Raspel.

Iïr. Ili. Stiick des mittleren Theils der Raspel, ron der Hinterseite;

$$
a \text { meliane, } b 6 \text { laterale Platten. }
$$

Fig. 17. Mediane Platten dreier lieihen.

ling. 1s. ac laterale Platten; bb imere, ce ïussere Haken.

liin. 19. Zwei inssere Tlaken.

Fig. 15-19 mit Cam. gezeichnet (Vergr. 350).

Fiı. 211. Penis, von der Imenseite; a freie Spitze des Samenganges.

Fi...-1. Achnlieher, mit geöthetem Kanale des Samenganges; a wio oben.

1\%i..... Ende des Samenganges, mit Cam. gezeichnet (Vergr. 350); a Spitze. 

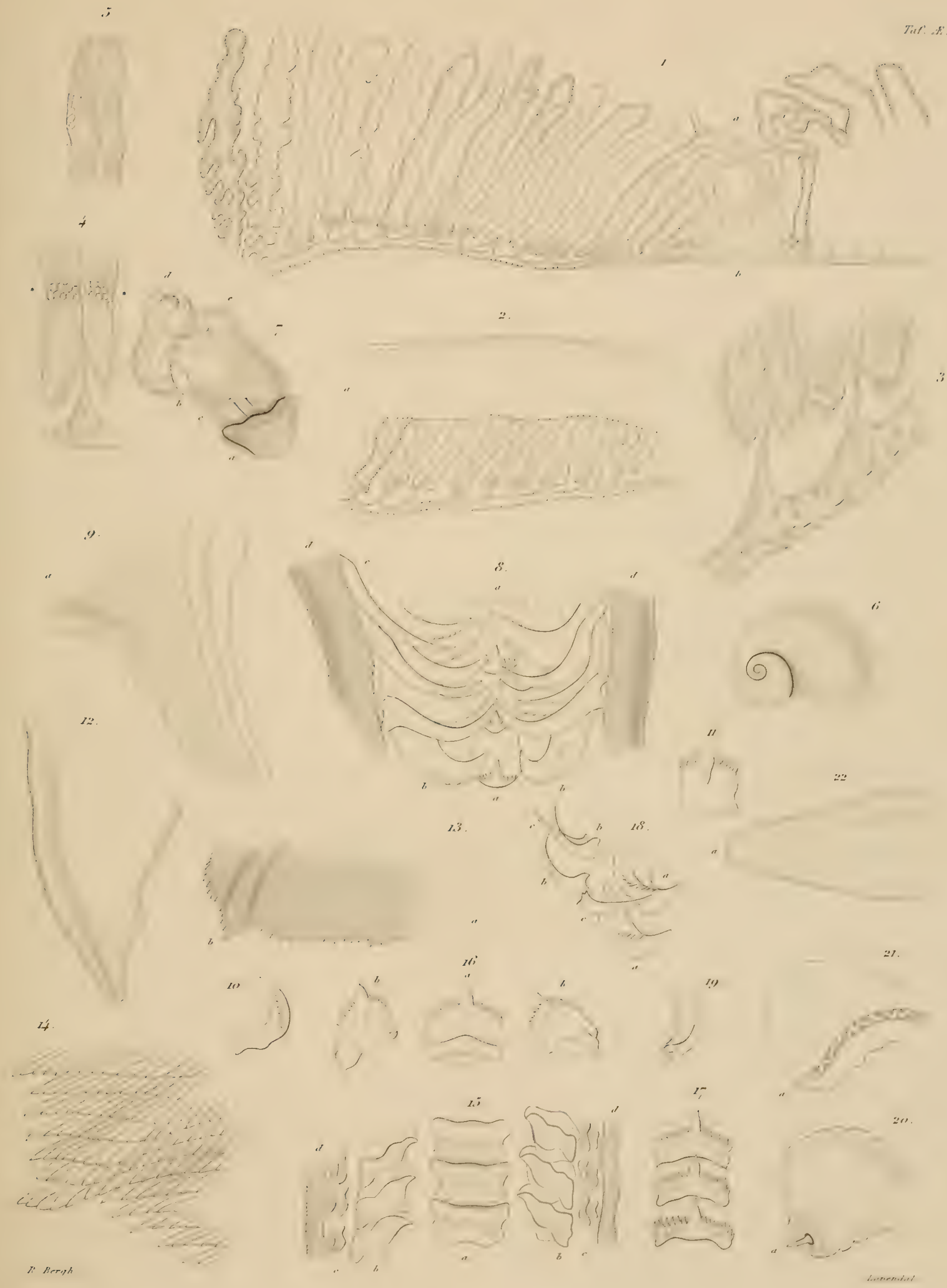

Tur: $x^{\prime}$ 


\section{REISEN}

III

\section{ARCHIPEL DER PHILIPPINEN}

TUN

\section{C. SEIMPER}

PROFESSOR DER ZOOLOGLE UND VERGLEICHENDEN ANATOME IN WÜRZBCRG.

ZWEITER THEIL.

\section{WISSENSCHAFTLICIE RESULTATE.}

ZWEITER BAND.

MALACOLOGISCHE UNTERSUCHUNGEN

voy

D ${ }^{\text {r. }}$ R U D. B E R G H.

SUPPLEMENT - MEFT I.

NACHTRÄGE UND ERGÄNZUNGEN.

MIT SECHS TAFELN ABBILDUNGEN, VON DENEN ZWEI COLORIRT.

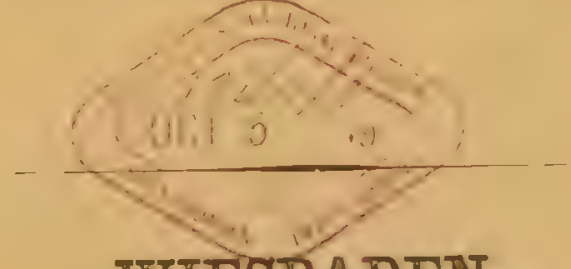

WIESBADEN.

C. W. KREI D E L'S V ERL $\Lambda$ G.

1880 . 



\section{REISEN}

III

\section{ARCHIPEL DER PHILIPPINEN}

\section{C. SEMPER}

PROFESSOR DER ZOOLOGIF, UND VERGLEICHFNDEN ANATOMIE IN WURZRURG.

ZWEITER THEIL.

WISSENSCIIAFTLICIIE RESULTATE.

ZWEITER BAND.

MALACOLOGISCHE UNTERSUCHUNGEN

vox

D! R U D。 B E R GH.

SUPPIEMENT - HEFT H.

DIE MARSENIADEN.

ERSTE HÄLFTE.

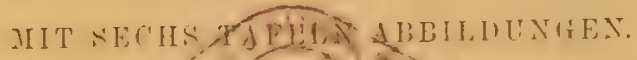

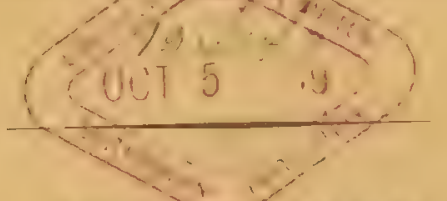

\section{WIESBADEN.}

C. W. KREIDEL'S VERLAG.

1886. 



\section{REISEN}

III

\section{ARCHIPEL DER PHILIPPINEN}

VON

D. C. SEIMPER

PROFESSOR DER ZOOLOGIE VND VERGLEICHENDEN ANATUMIIE IN WÜRZPLRO

ZWEITER THEIL.

\section{WISSENSCIIAFTLICIIE RESULTATE.}

ZTEITER BAND.

MALACOLOGISCHE UNTERSUCHUNGEN

D? R U D. B E R GH.

SUPPIEMENT- HEF'T' IV.

DIE MARSENIADEN.

ZWEITE HÄLFTE.

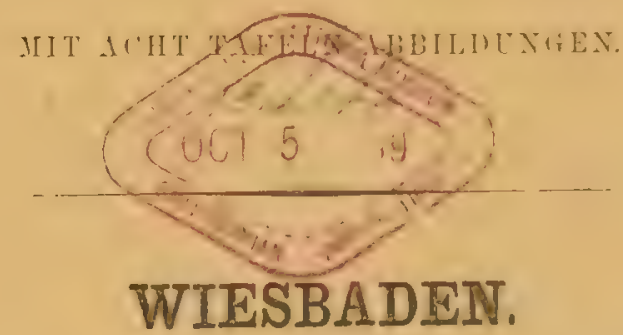

C. W. KREIDEL'S VERLAG.

1857.

Die mit diesem letzten Supplementhefte ausgegebenen Titel sind einzaheften:

In Heft I der Generaltitel und der Specialtitel der Nudibranchien.

In Heft III der Specialtitel der Marseniaden. 









(1N 
